FINNISH METEOROLOGICAL INSTITUTE

CONTRIBUTIONS

No. 174

\title{
The short-term effect of partial harvesting and clearcutting on greenhouse gas fluxes and evapotranspiration in a nutrient-rich peatland forest
}

\section{Mika Korkiakoski}

Doctoral Programme in Atmospheric Sciences

Institute for Atmospheric and Earth System Research / Physics

Faculty of Science

University of Helsinki

Academic dissertation presented for the degree of Doctor of Philosophy

To be presented for public examination with the permission of the Faculty of Science of the University of Helsinki in the Auditorium A129, A. I. Virtasen aukio 1, Helsinki, on 10th of December 2020 at 1 o'clock in the afternoon.

Finnish Meteorological Institute

Helsinki, 2020 
Author's contact: Climate System Research, Finnish Meteorological Institute, PL 503, FI-00101 Helsinki, Finland mika.korkiakoski@fmi.fi

https://orcid.org/0000-0001-6875-9978

Supervisor:

Assistant Professor Annalea Lohila, Ph.D.

Institute for Atmospheric and Earth System Research, University of Helsinki

Climate System Research, Finnish Meteorological Institute

Reviewers: $\quad$ Professor Janne Rinne, Ph.D.

Department of Physical Geography and Ecosystem Science

Lund University

Docent Mikko Peltoniemi, Ph.D.

Natural Resources Institute Finland (Luke)

Opponent: $\quad$ Professor Mats Nilsson, Ph.D.

Department of Forest Ecology and Management

Swedish University of Agricultural Sciences

Custos:

Professor Timo Vesala, Ph.D.

Institute for Atmospheric and Earth System Research

University of Helsinki

ISBN 978-952-336-129-4 (paperback)

ISSN 0782-6117

Edita Prima Oy

Helsinki 2020

ISBN 978-952-336-130-0 (PDF)

https://doi.org/10.35614/isbn.9789523361300

Helsinki 2020 
Published by

\author{
Finnish Meteorological Institute \\ Erik Palménin aukio 1 \\ P.O. Box 503 \\ FIN-00101 Helsinki, Finland
}

Series title, number and report code of publication FMI Contributions, 174, FMI-CONT-174

December 2020

ORCID iD

0000-0001-6875-9978

Mika Korkiakoski

\section{Title}

The short-term effect of partial harvesting and clearcutting on greenhouse gas fluxes and evapotranspiration in a nutrient-rich peatland forest

Abstract

Drained peatlands are a challenge to the climate change mitigation, due to acting as sources of carbon and greenhouse gases to the atmosphere. However, different management practices could be used to reduce these emissions. In this thesis, the objective was to quantify the changes in water table level (WTL), evapotranspiration (ET) and greenhouse gas (GHG) fluxes for the first few years following clearcutting and partial harvesting a nutrient-rich peatland forest. The experimental forest was divided to partial harvest, clear-cut and control subsites, where WTL was monitored and direct flux measurements were made with the eddy covariance (EC), and manual and automatic soil chamber methods.

Before clearcutting, the subsite was a small $\mathrm{CO}_{2}$ and $\mathrm{CH}_{4}$ sink, but $\mathrm{N}_{2} \mathrm{O}$ emissions were small. After clearcutting, WTL rose by $24 \mathrm{~cm}$ due to a $45 \%$ decrease in ET. The loss of photosynthesising biomass and addition of respiring logging residues turned the clear-cut subsite from $\mathrm{CO}_{2}$ sink into a large $\mathrm{CO}_{2}$ source for the next few years. Forest floor $\mathrm{N}_{2} \mathrm{O}$ fluxes increased significantly, possibly due to residues releasing reactive nitrogen, hence promoting $\mathrm{N}_{2} \mathrm{O}$ production. Also, soil compression and WTL rise might have enhanced $\mathrm{N}_{2} \mathrm{O}$ production through increased denitrification. The soil turned from $\mathrm{CH}_{4}$ sink into a small source as a result of thinning of oxic peat layer, which decreased $\mathrm{CH}_{4}$ oxidation.

The partially harvested subsite was a small $\mathrm{CO}_{2}$ source before the partial harvest, meaning more carbon was lost through peat decomposition than was taken up by growing trees. Forest floor was a small $\mathrm{CH}_{4} \operatorname{sink}$ and $\mathrm{N}_{2} \mathrm{O}$ source. After partial harvest, WTL rose by $12 \mathrm{~cm}$ and ET decreased by $17 \%$ compared to the control site. Also, $\mathrm{CO}_{2}$ emissions increased. However, compared to the clear-cut site, $\mathrm{CO}_{2}$ emissions were significantly smaller at the partial harvest site. No considerable changes in $\mathrm{CH}_{4}$ and $\mathrm{N}_{2} \mathrm{O}$ fluxes were observed after partial harvest. The difference in $\mathrm{CO}_{2}$ emissions between the harvest treatments can be explained with remaining tree stand, which kept ET higher, WTL lower and acted as $\mathrm{CO}_{2}$ sink. Also, the amount of decomposing logging residues was smaller after partial harvesting than after clearcutting.

Publishing unit

Climate System Research
Classification (UDC)

504.7, 551.511.6, 551.573, 630*461

Keywords

Carbon dioxide, methane, nitrous oxide, eddy covariance, soil chamber, water table, forest management

\begin{tabular}{lll}
\hline ISSN and series title & ISBN & \\
$0782-6117$ & $978-952-336-129-4$ (paperback) \\
Finnish Meteorological Institute Contributions & $978-952-336-130-0$ (pdf) \\
\hline DOI & Language & Pages \\
$10.35614 /$ isbn.9789523361300 & English & 75 \\
\hline
\end{tabular}


Julkaisija Ilmatieteen laitos

Erik Palménin aukio 1

PL 503

00101 Helsinki
Julkaisun sarja, numero ja raporttikoodi

FMI Contributions, 174, FMI-CONT-174

Joulukuu 2020

\section{Tekijä}

ORCID iD

Mika Korkiakoski

0000-0001-6875-9978

Nimeke

Avo- ja osittaishakkuun lyhytaikaiset vaikutukset kasvihuonekaasuvoihin ja haihduntaan ravinteikkaalla metsäojitetulla suolla

Tiivistelmä

Kuivatut turvemaat ovat haaste ilmastonmuutoksen kannalta, koska ne toimivat hiilen ja kasvihuonekaasujen lähteinä, mutta erilaisilla käsittelytavoilla voidaan mahdollisesti hillitä näitä päästöjä. Tässä väitöskirjassa tavoitteena oli määrittää muutokset runsasravinteisen suometsän pohjaveden korkeudessa (WTL), haihdunnassa (ET) sekä kasvihuonekaasuvoissa (KHK-voissa) ensimmäisinä vuosina avohakkuun sekä osittaishakkuun jälkeen. Tutkimusmetsä jaettiin kolmeen koealaan: osittaishakkuu, avohakkuu ja kontrolli. Koealoilla mitattiin WTL:ää, ET:tä ja KHK-voita pyörrekovarianssi, automaatti- ja manuaalikammiomenetelmillä.

Ennen avohakkuuta koeala oli pieni hiilidioksidin $\left(\mathrm{CO}_{2}\right)$ ja metaanin $\left(\mathrm{CH}_{4}\right)$ nielu ja pieni typpioksiduulin $\left(\mathrm{N}_{2} \mathrm{O}\right)$ lähde. Avohakkuun jälkeen ET laski 45\%, joka johti $24 \mathrm{~cm}$ vedenpinnan nousuun. Yhteyttävän biomassan häviäminen ja hajoavien hakkuutähteiden lisääminen muutti avohakatun alan suureksi $\mathrm{CO}_{2}$-lähteeksi. Metsänpohjan $\mathrm{N}_{2} \mathrm{O}$-vuot kasvoivat merkitsevästi todennäköisesti hakkutähteiden vapauttaman reaktiivisen typen vuoksi. Samaan aikaan maan tiivistyminen ja WTL:n nousu tehostivat denitrifikaatiota ja siten $\mathrm{N}_{2} \mathrm{O}: n$ tuottoa. Maaperä muuttui $\mathrm{CH}_{4}$-nielusta lähteeksi hapellisen turvekerroksen ohennuttua, joka pienensi $\mathrm{CH}_{4}: \mathrm{n}$ hapettumista.

Osittaishakattava ala oli pieni $\mathrm{CO}_{2}$-lähde ennen hakkuuta, eli turpeen hajoamisesta muodostuvat $\mathrm{CO}_{2}$-päästöt olivat suuremmat kuin mitä puusto sitoi. Metsänpohja oli pieni $\mathrm{CH}_{4}$ :n nielu ja $\mathrm{N}_{2} \mathrm{O}$ :n lähde. Osittaishakkuun jälkeen ET pieneni $17 \%$ ja WTL nousi $12 \mathrm{~cm}$ verrattuna kontrollialaan. $\mathrm{CO}_{2}$-päästöt kasvoivat verrattuna hakkuuta edeltävään tilaan, mutta merkittävästi vähemmän kuin avohakkuun jälkeen. $\mathrm{CH}_{4}-$ ja $\mathrm{N}_{2} \mathrm{O}$-voissa ei havaittu merkitsevästi muutoksia. Erot avohakkuun ja osittaishakkuun välillä selittyvät jäljelle jääneellä puustolla, joka piti haihdunnan korkeammalla, WTL:n matalammalla sekä sitoi $\mathrm{CO}_{2}$ :a. Myös hakkuutähteiden määrä oli merkittävästi pienempi osittaishakkuun jäljiltä.

\begin{tabular}{|c|c|c|}
\hline Julkaisijayksikkö & \multicolumn{2}{|c|}{ Luokitus (UDK) } \\
\hline Ilmastojärjestelmätutkimus & \multicolumn{2}{|c|}{$504.7,551.511 .6,551.573,630 * 461$} \\
\hline \multicolumn{3}{|l|}{ Asiasanat } \\
\hline \multicolumn{3}{|c|}{ Hiilidioksidi, metaani, typpioksiduuli, pyörrekovarianssi, maakammio, pohjavesi, metsänkäsittely } \\
\hline ISSN ja avainnimeke & \multicolumn{2}{|c|}{ ISBN } \\
\hline 0782-6117 & \multicolumn{2}{|c|}{ 978-952-336-129-4 (nidottu) } \\
\hline Finnish Meteorological Institute Contributions & \multicolumn{2}{|c|}{$978-952-336-130-0$ (pdf) } \\
\hline DOI & Kieli & Sivumäärä \\
\hline $10.35614 /$ isbn. 9789523361300 & englanti & 75 \\
\hline
\end{tabular}




\section{Acknowledgements}

I am grateful for having been able to work with such amazing colleagues from Finnish Meteorological Institute, University of Helsinki and Natural Resources Institute Finland. The knowledge shared by these scientists with different expertise has been invaluable in completing this multidisciplinary thesis. I appreciate the financial support from Maj and Tor Nessling Foundation, which initiated this $\mathrm{PhD}$ project. Also, I am grateful for the funding from the Academy of Finland and the Ministry of Transport and Communications through the Integrated Carbon Observing System (ICOS), which allowed me to finish this thesis.

Most of my gratitude goes to my sole supervisor Annalea Lohila, who has been guiding me through this whole process. I never felt I would have needed more than one supervisor or some committees as she was always able to help me with my problems. Next, I want to thank the head of greenhouse gases group Tuomas Laurila with whom I have had a pleasure to work with since starting my master's thesis in 2012. I am also grateful for Tuomas for offering me a position as a PI of an ICOS station, which has been a rewarding experience even though I had my doubts at the beginning.

I also appreciate the help of all my co-authors. I want to thank Juha-Pekka Tuovinen for helping with many scientific problems and greatly improving the papers he has been a part of. I also want to thank Timo Penttilä for sharing his knowledge of forestry and practical work in the field. Special thanks to Juha-Pekka and Timo for giving valuable feedback of my thesis even though I did not give them much time to do that. I am also grateful for Paavo Ojanen, Kari Minkkinen, Sakari Sarkkola, Kersti Leppä and Samuli Launiainen for scientific discussions, help with the papers, and overall being a key part this thesis. Many of the measurements would never have started or kept running without the technicians. Many thanks for Juuso Rainne, Juha Hatakka and Timo Mäkelä for helping me to maintain a measurement station.

I am thankful for pre-examiners Mikko Peltoniemi and Janne Rinne for reviewing and giving comments, which helped me to improve this thesis. Also, I want to thank Mats Nilsson for accepting the position of an Opponent and Timo Vesala for acting as a Custos during these covid-affected difficult times.

I am lucky to have such good colleagues and friends with whom I have been able to spend time during university classes, field courses, lunch and coffee breaks, badminton and other leisure activities: Lauri, Henriikka, Laura, Maiju, Jarmo, Hermanni, Tuula, Tiina, Aki, Stephanie, Elisa, Iikka, Mika, Olli, Pasi, Juho and Joni. Thank you for listening to my complaints about my studies and research.

Finally, I want to thank my family for all of their support. Especially my wife Heidi for sharing this journey with me. 



\section{Contents}

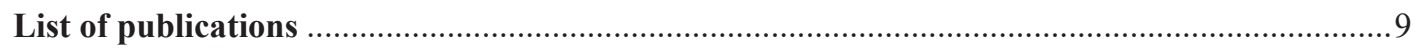

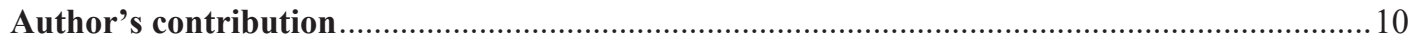

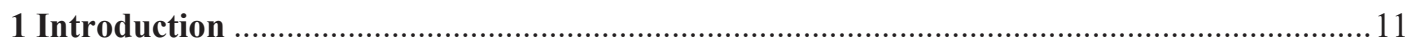

2 Physical and biological processes driving greenhouse gas exchange .................................... 13

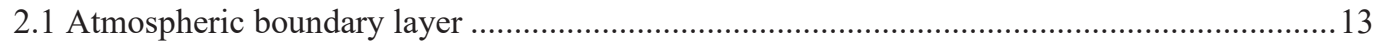

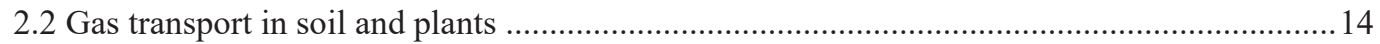

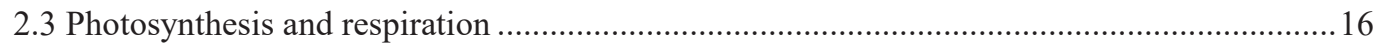

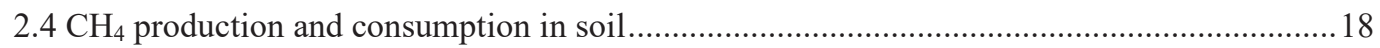

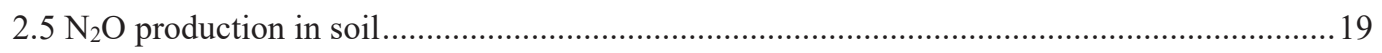

2.6 Evapotranspiration as a part of surface energy balance ....................................................21

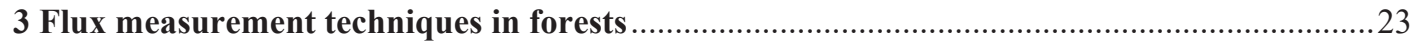

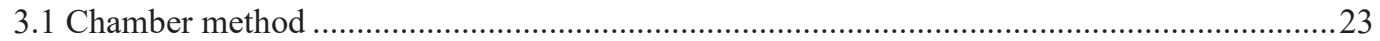

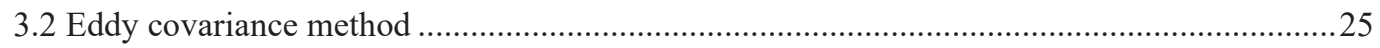

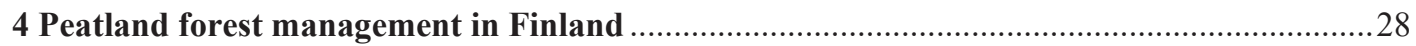

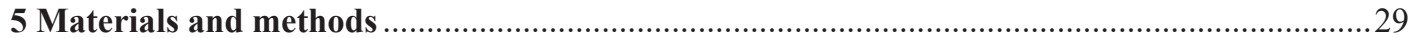

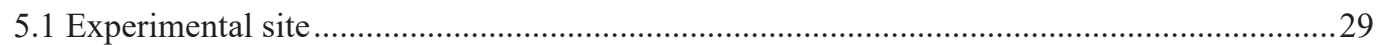

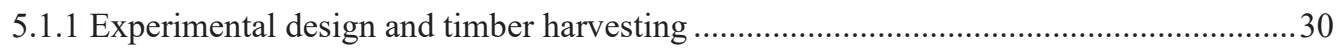

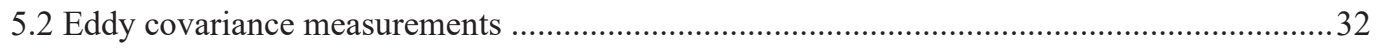

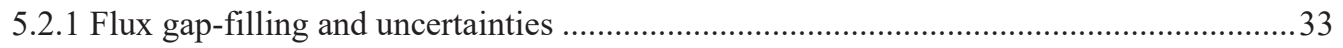

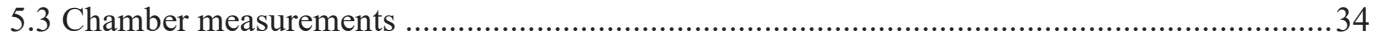

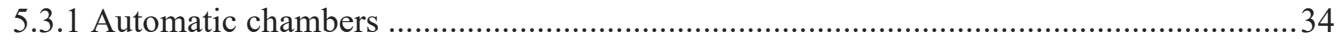

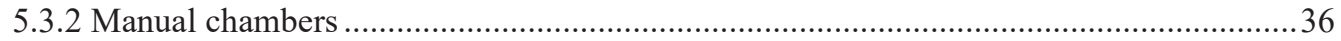

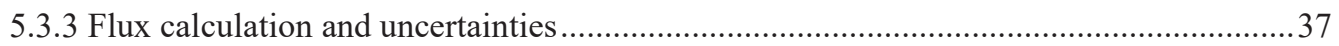

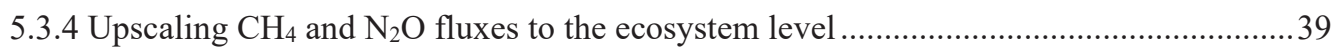

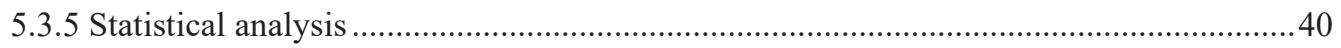

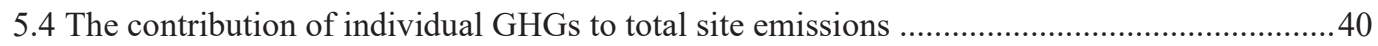

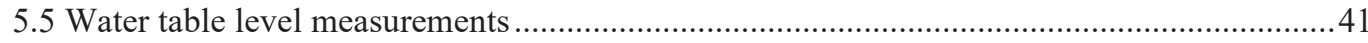

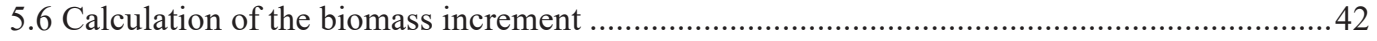


6.1 The effect of flux calculation methods on chamber GHG fluxes .........................................43

6.2 Changes in evapotranspiration and water table level....................................................... 45

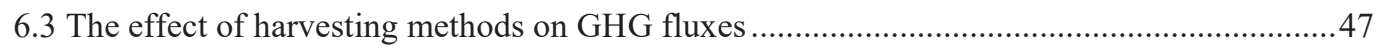

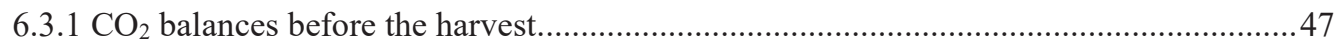

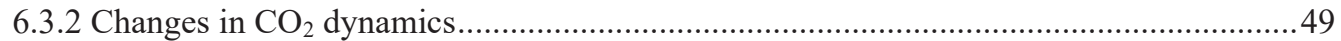

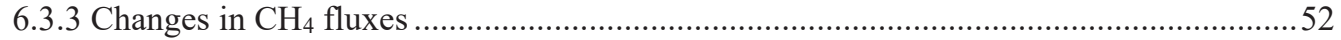

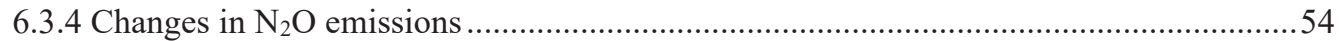

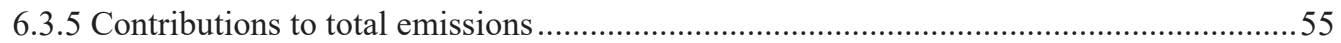

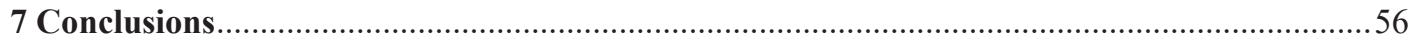

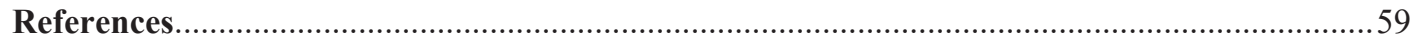




\section{List of publications}

This thesis consists of an introductory review and four research articles. In the introductory part, the papers are cited according to their roman numerals. Papers I-II are printed under the Creative Commons Attribution 4.0 license and Papers III-IV under Creative Commons BY-NC-ND license.

I Korkiakoski, M., Tuovinen, J.-P., Aurela, M., Koskinen, M., Minkkinen, K., Ojanen, P., Penttilä, T., Rainne, J., Laurila, T., and Lohila, A.: Methane exchange at the peatland forest floor - automatic chamber system exposes the dynamics of small fluxes, Biogeosciences, 14, 19471967, doi:10.5194/bg-14-1947-2017, 2017.

II Korkiakoski, M., Tuovinen, J.-P., Penttilä, T., Sarkkola, S., Ojanen, P., Minkkinen, K., Rainne, J., Laurila, T., and Lohila, A.: Greenhouse gas and energy fluxes in a boreal peatland forest after clear-cutting, Biogeosciences, 16, 3703-3723, doi:10.5194/bg-16-3703-2019, 2019.

III Korkiakoski, M., Ojanen, P., Penttilä, T., Minkkinen, K., Sarkkola, S., Rainne, J., Laurila, T., and Lohila, A.: Impact of partial harvest on $\mathrm{CH}_{4}$ and $\mathrm{N}_{2} \mathrm{O}$ balances of a drained boreal peatland forest, Agricultural and Forest Meteorology, 295, doi:10.1016/j.agrformet.2020.108168, 2020.

IV Leppä, K., Korkiakoski, M., Nieminen, M., Laiho, R., Hotanen, J.-P., Kieloaho, A.-J., Korpela, L., Laurila, T., Lohila, A., Minkkinen, K., Mäkipää, R., Ojanen, P., Pearson, M., Penttilä, T., Tuovinen, J.-P., and Launiainen, S.: Vegetation controls of water and energy balance of a drained peatland forest: Responses to alternative harvesting practices, Agricultural and Forest Meteorology, 295, doi:10.1016/j.agrformet.2020.108198, 2020. 


\section{Author's contribution}

I The author was responsible for the data analysis and wrote the paper with contributions from all co-authors.

II The author helped setting up and maintaining the EC measurement system. The author also took part in the chamber measurements, made all the data analysis excluding WTL data and footprint analysis. The author wrote the paper with contributions from all co-authors.

III The author maintained the automatic chamber systems, took part in the other chamber measurements, made all the data analysis, excluding WTL, and wrote the paper with contributions from all co-authors.

IV The author maintained the EC systems used to collect the data. The author also processed the flux data and contributed to the writing of the manuscript. 


\section{Introduction}

Most of the present-day peatlands have formed during the last 11000 years after the last glacial period (Gajewski et al., 2001). Peatlands are ecosystems with a high water table level (WTL) where carbon (C) has been fixed through photosynthesis and stored as partly decomposed organic matter called peat. In thousands of years, they have become large terrestrial reservoirs of C, containing about 30\% (1055 Pg C; Nichols and Peteet, 2019; Scharlemann et al., 2014) of the Earth's soil C. In addition, peatlands store around 10\% (8-15 Pg N; Batjes, 1996; Limpens and Heijmans, 2006) of total soil nitrogen $(\mathrm{N})$ pool, even though they cover less than 3\% of the Earth's surface area (Xu et al., 2018).

Peatlands have a warming effect on climate on decadal time scales due to high methane $\left(\mathrm{CH}_{4}\right)$ emissions. On the other hand, over millennial timescales, the radiative forcing of $\mathrm{CH}_{4}$ emissions stabilise because of shorter lifetime of $\mathrm{CH}_{4}$ in the atmosphere compared to carbon dioxide $\left(\mathrm{CO}_{2}\right)$. Over the years, the $\mathrm{C}$ storage keeps increasing in the formed peat layer (Whiting and Chanton, 2001), making peatlands climate coolers. However, peatlands have become vulnerable to drying (Swindles et al., 2019) because of climate change. Also, human activities resulting in land-use changes, such as peat extraction and drainage for forestry and agriculture, have increased greenhouse gas (GHG) emissions from peatlands (e.g. Leifeld and Menichetti, 2018). Peatland drainage lowers WTL creating oxic conditions in the surface peat, which decreases $\mathrm{CH}_{4}$ emissions but induces a peat decomposition process in which $\mathrm{C}$ and $\mathrm{N}$ are released to the atmosphere as $\mathrm{CO}_{2}$ and nitrous oxide $\left(\mathrm{N}_{2} \mathrm{O}\right)$. Drainage remains a common practice, especially in the tropics, and the cumulative GHG emissions from drained peatlands in 2015 (globally $80 \mathrm{Pg} \mathrm{CO}_{2}$-eq) are expected to triple by 2100 (Leifeld et al., 2019).

In Finland, more than half of the original peatland area of $100,000 \mathrm{~km}^{2}$ has been drained, mostly for forestry (Päivänen and Hånell, 2012). Drainage was a common practice in the 1960s, and currently these drained peatland forests are reaching their harvesting age. Yet, there is a lack of research focusing on different harvesting methods and their effect on GHG fluxes in peatland forests. The most common forest management method in Finland has been even-aged management (EM), including clearcutting with stem wood harvest, followed by soil preparation with either incorporated or separate amelioration of drainage, and forest regeneration by planting or sowing. However, due to the need for ditch network maintenance, in peatland forests EM requires substantial economic investments to establish and maintain the forest stand (Nieminen et al., 2018), and it also causes major environmental issues because of increased GHG emissions and decreased water quality. Large $\mathrm{CO}_{2}$ emissions have been measured for several years after clearcutting upland forests (Amiro et al., 2010; Clark et al., 2004; Humphreys et al., 2005; Kowalski et al., 2004, 2003; Takagi et al., 2009; Williams et al., 2013). Also, the net $\mathrm{CH}_{4}$ (Sundqvist et al., 2014; Vestin et al., 2020) and $\mathrm{N}_{2} \mathrm{O}$ (Huttunen et al., 2003; Saari et al., 2009) emissions have been observed to increase, even though the research is not as comprehensive as with $\mathrm{CO}_{2}$. These environmental and economic problems have raised a discussion if continuous cover forestry (CCF) could be a feasible alternative to EM in peatland forests (Nieminen et al., 2018). In CCF, no clear-cut is made, and the method is not based on stand rotations. Only part of the tree stand is harvested, and natural regeneration is expected to take place in openings and under the retained stand. Partial harvests are carried out at 10 to 20 -year intervals, depending on site productivity, instead of traditional clearcutting every 60 to 100 years. No ditch maintenance should be required since the remaining tree stand is presumed to maintain transpiration that is high enough 
to prevent the WTL from rising to a level that would harm tree growth (Nieminen et al., 2018; Sarkkola et al., 2010, 2012). Consequently, net $\mathrm{CH}_{4}$ emissions should not increase significantly. Further, stand management including regular partial cuttings are expected to keep WTL higher than the level resulting from EM due to lower average stand volume and missing ditch network maintenance operations. Therefore, peat decomposition and $\mathrm{CO}_{2}$ emissions should be reduced as less peat is exposed to oxic conditions, but no research exists to verify this.

Knowledge about the ecosystem and soil $\mathrm{C}$ balances can be acquired by directly measuring the stock changes in soil and vegetation. This method requires, however, a long time interval to obtain an estimate of the $\mathrm{C}$ balance, typically one to several decades, and it does not provide information on the short-term dynamics of the carbon cycle (Mäkipää et al., 2008; Smith et al., 2019). Alternatively, balances of $\mathrm{CO}_{2}$ and other key GHGs, such as $\mathrm{CH}_{4}$ and $\mathrm{N}_{2} \mathrm{O}$, can be determined by measuring the exchange between ecosystems and the atmosphere. This approach is applicable from hourly to decadal balances.

The most common flux measurement techniques are the eddy covariance (EC) and closed chamber methods. Both methods have been commonly used in peatland and forest research for decades. EC provides a direct way to measure the ecosystem-scale turbulent exchange of a gas, if wind components and gas mixing ratio can be detected with a high frequency. It is relatively maintenance-free (Aubinet et al., 2012), does not disturb the ecosystem under investigation, provides continuous measurements and allows a direct estimation of the ecosystem-scale GHG balances. In contrast, closed chambers are commonly used to measure gas exchange between the forest floor and the atmosphere. Chambers allow the investigation of small-scale processes, such as the gas exchange variation among different microtopographic surfaces (Keller et al., 1990; Singh et al., 1997). Traditionally, the measurements have been made manually by syringe sampling and subsequent analysis of the samples in a laboratory, but technical advances have made it possible to replace syringe sampling by portable gas analysers. In addition, automatic chamber systems have become more common (e.g. Görres et al., 2016; Koskinen et al., 2014; Pirk et al., 2016; Savage et al., 2014; Ueyama et al., 2015; Zhao et al., 2018), which allows using more accurate non-portable gas analysers and higher measurement frequencies, resulting in more reliable estimates of GHG balances. The EC and closed chamber methods can be used in parallel to obtain a more comprehensive view of the processes occurring within the ecosystem.

The general aim of this thesis is to quantify the short-term impact of different harvesting practices on GHG fluxes and balances in a boreal nutrient-rich peatland forest and to find the most optimal methods to measure them. The more specific research questions this thesis aims to answer are:

1) What is the optimal flux calculation method for the data collected with automated chambers (Paper I)?

2) What is the $\mathrm{CO}_{2}$ balance of a nutrient-rich peatland forest before harvesting?

3) How do the different harvesting practices affect evapotranspiration and WTL (Papers II, III and IV)?

4) How do the fluxes of $\mathrm{CO}_{2}, \mathrm{CH}_{4}$ and $\mathrm{N}_{2} \mathrm{O}$ change after clearcutting (Paper II) and partial harvesting (Paper III) in a nutrient-rich peatland forest? 


\section{Physical and biological processes driving greenhouse gas exchange}

Ecosystems and the atmosphere interact in many ways. In terms of climate, the most crucial surfaceatmosphere exchange processes are those of energy and GHGs, including $\mathrm{CO}_{2}, \mathrm{CH}_{4}$, and $\mathrm{N}_{2} \mathrm{O}$. Even though water vapour is a GHG, it is generally measured as an energy flux due to the energy bound to the phase transitions and its ability to transport energy between different parts of the atmosphere. Understanding these processes requires direct flux measurements, but it is important to note that the measured flux is always affected by both physical and biological processes. To deduce something about biological processes using flux measurements, one also needs to understand the physical processes affecting the gas flow in soil and the atmosphere above it.

\subsection{Atmospheric boundary layer}

The atmospheric boundary layer (ABL) is the lowest part of the atmosphere, which is in direct interaction with the underlying surface (e.g. Stull, 1988). Unlike the layer above ABL called free atmosphere, the flow field and air composition of the ABL respond to the surface forcing like heating and friction in hourly or shorter timescales. This interaction with the surface makes the air in the ABL turbulent where three-dimensional eddies of different sizes effectively mix the air. The turbulent transport of eddies is especially important in the vertical direction because the mean vertical wind component is typically small. The origin of the atmospheric turbulence and eddies can be mechanical or thermal (e.g. Stull, 1988). The mechanical production of turbulence is caused by surface drag slowing the wind near the ground surface, which leads to a vertical wind speed gradient and wind shear. Thermal production is caused by increased air temperature at the surface due to solar radiation. The increased temperature at the surface makes the air column unstable as the warm air rises because of free convection and turbulence is generated.

ABL can be divided to Ekman and surface layer, which can be split even further into inertial and roughness sublayer (Garratt, 1994). The height of the Ekman layer is about $90 \%$ of the ABL and in it the wind veers and fluxes decrease with height. In roughness sublayer, individual roughness elements can dominate the turbulence and affect the fluxes. However, in the inertial sublayer, the fluxes are almost constant with height, and traditional surface layer theories apply. Also, the wind speed profile follows a logarithmic behaviour in neutral conditions, which can be modified with Monin-Obukhov similarity theory under stable and unstable conditions.

The height of the ABL varies by the atmospheric stability (e.g. Kaimal and Finnigan, 1994; Stull, 1988). In the morning, solar radiation starts to increase the air temperature close to the surface. Because the warm air is more buoyant than cold air, the warm air begins to rise, making the air unstable and creating turbulence. During the daytime, the air is well-mixed due to this convection, and ABL height typically varies within 1-2 km, which mostly consists of the convective mixed layer (Fig. 1). The ABL and free atmosphere are separated by entrainment zone (or capping inversion), which is a stable layer where turbulence is limited. In that layer, the air from the free atmosphere can be entrained into the ABL, especially during morning when large convective eddies can penetrate through the stable layer into the free atmosphere. In the evening, when the solar radiation and convection stops, the surface starts to cool down. This creates a stable nocturnal boundary layer where 
turbulence is suppressed, limiting the ABL height to hundreds of meters. Some weak turbulence can develop during the night by mechanical production via wind shear. Above the nocturnal boundary layer is the residual layer, which is a leftover of the daytime ABL.

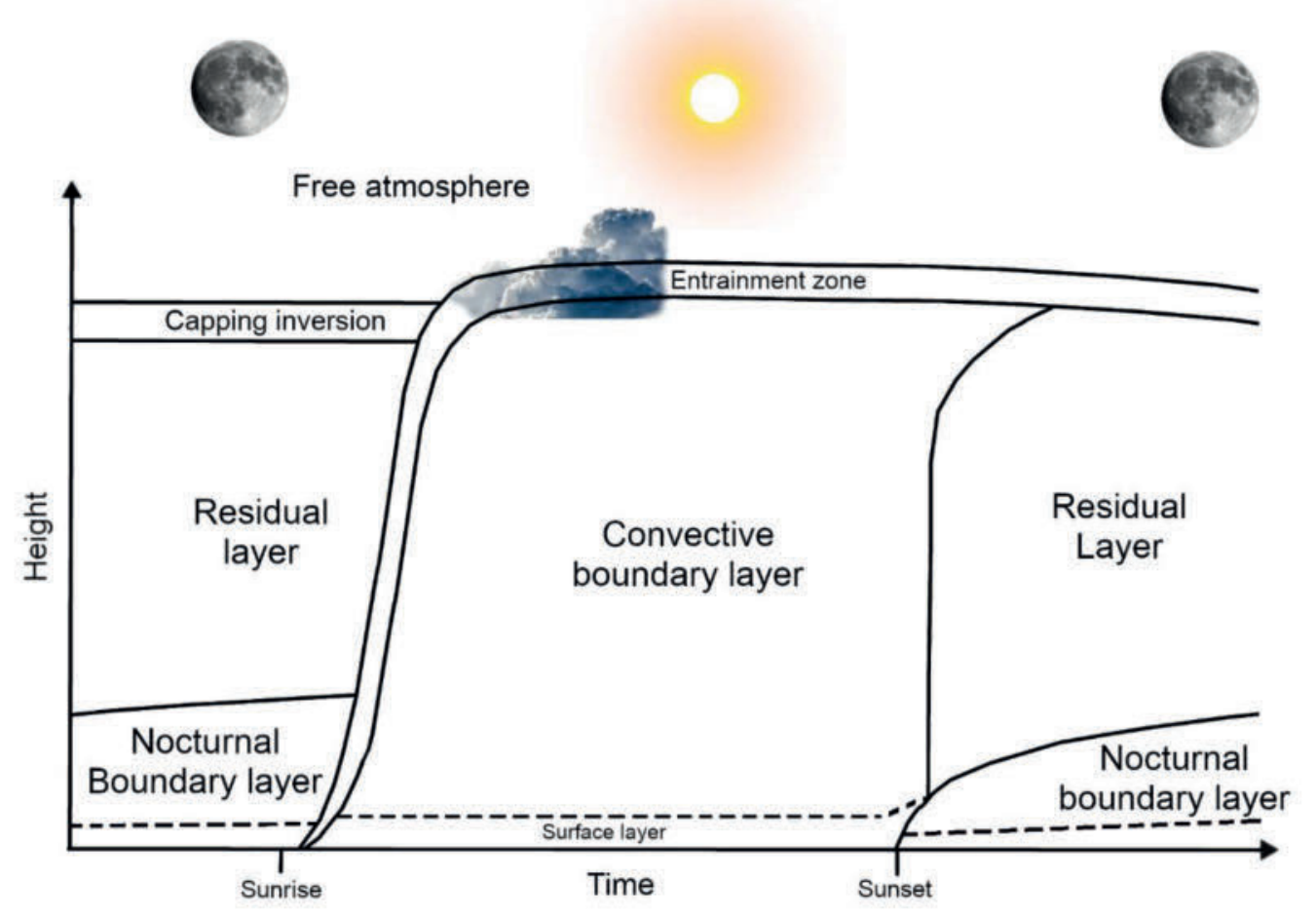

Figure 1. Simplified diel evolution of the atmospheric boundary layer over the course of one day. Modified after Stull (1988).

\subsection{Gas transport in soil and plants}

Gas transport in the soil is caused by diffusion, i.e. thermal motion of molecules. A concentration gradient, created by biological production or consumption, mainly drives diffusive gas flux in the soil $\left(F_{D}\right)$ while the pressure and temperature gradients are of minor importance in plant and soil processes under normal circumstances (Jaynes and Rogowski, 1983). In a steady state, $F_{D}$ in the soil can be described by Fick's first law (Neira et al., 2015):

$$
F_{D}=-D_{0} \tau \varepsilon \frac{d c}{d z}
$$

where $D_{0}$ is the gas diffusion coefficient $\left(\mathrm{m}^{2} \mathrm{~s}^{-1}\right)$ or diffusivity in air, $\tau$ is soil tortuosity $\left(\mathrm{m} \mathrm{m}^{-1}\right)$ or the geometry of air space in soil, $\varepsilon$ is the air-filled porosity $\left(\mathrm{m}^{3}\right.$ air $\mathrm{m}^{-3}$ soil), and $d c / d z$ is the concentration gradient of the diffusing gas. $\varepsilon$ and $\tau$ express the soil properties such as texture, water 
retention, bulk density and moisture, which affect the amount, size and connectivity of air-filled pores (Moldrup et al., 2001; Thorbjørn et al., 2008).

Peat soils have high total porosity (Caron et al., 2015; Dettmann et al., 2014) consisting of both relatively large pores, which are interconnected but highly irregular, and relatively small, closed, and dead-end pores formed from the plant cell remains (Hayward and Clymo, 1982; Rezanezhad et al., 2010). Peatland draining decreases total porosity and changes pore size distribution by increasing micropores and decreasing macropores (Silins and Rothwell, 1998; Wallor et al., 2018). Drained organic soils have very low pore connectivity due to platy and fibrous nature of some organic compounds (Caron and Nkongolo, 1999), which can cause lower gas diffusivity in peat than in mineral soils, even when the soils have similar total porosity (Caron et al., 2015). Gas diffusivity can also be reduced by soil compaction, which decreases the volume of air-filled pore spaces and increases soil bulk density (Cambi et al., 2015; Czyz, 2004; Neira et al., 2015). However, compared to soil, water is a more effective barrier for gas diffusion (Call, 1957) as the diffusion coefficient is about 10,000 times as high in air than in water. Increasing soil moisture changes air-filled pore configuration and adds water-blocked pores that diminish diffusion, which changes soil tortuosity and reduces the connectivity of air-filled pores (Thorbjørn et al., 2008).

In addition to diffusion, other gas transport mechanisms exist especially in water-filled ecosystems such as wetlands where these processes are primarily attributed to $\mathrm{CH}_{4}$ emissions. Ebullition is a process in which part of the gas trapped under the surface is quickly released as bubbles to the atmosphere. The bubbles are kept in place underwater by surface tension forces, and the ebullition occurs when the buoyancy of the bubbles becomes larger than the surface tension forces (e.g. Strack et al., 2005). The bubble release can be either steady or episodic (Coulthard et al., 2009; Goodrich et al., 2011), and it can have a substantial contribution to total wetland $\mathrm{CH}_{4}$ emissions (Stanley et al., 2019; Tokida et al., 2007; Yu et al., 2014), while in other studies their role has been estimated to be small (Männistö et al., 2019; Riutta et al., 2007).

Third, aquatic plants in wetlands can transport $\mathrm{CH}_{4}$ from anoxic soil layer to the atmosphere, bypassing the oxic soil layer and oxidation (Whalen, 2005). This plant-mediated gas transport happens through aerenchyma of the plants either by convective flow or diffusion (e.g. Joabsson et al., 1999; Lai, 2009). The diffusion gradient is created by the concentration difference between the peat and the aerenchyma of the roots, which can be considered as an extension of the atmosphere (Joabsson et al., 1999). In contrast, the bulk flow can be created by differences in temperature or water vapour pressure between the plant and the atmosphere (Lai, 2009). The contribution of plant-mediated transport to total $\mathrm{CH}_{4}$ emissions is highly variable and dependent on the plant species (Bhullar et al., 2013; Dorodnikov et al., 2011; Koelbener et al., 2010; Kutzbach et al., 2004; Schimel, 1995). In general, the presence of plants increases $\mathrm{CH}_{4}$ emissions to the atmosphere. However, the number of roots may enhance methanotrophic activity (Halmeenmäki et al., 2017), for example, by creating oxic pockets around their roots where $\mathrm{CH}_{4}$ oxidation can happen (Le Mer and Roger, 2001). In recent years, tree stems have been found to emit $\mathrm{CH}_{4}$ and $\mathrm{N}_{2} \mathrm{O}$ (e.g. Barba et al., 2018; Machacova et al., 2019). However, their origin, magnitudes and spatial and temporal patterns are still largely unknown (Barba et al., 2018), but it has been suggested that tropical trees can have similar levels of $\mathrm{CH}_{4}$ emissions than the entire Arctic zone (Pangala et al., 2017). 


\subsection{Photosynthesis and respiration}

Plants use solar radiation to synthesise $\mathrm{CO}_{2}$ and water into oxygen and chemical energy; this process is called photosynthesis. Chemical energy is stored in the form of glucose that plants require to survive. The factors affecting photosynthesis described below are based on the plants using C3 pathway, which is the most common method of photosynthesis in the boreal region (Still et al., 2003). In addition to the $\mathrm{C} 3$ pathway, there are also $\mathrm{C} 4$ and CAM pathways. These are used by plants living in hot and dry environments, but some $\mathrm{C} 4$ plants have also been found in the boreal region (Kubien and Sage, 2003; Schwarz and Redmann, 1988). The photosynthetic rate is mainly driven by solar radiation, atmospheric $\mathrm{CO}_{2}$ mixing ratio, temperature, water availability and humidity (IPCC, 2013). Solar radiation is the key driver of photosynthesis (e.g. Farquhar et al., 1980); if there is no light, plants cannot photosynthesise. Increasing light intensity increases the photosynthesis rate, but at some point the rate starts to plateau and increasing light intensity ceases to increase the rate of photosynthesis (Marshall and Biscoe, 1980). In addition to higher light intensity, higher $\mathrm{CO}_{2}$ mixing ratios enhance photosynthesis and stimulate plant growth (Ainsworth and Rogers, 2007; de Graaff et al., 2006). Also, too high or low temperatures reduce the rate of photosynthesis (e.g. Hew et al., 1969). Higher humidity increases photosynthesis by allowing plants to open their stomata wider for gas transport as there is no risk of losing too much water. In dry conditions, plants close their stomata to conserve water, but closing stomata also blocks $\mathrm{CO}_{2}$ from entering the plant and thus prevents photosynthesis.

Respiration is a process in which a cell uses glucose and oxygen to produce energy, and water and $\mathrm{CO}_{2}$ are released as by-products. There are two types of respiration: autotrophic and heterotrophic. Autotrophic respiration originates the metabolism of organic matter by plants and their symbiotic micro-organisms. Heterotrophic respiration is the metabolism of organic matter by fungi, bacteria and soil animals (e.g. Scott-Denton et al., 2006). Autotrophs consume the organic matter made by themselves through photosynthesis, while heterotrophs must consume organic matter produced by autotrophs. In drained peatland forests, decomposition of organic matter in peat can be a significant source of $\mathrm{CO}_{2}$ to the atmosphere. Soil respiration rate, which can be defined as a sum of root and heterotrophic respiration, is mainly controlled by temperature (e.g. Conant et al., 2011; Lloyd and Taylor, 1994; Reichstein et al., 2000), moisture (Carlyle and Ba Than, 1988; Howard and Howard, 1993; Moyano et al., 2013), and substrate availability, quality and accessibility (Dungait et al., 2012; Fernández-Martínez et al., 2014; Hättenschwiler and Jørgensen, 2010; Manzoni et al., 2010). Soil temperature and moisture together explain most of the variation in soil respiration when neither of these is too extreme. Respiration rate increases with temperature up to a universal threshold of about $25^{\circ} \mathrm{C}$, above which it starts to decrease with increasing temperature (Carey et al., 2016). However, soil respiration is not sensitive to moisture at low temperatures (below $5{ }^{\circ} \mathrm{C}$ ) or to the temperature at low moisture (below 7.5\%v) (Carlyle and Ba Than, 1988).

The net $\mathrm{CO}_{2}$ flux is generally, especially when using the EC method (Sect. 3.2), expressed as net exchange (NEE) between the ecosystem and the atmosphere. NEE is a combination of two processes: gross primary production (GPP) and ecosystem respiration (ER) (Fig. 2). ER is a sum of autotrophic and heterotrophic respiration, while GPP describes the gross amount of $\mathrm{C}$ the vegetation fixes from the atmosphere through photosynthesis. In this thesis, micrometeorological sign convention is adopted, which means that a positive NEE denotes a flux from the ecosystem to the atmosphere (net 
emission) and a negative NEE indicates a flux from the atmosphere into the ecosystem (net uptake). By definition, soil respiration includes heterotrophic (HR) and root respiration. When the aboveground parts of the ground vegetation are also included, one is measuring the total autotrophic and heterotrophic respiration whose sum in this thesis called the forest floor respiration (FFR). The total autotrophic forest floor respiration (FF, AR) includes the respiration by the tree and plant roots, and also the above-ground parts of the plants (Fig. 2).

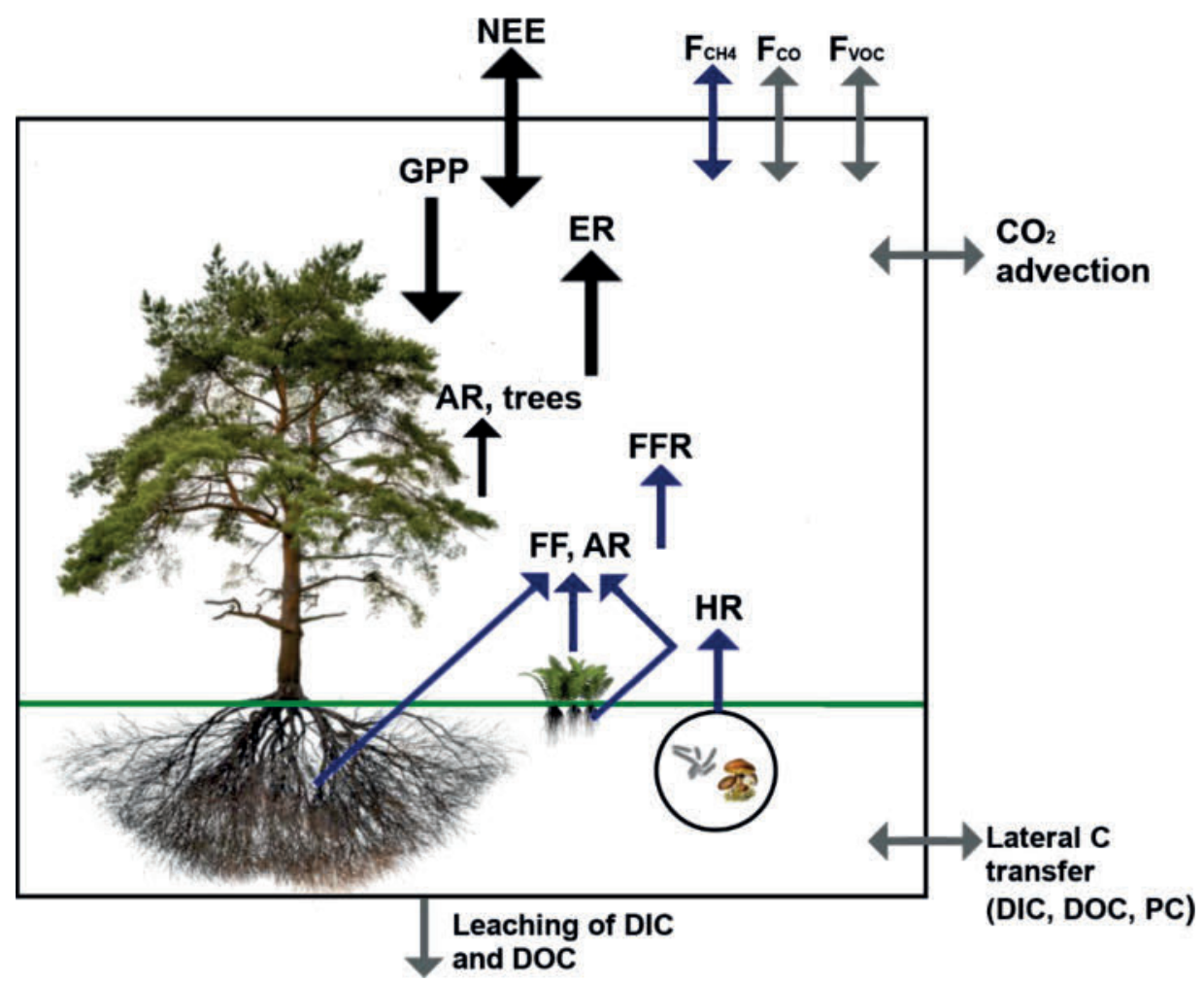

Figure 2. Most significant carbon (C) fluxes determining the carbon balance of an ecosystem. The box represents the ecosystem and green line the soil surface. The large black arrows indicate the vertical net ecosystem $\mathrm{CO}_{2}$ exchange (NEE) (emission or uptake) measured by the eddy covariance method and the components of NEE: gross primary production (GPP) and ecosystem respiration (ER). ER consists of autotrophic respiration of trees (AR, trees) and total forest floor respiration (FFR), respiration of forest floor plants and their roots (FF, AR), and heterotrophic respiration (HR). Blue arrows indicate the fluxes measured with the chamber method in this thesis (FF, AR, HR, and methane flux $\left(F_{C H 4}\right)$ ). The grey arrows indicate the fluxes not estimated in this thesis: carbon monoxide flux $\left(F_{C O}\right)$, volatile organic $\mathrm{C}$ flux $\left(F_{V O C}\right)$, leaching of dissolved organic and inorganic $\mathrm{C}$ (DOC and DIC), and movement of particulate $\mathrm{C}(\mathrm{PC})$. Advection of $\mathrm{CO}_{2}$ was also assumed negligible. The figure is modified from the original figure by Chapin et al. (2006).

One of the most relevant questions in peatland forestry is what is the long-term $\mathrm{C}$ balance of the forest ecosystem when considering all the negative effects of the harvesting and the positive effect of carbon uptake by the vegetation. Pristine peatlands are mainly small $\mathrm{CO}_{2}$ sinks (e.g. Aurela et al., 2002; 
Nilsson et al., 2008; Roulet et al., 2007; Sottocornola and Kiely, 2005) due to carbon accumulation by primary production dominating over the low decomposition rates, which are mostly attributed to anoxic soil conditions resulting from a high WTL. Draining peatlands exposes peat to oxygen, hence accelerating the decomposition process and increasing $\mathrm{C}$ loss and $\mathrm{CO}_{2}$ emissions; this occurs mainly on nutrient-rich soils (Ojanen et al., 2010). The growing tree stand uptakes $\mathrm{CO}_{2}$, which may offset the $\mathrm{CO}_{2}$ loss by peat decomposition, hence turning a peatland forest to a temporary $\mathrm{CO}_{2}$ sink (Hargreaves et al., 2003; Hommeltenberg et al., 2014; Lohila et al., 2011; Meyer et al., 2013; Minkkinen et al., 2018). Although, mature tree stands with high evapotranspiration may enhance peat decomposition due to lowered WTL (Ojanen et al., 2010). However, the trees are eventually harvested, and the C in wood is gradually lost back to the atmosphere. The rate of this $\mathrm{C}$ loss depends on the use of the wood.

\section{4 $\mathrm{CH}_{4}$ production and consumption in soil}

The $\mathrm{CH}_{4}$ production process is run by methanogenic archaea (methanogens; Garcia et al., 2000). This process is a part of the decomposition of organic matter, in which methanogens use hydrogen and acetate as energy sources to produce $\mathrm{CH}_{4}$ (Conrad, 1999). The production rate mostly depends on the supply of organic matter at low redox potential, soil temperature, and pH (Dunfield et al., 1993; Kotsyurbenko et al., 2004; Segers, 1998; Wang et al., 1993). The production rate increases with increasing temperatures until reaching the optimum of around $20-30{ }^{\circ} \mathrm{C}$ (Dunfield et al., 1993) and is lower on acidic soils. In peat and upland soil, anoxic conditions typically occur below WTL, which is generally the most important factor determining whether the soil is a net $\mathrm{CH}_{4}$ source or sink as it defines the thickness of the oxic and anoxic soil layers. However, there have been observations of $\mathrm{CH}_{4}$ production in oxic soils (von Fischer and Hedin, 2002, 2007), and it has been proposed that methanogens also live in oxic soils and activate, for example, in high soil moisture conditions (Angel et al., 2011, 2012; Angle et al., 2017; Lohila et al., 2016).

$\mathrm{CH}_{4}$ oxidation is carried out by methanotrophic bacteria (methanotrophs), which use $\mathrm{CH}_{4}$ as their energy source and assimilate $\mathrm{C}$. The traditional $\mathrm{CH}_{4}$ oxidation process uses oxygen as an oxidiser. However, anaerobic oxidation has also been observed in peat soils (Blazewicz et al., 2012), where it was likely mediated by methanogenic archaea. Independent of the electron acceptor, the final product of $\mathrm{CH}_{4}$ oxidation is $\mathrm{CO}_{2}$. $\mathrm{CH}_{4}$ oxidation rate depends on soil temperature, soil moisture, $\mathrm{pH}, \mathrm{CH}_{4}$ and oxygen concentrations, and nutrient availability (Boeckx and Van Cleemput, 1996; Dunfield et al., 1993; Ridgwell et al., 1999; Scheutz and Kjeldsen, 2004). $\mathrm{CH}_{4}$ oxidation increases with temperature and reaches its optimum at $19-30{ }^{\circ} \mathrm{C}$ (Börjesson et al., 2007; Einola et al., 2008; Scheutz et al., 2009; Stern et al., 2007). Also, extreme soil moistures inhibit $\mathrm{CH}_{4}$ consumption in the soil, probably due to physiological water stress on methanotrophs and decreased amount of oxygen in the soil in low and high soil moistures (Van Den Pol-van Dasselaar et al., 1998), respectively. The net $\mathrm{CH}_{4}$ flux $\left(F_{C H 4}\right)$ is a combination of anaerobic production and aerobic oxidation processes.

Generally, wetlands act as net $\mathrm{CH}_{4}$ emitters due to their high WTL and thin oxic layer that is not enough to oxidise the $\mathrm{CH}_{4}$ produced in the anoxic layer. Unlike wetlands, properly drained peatland forest soils generally act as $\mathrm{CH}_{4}$ sinks (Lohila et al., 2011; Martikainen et al., 1995; Minkkinen et al., 2007; Ojanen et al., 2010), but the drainage ditches may still yield significant local emissions (e.g. 
Luan and Wu, 2015; Minkkinen et al., 1997; Minkkinen and Laine, 2006). In some cases, drainage has been unsuccessful, and the soil has remained a $\mathrm{CH}_{4}$ source (Ojanen et al., 2010). Also, upland forest soils can be $\mathrm{CH}_{4}$ emitters after heavy rainfall or extended wetter periods (Lohila et al., 2016), which may be true also for peatland forests. Trees have also been found to emit $\mathrm{CH}_{4}$, but currently the origin, magnitudes, and temporal and spatial variation of these emissions are poorly understood (Sect. 2.2; Barba et al., 2018).

\section{$2.5 \mathrm{~N}_{2} \mathrm{O}$ production in soil}

In soil, $\mathrm{N}_{2} \mathrm{O}$ is produced as a by-product of two chained processes: aerobic nitrification and anaerobic denitrification (e.g. Smith et al., 2018). In nitrification, ammonium $\left(\mathrm{NH}_{4}^{+}\right)$is oxidised to nitrite $\left(\mathrm{NO}_{2}^{-}\right)$ and then to nitrate $\left(\mathrm{NO}_{3}^{-}\right)$by a combination of bacterial and archaea processes (Fig. 3). In denitrification, $\mathrm{NO}_{3}^{-}$is reduced to $\mathrm{NO}_{2}^{-}$, which is further reduced to nitric oxide (NO). Next, $\mathrm{NO}$ is reduced to $\mathrm{N}_{2} \mathrm{O}$ and finally to molecular nitrogen $\left(\mathrm{N}_{2}\right)$. N availability is one of the main factors driving these processes. However, in anoxic conditions in which denitrification process occurs, $\mathrm{N}$ is mainly bound to organic compounds and not readily available for the process, even though increased $\mathrm{N}_{2} \mathrm{O}$ emissions have been found from soils with high N supply (Augustin et al., 1998; Nykänen et al., 2002; Regina et al., 1998). Therefore, nitrification is required for producing inorganic $\mathrm{N}\left(\mathrm{NO}_{3}^{-}\right)$to run denitrification. However, nitrification is limited to the oxic rooting zone, and those conditions do not favour denitrification. Finally, $\mathrm{N}_{2} \mathrm{O}$ can also be produced by non-biological processes in neutral and acidic soils (Fig. 3).

The other crucial factor driving $\mathrm{N}_{2} \mathrm{O}$ fluxes $\left(F_{N 2 O}\right)$ in the soil is oxygen supply, which is driven by soil moisture. Soil moisture controls the transport of $\mathrm{NO}, \mathrm{N}_{2} \mathrm{O}$ and $\mathrm{N}_{2}$ out of the soil and the transport of oxygen into the soil. $F_{N 2 O}$ has been found to correlate both positively and negatively (e.g. (Dobbie et al., 1999; Schaufler et al., 2010; Skiba et al., 1998; Sosulski et al., 2014; Van Der Weerden et al., 2012) with soil moisture with an optimum value within 60-95\% depending on soil type (Balaine et al., 2013; Christiansen et al., 2012; Davidson et al., 2000; Schindlbacher et al., 2004). Nitrification dominates in dry soil due to mineralisation of organic $\mathrm{N}$ to $\mathrm{NH}_{4}^{+}$. As diffusion is also increased in dry soils because of the larger air-filled pores, more NO can diffuse from the soil to the atmosphere (Goldberg et al., 2010; Schaufler et al., 2010) before it is reduced to $\mathrm{N}_{2} \mathrm{O}$ (Bollmann and Conrad, 1997). Wetting the soil decreases the effective gas diffusivity, and more $\mathrm{NO}$ reduces to $\mathrm{N}_{2} \mathrm{O}$ assuming adequate $\mathrm{NO}_{3}^{-}$supply from nitrification. However, if the soil gets too wet, $\mathrm{N}_{2} \mathrm{O}$ could reduce to $\mathrm{N}_{2}$ before being emitted to the atmosphere (Davidson et al., 2000). Ultimately, $\mathrm{N}_{2} \mathrm{O}$ emissions decrease in very wet conditions as constrained nitrification causes a lack of $\mathrm{NO}_{3}^{-}$and hinders denitrification (Regina et al., 1999). 


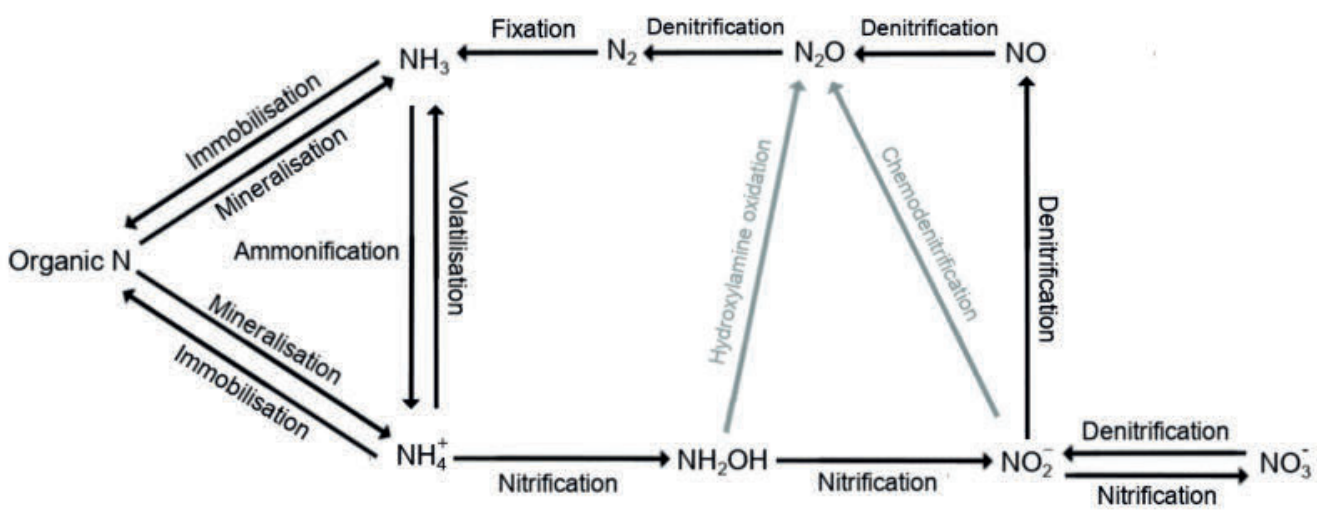

Figure 3. Nitrogen cycle. Black arrows denote biological and grey arrows non-biological processes. Modified after Signor and Cerri (2013).

Generally higher soil temperatures enhance $\mathrm{N}_{2} \mathrm{O}$ emissions (e.g. Dobbie and Smith, 2001; Schaufler et al., 2010; Schindlbacher et al., 2004; Sosulski et al., 2014), but negative relationships have also been observed (Dijkstra et al., 2012; Teh et al., 2011) suggesting that temperature alone cannot explain $F_{N 2 O}$, but it should be considered together with other factors such as soil moisture. An essential part of soil $\mathrm{N}_{2} \mathrm{O}$ emissions are the freeze-thaw cycles, which results in elevated emissions in times when the soil freezes and thaws. This phenomenon has been observed in multiple studies in temperate forests and agricultural soils, and the emissions during these cycles can constitute a substantial part of the annual $\mathrm{N}_{2} \mathrm{O}$ balance (Luo et al., 2012; Papen and Butterbach-Bahl, 1999; Peng et al., 2019; Röver et al., 1998). $\mathrm{N}_{2} \mathrm{O}$ fluxes are difficult to predict due to the high temporal variation and the fact that $F_{N 2 O}$ is not directly related to soil temperature and WTL, as is generally observed for $\mathrm{CO}_{2}$ and $\mathrm{CH}_{4}$ (Minkkinen et al., 2008). Predicting is hard even with detailed process models due to multiple $\mathrm{N}$ forms and microbial processes involved in $\mathrm{N}_{2} \mathrm{O}$ production (Butterbach-Bahl et al., 2013). However, reasonable success has been achieved in recent years (Leppelt et al., 2014; Pärn et al., 2018).

In pristine boreal peatlands, $\mathrm{N}_{2} \mathrm{O}$ emissions are generally low (e.g. Kløve et al., 2010; Martikainen et al., 1993; Nykänen et al., 1995; Regina et al., 1996). In forestry drained peatlands, multiple studies have observed highly variable emissions (2-104 $\mu \mathrm{g} \mathrm{N}_{2} \mathrm{O} \mathrm{m} \mathrm{m}^{-2} \mathrm{~h}^{-1}$ ) (e.g. Von Arnold et al., 2005; Aurangojeb et al., 2017; Ernfors et al., 2011; Mäkiranta et al., 2007), but on average the emissions from drained ombrotrophic peatlands are lower than from minerotrophic sites (Maljanen et al., 2010). Minerotrophic sites have lower $\mathrm{C}: \mathrm{N}$ ratios than the ombrotrophic ones and it has been shown that high $\mathrm{N}_{2} \mathrm{O}$ emissions occur mainly from sites with a soil C:N ratio lower than 25 (Ernfors et al., 2008; Klemedtsson et al., 2005; Minkkinen et al., 2020). 


\subsection{Evapotranspiration as a part of surface energy balance}

The surface energy balance is a concept used to explain how short-wave and long-wave radiation are distributed between sensible and latent heat fluxes and the subsurface storage in an ecosystem. The surface energy balance can be written as:

$$
(1-\alpha) R_{S \downarrow}+R_{L \downarrow}-R_{L \uparrow}=F_{H}+F_{L}+F_{G}
$$

where $R_{S \downarrow}$ is incoming short-wave radiation, $\alpha$ is albedo denoting how much $R_{S \downarrow}$ was reflected by the surface, $R_{L \downarrow}$ and $R_{L \uparrow}$ are the incoming and outgoing long-wave radiation, respectively, $F_{H}$ is sensible heat flux, $F_{L}$ is latent heat flux, and $F_{G}$ is ground heat flux. The left-hand side of Eq. (2) can also be expressed as net radiation, denoting how much the surface gains or loses energy. $F_{G}$ describes the transfer of heat by conduction, and it is positive when the heat is transferred from the surface into the ground. $F_{H}$ describes the heat transfer by atmospheric convection, and it is directly proportional to the temperature difference between the air and the surface. Finally, $F_{L}$ represents the heat absorbed or released in phase transitions of water and depends on the moisture gradient between the surface and the atmosphere. Even though small negative water vapour fluxes (deposition of water from the atmosphere into the surface) are possible during specific conditions when condensation on the surface occurs, $F_{L}$ is typically positive, i.e. the equivalent water vapour flux is from the ecosystem to atmosphere, due to evapotranspiration (ET).

ET is a combination of evaporation of water from a surface such as soil, and transpiration, which is the evaporation of water from vegetation. ET is a key process involved in both the surface energy balance and ecosystem water balance. It can be either directly measured by the EC method or indirectly estimated using the Penman-Monteith equation (Monteith, 1965). This equation is based on energy conservation and parameterisation of surface (or stomatal) and aerodynamic resistances. Even though the Penman-Montheith equation is widely used, it is challenging to implement due to problems in parameterising the resistance terms, especially the stomatal resistance (e.g. Fisher et al., 2008; Polhamus et al., 2013). Stomata are pores found in leaves of plants. Plants use stomata to exchange gases such as $\mathrm{CO}_{2}$, oxygen and water vapour by diffusion between plant cells and the atmosphere. One stoma consists of the pore and guard cells, which regulate the stomatal aperture according to light intensity, humidity and $\mathrm{CO}_{2}$ concentration (e.g. Ball et al., 1987; Leuning, 1995; Wong et al., 1979).

The carbon and nitrogen cycles of peatlands are profoundly affected by hydrological conditions (e.g. Samson et al., 2018), as WTL is one of the main drivers controlling NEE, $F_{C H 4}$ and $F_{N 2 O}$ in peatlands (Limpens et al., 2008; Waddington et al., 2015; Wu et al., 2011). A significant amount of water in peatlands is lost by ET, but this varies considerably by local climate and peatland characteristics such as vegetation type (Lafleur, 2008). The measurements have shown that boreal peatland ET increases more than forest ET with warming climate (Helbig et al., 2020), which could lower the WTL in northern peatlands (IPCC, 2013) and enhance C emissions from peat. However, it is possible that the emissions from peat could be offset by enhanced $\mathrm{C}$ accumulation due to changes in vegetation (Loisel and Yu, 2013; Strack and Waddington, 2007). Human-induced changes in the peatland water cycle include peatland drainage. During the first years after the drainage, runoff is increased and ET decreased (Ahti, 1987). As the tree stand develops, transpiration and interception increase leading to 
declined runoff volumes (Koivusalo et al., 2008). Also, evaporation diminishes as a result of the lesser amount of available energy at the surface (Kettridge et al., 2013). The enhanced transpiration from trees lowers WTL (e.g. Hökkä et al., 2008; Sarkkola et al., 2010), hence decreasing soil moisture. Decreasing soil moisture enhances peat subsidence (Grzywna, 2017; Zanello et al., 2011) and alters the bulk density of peat (Silins and Rothwell, 1998), which affects hydraulic properties of the peat and could further change WTL (Sarkkola et al., 2010). 


\section{Flux measurement techniques in forests}

Multiple direct measurement methods exist to estimate the exchange of $\mathrm{C}$ and $\mathrm{N}$ between ecosystems and the atmosphere. Changes in soil $\mathrm{C}$ and $\mathrm{N}$ stocks can be measured by soil sampling, but the vast background of soil $\mathrm{C}$ stock and spatial variation require long sampling intervals and large sample sizes to detect any meaningful changes (Mäkipää et al., 2008). Other methods, such as spectral (Smith et al., 2019) and soil gradient (Maier and Schack-Kirchner, 2014) techniques exist, but the most common methods to estimate changes in soil stocks and especially the GHG fluxes between ecosystems and the atmosphere are the chamber and EC methods.

\subsection{Chamber method}

The chambers used for determining the soil-atmosphere GHG fluxes can be divided into two main categories: closed and open chambers (e.g. Pavelka et al., 2018; Pumpanen et al., 2010). In open, dynamic (steady-state flow-through) chambers, the air is sampled to a gas analyser, and replacement air with a known gas mixing ratio is continuously inserted into the chamber to maintain pressure equilibrium. When the system reaches a steady-state condition, the flux can be calculated as the difference between gas concentration at the inlet and outlet of the chamber while taking into account the through-flow rate and the chamber surface area (e.g. Pumpanen et al., 2004, 2010). The closed chambers can be further divided into closed dynamic (non-steady-state flow-through) and closed static (non-steady-state non-flow-through) chambers. In closed chambers, the gas mixing ratio keeps increasing or decreasing until it equals the mixing ratio in soil, and the flux calculation is based on the change of gas mixing ratio in time inside the chamber. Static and dynamic closed chambers differ by the fact that while dynamic chambers are sampled continuously with a gas analyser and the sampled air is returned to the chamber, the static chambers have no continuous circulation of sample air between the analyser and the chamber, but are typically sampled intermittently by syringes, the gas from which is analysed afterwards in a laboratory. Consequently, static chambers are cheaper to deploy than dynamic chambers, but they may cause considerable uncertainty in the flux estimation (e.g. Norman et al., 1997; Pumpanen et al., 2004) possibly due to uncertainty of the effective volume of the closed system, especially the air volume in the soil (Rayment, 2000). In comparison to dynamic chambers, static chambers markedly alter the diffusion gradient between the chamber headspace and soil during long incubation times (e.g. Gao and Yates, 1998), unless more frequent initial samples are taken (Heinemeyer and McNamara, 2011). On the other hand, no significant differences have been observed between dynamic closed and open chambers in laboratory conditions (Pumpanen et al., 2004).

Soil chambers are especially useful for studying small-scale processes, but they have their shortcomings. The geometrical design of the chamber affects the measured flux (Pumpanen et al., 2004); increasing chamber height, area and volume have been shown to decrease the flux underestimation (Pihlatie et al., 2013), which complicates comparability between the studies. Also, chambers disturb the measurement target potentially causing a bias in the flux estimates. The air circulation in dynamic chambers and inserting a closed chamber can affect the vertical pressure gradient in the soil, which can result in under- or overestimation of the flux even with minimal 
pressure differences between the chamber headspace and the atmosphere (e.g. (Christiansen et al., 2011; Fang and Moncrieff, 1996; Hutchinson et al., 2000; Longdoz et al., 2000). The pressure changes can be minimised by using a vent tube (Hutchinson and Livingston, 2001; Xu et al., 2006). Also, even though the use of a fan is recommended to mix the air inside the chamber (Christiansen et al., 2011; Pumpanen et al., 2004), it disturbs the natural turbulent conditions in the chamber headspace. However, the air inside the closed chambers has to be mixed to determine the flux correctly, but the fan should spin at the minimum speed (Koskinen et al., 2014) to prevent turbulence-enhanced mass flow from the soil to the chamber (Pumpanen et al., 2004).

Most of the chamber systems used in the GHG flux measurements are based on the closed chamber systems (Pavelka et al., 2018; Pihlatie et al., 2013), likely as they are more mobile, making spatial sampling easier compared to dynamic chambers. Closed chambers require sealing the soil surface by pushing the chamber into the ground or by using a collar. An advantage of using a collar is the airtight connection between the chamber and soil, which leads to a lower sensitivity to leakages on porous soil and windy conditions. However, cutting roots should be avoided during collar installation as roots contribute significantly to soil respiration (Hanson et al., 2000).

The gas flux $\left(F_{\text {gas }}, \mu \mathrm{g}\right.$ gas $\left.\mathrm{m}^{-2} \mathrm{~s}^{-1}\right)$ in a closed chamber based on ideal gas law can be calculated as:

$$
F_{\text {gas }}=\left(\frac{d c}{d t}\right)_{t=0} \frac{M P V}{R T A}
$$

where $\mathrm{M}$ is the molecular mass of the gas $\left(\mathrm{g} \mathrm{mol}^{-1}\right), P$ is the air pressure $(\mathrm{Pa}), R$ is the universal gas constant $\left(8.31446 \mathrm{~J} \mathrm{~mol}^{-1} \mathrm{~K}^{-1}\right), T$ is the mean chamber headspace temperature $(\mathrm{K})$ during the closure, $V$ is the volume $\left(\mathrm{m}^{3}\right)$ of the chamber and the possible collar, and $A$ is the base area $\left(\mathrm{m}^{2}\right)$ of the chamber or a possible collar. $\left(\frac{d c}{d t}\right)_{t=0}$ is the rate of change of gas mixing ratio (ppm s$)^{-1}$ ) at the start of the chamber closure, which can be estimated by fitting a linear or non-linear model into the gas mixing ratio time series measured during a chamber closure.

The selection of the fitting method can be a large source of uncertainty in flux calculations from closed chamber data (Levy et al., 2011; Venterea, 2013) as the gas concentration gradient between the soil and the atmosphere may be disturbed (e.g. Conen and Smith, 2000; Davidson et al., 2002; Healy et al., 1996). For example, when the chamber is closed during respiration measurements, $\mathrm{CO}_{2}$ accumulates within the chamber headspace, which decreases the diffusion gradient and flattens the $\mathrm{CO}_{2}$ concentration development inside the chamber. Using linear regression in these conditions can cause significant flux underestimations (e.g. Hutchinson et al., 2000; Kutzbach et al., 2007; Livingston et al., 2005, 2006; Nakano et al., 2004; Pedersen et al., 2010; Pihlatie et al., 2013) as it assumes constant concentration development inside the chamber. Non-linear fitting models have been developed from diffusion theory (Kutzbach et al., 2007; Livingston et al., 2005, 2006) and such a model has been shown to significantly reduce the flux underestimation due to linear regression when using the initial concentration change in time (i.e. at the time when the chamber closes) to calculate the flux (Pihlatie et al., 2013). However, non-linear models are sensitive to initial noise caused by pressure and turbulence disturbances during chamber deployment (Kutzbach et al., 2007). The initial noise has to be discarded, and the starting time has to be delayed leading to inherent flux 
underestimation. Also, another disadvantage of non-linear regressions is the fact that they require more data points than linear regression, hence limiting their usage with data collected with static chamber.

\subsection{Eddy covariance method}

The lowest part of the atmosphere, i.e. the atmospheric boundary layer (ABL), can be depicted as a chaotic system that is composed of numerous turbulent vortices called eddies. The size of the eddies ranges from millimetres up to several kilometres. The turbulent eddies are the most significant mechanism behind the vertical transport of trace gases, heat and moisture in the ABL, except in the first few millimetres above the ground where molecular diffusion dominates. In the EC method, horizontal and vertical wind speed, and a scalar of interest are measured with a high frequency to obtain the vertical turbulent flux. The method is based on the conservation of mass, and after Reynolds averaging the scalar flux $\left(F_{c}\right)$ can be written as (e.g. Baldocchi, 2003; Loescher et al., 2006):

$$
F_{c}=\bar{\rho} \int_{0}^{z}(\underbrace{\frac{\partial \bar{c}}{\partial t}}_{\text {Term } 1}+\underbrace{\bar{u} \frac{\partial \bar{c}}{\partial x}+\bar{v} \frac{\partial \bar{c}}{\partial y}+\bar{w} \frac{\partial \bar{c}}{\partial z}}_{\text {Term } 2}+\underbrace{\frac{\partial \overline{u^{\prime} c^{\prime}}}{\partial x}+\frac{\partial \overline{v^{\prime} c^{\prime}}}{\partial y}+\frac{\partial \overline{w^{\prime} c^{\prime}}}{\partial z}}_{\text {Term } 3})
$$

where $c$ is the scalar (ex. gas mixing ratio), $\rho$ is the air density, $u, v$ and $w$ are the along-wind, crosswind and vertical wind speeds, respectively, and $x, y$, and $z$ are the corresponding Cartesian coordinates, and $t$ is time. Overbars represent time averaging, while primes denote the turbulent fluctuations, i.e. deviations from the mean. The mass balance equation can be simplified by noting that the horizontal flux divergence is significantly smaller than the vertical flux divergence, which makes it possible to remove the horizontal components from Term 3. Also, when the measurements are made over a horizontally homogeneous and flat surface, the advection component can be ignored (Term $2=0$ ). After these assumptions, integrating from the surface up to the measurement height results in:

$$
F_{C}=\bar{\rho} \overline{w^{\prime} c^{\prime}}(z)+\bar{\rho} \int_{0}^{z} \frac{\partial \bar{c}}{\partial t} d z=F_{E C}+F_{S T G}
$$

where $F_{E C}$ is the EC flux or the vertical turbulent flux and $F_{S T G}$ is the storage change flux, which accounts for the mass changes below the measurement height in the vertical column.

In practice, $F_{E C}$ is estimated by measuring the three wind components with a sonic anemometer, and the scalar is measured, in the case of a gas mixing ratio, with a fast-response gas analyser. Capturing all the different-sized eddies contributing to the flux requires that the scalar and wind components are sampled with an adequate frequency and duration. Using anemometers and gas analysers with fast response time and sampling frequency of $10 \mathrm{~Hz}$ is considered sufficient to capture the smallest eddies contributing to vertical transport (Rinne and Ammann, 2012). An averaging period of $30 \mathrm{~min}$ is 
generally used to sample the large eddies associated with the convective boundary layer (Moncrieff et al., 2004). After measurements, the covariance can be calculated as:

$$
\overline{w^{\prime} c^{\prime}}=\frac{1}{N} \sum_{i=1}^{N} w_{i}^{\prime} c_{i}^{\prime}
$$

where $N$ is the number of measurements within the averaging period.

Depending on atmospheric conditions and characteristics of the measurement site, the conditions can be non-stationary, and the storage term can be a significant component of the total flux. For example, in a forest with a high canopy, gas can build up during the night due to a lack of turbulence, and this build-up can be moved horizontally and vertically very fast by wind gusts. In this case, $F_{S T G}$ can remain undetected or cause overestimation of the $F_{C}$ unless it is corrected by $F_{S T G}$. Storage change fluxes are estimated by vertical gas profile measurements (e.g. Montagnani et al., 2018). Increasing the measured vertical levels increases the accuracy of $F_{S T G}$ as long as the vertical configuration of the profiling system is optimised (Yang et al., 2007). On daily and longer timescales, the storage change flux is approximately zero (Loescher et al., 2006), meaning it is not a necessary component when calculating, for example, annual balances.

After calculating the fluxes, their quality must be verified, for example, by discarding the periods when the flux did not originate from the target area and the periods of low turbulence. The source area of the measured flux can be estimated by using footprint models based on parameterisations of boundary layer mixing (Rannik et al., 2012). The footprint function, i.e. the relative contribution of each surface element to the measured flux, peaks at a certain distance from the measurement tower, after which it decreases towards the prevailing wind direction. The source area is calculated by integrating the footprint function up to a point where, for example, $75 \%$ of the measured flux originates from. If the source area does not fit within the target area, the measured flux is discarded.

The use of EC method requires turbulent flow conditions, and thus nighttimes can be problematic due to a lack of surface heating from solar radiation (no convective mixing) and the stably stratified surface layer that suppresses sheer-induced turbulence (e.g. Baldocchi, 2003; Loescher et al., 2006). The lack of turbulent mixing diminishes the vertical gas transport, hence decoupling the surface from the atmosphere and causing the $F_{E C}$ to underestimate ER (Baldocchi, 2003). The cases of low turbulence are usually discarded based on the friction velocity $\left(u_{*}\right)$ threshold (Foken et al., 2012; Moncrieff et al., 2004). When estimating mass and energy balances, the discarded periods need to be gap-filled. Multiple gap-filling methods based on mechanistic, parametric, statistical and neuralnetwork methods exist (e.g. Falge et al., 2001; Kim et al., 2019; Wutzler et al., 2018; Zhao and Huang, 2015).

The measured turbulent flux contains uncertainties which can be divided into random and systematic (bias) uncertainties. Random errors originate from instrument noise caused by the limited precision of the instruments, and also from the sampling errors related to both the stochastic nature of turbulence, and the flux footprint heterogeneity (e.g. Flanagan and Johnson, 2005; Lenschow et al., 1994; Richardson et al., 2012). Random errors cannot be corrected for, but they can be estimated (e.g. Billesbach, 2011; Finkelstein and Sims, 2001; Moncrieff et al., 1996; Salesky et al., 2012; Wienhold et al., 1995). Also, random errors decrease when extending the dataset (Moncrieff et al., 1996), and 
in annual ecosystem $\mathrm{C}$ balances; for example, they are generally small. Unlike random errors, systematic errors can remain constant over long time periods (e.g. Post et al., 2015), hence they may have a severe effect on the annually accumulated flux. On the other hand, some of the systematic errors can be corrected for, but this requires identification and quantification of the various error sources. Systematic errors may result from instrument calibration and design, and from data processing methods such as gap filling (e.g. Richardson et al., 2012). Other systematic errors may arise from measurements performed in non-ideal conditions (e.g. complex landscape), when the underlying assumptions of the EC method, most notably no advection or horizontal divergence, are violated (Loescher et al., 2006; Richardson et al., 2012). 


\section{Peatland forest management in Finland}

The most common forest management method in Finland has been the even-aged management (EM) (e.g. Nieminen et al., 2018). In EM, the aim is to grow stands consisting of one or two tree species with similar age, size and quality. During the growth stage, the forest is thinned to create space for the remaining trees to grow, until the stem harvest is made by clearcutting. After clearcutting, the forest is regenerated by soil preparation and seeding or planting tree seedlings. Also, ditch-mounding is typically needed after clearcutting to lower the temporarily risen WTL, and ditch network maintenance is further needed every 20-40 years to sustain the drainage conditions (e.g. Sikström and Hökkä, 2016). However, ditch-mounding decreases the water quality by releasing nutrients and C into water bodies (Joensuu et al., 1999; Kaila et al., 2014, 2015; Nieminen et al., 2010, 2015; Rodgers et al., 2010). All these actions require major economic investments. While small revenue can be achieved from thinnings, most of the income is received usually once during a lifetime after clearcutting (e.g. Kojola et al., 2012). On the other hand, clearcutting is associated with substantial adverse environmental impacts. In addition to effects on water quality, clearcutting alters microclimate, vegetation structure and the amount of biomass (e.g. Jandl et al., 2007; Kowalski et al., 2004), which affect forest's $\mathrm{C}, \mathrm{N}$ and water balances.

Continuous cover forestry $(\mathrm{CCF})$ has been proposed as an alternative to EM due to adverse environmental impacts of EM, and because EM is less profitable in peatland than upland forests (Hynynen et al., 2015; Kojola et al., 2012). In CCF, the forest is never clear-cut, and stem wood is collected by selective harvestings, which are decided depending on the forest features and the aims of the forest management, but not on stand rotations. Usually, both bigger and smaller trees are harvested, allowing the remaining stand to grow larger and the open places to regenerate naturally without planting new seedlings. As a result, the tree stand is uneven-aged and -structured. Also, as the tree stand is not entirely removed, ET of the remaining tree stand may keep the WTL low enough for optimal tree growth without ditch-mounding (Sarkkola et al., 2010, 2013). As ditch-mounding, seeding or planting trees, and ditch network maintenance are not needed, the economic investments of CCF are lower than those in EM, but the overall economic performance of CCF in peatland forests is still uncertain. However, using CCF could bring environmental benefits compared to EM as water quality should remain better due to the lack of ditch-mounding. Also, the GHG emissions could be lower compared to EM as the environmental conditions like WTL, radiation, and soil temperature would not change as much because of the remaining tree stand. 


\section{Materials and methods}

\subsection{Experimental site}

Lettosuo is a nutrient-rich peatland forest located in the Tammela municipality in southern Finland $\left(60^{\circ} 38^{\prime} 31^{\prime \prime} \mathrm{N}, 23^{\circ} 57^{\prime} 35^{\prime}\right.$ ' E). Lettosuo was originally a sedge fen which was sparsely drained in the 1930s, but proper drainage was carried out in 1969, after which the site was fertilised with phosphorous and potassium. Ditches were dug ca. $1 \mathrm{~m}$ deep with, on average, $45 \mathrm{~m}$ spacing from each other to lower the WTL to enhance aeration, and thereby larger rooting volume for trees, and microbial activity of the surface soil. During the next decades, the forest emerged and became dominated by Scots pine (Pinus sylvestris) and some downy birch (Betula pubescens). The understorey consisted of mostly Norway spruce (Picea abies) and some small-sized downy birch. Ground vegetation included herbs, such as Trientalis europaea and Dryopteris carthusiana, and dwarf shrubs, such as Vaccinium myrtillus (Bhuiyan et al., 2017). The moss layer was dominated by Pleurozium schreberi and Dicranum polysetum with some Sphagnum mosses, such as Sphagnum capillifolium, S. angustifolium and S. russowii, in wet patches. According to the site type classification of drained peatlands (Vasander and Laine, 2008), Lettosuo represents a Vaccinium myrtillus type site (Mtkg II).

Measured from 35 sampling points within a circular area with a $200 \mathrm{~m}$ radius, the soil organic $\mathrm{C}$ content at the site averaged $58 \pm 3 \%$, the $\mathrm{C}$ content being rather uniform across different soil layers. The total soil $\mathrm{N}$ content was lowest in the litter layer (1.7\%) and varied from $2.2 \%$ to $2.5 \%$ in the 0 $40 \mathrm{~cm}$ soil layer. The C:N ratio averaged at $27 \pm 4$ from humus up to the $50 \mathrm{~cm}$ depth, which is typical for peatland forests with a fen history. The mean soil bulk density of the $0-40 \mathrm{~cm}$ layer was $0.14 \pm 0.02$ $\mathrm{g} \mathrm{cm}^{-3}( \pm \mathrm{SD})$, and the ash content of the peat varied within 3.4-6.5\%. The present-day peat thickness at Lettosuo varies mostly between 1.5 and $2.5 \mathrm{~m}$. The area is flat, with an average slope of $0.2^{\circ}$. The mean long-term (1981-2010; Pirinen et al., 2012) annual temperature was $4.6{ }^{\circ} \mathrm{C}$, but all the measurement years (2015-2019; Table 1) were warmer than that average. While the long-term annual mean precipitation was $627 \mathrm{~mm}$, the measurement years 2016, and especially 2018 were drier than that. The mean maximum snow depth in 1981-2010 was $28 \mathrm{~cm}$, but all the post-harvest snow depths were lower than that.

Table 1. Mean annual and summertime (June-August) air temperature and precipitation and the maximum annual snow depth during the measurement years. The long-term mean values were acquired from Pirinen et al. (2012).

\begin{tabular}{c|cc|cc|c} 
& \multicolumn{2}{|c|}{ Air temperature $\left[{ }^{\circ} \mathrm{C}\right]$} & \multicolumn{2}{c|}{ Precipitation [mm] } & Maximum snow depth [cm] \\
\hline & Annual & Summer & Annual & Summer & Annual \\
$1981-2010$ & 4.6 & 15.2 & 627 & 218 & 28 \\
2015 & 6.3 & 14.4 & 680 & 208 & 33 \\
2016 & 5.3 & 15.5 & 536 & 199 & 19 \\
2017 & 5.2 & 14.1 & 657 & 240 & 12 \\
2018 & 5.8 & 17.2 & 437 & 133 & 22 \\
2019 & 5.9 & 16.2 & 662 & 175 & 52
\end{tabular}




\subsubsection{Experimental design and timber harvesting}

At the beginning of the experiment, Lettosuo was divided into three subsites: partially harvested site $\left(\mathrm{S}_{\mathrm{ph}}\right)(13 \mathrm{ha})$, clear-cut site $\left(\mathrm{S}_{\mathrm{cc}}\right)(2.35 \mathrm{ha})$, and control site $\left(\mathrm{S}_{\mathrm{c}}\right)$ (3.1 ha) (Fig. 4). The soon-to-be partially harvested site included long-term (since 2009) measurements of NEE with the EC technique and automated soil chambers. $F_{C H 4}$ had been measured with the automated chamber system in 20112013 (Paper I), and these measurements were restarted in the summer before the harvesting (2015) in conjunction with $F_{N 2 O}$ measurements. A similar automated chamber system was built at the $\mathrm{S}_{\mathrm{c}}$ for $F_{C H 4}$ measurements in summer 2015; however, the $F_{N 2 O}$ measurements were started at the beginning of 2017. The system at the $S_{c}$ was disassembled in May 2018. In addition to the automated chambers, manual measurements were performed at forest floor and ditch plots to better resolve the spatial variation in the GHG fluxes at all three sites in 2015-2018 (Fig. 4). The fluxes of $\mathrm{CO}_{2}, \mathrm{CH}_{4}$ and $\mathrm{N}_{2} \mathrm{O}$ were measured at these points with a varying interval of 1-2 weeks in the summertime and 1-2 months during the other seasons. After harvesting on, the $\mathrm{EC}$ measurements of $\mathrm{CO}_{2}$ flux were started at the $\mathrm{S}_{\mathrm{cc}}$ on April $8^{\text {th }}$ 2016. Around the same time, the logging trail GHG flux measurements at the $\mathrm{S}_{\mathrm{ph}}$ were initiated and continued until autumn 2017.

Table 2. The number of trees classified into species (sp), basal area (ba), mean height weighted by basal area and stem volumes at the control $\left(\mathrm{S}_{\mathrm{c}}\right)$, partial harvest $\left(\mathrm{S}_{\mathrm{ph}}\right)$, partial harvest central $\left(\mathrm{S}_{\mathrm{ph}}(\mathrm{c})\right)$ and clear-cut $\left(\mathrm{S}_{\mathrm{cc}}\right)$ sites before and after harvestings. The values include both overstorey and understorey trees. The partial harvest central data represent the mean values of the five tree stand inventory plots (see Fig. 4) closest to the eddy covariance mast. N/D means not determined.

\begin{tabular}{|c|c|c|c|c|c|c|c|c|c|c|c|c|c|c|c|c|c|}
\hline \multirow[t]{2}{*}{ Stand stratum } & \multirow[t]{2}{*}{ Tree species } & \multicolumn{4}{|c|}{ No of trees $\left[\mathrm{ha}^{-1}\right]$} & \multicolumn{4}{|c|}{ Basal area $\left[\mathrm{m}^{2} \mathrm{ha}^{-1}\right]$} & \multicolumn{4}{|c|}{$\begin{array}{c}\text { Mean height, weighted by } \\
\text { tree ba }[\mathrm{m}]\end{array}$} & \multicolumn{4}{|c|}{ Stem volume $\left[\mathrm{m}^{3} \mathrm{ha}^{-1}\right]$} \\
\hline & & $\mathrm{S}_{\mathrm{c}}$ & $\mathrm{S}_{\mathrm{ph}}$ & $S_{p h}(c)$ & $\mathbf{S}_{\mathrm{cc}}$ & $\mathrm{S}_{\mathrm{c}}$ & $\mathrm{S}_{\mathrm{ph}}$ & $\mathrm{S}_{\mathrm{ph}}(\mathrm{c})$ & $\mathrm{S}_{\mathrm{cc}}$ & $\mathrm{S}_{\mathrm{c}}$ & $S_{p h}$ & $\mathrm{~S}_{\mathrm{ph}}(\mathrm{c})$ & $\mathrm{S}_{\mathrm{cc}}$ & $\mathrm{S}_{\mathrm{c}}$ & $\mathrm{S}_{\mathrm{ph}}$ & $\mathrm{S}_{\mathrm{ph}}(\mathrm{c})$ & $\mathrm{S}_{\mathrm{cc}}$ \\
\hline \multirow{4}{*}{$\begin{array}{l}\text { all storeys } \\
\text { before } \\
\text { harvesting }\end{array}$} & All tree sp & 2550 & 2473 & 2560 & $\mathrm{~N} / \mathrm{D}$ & 30 & 36 & 37 & $N / D$ & 17 & 17 & 17 & $N / D$ & 245 & 295 & 294 & $209 *$ \\
\hline & Scots pine & 483 & 505 & 385 & $N / D$ & 18 & 21 & 17 & $N / D$ & 20 & 20 & 20 & $N / D$ & 171 & 198 & 161 & $\mathrm{~N} / \mathrm{D}$ \\
\hline & Norway spruce & 1333 & 1172 & 1505 & $N / D$ & 5 & 8 & 10 & $\mathrm{~N} / \mathrm{D}$ & 7 & 10 & 10 & $N / D$ & 21 & 44 & 55 & $\mathrm{~N} / \mathrm{D}$ \\
\hline & Pubescent birch & 733 & 797 & 670 & $N / D$ & 7 & 7 & 10 & $N / D$ & 13 & 14 & 17 & $N / D$ & 53 & 52 & 78 & $N / D$ \\
\hline \multirow{4}{*}{$\begin{array}{l}\text { all storeys } \\
\text { after } \\
\text { harvesting }\end{array}$} & All tree sp & 2550 & 1168 & 1405 & 0 & 30 & 11 & 16 & 0 & 17 & 13 & 15 & 0 & 245 & 77 & 113 & 0 \\
\hline & Scots pine & 483 & 7 & 9 & 0 & 18 & 0 & 1 & 0 & 20 & 1 & 2 & 0 & 171 & 2 & 7 & 0 \\
\hline & Norway spruce & 1333 & 763 & 964 & 0 & 5 & 5 & 7 & 0 & 7 & 10 & 10 & 0 & 21 & 32 & 43 & 0 \\
\hline & Pubescent birch & 733 & 398 & 432 & 0 & 7 & 5 & 8 & 0 & 13 & 14 & 18 & 0 & 53 & 43 & 63 & 0 \\
\hline
\end{tabular}

*Stem volume at the clear-cut was determined by harvesting machinery during cutting. The amount of waste wood was estimated from the closest tree measurement plot to the clear-cut site by using the ratio of stem volume to the waste wood at that specific plot.

Partial harvest and clearcut were performed between 2 February and 16 March 2016. Before harvestings in 2016, the two-storeyed tree stand was composed of Scots pine (Pinus sylvestris) with some downy birch (Betula pubescens) in the dominant tree storey. The understorey included mostly Norway spruce (Picea abies). In the partial harvest, all the overstorey pine trees (ca. 70\% of stem volume, $69 \%$ of basal area) were harvested. However, it should be noted that the central area of the $\mathrm{S}_{\mathrm{ph}}$ had a denser spruce and birch stand and fewer pine trees than the other parts of the $\mathrm{S}_{\mathrm{ph}}$, resulting in a smaller harvested number of trees (ca. $62 \%$ of stem volume, $57 \%$ of basal area; Table 2) than at the other parts of the $S_{\text {ph }}$. Heavy machinery was used to harvest the trees except for nearby the measurements, where the trees were cut manually to avoid damaging the measurement setups and instruments. Most of the logging residues were collected on the logging trails and left at the site to provide support for the harvesting machinery. No mounding or seedling planting was made at the 
partially harvested site. Also, the ditches were left in their original state. In contrast, at the $\mathrm{S}_{\mathrm{cc}}$, all the trees were harvested. Regeneration was carried out according to the prevailing management procedures including ditch mounding (on August $1^{\text {st }}-2^{\text {nd }} 2016$ ) and planting of spruce seedlings (in 2017).

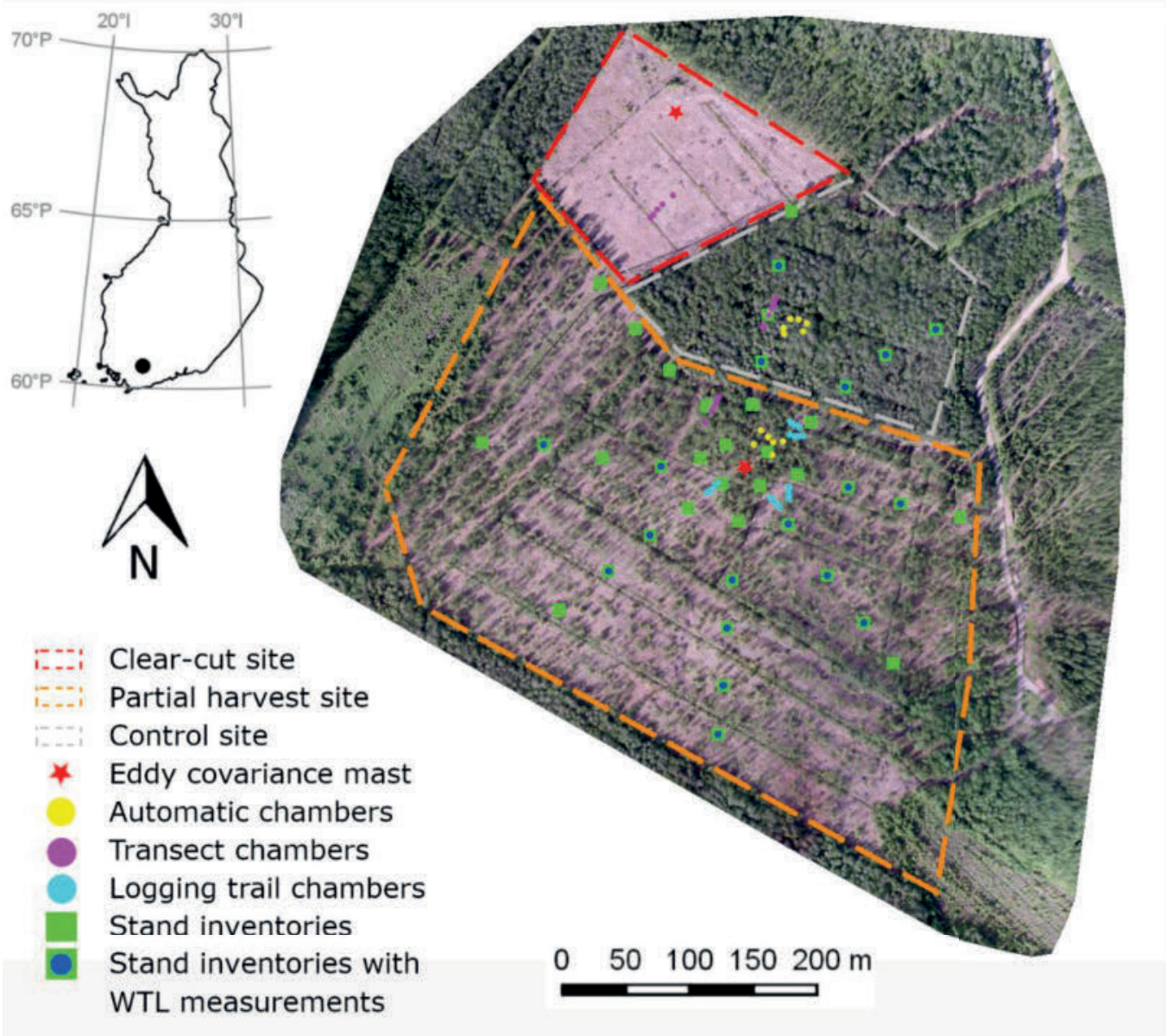

Figure 4. Location of Lettosuo in southern Finland, and the aerial photograph of the site after harvestings. The graphics depict the experimental setup. 


\subsection{Eddy covariance measurements}

The EC measurements at the later $\mathrm{S}_{\mathrm{ph}}$ started originally in autumn 2009, and the basic methods and instrument models have remained the same since then. The turbulent fluxes of ET (Paper IV) and $\mathrm{CO}_{2}$ (unpublished data) were measured on top of a $25.5 \mathrm{~m}$ telescopic mast. Also, supporting meteorological measurements like air temperature (HMP45D, Vaisala Corporation, Vantaa, Finland) and photosynthetic photon flux density (PPFD; PQS1 PAR Quantum Sensor, Kipp \& Zonen, Delft, the Netherlands) were made at the top of the mast. The height of the mast was not changed after partial harvest. Fluctuations in wind components were measured with a sonic anemometer (METEK USA1, METEK $\mathrm{GmbH})$ and those of $\mathrm{CO}_{2}$ mixing ratio $\left(\left[\mathrm{CO}_{2}\right]\right.$ ) with a closed-path infrared analyser (LI7000, LI-COR Inc.). The sampling rate was $10 \mathrm{~Hz}$. The gas analyser was located on a tower next to the mast at $6 \mathrm{~m}$ height, and the sample air was transported with a flow rate of ca. $61 \mathrm{~min}^{-1}$ from the top of the telescopic mast using a $20 \mathrm{~m}$ long heated tube ( $3.1 \mathrm{~mm}$ Bevaline $\mathrm{IV}$ ). $\mathrm{CO}_{2}$-free dry air was used as a reference gas for the gas analyser. The mean $\left[\mathrm{CO}_{2}\right]$ was also measured at two levels: at $7 \mathrm{~m}$ with a LI-820 (LI-COR Inc.) and at $1 \mathrm{~m}$ with a G1130 (Picarro Inc) that was also used in the automated chamber system (Sect. 5.3.1). These $\left[\mathrm{CO}_{2}\right]$ measurements were used in the storage flux calculation. At the $\mathrm{S}_{\mathrm{cc}}$ (Paper II), the EC measurement height was $2.75 \mathrm{~m}$, where the wind components were measured with a u-Sonic-3 Scientific sonic anemometer (METEK GmbH) and $\left[\mathrm{CO}_{2}\right]$ with a LI-7000. Due to the lower measurement height, the length of tubing was shorter $(8 \mathrm{~m})$ than at the $\mathrm{S}_{\mathrm{ph}}$, and no additional instruments were used for storage flux determination, but otherwise, the EC system at the $\mathrm{S}_{\mathrm{cc}}$ was similar to the one at the $\mathrm{S}_{\mathrm{ph}}$.

Standard EC methods were used to calculate the half-hourly turbulent $\mathrm{CO}_{2}$ fluxes for both EC systems (Aubinet et al., 2012). First, the $10 \mathrm{~Hz}$ raw data were de-spiked and block-averaged. Next, double rotation of the coordinate system was applied (McMillen, 1988), and the time lag between the sonic anemometer and gas analyser signals was accounted for by cross-correlation analysis. Also, the effect of water vapour fluctuations on flux measurements with the LI-7000 was compensated for (Webb et al., 1980); a corresponding compensation is not necessary for temperature (Rannik et al., 1997). The systematic losses caused by block averaging and attenuation of the highest frequencies in the cospectra between the $\left[\mathrm{CO}_{2}\right]$ and vertical wind speed were corrected by using the transfer function method with empirically determined time constants (Aubinet et al., 2000; Moore, 1986). The system response was determined by using temperature co-spectra as a reference. In order to calculate the correction as a function of wind speed and atmospheric stability, the transfer function was convoluted with generic co-spectral distributions (Kaimal and Finnigan, 1994). A source area analysis was carried out by using a micrometeorological footprint model (Kormann and Meixner, 2001) to estimate how well the measured fluxes represent the areas under interest.

At the $\mathrm{S}_{\mathrm{ph}}$, the storage flux (unpublished data) was calculated with the central difference method from the mean mixing ratio during the subsequent and preceding 30 -min periods and added to the measured turbulent flux (Eq. 5). The storage flux was calculated using available $\left[\mathrm{CO}_{2}\right]$ data from different sources, having the following priority: (1) all heights, (2) $\left[\mathrm{CO}_{2}\right]_{25.5 \mathrm{~m}}+\left[\mathrm{CO}_{2}\right]_{6 \mathrm{~m}},(3)\left[\mathrm{CO}_{2}\right]_{25.5 \mathrm{~m}}$ $+\left[\mathrm{CO}_{2}\right]_{1 \mathrm{~m}}$, and (4) $\left[\mathrm{CO}_{2}\right]_{25.5 \mathrm{~m}}$. In case of (1), the different measurements from top to bottom were assumed to represent air columns from 25.5 to $13 \mathrm{~m}, 13$ to $3 \mathrm{~m}$, and 3 to $0 \mathrm{~m}$, respectively. In case (2), the top and bottom air columns were assumed to be 12.5 and $13 \mathrm{~m}$ high, respectively. In case (3), 
the corresponding heights were 17.5 and $8 \mathrm{~m}$, respectively. At the $\mathrm{S}_{\mathrm{cc}}$, the storage flux was estimated from the change in the mean $\left[\mathrm{CO}_{2}\right]$ profile between consecutive half-hour periods with an assumption that the air column from the ground level to the measurement height was constant.

The calculated half-hour flux data were screened by following criteria: suitable wind directions $\left(\mathrm{S}_{\mathrm{ph}}\right.$ : $90^{\circ}-300^{\circ}, \mathrm{S}_{\mathrm{cc}}: 80^{\circ}-315^{\circ}$ ), relative stationarity (Foken and Wichura, 1996) $<100 \%$, internal LI-7000 pressure $>60 \mathrm{kPa}\left(\mathrm{S}_{\mathrm{ph}}\right)$ or $>75 \mathrm{kPa}\left(\mathrm{S}_{\mathrm{cc}}\right),\left[\mathrm{CO}_{2}\right]>350 \mathrm{ppm}$, number of spikes in the vertical wind speed and $\left[\mathrm{CO}_{2}\right]$ data $<150$ of 18000 . In addition, the periods of weak turbulence were removed; the data were discarded if $u_{*}$ was lower than a site-specific $u_{*} \operatorname{limit}\left(\mathrm{S}_{\mathrm{ph}}: 0.225 \mathrm{~m} \mathrm{~s}^{-1}, \mathrm{~S}_{\mathrm{cc}}: 0.125 \mathrm{~m} \mathrm{~s}^{-1}\right)$. Finally, the crosswind-integrated footprint accumulated within the target sectors was required to exceed $75 \%$ to ensure the measured flux originated predominantly from the target site.

\subsubsection{Flux gap-filling and uncertainties}

In order to calculate $\mathrm{CO}_{2}$ balances on annual or shorter timescales at $\mathrm{S}_{\mathrm{cc}}$ (Paper II) and $\mathrm{S}_{\mathrm{ph}}$ (unpublished data), full time series are needed; hence the gaps in the flux time series need to be filled. To perform this, the measured $\mathrm{CO}_{2}$ flux (NEE) was first partitioned into GPP and ER:

$$
\mathrm{NEE}=\mathrm{GPP}+\mathrm{ER}
$$

For gap-filling, GPP was expressed as a function of irradiance (e.g. Aurela et al., 2009; Lasslop et al., 2008):

$$
\mathrm{GPP}=\frac{\mathrm{A} \times P P F D \times G P_{\max }}{\mathrm{A} \times P P F D+G P_{\max }}
$$

where PPFD is the photosynthetic photon flux density, $A$ is an approximation of the canopy light utilization efficiency (i.e. quantum yield, the initial slope of the NEE response to PPFD), and $G P_{\max }$ is the asymptotic gross photosynthesis rate in optimal light conditions. ER was assumed to follow the Arrhenius-type model described by Lloyd and Taylor (1994):

$$
\mathrm{ER}=R_{0} \times e^{E\left(\frac{1}{T_{0}}-\frac{1}{T_{\text {soil }}-T_{1}}\right)}
$$

where $R_{0}$ is the ecosystem respiration at $10{ }^{\circ} \mathrm{C}, E$ is the temperature sensitivity of respiration, $T_{\text {soil }}$ is the measured soil temperature at $5 \mathrm{~cm}$ depth, $T_{0}=56.02 \mathrm{~K}$ and $T_{1}=227.13 \mathrm{~K}$.

The parameters $E$ and $R_{0}$ were defined from the night-time data (PPFD $<20 \mu \mathrm{mol} \mathrm{m}^{-2} \mathrm{~s}^{-1}$ ) in two parts. First, the parameter $E$ was determined with a 15-day moving window for each day, with the minimum number of observations set to 12 . If there were not enough observations within a time window, then the window size was increased by 1 day both at the beginning and at the end until enough data were found. Next, all the $E$ values that hit the allowed boundary values (200 and $500 \mathrm{~K}$ ) were discarded and filled with 14-day moving medians. Finally, a 15-day moving window was used to determine $R_{0}$ 
by using the fixed $E$ values. Also, using the same moving window, $G P_{\max }$ and $A$ were determined from the daytime data.

EC measurements have multiple potential error sources, but many of them are difficult to estimate. In this thesis, systematic errors of $u_{*}\left(E_{\text {ustar }}\right)$ and footprint $\left(E_{\mathrm{fp}}\right)$ filtering were included in addition to an estimate of the random error. The random error including the statistical measurement error ( $\left.E_{\text {meas }}\right)$ inherent in EC measurements and the error caused by gap-filling of missing data $\left(E_{\text {gap }}\right)$ was estimated as follows (Räsänen et al., 2017):

$$
E_{\text {meas } / \text { gap }}=\sqrt{\sum_{i} \frac{\left(N E E_{o b s, i}-N E E_{\text {mod }, i}\right)^{2}}{n_{\text {obs } / \text { mod }}} \sqrt{n_{\text {meas } / \text { gap }}}}
$$

where $N E E_{o b s}$ is the $30 \mathrm{~min}$ flux that passed all the filtering procedures, $N E E_{\text {mod }}$ is the corresponding fitted NEE, and $n_{\text {meas/gap }}$ is the number of the measured or gap-filled data. This method provides a conservative estimate for $E_{\text {meas }}$ (Aurela et al., 2002). Also, $E_{\text {gap }}$ includes the effect of random flux variability on the model fits.

$E_{\text {ustar }}$ was estimated by recalculating the $\mathrm{CO}_{2}$ balance with modified data sets that were screened with two different $u_{*}$ limits $\left(0.075\right.$ and $\left.0.175 \mathrm{~m} \mathrm{~s}^{-1}\right)$. $E_{\text {ustar }}$ was calculated as the average difference between the annual balance calculated with the optimal $u_{*}$ threshold $\left(0.125 \mathrm{~m} \mathrm{~s}^{-1}\right)$ and with the annual balances calculated with the modified $u_{*}$ limits. Similarly, two additional different footprint limits $(0.65$ and 0.85 ) were adopted to estimate the annual error caused by footprint filtering. The total uncertainty of the annual balance $\left(E_{\mathrm{tot}}\right)$ was calculated with the standard error propagation principle:

$$
E_{\text {tot }}=\sqrt{E_{\text {meas }}^{2}+E_{\text {gap }}^{2}+E_{\text {ustar }}^{2}+E_{f p}^{2}}
$$

\subsection{Chamber measurements}

\subsubsection{Automatic chambers}

Automatic chamber systems consisting of six transparent acrylic chambers (Fig. 5a) with dimensions $57 \mathrm{~cm} \times 57 \mathrm{~cm} \times 40 \mathrm{~cm}$ (length x width x height) were used at the both $\mathrm{S}_{\mathrm{ph}}$ and $\mathrm{S}_{\mathrm{c}}$. The chambers were used with permanently installed steel collars (height $5 \mathrm{~cm}$, inserted at a depth of $2 \mathrm{~cm}$ ) to cover different ground vegetation compositions within a ca. $15 \mathrm{~m}$ radius from the measurement cabin containing the measurement instruments. The cabin was located about $30 \mathrm{~m}$ from the $25.5 \mathrm{~m}$ tall EC mast (Sect. 5.2), where the wind speed above the canopy was measured. During the winters 20112012, 2012-2013 and 2016-2017, an extension collar (height $16 \mathrm{~cm}$ ) was placed between the chamber frame and the soil to raise the frame above the snow level. Also, the snow depth inside the chambers was recorded each time the site was visited, which took place one or two times a month during winter. The chambers included a fan for mixing the air inside the chamber headspace and a PPFD sensor (PQS1 PAR Quantum Sensor, Kipp \& Zonen). In addition, there was a temperature probe for headspace temperature measurement inside each chamber (Pt100, PT4T, Nokeval Oy). In Paper I 
soil temperature probes were placed at depths of 2, 5, 10, 20 and $30 \mathrm{~cm}$ next to the measurement cabin, while for Paper III the soil temperature data were collected at a distance of about $15 \mathrm{~m}$ from the chambers at the 5 and $30 \mathrm{~cm}$ depths at both the $\mathrm{S}_{\mathrm{ph}}$ and $\mathrm{S}_{\mathrm{c}}$. The air temperature was also collected with similar Pt100 probes at the top of the EC mast at $25.5 \mathrm{~m}$ above the ground. The chamber headspace temperature and PPFD data were collected as $10 \mathrm{~s}$ averages, and the soil temperatures as 30 min averages by two data loggers (QML201C, Vaisala Corporation).

a)

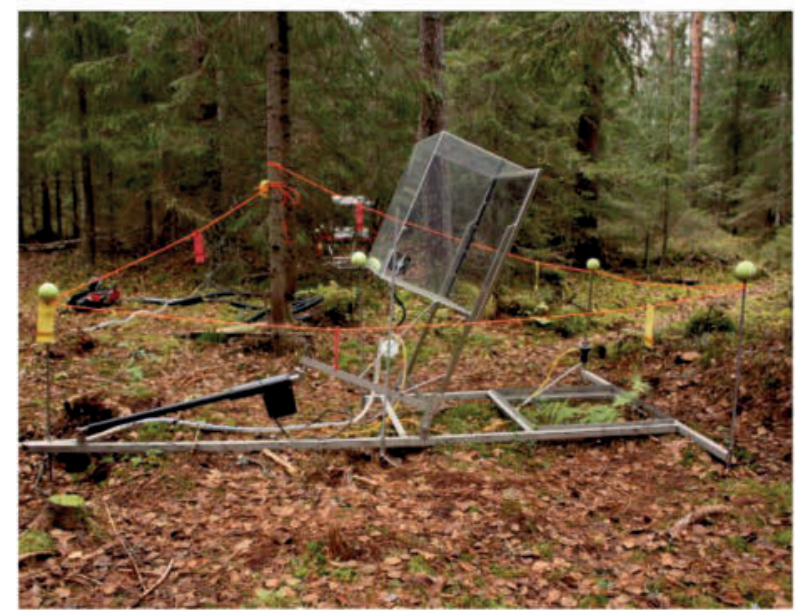

b)

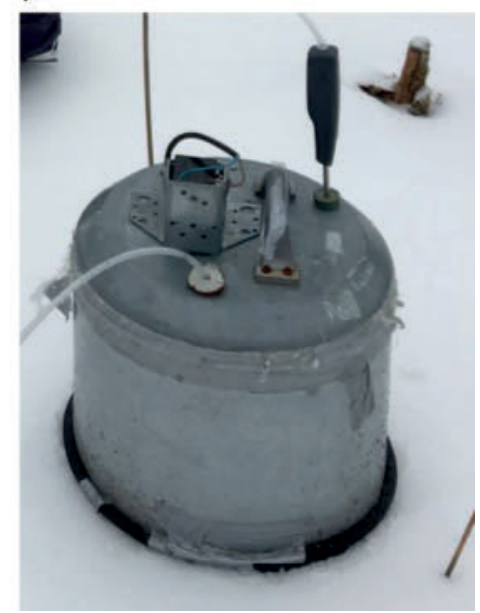

Figure 5. The automatic (a) and manual (b) chamber setups used in Papers I, II and III (Photos: Annalea Lohila).

Chambers generally closed once an hour for 6 min with some exceptions described in Paper I. When the chamber started to close, the sampling tubes were flushed with ambient air. After that, the sample air was drawn from the chamber at a flow rate of about $11 \mathrm{~min}^{-1}$ to the gas analysers, after which it was returned to the chamber. $\mathrm{CH}_{4}, \mathrm{CO}_{2}$, and water vapour mixing ratios (Papers I and III) were measured approximately every $4 \mathrm{~s}$ with a Picarro G1130 cavity ring-down spectroscopy gas analyser (Picarro Inc.), while $\mathrm{N}_{2} \mathrm{O}$ mixing ratios (Paper III) were measured every $2 \mathrm{~s}$ with a continuous-wave quantum cascade laser absorption spectrometer (LGR-CW-QCL, Model N2O/CO-23d, Los Gatos Research Inc.). At the $\mathrm{S}_{\mathrm{c}}$, Gasmet DX4015 based on Fourier transform infrared spectroscopy (Gasmet Technologies Oy) was also used in 2017 to measure $\mathrm{N}_{2} \mathrm{O}$ mixing ratio. When none of the chambers was closed, ambient air was sampled. The delay in the analyser response caused by the long tubing was taken into account by labelling each data point with the respective chamber number using a $20 \mathrm{~s}$ lag. However, as the flow rate varied slightly in time, some points were removed from the data before the flux calculation (Sect. 5.3.3). 


\subsubsection{Manual chambers}

\section{Transects and ditches}

Manual chamber (Fig. 5b) sampling transects were set up on the $\mathrm{S}_{\mathrm{ph}}$ (Paper III), $\mathrm{S}_{\mathrm{cc}}$ (Paper II), and $S_{c}$ (Paper II and III) sites before the harvest, in June 2015. Transects were established to cover the whole range of water levels which are lower closer to the ditch and higher in the middle of the strip. Measurements of FFR, $F_{C H 4}$ and $F_{N 2 O}$ were made between 29 June 2015 and 29 August 2017, mostly during the snow-free periods. The measurement interval mainly varied between one week and one month; however, there were a few longer gaps in autumn 2015 and spring 2016.

The transects at the $\mathrm{S}_{\mathrm{ph}}, \mathrm{S}_{\mathrm{cc}}$ and $\mathrm{S}_{\mathrm{c}}$ had two parallel flux measurement points (located within $2 \mathrm{~m}$ from each other) in the ditch and at a distance of 4, 8, 12 and $22.5 \mathrm{~m}$ from the ditch. Before starting the campaign in July 2015, $2 \mathrm{~cm}$ deep grooves were carved into the soil surface for the chambers, and the grooves were occasionally renewed when necessary to keep the chamber sealing adequate. However, if the soil surface was frozen, the measurements were not made as it was not possible to seal the chamber properly. No above-ground logging residues were introduced into the manual chamber points. For ditch measurements, extra collars (height $30 \mathrm{~cm}$ ) were installed into the ditch one hour before the measurement, and the air volume of the collar was recorded for flux calculation.

The fluxes were measured using a closed-chamber system with an opaque cylindrical chamber (height $30.5 \mathrm{~cm}$, diameter $31.5 \mathrm{~cm}$ ) including a mixing fan and a vent tube. The analysis of gas concentrations was made either using (1) a portable analyser or (2) inside-cabin laser analysers which were detached from the automatic chambers during the manual measurements. A DX4015 analyser (Gasmet Technologies Oy) was applied in the portable system to measure $\mathrm{CO}_{2}, \mathrm{CH}_{4}$ and $\mathrm{N}_{2} \mathrm{O}$ mixing ratios every $5 \mathrm{~s}$. In this case, air circulated in a loop between the gas analyser and the chamber with a 1011 min closure time. The portable gas analyser was used all the time at the clear-cut transect, but at the $S_{p h}$ and $S_{c}$, it was used only before the harvest in 2015. From March 2016 onwards, more precise inside-cabin analysers (Sect. 5.3.1) coupled with the automatic chamber system were exploited in manual measurements at the partially harvested and control transects. For these measurements, the automatic chambers were paused, and the manual chamber was connected to the ambient sampling line using a $50 \mathrm{~m}$ tubing. At the control transect, a Gasmet DX4015 was connected to the automatic chamber system to acquire the $F_{N 2 O}$ data from the control transect.

\section{Logging trail}

To study the impact of logging trails and residues on GHG fluxes, five parallel plots with four different types of measurement points were set up on the partially harvested site at the beginning of May 2016 by installing chamber collars $(55 \mathrm{~cm}$ x $55 \mathrm{~cm}$ x $20 \mathrm{~cm}$, length x width x height) into the soil (Paper III). The measurements started on 10 June 2016 and continued until 7 November 2017. Two of the points were set up on the logging trail where the residues were piled for additional support for the harvesting machinery. The first and second logging trail points were established on the part of the trail compressed and uncompressed, respectively, by the wheels of the heavy machinery. The two other points were located outside the logging trail, and they differed in the amount of logging residues. The dry mass of the logging residues inside the collars was estimated by taking two similar sample 
groups of which one was dried. The relations of these dry and fresh masses were used to determine the dry mass of the needles and woody material inside each collar.

The flux measurements were made by exploiting the instruments used in the automatic chamber system similarly to the transect measurements from 2016 onwards. In contrast to the transect measurements, a larger chamber $(60 \mathrm{~cm}$ x $60 \mathrm{~cm}$ x $30 \mathrm{~cm}$, length x width x height) was used in the logging trail measurements. The air volume of the collar was taken into account in flux calculation. During wintertime, the snow depth inside the collars was measured before the flux measurements.

\subsubsection{Flux calculation and uncertainties}

\section{Flux calculation}

In automatic chamber measurements, the first $30 \mathrm{~s}$ of the data was discarded due to slight variations in flow rate and to allow the air inside the chamber to mix properly. The dilution- and spectrally corrected $\mathrm{CO}_{2}, \mathrm{CH}_{4}$ and $\mathrm{N}_{2} \mathrm{O}$ mixing ratios reported by the Gasmet DX4015, Picarro G1130 and LGR $\mathrm{N} 2 \mathrm{O} / \mathrm{CO}-23 \mathrm{~d}$ analysers were used to calculate the fluxes.

To calculate the flux (Eq. 3; Sect. 3.1), the rate of change of the gas mixing ratio at the beginning of the chamber closure needs to be determined. In this thesis, this was made by regression analysis with two models: linear and exponential. Calculating the time derivative of the models yields the slope of the model $\left(\left(\frac{d c}{d t}\right)_{t=0}\right.$ in Eq. 3). The linear regression describing the change in the gas mixing ratio $\left(r_{\mathrm{gas}}\right)$ as a function of time was:

$$
r_{g a s}=a_{\text {lin }}+b_{\text {lin }} t
$$

where $a_{l i n}$ and $b_{\text {lin }}$ are model parameters and $t$ is the time from the start of the closure. The slope of this model at $t=0$ is $b_{\text {lin }}$.

The exponential model was:

$$
r_{g a s}=a_{\text {exp }}+b_{\text {exp }} e^{c_{e x p} t}
$$

where $a_{\text {exp }}, b_{\text {exp }}$ and $c_{\text {exp }}$ are model parameters. The time derivative of this model at $t=0$ is the product of $b_{\text {exp }}$ and $c_{\text {exp }}$. The exponential model is sensitive to the initial estimates for the parameter values, and the fitting commonly fails due to local minima unless good initial estimates are given for the parameter values. To overcome this and to avoid over-parameterisation, a Taylor power series expansion (Kutzbach et al., 2007) was used to provide the initial estimates.

When estimating the air volume of the headspace, the pore space of soil and snow was ignored. After calculating the fluxes by using both linear and exponential models, the fluxes were binned to inspect the lowest flux rate at which the exponential model still works (Paper I). These flux limits were estimated for each measurement system separately. If the flux estimated with the linear model was 
above the limit, the flux calculated from the exponential model was considered as the final flux for later analysis. Otherwise, the estimate from the linear model was adopted.

\section{Filtering of the flux data}

For manual chamber flux measurements (Paper II and III), the quality of the measurements was inspected visually, but for automatic measurements, the large amount of data required using more quantitative methods. The calculated fluxes were filtered according to several criteria to remove cases in which the automatic chamber system did not work correctly. The most common problems with the automatic system were related to mechanical malfunction causing the chamber to remain stuck. These cases were detected from the $\left[\mathrm{CO}_{2}\right]$ development during the closure, as the mixing ratio change was always, even during winter, large enough to be detected reliably. It should be noted that removing closures when $\left[\mathrm{CO}_{2}\right]$ did not change may remove closures when uptake by photosynthesis equals respiration rate, i.e. the net flux is zero. However, the number of such cases is low (Paper I). The goodness of the fit was estimated with the normalised root mean square error (NRMSE) (e.g. Christiansen et al., 2011; Pihlatie et al., 2013):

$$
N R M S E=\frac{\sqrt{\frac{1}{n} \sum_{i=1}^{n}\left(c_{f i t, i}-c_{i}\right)^{2}}}{c_{\max }-c_{\min }}
$$

where $n$ is the number of measurement points, $c_{f i t, i}$ is the $\mathrm{CO}_{2}$ mixing ratio calculated with the fit (Eqs. 11 or 12), $c_{i}$ is the corresponding $\mathrm{CO}_{2}$ mixing ratio, and $c_{\max }$ and $c_{\min }$ are the highest and lowest mixing ratios measured during the closure, respectively. If the NRMSE was larger than 0.05, the $\mathrm{CH}_{4}$ and $\mathrm{N}_{2} \mathrm{O}$ data from that closure were discarded.

After NRMSE filtering, random spiking was removed from the flux data by applying a 14-day moving window in which a running mean $\left(F_{\text {mean }}\right)$ and a corresponding standard deviation $(\sigma)$ were calculated. The fluxes which did not fall within $F_{\text {mean }} \pm 10 \sigma$ (Paper I) or $F_{\text {mean }} \pm 8 \sigma$ (Paper III) were discarded.

\section{Gas balances and uncertainties}

The gaps in the automatic chamber data need to be filled to calculate the GHG balances. In this thesis, $\mathrm{CH}_{4}$ and $\mathrm{N}_{2} \mathrm{O}$ balances were calculated only from the automatic chamber data (Paper I and Paper III). First, the gaps shorter than one day were filled with linear interpolation and the daily sums were calculated from this gap-filled data. Next, the gaps longer than one day were filled with linear interpolation of the daily sums. The monthly, seasonal and annual sums were calculated from these gap-filled daily sums.

The uncertainties of the gas balances were estimated for each chamber separately by assuming three primary error sources: (1) the error of the linear/exponential fit in flux calculation, (2) the error caused 
by gap filling, and (3) the error caused by the correction of the fluxes caused by the 2 min closure time used in the chamber system in 2011 and partly in 2012 (only in Paper I). The daily measurement error was estimated as the squared sum of uncertainties of every single measurement made within the day. The model fitting was assumed to be the most significant source of the uncertainty in a single measurement; this uncertainty was quantified by the standard error of the slope. The gap-filling error was estimated by taking a 12-month set of flux data, removing one month of the data at a time, which corresponded to a longest gap observed in the data. This one-month gap was filled with linear interpolation and the resulting annual balance was compared with the original balance estimate. This was repeated for each month of the year, and the mean absolute difference from the original gas balance was downscaled to one day. This daily uncertainty was multiplied by the number of missing days during each year to estimate the uncertainty associated with gap-filling. The uncertainty related to the transformation of the fluxes calculated from $2 \mathrm{~min}$ closures to represent the 6 min closure (Paper I) was estimated from the median absolute deviation assuming normally distributed medians. The total error estimate was calculated by using the standard accumulation principle of independent errors.

\subsubsection{Upscaling $\mathrm{CH}_{4}$ and $\mathrm{N}_{2} \mathrm{O}$ fluxes to the ecosystem level}

To be able to make a representative estimate of the areal GHG balances, the areas representing different surface types (forest, logging trails, ditches) were estimated from drone and satellite images. The area of the ditches was measured from the images by assuming a $1 \mathrm{~m}$ ditch width, which resulted in surface area of $2.4 \%$ of the total $\mathrm{S}_{\mathrm{ph}}$ area. The relative coverage of the ditch areas was assumed to be the same at the $S_{c}$. The rest of the surface area at the $S_{c}$ was classified as forest. At the $S_{\text {ph }}$, the width of the logging trails was measured to be about $4 \mathrm{~m}$. The drone images showed that there were two logging trails across one strip (width $40 \mathrm{~m}$ ); therefore, the logging trails constituted $20 \%$ of the forest area at the $\mathrm{S}_{\mathrm{ph}}$.

The upscaling was performed for the summers (June-August) of 2016 and 2017, separately for the $\mathrm{S}_{\mathrm{ph}}$ and $\mathrm{S}_{\mathrm{c}}$. The upscaling method was based on the relationship between the daily WTL and $F_{\mathrm{CH} 4}$. Any other factors affecting the flux were ignored. Since responses of $F_{N 2 O}$ to any environmental

variables were weak, the $F_{N 2 O}$ upscaling was based on the dynamic emission levels of the different surface types and their proportion of the total area. The ditch fluxes of both gases were gap-filled with linear interpolation separately for harvest and control ditches and later combined by calculating the daily means between of the sites. For the forest floor, daily mean fluxes of automatic, transect and logging trail chamber measurements were binned into WTL bins of $5 \mathrm{~cm}$ ranging from -10 to -75 $\mathrm{cm}$. The binning was made separately for the logging trails and the forest, and the mean flux for each WTL bin was calculated. Then, the $\mathrm{S}_{\mathrm{c}}$ and $\mathrm{S}_{\mathrm{ph}}$ were divided into equally sized plots according to the number of automated WTL measurements located around the site in different compass directions. To clarify, one WTL measurement represented an area of total subsite $\left(\mathrm{S}_{\mathrm{ph}}\right.$ or $\left.\mathrm{S}_{\mathrm{c}}\right)$ area divided by the number of WTL dipwells at that respective subsite. The areal coverage of different surface types was assumed to be the same across the plots. At each plot, the daily mean $F_{\mathrm{CH}_{4}}$ was acquired from the WTL bin corresponding to the daily mean WTL. Finally, the mean fluxes across the plots were calculated for each surface type and added together to acquire the net $F_{\mathrm{CH} 4}$ of the whole site. 
The uncertainty of the upscaling was estimated by taking into account the most significant uncertainty sources. The ditch area uncertainty was estimated at 51\% including the uncertainties associated with the ditch wetness $(50 \%)$ and the ditch area $(10 \%)$. The forest and logging trail areas were assumed to have a $5 \%$ uncertainty. The relative uncertainty estimate of the forest fluxes was based on the mean uncertainty of all the automatic chamber measurements separately for the $\mathrm{S}_{\mathrm{ph}}$ and $\mathrm{S}_{\mathrm{c}}$, and for different years. The uncertainty of the ditch and logging trail fluxes was estimated by dividing the standard error of the mean with the mean summertime flux. Individual uncertainties were combined with the standard error propagation principle.

\subsubsection{Statistical analysis}

A linear mixed-effect model was used for testing the statistical significance of differences in daily mean FFR, $F_{C H 4}$ and $F_{N 2 O}$ between the $\mathrm{S}_{\mathrm{ph}}, \mathrm{S}_{\mathrm{cc}}$, and $\mathrm{S}_{\mathrm{c}}$, and among the years for both automatic and transect chamber measurements (Paper II and III). In both cases, the measurement point was treated as a random effect. The normality of the model residuals was visually checked using the quantilequantile plot method. Tukey's HSD post hoc test was used for comparison of the GHG fluxes at the $\mathrm{S}_{\mathrm{ph}}, \mathrm{S}_{\mathrm{cc}}$, and $\mathrm{S}_{\mathrm{c}}$ in different measurement years.

The linear mixed-effect model was also used for explaining the $F_{C H 4}$ and $F_{N 2 O}$ variation on the logging trail. The fixed effects in the initial model were: logging trail (i.e. was the point located on the logging trail or not), dry mass of the needles, total dry mass of the logging residues (needles, branches and twigs of pines, spruces and birches), WTL and soil temperature at $5 \mathrm{~cm}$. The measurement point was treated as a random effect. The best model was selected by reducing the number of variables until the explanative power of the model, which was inspected with Akaike information criterion (AIC) did not increase anymore.

The $95 \%$ confidence interval $(p<0.05)$ was used to determine whether the results were statistically significant.

\subsection{The contribution of individual GHGs to total site emissions}

The total site emissions were calculated for the periods of July 2016 - June 2017 and September 2016 - August 2017 to capture the rapid year-to-year post-harvest variations and take into account the limitations of the manual chamber measurements (Sect. 5.3.2). A raw estimation of $\mathrm{CH}_{4}$ and $\mathrm{N}_{2} \mathrm{O}$ balances at the $\mathrm{S}_{\mathrm{cc}}$ was made by linearly interpolating between the chamber measurements for July 2016 - June 2017 while the $\mathrm{CO}_{2}$ balances were calculated from the EC data (Sect. 5.2, Paper II). At the $\mathrm{S}_{\mathrm{ph}}$, the $\mathrm{CH}_{4}$ and $\mathrm{N}_{2} \mathrm{O}$ balances were estimated from the automatic chamber measurements (Sect. 5.3.1, Paper III) and $\mathrm{CO}_{2}$ balances were estimated from the EC data (unpublished data). At the $\mathrm{S}_{\mathrm{c}}$, the $\mathrm{CH}_{4}$ balances were calculated from the automatic chamber measurements, and $\mathrm{N}_{2} \mathrm{O}$ balances were estimated from the manual chamber measurements (Paper III). However, there was no net $\mathrm{CO}_{2}$ flux measurements at the $\mathrm{S}_{\mathrm{c}}$. Therefore, the $\mathrm{CO}_{2}$ balance for $\mathrm{S}_{\mathrm{c}}$ for the inspected periods was assumed to 
be the six-year annual mean before the harvesting (Table 3, sectors $\mathrm{A}+\mathrm{B}$ for $\mathrm{S}_{\mathrm{ph}}$ and sectors $\mathrm{B}+\mathrm{C}+\mathrm{D}$ for $\mathrm{S}_{\mathrm{cc}}$ ). After calculating the mean balance of the periods of July 2016 - June 2017 and September 2016 - August 2017, the resulting $\mathrm{CH}_{4}$ and $\mathrm{N}_{2} \mathrm{O}$ balances were converted into $\mathrm{CO}_{2}$-equivalent balances by using the coefficients of sustained-flux global warming potential over 100 years ( $\mathrm{SGWP}_{100}$ ) (45 and 270 for $\mathrm{CH}_{4}$ and $\mathrm{N}_{2} \mathrm{O}$, respectively; Neubauer and Megonigal, 2015, 2019). After the conversion, the difference in $\mathrm{CO}_{2}$-eq fluxes between the $\mathrm{S}_{\mathrm{th}}$ and $\mathrm{S}_{\mathrm{c}}$, and $\mathrm{S}_{\mathrm{cc}}$ and $\mathrm{S}_{\mathrm{c}}$ were calculated to estimate the climatic effect of the harvests.

\subsection{Water table level measurements}

WTL was monitored hourly with automatic probes (TruTrack WT-HR, Intech Instruments Ltd, Auckland, New Zealand; Odyssey Capacitance Water Level Logger, Dataflow Systems Limited, Christchurch, New Zealand) in dipwells (perforated plastic tubes $120 \mathrm{~cm}$ long, $3.5 \mathrm{~cm}$ diameter) in multiple locations at the $\mathrm{S}_{\mathrm{ph}}, \mathrm{S}_{\mathrm{cc}}$, and $\mathrm{S}_{\mathrm{c}}$. Four dipwells were set up next to automatic chambers in December 2015. If the chambers were close to each other, only one dipwell was installed between them. At the $\mathrm{S}_{\mathrm{ph}}$ and control transects, dipwells were installed in May 2015 next to the chambers at four distances $(4,8,12$ and $22.5 \mathrm{~m})$ from the ditch. A similar installation was made at the $\mathrm{S}_{\mathrm{cc}}$ in June 2015. Also, each flux measurement plot on the logging trails had a WTL probe from May 2016 to October 2017. In addition to the measurements next to the chamber points, WTL was monitored automatically and manually around the $S_{c}$ and $S_{\text {ph }}$ at every $40 \mathrm{~m}$ in all cardinal and inter-cardinal directions from the EC mast. WTL was first monitored manually from weekly to bi-weekly intervals at these points starting from March 2015. In June 2016, five automatic WTL probes were installed at the $S_{c}$. At the same time, six automatic probes were installed at the $S_{p h}$ and seven additional probes in November 2016. Manual monitoring was continued from the rest of the dipwells until October 2017.

The WTL measured at the logging trail plots was used to estimate the WTL at each point in the plots by taking into account the ground elevation. These estimated WTLs were used in the mixed-model analysis when investigating the environmental variables affecting the logging trail fluxes.

The analysis of harvesting effects on WTL was based on the paired treatment approach (or calibration period - control area method) (e.g. Kaila et al., 2015; Laurén et al., 2009). First, the linear regressions were made between the WTL within the $S_{\mathrm{ph}}$ and $\mathrm{S}_{\mathrm{c}}$, and $\mathrm{S}_{\mathrm{cc}}$ and $\mathrm{S}_{\mathrm{c}}$ for the pre-harvest period using WTL data from 2015. Next, the regression models and post-harvest WTL data from the $S_{c}$ were used to predict the WTL at the harvested sites as if they were never harvested. The effect of the harvests was calculated as a difference between this background model WTL and the actual post-harvest WTL measured at the sites. However, there were slight differences in the pre-processing of the WTL data between the Papers II-IV. In Papers II and III, the automatic and manual measurements at the tree stand inventories were used in addition to the transect measurements to estimate the harvesting effect on WTL. Linear regression was made annually between the automatic and manual measurements to model continuous timeseries for the tree stand points lacking automatic loggers. In Paper IV, only WTL measurements made at the transects were used. 


\subsection{Calculation of the biomass increment}

Tree stand properties (spring 2009, autumn 2014) and ground vegetation projection coverage (summer 2009) were determined at stand inventory plots shown in Fig. 4. The tree stand was measured twice, in spring 2009 (before annual growth started) and autumn 2014 (after annual growth ended). The tree stand was measured and biomass increment calculated similarly to Lohila et al. (2011), using allometric functions for pine, spruce and birch (Laiho and Finér, 1996; Repola, 2008, 2009). Standard error of the estimate was calculated based on the parameter uncertainty and residual error of the tree stand models. Also, sampling error was included as the standard error of mean of the plot wise biomass increments. 


\section{Results and discussion}

\subsection{The effect of flux calculation methods on chamber GHG fluxes}

Using linear regression systematically resulted on average $27.5 \pm 0.3 \%$ ( $\pm 95 \%$ confidence interval) smaller $\mathrm{CH}_{4}$ flux estimates with 6 min closure time than the use of exponential regression (Paper I; Fig. 6a). Even though it is not possible to know the "true" flux in field conditions, it has been shown in laboratory conditions that linear regression systematically underestimates the actual flux. In contrast, the exponential regression significantly improves the flux estimation (Pihlatie et al., 2013). This fact is likely true also in the field, as exponential regression can capture the curvature and the initial concentration change in time inside the chamber, which best represent the conditions before the disturbance caused by the chamber placement. However, exponential regression is sensitive to the initial conditions caused by chamber placement (Kutzbach et al., 2007); hence the data under possibly disturbed conditions at the beginning of the closure have to be discarded. On a positive note, discarding data during 30-60 s from the start of the closure does not substantially affect the estimated flux (difference $<3 \%$, Paper I), especially when compared to the importance of the fitting method and the length of the fitting period. Another disadvantage of using exponential regression is the problem occurring with low fluxes when the signal-to-noise ratio is small. In these cases, the use of exponential regression could result in unphysically high or low fluxes caused by a sharp slope at the beginning of the fit (Forbrich et al., 2010) (Paper I; Fig. 6b). The problem of unphysically high fluxes can be evaded by using the more robust linear regression for these cases, while still using exponential regression to capture the curvature of the concentration development in the high flux cases. The gas balances during these low flux periods are likely underestimated by linear regression. However, their contribution to the annual balance is small as long as the flux limit (Sect. 5.3.3; Paper I) used to choose between linear and exponential regressions is significantly lower than the mean annual flux.

a)

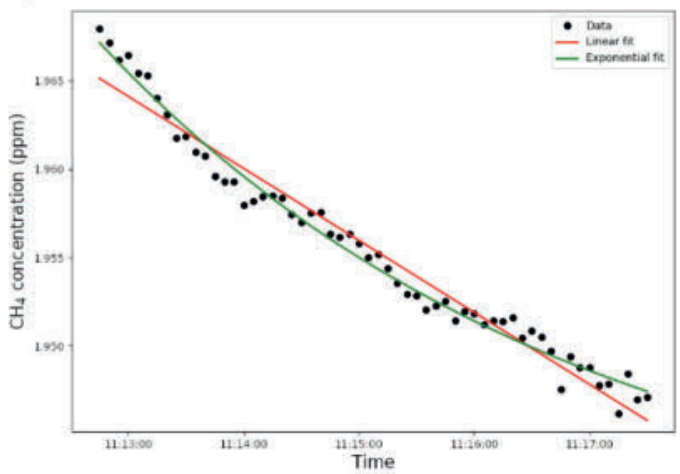

b)

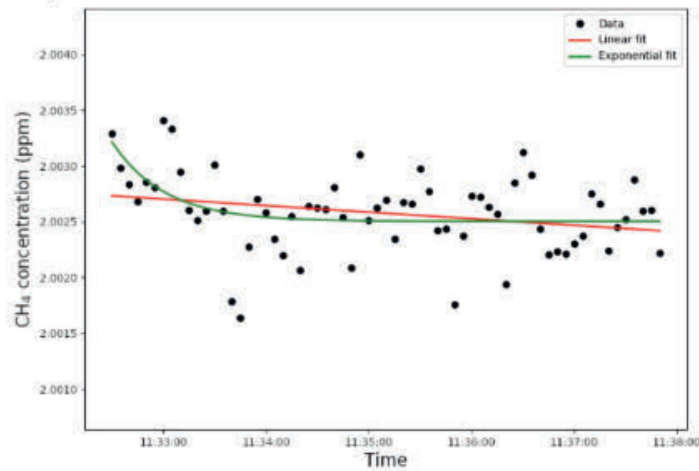

Figure 6. Measured $\mathrm{CH}_{4}$ concentration data during one chamber closure for a case (a) in which linear fitting noticeably underestimates the flux estimated from the concentration development and (b) in which exponential fitting fails due to measurement noise.

The length of the fitting period can have a significant effect on the flux estimate, but its impact depends on the fitting method. When using linear regression, the estimated flux did not change 
significantly when increasing the fitting window from the start of the closure up to $140 \mathrm{~s}$ (Fig. 7; Paper I). However, further increases in the fitting window decreased the estimated flux by about $1.3 \%$ for every $60 \mathrm{~s}$ increase. This decrease in the flux estimate is caused by the failed assumption of constant gas mixing ratio change in time, which has been recognised by multiple studies (e.g. Kutzbach et al., 2007; Nakano et al., 2004; Pihlatie et al., 2013). On the other hand, the estimated flux was strongly affected by the length of the fitting window up to $190 \mathrm{~s}$ when using exponential regression (Fig. 7). Further expansions of the fitting window did not have a significant effect, except making the regression more stable (Paper I). It should be noted that the effect of the fitting window size depends on both the properties of the measurement system and flux magnitude; hence these conclusions cannot be generalised. For example, Kutzbach et al. (2007) showed that using a $120 \mathrm{~s}$ fitting window with linear regression resulted in as much as $40 \%$ lower $\mathrm{CO}_{2}$ flux estimates than when using exponential regression.

(a)

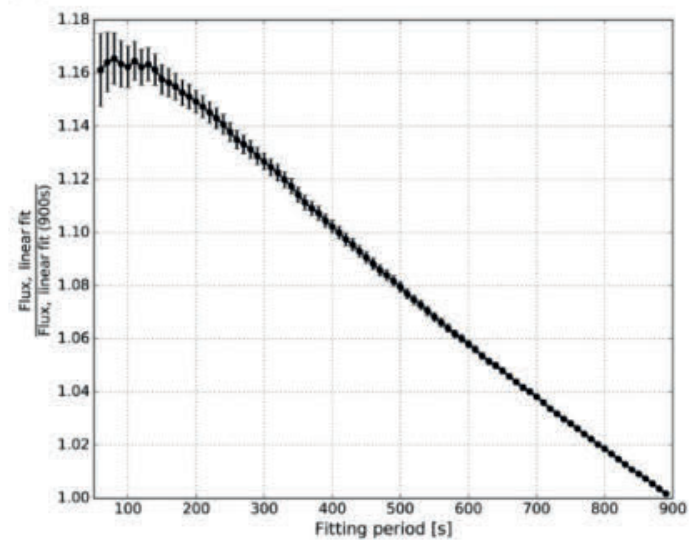

(b)

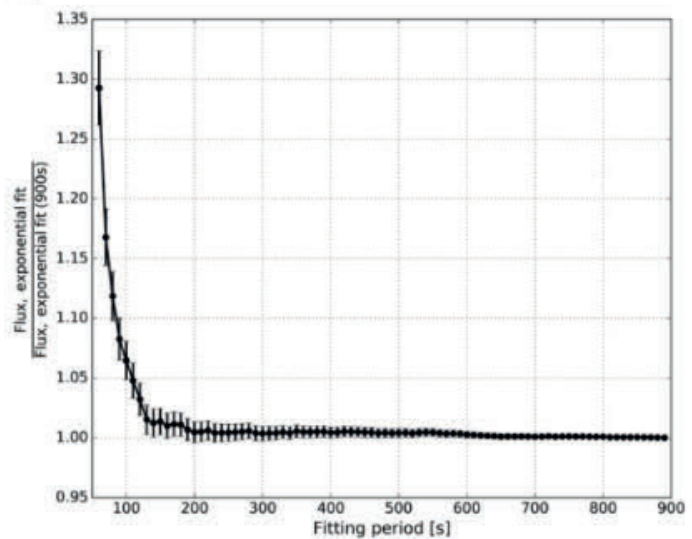

Figure 7. The $\mathrm{CH}_{4}$ flux determined by (a) linear and (b) exponential regression as a function of fitting period. The fluxes are scaled by the flux calculated with the longest fitting period ( $900 \mathrm{~s})$. The data are from summer 2012 and the error bars show the 95\% confidence intervals. The figure is adopted from Paper I.

To summarise, when using exponential regression, a long fitting window and a closure time of several minutes should be used to stabilise the fit. However, care should be taken when increasing the closure time as it could change the environmental conditions inside the chamber and affect the flux estimate. So, the choice of the closure time is a balance between optimal fitting window for the exponential fit and minimising the effect of the closure time on environmental conditions. Linear regression should be avoided due to its incorrect assumption of constant concentration development inside the chamber, which can cause flux underestimation even in short fitting windows. The exception to this recommendation is the case in which the concentration change is small and strongly affected by the measurement noise, causing the exponential fit to fail. 


\subsection{Changes in evapotranspiration and water table level}

The WTL significantly rose after both harvesting actions. According to the measurements, the mean pre-harvest WTL measured from the transects in the period July-August 2015 was $-50 \mathrm{~cm}$ at both the $\mathrm{S}_{\mathrm{c}}$ and $\mathrm{S}_{\mathrm{ph}}$ while the WTL at the $\mathrm{S}_{\mathrm{cc}}$ was higher at $-33 \mathrm{~cm}$ (Fig. 8, Papers II and III). After harvesting in July-August 2016, WTL was higher at the $S_{\mathrm{cc}}\left(-22 \mathrm{~cm}\right.$; Paper II) and $\mathrm{S}_{\mathrm{ph}}(-44 \mathrm{~cm}$; Paper III) as compared to the pre-harvest situation, while WTL at the $S_{c}$ decreased to $-55 \mathrm{~cm}$. In July-August 2017, WTL remained on the similar level $(-42 \mathrm{~cm})$ at the $S_{\mathrm{ph}}$ as compared to the same period in 2016. However, WTL was slightly lower at the $S_{\mathrm{cc}}$ at $-27 \mathrm{~cm}$ in 2017 than in 2016.

According to background models, WTL rise at $\mathrm{S}_{\mathrm{cc}}$ averaged $24 \pm 2 \mathrm{~cm}( \pm \mathrm{SD})$ for July-August in 20162017 (Paper II). In Paper IV, the WTL rise was evaluated to equal $18 \pm 2 \mathrm{~cm}$ in May-September 2016-2018, which is in agreement with the estimation made in Paper II considering the different periods used to calculate the WTL increase. At the $S_{\text {ph }}$, WTL rose by $12 \pm 1 \mathrm{~cm}$ in July-August 20162017 (Paper III). However, in Paper IV, the observed WTL rise $(5 \pm 3 \mathrm{~cm})$ at the $\mathrm{S}_{\mathrm{ph}}$ was slightly smaller as compared to that reported in Paper III, but the difference could not be explained by different time periods used to estimate the WTL rise. The analysis in Paper IV only included loggers located close to the chamber measurements where the tree stand was denser than the other parts of the $\mathrm{S}_{\mathrm{ph}}$ (Fig. 4). On the other hand, the WTL data in Paper III had higher spatial coverage at the $\mathrm{S}_{\mathrm{ph}}$, which also took into account the more harvested areas at the $S_{\text {ph. }}$ Expectedly, this results in slightly higher rise in WTL in Paper III than the rise estimated in Paper IV. Nevertheless, both methods suggested that the WTL increase was significantly different from zero at both $\mathrm{S}_{\mathrm{ph}}$ and $\mathrm{S}_{\mathrm{cc}}$.

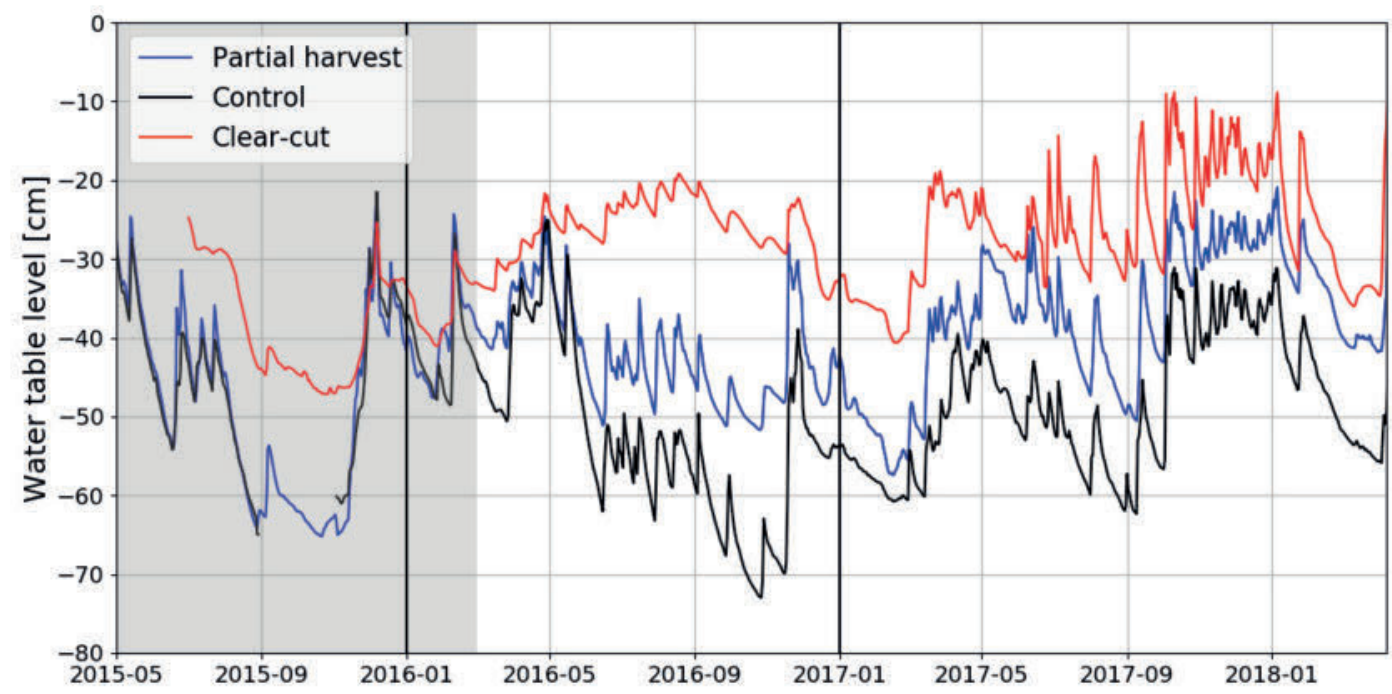

Figure 8. Daily mean WTL measured at the partial harvest (blue), control (black) and clear-cut (red) sites. The grey area denotes the period before the harvesting actions. The WTL data shown here is based on the data used in Papers II and III.

The raised WTL at both sites was caused by reduced biomass, which decreased transpiration (Paper IV; e.g. Sarkkola et al., 2010). At the $\mathrm{S}_{\mathrm{cc}}$, the increase in WTL was more substantial than at the $\mathrm{S}_{\mathrm{ph}}$ 
due to more radical changes in vegetation and tree stand. On the other hand, an even larger rise in WTL at the $S_{\mathrm{cc}}$ was prevented by ditch mounding, which enhanced water flow from the subsite. A slight rise $(\max .7 \mathrm{~cm})$ in WTL after thinning have also been observed at Scots pine peatland forest by Päivänen and Sarkkola (2000), but their heaviest thinning was only $28 \%$ of the stand volume, being less than half of that at Lettosuo. However, Heikurainen and Päivänen (1970) reported that harvesting $60 \%$ of the volume of a Scots pine stand resulted in a WTL rise that was half of the response observed at a parallel $\mathrm{S}_{\mathrm{cc}}$. This result is in good agreement with those observed at Lettosuo.

Before the harvests, ET varied within 290-365 mm during the May-September period, and it exceeded precipitation during this period except the rainiest years of 2011 and 2014 (Paper IV). This exceedance is typical for boreal upland and peatland forests (Grelle et al., 1997; Launiainen, 2010; Sarkkola et al., 2013). On the other hand, the highest pre-harvest ET was observed in 2010, which was the driest and warmest year. The dominant pines and birches contributed by $47 \%$ and $27 \%$ to the total site transpiration while the remaining $17 \%$ and $9 \%$ originated from the understorey spruces and ground vegetation, respectively (Paper IV). After clearcutting, the total ET in May-September decreased to $176 \mathrm{~mm}$ (Papers II and IV) in 2016. The drop in ET is consistent with previous studies conducted in boreal forests (Amiro, 2001; Mamkin et al., 2019; Rannik et al., 2002). The drop in the May-September ET at the $\mathrm{S}_{\mathrm{ph}}$ was smaller than at the $\mathrm{S}_{\mathrm{cc}}$ in 2016. At $\mathrm{S}_{\mathrm{ph}}$, the ET equalled $264 \mathrm{~mm}$, which is $83 \%$ of the modelled ET at the $S_{c}\left(320 \mathrm{~mm}\right.$, Paper IV). In May-September 2017, the $\mathrm{S}_{\mathrm{cc}}$ $(261 \mathrm{~mm})$ and $\mathrm{S}_{\mathrm{ph}}(263 \mathrm{~mm})$ had a similar ET, but in 2018 the $\mathrm{S}_{\mathrm{cc}}$ had a considerably smaller ET (268 $\mathrm{mm})$ again, as compared to the similar ET level measured at the $\mathrm{S}_{\mathrm{ph}}(388 \mathrm{~mm})$ and modelled for the $\mathrm{S}_{\mathrm{c}}(380 \mathrm{~mm})$.

The substantial decrease in ET at the $\mathrm{S}_{\mathrm{cc}}$ was expected and attributed to harvesting all the transpiring trees and the destruction of ground vegetation (Paper II and IV). The fast recovery in the following year could be attributed to the quickly recovered ground vegetation (visual inspection, not directly measured). This is further supported by the fact that in 2018 the ET at the $\mathrm{S}_{\mathrm{cc}}$ did not significantly increase from 2017 (Fig. 9), even though that summer was exceptionally warm and dry. The smaller decrease in ET at the $S_{\text {ph }}$ was attributed to increased transpiration of spruces and ground vegetation and to forest floor evaporation, which compensated part of the transpiration by pines prior to the harvest (Paper IV). According to the model results, spruce transpiration roughly doubled in response to the increased light availability after harvesting the overlying pine canopy. Similarly to the increase in spruce ET, the ground vegetation ET increased after being exposed to increased wind and light, and higher VPD. The increased ET of spruces and ground vegetation compensated the reduced transpiration of the pine trees, thus limiting the drop in ET.

According to the model results, the species composition and canopy structure had a substantial effect on WTL after the harvest. Even though $69 \%$ of the tree basal area was removed in the harvest, the WTL rise was only $60 \%$ of that measured at the $\mathrm{S}_{\mathrm{cc}}$. Removing pine trees, but leaving birches and spruces with high transpiration capacity at the $\mathrm{S}_{\mathrm{ph}}$, limited the WTL rise (Paper IV). This information could be used in harvest planning to preserve undisturbed growth of the trees as understorey birches with high transpiration rate per leaf area are commonly found in peatland forests (Sarkkola et al., 2005). Retaining a high transpiration rate could prevent ditch maintenance and thus reduce costs associated with peatland forestry. 

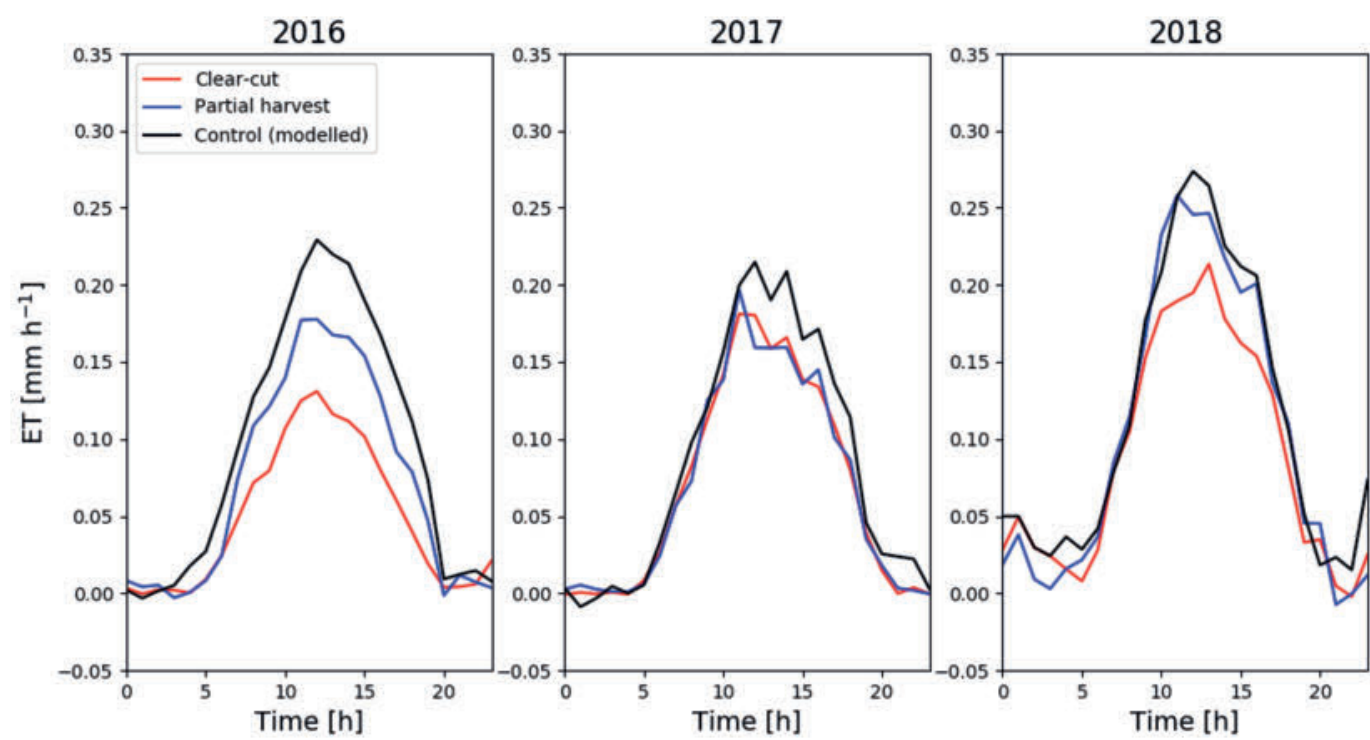

Figure 9. Measured mean ET diel cycles at the $\mathrm{S}_{\mathrm{ph}}$ (blue) and $\mathrm{S}_{\mathrm{cc}}$ (red) during May-September in 2016-2018. The black line shows the modelled ET for the $S_{c}$. The cycles represent periods when measurements were available from both sites, excluding periods with $>5.0 \mathrm{~mm}$ of rainfall within the past 24 h. The figure is modified from Paper IV.

\subsection{The effect of harvesting methods on GHG fluxes}

\subsection{1 $\mathrm{CO}_{2}$ balances before the harvest}

The annual $\mathrm{CO}_{2}$ balance before the harvesting varied within $-170-20 \mathrm{~g} \mathrm{CO}_{2} \mathrm{~m}^{-2} \mathrm{yr}^{-1}$ in 2010-2015 and averaged at $-50 \pm 30 \mathrm{~g} \mathrm{CO}_{2} \mathrm{~m}^{-2} \mathrm{yr}^{-1}( \pm \mathrm{SEM}$ ) during these six study years (unpublished data) (area weighted sectors A-D in Fig. 10). This is in agreement with many of the previous studies in nutrientrich peatland forests, which have shown that peatland forests can act as small $\mathrm{CO}_{2}$ sinks in the growing stage while mature and over-matured forests are $\mathrm{CO}_{2}$ neutral and sources, respectively (Meyer et al., 2013; Ojanen et al., 2013; Uri et al., 2017). Interestingly, an almost twice as high mean respiration rate (after being standardised for temperature) was observed in the sector A (Fig. 10) as in the sectors B-D. No apparent reason for the higher respiration was found from the supporting data collected. Also, the possible biases originating from the measurement system and source area variations could be excluded by thoroughly inspecting the quality of the flux data. Due to this anomalous sector, gapfilling of the 30-min $\mathrm{CO}_{2}$ fluxes had to be done separately for the sector A and sectors $\mathrm{B}-\mathrm{D}$. Also, for an unbiased estimate of the impact of different harvesting actions, the pre-harvest $\mathrm{CO}_{2}$ balances (Table 3) were estimated separately for the later partially harvested area (sectors A and B, Fig. 10). To compare the effect of clearcutting (sector D, Fig. 10) on $\mathrm{CO}_{2}$ balances, the pre-harvest balance of the sectors B-D was used (i.e. the sector with high respiration was excluded here). Because elevated respiration rates were not observed after partial harvest (based on EC data and spatial chamber flux 
campaign, data not shown), the sectors A and B were not separated in the gap-filling of the postthinning data.

Because of the sector with high respiration rates, the area which would be partially harvested in 2016 (sectors A-B in Fig. 10) was a small $\mathrm{CO}_{2}$ source in 2010-2015, the balance averaging at $140 \pm 20 \mathrm{~g}$ $\mathrm{CO}_{2} \mathrm{~m}^{-2} \mathrm{yr}^{-1}( \pm \mathrm{SEM})$ (Table 3) (unpublished data). This means that this area was already losing more carbon from peat decomposition than was uptaken by trees. The annual mean biomass increment at Lettosuo was estimated at $790 \pm 70 \mathrm{~g} \mathrm{CO}_{2} \mathrm{~m}^{-2} \mathrm{yr}^{-1}$ in 2009-2014. On the other hand, sectors $\mathrm{B}+\mathrm{C}+\mathrm{D}$, which would be used as the pre-harvest reference for the later clear-cut site, acted as a $\mathrm{CO}_{2}$ sink with a mean annual $\mathrm{CO}_{2}$ balance of $-400 \pm 30 \mathrm{~g} \mathrm{CO}_{2} \mathrm{~m}^{-2} \mathrm{yr}^{-1}$ in 2010-2015. The differences in $\mathrm{CO}_{2}$ balances between these two areas were attributed to ER that was on average $16 \%$ larger in the later partially harvested area than in the sectors B-D, which was only partly compensated by a $6 \%$ larger GPP.

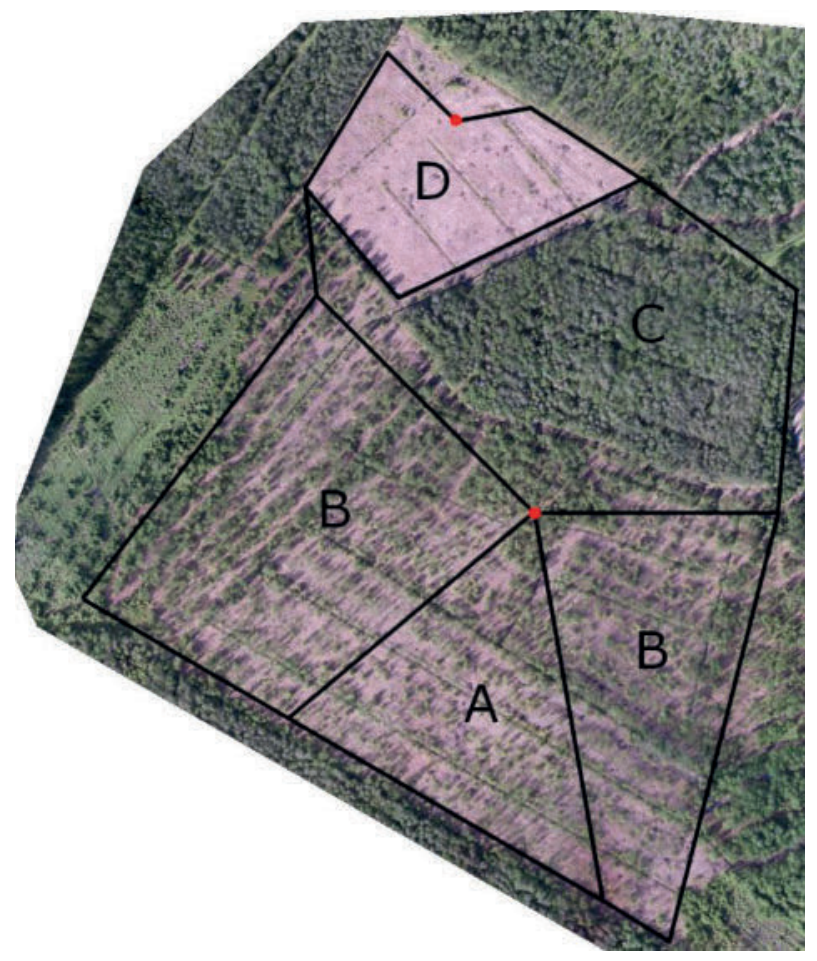

Figure 10. Aerial view of the site showing the eddy covariance masts (red dots) and their target areas, as well as the sectors used to draw conclusions about the impact of management on $\mathrm{CO}_{2}$ balances. 
Table 3. Annual net ecosystem exchange of $\mathrm{CO}_{2}$ (NEE), modelled absolute value of gross primary production $(|\mathrm{GPP}|)$, and modelled ecosystem respiration (ER) before and after partial harvest and clearcutting, and changes in the components after harvesting actions compared to the mean preharvest balance. The sectors from which the values are calculated are shown in Fig. 10.

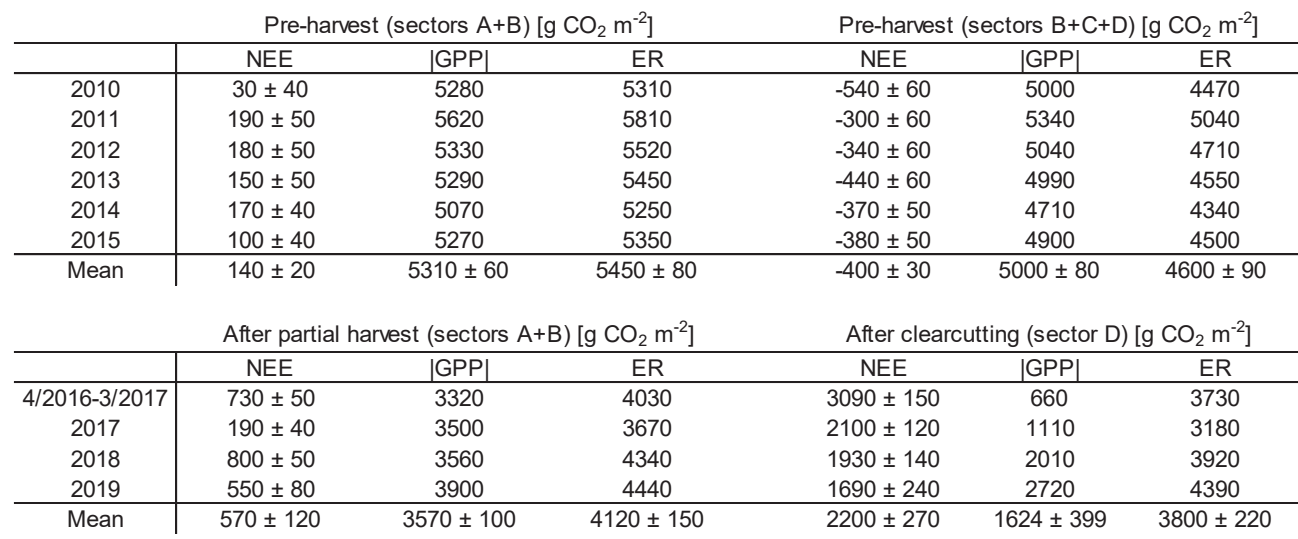

\begin{tabular}{c|cccccc}
\multicolumn{4}{c}{ Change after partial harvest (sectors $\mathrm{A}+\mathrm{B})\left[\mathrm{g} \mathrm{CO}_{2} \mathrm{~m}^{-2}\right]$} & \multicolumn{3}{c}{ Change after clearcutting (sector D) $\left[\mathrm{g} \mathrm{CO}_{2} \mathrm{~m}^{-2}\right]$} \\
\hline & NEE & GPP| & ER & NEE & $|\mathrm{GPP}|$ & ER \\
\hline $4 / 2016-3 / 2017$ & +590 & -1990 & -1420 & +3480 & -4340 & -880 \\
2017 & +50 & -1820 & -1780 & +2500 & -3890 & -1430 \\
2018 & +660 & -1760 & -1110 & +2320 & -2990 & -680 \\
2019 & +420 & -1420 & -1000 & +2080 & -2280 & -210
\end{tabular}

\subsubsection{Changes in $\mathrm{CO}_{2}$ dynamics}

After clearcutting, the site became a substantial $\mathrm{CO}_{2}$ source for the first two years (1st year: $3090 \pm 150$ g CO $\mathrm{m}^{-2} \mathrm{yr}^{-1}$, 2nd year: $2100 \pm 120 \mathrm{~g} \mathrm{CO}_{2} \mathrm{~m}^{-2} \mathrm{yr}^{-1}$; Paper II), which was caused by a $87 \%$ reduction in GPP (Table 3, Fig. 11). GPP decreased as a result of the removal of trees and destruction of ground vegetation. However, the GPP recovery has been fast due to growth of ground vegetation, and in the second post-clear-cut summer, GPP had almost doubled from the first summer, being ca. $20 \%$ of the pre-harvest level (Table 3; Paper II). Fast recovery has also previously been observed in a nutrientpoor peatland forest, where NEE after clearcutting was slightly smaller than at the study site (Mäkiranta et al., 2010). Four years after clearcutting, GPP at Lettosuo was about $46 \%$ of the mean pre-harvest GPP (Table 3; unpublished data). ER also decreased from the pre-harvest level, by 19\% (Table 3; Fig. 11; unpublished data), which is likely due to a decrease in plant respiration caused by removal of respiring biomass. Also, a decrease in FFR was observed (Paper II), which is likely resulted from raised WTL that limited peat decomposition. However, the addition of decomposing logging residues limited the decrease in ER, as the respiration from the residues was shown to be $49 \%$ of the total ER, while the rest originated from FFR (Paper II). In the second post-clearcutting year, FFR did not change significantly. Still, ER continued to decrease further, suggesting that the decrease in ER was due to the fact that the most easily decomposable residues had already decomposed during the first summer. In the following years, it is expected that the vegetation will continue to recover, which would increase GPP and plant respiration. In addition, this would also increase transpiration, leading to a lower WTL and higher peat decomposition rates. Compared to the first and second post- 
harvest year, the third and fourth years show a recovery of ER closer to the pre-clearcut values (Table 3; unpublished data).

a)

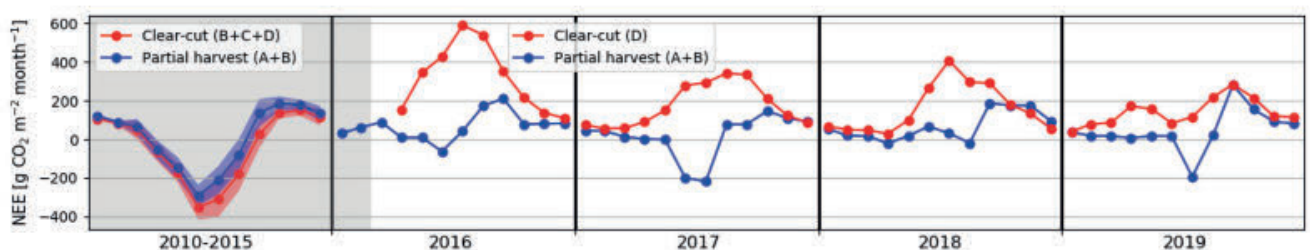

b)

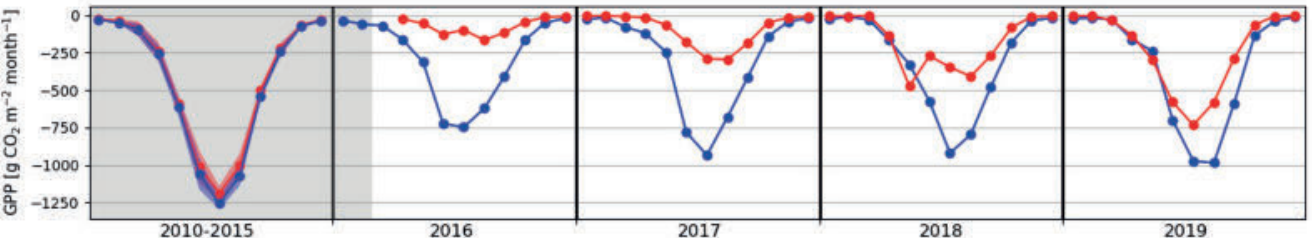

c)

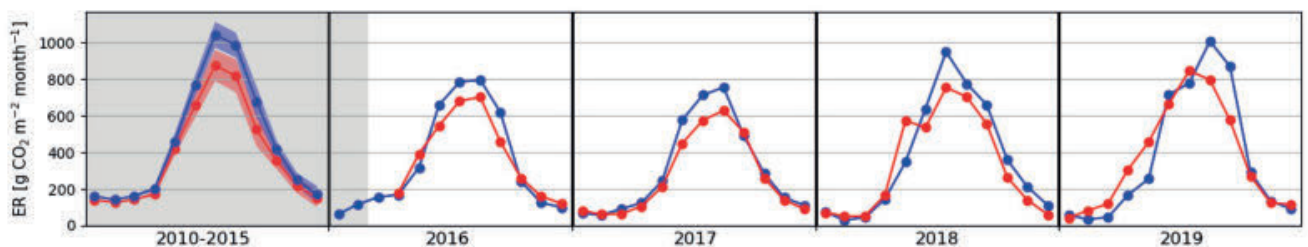

Figure 11. Time series of monthly sums of (a) $\mathrm{CO}_{2}$ net ecosystem exchange (NEE), (b) gross primary production (GPP), and (c) ecosystem respiration (ER) measured before harvesting (shaded period, mean of 2010-2015) and after clearcutting (red line) and partial harvesting (blue line). The shading on the curves shows the standard deviation of the monthly sums before the harvests. The letters in the legends show the sectors (Fig. 10) from which the monthly sums are calculated.

At the $\mathrm{S}_{\mathrm{ph}}$, the increase in NEE after partial harvest was moderate (Table 3; Fig. 11; unpublished data). During the first four post-harvest years, the annual NEE varied within 190-800 $\mathrm{g} \mathrm{CO}_{2} \mathrm{~m}^{-2} \mathrm{yr}^{-1}$ (Table 3). The smaller NEE compared to $\mathrm{S}_{\mathrm{cc}}$ were caused by the more limited harvest and the improved light conditions for the ground vegetation and Picea Abies that formed the previous understorey; this kept GPP relatively high. GPP decreased on average by $37 \%$ from the pre-harvest mean GPP, and remained at a similar level for the two following years. This difference in GPP between $S_{c c}$ and $S_{p h}$ in the post-harvest years was attributed to the improved light conditions for the spruce trees of the previous understorey after removal of the overstorey pine trees. This increased spruce photosynthesis limited the decline of GPP at the $S_{p h}$, while at the $S_{c c}$ most of the photosynthesizing biomass was destroyed. However, the recovery of GPP at the $\mathrm{S}_{\mathrm{ph}}$ has been much slower than at the $\mathrm{S}_{\mathrm{cc}}$ (Table 3; Fig. 11). In the first post-harvest year, the recovery might have been limited by the light stress imposed to spruce trees (Paper IV), which has previously been observed to last from four to five years in mineral soil forests after overstorey removal (Koistinen and Valkonen, 1993). Finally, the retained spruce cover at the $\mathrm{S}_{\mathrm{ph}}$ still prevent some of the solar radiation reaching the soil surface, hence limiting the growth of new ground vegetation, while at $\mathrm{S}_{\mathrm{cc}}$ there is no tree cover and the relative increase in the ground vegetation density was much larger (visual 
inspection). In the fourth post-harvest year, a slight recovery in GPP seems to have happened at $\mathrm{S}_{\mathrm{ph}}$, but more data is needed to exclude the role of natural variation in this change.

At the $\mathrm{S}_{\mathrm{ph}}$, ER decreased by $26 \%$ in the first post-harvest year and declined even further in the next year (33\% lower than the pre-harvest mean). However, in the third and fourth post-harvest year, ER increased noticeably, but was still 19\% lower than before partial harvest (Table 3; Fig. 11). The observed reduction in ER from the first post-harvest year was likely caused by the same reasons as at the $\mathrm{S}_{\mathrm{cc}}$, i.e. the decrease in plant respiration due to removal of overstorey trees and some disturbance to the ground vegetation, especially on the logging trails. The decline in ER was partly offset by the addition of logging residues. Indeed, elevated $\mathrm{CO}_{2}$ emissions were observed from the logging trails in the first post-harvest summer 2016 compared to the automatic chambers and transect measurements at the harvest, but not anymore in summer 2017 (unpublished data). However, FFR did not decrease at $\mathrm{S}_{\mathrm{ph}}$ contrary to what was observed at $\mathrm{S}_{\mathrm{cc}}$ (Fig. 12). This difference between the sites might be explained by the fact that the removal of fewer trees from the transect, leading to a smaller belowground logging residue volume and a smaller rise in WTL at $\mathrm{S}_{\mathrm{ph}}$ compared to $\mathrm{S}_{\mathrm{cc}}$. These respiring residues and reduced peat decomposition could have balanced each other, resulting in only a minor change in FFR.

Comparing the partial harvest and clearcut-induced changes in NEE at the study site to other harvesting studies reveals some important differences. In the clear-cut mineral soil forests the reported annual balances vary from ca. 400 to $4700 \mathrm{~g} \mathrm{CO}_{2} \mathrm{~m}^{-2} \mathrm{yr}^{-1}$ (Amiro et al., 2010; Clark et al., 2004; Humphreys et al., 2005; Kowalski et al., 2004, 2003; Takagi et al., 2009; Williams et al., 2013). Forests in warmer climates emit more $\mathrm{CO}_{2}$ after clearcutting (Amiro et al., 2010). However, compared to the studies listed above, Lettosuo, which is located in the boreal zone, was the second-largest $\mathrm{CO}_{2}$ source $\left(3086 \pm 148 \mathrm{~g} \mathrm{CO}_{2} \mathrm{~m}^{-2} \mathrm{yr}^{-1}\right)$ after slash pine plantation in Florida (Clark et al., 2004). The apparent difference between the mineral soil forests and Lettosuo is due to the decomposition of the oxic peat layer, which can act as $\mathrm{CO}_{2}$ sources up to $1000 \mathrm{~g} \mathrm{CO}_{2} \mathrm{~m}^{-2} \mathrm{yr}^{-1}$ (Ojanen et al., 2013; Uri et al., 2017). Mineral soil forests do not have such $\mathrm{C}$ storage, which explains the relatively high $\mathrm{CO}_{2}$ emissions at Lettosuo. Assessment of how NEE depends on partial cuttings is difficult because of the diversity of approaches (e.g. reduction in the basal area; Nieminen et al., 2018), and no thinning studies have been made on peat soil to the author's knowledge. Some studies were made on mineral soil with a relatively small 21-27\% reduction in basal area (Lindroth et al., 2018; Saunders et al., 2012; Scott et al., 2004; Vesala et al., 2005; Wilkinson et al., 2016), but no significant changes were observed in annual NEE, except in one study in which NEE increased slightly for the first and third year after thinning (Lindroth et al., 2018), but otherwise no differences were observed. A slightly stronger thinning (35\% of basal area) in a ponderosa pine forest in Arizona, USA, resulted in an increased NEE and turned the forest into a $\mathrm{CO}_{2}$ source; after four years, however, this ecosystem returned to an even stronger sink state than before thinning (Dore et al., 2012). These thinnings were relatively limited compared to the $69 \%$ reduction in basal area at Lettosuo. Indeed, the removal of overstorey trees in this thesis resulted in a noticeable increase in NEE (Fig. 11; Table 3; unpublished data). 


\subsubsection{Changes in $\mathrm{CH}_{4}$ fluxes}

The net $\mathrm{CH}_{4}$ emissions increased significantly at the $\mathrm{S}_{\mathrm{cc}}$. The $\mathrm{S}_{\mathrm{cc}}$ turned from a $\mathrm{CH}_{4}$ sink $(-94 \pm 18 \mu \mathrm{g}$ $\mathrm{CH}_{4} \mathrm{~m}^{-2} \mathrm{~h}^{-1}$ in 2015) into a small $\mathrm{CH}_{4}$ source $\left(14 \pm 11 \mu \mathrm{g} \mathrm{CH}_{4} \mathrm{~m}^{-2} \mathrm{~h}^{-1}\right.$ in $2016,22 \pm 7 \mu \mathrm{g} \mathrm{CH}_{4} \mathrm{~m}^{-2} \mathrm{~h}^{-1}$ in 2017; Paper II). The $24 \mathrm{~cm}$ rise in WTL was the most likely reason for this change. The WTL rise decreased the thickness of the oxic layer in peat, increasing the volume of the soil layer below the WTL in which the production of $\mathrm{CH}_{4}$ occurs, and thinning the layer capable of oxidising $\mathrm{CH}_{4}$ before it reaches the atmosphere. At the $\mathrm{S}_{\mathrm{cc}}$, the decrease of oxic layer thickness was large enough to turn the soil into a net $\mathrm{CH}_{4}$ source (Figs. 12 and 13). Similar results of the soil turning from a $\mathrm{CH}_{4}$ sink to a source after clearcutting have been found on both peat (Zerva and Mencuccini, 2005) and mineral soil (Castro et al., 2000; Sundqvist et al., 2014; Vestin et al., 2020) soil, which were attributed to increases in WTL and soil moisture. However, opposing results have also been observed on both soil types. Mazza et al. (2019) recorded an increase in the $\mathrm{CH}_{4}$ sink in a Mediterranean upland forest, while no noticeable changes were observed in some peatland forests despite the substantial rise in WTL (Huttunen et al., 2003).
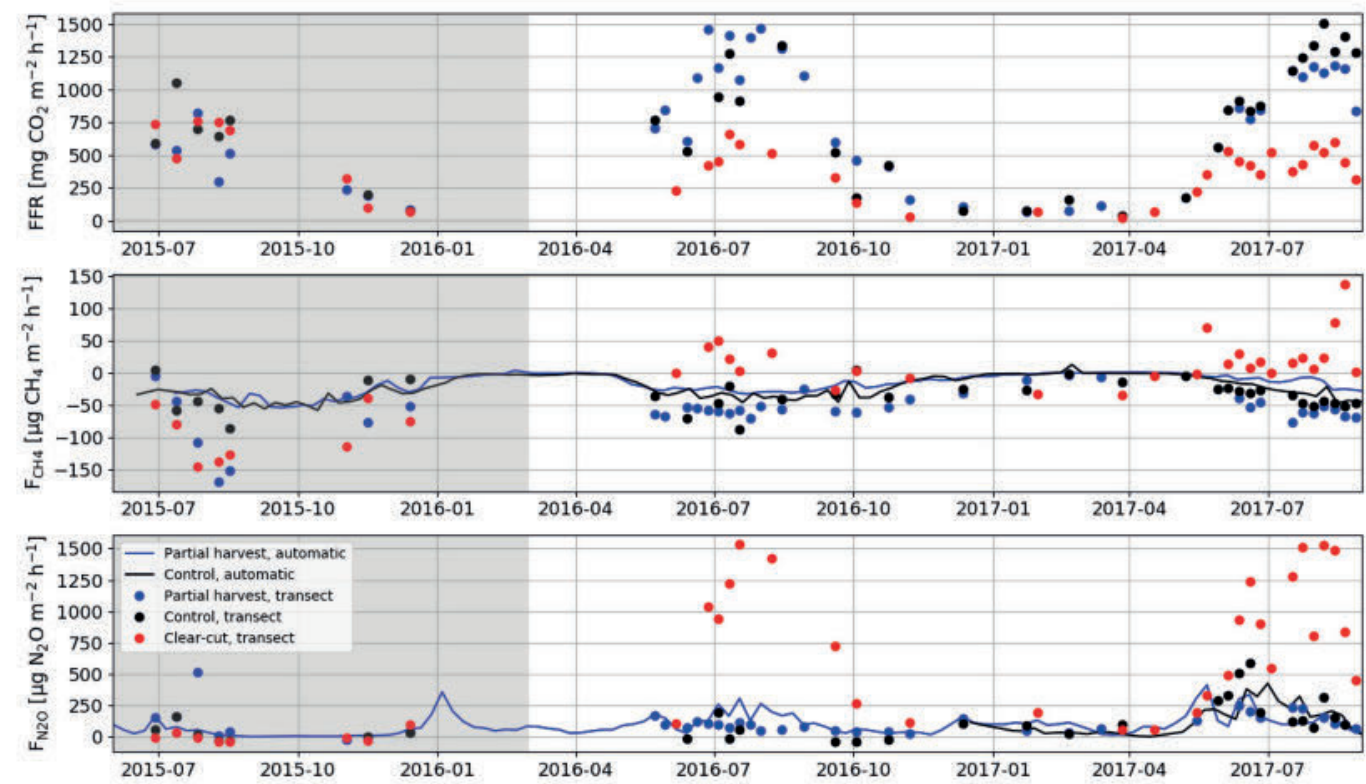

Figure 12. Time series of the daily mean forest floor respiration (FFR), $\mathrm{CH}_{4}$ flux $\left(F_{C H 4}\right)$, and $\mathrm{N}_{2} \mathrm{O}$ flux $\left(F_{N 2 O}\right)$ measured at the partial harvest (blue), control (black) and clear-cut (red) sites before (shaded period) and after harvests. Lines and dots show the measurements made with automatic and manual chambers, respectively. 

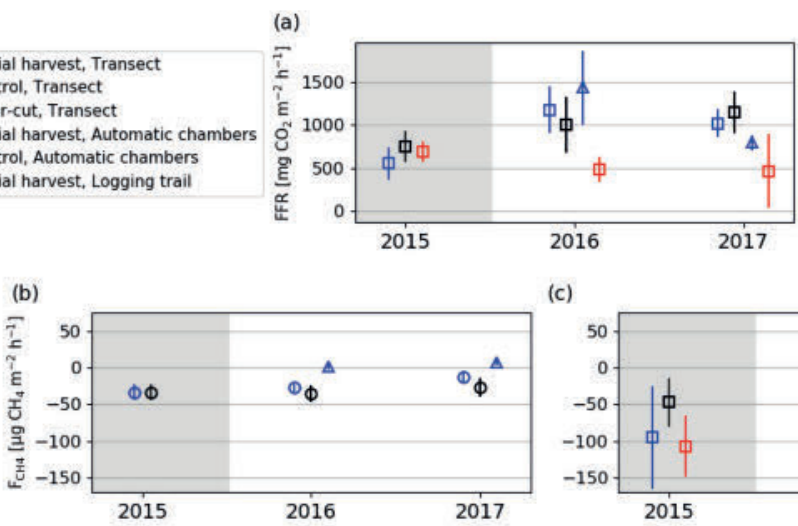

(c)
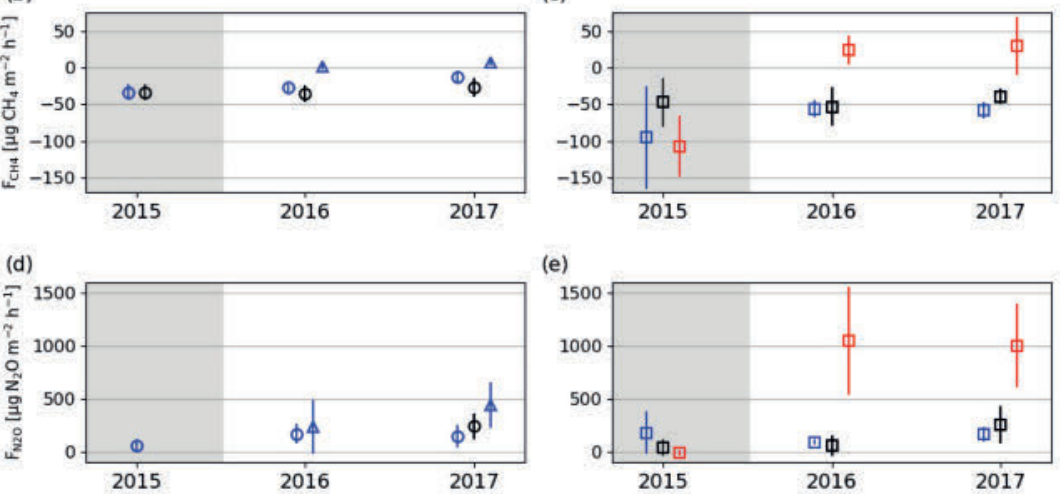

(e)

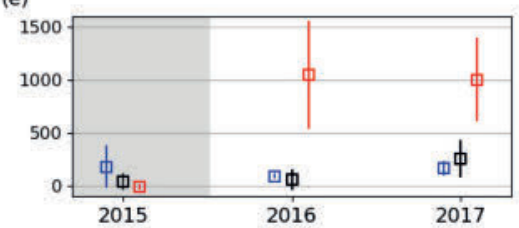

Figure 13. Hourly mean (a) forest floor respiration (FFR), (b and c) $\mathrm{CH}_{4}\left(F_{C H 4}\right)$ and (d and e) $\mathrm{N}_{2} \mathrm{O}$ $\left(F_{N 2 O}\right)$ fluxes measured at the partial harvest (blue), control (black), clear-cut (red) sites by automatic chambers (circle), manual chambers at the transect (square) and the logging trail (triangle) in pre(shaded period) and post-harvest summers (JJA) 2015-2017. The error bars show the standard deviation. Figure is modified from Paper III.

No significant differences could be found when comparing $\mathrm{CH}_{4}$ fluxes between the $\mathrm{S}_{\mathrm{ph}}$ and the $\mathrm{S}_{\mathrm{c}}$ (Paper III). WTL rose by $5 \pm 3 \mathrm{~cm}$ next to the chambers at the $\mathrm{S}_{\mathrm{ph}}$ site (Sect. 6.2), which was apparently not enough to cause significant changes in $\mathrm{F}_{\mathrm{CH} 4}$ between the sites. The annual post-partial harvest $\mathrm{CH}_{4}$ sinks (90-170 $\left.\mathrm{mg} \mathrm{CH}_{4} \mathrm{~m}^{-2} \mathrm{yr}^{-1}\right)$ were smaller than those measured in 2011-2013 (220 $\mathrm{mg} \mathrm{CH}_{4}$ $\mathrm{m}^{-2} \mathrm{yr}^{-1}$; Paper I), but due to the fact that $\mathrm{CH}_{4}$ sink also decreased at the $\mathrm{S}_{\mathrm{c}}$ in 2016-2017 compared to 2015 , the effect of spatial and year-to-year variation hid the possible changes caused by the small WTL rise at the $\mathrm{S}_{\mathrm{ph}}$. On the other hand, the partially harvested forest was quite heterogeneous, and the automatic and transect measurements were made at the area with higher tree stand density (Table 2). This could cause a bias in the estimated harvesting effect on the fluxes. The tree stand heterogeneity was taken into account by upscaling $F_{C H 4}$ to the ecosystem level using the WTL measured around the forest (Fig. 4) as a proxy (Paper III). As a result, the upscaled $\mathrm{CH}_{4}$ sinks (Table 4) for summers 2016 and 2017 were found to be $49 \%$ and $34 \%$ lower than the sinks estimated from the automatic chamber measurements, and $49-58 \%$ smaller than the upscaled fluxes at the $\mathrm{S}_{\mathrm{c}}$. The smaller upscaled $\mathrm{CH}_{4}$ sink is a result of the $12 \mathrm{~cm}$ rise in WTL (Sect. 6.2) outside the transect plot, which was caused by differences in tree stand densities (more trees were removed outside the transects). In addition, there were logging trails used by the harvesting machinery at the partially harvested site where the forest floor was a source of $\mathrm{CH}_{4}$. However, the magnitude of the emissions from the logging trails was low, making their contribution to ecosystem-level emissions small (Fig. 13; Table 4; Paper III). The higher net emissions from the logging trails were most likely caused by the changes in the soil physical properties due to soil compression and lowering of the soil surface 
relative to WTL. As a result, the thickness of the oxic layer decreased, leading to reduced $\mathrm{CH}_{4}$ oxidation. Also, $\mathrm{CH}_{4}$ production could have increased as a result of soil compression creating anoxic spots in the soil.

\subsubsection{Changes in $\mathrm{N}_{2} \mathrm{O}$ emissions}

$\mathrm{N}_{2} \mathrm{O}$ emissions increased significantly after the clearcutting (Paper II), but no significant change was observed after the partial harvest (Paper III). All sites were relatively small $\mathrm{N}_{2} \mathrm{O}$ sources before the harvesting according to the summertime manual measurements at the transects $\left(4 \pm 18 \mu \mathrm{g} \mathrm{N}_{2} \mathrm{O} \mathrm{m}^{-2} \mathrm{~h}^{-1}\right.$ at $\mathrm{S}_{\mathrm{cc}}, 180 \pm 110 \mu \mathrm{g} \mathrm{N}_{2} \mathrm{O} \mathrm{m}^{-2} \mathrm{~h}^{-1}$ at $\mathrm{S}_{\mathrm{ph}}, 38 \pm 33 \mu \mathrm{g} \mathrm{N} \mathrm{N} \mathrm{m}^{-2} \mathrm{~h}^{-1}$ at $\mathrm{S}_{\mathrm{c}}$; Fig. 12), but after the clearcutting the mean summertime flux increased to $1050 \pm 210 \mu \mathrm{g} \mathrm{N}_{2} \mathrm{O} \mathrm{m}^{-2} \mathrm{~h}^{-1}$ (Figs. 12 and 13; Paper II). The spatial variation in $S_{p h}$ and $S_{c}$ resulted in relatively large confidence intervals for the mean flux estimates (Fig. 13; Paper III), and no significant changes in $F_{N 2 O}$ were found after partial harvest from the manual chamber measurements at the transects. This suggests that the harvesting effect on $F_{N 2 O}$ was either negligible or at least much smaller for partial harvesting than clearcutting. At $\mathrm{S}_{\mathrm{ph}}$ and $\mathrm{S}_{\mathrm{c}}, F_{N 2 O}$ was also measured with automatic chambers, which allowed capturing the temporal variation better than when using manual chambers. The automatic measurements showed substantial temporal and spatial variation in $F_{N 2 O}$ (Paper III) at the $\mathrm{S}_{\mathrm{c}}$ and $\mathrm{S}_{\mathrm{ph}}$. The annual post-harvest emissions measured with automated chambers varied from 120 to $1620 \mathrm{mg} \mathrm{N}_{2} \mathrm{O} \mathrm{m}^{-2} \mathrm{yr}^{-1}$ at the $\mathrm{S}_{\mathrm{ph}}$, while at the $\mathrm{S}_{\mathrm{c}}$ this range was $410-2240 \mathrm{mg} \mathrm{N}_{2} \mathrm{O} \mathrm{m} \mathrm{m}^{-2} \mathrm{yr}^{-1}$. However, due to the lack of automatic chamber measurements at $S_{c}$ prior to 2017 , no conclusions could be drawn about harvesting effects.

Considering the spatial variation, the logging trails at the $\mathrm{S}_{\mathrm{ph}}$ contributed substantially to the ecosystem-scale $\mathrm{N}_{2} \mathrm{O}$ emissions (Paper III). The upscaling of the fluxes revealed that the emissions from the logging trails, which constituted 20\% of the total surface area (Paper III), emitted 35-38\% of the total emissions from the whole harvested area (Table 4). The explanation behind the increased emissions could be the same as with $\mathrm{CH}_{4}$; the compaction of soil could have created anoxic pockets in the soil, which enhanced denitrification. Also, logging residues have been shown to increase $\mathrm{N}_{2} \mathrm{O}$ emissions (Paper III, Mäkiranta et al., 2012) as they stabilise soil temperature and moisture by preventing direct sunlight and evaporation, which favour mineralisation and nitrification processes in the soil organic layer (Roberts et al., 2005; Rosén and Lundmark-Thelin, 1987). This means that the emissions might have increased due to the reactive $\mathrm{N}\left(\mathrm{NO}_{3}^{-}, \mathrm{NH}_{4}^{+}\right)$released from the residues and destroyed ground vegetation.

On the other hand, outside the logging trails, none of the chamber points included above-ground residues. So, especially at the $S_{c c}$ where the residues were not piled on any logging trails, our measured fluxes potentially underestimate the overall $\mathrm{N}_{2} \mathrm{O}$ emissions from the area. However, below-ground residues such as roots (Paper II) have probably provided additional reactive $\mathrm{N}$ to the production processes, especially at the $\mathrm{S}_{\mathrm{cc}}$ where all the trees were cut. Also, increased WTL might have moved the anoxic layer closer to the surface, which allowed anoxic conditions for denitrification to occur closer to the surface, hence increasing $\mathrm{N}_{2} \mathrm{O}$ emissions more at the $\mathrm{S}_{\mathrm{cc}}$ than at the $\mathrm{S}_{\mathrm{ph}}$. At the $\mathrm{S}_{\mathrm{ph}}$, the amount of residues was noticeably smaller and the residues were mostly piled on the trails, while at 
$\mathrm{S}_{\mathrm{cc}}$ they were spread out. Also, WTL stayed relatively low at the $\mathrm{S}_{\mathrm{ph}}$; therefore, the conditions for $\mathrm{N}_{2} \mathrm{O}$ production after the harvest did not change considerably, and no significant rise in the emissions was observed. The higher WTL at the $\mathrm{S}_{\mathrm{cc}}$ might also be the reason why the $\mathrm{N}_{2} \mathrm{O}$ emissions at the $\mathrm{S}_{\mathrm{cc}}$ were higher than at the logging trail at the $\mathrm{S}_{\mathrm{ph}}(p<0.001$; Fig. 13) even though the logging trail measurements included above-ground residues, unlike the transect measurements.

The studies concerning the effects of harvesting practices are scarce, but increased $\mathrm{N}_{2} \mathrm{O}$ emissions after clearcutting have been recorded in both mineral and peatland forests (Huttunen et al., 2003; Saari et al., 2009), although the emissions were an order of magnitude smaller than at Lettosuo.

Table 4. Upscaled $\mathrm{CH}_{4}$ and $\mathrm{N}_{2} \mathrm{O}$ balances ( \pm uncertainty, see Sect. 5.3.4) from different surface types weighted by their relative surface area at the $S_{p h}$ and $S_{c}$ for summers 2016 and 2017. The summer (JJA) balances are also reported in $\mathrm{CO}_{2}$-equivalents in terms of the global warming potential over 100 yr. The table is adopted and modified from Paper III.

\begin{tabular}{|c|c|c|c|c|c|}
\hline \multicolumn{6}{|c|}{$\mathrm{CH}_{4}$ flux $\left[\mathrm{mg} \mathrm{CH}_{4} \mathrm{~m}^{-2}\right.$ summer $\left.{ }^{-1}\right]$} \\
\hline Area \& Year & Total & Ditch & Forest & Logging trail & Total $\left[\mathrm{g} \mathrm{CO}_{2}\right.$-eq m $\left.\mathrm{m}^{-2}\right]$ \\
\hline $\mathrm{S}_{\mathrm{ph},}, 2016$ & $10 \pm 28$ & $43 \pm 28$ & $-31 \pm 2$ & $-1.8 \pm 0.9$ & $0.3 \pm 1.0$ \\
\hline $\mathrm{S}_{\mathrm{ph},}, 2016$ & $47 \pm 43$ & $64 \pm 43$ & $-19 \pm 4$ & $2.1 \pm 0.5$ & $1.6 \pm 1.5$ \\
\hline$S_{c}, 2016$ & $-18 \pm 28$ & $43 \pm 28$ & $-61 \pm 5$ & NA & $0.6 \pm 1.0$ \\
\hline $\mathrm{S}_{\mathrm{c},} 2016$ & $19 \pm 43$ & $64 \pm 43$ & $-45 \pm 3$ & NA & $0.6 \pm 1.5$ \\
\hline \multicolumn{6}{|c|}{$\mathrm{N}_{2} \mathrm{O}$ flux $\left[\mathrm{mg} \mathrm{N}_{2} \mathrm{O} \mathrm{m}^{-2}\right.$ summer $\left.^{-1}\right]$} \\
\hline Area \& Year & Total & Ditch & Forest & Logging trail & Total $\left[\mathrm{g} \mathrm{CO}_{2}\right.$-eq m $\left.\mathrm{m}^{-2}\right]$ \\
\hline $\mathrm{S}_{\mathrm{ph},}, 2016$ & $370 \pm 30$ & $-0.2 \pm 0.3$ & $240 \pm 20$ & $130 \pm 20$ & $110 \pm 10$ \\
\hline $\mathrm{S}_{\mathrm{ph}, 2016}$ & $530 \pm 110$ & $0.6 \pm 0.4$ & $330 \pm 110$ & $200 \pm 30$ & $160 \pm 30$ \\
\hline $\mathrm{S}_{\mathrm{c},} 2016$ & $120 \pm 40$ & $-0.2 \pm 0.2$ & $120 \pm 40$ & NA & $36 \pm 12$ \\
\hline$S_{c}, 2016$ & $500 \pm 50$ & $0.6 \pm 0.3$ & $490 \pm 50$ & NA & $150 \pm 14$ \\
\hline
\end{tabular}

\subsubsection{Contributions to total emissions}

The increased total GHG emissions after the forest management were about fourteen times as high as at the $\mathrm{S}_{\mathrm{cc}}\left(3650 \mathrm{~g} \mathrm{CO}_{2}\right.$-eq m$\left.{ }^{-2} \mathrm{yr}^{-1}\right)$ than at the $\mathrm{S}_{\mathrm{ph}}\left(260 \mathrm{~g} \mathrm{CO}_{2}\right.$-eq $\left.\mathrm{m}^{-2} \mathrm{yr}^{-1}\right)$. Even though the change from a $\mathrm{CH}_{4}$ sink to source was significant at the $\mathrm{S}_{\mathrm{cc}}$, the relatively small increase in emissions $(6.5 \mathrm{~g}$ $\mathrm{CO}_{2}$-eq $\left.\mathrm{m}^{-2} \mathrm{yr}^{-1}\right)$ had a negligible impact $(<1 \%)$ on the increased GHG emissions. It should be noted that the total GHG emissions estimated for $\mathrm{S}_{\mathrm{ph}}$ do not include $\mathrm{CH}_{4}$ and $\mathrm{N}_{2} \mathrm{O}$ fluxes as they did not change significantly due to the harvest (chapters 6.3.3 and 6.3.4). However, logging trails were not included, which likely underestimates the contribution of $\mathrm{N}_{2} \mathrm{O}$ component at the $\mathrm{S}_{\text {ph }}$ due to increased emissions observed on logging trails after the harvest. At the $\mathrm{S}_{\mathrm{cc}}, \mathrm{N}_{2} \mathrm{O}$ emissions increased on average by $830 \mathrm{~g} \mathrm{CO}_{2}$-eq $\mathrm{m}^{-2} \mathrm{yr}^{-1}$ corresponding to $20 \%$ of the total increased emissions, making $\mathrm{N}_{2} \mathrm{O}$ emissions an important part of peatland forestry. Even though $\mathrm{SGWP}_{100}$ (sustained emissions) is an improved approach of GWP (pulse emission), it does not consider temporal dynamics (Frolking et al., 2006; Neubauer and Megonigal, 2015). The estimation of climatic effect could be improved by accounting for the temporal dynamics, which would require using a metric based on step change or using models based on instantaneous radiative forcing due to time-integrated GHG exchange (Berntsen et al., 2005; Lohila et al., 2010), but this was not considered relevant in this work. 


\section{Conclusions}

The main objectives of this thesis were to study how WTL, ET and GHG fluxes respond to the partial harvesting and clearcutting performed in a peatland forest. Related to this, a specific objective was to improve the flux calculation methods for the data collected with automatic soil chambers, which were used to investigate the harvesting effects. This examination resulted in a conclusion that the exponential regression should always be preferred when calculating the GHG fluxes from the chamber measurements as linear regression has an in-built incorrect assumption of constant concentration development inside the chamber. However, the use of linear regression is acceptable when the signal-to-noise ratio is so large that the exponential regression fails. In those cases, using linear regression does not cause a significant effect on annual balances, assuming the annual mean flux is markedly higher than the fluxes estimated by linear regression. When using exponential regression, the fitting period should be long enough so that the fit is stable, but care should be taken when increasing the chamber closure time as it may significantly change the environmental conditions inside the chamber. The adequate length of the fitting period, as well as the flux limit for choosing between the fitting methods, depends on the measurement system characteristics, such as instrument precision, and they cannot be generalised.

The impact of partial harvesting on GHG emissions in a nutrient-rich peatland forest was noticeably smaller than that of clearcutting. NEE increased after the harvest for both methods, but the $\mathrm{CO}_{2}$ emissions were more substantial after clearcutting as a result of a major decline in GPP following the complete removal of trees and destruction of ground vegetation. At the $\mathrm{S}_{\mathrm{cc}}$, total ecosystem respiration decreased due to decreased forest floor respiration, as more peat was exposed to anoxic conditions than before clearcutting as a result of raised WTL, which was caused by a decline in ET. The reduction in GPP was even more considerable, leading to large net $\mathrm{CO}_{2}$ emissions at the $\mathrm{S}_{\mathrm{cc}}$. Similar phenomena with decreased GPP and ER were observed after partial harvest, but the reductions were slighter as fewer trees were removed. This led to a smaller rise in WTL, because the remaining tree stand was able to maintain a relatively high ET. At $\mathrm{S}_{\mathrm{cc}}$, the recovery of ground vegetation and GPP was relatively fast, whereas no significant recovery in GPP was observed at $S_{\text {ph }}$ during the four post-partial harvest years. The limited recovery could be attributed to the previously understorey spruces suffering from light stress, and also to the fact that spruces were still shading the forest floor limiting the photosynthesis of ground vegetation.

The $\mathrm{S}_{\mathrm{cc}}$ turned from a $\mathrm{CH}_{4}$ sink to a $\mathrm{CH}_{4}$ source due to the relatively large $(24 \mathrm{~cm})$ rise in WTL caused by the decrease in ET, which limited $\mathrm{CH}_{4}$ oxidation in soil and increased the anoxic layer where $\mathrm{CH}_{4}$ is produced. Also, $\mathrm{CH}_{4}$ emissions increased at the logging trails at the $\mathrm{S}_{\mathrm{ph}}$ possibly due to soil compaction increasing soil moisture and creating anoxic spots in the soil; therefore, limiting $\mathrm{CH}_{4}$ oxidation and promoting $\mathrm{CH}_{4}$ production. On the other hand, the $5 \mathrm{~cm}$ rise in WTL at the flux measurement points at the $\mathrm{S}_{\mathrm{ph}}$ was insufficient to cause considerable changes in $\mathrm{CH}_{4}$ fluxes outside logging trails. To account for the heterogeneity of the tree stand at the $\mathrm{S}_{\mathrm{ph}}$, the $\mathrm{CH}_{4}$ flux data were upscaled to the ecosystem level by using WTL measurements made at multiple locations within the $\mathrm{S}_{\mathrm{ph}}$. This revealed that the ecosystem-level $\mathrm{CH}_{4}$ sink was $54 \%$ smaller at the $\mathrm{S}_{\mathrm{ph}}$ than at the $\mathrm{S}_{\mathrm{c}}$ and $42 \%$ smaller than the fluxes estimated only from the automatic chambers within the $S_{\text {ph. }}$ The lower $\mathrm{CH}_{4}$ sink estimates after upscaling were attributed to the smaller tree stand density and larger rise in 
WTL $\left(12 \mathrm{~cm}\right.$ ) outside the chamber measurement points. However, the $\mathrm{CH}_{4}$ fluxes were insignificant when considering their climatic effect after partial harvest and clearcutting in terms of $\mathrm{SGWP}_{100}$ at both $\mathrm{S}_{\mathrm{cc}}$ and $\mathrm{S}_{\mathrm{ph}}$.

$\mathrm{N}_{2} \mathrm{O}$ emissions increased markedly at the $\mathrm{S}_{\mathrm{cc}}$, but not significantly at the $\mathrm{S}_{\mathrm{ph}}$, except on the logging trails. The increased emissions at the $\mathrm{S}_{\mathrm{cc}}$ and on the logging trails could be attributed to the reactive nitrogen released from residues. Also, the raised WTL at the $\mathrm{S}_{\mathrm{cc}}$ and the compressed soil on the logging trails may have improved conditions for denitrification, hence increasing $\mathrm{N}_{2} \mathrm{O}$ production. However, because none of the measurement points outside the logging trails included above-ground logging residues, the true $\mathrm{N}_{2} \mathrm{O}$ fluxes are likely underestimated. Indeed, upscaling $\mathrm{N}_{2} \mathrm{O}$ fluxes to an ecosystem-level revealed that the logging trails at the $\mathrm{S}_{\mathrm{ph}}$, with only a $20 \%$ surface coverage, emitted more than a third of the total ecosystem $\mathrm{N}_{2} \mathrm{O}$ emissions. Outside the logging trails, at the $\mathrm{S}_{\mathrm{c}}$ and $\mathrm{S}_{\mathrm{ph}}$, the $\mathrm{N}_{2} \mathrm{O}$ fluxes were highly variable both in time and space, making it impossible to distinguish the harvesting effect. This means that the change in $\mathrm{N}_{2} \mathrm{O}$ fluxes due to partial harvest was so small that it was not observable with the methods used in this thesis. However, the observed increases in $\mathrm{N}_{2} \mathrm{O}$ emissions after clearcutting and from logging trails suggest that $\mathrm{N}_{2} \mathrm{O}$ fluxes should be considered when inspecting the climatic impact of peatland forestry.

ET decreased at both the $\mathrm{S}_{\mathrm{cc}}$ and $\mathrm{S}_{\mathrm{ph}}$ after the harvestings as a result of the removal of transpiring trees and destruction of forest floor vegetation. The drop in ET was more substantial at the $\mathrm{S}_{\mathrm{cc}}$, and, as WTL and ET are tightly coupled to each other, the WTL increase was greater at the $\mathrm{S}_{\mathrm{cc}}$ than $\mathrm{S}_{\mathrm{ph}}$. The improved light conditions for the understorey spruces and ground vegetation compensated for the decreased ET from the pine trees. Because of this, the forest-scale ET at the $\mathrm{S}_{\mathrm{ph}}$ recovered to the similar ET level of $S_{c}$ in the third post-harvest summer. This suggests that removal of the overstorey as a harvesting practice does not lead to a significant WTL rise that could affect the tree growth. However, tree stand characteristics should be considered when deciding on the harvesting practice, as some species such as birches have a higher transpiration capacity than coniferous trees. In conclusion, by favouring mixed stands and maintaining an admixture of deciduous species, one could avoid ditch cleaning, a large investment in peatland forestry, and support biodiversity.

One of the major harmful effects of peatland forestry is its impact on water quality. The increased amount of humus, dissolved carbon and nutrients cause eutrophication and increase the turbidity of water, which among other consequences lowers the recreational value of lakes and ponds. Especially the ditch network maintenance affects negatively the water quality, possibly even the groundwater quality. The leached nutrients can cause oxygen deficiency, killing aquatic organisms. Also, nutrients can be transported to lakes, increasing algae growth, thus affecting the living conditions of humans and animals within a larger area. This thesis did not consider the effects of harvests on water quality. Excluding the water component means that a potentially essential part of the carbon cycle, namely the runoff of dissolved organic and inorganic carbon, was not considered. However, partial harvesting should not decrease water quality as much as clearcutting, as it causes less disturbance to the forest and requires no ditch network maintenance.

This thesis demonstrated the immediate climatic effects of peatland forestry by direct ecosystematmosphere flux measurements of the key GHGs and ET. Based on these results, it seems evident that in terms of changes to Earth's radiative balance, the climatic impacts of harvest are much smaller after partial harvesting than clearcutting. However, it should be noted that $\mathrm{S}_{\mathrm{ph}}$ was already before 
partial harvest a $\mathrm{CO}_{2}$ source due to peat decomposition exceeding tree growth and harvesting further increased the source, at least temporarily. This study does not answer to the critical question which forest management method is better when considering the whole forest rotation. Nevertheless, the collected data can be used by modellers to address that question. In addition to the climatic effect there are other critical issues, such as water quality, biodiversity, recreational values and economic questions that should be taken into account when assessing the overall impact of peatland forestry. An analysis of flux measurements carried out over a few years obviously cannot address these issues, but it provides an invaluable contribution to a bigger picture that can be achieved by collaboration of different research fields and a combination of measurements and models. 


\section{References}

Ahti, E.: Water Balance of Drained Peatlands on the Basis of Water Table Simulation During the Snowless Period, Metsäntutkimuslaitos., 1987.

Ainsworth, E. A. and Rogers, A.: The response of photosynthesis and stomatal conductance to rising [CO 2]: Mechanisms and environmental interactions, Plant, Cell Environ., 30(3), 258-270, doi:10.1111/j.13653040.2007.01641.x, 2007.

Amiro, B. D.: Paired-tower measurements of carbon and energy fluxes following disturbance in the boreal forest, Glob. Chang. Biol., 7(3), 253-268, doi:10.1046/j.1365-2486.2001.00398.x, 2001.

Amiro, B. D., Barr, A. G., Barr, J. G., Black, T. A., Bracho, R., Brown, M., Chen, J., Clark, K. L., Davis, K. J., Desai, A. R., Dore, S., Engel, V., Fuentes, J. D., Goldstein, A. H., Goulden, M. L., Kolb, T. E., Lavigne, M. B., Law, B. E., Margolis, H. A., Martin, T., McCaughey, J. H., Misson, L., Montes-Helu, M., Noormets, A., Randerson, J. T., Starr, G. and Xiao, J.: Ecosystem carbon dioxide fluxes after disturbance in forests of North America, J. Geophys. Res. Biogeosciences, 115(4), doi:10.1029/2010JG001390, 2010.

Angel, R., Matthies, D. and Conrad, R.: Activation of methanogenesis in arid biological soil crusts despite the presence of oxygen, PLoS One, 6(5), 1-8, doi:10.1371/journal.pone.0020453, 2011.

Angel, R., Claus, P. and Conrad, R.: Methanogenic archaea are globally ubiquitous in aerated soils and become active under wet anoxic conditions, ISME J., 6(4), 847-862, doi:10.1038/ismej.2011.141, 2012.

Angle, J. C., Morin, T. H., Solden, L. M., Narrowe, A. B., Smith, G. J., Borton, M. A., Rey-Sanchez, C., Daly, R. A., Mirfenderesgi, G., Hoyt, D. W., Riley, W. J., Miller, C. S., Bohrer, G. and Wrighton, K. C.: Methanogenesis in oxygenated soils is a substantial fraction of wetland methane emissions, Nat. Commun., 8(1), 1-9, doi:10.1038/s41467-017-01753-4, 2017.

Von Arnold, K., Weslien, P., Nilsson, M., Svensson, B. H. and Klemedtsson, L.: Fluxes of CO2, CH4 and N2O from drained coniferous forests on organic soils, For. Ecol. Manage., 210(1-3), 239-254, doi:10.1016/j.foreco.2005.02.031, 2005.

Aubinet, M., Grelle, A., Ibrom, A., Rannik, Ü., Moncrieff, J., Foken, T., Kowalski, A., Martin, P.-H., Berbigier, P., Bernhofer, C., Clement, R., Elbers, J., Granier, A., Grünwald, T., Morgenstern, K., Pilegaard, K., Rebmann, C., Snijders, W., Valentini, R. and Vesala, T.: Estimates of the Annual Net Carbon and Water Exchange of Forests: The EUROFLUX Methodology, Adv. Ecol. Res., 30, 113-175, doi:10.1016/S0065-2504(08)60047-1, 2000.

Aubinet, M., Vesala, T. and Papale, D., Eds.: Eddy Covariance: a practical guide to measurement and data analysis, Springer Science \& Business Media., 2012.

Augustin, J., Merbach, W. and Rogasik, J.: Factors influencing nitrous oxide and methane emissions from minerotrophic fens in northeast Germany, Biol. Fertil. Soils, 28(1), 1-4, doi:10.1007/s003740050455, 1998.

Aurangojeb, M., Klemedtsson, L., Rütting, T., He, H., Weslien, P., Banzhaf, S. and Kasimir, A.: Nitrous oxide emissions from Norway spruce forests on drained organic and mineral soil, Can. J. For. Res., 47(11), 1482-1487, doi:10.1139/cjfr-2016-0541, 2017.

Aurela, M., Laurila, T. and Tuovinen, J.-P.: Annual CO2 balance of a subarctic fen in northern Europe: Importance of the wintertime efflux, J. Geophys. Res. Atmos., 107(21), 1-12, doi:10.1029/2002JD002055, 2002.

Aurela, M., Lohila, A., Tuovinen, J.-P., Hatakka, J., Riutta, T. and Laurila, T.: Carbon dioxide exchange on a northern boreal fen, Boreal Environ. Res., 14(4), 699-710, doi:10.1093/treephys/tpn047, 2009.

Balaine, N., Clough, T. J., Beare, M. H., Thomas, S. M., Meenken, E. D. and Ross, J. G.: Changes in Relative Gas Diffusivity Explain Soil Nitrous Oxide Flux Dynamics, Soil Sci. Soc. Am. J., 77(5), 1496-1505, doi:10.2136/sssaj2013.04.0141, 2013.

Baldocchi, D. D.: Assessing the eddy covariance technique for evaluating carbon dioxide exchange rates of ecosystems: Past, present and future, Glob. Chang. Biol., 9(4), 479-492, doi:10.1046/j.13652486.2003.00629.x, 2003.

Ball, J. T., Wood, I. E. and Berry, J. A.: A Model Predicting Stomatal Conductance and its Contribution to the Control of Photosynthesis under Different Environmental Conditions, Progress i., edited by J. Biggins, Springer, Dordrecht., 1987. 
Barba, J., Cueva, A., Bahn, M., Barron-Gafford, G. A., Bond-Lamberty, B., Hanson, P. J., Jaimes, A., Kulmala, L., Pumpanen, J., Scott, R. L., Wohlfahrt, G. and Vargas, R.: Comparing ecosystem and soil respiration: Review and key challenges of tower-based and soil measurements, Agric. For. Meteorol., 249(March 2017), 434-443, doi:10.1016/j.agrformet.2017.10.028, 2018.

Batjes, N. H.: Total carbon and nitrogen in the soils of the world, Eur. J. Soil Sci., 47(2), 151-163, doi:10.1111/j.1365-2389.1996.tb01386.x, 1996.

Berntsen, T. K., Fuglestvedt, J. S., Joshi, M. M., Shine, K. P., Stuber, N., Ponater, M., Sausen, R., Hauglustaine, D. A. and Li, L.: Response of climate to regional emissions of ozone precursors: sensitivities and warming potentials, Tellus B Chem. Phys. Meteorol., 57(4), 283-304, doi:10.3402/tellusb.v57i4.16549, 2005.

Bhuiyan, R., Minkkinen, K., Helmisaari, H.-S., Ojanen, P., Penttilä, T. and Laiho, R.: Estimating fine-root production by tree species and understorey functional groups in two contrasting peatland forests, Plant Soil, 412(1-2), 299-316, doi:10.1007/s11104-016-3070-3, 2017.

Bhullar, G. S., Edwards, P. J. and Olde Venterink, H.: Variation in the plant-mediated methane transport and its importance for methane emission from intact wetland peat mesocosms, J. Plant Ecol., 6(4), 298-304, doi:10.1093/jpe/rts045, 2013.

Billesbach, D. P.: Estimating uncertainties in individual eddy covariance flux measurements: A comparison of methods and a proposed new method, Agric. For. Meteorol., 151(3), 394-405, doi:10.1016/j.agrformet.2010.12.001, 2011.

Blazewicz, S. J., Petersen, D. G., Waldrop, M. P. and Firestone, M. K.: Anaerobic oxidation of methane in tropical and boreal soils: Ecological significance in terrestrial methane cycling, J. Geophys. Res. Biogeosciences, 117(2), 1-9, doi:10.1029/2011JG001864, 2012.

Boeckx, P. and Van Cleemput, O.: Methane Oxidation in a Neutral Landfill Cover Soil: Influence of Moisture Content, Temperature, and Nitrogen-Turnover, J. Environ. Qual., 25(1), 178, doi:10.2134/jeq1996.00472425002500010023x, 1996.

Bollmann, A. and Conrad, R.: Acetylene blockage technique leads to underestimation of denitrificat1on rates in oxic soils due to scavenging of intermediate nitric oxide, Soil Biol. Biochem., 29(7), 1067-1077, doi:10.1016/S0038-0717(97)00007-2, 1997.

Börjesson, G., Samuelsson, J. and Chanton, J.: Methane oxidation in Swedish landfills quantified with the stable carbon isotope technique in combination with an optical method for emitted methane, Environ. Sci. Technol., 41(19), 6684-6690, doi:10.1021/es062735v, 2007.

Butterbach-Bahl, K., Baggs, E. M., Dannenmann, M., Kiese, R. and Zechmeister-Boltenstern, S.: Nitrous oxide emissions from soils : how well do we understand the processes and their controls?, Philos. Trans. R. Soc. B, 368(1621), doi:http://dx.doi.org/10.1098/rstb.2013.0122, 2013.

Call, F.: Soil Fumigation, V. Diffusion of Ethylene Dibromide through Soils, J. Sci. Food Agr., 8, 143-150, doi:https://doi.org/10.1002/jsfa.2740080307, 1957.

Cambi, M., Certini, G., Neri, F. and Marchi, E.: The impact of heavy traffic on forest soils: A review, For. Ecol. Manage., 338, 124-138, doi:10.1016/j.foreco.2014.11.022, 2015.

Carey, J. C., Tang, J., Templer, P. H., Kroeger, K. D., Crowther, T. W., Burton, A. J., Dukes, J. S., Emmett, B., Frey, S. D., Heskel, M. A., Jiang, L., Machmuller, M. B., Mohan, J., Panetta, A. M., Reich, P. B., Reinschj, S., Wang, X., Allison, S. D., Bamminger, C., Bridgham, S., Collins, S. L., De Dato, G., Eddy, W. C., Enquist, B. J., Estiarte, M., Harte, J., Henderson, A., Johnson, B. R., Larsen, K. S., Luo, Y., Marhan, S., Melillo, J. M., Peñuelas, J., Pfeifer-Meister, L., Poll, C., Rastetter, E., Reinmann, A. B., Reynolds, L. L., Schmidt, I. K., Shaver, G. R., Strong, A. L., Suseela, V. and Tietema, A.: Temperature response of soil respiration largely unaltered with experimental warming, Proc. Natl. Acad. Sci. U. S. A., 113(48), 13797-13802, doi:10.1073/pnas.1605365113, 2016.

Carlyle, J. C. and Ba Than, U.: Abiotic Controls of Soil Respiration Beneath an Eighteen-Year-Old Pinus Radiata Stand in South-Eastern Australia, J. Ecol., 76(3), 654-662, doi:10.2307/2260565, 1988.

Caron, J. and Nkongolo, N. V.: Aeration in Growing Media: Recent Developments, Acta Hortic, 481, 545-552, doi:10.17660/ActaHortic.1999.481.64, 1999.

Caron, J., Price, J. S. and Rochefort, L.: Physical Properties of Organic Soil: Adapting Mineral Soil Concepts to Horticultural Growing Media and Histosol Characterization, Vadose Zo. J., 14(6), vzj2014.10.0146, doi:10.2136/vzj2014.10.0146, 2015. 
Castro, M. S., Gholz, H. L., Clark, K. L. and Steudler, P. A.: Effects of forest harvesting on soil methane fluxes in Florida slash pine plantations, Can. J. For. Res., 30(10), 1534-1542, doi:10.1139/x00-084, 2000.

Chapin, F. S. I., Woodwell, G. M., Randerson, J. T., Rastetter, E. B., Lovett, G. M., Baldocchi, D. D., Clark, D. A., Harmon, M. E., Schimel, D. S., Valentini, R., Wirth, C., Aber, J. D., Cole, J. J., Goulden, M. L., Harden, J. W., Heimann, M., Howarth, R. W., Matson, P. A., Houghton, R. A., Pace, M. L., Ryan, M. G., Running, S. W., Sala, O. E., Schlesinger, W. H. and Schulze, E.: Reconciling Carbon-cycle Concepts, Terminology, and Methods, Ecosystems, 9, 1041-1050, doi:10.1007/s10021-005-0105-7, 2006.

Christiansen, J. R., Korhonen, J. F. J., Juszczak, R., Giebels, M. and Pihlatie, M.: Assessing the effects of chamber placement, manual sampling and headspace mixing on $\mathrm{CH} 4$ fluxes in a laboratory experiment, Plant Soil, 343(1-2), 171-185, doi:10.1007/s11104-010-0701-y, 2011.

Christiansen, J. R., Vesterdal, L. and Gundersen, P.: Nitrous oxide and methane exchange in two small temperate forest catchments-effects of hydrological gradients and implications for global warming potentials of forest soils, Biogeochemistry, 107(1-3), 437-454, doi:10.1007/s10533-010-9563-x, 2012.

Clark, K. L., Gholz, H. L. and Castro, M. S.: Carbon dynamics along a chronosequence of slash pine plantations in north Florida, Ecol. Appl., 14(4), 1154-1171 [online] Available from: http://www.esajournals.org/doi/pdf/10.1890/025391\%5Cnhttp://www.esajournals.org/doi/abs/10.1890/02-5391, 2004.

Conant, R. T., Ryan, M. G., Ågren, G. I., Birge, H. E., Davidson, E. A., Eliasson, P. E., Evans, S. E., Frey, S. D., Giardina, C. P., Hopkins, F. M., Hyvönen, R., Kirschbaum, M. U. F., Lavallee, J. M., Leifeld, J., Parton, W. J., Megan Steinweg, J., Wallenstein, M. D., Martin Wetterstedt, J. A. and Bradford, M. A.: Temperature and soil organic matter decomposition rates - synthesis of current knowledge and a way forward, Glob. Chang. Biol., 17(11), 3392-3404, doi:10.1111/j.1365-2486.2011.02496.x, 2011.

Conen, F. and Smith, K. A.: An explanation of linear increases in gas concentration under closed chambers used to measure gas exchange between soil and the atmosphere, Eur. J. Soil Sci., 51(1), 111-117, doi:10.1046/j.1365-2389.2000.00292.x, 2000.

Conrad, R.: Contribution of hydrogen to methane production and control of hydrogen concentrations in methanogenic soils and sediments, FEMS Microbiol. Ecol., 28, 193-202, 1999.

Coulthard, T. J., Baird, A. J., Ramirez, J. and Waddington, J. M.: Methane Dynamics in Peat: Importance of Shallow Peats and a Novel Reduced-Complexity Approach for Modeling Ebullition, in Carbon Cycling in Northern Peatlands; Geophysical Monograph Series, edited by A. J. Baird, L. R. Belyea, X. Comas, A. S. Reeve, and L. Slater, pp. 173-185, American Geophysical Union., 2009.

Czyz, E. A.: Effects of traffic on soil aeration, bulk density and growth of spring barley, Soil Tillage Res., 79(2 SPEC.ISS.), 153-166, doi:10.1016/j.still.2004.07.004, 2004.

Davidson, E., Keller, M., Erickson, H. E., Verchot, L. V. and Veldkamp, E.: Testing a Conceptual Model of Soil Emissions of Nitrous and Nitric Oxides, Bioscience, 50(8), 667, doi:10.1641/00063568(2000)050[0667:TACMOS]2.0.CO;2, 2000.

Davidson, E., Savage, K., Verchot, L. V. and Navarro, R.: Minimizing artifacts and biases in chamber-based measurements of soil respiration, Agric. For. Meteorol., 113(1-4), 21-37, doi:10.1016/S01681923(02)00100-4, 2002.

Dettmann, U., Bechtold, M., Frahm, E. and Tiemeyer, B.: On the applicability of unimodal and bimodal van Genuchten-Mualem based models to peat and other organic soils under evaporation conditions, J. Hydrol., 515, 103-115, doi:10.1016/j.jhydrol.2014.04.047, 2014.

Dijkstra, F. A., Prior, S. A., Runion, G. B., Torbert, H. A., Tian, H., Lu, C. and Venterea, R. T.: Effects of elevated carbon dioxide and increased temperature on methane and nitrous oxide fluxes: Evidence from field experiments, Front. Ecol. Environ., 10(10), 520-527, doi:10.1890/120059, 2012.

Dobbie, K. E. and Smith, K. A.: The effects of temperature, water-filled pore space and land use on N2O emissions from an imperfectly drained gleysol, Eur. J. Soil Sci., 52(4), 667-673, doi:10.1046/j.13652389.2001.00395.x, 2001.

Dobbie, K. E., McTaggart, I. P. and Smith, K. A.: Nitrous oxide emissions from intensive agricultural systems: Variations between crops and seasons, key driving variables, and mean emission factors, J. Geophys. Res. Atmos., 104(D21), 26891-26899, doi:10.1029/1999JD900378, 1999.

Dore, S., Montes-Helu, M., Hart, S. C., Hungate, B. A., Koch, G. W., Moon, J. B., Finkral, A. J. and Kolb, T. E.: Recovery of ponderosa pine ecosystem carbon and water fluxes from thinning and stand-replacing 
fire, Glob. Chang. Biol., 18(10), 3171-3185, doi:10.1111/j.1365-2486.2012.02775.x, 2012.

Dorodnikov, M., Knorr, K. H., Kuzyakov, Y. and Wilmking, M.: Plant-mediated CH4 transport and contribution of photosynthates to methanogenesis at a boreal mire: A 14C pulse-labeling study, Biogeosciences, 8(8), 2365-2375, doi:10.5194/bg-8-2365-2011, 2011.

Dunfield, P., Knowles, R., Dumont, R. and Moore, T.: Methane production and consumption in temperate and subarctic peat soils: Response to temperature and pH, Soil Biol. Biochem., 25(3), 321-326, doi:10.1016/0038-0717(93)90130-4, 1993.

Dungait, J. A. J., Hopkins, D. W., Gregory, A. S. and Whitmore, A. P.: Soil organic matter turnover is governed by accessibility not recalcitrance, Glob. Chang. Biol., 18(6), 1781-1796, doi:10.1111/j.13652486.2012.02665.x, 2012.

Einola, J. K. M., Karhu, A. E. and Rintala, J. A.: Mechanically-biologically treated municipal solid waste as a support medium for microbial methane oxidation to mitigate landfill greenhouse emissions, Waste Manag., 28(1), 97-111, doi:10.1016/j.wasman.2007.01.002, 2008.

Ernfors, M., Von Arnold, K., Stendahl, J., Olsson, M. and Klemedtsson, L.: Nitrous oxide emissions from drained organic forest soils - An up-scaling based on C:N ratios, Biogeochemistry, 89(1), 29-41, doi:10.1007/s10533-008-9190-y, 2008.

Ernfors, M., Rütting, T. and Klemedtsson, L.: Increased nitrous oxide emissions from a drained organic forest soil after exclusion of ectomycorrhizal mycelia, Plant Soil, 343(1-2), 161-170, doi:10.1007/s11104-0100667-9, 2011.

Falge, E., Baldocchi, D., Olson, R., Anthoni, P., Aubinet, M., Bernhofer, C., Burba, G., Ceulemans, R., Clement, R., Dolman, H., Granier, A., Gross, P., Grünwald, T., Hollinger, D., Jensen, N. O., Katul, G., Keronen, P., Kowalski, A., Ta Lai, C., Law, B. E., Meyers, T., Moncrieff, J., Moors, E., William Munger, J., Pilegaard, K., Rannik, Ü., Rebmann, C., Suyker, A., Tenhunen, J., Tu, K., Verma, S., Vesala, T., Wilson, K. and Wofsy, S.: Short communication: Gap filling strategies for long term energy flux data sets, Agric. For. Meteorol., 107(1), 71-77, doi:10.1016/S0168-1923(00)00235-5, 2001.

Fang, C. and Moncrieff, J. B.: An Improved Dynamic Chamber Technique for Measuring CO2 Efflux from the Surface of Soil, Funct. Ecol., 10(2), 297, doi:10.2307/2389856, 1996.

Farquhar, G. D., von Caemmerer, S. and Berry, J. A.: A biochemical model of photosynthetic $\mathrm{CO}<$ Subscript $>2</$ Subscript $>$ assimilation in leaves of $\mathrm{C}<$ Subscript $>3</$ Subscript $>$ species, Planta, 149(1), 78-90 [online] Available from:

https://link.springer.com/article/10.1007/BF00386231\%0Apapers3://publication/doi/10.1007/BF0038623 $1,1980$.

Fernández-Martínez, M., Vicca, S., Janssens, I. A., Sardans, J., Luyssaert, S., Campioli, M., Chapin, F. S., Ciais, P., Malhi, Y., Obersteiner, M., Papale, D., Piao, S. L., Reichstein, M., Rodà, F. and Peñuelas, J.: Nutrient availability as the key regulator of global forest carbon balance, Nat. Clim. Chang., 4(6), 471476, doi:10.1038/nclimate2177, 2014.

Finkelstein, P. L. and Sims, F.: Sampling error in eddy correlation flux measurements, J. Geophys. Res., 106, 3503-3509, doi:10.1029/2000JD900731, 2001.

von Fischer, J. C. and Hedin, L. O.: Separating methane production and consumption with a field-based isotope pool dilution technique, Global Biogeochem. Cycles, 16(3), 8-1-8-13, doi:10.1029/2001gb001448, 2002.

von Fischer, J. C. and Hedin, L. O.: Controls on soil methane fluxes: Tests of biophysical mechanisms using table isotope tracers, Global Biogeochem. Cycles, 21(2), 1-9, doi:10.1029/2006GB002687, 2007.

Fisher, J. B., Tu, K. P. and Baldocchi, D. D.: Global estimates of the land-atmosphere water flux based on monthly AVHRR and ISLSCP-II data, validated at 16 FLUXNET sites, Remote Sens. Environ., 112(3), 901-919, doi:10.1016/j.rse.2007.06.025, 2008.

Flanagan, L. B. and Johnson, B. G.: Interacting effects of temperature, soil moisture and plant biomass production on ecosystem respiration in a northern temperate grassland, Agric. For. Meteorol., 130(3-4), 237-253, doi:10.1016/j.agrformet.2005.04.002, 2005.

Foken, T. and Wichura, B.: Tools for quality assessment of surface-based flux measurements, Agric. For. Meteorol., 78(1-2), 83-105, doi:10.1016/0168-1923(95)02248-1, 1996.

Foken, T., Leuning, R., Oncley, S. R., Mauder, M. and Aubinet, M.: The eddy covariance method. Springer Netherlands., in Eddy Covariance: a practical guide to measurement and data analysis, edited by M. Aubinet, T. Vesala, and D. Papale, pp. 1-19, Springer Atmospheric Sciences., 2012. 
Forbrich, I., Kutzbach, L., Hormann, A. and Wilmking, M.: A comparison of linear and exponential regression for estimating diffusive CH4 fluxes by closed-chambers in peatlands, Soil Biol. Biochem., 42(3), 507515, doi:10.1016/j.soilbio.2009.12.004, 2010.

Frolking, S., Roulet, N. and Fuglestvedt, J.: How northern peatlands influence the Earth's radiative budget: Sustained methane emission versus sustained carbon sequestration, J. Geophys. Res. Biogeosciences, 111(1), 1-10, doi:10.1029/2005JG000091, 2006.

Gajewski, K., Viau, A., Sawada, M., Atkinson, D. and Wilson, S.: Sphagnum peatland distribution in North America and Eurasia during the past 21,000 years, Global Biogeochem. Cycles, 15(2), 297-310, doi:10.1029/2000GB001286, 2001.

Gao, F. and Yates, S. R.: Laboratory study of closed and dynamic flux chambers: Experimental results and implications for field application, J. Geophys. Res., 103, 115-125, doi:10.1029/98JD01346, 1998.

Garcia, J. L., Patel, B. K. C. and Ollivier, B.: Taxonomic, phylogenetic, and ecological diversity of methanogenic Archaea, Anaerobe, 6(4), 205-226, doi:10.1006/anae.2000.0345, 2000.

Garratt, J. R.: The atmospheric boundary layer. First paperback edition with corrections., Cambridge University Press, Cambridge, UK., 1994.

Goldberg, S. D., Knorr, K. H., Blodau, C., Lischeid, G. and Gebauer, G.: Impact of altering the water table height of an acidic fen on N2O and NO fluxes and soil concentrations, Glob. Chang. Biol., 16(1), 220233, doi:10.1111/j.1365-2486.2009.02015.x, 2010.

Goodrich, J. P., Varner, R. K., Frolking, S., Duncan, B. N. and Crill, P. M.: High-frequency measurements of methane ebullition over a growing season at a temperate peatland site, Geophys. Res. Lett., 38(7), 1-5, doi:10.1029/2011GL046915, 2011.

Görres, C.-M., Kammann, C. and Ceulemans, R.: Automation of soil flux chamber measurements : potentials and pitfalls, Biogeosciences, 13, 1949-1966, doi:10.5194/bg-13-1949-2016, 2016.

de Graaff, M. A., van Groenigen, K. J., Six, J., Hungate, B. and van Kessel, C.: Interactions between plant growth and soil nutrient cycling under elevated CO2: A meta-analysis, Glob. Chang. Biol., 12(11), 20772091, doi:10.1111/j.1365-2486.2006.01240.x, 2006.

Grelle, A., Lundberg, A., Lindroth, A., Morén, A. S. and Cienciala, E.: Evaporation components of a boreal forest: Variations during the growing season, J. Hydrol., 197(1-4), 70-87, doi:10.1016/S00221694(96)03267-2, 1997.

Grzywna, A.: The degree of peatland subsidence resulting from drainage of land, Environ. Earth Sci., 76(16), 1-8, doi:10.1007/s12665-017-6869-1, 2017.

Halmeenmäki, E., Heinonsalo, J., Putkinen, A., Santalahti, M., Fritze, H. and Pihlatie, M.: Above- and belowground fluxes of methane from boreal dwarf shrubs and Pinus sylvestris seedlings, Plant Soil, 420(1-2), 361-373, doi:10.1007/s11104-017-3406-7, 2017.

Hanson, P. J., Edwards, N. T., Garten, C. T. and Andrews, J. A.: Separating root and soil microbial contributions to soil respiration: A review ofmethods and observations, Biogeochemistry, 48, 115-146, doi:10.1023/a:1006244819642, 2000.

Hargreaves, K. J., Milne, R. and Cannell, M. G. R.: Carbon balance of afforested peatland in Scotland, Forestry, 76(3), 299-317, doi:10.1093/forestry/76.3.299, 2003.

Hättenschwiler, S. and Jørgensen, H. B.: Carbon quality rather than stoichiometry controls litter decomposition in a tropical rain forest, J. Ecol., 98(4), 754-763, doi:10.1111/j.1365-2745.2010.01671.x, 2010.

Hayward, P. M. and Clymo, R. S.: Profiles of water content and pore size in Sphagnum and peat, and their relation to peat bog ecology, Proc. R. Soc. London - Biol. Sci., 215(1200), 299-325, doi:10.1098/rspb.1982.0044, 1982.

Healy, R. W., Striegl, R. G., Russell, T. F., Hutchinson, G. L. and Livingston, G. P.: Numerical Evaluation of Static-Chamber Measurements of Soil-Atmosphere Gas Exchange: Identification of Physical Processes, Soil Sci. Soc. Am. J., 60(3), 740-747, doi:10.2136/sssaj1996.03615995006000030009x, 1996.

Heikurainen, L. and Päivänen, J.: The effect of thinning, clear cutting, and fertilization on the hydrology of peatland drained for forestry, Acta For. Fenn., 104, doi:10.14214/aff.7538, 1970.

Heinemeyer, A. and McNamara, N. P.: Comparing the closed static versus the closed dynamic chamber flux methodology: Implications for soil respiration studies, Plant Soil, 346(1), 145-151, doi:10.1007/s11104011-0804-0, 2011. 
Helbig, M., Waddington, J. M., Alekseychik, P., Amiro, B. D., Aurela, M., Barr, A. G., Black, T. A., Blanken, P. D., Carey, S. K., Chen, J., Chi, J., Desai, A. R., Dunn, A., Euskirchen, E. S., Flanagan, L. B., Forbrich, I., Friborg, T., Grelle, A., Harder, S., Heliasz, M., Humphreys, E. R., Ikawa, H., Isabelle, P. E., Iwata, H., Jassal, R., Korkiakoski, M., Kurbatova, J., Kutzbach, L., Lindroth, A., Löfvenius, M. O., Lohila, A., Mammarella, I., Marsh, P., Maximov, T., Melton, J. R., Moore, P. A., Nadeau, D. F., Nicholls, E. M., Nilsson, M. B., Ohta, T., Peichl, M., Petrone, R. M., Petrov, R., Prokushkin, A., Quinton, W. L., Reed, D. E., Roulet, N. T., Runkle, B. R. K., Sonnentag, O., Strachan, I. B., Taillardat, P., Tuittila, E. S., Tuovinen, J. P., Turner, J., Ueyama, M., Varlagin, A., Wilmking, M., Wofsy, S. C. and Zyrianov, V.: Increasing contribution of peatlands to boreal evapotranspiration in a warming climate, Nat. Clim. Chang., doi:10.1038/s41558-020-0763-7, 2020.

Hew, C.-S., Krotkov, G. and Canvin, D. T.: Effects of Temperature on Photosynthesis and CO2 Evolution in Light and Darkness by Green Leaves, Plant Physiol., 44(5), 671-677, doi:10.1104/pp.44.5.671, 1969.

Hökkä, H., Repola, J. and Laine, J.: Quantifying the interrelationship between tree stand growth rate and water table level in drained peatland sites within Central Finland, Can. J. For. Res., 38(7), 1775-1783, doi:10.1139/X08-028, 2008.

Hommeltenberg, J., Schmid, H. P., Drösler, M. and Werle, P.: Can a bog drained for forestry be a stronger carbon sink than a natural bog forest?, Biogeosciences, 11(13), 3477-3493, doi:10.5194/bg-11-34772014, 2014.

Howard, D. M. and Howard, P. J. A.: Relationships between CO2 evolution, moisture content and temperature for a range of soil types, Soil Biol. Biochem., 25(11), 1537-1546, doi:10.1016/0038-0717(93)90008-Y, 1993.

Humphreys, E. R., Black, T. A., Morgenstern, K., Li, Z. and Nesic, Z.: Net ecosystem production of a Douglasfir stand for 3 years following clearcut harvesting, Glob. Chang. Biol., 11(3), 450-464, doi:10.1111/j.1365-2486.2005.00914.x, 2005.

Hutchinson, G. L. and Livingston, G. P.: Vents and seals in non-steady-state chambers used for measuring gas exchange between soil and the atmosphere, Eur. J. Soil Sci., 52(4), 675-682, doi:10.1046/j.13652389.2001.00415.x, 2001.

Hutchinson, G. L., Livingston, G. P., Healy, R. W. and Striegl, R. G.: Chamber measurement of surfaceatmosphere trace gas exchange: Numerical evaluation of dependence on soil, interfacial layer, and source/sink properties, J. Geophys. Res. Atmos., 105(D7), 8865-8875, doi:10.1029/1999JD901204, 2000.

Huttunen, J. T., Nykänen, H., Martikainen, P. J. and Nieminen, M.: Fluxes of nitrous oxide and methane from drained peatlands following forest clear-felling in southern Finland, Plant Soil, 255(2), 457-462, doi:10.1023/A:1026035427891, 2003.

Hynynen, J., Salminen, H., Ahtikoski, A., Huuskonen, S., Ojansuu, R., Siipilehto, J., Lehtonen, M. and Eerikäinen, K.: Long-term impacts of forest management on biomass supply and forest resource development: A scenario analysis for Finland, Eur. J. For. Res., 134(3), 415-431, doi:10.1007/s10342014-0860-0, 2015.

IPCC: Climate Change 2013: The Physical Science Basis. Contribution of Working Group I to the Fifth Assessment Report of the Intergovernmental Panel on Climate Change [Stocker, T.F., D. Qin, G.-K. Plattner, M. Tignor, S.K. Allen, J. Boschung, A. Nauels, Y. Xia, Cambridge University Press, Cambridge, United Kingdom and New York, NY, USA., 2013.

Jandl, R., Lindner, M., Vesterdal, L., Bauwens, B., Baritz, R., Hagedorn, F., Johnson, D. W., Minkkinen, K. and Byrne, K. A.: How strongly can forest management influence soil carbon sequestration?, Geoderma, 137(3-4), 253-268, doi:10.1016/j.geoderma.2006.09.003, 2007.

Jaynes, D. B. and Rogowski, A. S.: Applicability of Pick's Law to Gas Diffusion, Soil Sci. Soc. Am. J., 47, 425-430, 1983.

Joabsson, A., Christensen, T. R. and Wallén, B.: Vascular plant controls on methane emissions from northern peatforming wetlands, Trends Ecol. Evol., 14(10), 385-388, doi:10.1016/S0169-5347(99)01649-3, 1999.

Joensuu, S., Ahti, E. and Vuollekoski, M.: The effects of peatland forest ditch maintenance on suspended solids in runoff, Boreal Environ. Res., 4(4), 343-355, 1999.

Kaila, A., Sarkkola, S., Laurén, A., Ukonmaanaho, L., Koivusalo, H., Xiao, L., O’Driscoll, C., Asam, Z. U. Z., Tervahauta, A. and Nieminen, M.: Phosphorus export from drained Scots pine mires after clear-felling 
and bioenergy harvesting, For. Ecol. Manage., 325, 99-107, doi:10.1016/j.foreco.2014.03.025, 2014.

Kaila, A., Laurén, A., Sarkkola, S., Koivusalo, H., Ukonmaanaho, L., O’Driscoll, C., Xiao, L., Asam, Z. and Nieminen, M.: Effect of clear-felling and harvest residue removal on nitrogen and phosphorus export from drained norway spruce mires in southern finland, Boreal Environ. Res., 20(6), 693-706, 2015.

Kaimal, J. C. and Finnigan, J. J.: Atmospheric boundary layer flows: their structure and measurement, Oxford University Press, Oxford., 1994.

Keller, M., Mitre, M. E. and Stallard, R. F.: Consumption of atmospheric methane in soils of central Panama: Effects of agricultural development, Global Biogeochem. Cycles, 4(1), 21-27, doi:10.1029/GB004i001p00021, 1990.

Kettridge, N., Thompson, D. K., Bombonato, L., Turetsky, M. R., Benscoter, B. W. and Waddington, J. M.: The ecohydrology of forested peatlands: Simulating the effects of tree shading on moss evaporation and species composition, J. Geophys. Res. Biogeosciences, 118(2), 422-435, doi:10.1002/jgrg.20043, 2013.

Kim, Y., Johnson, M. S., Knox, S. H., Black, T. A., Dalmagro, H. J., Kang, M., Kim, J. and Baldocchi, D.: Gap-filling approaches for eddy covariance methane fluxes: A comparison of three machine learning algorithms and a traditional method with principal component analysis, Glob. Chang. Biol., 26(3), 14991518, doi:10.1111/gcb.14845, 2019.

Klemedtsson, L., Von Arnold, K., Weslien, P. and Gundersen, P.: Soil CN ratio as a scalar parameter to predict nitrous oxide emissions, Glob. Chang. Biol., 11(7), 1142-1147, doi:10.1111/j.1365-2486.2005.00973.x, 2005.

Kløve, B., Sveistrup, T. E. and Hauge, A.: Leaching of nutrients and emission of greenhouse gases from peatland cultivation at Bodin, Northern Norway, Geoderma, 154(3-4), 219-232, doi:10.1016/j.geoderma.2009.08.022, 2010.

Koelbener, A., Ström, L., Edwards, P. J. and Olde Venterink, H.: Plant species from mesotrophic wetlands cause relatively high methane emissions from peat soil, Plant Soil, 326(1), 147-158, doi:10.1007/s11104009-9989-x, 2010.

Koistinen, E. and Valkonen, S.: Models for height development of Norway spruce and Scots pine advance growth after release in southern Finland, Silva Fenn., 27(3), 179-194, 1993.

Koivusalo, H., Ahti, E., Laurén, A., Kokkonen, T., Karvonen, T., Nevalainen, R. and Finér, L.: Impacts of ditch cleaning on hydrological processes in a drained peatland forest, Hydrol. Earth Syst. Sci. Discuss., 5(1), 147-182, doi:10.5194/hessd-5-147-2008, 2008.

Kojola, S., Ahtikoski, A., Hökkä, H. and Penttilä, T.: Profitability of alternative management regimes in Scots pine stands on drained peatlands, Eur. J. For. Res., 131(2), 413-426, doi:10.1007/s10342-011-0514-4, 2012.

Kormann, R. and Meixner, F. X.: An analytical footprint model for non-neutral stratification, Boundary-Layer Meteorol., 99(2), 207-224, doi:10.1023/A:1018991015119, 2001.

Koskinen, M., Minkkinen, K., Ojanen, P., Kämäräinen, M., Laurila, T. and Lohila, A.: Measurements of CO2 exchange with an automated chamber system throughout the year: Challenges in measuring night-time respiration on porous peat soil, Biogeosciences, 11(2), 347-363, doi:10.5194/bg-11-347-2014, 2014.

Kotsyurbenko, O. R., Chin, K. J., Glagolev, M. V., Stubner, S., Simankova, M. V., Nozhevnikova, A. N. and Conrad, R.: Acetoclastic and hydrogenotrophic methane production and methanogenic populations in an acidic West-Siberian peat bog, Environ. Microbiol., 6(11), 1159-1173, doi:10.1111/j.14622920.2004.00634.x, 2004.

Kowalski, A. S., Loustau, D., Berbigier, P., Manca, G., Tedeschi, V., Borghetti, M., Valentini, R., Kolari, P., Berninger, F., Rannik, Ü., Hari, P., Rayment, M., Mencuccini, M., Moncrieff, J. and Grace, J.: Paired comparisons of carbon exchange between undisturbed and regenerating stands in four managed forest in Europe, Glob. Chang. Biol., 10(10), 1707-1723, doi:10.1111/j.1365-2486.2004.00846.x, 2004.

Kowalski, S., Sartore, M., Burlett, R., Berbigier, P. and Loustau, D.: The annual carbon budget of a French pine forest (Pinus pinaster) following harvest, Glob. Chang. Biol., 9(7), 1051-1065, doi:10.1046/j.13652486.2003.00627.x, 2003.

Kubien, D. S. and Sage, R. F.: C4 grasses in boreal fens: Their occurrence in relation to microsite characteristics, Oecologia, 137(3), 330-337, doi:10.1007/s00442-003-1369-2, 2003.

Kutzbach, L., Wagner, D. and Pfeiffer, E. M.: Effect of microrelief and vegetation on methane emission from wet polygonal tundra, Lena Delta, Northern Siberia, Biogeochemistry, 69(3), 341-362, 
doi:10.1023/B:BIOG.0000031053.81520.db, 2004.

Kutzbach, L., Schneider, J., Sachs, T., Giebels, M., Nykänen, H., Shurpali, N. J., Martikainen, P. J., Alm, J. and Wilmking, M.: CO2 flux determination by closed-chamber methods can be seriously biased by inappropriate application of linear regression, Biogeosciences, 4(4), 2279-2328, doi:10.5194/bgd-42279-2007, 2007.

Lafleur, P. M.: Connecting Atmosphere and Wetland: Energy and Water Vapour Exchange, Geogr. Compass, 2(4), 1027-1057, doi:10.1111/j.1749-8198.2007.00132.x, 2008.

Lai, D. Y. F.: Methane Dynamics in Northern Peatlands: A Review, Pedosphere, 19(4), 409-421, doi:10.1016/S1002-0160(09)00003-4, 2009.

Laiho, R. and Finér, L.: Changes in root biomass after water-level drawdown on pine mires in southern Finland, Scand. J. For. Res., 11(1-4), 251-260, doi:10.1080/02827589609382934, 1996.

Lasslop, G., Reichstein, M., Kattge, J. and Papale, D.: Influences of observation errors in eddy flux data on inverse model parameter estimation, Biogeosciences, 5(1), 751-785, doi:10.5194/bgd-5-751-2008, 2008.

Launiainen, S.: Seasonal and inter-annual variability of energy exchange above a boreal Scots pine forest, Biogeosciences, 7(12), 3921-3940, doi:10.5194/bg-7-3921-2010, 2010.

Laurén, A., Heinonen, J., Koivusalo, H., Sarkkola, S., Tattari, S., Mattsson, T., Ahtiainen, M., Joensuu, S., Kokkonen, T. and Finér, L.: Implications of uncertainty in a pre-treatment dataset when estimating treatment effects in paired catchment studies: Phosphorus loads from forest clear-cuts, Water. Air. Soil Pollut., 196(1-4), 251-261, doi:10.1007/s11270-008-9773-1, 2009.

Leifeld, J. and Menichetti, L.: The underappreciated potential of peatlands in global climate change mitigation strategies, Nat. Commun., 9(1), doi:10.1038/s41467-018-03406-6, 2018.

Leifeld, J., Wüst-Galley, C. and Page, S.: Intact and managed peatland soils as a source and sink of GHGs from 1850 to 2100, Nat. Clim. Chang., 9(12), 945-947, doi:10.1038/s41558-019-0615-5, 2019.

Lenschow, D. H., Mann, J. and Kristensen, L.: How long is long enough when measuring fluxes and other turbulence statistics?, J. Atmos. Ocean. Technol., 11(3), 661-673, doi:10.1175/15200426(1994)011<0661:HLILEW>2.0.CO;2, 1994.

Leppelt, T., Dechow, R., Gebbert, S., Freibauer, A., Lohila, A., Augustin, J., Drösler, M., Fiedler, S., Glatzel, S., Höper, H., Järveoja, J., Lærke, P. E., Maljanen, M., Mander, Mäkiranta, P., Minkkinen, K., Ojanen, P., Regina, K. and Strömgren, M.: Nitrous oxide emission budgets and land-use-driven hotspots for organic soils in Europe, Biogeosciences, 11(23), 6595-6612, doi:10.5194/bg-11-6595-2014, 2014.

Leuning, R.: Stomatal function in relation to leaf metabolism and environment, Plant. Cell Environ., 18, 339355, doi:10.1111/j.1365-3040.1995.tb00370.x, 1995.

Levy, P. E., Gray, A., Leeson, S. R., Gaiawyn, J., Kelly, M. P. C., Cooper, M. D. A., Dinsmore, K. J., Jones, S. K. and Sheppard, L. J.: Quantification of uncertainty in trace gas fluxes measured by the static chamber method, Eur. J. Soil Sci., 62(6), 811-821, doi:10.1111/j.1365-2389.2011.01403.x, 2011.

Limpens, J. and Heijmans, M. M. P. D.: The Nitrogen Cycle in Boreal Peatlands, in Boreal Peatland Ecosystems. Ecological Studies (Analysis and Synthesis), vol. 188, edited by R. K. Wieder and D. H. Vitt, Springer, Berlin, Heidelberg., 2006.

Limpens, J., Berendse, F., Blodau, C., Canadell, J. G., Freeman, C., Holden, J., Roulet, N., Rydin, H. and Schaepman-Strub, G.: Peatlands and the carbon cycle: from local processes to global implications - a synthesis, Biogeosciences, 5(6), 1475-1491, doi:https://doi.org/10.5194/bg-5-1475-2008, 2008.

Lindroth, A., Holst, J., Heliasz, M., Vestin, P., Lagergren, F., Biermann, T., Cai, Z. and Mölder, M.: Effects of low thinning on carbon dioxide fluxes in a mixed hemiboreal forest, Agric. For. Meteorol., 262(July 2017), 59-70, doi:10.1016/j.agrformet.2018.06.021, 2018.

Livingston, G. P., Hutchinson, G. L. and Spartalian, K.: Diffusion theory improves chamber-based measurements of trace gas emissions, Geophys. Res. Lett., 32(24), 1-3, doi:10.1029/2005GL024744, 2005.

Livingston, G. P., Hutchinson, G. L. and Spartalian, K.: Trace Gas Emission in Chambers, Soil Sci. Soc. Am. J., 70(5), 1459, doi:10.2136/sssaj2005.0322, 2006.

Lloyd, J. and Taylor, J. A.: On the Temperature Dependence of Soil Respiration, Funct. Ecol., 8, 315-323, 1994.

Loescher, H. W., Law, B. E., Mahrt, L., Hollinger, D. Y., Campbell, J. and Wofsy, S. C.: Uncertainties in, and 
interpretation of, carbon flux estimates using the eddy covariance technique, J. Geophys. Res. Atmos., 111(21), 1-19, doi:10.1029/2005JD006932, 2006.

Lohila, A., Minkkinen, K., Laine, J., Savolainen, I., Tuovinen, J. P., Korhonen, L., Laurila, T., Tietäväinen, H. and Laaksonen, A.: Forestation of boreal peatlands: Impacts of changing albedo and greenhouse gas fluxes on radiative forcing, J. Geophys. Res. Biogeosciences, 115(4), 1-15, doi:10.1029/2010JG001327, 2010.

Lohila, A., Minkkinen, K., Aurela, M., Tuovinen, J.-P., Penttilä, T., Ojanen, P. and Laurila, T.: Greenhouse gas flux measurements in a forestry-drained peatland indicate a large carbon sink, Biogeosciences, 8(11), 3203-3218, doi:10.5194/bg-8-3203-2011, 2011.

Lohila, A., Aalto, T., Aurela, M., Hatakka, J., Tuovinen, J.-P., Kilkki, J., Penttilä, T., Vuorenmaa, J., Hänninen, P., Sutinen, R., Viisanen, Y. and Laurila, T.: Large contribution of boreal upland forest soils to a catchment-scale CH4 balance in a wet year, Geophys. Res. Lett., 43(6), 2946-2953, doi:10.1002/2016GL067718, 2016.

Loisel, J. and Yu, Z.: Recent acceleration of carbon accumulation in a boreal peatland, south central Alaska, J. Geophys. Res. Biogeosciences, 118(1), 41-53, doi:10.1029/2012JG001978, 2013.

Longdoz, B., Yernaux, M. and Aubinet, M.: Soil CO2 efflux measurements in a mixed forest: Impact of chamber disturbances, spatial variability and seasonal evolution, Glob. Chang. Biol., 6(8), 907-917, doi:10.1046/j.1365-2486.2000.00369.x, 2000.

Luan, J. and Wu, J.: Long-term agricultural drainage stimulates $\mathrm{CH} 4$ emissions from ditches through increased substrate availability in a boreal peatland, Agric. Ecosyst. Environ., 214, 68-77, doi:10.1016/j.agee.2015.08.020, 2015.

Luo, G. J., Brüggemann, N., Wolf, B., Gasche, R., Grote, R. and Butterbach-Bahl, K.: Decadal variability of soil CO2, NO, N2O, and CH4 fluxes at the Höglwald Forest, Germany, Biogeosciences, 9(5), 17411763, doi:10.5194/bg-9-1741-2012, 2012.

Machacova, K., Vainio, E., Urban, O. and Pihlatie, M.: Seasonal dynamics of stem N2O exchange follow the physiological activity of boreal trees, Nat. Commun., 10(1), 1-13, doi:10.1038/s41467-019-12976-y, 2019.

Maier, M. and Schack-Kirchner, H.: Using the gradient method to determine soil gas flux: A review, Agric. For. Meteorol., 192-193, 78-95, doi:10.1016/j.agrformet.2014.03.006, 2014.

Mäkipää, R., Häkkinen, M., Muukkonen, P. and Peltoniemi, M.: The costs of monitoring changes in forest soli carbon stocks, Boreal Environ. Res., 13(SUPPL. B), 120-130, 2008.

Mäkiranta, P., Hytönen, J., Aro, L., Maljanen, M., Pihlatie, M., Potila, H., Shurpali, N. J., Laine, J., Lohila, A., Martikainen, P. J. and Minkkinen, K.: Soil greenhouse gas emissions from afforested organic soil croplands and cutaway peatlands, Boreal Environ. Res., 12(2), 159-175, 2007.

Mäkiranta, P., Riutta, T., Penttilä, T. and Minkkinen, K.: Dynamics of net ecosystem $\mathrm{CO}_{2}$ exchange and heterotrophic soil respiration following clearfelling in a drained peatland forest, Agric. For. Meteorol., 150(12), 1585-1596, doi:10.1016/j.agrformet.2010.08.010, 2010.

Mäkiranta, P., Laiho, R., Penttilä, T. and Minkkinen, K.: The impact of logging residue on soil GHG fluxes in a drained peatland forest, Soil Biol. Biochem., 48, 1-9, doi:10.1016/j.soilbio.2012.01.005, 2012.

Maljanen, M., Sigurdsson, B. D., Guðmundsson, J., Óskarsson, H., Huttunen, J. T. and Martikainen, P. J.: Greenhouse gas balances of managed peatlands in the Nordic countries present knowledge and gaps, Biogeosciences, 7(9), 2711-2738, doi:10.5194/bg-7-2711-2010, 2010.

Mamkin, V., Kurbatova, J., Avilov, V., Ivanov, D., Kuricheva, O., Varlagin, A., Yaseneva, I. and Olchev, A.: Energy and $\mathrm{CO} 2$ exchange in an undisturbed spruce forest and clear-cut in the Southern Taiga, Agric. For. Meteorol., 265(November 2018), 252-268, doi:10.1016/j.agrformet.2018.11.018, 2019.

Männistö, E., Korrensalo, A., Alekseychik, P., Mammarella, I., Peltola, O., Vesala, T. and Tuittila, E. S.: Multi-year methane ebullition measurements from water and bare peat surfaces of a patterned boreal bog, Biogeosciences, 16(11), 2409-2421, doi:10.5194/bg-16-2409-2019, 2019.

Manzoni, S., Trofymow, J. A., Jackson, R. B. and Porporato, A.: Stoichiometric controls on carbon, nitrogen, and phosphorus dynamics in decomposing litter, Ecol. Monogr., 80(1), 89-106, doi:10.1890/09-0179.1, 2010.

Marshall, B. and Biscoe, P. V.: A model for $\mathrm{c} 3$ leaves describing the dependence of net photosynthesis on irradiance: II. Application to the analysis of flag leaf photosynthesis, J. Exp. Bot., 31(1), 41-48, 
doi:10.1093/jxb/31.1.41, 1980.

Martikainen, P. J., Nykänen, H., Crill, P. M. and Silvola, J.: Effect of a lowered water table on nitrous oxide fluxes from northern peatlands, Nature, 366, 51-53, 1993.

Martikainen, P. J., Nykänen, H., Alm, J. and Silvola, J.: Change in Fluxes of Carbon-Dioxide, Methane and Nitrous-Oxide Due To Forest Drainage of Mire Sites of Different Trophy, Plant Soil, 168, 571-577, doi:10.1007/bf00029370, 1995.

Mazza, G., Agnelli, A. E., Cantiani, P., Chiavetta, U., Doukalianou, F., Kitikidou, K., Milios, E., Orfanoudakis, M., Radoglou, K. and Lagomarsino, A.: Short-term effects of thinning on soil CO2, N2O and CH4 fluxes in Mediterranean forest ecosystems, Sci. Total Environ., 651, 713-724, doi:10.1016/j.scitotenv.2018.09.241, 2019.

McMillen, R. T.: An eddy correlation technique with extended applicability to non-simple terrain, BoundaryLayer Meteorol., 43(3), 231-245, doi:10.1007/BF00128405, 1988.

Le Mer, J. and Roger, P.: Production, oxidation, emission and consumption of methane by soils: A review, Eur. J. Soil Biol., 37(1), 25-50, doi:10.1016/S1164-5563(01)01067-6, 2001.

Meyer, A., Tarvainen, L., Nousratpour, A., Björk, R. G., Ernfors, M., Grelle, A., Kasimir-Klemedtsson, A., Lindroth, A., Räntfors, M., Rütting, T., Wallin, G., Weslien, P. and Klemedtsson, L.: A fertile peatland forest does not constitute a major greenhouse gas sink, Biogeosciences, 10(11), 7739-7758, doi:10.5194/bg-10-7739-2013, 2013.

Minkkinen, K. and Laine, J.: Vegetation heterogeneity and ditches create spatial variability in methane fluxes from peatlands drained for forestry, Plant Soil, 285(1-2), 289-304, doi:10.1007/s11104-006-9016-4, 2006.

Minkkinen, K., Laine, J., Nykänen, H. and Martikainen, P. J.: Importance of drainage ditches in emissions of methane from mires drained for forestry, Can. J. For. Res., 27(6), 949-952, doi:10.1139/x97-016, 1997.

Minkkinen, K., Laine, J., Shurpali, N. J., Mäkiranta, P., Alm, J. and Penttilä, T.: Heterotrophic soil respiration in forestry-drained peatlands, Boreal Environ. Res., 12, 115-126, 2007.

Minkkinen, K., Byrne, K. A. and Trettin, C.: Climate impacts of peatland forestry, edited by M. Strack, International Peat Society., 2008.

Minkkinen, K., Ojanen, P., Penttilä, T., Aurela, M., Laurila, T., Tuovinen, J.-P. and Lohila, A.: Persistent carbon sink at a boreal drained bog forest, Biogeosciences, 15(11), 3603-3624, doi:10.5194/bg-15-36032018, 2018

Minkkinen, K., Ojanen, P., Koskinen, M. and Penttilä, T.: Nitrous oxide emissions of undrained, forestrydrained, and rewetted boreal peatlands, For. Ecol. Manage., Accepted manuscript, 2020.

Moldrup, P., Olesen, T., Komatsu, T., Schjønning, P. and Rolston, D. E.: Tortuosity, Diffusivity, and Permeability in the Soil Liquid and Gaseous Phases Tortuosity phenomena of pore space influence the transport of, Soil Sci. Soc. Am. J., 65, 613-623, 2001.

Moncrieff, J., Malhi, Y. and Leuning, R.: The propagation of errors in long-term measurements of landatmosphere fluxes of carbon and water, Glob. Chang. Biol., 2(3), 231-240, doi:10.1111/j.13652486.1996.tb00075.x, 1996.

Moncrieff, J., Clement, R., Finnigan, J. and Meyers, T.: Averaging, detrending, and filtering of eddy covariance time series, in Handbook of Micrometeorology, edited by X. Lee, W. Massman, and B. Law, pp. 7-13, Kluwer Academic Publishers., 2004.

Montagnani, L., Grünwald, T., Kowalski, A., Mammarella, I., Merbold, L., Metzger, S., Sedlák, P. and Siebicke, L.: Estimating the storage term in eddy covariance measurements: The ICOS methodology, Int. Agrophysics, 32(4), 551-567, doi:10.1515/intag-2017-0037, 2018.

Monteith, J. L.: Evaporation and Environment, Symp. Soc. Exp. Biol., 19, 205-234, 1965.

Moore, C. J.: Frequency response corrections for eddy correlation systems, Boundary-Layer Meteorol., 37, 17 35, doi:10.1007/BF00122754, 1986.

Moyano, F. E., Manzoni, S. and Chenu, C.: Responses of soil heterotrophic respiration to moisture availability: An exploration of processes and models, Soil Biol. Biochem., 59, 72-85, doi:10.1016/j.soilbio.2013.01.002, 2013.

Nakano, T., Sawamoto, T., Morishita, T., Inoue, G. and Hatano, R.: A comparison of regression methods for estimating soil-atmosphere diffusion gas fluxes by a closed-chamber technique, Soil Biol. Biochem., 
36(1), 107-113, doi:10.1016/j.soilbio.2003.07.005, 2004.

Neira, J., Ortiz, M., Morales, L. and Acevedo, E.: Oxygen diffusion in soils: Understanding the factors and processes needed for modeling, Chil. J. Agric. Res., 75(August), 35-44, doi:10.4067/S0718$58392015000300005,2015$.

Neubauer, S. C. and Megonigal, J. P.: Moving Beyond Global Warming Potentials to Quantify the Climatic Role of Ecosystems, Ecosystems, 18(6), 1000-1013, doi:10.1007/s10021-015-9879-4, 2015.

Neubauer, S. C. and Megonigal, J. P.: Correction to: Moving Beyond Global Warming Potentials to Quantify the Climatic Role of Ecosystems (Ecosystems, (2015), 18, 6, (1000-1013), 10.1007/s10021-015-9879-4), Ecosystems, 22(8), 1931-1932, doi:10.1007/s10021-019-00422-5, 2019.

Nichols, J. E. and Peteet, D. M.: Rapid expansion of northern peatlands and doubled estimate of carbon storage, Nat. Geosci., 12(11), 917-921, doi:10.1038/s41561-019-0454-z, 2019.

Nieminen, M., Ahti, E., Koivusalo, H., Mattsson, T., Sarkkola, S. and Laurén, A.: Export of suspended solids and dissolved elements from peatland areas after ditch network maintenance in south-central Finland, Silva Fenn., 44(1), 39-49, doi:10.14214/sf.161, 2010.

Nieminen, M., Koskinen, M., Sarkkola, S., Laurén, A., Kaila, A., Kiikkilä, O., Nieminen, T. M. and Ukonmaanaho, L.: Dissolved organic carbon export from harvested peatland forests with differing site characteristics, Water. Air. Soil Pollut., 226(6), doi:10.1007/s11270-015-2444-0, 2015.

Nieminen, M., Hökkä, H., Laiho, R., Juutinen, A., Ahtikoski, A., Pearson, M., Kojola, S., Sarkkola, S., Launiainen, S., Valkonen, S., Penttilä, T., Lohila, A., Saarinen, M., Haahti, K., Mäkipää, R., Miettinen, J. and Ollikainen, M.: Could continuous cover forestry be an economically and environmentally feasible management option on drained boreal peatlands?, For. Ecol. Manage., 424(April), 78-84, doi:10.1016/j.foreco.2018.04.046, 2018.

Nilsson, M., Sagerfors, J., Buffam, I., Laudon, H., Eriksson, T., Grelle, A., Klemedtsson, L., Weslien, P. and Lindroth, A.: Contemporary carbon accumulation in a boreal oligotrophic minerogenic mire - A significant sink after accounting for all C-fluxes, Glob. Chang. Biol., 14(10), 2317-2332, doi:10.1111/j.1365-2486.2008.01654.x, 2008.

Norman, J. M., Kucharik, C. J., Gower, S. T., Baldocchi, D. D., Crill, P. M., Rayment, M., Savage, K. and Striegl, R. G.: A comparison of six methods for measuring soil-surface carbon a field comparison aspen Fluxes, Boreas, 102, 771-777, 1997.

Nykänen, H., Alm, J., Lang, K., Silvola, J. and Martikainen, P. J.: Emissions of CH4, N2O and CO2 from a virgin fen and a fen drained for grassland in finland, J. Biogeogr, 22(2), 351-357, doi:10.2307/2845930, 1995.

Nykänen, H., Vasander, H., Huttunen, J. T. and Martikainen, P. J.: Effect of experimental nitrogen load on methane and nitrous oxide fluxes on ombrotrophic boreal peatland, Plant Soil, 242(1), 147-155, doi:10.1023/A:1019658428402, 2002.

Ojanen, P., Minkkinen, K., Alm, J. and Penttilä, T.: Soil-atmosphere $\mathrm{CO}_{2}, \mathrm{CH}_{4}$ and $\mathrm{N}_{2} \mathrm{O}$ fluxes in boreal forestry-drained peatlands, For. Ecol. Manage., 260(3), 411-421, doi:10.1016/j.foreco.2010.04.036, 2010.

Ojanen, P., Minkkinen, K. and Penttilä, T.: The current greenhouse gas impact of forestry-drained boreal peatlands, For. Ecol. Manage., 289, 201-208, doi:10.1016/j.foreco.2012.10.008, 2013.

Päivänen, J. and Hånell, B.: Peatland ecology and forestry : a sound approach, Unicersity of Helsinki Department of Forest Sciences Publications 3, Helsinki, Finland., 2012.

Päivänen, J. and Sarkkola, S.: The effect of thinning and ditch network maintenance on the water table level in a Scots pine stand on peat soil, Suo, 51(3), 131-138, 2000.

Pangala, S. R., Enrich-prast, A., Basso, L. S., Peixoto, R. B., Bastviken, D., Marotta, H., Silva, L., Calazans, B., Hornibrook, E. R. C. and Luciana, V.: Large emissions from floodplain trees close the Amazon methane budget, Nature, 552(7684), 230-234, doi:10.1038/nature24639, 2017.

Papen, H. and Butterbach-Bahl, K.: A 3-year continuous record of nitrogen trace gas fluxes from untreated and limed soil of a N-saturated spruce and beech forest ecosystem in Germany. 2. NO and NO2 fluxes, J. Geophys. Res., 104(15), 487-503, doi:https://doi.org/10.1029/1999JD900293, 1999.

Pärn, J., Verhoeven, J. T. A., Butterbach-Bahl, K., Dise, N. B., Ullah, S., Aasa, A., Egorov, S., Espenberg, M., Järveoja, J., Jauhiainen, J., Kasak, K., Klemedtsson, L., Kull, A., Laggoun-Défarge, F., Lapshina, E. D., Lohila, A., Lõhmus, K., Maddison, M., Mitsch, W. J., Müller, C., Niinemets, Ü., Osborne, B., Pae, T., 
Salm, J.-O., Sgouridis, F., Sohar, K., Soosaar, K., Storey, K., Teemusk, A., Tenywa, M. M., Tournebize, J., Truu, J., Veber, G., Villa, J. A., Zaw, S. S. and Mander, Ü.: Nitrogen-rich organic soils under warm well-drained conditions are global nitrous oxide emission hotspots, Nat. Commun., 9(1), 1135, doi:10.1038/s41467-018-03540-1, 2018.

Pavelka, M., Acosta, M., Kiese, R., Altimir, N., Brümmer, C., Crill, P., Darenova, E., Fuß, R., Gielen, B., Graf, A., Klemedtsson, L., Lohila, A., Longdoz, B., Lindroth, A., Nilsson, M., Jiménez, S. M., Merbold, L., Montagnani, L., Peichl, M., Pihlatie, M., Pumpanen, J., Ortiz, P. S., Silvennoinen, H., Skiba, U., Vestin, P., Weslien, P., Janous, D. and Kutsch, W.: Standardisation of chamber technique for CO2, N2O and CH4 fluxes measurements from terrestrial ecosystems, Int. Agrophysics, 32(4), 569-587, doi:10.1515/intag-2017-0045, 2018.

Pedersen, A. R., Petersen, S. O. and Schelde, K.: A comprehensive approach to soil-atmosphere trace-gas flux estimation with static chambers, Eur. J. Soil Sci., 61(6), 888-902, doi:10.1111/j.13652389.2010.01291.x, 2010.

Peng, B., Sun, J., Liu, J., Dai, W., Sun, L., Pei, G., Gao, D., Wang, C., Jiang, P. and Bai, E.: N2O emission from a temperate forest soil during the freeze-thaw period: A mesocosm study, Sci. Total Environ., 648(72), 350-357, doi:10.1016/j.scitotenv.2018.08.155, 2019.

Pihlatie, M., Christiansen, J. R., Aaltonen, H., Korhonen, J. F. J., Nordbo, A., Rasilo, T., Benanti, G., Giebels, M., Helmy, M., Sheehy, J., Jones, S., Juszczak, R., Klefoth, R., Lobo-do-vale, R., Paula, A., Schreiber, P., Serc, D., Vicca, S., Wolf, B. and Pumpanen, J.: Comparison of static chambers to measure CH4 emissions from soils, Agric. For. Meteorol., 172, 124-136, 2013.

Pirinen, P., Simola, H., Aalto, J., Kaukoranta, J.-P., Karlsson, P. and Ruuhela, R.: Climatological statistics of Finland 1981-2010, Reports, 2., Finnish Meteorological Institute, Helsinki, Finland., 2012.

Pirk, N., Mastepanov, M., Parmentier, F.-J. W., Lund, M., Crill, P. M. and Christensen, T. R.: Calculations of automatic chamber flux measurements of methane and carbon dioxide using short time series of concentrations, Biogeosciences, 13(4), 903-912, doi:10.5194/bg-13-903-2016, 2016.

Van Den Pol-van Dasselaar, A., Van Beusichem, M. L. and Oenema, O.: Effects of soil moisture content and temperature on methane uptake by grasslands on sandy soils, Plant Soil, 204(2), 213-222, doi:10.1023/A:1004371309361, 1998.

Polhamus, A., Fisher, J. B. and Tu, K. P.: What controls the error structure in evapotranspiration models?, Agric. For. Meteorol., 169, 12-24, doi:10.1016/j.agrformet.2012.10.002, 2013.

Post, H., Hendricks Franssen, H. J., Graf, A., Schmidt, M. and Vereecken, H.: Uncertainty analysis of eddy covariance $\mathrm{CO} 2$ flux measurements for different EC tower distances using an extended two-tower approach, Biogeosciences, 12(4), 1205-1221, doi:10.5194/bg-12-1205-2015, 2015.

Pumpanen, J., Kolari, P., Ilvesniemi, H., Minkkinen, K., Vesala, T., Niinistö, S., Lohila, A., Larmola, T., Morero, M., Pihlatie, M., Janssens, I., Yuste, J. C., Grünzweig, J. M., Reth, S., Subke, J. A., Savage, K., Kutsch, W., Østreng, G., Ziegler, W., Anthoni, P., Lindroth, A. and Hari, P.: Comparison of different chamber techniques for measuring soil CO2 efflux, Agric. For. Meteorol., 123(3-4), 159-176, doi:10.1016/j.agrformet.2003.12.001, 2004.

Pumpanen, J., Longdoz, B. and Kutsch, W. L.: Field measurements of soil respiration: Principles and constraints, potentials and limitations of different methods, Soil Carbon Dyn. An Integr. Methodol., 1633, doi:10.1017/CBO9780511711794.003, 2010.

Rannik, Ü., Vesala, T. and Keskinen, R.: On the damping of temperature fluctuations in a circular tube relevant to the eddy covariance measurement technique, J. Geophys. Res. Atmos., 102(D11), 12789-12794, 1997.

Rannik, Ü., Altimir, N., Raittila, J., Suni, T., Gaman, A., Hussein, T., Hölttä, T., Lassila, H., Latokartano, M., Lauri, A., Natsheh, A., Petäjä, T., Sorjamaa, R., Ylä-Mella, H., Keronen, P., Berninger, F., Vesala, T., Hari, P. and Kulmala, M.: Fluxes of carbon dioxide and water vapour over Scots pine forest and clearing, Agric. For. Meteorol., 111(3), 187-202, doi:10.1016/S0168-1923(02)00022-9, 2002.

Rannik, Ü., Sogachev, A. F., Foken, T., Gockede, M., Kljun, N., Leclerc, Monique, Y. and Vesala, T.: Footprint analysis, in Eddy Covariance: a practical guide, edited by M. Aubinet, T. Vesala, and D. Papale, pp. 211-262, Springer Atmospheric Sciences., 2012.

Räsänen, M., Aurela, M., Vakkari, V., Beukes, J. P., Tuovinen, J.-P., Van Zyl, P. G., Josipovic, M., Venter, A. D., Jaars, K., Siebert, S. J., Laurila, T., Rinne, J. and Laakso, L.: Carbon balance of a grazed savanna grassland ecosystem in South Africa, Biogeosciences, 14(5), 1039-1054, doi:10.5194/bg-14-1039-2017, 
2017.

Rayment, M. B.: Closed chamber systems underestimate soil CO2 efflux, Eur. J. Soil Sci., 51(1), 107-110, doi:10.1046/j.1365-2389.2000.00283.x, 2000.

Regina, K., Nykänen, H., Silvola, J. and Martikainen, P. J.: Fluxes of nitrous oxide from boreal peatlands as affected by peatland type, water table level and nitrification capacity, Biogeochemistry, 35(3), 401-418, doi:10.1007/BF02183033, 1996.

Regina, K., Nykänen, H., Maljanen, M., Silvola, J. and Martikainen, P. J.: Emissions of N2O and NO and net nitrogen mineralization in a boreal forested peatland treated with different nitrogen compounds, Can. J. For. Res. Can. Rech. For., 28(1), 132-140, doi:10.1139/cjfr-28-1-132, 1998.

Regina, K., Silvola, J. and Martikainen, P. J.: Short-term effects of changing water table on N2O fluxes from peat monoliths from natural and drained boreal peatlands, Glob. Chang. Biol., 5(2), 183-189, doi:10.1046/j.1365-2486.1999.00217.x, 1999.

Reichstein, M., Bednorz, F., Broll, G. and Kätterer, T.: Temperature dependence of carbon mineralisation: Conclusions from a long-term incubation of subalpine soil samples, Soil Biol. Biochem., 32(7), 947-958, doi:10.1016/S0038-0717(00)00002-X, 2000.

Repola, J.: Biomass equations for birch in Finland, Silva Fenn., 42(4), 605-624, doi:10.14214/sf.236, 2008.

Repola, J.: Biomass equations for Scots pine and Norway spruce in Finland, Silva Fenn., 43(4), 625-647, doi:10.14214/sf.184, 2009.

Rezanezhad, F., Quinton, W. L., Price, J. S., Elliot, T. R., Elrick, D. and Shook, K. R.: Influence of pore size and geometry on peat unsaturated hydraulic conductivity computed from 3D computed tomography image analysis, Hydrol. Process., 24(21), 2983-2994, doi:10.1002/hyp.7709, 2010.

Richardson, A. D., Aubinet, M., Barr, A. G., Hollinger, D. Y., Ibrom, A. and Lasslop, G.: Uncertainty Quantification, in Eddy Covariance: a practical guide to measurement and data analysis, edited by M. Aubinet, T. Vesala, and D. Papale, pp. 173-210, Springer Atmospheric Sciences., 2012.

Ridgwell, A. J., Marshall, S. J. and Gregson, K.: Consumption of atmospheric methane by soils: A processbased model, Global Biogeochem. Cycles, 13(1), 59-70, doi:10.1029/1998GB900004, 1999.

Rinne, J. and Ammann, C.: Disjunct Eddy Covariance Method, in Eddy Covariance: a practical guide to measurement and data analysis, edited by M. Aubinet, T. Vesala, and D. Papale, pp. 289-305, Springer., 2012.

Riutta, T., Laine, J. and Tuittila, E.-S.: Sensitivity of $\mathrm{CO}_{2}$ exchange of fen ecosystem components to water level variation, Ecosystems, 10(5), 718-733, doi:10.1007/s10021-007-9046-7, 2007.

Roberts, S. D., Harrington, C. A. and Terry, T. A.: Harvest residue and competing vegetation affect soil moisture, soil temperature, $\mathrm{N}$ availability, and Douglas-fir seedling growth, , 205, 333-350, doi:10.1016/j.foreco.2004.10.036, 2005.

Rodgers, M., O’Connor, M., Healy, M. G., O’Driscoll, C., Asam, Z. U. Z., Nieminen, M., Poole, R., Müller, M. and Xiao, L.: Phosphorus release from forest harvesting on an upland blanket peat catchment, For. Ecol. Manage., 260(12), 2241-2248, doi:10.1016/j.foreco.2010.09.037, 2010.

Rosén, K. and Lundmark-Thelin, A.: Increased nitrogen leaching under piles of slash-A consequence of modern forest harvesting techniques, Scand. J. For. Res., 2(1-4), 21-29, doi:10.1080/02827588709382443, 1987.

Roulet, N. T., Lafleur, P. M., Richard, P. J. H., Moore, T. R., Humphreys, E. R. and Bubier, J.: Contemporary carbon balance and late Holocene carbon accumulation in a northern peatland, Glob. Chang. Biol., 13(2), 397-411, doi:10.1111/j.1365-2486.2006.01292.x, 2007.

Röver, M., Heinemeyer, O. and Kaiser, E. A.: Microbial induced nitrous oxide emissions from an arable soil during winter, Soil Biol. Biochem., 30(14), 1859-1865, doi:10.1016/S0038-0717(98)00080-7, 1998.

Saari, P., Saarnio, S., Kukkonen, J. V. K., Akkanen, J., Heinonen, J., Saari, V. and Alm, J.: DOC and $\mathrm{N}_{2} \mathrm{O}$ dynamics in upland and peatland forest soils after clear-cutting and soil preparation, Biogeochemistry, 94(3), 217-231, doi:10.1007/s10533-009-9320-1, 2009.

Salesky, S. T., Chamecki, M. and Dias, N. L.: Estimating the Random Error in Eddy-Covariance Based Fluxes and Other Turbulence Statistics: The Filtering Method, Boundary-Layer Meteorol., 144(1), 113-135, doi:10.1007/s10546-012-9710-0, 2012.

Samson, M., Słowińska, S., Słowiński, M., Lamentowicz, M., Barabach, J., Harenda, K., Zielińska, M., 
Robroek, B. J. M., Jassey, V. E. J., Buttler, A. and Chojnicki, B. H.: The Impact of Experimental Temperature and Water Level Manipulation on Carbon Dioxide Release in a Poor Fen in Northern Poland, Wetlands, 38(3), 551-563, doi:10.1007/s13157-018-0999-4, 2018.

Sarkkola, S., Hökkä, H., Laiho, R., Päivänen, J. and Penttilä, T.: Stand structural dynamics on drained peatlands dominated by Scots pine, For. Ecol. Manage., 206(1-3), 135-152, doi:10.1016/j.foreco.2004.10.064, 2005.

Sarkkola, S., Hökkä, H., Koivusalo, H., Nieminen, M., Ahti, E., Päivänen, J. and Laine, J.: Role of tree stand evapotranspiration in maintaining satisfactory drainage conditions in drained peatlands, Can. J. For. Res., 40(8), 1485-1496, doi:10.1139/X10-084, 2010.

Sarkkola, S., Hökkä, H., Ahti, E., Koivusalo, H. and Nieminen, M.: Depth of water table prior to ditch network maintenance is a key factor for tree growth response, Scand. J. For. Res., 27(7), 649-658, doi:10.1080/02827581.2012.689004, 2012.

Sarkkola, S., Nieminen, M., Koivusalo, H., Laurén, A., Ahti, E., Launiainen, S., Nikinmaa, E., Marttila, H., Laine, J. and Hökkä, H.: Domination of growing-season evapotranspiration over runoff makes ditch network maintenance in mature peatland forests questionable, Mires Peat, 11, 1-11, 2013.

Saunders, M., Tobin, B., Black, K., Gioria, M., Nieuwenhuis, M. and Osborne, B. A.: Thinning effects on the net ecosystem carbon exchange of a Sitka spruce forest are temperature-dependent, Agric. For. Meteorol., 157, 1-10, doi:10.1016/j.agrformet.2012.01.008, 2012.

Savage, K., Phillips, R. and Davidson, E.: High temporal frequency measurements of greenhouse gas emissions from soils, Biogeosciences, 11(10), 2709-2720, doi:10.5194/bg-11-2709-2014, 2014.

Scharlemann, J. P. W., Tanner, E. V. J., Hiederer, R. and Kapos, V.: Global soil carbon: Understanding and managing the largest terrestrial carbon pool, Carbon Manag., 5(1), 81-91, doi:10.4155/cmt.13.77, 2014.

Schaufler, G., Kitzler, B., Schindlbacher, A., Skiba, U., Sutton, M. A. and Zechmeister-Boltenstern, S.: Greenhouse gas emissions from European soils under different land use: Effects of soil moisture and temperature, Eur. J. Soil Sci., 61(5), 683-696, doi:10.1111/j.1365-2389.2010.01277.x, 2010.

Scheutz, C. and Kjeldsen, P.: Environmental Factors Influencing Attenuation of Methane and Hydrochlorofluorocarbons in Landfill Cover Soils, J. Environ. Qual., 33(1), 72, doi:10.2134/jeq2004.0072, 2004.

Scheutz, C., Kjeldsen, P., Bogner, J. E., De Visscher, A., Gebert, J., Hilger, H. A., Huber-Humer, M. and Spokas, K.: Microbial methane oxidation processes and technologies for mitigation of landfill gas emissions, Waste Manag. Res., 27(5), 409-455, doi:10.1177/0734242X09339325, 2009.

Schimel, J. P.: Plant transport and methane production as controls on methane flux from arctic wet meadow tundra, Biogeochemistry, 28(3), 183-200, doi:10.1007/BF02186458, 1995.

Schindlbacher, A., Zechmeister-Boltenstern, S. and Butterbach-Bahl, K.: Effects of soil moisture and temperature on NO, NO2, and N $2 \mathrm{O}$ emissions from European forest soils, J. Geophys. Res. D Atmos., 109(17), 1-12, doi:10.1029/2004JD004590, 2004.

Schwarz, A. G. and Redmann, R. E.: C4 grasses from the boreal forest region of northwestern Canada, Can. J. Bot., 66(12), 2424-2430, doi:10.1139/b88-329, 1988.

Scott-Denton, L. E., Rosenstiel, T. N. and Monson, R. K.: Differential controls by climate and substrate over the heterotrophic and rhizospheric components of soil respiration, Glob. Chang. Biol., 12(2), 205-216, doi:10.1111/j.1365-2486.2005.01064.x, 2006.

Scott, N. A., Rodrigues, C. A., Hughes, H., Lee, J. T., Davidson, E. A., Dail, D. B., Malerba, P. and Hollinger, D. Y.: Changes in carbon storage and net carbon exchange one year after an initial shelterwood harvest at Howland Forest, ME, Environ. Manage., 33(SUPPL. 1), 9-22, doi:10.1007/s00267-003-9114-5, 2004.

Segers, R.: Methane production and methane consumption: A review of processes underlying wetland methane fluxes, Biogeochemistry, 41(1), 23-51, doi:10.1023/A:1005929032764, 1998.

Signor, D. and Cerri, C. E. P.: Nitrous oxide emissions in agricultural soils: a review, Pesqui. Agropecu. Trop., 43(3), 322-338, doi:10.1590/S1983-40632013000300014, 2013.

Sikström, U. and Hökkä, H.: Interactions between soil water conditions and forest stands in boreal forests with implications for ditch network maintenance, Silva Fenn., 50(1), 1-29, doi:10.14214/sf.1416, 2016.

Silins, U. and Rothwell, R. L.: Forest Peatland Drainage and Subsidence Affect Soil Water Retention and Transport Properties in an Alberta Peatland, Soil Sci. Soc. Am. J., 62(4), 1048-1056, doi:10.2136/sssaj1998.03615995006200040028x, 1998. 
Singh, J. S., Singh, S., Raghubanshi, A. S., Singh, S., Kashyap, A. K. and Reddy, V. S.: Effect of soil nitrogen, carbon and moisture on methane uptake by dry tropical forest soils, Plant Soil, 196(1), 115-121, doi:10.1023/A:1004233208325, 1997.

Skiba, U. M., Sheppard, L. J., MacDonald, J. and Fowler, D.: Some key environmental variables controlling nitrous oxide emissions from agricultural and semi-natural soils in Scotland, Atmos. Environ., 32(19), 3311-3320, doi:10.1016/S1352-2310(97)00364-6, 1998.

Smith, K. A., Ball, T., Conen, F., Dobbie, K. E., Massheder, J. and Rey, A.: Exchange of greenhouse gases between soil and atmosphere: interactions of soil physical factors and biological processes, Eur. J. Soil Sci., 69(1), 10-20, doi:10.1111/ejss.12539, 2018.

Smith, P., Soussana, J. F., Angers, D., Schipper, L., Chenu, C., Rasse, D. P., Batjes, N. H., van Egmond, F., McNeill, S., Kuhnert, M., Arias-Navarro, C., Olesen, J. E., Chirinda, N., Fornara, D., Wollenberg, E., Álvaro-Fuentes, J., Sanz-Cobena, A. and Klumpp, K.: How to measure, report and verify soil carbon change to realize the potential of soil carbon sequestration for atmospheric greenhouse gas removal, Glob. Chang. Biol., 26(1), 219-241, doi:10.1111/gcb.14815, 2019.

Sosulski, T., Szara, E., Stępień, W. and Szymańska, M.: Nitrous oxide emissions from the soil under different fertilization systems on a long-term experiment, Plant, Soil Environ., 60(11), 481-488, doi:10.17221/943/2013-pse, 2014.

Sottocornola, M. and Kiely, G.: An Atlantic blanket bog is a modest CO2 sink, Geophys. Res. Lett., 32(23), 14, doi:10.1029/2005GL024731, 2005.

Stanley, K. M., Heppell, C. M., Belyea, L. R., Baird, A. J. and Field, R. H.: The Importance of CH4 Ebullition in Floodplain Fens, J. Geophys. Res. Biogeosciences, 124(7), 1750-1763, doi:10.1029/2018JG004902, 2019.

Stern, J. C., Chanton, J., Abichou, T., Powelson, D., Yuan, L., Escoriza, S. and Bogner, J.: Use of a biologically active cover to reduce landfill methane emissions and enhance methane oxidation, Waste Manag., 27(9), 1248-1258, doi:10.1016/j.wasman.2006.07.018, 2007.

Still, C. J., Berry, J. A., Collatz, G. J. and DeFries, R. S.: Global distribution of C3 and C4 vegetation: Carbon cycle implications, Global Biogeochem. Cycles, 17(1), doi:10.1029/2001gb001807, 2003.

Strack, M. and Waddington, J. M.: Response of peatland carbon dioxide and methane fluxes to a water table drawdown experiment, Global Biogeochem. Cycles, 21(1), 1-13, doi:10.1029/2006GB002715, 2007.

Strack, M., Kellner, E. and Waddington, J. M.: Dynamics of biogenic gas bubbles in peat and their effects on peatland biogeochemistry, Global Biogeochem. Cycles, 19(1), 1-9, doi:10.1029/2004GB002330, 2005.

Stull, R. B.: An introduction to boundary layer meteorology, Kluwer Academic Publishers, Boston., 1988.

Sundqvist, E., Vestin, P., Crill, P. M., Persson, T. and Lindroth, A.: Short-term effects of thinning, clear-cutting and stump harvesting on methane exchange in a boreal forest, Biogeosciences, 11(21), 6095-6105, doi:10.5194/bg-11-6095-2014, 2014.

Swindles, G. T., Morris, P. J., Mullan, D. J., Payne, R. J., Roland, T. P., Amesbury, M. J., Lamentowicz, M., Turner, T. E., Gallego-Sala, A., Sim, T., Barr, I. D., Blaauw, M., Blundell, A., Chambers, F. M., Charman, D. J., Feurdean, A., Galloway, J. M., Gałka, M., Green, S. M., Kajukało, K., Karofeld, E., Korhola, A., Lamentowicz, Ł., Langdon, P., Marcisz, K., Mauquoy, D., Mazei, Y. A., McKeown, M. M., Mitchell, E. A. D., Novenko, E., Plunkett, G., Roe, H. M., Schoning, K., Sillasoo, Ü., Tsyganov, A. N., van der Linden, M., Väliranta, M. and Warner, B.: Widespread drying of European peatlands in recent centuries, Nat. Geosci., 12(11), 922-928, doi:10.1038/s41561-019-0462-z, 2019.

Takagi, K., Fukuzawa, K., Liang, N., Kayama, M., Nomura, M., Hojyo, H., Sugata, S., Shibata, H., Fukazawa, T., Takahashi, Y., Nakaji, T., Oguma, H., Mano, M., Akibayashi, Y., Murayama, T., Koike, T., Sasa, K. and Fujinuma, Y.: Change in $\mathrm{CO}_{2}$ balance under a series of forestry activities in a cool-temperate mixed forest with dense undergrowth, Glob. Chang. Biol., 15(5), 1275-1288, doi:10.1111/j.13652486.2008.01795.x, 2009.

Teh, Y. A., Silver, W. L., Sonnentag, O., Detto, M., Kelly, M. and Baldocchi, D. D.: Large Greenhouse Gas Emissions from a Temperate Peatland Pasture, Ecosystems, 14(2), 311-325, doi:10.1007/s10021-0119411-4, 2011.

Thorbjørn, A., Moldrup, P., Blendstrup, H., Komatsu, T. and Rolston, D. E.: A Gas Diffusivity Model Based on Air-, Solid-, and Water-Phase Resistance in Variably Saturated Soil, Vadose Zo. J., 7(4), 1276-1286, doi:10.2136/vzj2008.0023, 2008. 
Tokida, T., Miyazaki, T., Mizoguchi, M., Nagata, O., Takakai, F., Kagemoto, A. and Hatano, R.: Falling atmospheric pressure as a trigger for methane ebullition from peatland, Global Biogeochem. Cycles, 21(2), 1-8, doi:10.1029/2006GB002790, 2007.

Ueyama, M., Takeuchi, R., Takahashi, Y., Ide, R., Ataka, M., Kosugi, Y., Takahashi, K. and Saigusa, N.: Methane uptake in a temperate forest soil using continuous closed-chamber measurements, Agric. For. Meteorol., 213, 1-9, doi:10.1016/j.agrformet.2015.05.004, 2015.

Uri, V., Kukumägi, M., Aosaar, J., Varik, M., Becker, H., Morozov, G. and Karoles, K.: Ecosystems carbon budgets of differently aged downy birch stands growing on well-drained peatlands, For. Ecol. Manage., 399, 82-93, doi:10.1016/j.foreco.2017.05.023, 2017.

Vasander, H. and Laine, J.: Site type classification on drained peatlands, in Finland - Fenland: research and sustainable utilisation of mires and peat, edited by R. Korhonen, L. Korpela, and S. Sarkkola, pp. 146151, Finnish Peatland Society Maahenki, Helsinki., 2008.

Venterea, R. T.: Theoretical Comparison of Advanced Methods for Calculating Nitrous Oxide Fluxes using Non-steady State Chambers, Soil Sci. Soc. Am. J., 77(3), 709, doi:10.2136/sssaj2013.01.0010, 2013.

Vesala, T., Suni, T., Rannik, Ü., Keronen, P., Markkanen, T., Sevanto., S., Grönholm, T., Smolander, S., Kulmala, M., Ilvesniemi, H., Ojansuu, R., Uotila, A., Levula, J., Mäkelä, A., Pumpanen, J., Kolari, P., Kulmala, L., Altimir, N., Berninger, F., Nikinmaa, E. and Hari, P.: Effect of thinning on surface fluxes in a boreal forest, Global Biogeochem. Cycles, 19(2), 1-11, doi:10.1029/2004GB002316, 2005.

Vestin, P., Mölder, M., Kljun, N., Cai, Z., Hasan, A., Holst, J., Klemedtsson, L. and Lindroth, A.: Impacts of Clear-Cutting of a Boreal Forest on Carbon Dioxide, Methane and Nitrous Oxide Fluxes, Forests, 11(961), 1-28, doi:10.3390/f11090961, 2020.

Waddington, J. M., Morris, P. J., Kettridge, N., Granath, G., Thompson, D. K. and Moore, P. A.: Hydrological feedbacks in northern peatlands, Ecohydrology, 8(1), 113-127, doi:10.1002/eco.1493, 2015.

Wallor, E., Rosskopf, N. and Zeitz, J.: Hydraulic properties of drained and cultivated fen soils part I - Horizonbased evaluation of van Genuchten parameters considering the state of moorsh-forming process, Geoderma, 313(October 2017), 69-81, doi:10.1016/j.geoderma.2017.10.026, 2018.

Wang, Z. P., DeLaune, R. D., Masscheleyn, P. H. and Patrick, William H., J.: Soil Redox and pH Effects on Methane Production in a Flooded Rice Soil, Soil Sci. Soc. Am., 57(2), 382-385, doi:10.2136/sssaj1993.03615995005700020016x, 1993.

Webb, E. K., Pearman, G. I. and Leuning, R.: Correction of flux measurements for density effects due to heat and water vapour transfer, Q. J. Roy. Meteorol. Soc., 106(447), 85-100, doi:http://dx.doi.org/10.1002/qj.49710644707, 1980.

Van Der Weerden, T. J., Kelliher, F. M. and De Klein, C. A. M.: Influence of pore size distribution and soil water content on nitrous oxide emissions, Soil Res., 50(2), 125-135, doi:10.1071/SR11112, 2012.

Whalen, S. C.: Natural Wetlands and the Atmosphere, Environ. Eng. Sci., 22(1), 73-94, doi:10.1089/ees.2005.22.73, 2005.

Whiting, G. J. and Chanton, J. P.: Greenhouse carbon balance of wetlands: Methane emission versus carbon sequestration, Tellus, Ser. B Chem. Phys. Meteorol., 53(5), 521-528, doi:10.3402/tellusb.v53i5.16628, 2001.

Wienhold, F. G., Welling, M. and Harris, G. W.: Micrometeorological Measurement And Source Region Analysis of Nitrous Oxide Fluxes from An Agricultural Soil, Atmos. Environ., 29(17), 2219-2227, doi:10.1016/1352-2310(95)00165-u, 1995.

Wilkinson, M., Crow, P., Eaton, E. L. and Morison, J. I. L.: Effects of management thinning on CO2 exchange by a plantation oak woodland in south-eastern England, Biogeosciences, 13(8), 2367-2378, doi:10.5194/bg-13-2367-2016, 2016.

Williams, C., Vanderhoof, M., Khomik, M. and Ghimire, B.: Post-clearcut dynamics of carbon, water and energy exchanges in a midlatitude temperate, deciduous broadleaf forest environment, Glob. Chang. Biol., 20(3), 992-1007, doi:10.1111/gcb.12388, 2013.

Wong, S. C., Cowan, I. R. and Farquhar, G. D.: Stomatal conductance correlates with photosynthetic capacity, Nature, 282, 424-426, 1979.

Wu, J., Roulet, N. T., Moore, T. R., Lafleur, P. and Humphreys, E.: Dealing with microtopography of an ombrotrophic bog for simulating ecosystem-level CO2 exchanges, Ecol. Modell., 222(4), 1038-1047, doi:10.1016/j.ecolmodel.2010.07.015, 2011. 
Wutzler, T., Lucas-Moffat, A., Migliavacca, M., Knauer, J., Sickel, K., Šigut, L., Menzer, O. and Reichstein, M.: Basic and extensible post-processing of eddy covariance flux data with REddyProc, Biogeosciences, 15(16), 5015-5030, doi:10.5194/bg-15-5015-2018, 2018.

Xu, J., Morris, P. J., Liu, J. and Holden, J.: PEATMAP: Refining estimates of global peatland distribution based on a meta-analysis, Catena, 160(April 2017), 134-140, doi:10.1016/j.catena.2017.09.010, 2018.

Xu, L., Furtaw, M. D., Madsen, R. A., Garcia, R. L., Anderson, D. J. and McDermitt, D. K.: On maintaining pressure equilibrium between a soil CO2 flux chamber and the ambient air, J. Geophys. Res. Atmos., 111(8), 1-14, doi:10.1029/2005JD006435, 2006.

Yang, B., Hanson, P. J., Riggs, J. S., Pallardy, S. G., Heuer, M., Hosman, K. P., Meyers, T. P., Wullschleger, S. D. and $\mathrm{Gu}, \mathrm{L}$. H.: Biases of $\mathrm{CO} 2$ storage in eddy flux measurements in a forest pertinent to vertical configurations of a profile system and CO2 density averaging, J. Geophys. Res. Atmos., 112(20), 1-15, doi:10.1029/2006JD008243, 2007.

Yu, Z., Slater, L., Schäfer, K. V. R., Reeve, A. S. and Varner, R. K.: Dynamics of methane ebullition from a peat monolith revealed from a dynamic flux chamber system, J. Geophys. Res. Biogeosciences, 119, 1789-1806, doi:10.1002/2014JG002654, 2014.

Zanello, F., Teatini, P., Putti, M. and Gambolati, G.: Long term peatland subsidence: Experimental study and modeling scenarios in the Venice coastland, J. Geophys. Res. Earth Surf., 116(4), 1-14, doi:10.1029/2011JF002010, 2011.

Zerva, A. and Mencuccini, M.: Short-term effects of clearfelling on soil $\mathrm{CO}_{2}, \mathrm{CH}_{4}$, and $\mathrm{N}_{2} \mathrm{O}$ fluxes in a Sitka spruce plantation, Soil Biol. Biochem., 37(11), 2025-2036, doi:10.1016/j.soilbio.2005.03.004, 2005.

Zhao, P., Hammerle, A., Zeeman, M. and Wohlfahrt, G.: On the calculation of daytime $\mathrm{CO} 2$ fluxes measured by automated closed transparent chambers, Agric. For. Meteorol., 263(January), 267-275, doi:10.1016/j.agrformet.2018.08.022, 2018.

Zhao, X. and Huang, Y.: A comparison of three gap filling techniques for eddy covariance net carbon fluxes in short vegetation ecosystems, Adv. Meteorol., 2015, doi:10.1155/2015/260580, 2015. 




\title{
Methane exchange at the peatland forest floor - automatic chamber system exposes the dynamics of small fluxes
}

\author{
Mika Korkiakoski ${ }^{1}$, Juha-Pekka Tuovinen ${ }^{1}$, Mika Aurela ${ }^{1}$, Markku Koskinen $^{2}$, Kari Minkkinen ${ }^{2}$, Paavo Ojanen ${ }^{3}$, \\ Timo Penttilä ${ }^{3}$, Juuso Rainne ${ }^{1}$, Tuomas Laurila ${ }^{1}$, and Annalea Lohila ${ }^{1}$ \\ ${ }^{1}$ Finnish Meteorological Institute, Atmospheric Composition Research, P.O. Box 503, 00101 Helsinki, Finland \\ ${ }^{2}$ University of Helsinki, Department of Forest Sciences, P.O. Box 27, 00014 University of Helsinki, Finland \\ ${ }^{3}$ Natural Resources Institute Finland, Viikinkaari 4, 00790 Helsinki, Finland
}

Correspondence to: Mika Korkiakoski (mika.korkiakoski@fmi.fi)

Received: 2 June 2016 - Discussion started: 26 July 2016

Revised: 18 January 2017 - Accepted: 13 March 2017 - Published: 10 April 2017

\begin{abstract}
We measured methane $\left(\mathrm{CH}_{4}\right)$ exchange rates with automatic chambers at the forest floor of a nutrient-rich drained peatland in 2011-2013. The fen, located in southern Finland, was drained for forestry in 1969 and the tree stand is now a mixture of Scots pine, Norway spruce, and pubescent birch. Our measurement system consisted of six transparent chambers and stainless steel frames, positioned on a number of different field and moss layer compositions. Gas concentrations were measured with an online cavity ring-down spectroscopy gas analyzer. Fluxes were calculated with both linear and exponential regression. The use of linear regression resulted in systematically smaller $\mathrm{CH}_{4}$ fluxes by $10-45 \%$ as compared to exponential regression. However, the use of exponential regression with small fluxes $\left(<2.5 \mu \mathrm{g} \mathrm{CH}_{4} \mathrm{~m}^{-2} \mathrm{~h}^{-1}\right)$ typically resulted in anomalously large absolute fluxes and high hour-to-hour deviations. Therefore, we recommend that fluxes are initially calculated with linear regression to determine the threshold for "low" fluxes and that higher fluxes are then recalculated using exponential regression. The exponential flux was clearly affected by the length of the fitting period when this period was $<190 \mathrm{~s}$, but stabilized with longer periods. Thus, we also recommend the use of a fitting period of several minutes to stabilize the results and decrease the flux detection limit. There were clear seasonal dynamics in the $\mathrm{CH}_{4}$ flux: the forest floor acted as a $\mathrm{CH}_{4}$ sink particularly from early summer until the end of the year, while in late winter the flux was very small and fluctuated around zero. However, the magnitude of fluxes was relatively small throughout the year, ranging mainly from -130 to $+100 \mu \mathrm{g} \mathrm{CH}_{4} \mathrm{~m}^{-2} \mathrm{~h}^{-1}$. $\mathrm{CH}_{4}$ emission
\end{abstract}

peaks were observed occasionally, mostly in summer during heavy rainfall events. Diurnal variation, showing a lower $\mathrm{CH}_{4}$ uptake rate during the daytime, was observed in all of the chambers, mainly in the summer and late spring, particularly in dry conditions. It was attributed more to changes in wind speed than air or soil temperature, which suggest that physical rather than biological phenomena are responsible for the observed variation. The annual net $\mathrm{CH}_{4}$ exchange varied from $-104 \pm 30$ to $-505 \pm 39 \mathrm{mg} \mathrm{CH}_{4} \mathrm{~m}^{-2} \mathrm{yr}^{-1}$ among the six chambers, with an average of $-219 \mathrm{mg} \mathrm{CH}_{4} \mathrm{~m}^{-2} \mathrm{yr}^{-1}$ over the 2-year measurement period.

\section{Introduction}

Methane $\left(\mathrm{CH}_{4}\right)$ is one of the most important atmospheric greenhouse gases due to its capability to absorb thermal radiation and warm the climate (IPCC, 2014). One of the main sources of $\mathrm{CH}_{4}$ globally is peatland (e.g., Denman et al., 2007), where $\mathrm{CH}_{4}$ is produced by the decomposition of organic matter in anaerobic conditions. Around $3 \%$ (ca. $4000000 \mathrm{~km}^{2}$ ) of the Earth's land surface is covered by peatlands (Clarke and Rieley, 2010) and the majority of these are located in the boreal region (Fischlin et al., 2007). About one third $\left(104000 \mathrm{~km}^{2}\right)$ of European mire and peat resources are located in Finland (Montanarella et al., 2006) and more than half $\left(55000 \mathrm{~km}^{2}\right)$ of this area has been drained for forestry (Päivänen and Hånell, 2012).

Methane can be both produced and consumed in soil so that the net $\mathrm{CH}_{4}$ flux depends on the rate of $\mathrm{CH}_{4}$ produc- 
tion in anoxic soil layers and on the rate of $\mathrm{CH}_{4}$ oxidation in the oxic soil layers. In peatlands, the thickness and depth of $\mathrm{CH}_{4}$ producing and oxidizing layers are largely determined by the water table (Bubier and Moore, 1994), which controls the vertical distribution of oxygen in the soil profile. $\mathrm{CH}_{4}$ is produced under anaerobic conditions by microbes known as methanogens. The production rate is dependent on the availability of organic substrates at low redox potential (Eh) values and is controlled by soil temperature and $\mathrm{pH}$ (Dunfield et al., 1993; Wang et al., 1993; Segers, 1998; Kotsyurbenko et al., 2004). In contrast, oxidation of $\mathrm{CH}_{4}$ occurs in the oxic soil layer closer to the surface and potentially also in the moss layer (Larmola et al., 2010). Like the production rate, the oxidation rate is controlled by soil temperature and $\mathrm{pH}$ (Dunfield et al., 1993; Scheutz and Kjeldsen, 2004; Boeckx and Van Cleemput, 1996), but many other factors also affect oxidation processes, such as soil water content, soil texture, nutrients, and $\mathrm{CH}_{4}$ and oxygen concentration (Boeckx and Van Cleemput, 1996; Ridgwell et al., 1999; Scheutz and Kjeldsen, 2004). In addition to the direct control of production and oxidation rates, there are other phenomena which may affect the observed net $\mathrm{CH}_{4}$ flux above the soil surface, including lateral $\mathrm{CH}_{4}$ transport in the soil (Christophersen and Kjeldsen, 2001) and subsurface storage (Hutchinson et al., 2000).

In environments with low soil $\mathrm{CH}_{4}$ production, such as upland forest soils, grasslands, and tundra, uptake of atmospheric $\mathrm{CH}_{4}$ by the methanotrophic microbes dominates (Dutaur and Verchot, 2007). This is also what commonly happens after the drainage of peatlands, which results in water level drawdown and increased oxic layer thickness. Thereby, $\mathrm{CH}_{4}$ production is decreased and the fraction of oxidized $\mathrm{CH}_{4}$ increased (e.g., Moore and Knowles, 1989; Roulet et al., 1992). Consequently, the $\mathrm{CH}_{4}$ oxidation rate in the aerated surface soil and mosses typically exceeds $\mathrm{CH}_{4}$ production that occurs deeper in the soil, thus turning in particular well-drained peatlands into net $\mathrm{CH}_{4}$ sinks (Martikainen et al., 1995; Minkkinen et al., 2007; Ojanen et al., 2010; Lohila et al., 2011). However, poorly drained sites may remain to act as $\mathrm{CH}_{4}$ sources (Ojanen et al., 2010). In addition, the drainage ditches even at well-drained sites typically continue to emit $\mathrm{CH}_{4}$ at rates similar to pristine boreal peatlands (Minkkinen et al., 1997; Minkkinen and Laine, 2006; Luan and $\mathrm{Wu}, 2015)$.

Closed chambers are commonly used in the measurement of greenhouse gas exchange between the forest floor and the atmosphere (e.g., Denmead, 2008; Forbrich et al., 2010; Koskinen et al., 2014). Unlike the eddy covariance (EC) method, which is more suitable for measuring fluxes at the ecosystem level, the chamber method permits the investigation of small-scale processes, such as the gas exchange of different microtopographic surfaces, and enables the quantification of spatial variation (Keller et al., 1990; Singh et al., 1997). However, there are various details related to the chamber design and the deployment of this measurement technique in practice that may have a significant impact on the flux that is estimated from the observed concentration change in the chamber headspace. For example, the flux estimate seems to depend on the dimensions of the chamber (Pihlatie et al., 2013). In addition, chambers should include a fan to evenly distribute the air in the chamber headspace (Pumpanen et al., 2004; Christiansen et al., 2011) although the rotational speed of the fan should be kept low to avoid excessive turbulence (Koskinen et al., 2014). A major source of uncertainty is the impact of the chamber itself on the gas concentration gradient in the soil (Healy et al., 1996; Hutchinson et al., 2000; Conen and Smith, 2000; Davidson et al., 2002; Livingston et al., 2005) and in the boundary layer just above it. The concentration gradient is critical as it drives the soilatmosphere gas exchange and thus any aerodynamic disturbance may impact the observed flux.

The gradient between the soil and the air inside the chamber changes when the gas concentration inside the chamber changes during the measurement. This changes the flux, which makes the concentration change nonlinear in time. However, nonlinearity of the concentration during the chamber closure may also result from chamber leaking. For example, Pirk et al. (2016) demonstrated that the degree of convex curvature in the increasing methane concentration correlated positively with wind speed (WS) outside the chamber. Furthermore, in the case of soil acting as a methane sink, the methane consumption by soil methanotrophs obeys the firstorder reaction kinetics, which should lead to curvilinear concentration dynamics in the chamber (e.g., Sabrekov et al., 2016). However, the different processes responsible for the curvature in the concentration time series may be difficult to separate from each other (Kutzbach et al., 2007).

There are many studies that have recognized that the use of linear regression in flux calculation can cause significant underestimation of the flux (e.g., Healy et al., 1996; Hutchinson et al., 2000; Nakano et al., 2004; Livingston et al., 2005, 2006; Kutzbach et al., 2007; Kroon et al., 2008; Pedersen et al., 2010; Pihlatie et al., 2013). However, many studies have used linear regression (e.g., Laine et al., 2006; Alm et al., 2007; Jones et al., 2011; Bergier et al., 2013; Fassbinder et al., 2013), because under field conditions it is more robust to random measurement errors than nonlinear methods. Moreover, the use of linear regression is preferred when comparing measurement sites as it is not as sensitive as nonlinear models to small differences in soil properties (Venterea et al., 2009). The selection of the optimal fitting method is important as it can be a large source of uncertainty in flux calculations (Levy et al., 2011; Venterea, 2013).

Although several studies have examined the different fitting methods for calculating fluxes from chamber data, there exist only a few papers exploring the dynamics of $\mathrm{CH}_{4}$ flux data that mainly consist of small uptake fluxes and are measured with automatic chambers coupled to a high-resolution gas analyzer (e.g., Savage et al., 2014; Ueyama et al., 2015). In this study, we measured the $\mathrm{CH}_{4}$ flux between a forest 
Table 1. CN ratio, bulk density, and ash content $( \pm \mathrm{SD})$ of the peat at Lettosuo $(n=4)$.

\begin{tabular}{lrrr}
\hline & CN ratio & Bulk density $\left(\mathrm{g} \mathrm{cm}^{-3}\right)$ & Ash content $(\%)$ \\
\hline Humus & $29.2 \pm 1.8$ & $0.005 \pm 0.003$ & $3.1 \pm 0.4$ \\
$0-10 \mathrm{~cm}$ & $23.9 \pm 1.0$ & $0.107 \pm 0.014$ & $6.5 \pm 1.5$ \\
$10-20 \mathrm{~cm}$ & $24.3 \pm 0.7$ & $0.170 \pm 0.011$ & $3.4 \pm 0.4$ \\
\hline
\end{tabular}

floor and the atmosphere continuously throughout 2 years at a boreal nutrient-rich forestry-drained peatland site with typically small $\mathrm{CH}_{4}$ exchange rates. We used six automatic soil chambers and a cavity ring-down spectroscopy analyzer, which allowed us to measure with a relatively high sampling rate during each chamber closure and to perform multiple daily measurements with each chamber. Our particular aims with this setup were to answer the following questions:

1. What is the optimal fitting method for calculating the $\mathrm{CH}_{4}$ flux?

2. How large are the diurnal, seasonal, and interannual variations in the $\mathrm{CH}_{4}$ flux?

3. What is the annual $\mathrm{CH}_{4}$ balance of the study site?

\section{Materials and methods}

\subsection{Site description}

The measurements were made in southern Finland at Lettosuo $\left(60^{\circ} 38^{\prime} \mathrm{N}, 23^{\circ} 57^{\prime} \mathrm{E}\right)$ (Fig. S1a in the Supplement), which is a nutrient-rich peatland forest that was drained in 1969 and fertilized with phosphorus and potassium soon after. The open ditches, located in approximately $45 \mathrm{~m}$ intervals (Fig. S1b), were originally about $1 \mathrm{~m}$ deep but have since been partly filled with new vegetation. Before drainage, the tree stand was dominated by Scots pine (Pinus sylvestris) with some pubescent birch (Betula pubescens). After drainage, the stand has developed to a mixture of Scots pine and pubescent birch in the dominant canopy layer, with an understorey of Norway spruce (Picea abies) with some scattered small-sized pubescent birch. The stem volumes at the time of this study equaled 174,46 , and $28 \mathrm{~m}^{3} \mathrm{ha}^{-1}$ for Scots pine, pubescent birch, and Norway spruce respectively. The tree stand is quite dense, which results in irregular shading and, consequently, patchy and variable ground vegetation layer. For example, herbs such as Dryopteris carthusiana and Trientalis europaea and dwarf shrubs such as Vaccinium myrtillus are common in the ground vegetation (Bhuiyan et al., 2017). In addition, the moss layer is patchy and is dominated by Pleurozium schreberi and Dicranum polysetum with some Sphagna (Sphagnum girgensohnii, Sphagnum angustifolium, and Sphagnum russowii) appearing in moist patches.
Table 2. Ground vegetation, all-sided maximum vascular green area $\left(\mathrm{VGA}_{\max }\right.$; vascular green surface, $\mathrm{m}^{2}$, divided by forest floor, $\mathrm{m}^{2}$ ) and coverage $(\%)$ of forest mosses $\left(C_{\mathrm{FM}}\right)$ and Sphagnum mosses $\left(C_{\mathrm{SP}}\right)$.

\begin{tabular}{|c|c|c|c|c|}
\hline Chamber & Vegetation & $\mathrm{VGA}_{\max }$ & $C_{\mathrm{FM}}$ & $C_{\mathrm{SP}}$ \\
\hline 1 & $\begin{array}{l}\text { Pleurozium schreberi } \\
\text { Dicranum polysetum } \\
\text { Vaccinium myrtillus }\end{array}$ & 2.04 & 56 & 0 \\
\hline 2 & $\begin{array}{l}\text { Pleurozium schreberi } \\
\text { Dicranum polysetum } \\
\text { Vaccinium vitis-idaea }\end{array}$ & 0.85 & 60 & 0 \\
\hline 3 & $\begin{array}{l}\text { Maianthemum bifolium } \\
\text { Pleurozium schreberi } \\
\text { Dicranum polysetum }\end{array}$ & 0.01 & 3 & 0 \\
\hline 4 & $\begin{array}{l}\text { Dryopteris carthusiana } \\
\text { Vaccinium myrtillus } \\
\text { Vaccinium vitis-idaea } \\
\text { Pleurozium schreberi } \\
\text { Dicranum polysetum }\end{array}$ & 2.34 & 26 & 0 \\
\hline 5 & $\begin{array}{l}\text { Pleurozium schreberi } \\
\text { Dicranum polysetum }\end{array}$ & 0.11 & 30 & 0 \\
\hline 6 & Sphagnum girgensohnii & - & 0 & 90 \\
\hline
\end{tabular}

$\mathrm{CN}$ ratio of the surface peat, sampled at four points located at a $20-40 \mathrm{~m}$ distance from the chamber plots, averaged 24 for the $0-20 \mathrm{~cm}$ layer (Table 1 ). The relatively low $\mathrm{CN}$ ratio is typical for fertile peatland forests and reflects the fen history of the site. The bulk density of these samples was 0.11 and $0.17 \mathrm{~g} \mathrm{~cm}^{-3}$ for the $0-10$ and $10-20 \mathrm{~cm}$ layers, respectively, while the average bulk density of the $0-20 \mathrm{~cm}$ layer below each chamber varied from 0.03 to $0.13 \mathrm{~g} \mathrm{~cm}^{-3}$ (Koskinen et al., 2014). The ash content of the peat varied from 3.4 to $6.5 \%$.

The vascular green area (VGA) was estimated for each chamber and vascular plant species every 2 weeks during the growing seasons 2011 and 2012 (Ojanen, unpublished data). This was done by estimating the number and dimensions of leaves within each chamber and calculating green area by species-specific regression models between leaf dimensions and green area. For Vaccinium myrtillus, the surface area of the green stems was also included into VGA. The coverage of the mosses was estimated visually. The maximum VGA and the coverages for each chamber are shown in Table 2.

\subsection{Flux measurement system and ancillary measurements}

The automatic chamber measurement system is the same as used for $\mathrm{CO}_{2}$ exchange by Koskinen et al. (2014). The $\mathrm{CO}_{2}$ flux measurements started in autumn 2010, and the $\mathrm{CH}_{4}$ analyzer was added to the system in March 2011. Here we report the $\mathrm{CH}_{4}$ fluxes measured from then until April 2013. Forest floor gas exchange, including the tree roots, was monitored using six transparent soil chambers connected to an instrument cabin. The cabin was located at a distance of about $30 \mathrm{~m}$ 
from the $25.5 \mathrm{~m}$ tall EC mast (Koskinen et al., 2014) from which the WS above the canopy was measured. The locations of the chambers were selected to maximize the number of different ground vegetation compositions (Table 2) within a circle of ca. $15 \mathrm{~m}$ radius around the cabin.

The details of the chamber system can be found in Koskinen et al. (2014), and thus here we only describe the main features of the system. The size of the chamber boxes were $57 \mathrm{~cm} \times 57 \mathrm{~cm} \times 30 \mathrm{~cm}$ (length $\times$ width $\times$ height $).$ We used a permanently installed steel collar (height $5 \mathrm{~cm}$, inserted at a depth of $2 \mathrm{~cm}$ ) below each chamber to minimize the disturbance to the soil and to enhance the sealing between the soil and the chamber. There was a U profile at the bottom of the chamber edges, insulated with a foam tape, to further improve the sealing. In winter, the whole chamber frame was raised above the snow level by placing one or two extension collars (height $16 \mathrm{~cm}$ ) between the frame and soil.

A 24 V fan (Maglev KDE2408PTV1, Sunon Ltd, Kaohsiung, Taiwan) (size $8 \mathrm{~cm} \times 8 \mathrm{~cm}$ ) was used to mix the air inside the chamber headspace. The voltage of the fan was regulated to keep the mixing steady, but as low as possible (Koskinen et al., 2014). Sample gas was drawn from the chamber typically once an hour (with some exceptions explained below) at a flow rate of about $1 \mathrm{~L} \mathrm{~min}^{-1}$ and returned back to the chamber from the gas analyzers. $\mathrm{CH}_{4}, \mathrm{CO}_{2}$, and water vapor concentrations were measured approximately every $4 \mathrm{~s}$ with a Picarro G1130 cavity ring-down spectroscopy gas analyzer (Picarro Inc., Santa Clara, CA, USA). The inlet and outlet gas tubes (Festo Oy, Vantaa, Finland) were made of polyurethane and were $15 \mathrm{~m}$ in length and had an inner and outer diameter of 4 and $6 \mathrm{~mm}$ respectively.

The tubes were flushed with ambient air just before the chamber was closed. When all the chambers were open, ambient air was sampled. The delay in the analyzer response caused by the long tubing was taken into account using a flagging system in the computer program collecting the data, which labeled each data point with the respective chamber number using a $20 \mathrm{~s}$ lag. However, as the flow rate varied slightly in time, some points were removed from the data before the flux calculation (Sect. 2.4).

Air and soil temperature data were collected every $10 \mathrm{~s}$ using Pt100 probes (PT4T, Nokeval Oy, Nokia, Finland) and Nokeval 680 loggers (Nokeval Oy, Nokia, Finland). One probe was located inside each chamber at a height of $30 \mathrm{~cm}$ and positioned next to the fan under a metal heat shield to prevent direct solar radiation from affecting the measurements. Furthermore, soil surface temperature was monitored inside each chamber just below the surface of the moss or litter layer. In addition, soil temperature probes were placed at depths of $2,5,10,20$, and $30 \mathrm{~cm}$ at one location near the chambers. Water table level (WTL) was monitored every hour at four different points at the site (TruTrack WTHR data loggers, Intech Instruments Ltd, Auckland, New Zealand). The air pressure, precipitation, and snow depth data were acquired from the nearby Finnish Meteorological
Institute observatory at Jokioinen $(\sim 35 \mathrm{~km}$ northwest of Lettosuo).

\subsection{Meteorological conditions}

The climate at the site has both continental and maritime influences. The annual mean temperature and precipitation at the nearby weather station in $1981-2010$ were $4.6^{\circ} \mathrm{C}$ and $627 \mathrm{~mm}$ respectively (Pirinen et al., 2012). During this study, the first measurement year (April 2011-March 2012) was significantly warmer (annual mean temperature $5.8^{\circ} \mathrm{C}$ ) than the second measurement year (April 2012-March 2013) $\left(1.4^{\circ} \mathrm{C}\right)$ (Fig. 1). The first year was slightly warmer and the second year was significantly colder than the long-term mean recorded at the nearby weather station $\left(4.6^{\circ} \mathrm{C}\right)$. Both the summer (JJA) $\left(17.6^{\circ} \mathrm{C}\right)$ and winter (DJF) $\left(2.7^{\circ} \mathrm{C}\right)$ temperatures in 2011 were warmer than those of 2012 (12.1 and $-2.3^{\circ} \mathrm{C}$ ). In particular, the beginning of summer 2012 was much colder than the same period in 2011.

Annual precipitation during the first $(976 \mathrm{~mm})$ and second $(780 \mathrm{~mm})$ measurement years was higher than the longterm mean $(627 \mathrm{~mm})$. Summertime precipitation was $9 \%$ higher in the first $(309 \mathrm{~mm})$ year as compared to the second (284 mm) year, while in winter the difference was $18 \%$ (577 and $490 \mathrm{~mm}$ in the first and second winters respectively). The first snow appeared on 5 December in 2011 and 25 October in 2012, and the first permanent snow was recorded on 7 January in 2012 and 28 November in 2012. In spring (MAM) 2011, the snow had melted by 13 April. For spring 2012, we do not know the exact day of snowmelt due to missing data, although the snow had melted at latest by 4 April. From the temperature data we estimate that the snow cover disappeared sometime in mid-March.

WTL varied from -8 to $-59 \mathrm{~cm}$ from the soil surface (negative sign denotes WTL below the surface) and was highest in the spring and late autumn (SON). The lowest (i.e., deepest) values were recorded at the end of summer. The average WTL in summer 2011 was $-47.2 \pm 7.4 \mathrm{~cm}( \pm \mathrm{SD})$ and $-49.1 \pm 7.1$ in summer 2012. Occasional sudden increases in WTL were observed after rainfall events and it usually took 1-2 weeks to reach the WTL observed prior to the event.

\subsection{Flux calculation}

During the study period, the chambers were operated with varying closure times ranging from 2 to $16 \mathrm{~min}$. In 2011, 2 min closures were used with the exception of 6 min measurements made four times per day. After mid-March 2012, the minimum closure time was 6 min. Thus, each chamber was typically sampled once an hour, with the exception of summer 2012 (JJA) when a longer closure time of $16 \mathrm{~min}$ was tested and each chamber was sampled every $2 \mathrm{~h}$. For the analysis of $\mathrm{CH}_{4}$ exchange dynamics (Sect. 3.3-3.4), we used the fluxes calculated with a 6 min closure time (as justified in Sect. 3.2). In addition to removing $20 \mathrm{~s}$ from the start of the 

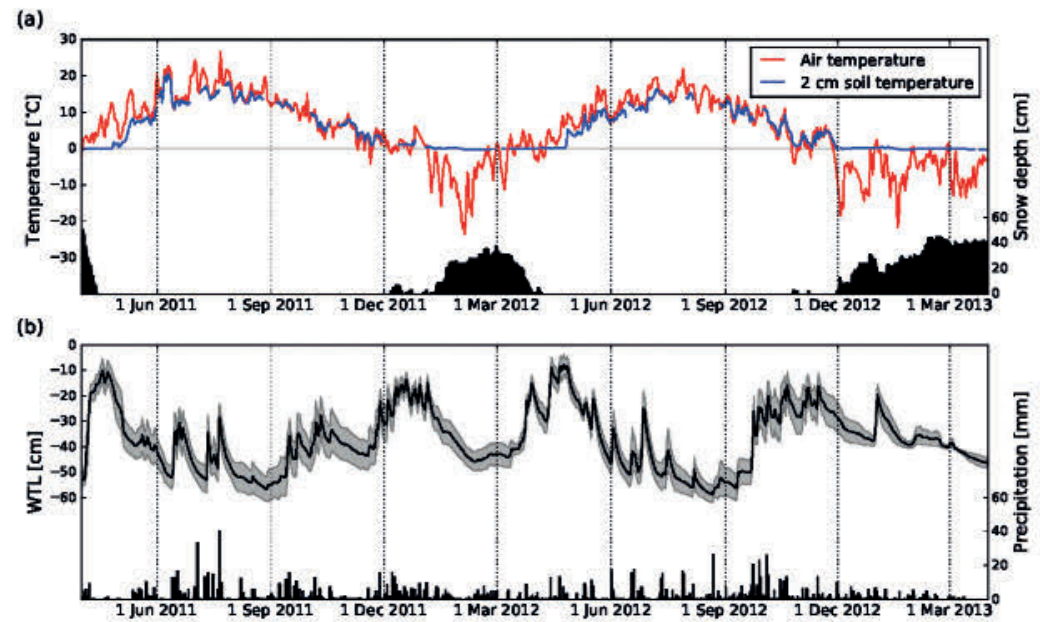

Figure 1. (a) The daily mean of air temperature (red) and soil temperature at $2 \mathrm{~cm}$ depth (blue) at Lettosuo during the measurement period (1 April 2011 to 31 March 2013) and the daily snow depth (bars) measured at the nearby Jokioinen observatory. (b) The daily mean water table (WTL) (line) and its standard deviation (shading) from four different points at Lettosuo and the daily precipitation (bars) measured at Jokioinen.

measurement due to lag caused by long tubing (Sect. 2.2), $18 \mathrm{~s}$ was discarded from the start of a measurement to ensure that the air inside the chamber was properly mixed. Dilution and spectral corrected $\mathrm{CH}_{4}$ concentrations reported by Picarro G1130 were used to calculate the fluxes.

Two different regression types were fitted to the data: linear and exponential. The linear function describing the change in the concentration, $C$, as a function of time was

$C(t)=a_{\operatorname{lin}}+b_{\operatorname{lin}} t$,

where $a_{\mathrm{lin}}$ and $b_{\mathrm{lin}}$ are parameters and $t$ is the time from the start of the closure. In this model, the slope $b_{\text {lin }}$ equals the concentration change in time.

The exponential function we fitted was

$C(t)=a_{\mathrm{exp}}+b_{\exp } \exp \left(c_{\exp } t\right)$

where $a_{\exp }, b_{\exp }$, and $c_{\text {exp }}$ are parameters. When differentiating Eq. (2) with respect to time and inspecting the moment when the chamber closes $(t=0)$, it follows that the concentration change with time is the product of parameters $b_{\exp }$ and $c_{\text {exp. }}$. It is generally considered that this initial rate of concentration change best represents the flux at that time. However, when fitting the exponential function to the data using the least-squares approach, the fitting frequently fails due to local minima. To overcome this and to avoid overparameterization, a Taylor power series expansion (Kutzbach et al., 2007) was fitted to the data to determine initial estimates of the parameters of the exponential regression.

The exponential regression should capture the flux better than the linear regression as it takes into account the change in the gradient between soil and chamber headspace during chamber closure, which is evident when diffusion flux is decreasing the concentration difference. However, exponential regression is very sensitive to possible disturbances to the data at the beginning of chamber closure. In our study, we attempted to minimize these disturbances by closing the chamber slowly and smoothly, which seemed to prevent pressure fluctuations related to chamber closing. For the analysis of $\mathrm{CH}_{4}$ exchange dynamics (Sect. 3.3-3.4), we used flux data that are based on a combination of linear and exponential fits: first all fluxes were calculated using the linear regression, and below and above a limit of $2.5 \mu \mathrm{g} \mathrm{CH}_{4} \mathrm{~m}^{-2} \mathrm{~h}^{-1}$ the fluxes were calculated with the linear and exponential method respectively (for justification see Sect. 3.1).

The $\mathrm{CH}_{4}$ flux $\left(F, \mu \mathrm{g} \mathrm{CH}_{4} \mathrm{~m}^{-2} \mathrm{~h}^{-1}\right)$ was calculated according to Eq. (3), which is based on the ideal gas law:

$F=\left(\frac{\mathrm{d} C(t)}{\mathrm{d} t}\right)_{t=0} \frac{M P V}{R T A} 3600 \frac{\mathrm{s}}{h}$,

where $\left(\frac{\mathrm{d} C(t)}{\mathrm{d} t}\right)_{t=0}$ is the time derivative $\left(\mathrm{ppm} \mathrm{s}^{-1}\right)$ of a linear $\left(b_{\text {lin }}\right)$ or exponential $\left(b_{\exp } \times c_{\text {exp }}\right)$ regression at the beginning of the closure, $M$ is the molecular mass of $\mathrm{CH}_{4}$ $\left(16.042 \mathrm{~g} \mathrm{~mol}^{-1}\right), P$ is air pressure $(\mathrm{Pa}), R$ is the universal gas constant $\left(8.31446 \mathrm{~J} \mathrm{~mol}^{-1} \mathrm{~K}^{-1}\right), T$ is the mean chamber headspace temperature during closure $(\mathrm{K})$, and $V$ and $A$ are the volume $\left(\mathrm{m}^{3}\right)$ and the base area $\left(\mathrm{m}^{2}\right)$ of the chamber headspace respectively. Here, a micrometeorological sign convention is used: a positive flux indicates a flux from the ecosystem to the atmosphere (emission) and a negative flux indicates a flux from the atmosphere into the ecosystem (uptake). 
When estimating the volume of the chamber headspace, the height of the moss and snow surfaces was assumed to represent the interface between the soil and air. In other words, the pore space in the soil and snow was ignored from the headspace volume. The error caused by this in flux calculations was estimated to be only a few percent (Koskinen et al., 2014). To create a continuous data set of snow depth, the manual measurements carried out irregularly at the site were combined with those measured daily at the Jokioinen observatory. In addition to snow depth, the height of the chamber headspace was measured at the start and end of the growing season from 16 points inside each collar by gently placing the end of a tape measure on top of the surface mosses (Koskinen et al., 2014). The height of the chamber headspace between these manual measurements was determined with linear interpolation.

All the calculations and analyses were made with the Python programming language (Python Software Foundation, version 2.7, https://www.python.org) using the following libraries: NumPy (http://www.numpy.org/), SciPy (http://www.scipy.org/), Pandas (http://pandas.pydata.org/), and matplotlib (http://www.matplotlib.org). All the Python scripts were developed specifically for this study. For the fits, the least-squares method was used through the "polyfit" function of NumPy library for the linear regression and the "curve_fit" function of SciPy library for the nonlinear fits.

\subsection{Filtering of the flux data}

After the fluxes were calculated, several filters were applied to remove cases where the measurement system did not work adequately. The most common reason for discarding data was due to the problems with the chamber operation, for example, for the improper functioning of a linear actuator, which caused the chambers to remain stuck either open or closed. These cases were detected by monitoring the simultaneously measured $\mathrm{CO}_{2}$ concentration data during the closure. The goodness of fit was checked by calculating the normalized root mean square error (NRMSE) (e.g., Christiansen et al., 2011; Pihlatie et al., 2013) for each fit:

$\mathrm{NRMSE}=\frac{\sqrt{\frac{1}{n} \sum_{i=1}^{n}\left(C_{\mathrm{fit}, i}-C_{i}\right)^{2}}}{C_{\max }-C_{\min }}$,

where $n$ is the number of measurement points, $C_{\text {fit }, i}$ is the $\mathrm{CO}_{2}$ concentration calculated from the fit, $C_{i}$ is the measured $\mathrm{CO}_{2}$ concentration, and $C_{\max }$ and $C_{\min }$ are the highest and lowest concentrations measured during closure. If the NRMSE was larger than 0.05 , the $\mathrm{CH}_{4}$ data from that closure were discarded. It should be noted that the application of this criterion removes closures with no change in $\mathrm{CO}_{2}$ concentration, which may result when photosynthesis rate equals respiration rate. Here we found $<20$ of such cases, meaning that this criterion could be applied without removing a significant amount of potentially suitable data. (a)

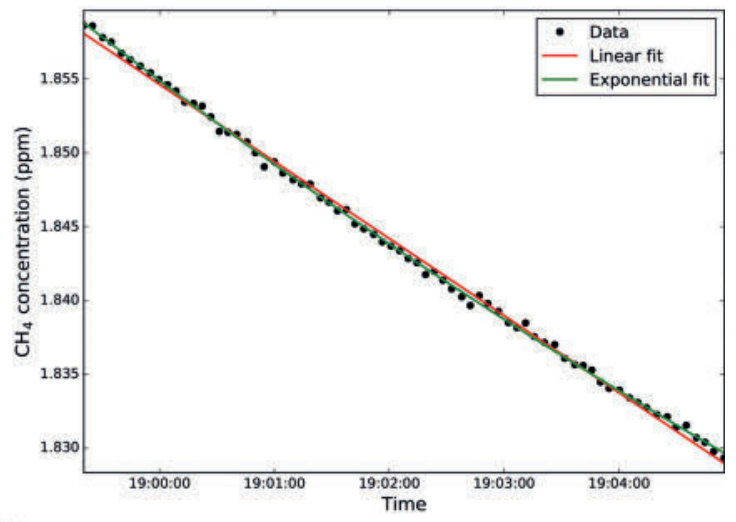

(b)

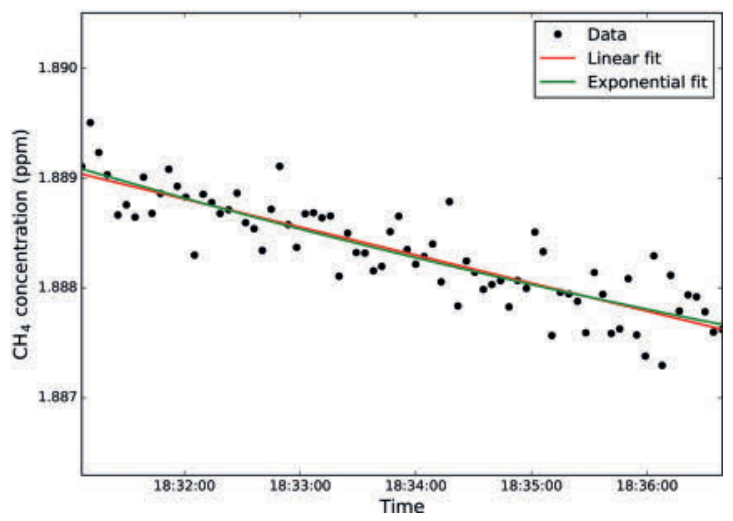

Figure 2. Concentration data during one chamber closure for a case with a higher (a linear and exponential: -90 and $104 \mu \mathrm{g} \mathrm{CH}_{4} \mathrm{~m}^{-2} \mathrm{~h}^{-1}$ respectively) and lower (b lin -3.5 , exp $-4.3 \mu \mathrm{g} \mathrm{CH}_{4} \mathrm{~m}^{-2} \mathrm{~h}^{-1}$ ) flux.

In addition to NRMSE filtering, the running mean of $\mathrm{CH}_{4}$ flux $\left(F_{\mathrm{CH}_{4}}\right)$ with a time window of 14 days (shifting one day at a time) and the corresponding standard deviation $(\sigma)$ were calculated to remove random spiking in the data. The data points that failed to fall within $F_{\mathrm{CH}_{4}} \pm 10 \sigma$ were removed iteratively. In total, 71229 closures were recorded from which $14 \%(n=9987)$ were discarded due to large NRMSE values (problems with the chambers) and $<0.001 \%(n=40)$ were removed with the $\sigma$ filter as outliers.

\subsection{Detection limit}

The minimum detectable flux (MDF) was estimated by using the metric originally developed by Christiansen et al. (2015), which was modified by Nickerson (2016) to make it more suitable for high-frequency measurements: 


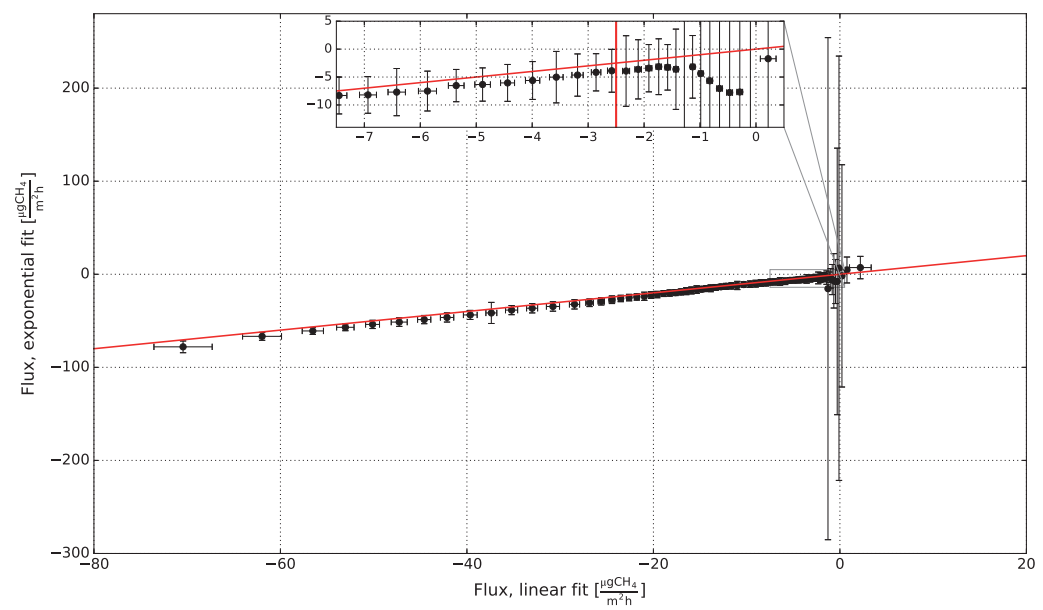

Figure 3. Bin averages $(n=500)$ of the linear and exponential fluxes of the whole data set ( 6 min closures only). In the small zoomed figure the red vertical line denotes the selected flux limit of $2.5 \mu \mathrm{g} \mathrm{CH}_{4} \mathrm{~m}^{-2} \mathrm{~h}^{-1}$. Vertical and horizontal error bars show the standard deviation of flux determined with the exponential and linear fit respectively.

$\mathrm{MDF}=\left(\frac{P_{\mathrm{I}}}{t_{\mathrm{c}} \sqrt{\frac{t_{\mathrm{c}}}{p_{\mathrm{s}}}}}\right)\left(\frac{V P}{A R T}\right) M$,

where $P_{\mathrm{I}}$ is the analytical precision of the instrument (ppm), $t_{\mathrm{c}}$ is the closure time of the chamber (h), and $p_{\mathrm{s}}$ is the sampling periodicity (h). The $P_{\mathrm{I}}$ for the Picarro G1130 analyzer, tested and reported by the manufacturer for the specific instrument used in this study, was $0.256 \mathrm{ppb}$ and $p_{\mathrm{s}}$ was $5 \mathrm{~s}$. On a typical summer day $\left(T=20^{\circ} \mathrm{C}\right)$, the MDF of the system was about $0.06 \mu \mathrm{g} \mathrm{CH}_{4} \mathrm{~m}^{-2} \mathrm{~h}^{-1}$. However, during winter the MDF was higher due to lower temperatures and the use of the extension collars, which together about double the headspace volume (without snow) and therefore also the MDF.

\subsection{The annual balance and its uncertainty}

The annual balance of $\mathrm{CH}_{4}$ was estimated for each chamber by first calculating the daily flux sums from the hourly fluxes and then summing these over a year. The gaps in the data were filled by using linear interpolation between the existing hourly and daily fluxes. As most of the fluxes in 2011 and in the first quarter of 2012 were measured with a 2 min closure time, which was considered too short for the exponential regression (Sect. 3.2), we corrected the fluxes calculated with linear regression from the $2 \mathrm{~min}$ closures to correspond to those measured using a 6 min closure available four times a day during this period as a reference. This correction was implemented by calculating the daily median ratios between the fluxes from 6 and 2 min closure times, which were smoothed by a running median with a moving window of 14 days. Fi- nally, the 2 min data from 2011 to March 2012 were multiplied by this ratio (Fig. S2).

The uncertainty of the $\mathrm{CH}_{4}$ balance estimate derived from the measurements was evaluated by identifying three key error sources: (1) the random error of regression, (2) the error caused by gap filling, and (3) the error caused by the correction of the fluxes measured using the 2 min closure time during the first measurement year. First, because the annual balance of each chamber was calculated from the mean daily fluxes, we estimated the daily random error as the squared sum of the uncertainties of the hourly flux data of each day. Assuming that the goodness of fit reflects all the uncertainties related to a single flux measurement, the standard deviation of the slope estimate obtained $\left(\left(\frac{\mathrm{d} C(t)}{\mathrm{d} t}\right)_{t=0}\right.$; Eq. 3) provides a measure of this uncertainty.

Next, the error caused by the gap-filling procedure was estimated by removing 1 month of flux data from different parts of the whole data set and inspecting how this affected the annual balance of the different chambers. The average value of the effect of these monthly gaps was calculated and downscaled to represent the effect of one missing day. Multiplying this value by the number of missing days during the year gives an estimate of the gap-filling error. It must be noted that the length of the removed period was similar to the longest gap observed in our data.

Last, the error estimate related to the ratio used to transform the fluxes calculated from $2 \mathrm{~min}$ closure to represent the 6 min closure was estimated from the median absolute deviation assuming normally distributed medians. Finally, these three error estimates were added together by using the standard accumulation principle of independent errors. 
(a)

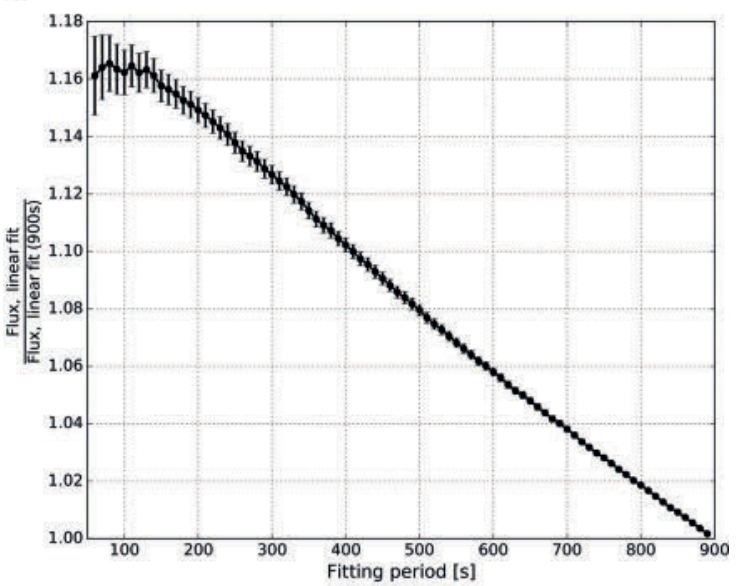

(b)

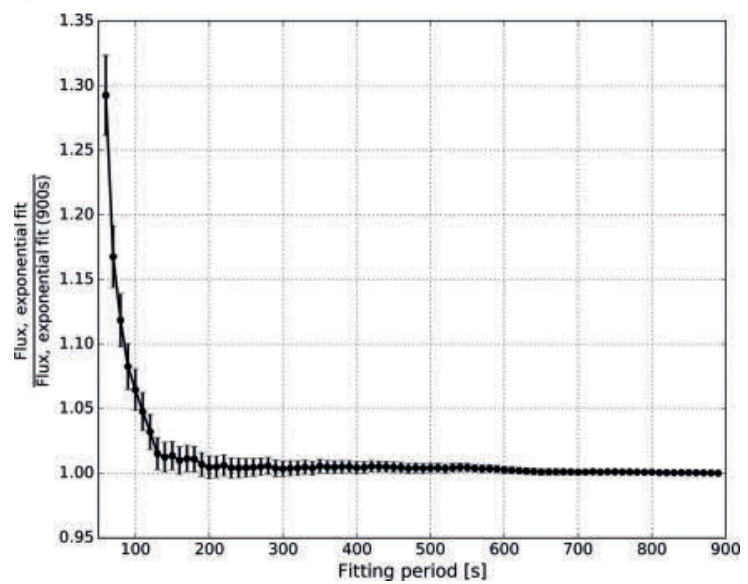

Figure 4. The linear (a) and the exponential flux (b) as a function of fitting period. The fluxes are scaled by the flux calculated with the longest fitting period $(900 \mathrm{~s})$. The error bars show the $95 \%$ confidence intervals. The data are from summer 2012.

As our measurements started in April 2011 and ended in March 2013, after exactly 2 years, from now on in this paper the expressions "first year" and "second year" denote the time periods of April 2011-March 2012 and April 2012March 2013 respectively.

\section{Results}

\subsection{Flux calculation method}

Examples of typical concentration development inside a chamber during one measurement are shown in Fig. 2, for both "high flux" case in summer (Fig. 2a) and a "low flux" case in winter (Fig. 2b). In summer and autumn, when the

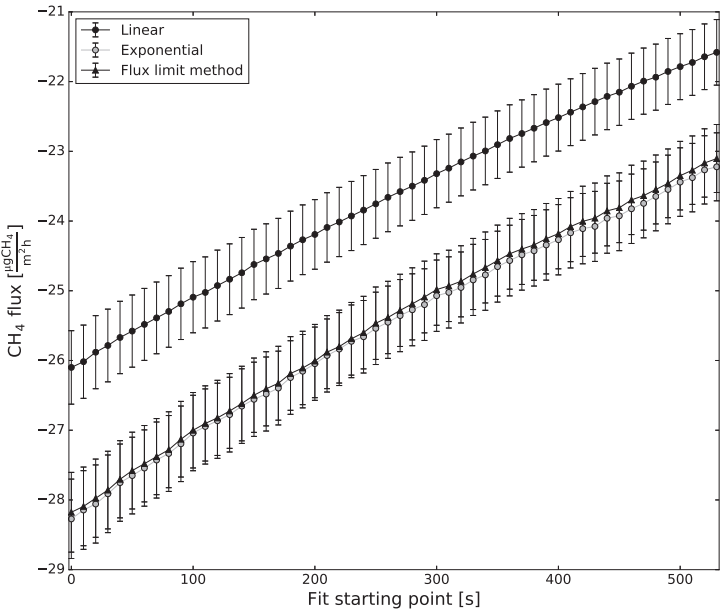

Figure 5. Fluxes calculated with the linear, exponential, and "flux limit" methods using a 6 min fitting period with different starting points for the fits. The error bars show the $95 \%$ confidence intervals. The data are from summer 2012.

fluxes were the highest, the concentration development inside a chamber usually was not adequately approximated by a linear function and thus the slope calculated with the linear regression (Eq. 1) did not properly represent the initial "undisturbed" slope from which the flux should be calculated. As a result, linear regression resulted in lower flux estimates for these cases than exponential regression (Eq. 2). However, during the periods when the flux approached the detection limit and the concentration data became noisier, the use of exponential regression resulted in noisier flux data. Often, exponential regression created a sharp slope at the beginning of the fit in the concentration time series that resulted in unphysically high fluxes. To be able to reliably estimate the $\mathrm{CH}_{4}$ exchange for the whole range of fluxes, we determined the flux limit below which the exponential regression resulted in unreliable flux estimates and the linear fit should be preferred. This limit was estimated by comparing bin $(n=500)$ averages of linear and exponential fluxes for the whole data set (using a 6 min closure time) (Fig. 3). When the linearly calculated fluxes fell below ca. $2.5 \mu \mathrm{g} \mathrm{CH} \mathrm{Cm}^{-2} \mathrm{~h}^{-1}$, the noise in the flux calculated using the exponential regression increased steeply and the shape of the relationship changed (Fig. 3). Therefore, we decided to first calculate the flux with the linear regression and to recalculate all the fluxes exceeding the limit of $2.5 \mu \mathrm{g} \mathrm{CH}_{4} \mathrm{~m}^{-2} \mathrm{~h}^{-1}$ with the exponential regression. Henceforth, all the data shown in this paper have been calculated in this way unless stated otherwise.

The whole 2-year data set showed that the $\mathrm{CH}_{4}$ fluxes calculated with linear regression (Eq. 1) were systematically and significantly lower than those calculated with exponential regression (Eq. 2) (Table 3). The seasonal average flux 

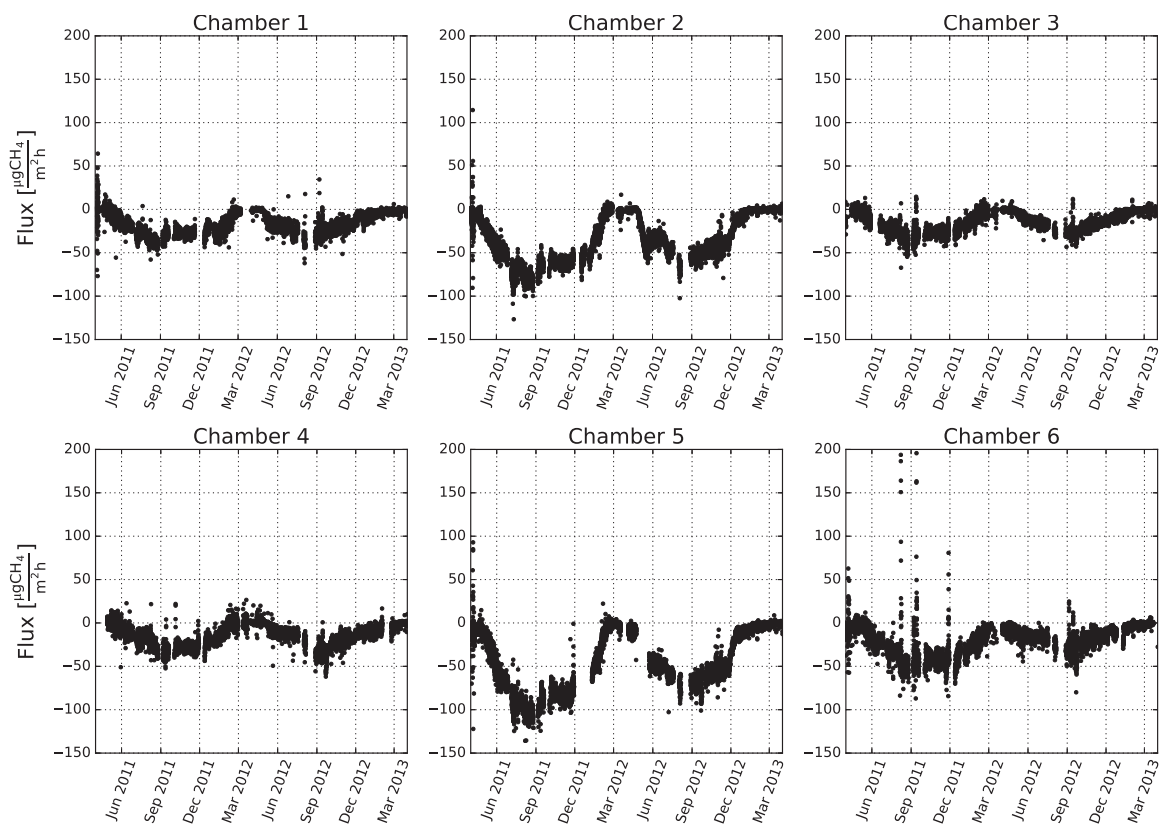

Figure 6. Hourly $\mathrm{CH}_{4}$ fluxes from April 2011 to March 2013 measured in each chamber. Negative values indicate uptake by the soil, and positive values indicate emission to the atmosphere. Fluxes have been calculated using the exponential fit unless the value of the flux obtained from the linear fit was below $2.5 \mu \mathrm{g} \mathrm{CH}_{4} \mathrm{~m}^{-2} \mathrm{~h}^{-1}$.

difference between the linear and exponential regressions varied within $10.9-44.4 \%$ (average over 2 year $27.5 \pm 0.3 \%$, $\pm 95 \%$ confidence interval). The mean relative difference was dependent on the time of the year: it was largest during the winter and spring (24.9-44.4\%) when the soil $\mathrm{CH}_{4}$ sink was at its lowest and smallest in summer and autumn (10.9$14.4 \%)$ when the sink was at its highest. When comparing individual measurements, the average relative difference between the linear and exponential regression was slightly smaller in 2012 compared to 2011. Also, the uncertainties associated with the fluxes were slightly larger in 2011 due probably to the fewer measurements available with 6 min closure time.

\subsection{Effect of closure time on fluxes}

The effect of the different fitting time windows was tested by both increasing the fitting period from the beginning of the closure with $10 \mathrm{~s}$ steps and by keeping the fitting window constant but moving its starting point. For these tests, we used the data from summer 2012, when the measurements were made with a $16 \mathrm{~min}$ closure time. The flux from the exponential fit was clearly affected by the length of the fit when the fitting period was $<190 \mathrm{~s}$ (Fig. 4b). After that, the mean difference was mostly statistically insignificant $(p>0.05)$, as compared to the flux calculated with the $900 \mathrm{~s}$ period. However, the estimated linear flux stayed about the same for the first $140 \mathrm{~s}$ resulting in $16.2 \pm 0.6 \%$ higher fluxes than obtained with the $900 \mathrm{~s}$ fitting window (Fig. 4a). However, further increase of the fitting period systematically decreased the estimated flux by about $1.3 \%$ per $60 \mathrm{~s}$. A decrease of $17.3 \pm 3.0 \%$ was also observed when the starting point of the fit was delayed by $530 \mathrm{~s}$, but the fitting period was kept constant at 6 min (Fig. 5).

Even though the results above might support the selection of a fitting period of $190 \mathrm{~s}$, a 6 min fitting period was applied in further analysis. This was selected based on three arguments: (1) it made the exponential regression results more stable; (2) we wanted to use the same fitting period in both linear and exponential regressions; and (3) a longer fitting period decreases the detection limit (Eq. 5). The last point was mainly related to winter measurements when the detection limit was increased by lower temperatures and the use of extension collars (increasing the effective volume before the collars were filled with snow). However, in 2011 and in the first quarter of 2012, a 2 min closure time was mostly used, which proved to be too short for accurate estimates with the exponential fit. As a result, the results from these shorter measurements were corrected to correspond to those obtained with the 6 min closure time (Sect. 2.7). 


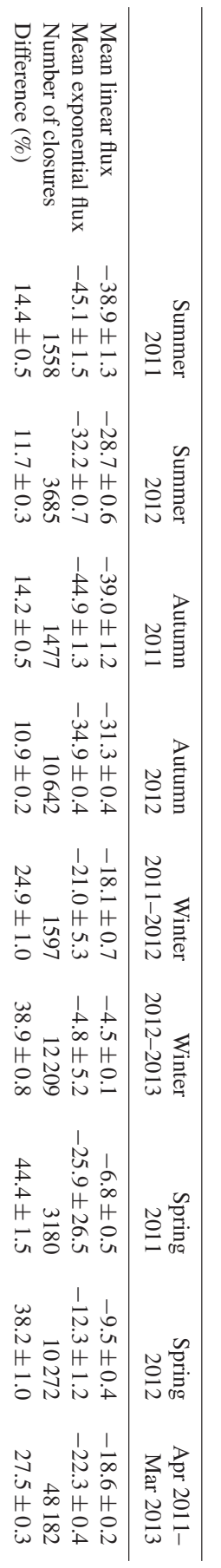

(a)

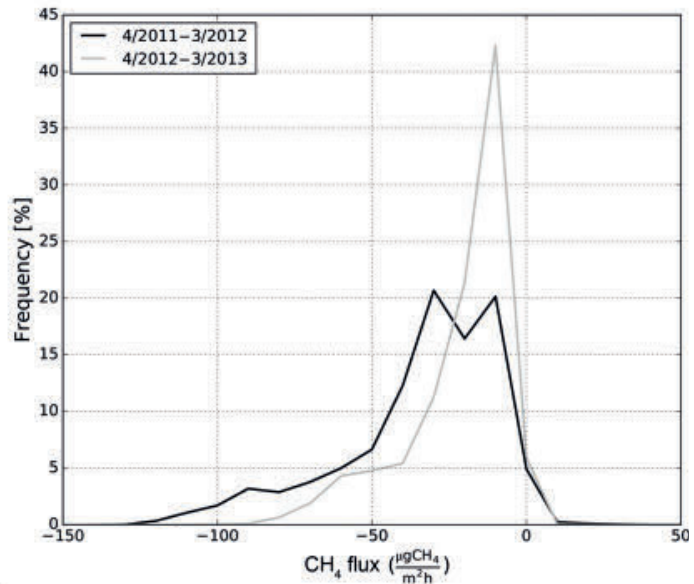

(b)

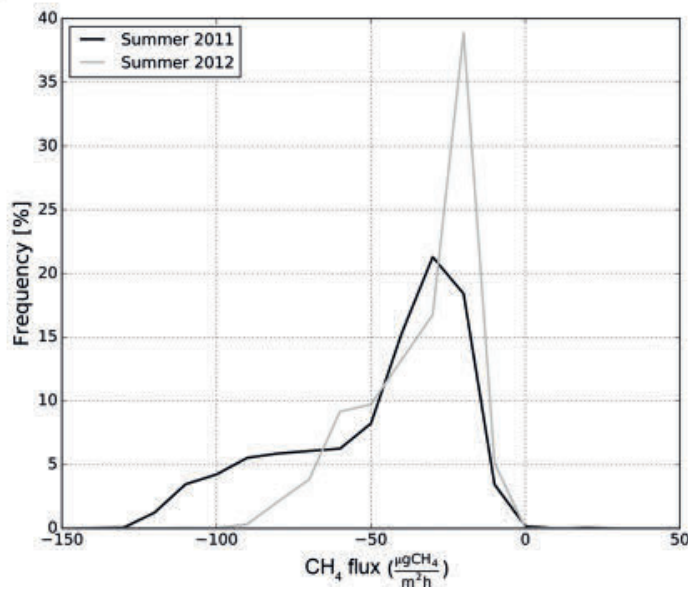

Figure 7. The frequency distribution of fluxes measured with all chambers in (a) different years and (b) different summers. The fluxes were grouped into classes of $10 \mu \mathrm{g} \mathrm{CH}_{4} \mathrm{~m}^{-2} \mathrm{~h}^{-1}$.

\subsection{Seasonal dynamics of $\mathrm{CH}_{4}$ flux and comparison between the chambers}

During the 2-year measurement period, $\mathrm{CH}_{4}$ fluxes varied mainly between -120 and $+20 \mu \mathrm{g} \mathrm{CH}_{4} \mathrm{~m}^{-2} \mathrm{~h}^{-1}$ (Figs. 6 and 7). Higher uptake rates $\left(70 \mu g \mathrm{CH}_{4} \mathrm{~m}^{-2} \mathrm{~h}^{-1}\right)$ were measured more often during the first year (Fig. 7a) and during summer 2011 (Fig. 7b) than in the second year and in summer 2012. The number of emission cases was low in both years and the soil acted as a $\mathrm{CH}_{4}$ sink for most of the time in all chambers, although a few emission peaks of up to $200 \mu \mathrm{g} \mathrm{CH}_{4} \mathrm{~m}^{-2} \mathrm{~h}^{-1}$ were recorded during and following heavy rainfall events. The data filtering (Sect. 2.5) was designed to be flexible to prevent the removal of these short-lasting $\mathrm{CH}_{4}$ bursts from the accepted data set. While some emission peaks were ob- 
(a)

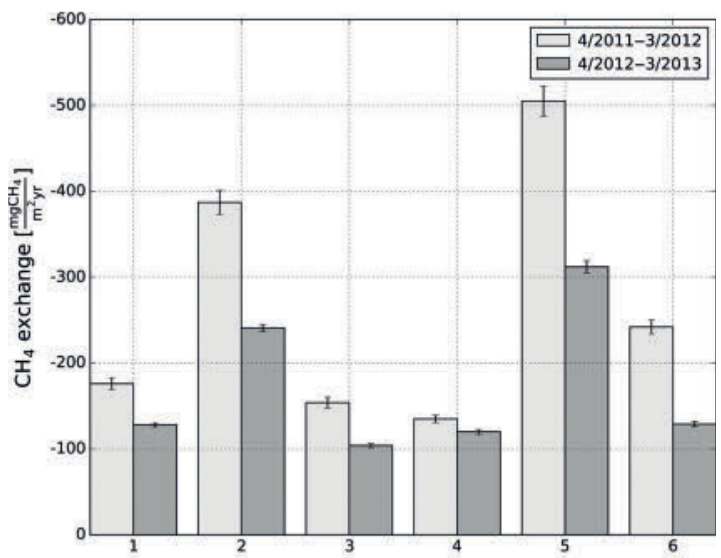

(b)

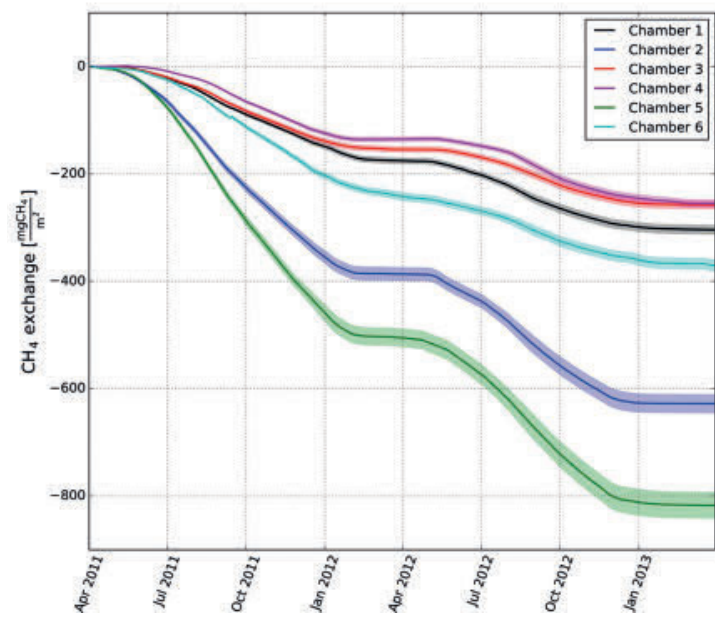

Figure 8. (a) Annual $\mathrm{CH}_{4}$ exchange for each chamber for two 1year monitoring periods and (b) cumulative $\mathrm{CH}_{4}$ exchange for each chamber from 1 April 2011 to 31 March 2013. The error bars (a) and shading (b) include estimations of the random error, the error caused by gap filling, and the uncertainty of the correction of the fluxes measured using the 2 min closure time (see Sect. 2.7).

served in most of the chambers, the peaks were largest in chamber 6. However, the peaks did not necessarily occur at the same time in different chambers.

$\mathrm{CH}_{4}$ fluxes showed a clear seasonal variation. In spring, when the snow melted and thawing of the soil surface had started, $\mathrm{CH}_{4}$ emissions fluctuated around $2 \mu \mathrm{g} \mathrm{CH}_{4} \mathrm{~m}^{-2} \mathrm{~h}^{-1}$ in all chambers (Fig. 6). As the temperature rise continued, increasing $\mathrm{CH}_{4}$ uptake was observed. In both years, $\mathrm{CH}_{4}$ uptake was largest in August, when fluxes varied between -30 and $-130 \mu \mathrm{g} \mathrm{CH}_{4} \mathrm{~m}^{-2} \mathrm{~h}^{-1}$. In September, the uptake decreased and by the end of November it had dropped to half of that in the summer. However, the soil acted as a sink until the soil surface froze, after which $\mathrm{CH}_{4}$ fluxes fluctuated around zero.

Considerable systematic differences in fluxes between the chambers were detected. The largest 2-year average sinks were measured in chambers 5 and 2 (Fig. 8), which were dominated by forest mosses Pleurozium schreberi and Dicranum polysetum (Table 2 ). The third largest sink was observed in chamber 6 (Fig. 8) with a Sphagnum sp. carpet, while the remainder of the chambers showed similar fluxes. Annual net $\mathrm{CH}_{4}$ exchange rates were on average $-267 \pm 55$ and $-172 \pm 31 \mathrm{mg} \mathrm{CH}_{4} \mathrm{~m}^{-2} \mathrm{yr}^{-1}$ ( \pm standard error of the mean) in 2011-2012 and 2012-2013 respectively. The forest floor sink was 10-44\% lower during the second than first annual period and this difference was statistically significant $(p<0.05)$ for all the chambers except chamber 4 . The largest absolute year-to-year reduction in annual $\mathrm{CH}_{4}$ exchange was observed in the two chambers dominated by Pleurozium schreberi and Dicranum polysetum (5 and 2), followed by the chamber dominated by Sphagnum sp. (6). However, the largest relative decrease in net $\mathrm{CH}_{4}$ exchange happened in chamber $6(44 \%)$ while in the rest of the chambers the decrease varied within 10-37\%.

The sink period, i.e., the period when all chambers acted as $\mathrm{CH}_{4}$ sinks (daily mean flux $<-2 \mu \mathrm{g} \mathrm{CH}_{4} \mathrm{~m}^{-2} \mathrm{~h}^{-1}$ ), was slightly longer in the first than in the second year. In the first year, all chambers acted as sinks from 14 May 2011 to 20 February 2012, a total of 282 days. During the second year, the sink period lasted for 269 days from 10 May 2012 until 3 February 2013. In addition, chamber 6 acted as a sink over the whole winter and spring in 2012, while from chambers 2 and 5 daily mean fluxes of $<-2 \mu \mathrm{g} \mathrm{CH}_{4} \mathrm{~m}^{-2} \mathrm{~h}^{-1}$ were measured already at the start of the study in April 2011.

\subsection{Factors controlling the short- and long-term variations in $\mathrm{CH}_{4}$ exchange}

\subsubsection{Seasonal cycle}

There was an observable, exponential relationship between the mean daily $\mathrm{CH}_{4}$ fluxes and the deeper soil temperatures when the data from the spring and summer of 2011 were pooled (Fig. 9a). Splitting these data into shorter periods showed that the relationship was rather strong in April-May and in June-early July, but after that, when the soil temperature at $30 \mathrm{~cm}$ depth exceeded $12^{\circ} \mathrm{C}$, the relationship was absent. It is evident that there is some covariation between soil temperature and WTL with typically higher $\mathrm{CH}_{4}$ uptake taking place at lower WTL. The plot between the residuals of the temperature response against WTL (Fig. 9b) suggests that the variation in the $\mathrm{CH}_{4}$ uptake during the latter half of July and August was better explained by the WTL than temperature. All the chambers recorded similar behavior in 2011 and 2012, although in 2012 the data were noisier and the relationships observed in 2011 were not as clear. 
(a)

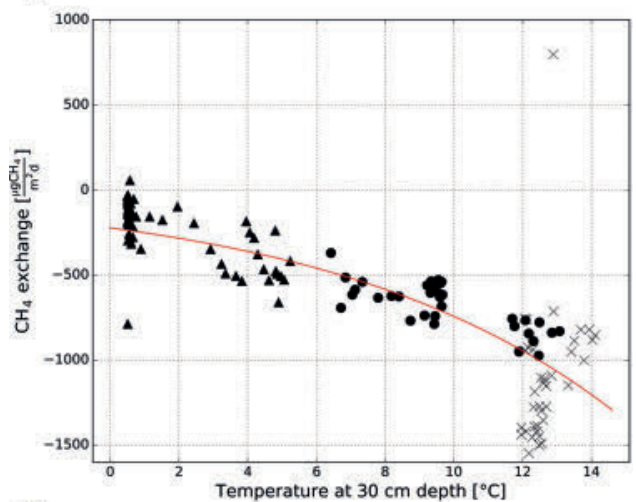

(b)

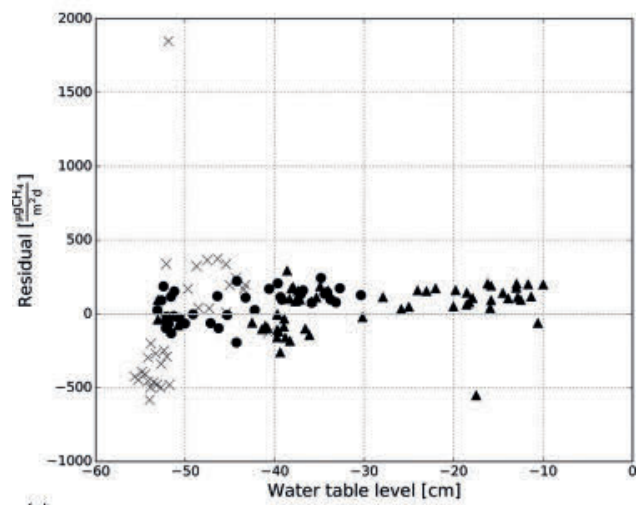

(c)

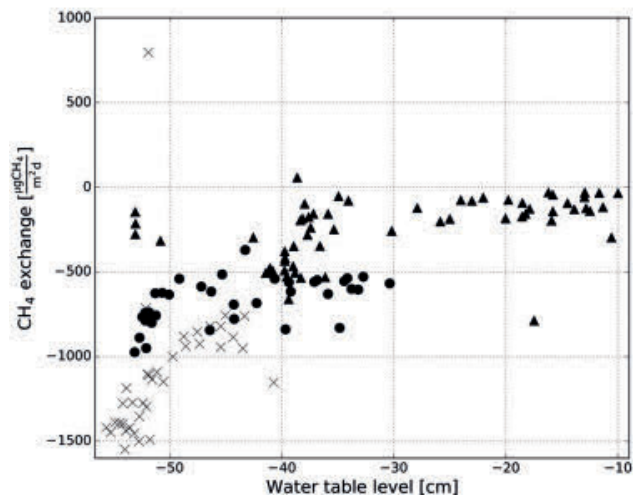

Figure 9. (a) Daily $\mathrm{CH}_{4}$ exchange plotted against soil temperature at $30 \mathrm{~cm}$ in chamber 6 for spring (April and May) (triangles), for the first half of the summer (1 June to 15 July) (circles) and for the second half of the summer (16 July to 31 August) (crosses) in 2011. Red curve in (a) denotes the exponential fitting (Eq. 2) to the data. (b) Residuals of the exponential fitting in (a) against water table level. (c) Daily $\mathrm{CH}_{4}$ exchange in chamber 6 against water table level (the same flux data as in panel a).

\subsubsection{Diurnal cycle}

In addition to seasonal dynamics, diurnal variation was observed in $\mathrm{CH}_{4}$ fluxes at least occasionally in all chambers, mostly in May and in the first half of June. Such variation was more common in 2012 and was observed in all of the chambers, while in 2011 the variation occurred mostly in chambers 2, 5, and 6. For example, during the first 2 weeks of June 2011 a clear diurnal cycle coinciding with the variation in air temperature was observed (Figs. 10 and 11a-b). Higher $\mathrm{CH}_{4}$ uptake was observed during the night and morning hours, while the sink decreased towards the midday and started to grow again towards the night (Fig. 11a). This particular 2-week period was associated with high daytime air temperatures, reaching almost $+30^{\circ} \mathrm{C}$, and a relatively low WTL (Figs. 10 and 11a-b). After that, at about mid-June, the weather type changed to cool and wet and the diurnal variation was diminished or absent (Figs. 10 and 11d-e). Such behavior, illustrated in Fig. 10, was typical for the rest of the growing season data: diurnal variation occurred more often with dry weather, while during and after the rain the variation ceased for a while. However, WTL itself did not have an impact on the diurnal cycle.

Pooling the data of these 2-week periods into hourly means implies that the soil temperature may exert a strong control on the $\mathrm{CH}_{4}$ exchange (Fig. 11). However, as temperature often - though not always - tends to correlate with wind speed, particularly in the summer, it is necessary to consider the effect of both these variables. The correlations calculated from hourly data indicate that it was the wind speed and not the temperature which played the major role in causing the diurnal variation in $\mathrm{CH}_{4}$ flux (Figs. S6-S27). However, this relationship was not comprehensive, as the correlation with wind speed was absent during some periods. In qualitative terms, we observed that the drier the soil was, the greater the impact of wind speed.

To explain this correlation, we investigated the relationship between the parameter $c_{\exp }$ (Eq. 2) and ambient WS in 2-week to 1-month periods to diminish the possible impact of seasonality (Figs. S28-S40). $c_{\exp }$ represents the curvature of concentration time series during each chamber closure. For example, the $c_{\text {exp }}$ determined for chamber 2 became less negative when WS exceeded $2 \mathrm{~m} \mathrm{~s}^{-1}$. This means that the curvature was weaker for cases of high WS.

\subsubsection{Correlation between the flux and meteorological variables}

To understand the general driving factors behind all the variation, either diurnal or seasonal, Pearson correlation coefficients between the hourly $\mathrm{CH}_{4}$ flux and key environmental variables were calculated for different seasons, averaging the correlations determined separately for each chamber (Table 4). 


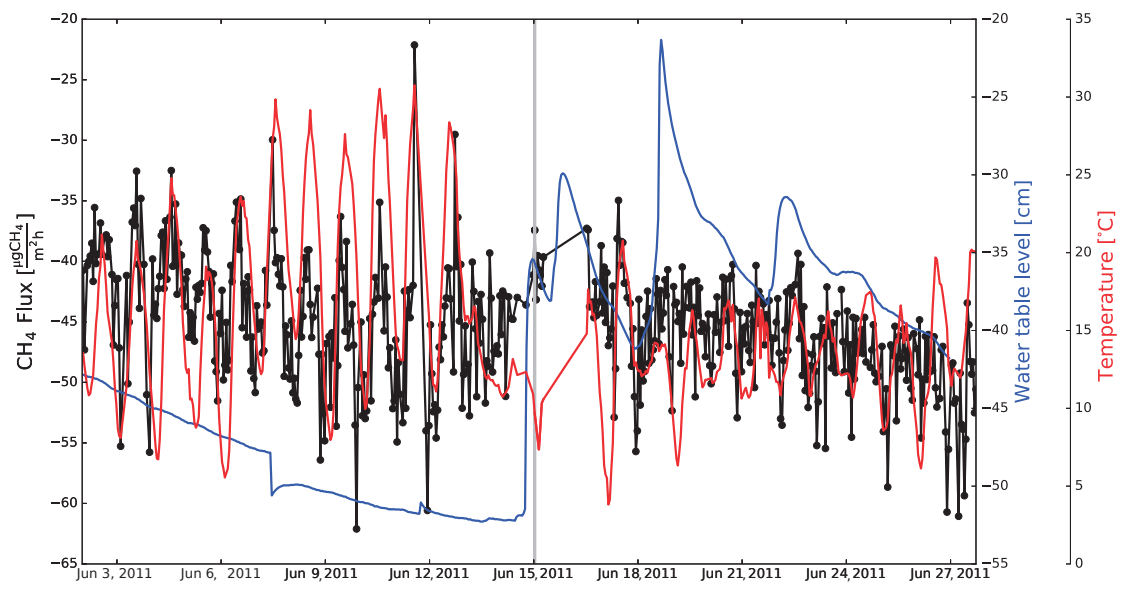

Figure 10. Hourly $\mathrm{CH}_{4}$ flux (black circles), air temperature (red curve), and water table level (WTL) (blue curve) in June 2011 in chamber 5. The grey vertical bar shows the split of the data for Fig. 11.

Table 4. Correlation coefficients $(r)$ between hourly $\mathrm{CH}_{4}$ flux and environmental variables averaged for six chambers during different seasons. All six chambers with $p<0.01$ are bolded and underlined; five chambers with $p<0.01$ are bolded; four chambers with $p<0.01$ are underlined; three chambers with $p<0.01$ are italicized. AirT is air temperature, ST is soil surface temperature, PAR is photosynthetically active radiation, WS is wind speed measured above the canopy, Tx is soil temperature at a depth of $x \mathrm{~cm}$, and WTL is water table level. For clarity, negative $r$ values typically denote situations where $\mathrm{CH}_{4}$ uptake increases when the value of explaining variable increases. The season definitions are the same as in Table 3.

\begin{tabular}{lrrrrrrrrrr}
\hline Season & AirT & ST & PAR & WS & T2 & T5 & T10 & T20 & T30 & WTL* \\
\hline Spring 2011 & -0.03 & $-\mathbf{0 . 0 4}$ & -0.18 & -0.08 & $-\underline{\mathbf{0 . 4 1}}$ & $-\underline{\mathbf{0 . 5 2}}$ & $-\underline{\mathbf{0 . 6 1}}$ & $-\underline{\mathbf{0 . 6 7}}$ & $-\underline{\mathbf{0 . 7 0}}$ & $\underline{\mathbf{0 . 5 2}}$ \\
Summer 2011 & -0.05 & 0.05 & $\mathbf{0 . 1 7}$ & $\underline{\mathbf{0 . 3 0}}$ & $\underline{0.08}$ & $-\mathbf{0 . 2 6}$ & $-\mathbf{0 . 3 7}$ & $-\underline{\mathbf{0 . 5 4}}$ & $-\underline{\mathbf{0 . 6 1}}$ & $\underline{\mathbf{0 . 6 0}}$ \\
Autumn 2011 & $-\underline{\mathbf{0 . 1 9}}$ & $-\underline{\mathbf{0 . 1 6}}$ & $\underline{0.16}$ & $\underline{\mathbf{0 . 4 0}}$ & $-\underline{\mathbf{0 . 1 9}}$ & $-\underline{\mathbf{0 . 1 9}}$ & $-\underline{\mathbf{0 . 2}}$ & $-\underline{\mathbf{0 . 2 1}}$ & $-\underline{\mathbf{0 . 2 2}}$ & $\mathbf{0 . 3 9}$ \\
Winter 2011-2012 & $-\underline{\mathbf{0 . 3 4}}$ & $-\mathbf{0 . 2 3}$ & $-\underline{0.17}$ & -0.05 & $-\underline{\mathbf{0 . 7 0}}$ & $-\underline{\mathbf{0 . 7 5}}$ & $-\mathbf{0 . 5 9}$ & $-\underline{\mathbf{0 . 8 3}}$ & $-\underline{\mathbf{0 . 8 3}}$ & $-\underline{\mathbf{0 . 8 3}}$ \\
Spring 2012 & $-\underline{\mathbf{0 . 4 8}}$ & $-\underline{\mathbf{0 . 5 7}}$ & 0.00 & $\underline{\mathbf{0 . 1 5}}$ & $-\underline{\mathbf{0 . 6 9}}$ & $-\underline{\mathbf{0 . 7 4}}$ & nd & $-\underline{\mathbf{0 . 8 2}}$ & $-\underline{\mathbf{0 . 8 2}}$ & $\underline{\mathbf{0 . 4 7}}$ \\
Summer 2012 & $-\underline{0.16}$ & $-\underline{0.17}$ & $\underline{0.14}$ & $\underline{\mathbf{0 . 2 1}}$ & $-\underline{\mathbf{0 . 3 0}}$ & $-\underline{\mathbf{0 . 4 2}}$ & nd & $-\underline{\mathbf{0 . 6 0}}$ & $-\underline{\mathbf{0 . 6 5}}$ & $\underline{\mathbf{0 . 5 9}}$ \\
Autumn 2012 & $-\underline{\mathbf{0 . 4 7}}$ & $-\underline{\mathbf{0 . 5 3}}$ & $\mathbf{0 . 1 1}$ & $\underline{\mathbf{0 . 2 8}}$ & $-\underline{\mathbf{0 . 5 8}}$ & $-\underline{\mathbf{0 . 6 1}}$ & $-\underline{\mathbf{0 . 4 5}}$ & $-\underline{\mathbf{0 . 6 4}}$ & $-\underline{\mathbf{0 . 6 4}}$ & $\underline{\mathbf{0 . 6 0}}$ \\
Winter 2012-2013 & $\underline{\mathbf{0 . 2 9}}$ & $\underline{\mathbf{0 . 3 7}}$ & 0.07 & $\underline{0.02}$ & $-\underline{\mathbf{0 . 3 7}}$ & $-\underline{\mathbf{0 . 7 3}}$ & $-\underline{\mathbf{0 . 7 9}}$ & $-\underline{\mathbf{0 . 7 9}}$ & $-\underline{\mathbf{0 . 7 9}}$ & $-\underline{\mathbf{0 . 3 5}}$ \\
\hline
\end{tabular}

* Negative WTL denotes water level below the soil surface, i.e., positive correlation results from increasing uptake with decreasing WTL. nd means not determined

There was a highly significant negative correlation between $\mathrm{CH}_{4}$ flux and soil temperature (i.e., higher uptake at higher temperature). The deeper soil temperatures (at 20 and $30 \mathrm{~cm}$ depths) showed the best correlation in all seasons. Also, T5 and T2 often correlated with $\mathrm{CH}_{4}$ flux. The highest correlations were observed in springs, winters, and in autumn 2012, and all these correlations were significant in all the chambers with the exception of summer 2011. Also, the correlations of ambient and soil surface temperature were systematically lower than those of the deeper soil temperatures. The correlation with surface soil temperatures was absent or very low in summer 2011, when only the deeper soil temperatures showed a significant correlation.

WTL and $\mathrm{CH}_{4}$ flux correlated positively in both summers (i.e., the deeper the WTL, the higher the uptake), while a negative correlation (i.e., the deeper the WTL, the higher the emission) was found for the winters. The correlation between the flux and PAR was always low $(|r|<0.2)$ or absent.

A significant positive correlation between WS and the flux was found in both summers and autumns and in spring 2012, meaning that the estimated sink decreased when WS increased. This correlation was especially clear in the time periods when there was diurnal variation in the flux, but it was nonexistent when no diurnal cycle was observed, which is consistent with the result reported above. However, even though the correlation was high in autumn 2011, no statistically significant diurnal variation in the flux was observed at that time (data not shown). Of all the inspected quantities, WS was the best explanatory factor of the diurnal cycle of $\mathrm{CH}_{4}$ flux; this was followed by temperature quantities. 

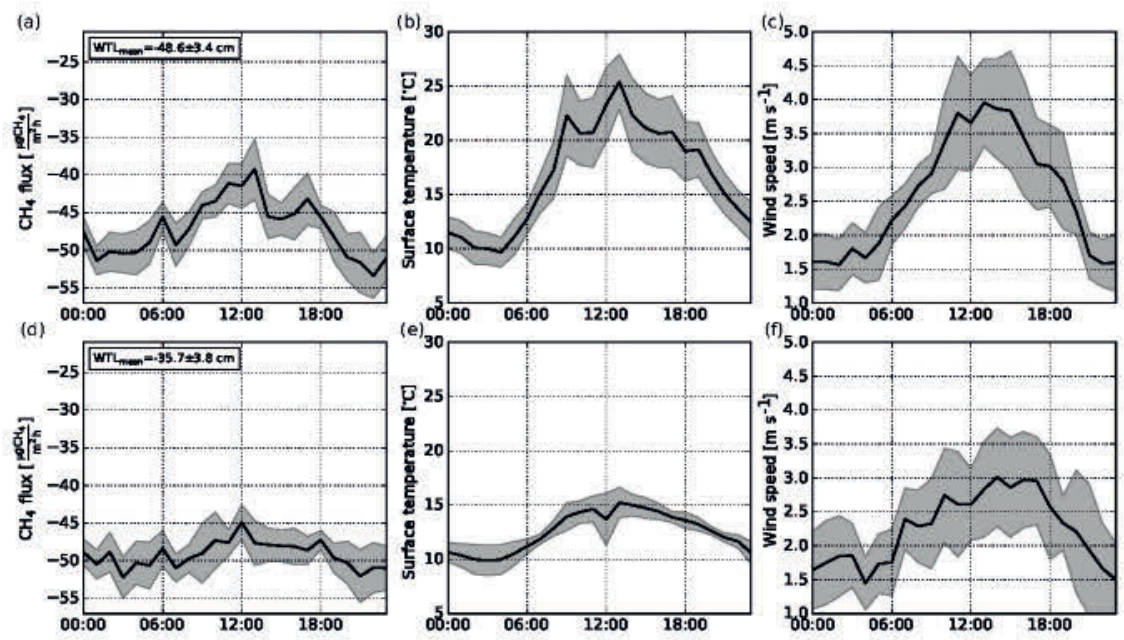

Figure 11. Diurnal variation of mean $\mathrm{CH}_{4}$ flux $(\mathbf{a}, \mathbf{d})$ and soil surface temperature $\left({ }^{\circ} \mathrm{C}\right)(\mathbf{b}, \mathbf{e})$ measured in chamber 2 , and the wind speed $(\mathbf{c}$, f) measured above the canopy, on 2-14 June 2011 (a, b, c) and 15-27 June $2011(\mathbf{d}, \mathbf{e}, \mathbf{f})$. Shading shows the $95 \%$ confidence intervals.

\section{Discussion}

\subsection{Chamber closure time and flux calculation method}

In this study, we found that using the linear regression method in flux calculations resulted in 20-50\% lower flux estimates for most of the time, in comparison to fluxes calculated with an exponential fit. However, in winter and early spring, i.e., at the time of low absolute $\mathrm{CH}_{4}$ fluxes $\left(<2.5 \mu \mathrm{g} \mathrm{CH}_{4} \mathrm{~m}^{-2} \mathrm{~h}^{-1}\right)$, linear regression gave more reliable results with clearly lower hour-to-hour noise in the fluxes. The uncertainty associated with exponential regression with low fluxes was caused by the decreased signalto-noise ratio in the concentration data, leading to more or less arbitrary values of the concentration change estimated at $t=0$. This explains why the difference between the fluxes estimated by the linear and exponential models was highest during winter and spring.

The use of exponential regression can be considered especially justified during summer and autumn when the concentration development inside the chamber is strongly nonlinear. During these periods, linear regression gave significantly lower flux estimates with an average difference of $12.8 \pm 1.8 \%$. In winter and spring, however, the average seasonal difference was as high as $44 \%$. Concerning the annual balance, it should be noted that this difference has a greater influence during summer and autumn when the fluxes are up to 2 orders of magnitude larger. The mean difference during the whole measurement period $(27.5 \pm 0.3 \%)$ is in agreement with many previous studies; for example, Anthony et al. (1995) and Pedersen et al. (2010) reported a 35 and $34 \%$ decrease in flux values, respectively, when using linear regression instead of exponential regression. Kutzbach et al. (2007) reported that underestimations for multiple sites varied mostly within $20-60 \%$, while Pihlatie et al. (2013) found an average underestimation of $30 \%$ under laboratory conditions at different flux levels. However, the abovementioned studies focused on either $\mathrm{CH}_{4}$ and $\mathrm{CO}_{2}$ emissions or $\mathrm{CO}_{2}$ uptake and did not include measurements related to a small soil sink of $\mathrm{CH}_{4}$. Since the exponential fit results in larger uptake estimates, which we consider to better represent the correct flux at the time of the chamber closure, we agree with the previous studies that recommend the use of exponential regression in flux calculation. However, due to the considerable noise generated for small fluxes, we recommend that, in future studies employing temporally highresolution data, the fluxes should be calculated initially with both methods to determine the threshold for "low" fluxes. As this threshold value is dependent on the measurement system and method, it cannot be generalized.

We found that increasing the fitting period up to $15 \mathrm{~min}$ from the beginning of the concentration time series systematically decreased the flux estimated by the linear regression model, but only after this period exceeded 140 s. In contrast, the flux estimated by the exponential regression decreased until the fitting window covered $190 \mathrm{~s}$ after which the estimated flux was stabilized. To disentangle whether these anomalous patterns in the beginning of both curves were caused by an initial disturbance to the measurement or they represented a real phenomenon affecting the flux, we removed $2 \mathrm{~min}$ of data from the beginning of concentration time series. This removed the plateau with large variation from the linear fit results but did not change the shape shown for the exponential fit in Fig. 4b (results not shown). This suggests that the concentration data during the first minute of measurement are perturbed by chamber closure and that 
the linear fit is more sensitive to this than the exponential fit, when using a short fitting period. However, the exponential fit seems to overestimate the flux if the fit is limited to a short time window, but this overestimation is not related to a possible disturbance in the beginning of the data.

Because the concentration development is nonlinear, it is not only the length of the fitting period but also the start of this period, which is important for the flux estimate. The more data are removed from the beginning, the smaller the estimated $\mathrm{CH}_{4}$ uptake becomes. Ueyama et al. (2015) noticed that the flux estimates by linear and exponential regressions both decreased with increasing closure time. Their slopes of linear regression ( $14 \pm 2 \%$ over $5 \mathrm{~min}$ ) decreased faster than those in our study $(16.2 \pm 0.2 \%$ over $13 \mathrm{~min})$, suggesting that their concentration data were more nonlinear. The difference could be partly explained by the fact that Ueyama et al. (2015) used smaller chambers and measured higher fluxes, which both result in a faster decrease of the vertical concentration gradient between the soil and the chamber headspace.

\section{2 $\mathrm{CH}_{4}$ exchange dynamics in a peatland forest}

\subsubsection{Annual balances}

The measurement site (excluding the ditches) was a small annual $\mathrm{CH}_{4}$ sink (varying from $172 \pm 31$ to $267 \pm 55 \mathrm{mg} \mathrm{CH}_{4} \mathrm{~m}^{-2} \mathrm{yr}^{-1}, \pm$ standard error of the mean) over the 2-year measurement period. While we do not have measurements prior to drainage, it is possible to roughly estimate the pre-drainage fluxes from measurements conducted at similar sites. As Lettosuo was originally a herb-rich, tall sedge birch-pine fen, it can be considered similar to the site reported by Nykänen et al. (1998). That site has high $\mathrm{CH}_{4}$ emissions of $25 \mathrm{~g} \mathrm{CH}_{4} \mathrm{~m}^{-2} \mathrm{yr}^{-1}$, so it is obvious that the drainage of Lettosuo has turned the peat soil from a $\mathrm{CH}_{4}$ source to a small $\mathrm{CH}_{4}$ sink. However, it should be noted that our calculations of annual and daily $\mathrm{CH}_{4}$ exchange do not include the emissions from the ditches, which have been found to be highly variable: from 0 to $600 \mathrm{mg} \mathrm{CH}_{4} \mathrm{~m}^{-2}$ day ${ }^{-1}$ (e.g., Minkkinen et al., 1997; Minkkinen and Laine, 2006; Luan and $\mathrm{Wu}, 2015)$. At Lettosuo, where the ditches cover 2-3\% of the area, we estimated, based on 41 manual chamber flux measurements from six points made in the latter half of 2011 , that $\mathrm{CH}_{4}$ emissions (per $\mathrm{m}^{2}$ ditch) from the ditches averaged $22( \pm 38, \pm \mathrm{SD}) \mathrm{g} \mathrm{CH}_{4} \mathrm{~m}^{-2} \mathrm{yr}^{-1}$ (unpublished data). Simple upscaling suggests that, when ditches are accounted for, Lettosuo is a small annual source of $\mathrm{CH}_{4}$ to the atmosphere, although the high uncertainties associated with this calculation should be noted.

Previous studies of drained peatland forests in Finland have reported uptake rates varying between 10 and $970 \mathrm{mg} \mathrm{CH}_{4} \mathrm{~m}^{-2} \mathrm{yr}^{-1}$ (Alm et al., 1999; Minkkinen et al., 2007; Ojanen et al., 2010; Lohila et al., 2011). The average annual uptake in boreal upland forests typically varies from about 100 to $500 \mathrm{mg} \mathrm{CH}_{4} \mathrm{~m}^{-2} \mathrm{yr}^{-1}$ (Smith et al., 2000; Dutaur and Verchot, 2007; Lohila et al., 2016), but also annual net emissions from upland forests have been reported (e.g., Sundqvist et al., 2015; Lohila et al., 2016). Thus, the net annual $\mathrm{CH}_{4}$ exchange measured at Lettosuo (excluding the ditches) was well within the typical range of the average $\mathrm{CH}_{4}$ sinks reported for boreal upland forests.

\subsubsection{Emission peaks}

A few larger $\mathrm{CH}_{4}$ emission peaks were observed during and after heavy rainfall events in summer, but not all chambers responded to the same rainfall events. The largest number and magnitude of these short bursts of $\mathrm{CH}_{4}$ were recorded with the Sphagnum-dominated chamber (6), which was expected as Sphagnum mosses favor wet spots. These rainfall events turned the soil from a sink to a source (up to $200 \mu \mathrm{g} \mathrm{CH}_{4} \mathrm{~m}^{-2} \mathrm{~h}^{-1}$ in chamber 6) for a short period ranging from a few hours to few days. This was possibly due to increased water saturation and decreased air-filled pore space leading to reduction in oxygen diffusion, which could promote methanogenic activity and suppress methane oxidation.

Similarly to our results, Nykänen et al. (1995) observed that a drained peatland soil can switch to a $\mathrm{CH}_{4}$ source (up to $200 \mu \mathrm{g} \mathrm{CH}_{4} \mathrm{~m}^{-2} \mathrm{~h}^{-1}$ ) during water saturation event. However, the emission peaks at Lettosuo were relatively small when compared to upland mineral soil forest sites, where emissions of up to $3.7 \mathrm{mg} \mathrm{CH}_{4} \mathrm{~m}^{-2} \mathrm{~h}^{-1}$ have been observed in wet conditions (e.g., Savage et al., 1997; Lohila et al., 2016). Similarly, the maximum hourly uptake in summer at Lettosuo was rather similar to the fluxes reported for the above-mentioned upland forests (from -50 to $-120 \mu \mathrm{g} \mathrm{CH}_{4} \mathrm{~m}^{-2} \mathrm{~h}^{-1}$ at Lettosuo vs. -40 to $-80 \mu \mathrm{g} \mathrm{CH}_{4} \mathrm{~m}^{-2} \mathrm{~h}^{-1}$ at upland forests).

\subsubsection{Spatial variation}

There were relatively large differences in the annual net $\mathrm{CH}_{4}$ exchange rates between the chambers (from $-104 \mathrm{mg} \mathrm{CH}_{4} \mathrm{~m}^{-2} \mathrm{yr}^{-1}$ in chamber 3 to $-505 \mathrm{mg} \mathrm{CH}_{4} \mathrm{~m}^{-2} \mathrm{yr}^{-1}$ in chamber 5), even though all the chambers were located within a maximum distance of about $15 \mathrm{~m}$ from each other. The difference in the soil surface temperature between the chambers was usually less than $2 \mathrm{~K}$, which indicates that the soil temperature was not the main factor determining the observed spatial variation in fluxes. Since we do not have WTL data for each of the chambers separately, we cannot quantitatively evaluate its role in the spatial variation of fluxes. It is unlikely that the variation in the WTL solely could explain the difference: even though chambers 4 and 5 were located at the same distance from a ditch, and probably had the deepest WTL, chamber 5 showed the highest uptake, while chamber 4 was one of the smallest sinks. Hence, although WTL is likely to explain part of the spatial variation in the $\mathrm{CH}_{4}$ fluxes, there are potentially 
many other factors, such as the vegetation composition and small-scale soil properties. The smallest sink was observed in chambers 1,3 , and 4 , which were characterized with the lowest $(3)$ and highest $(1,4)$ vascular green area $\left(\mathrm{VGA}_{\max }\right)$ values. Thus it seems that it was not the amount of ground vegetation which affected the sink, but a more relevant factor could have been the coverage of mosses vs. that of vascular plants within the collar, especially that of the forest mosses Pleurozium schreberi and Dicranum polysetum, which were particularly abundant in the highly oxidizing chambers 2 and 5. Due to the small number of chambers, however, the relationship between the forest floor vegetation and the $\mathrm{CH}_{4}$ exchange may be coincidental and can only be speculated.

\subsubsection{Diurnal variation}

All the chambers recorded diurnal variation in $\mathrm{CH}_{4}$ flux at some time during the study period with most of the variation observed during late spring and early summer. Typically, $\mathrm{CH}_{4}$ uptake was at its highest during the night and decreased towards the afternoon. The diurnal variation was more common and occurred more often in all chambers in 2012, while in 2011 it occurred mostly in chamber 2 . This variation usually ceased or was at least greatly diminished during and after rainfall events, but usually it appeared again after a couple of days. WTL as such, however, did not have an impact on the diurnal cycle, which suggests that the conditions in the soil surface were much more important for this phenomenon.

Although the diurnal variation seemingly followed the patterns in the air and soil surface temperatures, it was best explained by the WS measured above the canopy (below canopy WS is not available). To further study this relationship, we tested the correlation between the parameter $c_{\exp }$ (Eq. 2) and WS. $c_{\text {exp }}$ represents the curvature in the exponential fit, being negative whenever the concentration increase during a chamber closure shows a slowing shape. As we only selected negative, i.e., uptake, fluxes here, it follows that a more negative $c_{\text {exp }}$ indicates a higher curvature in the concentration evolution. Should leaking be responsible for the smaller $\mathrm{CH}_{4}$ uptake during daytime, as the observed relationship between WS and $\mathrm{CH}_{4}$ exchange implied, it would be logical to find higher curvatures with higher WS. Such a relationship was recently found by Pirk et al. (2016) for $\mathrm{CH}_{4}$ emission chamber flux data from pristine peatlands. However, we did not observe such a relationship in our $\mathrm{CH}_{4}$ uptake data. For example, in chamber 2, in which the diurnal cycle was most explicit, an increasing $c_{\exp }$ was determined for most of the periods studied. There were only a few chambers and periods when $c_{\text {exp }}$ decreased with increasing WS. Thus we must conclude that the diurnal variation in our data is related to the technical operation of the chamber rather than environmental conditions. Nevertheless, as the temperature and WS correlated strongly, it is possible that some of the observed pattern was due to some microbial or environmental factor.
We hypothesize that, rather than chamber leaking, the main underlying factor for the clear negative correlation between WS and $\mathrm{CH}_{4}$ uptake is related to changes in the soil storage and thus the changes imposed by chamber closure to the concentration gradient within the top soil and the adjacent air layer. Prior to the closure, this gradient is controlled by atmospheric mixing and hence strongly affected by the ambient WS. During a calm night with a cool soil surface, turbulent mixing is strongly suppressed and molecular diffusion gains importance, while windy and sunny conditions result in much smaller vertical gradients due to vigorous turbulence that is also able to perturb the top-soil pore space. After the chamber is closed, the concentration gradient adjusts to the constant mixing generated by a fan. Thus, the change in concentration gradient depends on the mixing conditions that prevail above the target surface just before the chamber is introduced and how these relate to the mixing rate of the chamber headspace air. In the nocturnal case outlined above, mixing is enhanced after the chamber closure, resulting in a higher $\mathrm{CH}_{4}$ uptake in the chamber.

The absence of the diurnal cycle in winter, and during and after the rain in summer, can be explained by the increased soil moisture content, which decreases the air-filled pore space in soil, thus hampering the wind-induced mixing effect at the soil-atmosphere interface and by slowing down the diffusion rate (Pirk et al., 2016).

It should be noted that the situation is different when $\mathrm{CH}_{4}$ exchange is measured above a forest canopy with the EC method. In that case, the measurement does not significantly disturb atmospheric mixing and increased mechanical turbulence potentially enhances vertical gas exchange. Such positive correlation between the downward $\mathrm{CH}_{4}$ flux and WS, with higher sinks during the daytime, has been reported by Wang et al. (2013). This is consistent with the results of our fan-speed test, described in Koskinen et al. (2014) who measured $\mathrm{CO}_{2}$ respiration by the same chamber system. The $\mathrm{CH}_{4}$ flux data from the same test showed a higher $\mathrm{CH}_{4}$ uptake with higher fan speed (data not shown).

A wind-induced diurnal cycle suggests that the current chamber setup potentially leads to an over- or underestimate of the actual uptake rate during lower or higher faninduced mixing, respectively, as compared to ambient mixing by wind. The chamber construction could be improved by making the fan speed vary as a function of the ambient wind speed, so as to mimic the variations in atmospheric mixing. However, we can expect that the systematic bias resulting from the wind response is minimized when employing automated sampling that facilitates continuous measurements. Our results imply that sporadic sampling with manual chambers, which is typically limited to the daytime, would have resulted in lower uptake estimates for this site than the extensive data collected with our automatic system. 


\subsection{Driving factors for the $\mathrm{CH}_{4}$ efflux}

The seasonal $\mathrm{CH}_{4}$ fluxes correlated best with soil temperatures at the depths of $20 \mathrm{~cm}$ and $30 \mathrm{~cm}$, but significant correlations occurred also with soil temperatures at other depths for most of the study period. The correlations with air and soil surface temperatures were lower. The correlations were always negative, indicating that higher temperatures promoted the soil $\mathrm{CH}_{4}$ uptake. This observation could be attributed to increased consumption of $\mathrm{CH}_{4}$ by methanotrophs in higher temperatures that enhance methanotrophic activity (e.g., Mohanty et al., 2007). However, it is likely that in addition to - or even instead of - the increased methanotrophic activity, there are other reasons behind this relationship. The covariation of temperature with other variables, such as ground water level and phenology, all typically peaking in July-August, may lead to spurious correlation between temperature and $\mathrm{CH}_{4}$ flux. Indeed, the flux was also correlated with WTL, the correlation being significantly positive (higher uptake with lower WTL) in spring, summer, and autumn, but negative in winter. At our site, the soil layers most favorable for methane production and oxidation are located at clearly different depths in the soil, the first being found below the water table and the latter much closer to the soil surface (A. Putkinen, unpublished data). Both of these have distinct temperature and moisture responses, which are practically impossible to disentangle by examining the net $\mathrm{CH}_{4}$ flux observed at the surface.

In addition to the correlations found in the hourly data, we found evidence that lowering WTL increases the daily $\mathrm{CH}_{4}$ uptake in the latter part of summer, when WTL $<-40 \mathrm{~cm}$. In the beginning of the summer, the daily fluxes were better explained by the soil temperature, while after mid-July the WTL overshadowed the temperature as a control of the daily fluxes.

In pristine peatlands, temperature has been shown to correlate positively with the $\mathrm{CH}_{4}$ emission rate (e.g., Mikkelä et al., 1995; Bellisario et al., 1999; Mastepanov et al., 2013). In drained peatland forests, significant correlations between $\mathrm{CH}_{4}$ flux and temperature have been found in $\mathrm{CH}_{4}$-emitting ecosystems (Nykänen et al., 1998; Minkkinen and Laine, 2006), although the direction of the correlation has been found to differ between fens and bogs. In contrast, no significant correlations with temperature were found in peatland forests that mainly showed $\mathrm{CH}_{4}$ uptake (Ojanen et al., 2010; Wang et al., 2013). Both $\mathrm{CH}_{4}$ emission and uptake have been found to correlate with WTL (e.g., Bellisario et al., 1999; Ojanen et al., 2010).

In addition to temperature, WTL, and $\mathrm{WS}, \mathrm{CH}_{4}$ flux has been found to correlate with tree stand volume (Ojanen et al., 2010; Minkkinen et al., 2007), which is, in contrast, an indirect measure of the WTL. Also, PAR has been observed to correlate positively with $\mathrm{CH}_{4}$ emissions in a Sphagnumdominated mixed mire (Mikkelä et al., 1995). In this study, however, the correlations with PAR were low or absent.

\section{Conclusions}

In this paper, we have presented a 2-year data set of $\mathrm{CH}_{4}$ exchange measured at the forest floor of a boreal forestrydrained fen. These results show that automated chamber measurements with an accurate online gas analyzer make it possible to observe small $\mathrm{CH}_{4}$ fluxes even during the winter with snow cover. Although the fluxes at our site were relatively low throughout the year, we succeeded in catching the annual cycle in the $\mathrm{CH}_{4}$ uptake. Our results indicate that the forest floor of this peatland site acted as a small annual $\mathrm{CH}_{4}$ sink (mean balance - $219 \mathrm{mg} \mathrm{CH}_{4} \mathrm{~m}^{-2} \mathrm{yr}^{-1}$ ), although completing the balance with the emissions from ditches indicates that the site is likely to be a small $\mathrm{CH}_{4}$ source.

In spite of the low flux detection limit of the measurement system, our results indicate that it is necessary to pay attention to the flux calculation methods, and instead of choosing between linear and exponential fits we decided on a combination of both. Even though the fit based on linear regression was observed to typically result in a smaller flux than an exponential fit, its use was justified for low fluxes by showing that it produced more robust estimates when the concentration change during chamber closure was small and thus more affected by measurement noise. In addition, we demonstrated that both the length of the fitting period and the starting time of this window had a significant effect on the flux estimates and thus cannot be selected arbitrarily.

The $\mathrm{CH}_{4}$ uptake, measured with closed chambers, was observed to correlate with wind speed, which caused a corresponding diurnal cycle. However, this was partly attributed to aerodynamic effects due to chamber closure, which are dependent on atmospheric mixing prior to the closure. Thus, the chamber construction could be potentially improved by adjusting the chamber fan speed according to the ambient wind speed. As this variation is partly related to changes in the soil $\mathrm{CH}_{4}$ storage, the error introduced in the annual balance estimated from short-term fluxes can be diminished by continuous measurements fully covering the diurnal cycle. Continuous long-term measurements also facilitate the analysis of the environmental factors that control $\mathrm{CH}_{4}$ exchange. However, in order to understand the biological processes involved in $\mathrm{CH}_{4}$ production and oxidation, i.e., the processes behind the net $\mathrm{CH}_{4}$ flux observed, additional measurements are necessary, focusing on the production and oxidation potentials and the within-soil gas gradients.

Since the considerations of the measurement system performance are site and system specific, we recommend that any future study should address the procedures involved in flux calculation, including the fitting method and the length and delay of the fitting period, based on the analysis presented above. In particular, we recommend using the flux limit method applied in this study, i.e., using linear regression for low fluxes and exponential regression for fluxes above a threshold to be determined. 
Data availability. The calculated fluxes and measured headspace temperatures are included in the Supplement. The rest of the meteorological data can be requested from the corresponding author.

\section{The Supplement related to this article is available online at doi:10.5194/bg-14-1947-2017-supplement.}

Competing interests. The authors declare that they have no conflict of interest.

Acknowledgements. We are grateful for the financial support from the Maj and Tor Nessling foundation and from the Ministry of Transport and Communications through the Integrated Carbon Observing System (ICOS) research. We would also like to thank Pentti Arffman and Tero Hirvonen for their help in data treatment and for measurements at the site.

Edited by: U. Seibt

Reviewed by: C.-M. Görres and M. Mastepanov

\section{References}

Alm, J., Saarnio, S., Nykänen, H., Silvola, J., and Martikainen, P. J.: Winter $\mathrm{CO}_{2}, \mathrm{CH}_{4}$ and $\mathrm{N}_{2} \mathrm{O}$ fluxes on some natural and drained boreal peatlands, Biogeochemistry, 44, 163-186, doi:10.1023/A:1006074606204, 1999.

Alm, J., Shurpali, N., Tuittila, E.-S., Laurila, T., Maljanen, M., Saarnio, S., and Minkkinen, K.: Methods for determining emission factors for the use of peat and peatlands - flux measurements and modelling, Boreal Environ. Res., 12, 85-100, 2007.

Anthony, W. H., Hutchinson, G. L., and Livingston, G. P.: Chamber measurements of soil-atmosphere gas exchange: linear vs. diffusion-based flux models, Soil Sci. Soc. Am. J., 59, 13081310, doi:10.2136/sssaj1995.03615995005900050015x, 1995.

Bellisario, L. M., Bubier, J. L., Moore, T. R., and Chanton, J. P.: Controls on $\mathrm{CH}_{4}$ emissions from a northern peatland, Global Biogeochem. Cy., 13, 81-91, doi:10.1029/1998GB900021, 1999.

Bergier, I., Rech, R., Monteiro, H., and Soriano, E.: User effects on chamber nitrous oxide emissions from oxisol soils in notillage maize fertirrigated with anaerobically digested swine manure, Environment and Natural Resources Research, 3, 1-11, doi:10.5539/enrr.v3n4p1, 2013.

Bhuiyan, R., Minkkinen, K., Helmisaari, H.-S., Ojanen, P., Penttilä, $\mathrm{T}$., and Laiho, R.: Estimating fine-root production by tree species and understorey functional groups in two contrasting peatland forests, Plant Soil, 412, 299-316, doi:10.1007/s11104-016-30703, 2017.

Boeckx, P. and Van Cleemput, O.: Methane oxidation in a neutral landfill cover soil: Influence of moisture content, temperature and nitrogen-turnover, J. Environ. Qual., 25, 178-183, doi:10.2134/jeq1996.00472425002500010023x, 1996.

Bubier, J. L. and Moore, T. R.: An ecological perspective on methane emissions from northern wetlands, Trends Ecol. Evol., 9, 460-464, doi:10.1016/0169-5347(94)90309-3, 1994.
Christiansen, J. R., Korhonen, J. F. J., Juszczak, R., Giebels, M., and Pihlatie, M.: Assessing the effects of chamber placement, manual sampling and headspace mixing on $\mathrm{CH}_{4}$ fluxes in a laboratory experiment, Plant Soil, 343, 171-185, doi:10.1007/s11104-0100701-y, 2011.

Christiansen, J. R., Outhwaite, J., and Smukler, S. M.: Comparison of $\mathrm{CO}_{2}, \mathrm{CH}_{4}$, and $\mathrm{N}_{2} \mathrm{O}$ soil-atmosphere exchange measured in static chambers with cavity ring-down spectroscopy and gas chromatography, Agr. Forest Meterol., 211, 48-57, doi:10.1016/j.agrformet.2015.06.004, 2015.

Christophersen, M. and Kjeldsen, P.: Lateral gas transport in soil adjacent to an old landfill: factors governing gas migration, Waste Manage. Res., 19, 579-594, doi:10.1177/0734242X0101900615, 2001.

Clarke, D. and Rieley, J.: Strategy for responsible peatland management, International Peat Society, Jyväskylä, Finland, 11, 2010.

Conen, F. and Smith, K. A.: An explanation of linear increases in gas concentration under closed chambers used to measure gas exchange between soil and the atmosphere, Eur. J. Soil. Sci., 51, 111-117, doi:10.1046/j.1365-2389.2000.00292.x, 2000.

Davidson, E. A., Savage, K., Verchot, L. V., and Navarro, R.: Minimizing artifacts and biases in chamber-based measurements of soil respiration, Agr. Forest Meteorol., 113, 21-37, doi:10.1016/S0168-1923(02)00100-4, 2002.

Denman, K. L., Brasseur, G., Chidthaisong, A., Ciais, P., Cox, P. M., Dickinson, R.E., Hauglustaine, D., Heinze, C., Holland, E., Jacob, D., Lohmann, U., Ramachandran, S., da Silva Dias, P. L., Wofsy, S. C., and Zhang, X.: Couplings Between Changes in the Climate System and Biogeochemistry, in: Climate Change 2007: The Physical Science Basis. Contribution of Working Group I to the Fourth Assessment Report of the Intergovernmental Panel on Climate Change, edited by: Solomon, S., Qin, D., Manning, M., Chen, Z., Marquis, M., Averyt, K. B., Tignor, M., and Miller, H. L., Cambridge University Press, Cambridge, UK and New York, NY, USA, 2007.

Denmead, O.: Approaches to measuring fluxes of methane and nitrous oxide between landscapes and the atmosphere, Plant Soil, 309, 5-24, doi:10.1007/s11104-008-9599-z, 2008.

Dunfield, P., Knowles, R., Dumont, R., and Moore, T. R.: Methane production and consumption in temperate and subarctic peat soils: Response to temperature and $\mathrm{pH}$, Soil Biol. Biochem., 25, 321-326, doi:10.1016/0038-0717(93)90130-4, 1993.

Dutaur, L. and Verchot, V.: A global inventory of the soil $\mathrm{CH}_{4}$ sink, Global Biogeochem. Cy., 21, GB4013, doi:10.1029/2006GB002734, 2007.

Fassbinder, J. J., Schultz, N. M., Baker, J. M., and Griffis, T. J.: Automated, low-power chamber system for measuring nitrous oxide emissions, J. Environ. Qual., 42, 606-614, doi:10.2134/jeq2012.0283, 2013.

Fischlin, A., Midgley, G. F., Price, J. T., Leemans, R., Gopal, B., Turley, C., Rounsevell, M. D. A., Dube, O. P., Tarazona, J., and Velichko, A. A.: Ecosystems, their properties, goods, and services, in: Climate Change 2007: Impacts, Adaptation and Vulnerability. Contribution of working group II to the Fourth Assessment Report of the Intergovernmental Panel on Climate Change, edited by: Parry, M. L., Canziani, O. F., Palutikof, J. P., van der Linden, P. J., and Hanson, C. E., Cambridge University Press, Cambridge, 211-272, 2007. 
Forbrich, I., Kutzbach, L., Hormann, A., and Wilmking, M.: A comparison of linear and exponential regression for estimating diffusive $\mathrm{CH}_{4}$ fluxes by closed-chambers in peatlands, Soil Biol. Biochem., 42, 507-515, doi:10.1016/j.soilbio.2009.12.004, 2010.

Healy, R. W., Striegl, R. G., Russell, T. F., Hutchinson, G. L., and Livingston, G. P.: Numerical evaluation of static-chamber measurements of soil-atmosphere gas exchange: identification of physical processes, Soil Sci. Soc. Am. J., 60, 740-747, doi:10.2136/sssaj1996.03615995006000030009x, 1996.

Hutchinson, G. L., Livingston, G. P., Healy, R. W., and Striegl, R. G.: Chamber measurement of surface-atmosphere trace gas exchange: numerical evaluation of dependence on soil, interfacial layer, and source/sink properties, J. Geophys. Res.-Atmos., 105, 8865-8875, doi:10.1029/1999JD901204, 2000.

IPCC: Climate Change 2014: Impacts, Adaptation, and Vulnerability. Part A: Global and Sectoral Aspects. Contribution of Working Group II to the Fifth Assessment Report of the Intergovernmental Panel on Climate Change, edited by: Field, C. B., Barros, V. R., Dokken, D. J., Mach, K. J., Mastrandrea, M. D., Bilir, T. E., Chatterjee, M., Ebim, K. L., Estrada, Y. O., Genova, R. C., Girma, B., Kissel, E. S., Levy, A. N., MacCracken, S., Mastrandrea, P. R., and White, L. L., Cambridge University Press, Cambridge, UK and New York, NY, USA, 2014.

Jones, S. K., Famulari, D., Di Marco, C. F., Nemitz, E., Skiba, U. M., Rees, R. M., and Sutton, M. A.: Nitrous oxide emissions from managed grassland: a comparison of eddy covariance and static chamber measurements, Atmos. Meas. Tech., 4, 21792194, doi:10.5194/amt-4-2179-2011, 2011.

Keller, M., Mitre, M. E., and Stallard, R. F.: Consumption of atmospheric methane in soils of central Panama: Effects of agricultural development, Global Biogeochem. Cy., 4, 21-27, doi:10.1029/GB004i001p00021, 1990.

Koskinen, M., Minkkinen, K., Ojanen, P., Kämäräinen, M., Laurila, T., and Lohila, A.: Measurements of $\mathrm{CO}_{2}$ exchange with an automated chamber system throughout the year: challenges in measuring night-time respiration on porous peat soil, Biogeosciences, 11, 347-363, doi:10.5194/bg-11-347-2014, 2014.

Kotsyurbenko, O. R., Chin, K.-J., Glagolev, M. V., Stubner, S., Simankova, M. V., Nozhevnikova, A. N., and Conrad, R.: Acetoclastic and hydrogenotrophic methane production and methanogenic populations in an acidic West-Siberian peat bog, Environ. Microbiol., 6, 1159-1173, doi:10.1111/j.14622920.2004.00634.x, 2004.

Kroon, P. S., Hensen, A., Bulk, W. C. M., Jongejan, P. A. C., and Vermeulen, A. T.: The importance of reducing the systematic error due to non-linearity in $\mathrm{N}_{2} \mathrm{O}$ flux measurements by static chambers, Nutr. Cycl. Agroecosys., 82, 175-186, doi:10.1007/s10705-008-9179-x, 2008.

Kutzbach, L., Schneider, J., Sachs, T., Giebels, M., Nykänen, H., Shurpali, N. J., Martikainen, P. J., Alm, J., and Wilmking, M.: $\mathrm{CO}_{2}$ flux determination by closed-chamber methods can be seriously biased by inappropriate application of linear regression, Biogeosciences, 4, 1005-1025, doi:10.5194/bg-4-10052007, 2007.

Laine, A., Sottocornola, M., Kiely, G., Byrne, K. A., Wilson, D., and Tuittila, E.-S.: Estimating net ecosystem exchange in a patterned ecosystem: Example from blanket bog, Agr. Forest Meteorol., 18, 231-243, doi:10.1016/j.agrformet.2006.05.005, 2006.
Larmola, T., Tuittila, E.-S., Tiirola, M., Nykänen, H., Martikainen, P. J., Yrjälä, K., Tuomivirta, T., and Fritze, H.: The role of Sphagnum mosses in the methane cycling of a boreal mire, Ecology, 91, 2356-2365, doi:10.1890/09-1343.1, 2010.

Levy, P. E., Gray, A., Leeson, S. R., Gaiawyn, J., Kelly, M. P. C., Cooper, M. D. A., Dinsmore, K. J., Jones, S. K., and Sheppard, L. J.: Quantification of uncertainty in trace gas fluxes measured by the static chamber method, Eur. J. Soil Sci., 62, 811-821, doi:10.1111/j.1365-2389.2011.01403.x, 2011.

Livingston, G. P., Hutchinson, G. L., and Spartalian, K.: Diffusion theory improves chamber-based measurements of trace gas emissions, Geophys. Res. Lett., 32, L24817, doi:10.1029/2005GL024744, 2005.

Livingston, G. P., Hutchinson, G. L., and Spartalian, K.: Trace gas emission in chambers: a non-steady-state diffusion model, Soil Sci. Soc. Am. J., 70, 1459-1469, doi:10.2136/sssaj2005.0322, 2006.

Lohila, A., Minkkinen, K., Aurela, M., Tuovinen, J.-P., Penttilä, T., Ojanen, P., and Laurila, T.: Greenhouse gas flux measurements in a forestry-drained peatland indicate a large carbon sink, Biogeosciences, 8, 3203-3218, doi:10.5194/bg-8-3203-2011, 2011.

Lohila, A., Aalto, T., Aurela, M., Hatakka, J., Tuovinen, J.-P., Kilkki, J., Penttilä, T., Vuorenmaa, J., Hänninen, P., Sutinen, R., Viisanen, R., and Laurila, T.: Large contribution of boreal upland forest soils to a catchment-scale $\mathrm{CH}_{4}$ balance in a wet year, Geophys. Res. Lett., 43, 2946-2953, doi:10.1002/2016GL067718, 2016.

Luan, J. and Wu, J.: Long-term agricultural drainage stimulates $\mathrm{CH}_{4}$ emissions from ditches through increased substrate availability in a boreal peatland, Agr. Ecosyst. Environ., 214, 68-77, doi:10.1016/j.agee.2015.08.020, 2015.

Martikainen, P. J., Nykänen, H., Alm, J., and Silvola, J.: Change in fluxes of carbon dioxide, methane and nitrous oxide due to forest drainage of mire sites of different trophy, Plant Soil, 168, 571-577, doi:10.1007/BF00029370, 1995.

Mastepanov, M., Sigsgaard, C., Tagesson, T., Ström, L., Tamstorf, M. P., Lund, M., and Christensen, T. R.: Revisiting factors controlling methane emissions from high-Arctic tundra, Biogeosciences, 10, 5139-5158, doi:10.5194/bg-10-5139-2013, 2013.

Mikkelä, C., Sundh, I., Svensson, B. H., and Nilsson, M.: Diurnal variation in methane emission in relation to the water table, soil temperature, climate and vegetation cover in a Swedish acid mire, Biogeochemistry, 28, 93-114, doi:10.1007/BF02180679, 1995.

Minkkinen, K. and Laine, J.: Vegetation heterogeneity and ditches create spatial variability in methane fluxes from peatlands drained for forestry, Plant Soil, 285, 289-304, doi:10.1007/s11104-006-9016-4, 2006.

Minkkinen, K., Laine, J., Nykänen, H., and Martikainen, P. J.: Importance of drainage ditches in emissions of methane from mires drained for forestry, Can. J. Forest Res., 27, 949-952, doi:10.1139/cjfr-27-6-949, 1997.

Minkkinen, K., Penttilä, T., and Laine, J.: Tree stand volume as a scalar for methane fluxes in forestry-drained peatlands in Finland, Boreal Environ. Res., 12, 127-132, 2007.

Mohanty, S. R., Bodelier, P. L. E., and Conrad, R.: Effect of temperature on composition of the methanotrophic community in rice field and forest soil, FEMS Microbiol. Ecol., 62, 24-31, doi:10.1111/j.1574-6941.2007.00370.x, 2007. 
Montanarella, L., Jones, R. J. A., and Hiederer, R.: The distribution of peatland in Europe, Mires and Peat, 1, 1-10, 2006.

Moore, T. R. and Knowles, R.: The influence of water table levels on methane and carbon dioxide emissions from peatland soils, Can. J. Soil Sci., 69, 33-38, doi:10.4141/cjss89-004, 1989.

Nakano, T., Sawamoto, T., Morishita, T., Inoue, G., and Hatano, R.: A comparison of regression methods for estimating soil-atmosphere diffusion gas fluxes by a closed chamber technique, Soil Biol. Biochem., 36, 107-113, doi:10.1016/j.soilbio.2003.07.005, 2004.

Nickerson, N.: Evaluating gas emission measurements using Minimum Detectable Flux (MDF), Eosense Inc., Dartmouth, Nova Scotia, Canada, 2016.

Nykänen, H., Alm, J., Lång, K., Silvola, J., and Martikainen, P. J.: Emissions of $\mathrm{CH}_{4}, \mathrm{~N}_{2} \mathrm{O}$ and $\mathrm{CO}_{2}$ from a virgin fen and a fen drained for grassland in Finland, J. Biogeogr., 22, 351-357, doi:10.2307/2845930, 1995.

Nykänen, H., Alm, J., Silvola, J., Tolonen, K., and Martikainen, P. J.: Methane fluxes on boreal peatlands of different fertility and the effect of long-term experimental lowering of the water table on flux rates, Global Biogeochem. Cy., 12, 53-69, doi:10.1029/97GB02732, 1998.

Ojanen, P., Minkkinen, K., Alm, J., and Penttilä, T.: Soilatmosphere $\mathrm{CO}_{2}, \mathrm{CH}_{4}$ and $\mathrm{N}_{2} \mathrm{O}$ fluxes in boreal forestrydrained peatlands, Forest Ecol. Manage., 260, 411-421, doi:10.1016/j.foreco.2010.04.036, 2010.

Päivänen, J. and Hånell, B.: Peatland Ecology and Forestry - a Sound Approach, University of Helsinki Department of Forest Sciences Publications 3, 21 pp., 2012.

Pedersen, A. R., Petersen, S. O., and Schelde, K.: A comprehensive approach to soil-atmosphere trace-gas flux estimation with static chambers, Eur. J. Soil Sci., 61, 888-902, doi:10.1111/j.13652389.2010.01291.x, 2010.

Pihlatie, M., Christiansen, J. R., Aaltonen, H., Korhonen, J. F., Nordbo, A., Rasilo, T., Benanti, G., Giebels, M., Helmy, M., Sheehy, J., Jones, S., Juszczak, R., Klefoth, R., Lobo-do Vale, R., Rosa, A. P., Schreiber, P., Serça, D., Vicca, S., Wolf, B., and Pumpanen, J.: Comparison of static chambers to measure $\mathrm{CH}_{4}$ emissions from soils, Agr. Forest Meteorol., 171, 124-136, doi:10.1016/j.agrformet.2012.11.008, 2013.

Pirinen, P., Simola, H., Aalto, J., Kaukoranta, J.-P., Karlsson, P., and Ruuhela, R.: Climatological statistics of Finland 1981-2010, Reports, 2012:1, Finnish Meteorological Institute, Helsinki, Finland, 2012.

Pirk, N., Mastepanov, M., Parmentier, F.-J. W., Lund, M., Crill, P., and Christensen, T. R.: Calculations of automatic chamber flux measurements of methane and carbon dioxide using short time series of concentrations, Biogeosciences, 13, 903912, doi:10.5194/bg-13-903-2016, 2016.

Pumpanen, J., Kolari, P., Ilvesniemi, H., Minkkinen, K., Vesala, T., Niinistö, S., Lohila, A., Larmola, T., Morero, M., Pihlatie, M., Janssens, I. A., Yuste, J. C., Grünzweig, J. M., Reth, S., Subke, J.-A., Savage, K., Kutsch, W., Østreng, G., Ziegler, W., Anthoni, P., Lindroth, A., and Hari, P.: Comparison of different chamber techniques for measuring soil $\mathrm{CO}_{2}$ efflux, Agr. Forest Meteorol., 123, 159-176, doi:10.1016/j.agrformet.2003.12.001, 2004.
Ridgwell, A. J., Marshall, S. J., and Gregson, K.: Consumption of atmospheric methane by soils: a process-based model, Global Biogeochem. Cy., 13, 59-70, doi:10.1029/1998GB900004, 1999.

Roulet, N., Moore, T. R., Bubier, J., and Lafleur, P.: Northern fens: methane flux and climatic change, Tellus B, 44, 100-105, 1992.

Sabrekov, A. F., Glagolev, M. V., Alekseychik, P. K., Smolentsev, B. A., Terentieva, I. E., Krivenok, L. A., and Maksyutov, S. S.: A process-based model of methane consumption by upland soils, Environ. Res. Lett., 11, 075001, doi:10.1088/17489326/11/7/075001, 2016.

Savage, K., Moore, T. R., and Crill, P. M.: Methane and carbon dioxide exchanges between the atmosphere and northern boreal forest soils, J. Geophys. Res., 102, 29279-29288, doi:10.1029/97JD02233, 1997.

Savage, K., Phillips, R., and Davidson, E.: High temporal frequency measurements of greenhouse gas emissions from soils, Biogeosciences, 11, 2709-2720, doi:10.5194/bg-11-2709-2014, 2014.

Scheutz, C. and Kjeldsen, P.: Environmental factors influencing attenuation of methane and hydrochlorofluorocarbons in landfill cover soils, J. Environ. Qual., 33, 72-79, doi:10.2134/jeq2004.0072, 2004.

Segers, R.: Methane production and methane consumption: a review of processes underlying wetland methane fluxes, Biogeochemistry, 41, 23-51, doi:10.1023/A:1005929032764, 1998.

Singh, J. S., Singh, S., Raghubanshi, A. S., Singh, S., Kashyap, A. K., and Reddy, V. S.: Effect of soil nitrogen, carbon and moisture on methane uptake by dry tropical forest soils, Plant Soil, 196, 115-121, doi:10.1023/A:1004233208325, 1997.

Sundqvist, E., Mölder, M., Crill, P., Kljun, N., and Lindroth, A.: Methane exchange in a boreal forest estimated by gradient method, Tellus B, 67, 26688, doi:10.3402/tellusb.v67.26688, 2015.

Smith, K. A., Dobbie, K. E., Ball, B. C., Bakken, L. R., Sitaula, B. K., Hansen, S., Brumme, R., Borken, W., Christensen, S., Priemé, A., Fowler, D., Macdonald, J. A., Skiba, U., Klemedtsson, L., Kasimir-Klemedtsson, A., Degórska, A., and Orlanski, P.: Oxidation of atmospheric methane in Northern European soils, comparison with other ecosystems, and uncertainties in the global terrestrial sink, Glob. Change Biol., 6, 791-803, doi:10.1046/j.1365-2486.2000.00356.x, 2000.

Ueyama, M., Takeuchi, R., Takahashi, Y., Ide, R., Ataka, M., Kosugi, Y., Takahashi, K., and Saigusa, N.: Methane uptake in a temperate forest soil using continuous closedchamber measurements, Agr. Forest Meteorol., 213, 1-9, doi:10.1016/j.agrformet.2015.05.004, 2015.

Venterea, R. T.: Theoretical comparison of advanced methods for calculating nitrous oxide fluxes using non-steady state chambers, Soil Sci. Soc. Am. J., 77, 709-720, doi:10.2136/sssaj2013.01.0010, 2013.

Venterea, R. T., Spokas, K. A., and Baker, J. M.: Accuracy and precision analysis of chamber-based nitrous oxide gas flux estimates, Soil Sci. Soc. Am. J., 73, 1087-1093, doi:10.2136/sssaj2008.0307, 2009. 
Wang, J. M., Murphy, J. G., Geddes, J. A., Winsborough, C. L., Basiliko, N., and Thomas, S. C.: Methane fluxes measured by eddy covariance and static chamber techniques at a temperate forest in central Ontario, Canada, Biogeosciences, 10, 43714382, doi:10.5194/bg-10-4371-2013, 2013.
Wang, Z. P., DeLaune, R. D., Masscheleyn, P. H., and Patrick, W. H.: Soil redox and $\mathrm{pH}$ effects on methane production in a flooded rice soil, Soil Sci. Soc. Am., 57, 382-385, doi:10.2136/sssaj1993.03615995005700020016x, 1993. 

II

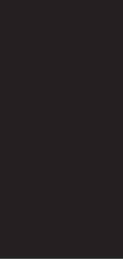





\title{
Greenhouse gas and energy fluxes in a boreal peatland forest after clear-cutting
}

\author{
Mika Korkiakoski ${ }^{1}$, Juha-Pekka Tuovinen ${ }^{1}$, Timo Penttilä ${ }^{2}$, Sakari Sarkkola ${ }^{2}$, Paavo Ojanen ${ }^{3}$, Kari Minkkinen ${ }^{3}$, \\ Juuso Rainne ${ }^{1}$, Tuomas Laurila ${ }^{1}$, and Annalea Lohila ${ }^{1}$ \\ ${ }^{1}$ Finnish Meteorological Institute, P.O. Box 503, 00101 Helsinki, Finland \\ ${ }^{2}$ Natural Resources Institute Finland, Viikinkaari 4, 00790 Helsinki, Finland \\ ${ }^{3}$ University of Helsinki, Department of Forest Sciences, P.O. Box 27, 00014 Helsinki, Finland
}

Correspondence: Mika Korkiakoski (mika.korkiakoski@fmi.fi)

Received: 5 November 2018 - Discussion started: 19 November 2018

Revised: 29 May 2019 - Accepted: 29 August 2019 - Published: 30 September 2019

\begin{abstract}
The most common forest management method in Fennoscandia is rotation forestry, including clear-cutting and forest regeneration. In clear-cutting, stem wood is removed and the logging residues are either removed or left on site. Clear-cutting changes the microclimate and vegetation structure at the site, both of which affect the site's carbon balance. Peat soils with poor aeration and high carbon densities are especially prone to such changes, and significant changes in greenhouse gas exchange can be expected. We measured carbon dioxide $\left(\mathrm{CO}_{2}\right)$ and energy fluxes with the eddy covariance method for 2 years (April 2016-March 2018) after clear-cutting a drained peatland forest. We observed a significant rise $(23 \mathrm{~cm})$ in the water table level and a large $\mathrm{CO}_{2}$ source (first year: $3086 \pm 148 \mathrm{~g} \mathrm{CO}_{2} \mathrm{~m}^{-2} \mathrm{yr}^{-1}$; second year: $2072 \pm 124 \mathrm{~g} \mathrm{CO}_{2} \mathrm{~m}^{-2} \mathrm{yr}^{-1}$ ). These large $\mathrm{CO}_{2}$ emissions resulted from the very low gross primary production (GPP) following the removal of photosynthesizing trees and the decline of ground vegetation, unable to compensate for the decomposition of logging residues and peat. During the second summer (June-August) after the clear-cutting, GPP had already increased by $96 \%$ and total ecosystem respiration decreased by $14 \%$ from the previous summer. The mean daytime ratio of sensible to latent heat flux decreased after harvesting from 2.6 in May 2016 to 1.0 in August 2016, and in 2017 it varied mostly within 0.6-1.0. In April-September, the mean daytime sensible heat flux was $33 \%$ lower and latent heat flux $40 \%$ higher in 2017 , probably due to the recovery of ground vegetation that increased evapotranspiration and albedo of the site. In addition to $\mathrm{CO}_{2}$ and energy fluxes, we measured methane $\left(\mathrm{CH}_{4}\right)$ and nitrous oxide $\left(\mathrm{N}_{2} \mathrm{O}\right)$
\end{abstract}

fluxes with manual chambers. After the clear-cutting, the site turned from a small $\mathrm{CH}_{4}$ sink into a small source and from $\mathrm{N}_{2} \mathrm{O}$ neutral to a significant $\mathrm{N}_{2} \mathrm{O}$ source. Compared to the large $\mathrm{CO}_{2}$ emissions, the 100-year global warming potential $\left(\mathrm{GWP}_{100}\right)$ of the $\mathrm{CH}_{4}$ emissions was negligible. Also, the $\mathrm{GWP}_{100}$ due to increased $\mathrm{N}_{2} \mathrm{O}$ emissions was less than $10 \%$ of that of the $\mathrm{CO}_{2}$ emission change.

\section{Introduction}

Northern peatlands cover approximately $3 \%$ of the Earth's land surface (Clarke and Rieley, 2010), most of which is located in the boreal region (Fischlin et al., 2007). Boreal and subarctic peatlands are substantial reservoirs of carbon (C), storing 270-550 Pg C in total (Turunen et al., 2002; Yu, 2011). These reservoirs are affected by peatland drainage, which has been a common practice in northern countries. In Finland, more than half of the original peatland area of $100000 \mathrm{~km}^{2}$ has been drained, mostly for forestry (Päivänen and Hånell, 2012). Drainage lowers water table level (WTL), which accelerates the peat decomposition rate due to the increased availability of oxygen (Drzymulska, 2016). This often leads to higher carbon dioxide $\left(\mathrm{CO}_{2}\right)$ emissions from the soil (Maljanen et al., 2010; Ojanen et al., 2013). On the other hand, a well-performed drainage increases root aeration and nutrient availability, which enhances tree growth and $\mathrm{CO}_{2}$ uptake by trees (Minkkinen et al., 2001). In addition, methane $\left(\mathrm{CH}_{4}\right)$ emissions decrease, and the soil may even turn into a net $\mathrm{CH}_{4}$ sink if the site is well-drained (Maljanen 
et al., 2010; Ojanen et al., 2010). This results from the thickening of the oxic peat layer, which enhances $\mathrm{CH}_{4}$ oxidation in the soil and from the disappearance of deep-rooted vascular plants, which in natural mires feed anaerobic microbes with fresh carbon and transport methane from the anoxic peat layer to atmosphere through their aerenchyma. In contrast to $\mathrm{CH}_{4}$, nitrous oxide $\left(\mathrm{N}_{2} \mathrm{O}\right)$ emissions often increase after drainage in nitrogen-rich minerotrophic peatlands (Maljanen et al., 2010; Ojanen et al., 2010, 2018) because nitrification (the process that produces nitrate and $\mathrm{N}_{2} \mathrm{O}$ as a by-product) needs nitrogen and oxic conditions.

The most common method of forest management in Finland is rotation forestry including clear-cutting and forest regeneration. In clear-cutting, stem wood is removed, while the logging residues, i.e. foliage biomass, branches, stumps and roots, are either removed or left on site. After clearcutting, the site is prepared, e.g. by mounding or scalping, and a new tree generation is established by planting or sowing or naturally from surrounding seed trees. Removing the trees changes the local microclimate as more solar radiation reaches the soil surface, which increases soil temperature (Edwards and Ross-Todd, 1983; Londo et al., 1999) and its diel variation. This affects the carbon cycle, as higher soil temperature potentially increases soil respiration. In peatland forests, however, removing tree biomass raises the WTL by diminishing transpiration (Sarkkola et al., 2010), which in turn may decrease soil respiration and slow down the peat decomposition rate due to the reduced volume of aerated peat. On the other hand, photosynthesis is diminished due to the removal of trees and decline of ground vegetation. Mäkiranta et al. (2010) found that ground vegetation recovers rather fast in a peatland forest after clear-cutting; however, after 3 years the recovery was still insufficient to compensate for the high ecosystem respiration produced by the large amount of fresh organic matter. The increase in ecosystem respiration is accounted for by the decay of logging residues and possibly also by increased soil organic matter decomposition under these residues (Mäkiranta et al., 2012; Ojanen et al., 2017). As boreal forest grows slowly, it may take from 8 up to 20 years to turn the forest back to a net carbon sink (Fredeen et al., 2007; Kolari et al., 2004; Mäkiranta et al., 2010; Pypker and Fredeen, 2002; Rannik et al., 2002; Schulze et al., 1999).

The $\mathrm{CO}_{2}$ and energy fluxes between ecosystems and the atmosphere are commonly measured with the eddy covariance (EC) method (Aubinet et al., 2012). Previous work concerning clear-cutting in forests with mineral soil has involved both EC (Clark et al., 2004; Humphreys et al., 2005; Kolari et al., 2004; Kowalski et al., 2004, 2003; Machimura et al., 2005; Mamkin et al., 2016; Takagi et al., 2009; Williams et al., 2013) and soil chambers (Howard et al., 2004; Londo et al., 1999; Zerva and Mencuccini, 2005). Also, soil chambers have been used on clear-cut peatland forests (Mäkiranta et al., 2010; Pearson et al., 2012), whereas EC measurements have been lacking. In addition, most of this peatland forest gas exchange research has concentrated on carbon dynamics and overlooked the possibly important variations in energy and water fluxes.

Exchange of sensible and latent heat constitutes an important part of the surface energy balance, driving many local, regional- and global-scale climatological processes. The available energy for these turbulent fluxes is determined predominantly by net radiation and the ground heat flux. The partitioning of available energy between the sensible and latent heat fluxes, which can be described in terms of the Bowen ratio, is strongly influenced by vegetation and soil properties (Betts et al., 2007). Also, release of latent heat to the atmosphere, i.e. evapotranspiration, is a key component of the water cycle in peatlands and forests, also affecting soil moisture and forest productivity, which further affect the GHG fluxes in a forest. In a temperate deciduous broadleaf forest, evapotranspiration has been found to recover rapidly after clear-cutting: the latent heat flux increased over the first 3 years, while the sensible heat flux declined correspondingly (Williams et al., 2013). It is unknown if this also happens in peatland forests.

In this study, we investigated the GHG and energy fluxes between the forest floor and the atmosphere and their environmental drivers after clear-cutting in a boreal peatland forest in southern Finland. The study was based on EC measurements made for 2 years (April 2016-March 2018) after clear-cutting and on soil chamber measurements performed during the period of June 2015-August 2017. Our specific aims were as follows:

1. to estimate the magnitude of $\mathrm{CO}_{2}$ fluxes and their environmental drivers after clear-cutting,

2. to quantify the development of surface heat fluxes after clear-cutting,

3. to investigate how soil $\mathrm{CH}_{4}$ and $\mathrm{N}_{2} \mathrm{O}$ fluxes change due to clear-cutting.

\section{Materials and methods}

\subsection{Measurement site}

The measurements were set up in a nutrient-rich peatland forest called Lettosuo, which is located in southern Finland $\left(60^{\circ} 38^{\prime} \mathrm{N}, 23^{\circ} 57^{\prime} \mathrm{E}\right)$. The site was drained with widely spaced, manually dug ditches probably during the 1930s, then drained more effectively in 1969 and fertilized with phosphorus and potassium. The distance between the ditches is on average $45 \mathrm{~m}$, and they were dug ca. $1 \mathrm{~m}$ deep but have since been partially filled with vegetation. After drainage and before clear-cutting in 2016, the tree stand was dominated by Scots pine (Pinus sylvestris), with some pubescent birch (Betula pubescens). The understorey included mostly Norway spruce (Picea abies) and some small-sized pubescent birch. The tree stand was quite dense, which made the ground 
vegetation and moss layer patchy and variable due to irregular shading. Ground vegetation included herbs, such as Trientalis europaea and Dryopteris carthusiana, and dwarf shrubs, such as Vaccinium myrtillus (Bhuiyan et al., 2017). The moss layer was dominated by Pleurozium schreberi and Dicranum polysetum, with some Sphagnum mosses, such as Sphagnum capillifolium, $S$. angustifolium and S. russowii, in moist patches.

Before clear-cutting, the average soil organic carbon content at the site was $58 \%$ and carbon distribution was rather uniform across different soil layers (Table 1). The total soil nitrogen content was lowest in the litter layer (1.7\%) and varied from $2.2 \%$ up to $2.5 \%$ among the other soil layers. The $\mathrm{C}: \mathrm{N}$ ratio averaged at 27 , which is typical for peatland forests with a fen history. The mean soil bulk density of the $0-40 \mathrm{~cm}$ layer was $0.14 \mathrm{~g} \mathrm{~cm}^{-3}$. The present-day peat thickness at Lettosuo varies mostly between 1.5 and $2.5 \mathrm{~m}$. Assuming a thickness of $2 \mathrm{~m}$ results in soil organic carbon and nitrogen stock estimates of $156 \pm 72 \mathrm{~kg} \mathrm{C} \mathrm{m}^{-2}$ and $6.4 \pm 2.9 \mathrm{~kg} \mathrm{~N} \mathrm{~m}^{-2}( \pm \mathrm{SD})$, respectively.

Clear-cutting was performed within a trapezoidal area of $23500 \mathrm{~m}^{2}$ (Fig. 1) between 29 February and 16 March 2016. After clear-cutting, the logging residues were left at the site. The previous ground vegetation was almost totally destroyed in the harvesting operation and the following drastic increase in solar radiation. In the following summer, some species adapted to the open, well-lit conditions; for example, Rubus idaeus, Carex canescens and Dryopteris carthusiana were observed here and there within the clear-cut site. Mounding was performed on 1-2 August 2016, and spruce (Picea abies) seedlings were planted in 2017. In addition to the clear-cut site, we conducted GHG measurements on a similarly sized control site located southwest of the clear-cut site, where the forest was left in its original state with similar tree stand and vegetation composition to at the preharvest clear-cut site.

\subsection{Measurement system}

An EC system to measure turbulent $\mathrm{CO}_{2}$ and energy fluxes was set up in the northeastern part of the clear-cut (Fig. 1), and the measurements started on 8 April 2016, approximately 3 weeks after the clear-cutting had ended. The measurements continued until 7 April 2018. From this point on, the time periods of 8 April 2016-7 April 2017 and 8 April 2017-7 April 2018 are referred to as the first and second EC measurement year, respectively. The EC system included a three-axis sonic anemometer (uSonic-3 Scientific, METEK, Elmshorn, Germany) for wind speed and air temperature and a closed-path infrared gas analyser (LI-7000, Licor Biosciences, Lincoln, NE, USA) for $\mathrm{CO}_{2}$ and $\mathrm{H}_{2} \mathrm{O}$ mixing ratios. A sampling rate of $10 \mathrm{~Hz}$ was used for the EC system. The measurement height was $2.75 \mathrm{~m}$, the flow rate was about $6 \mathrm{~L} \mathrm{~min}^{-1}$ and the length of the inlet tube (inner diameter $3.1 \mathrm{~mm}$, Bevaline IV) was $8 \mathrm{~m}$. The mouth of the inlet tube was positioned $15 \mathrm{~cm}$ below the sonic anemometer.
Air with a zero $\mathrm{CO}_{2}$ concentration was used as the reference gas when calibrating the gas analyser. The micrometeorological sign convention is used throughout the paper: a positive flux indicates a flux from the ecosystem to the atmosphere (net emission) and a negative flux indicates a flux from the atmosphere into the ecosystem (net uptake).

Auxiliary meteorological measurements were installed at the centre of the clear-cut ( $80 \mathrm{~m}$ south of the EC mast) on 24 July 2015, i.e. before the clear-cutting. A similar system was installed 2 weeks earlier for the control site $(180 \mathrm{~m}$ southeast of the EC mast). Air temperature and relative humidity were measured at $2 \mathrm{~m}$ height (HMP155, Vaisala Corporation, Vantaa, Finland) and soil temperature profile was measured at 5, 10, 20 and $30 \mathrm{~cm}$ depths (Pt100, Vaisala Corporation, Vantaa, Finland); the measurements also included net radiation (NR Lite2 Net Radiometer, Kipp \& Zonen, Delft, The Netherlands), photosynthetically active photon flux density (PPFD) (PQS1 PAR Quantum Sensor, Kipp \& Zonen, Delft, the Netherlands) and ground heat flux (HFP01, Hukseflux Thermal Sensors B.V., Delft, the Netherlands). In addition to these, global radiation (Pyranometer CMP3, Kipp \& Zonen, Delft, The Netherlands) was measured from another EC mast above the canopy of the surrounding forest ( $250 \mathrm{~m}$ south from the clear-cut EC mast). The data were collected by data loggers (QML201C, Vaisala Corporation, Vantaa, Finland) as $30 \mathrm{~min}$ averages.

\subsection{EC data processing}

Half-hourly turbulent fluxes were calculated using standard EC methods (Aubinet et al., 2012). The $10 \mathrm{~Hz}$ raw data were block-averaged, and a double rotation of the coordinate system was applied (McMillen, 1988). The time lag between the gas analyser and sonic anemometer signals was determined by cross-correlation analysis for each flux variable and $30 \mathrm{~min}$ period. Water vapour fluctuations affecting flux measurements with LI-7000 were compensated for (Webb et al., 1980); a corresponding compensation is not necessary for temperature (Rannik et al., 1997). The fluxes were corrected for systematic losses due to block averaging and attenuation of the highest frequencies in the cospectra between vertical wind speed and mixing ratio; the transfer function method of Moore (1986) was used for this. For the high-frequency losses, the transfer functions describing the flux attenuation were determined separately for $\mathrm{CO}_{2}$ and water vapour fluxes (with half-power frequencies of 1.3 and $0.6 \mathrm{~Hz}$, respectively) using temperature cospectra as the reference. These functions were convoluted with generic cospectral distributions (Kaimal and Finnigan, 1994) to calculate the flux correction as a function of wind speed and atmospheric stability.

The $30 \mathrm{~min}$ averaged data were screened according to the following acceptance criteria: relative stationarity (Foken and Wichura, 1996) < 100\%, internal LI-7000 pressure $>60 \mathrm{kPa}, \mathrm{CO}_{2}$ mixing ratio $>350 \mathrm{ppm}$, wind direction within $80-315^{\circ}$, number of spikes in the vertical wind speed 
Table 1. Mean soil organic carbon, nitrogen, $\mathrm{C}: \mathrm{N}$ ratio, bulk density and their standard deviation in different soil layers determined before the harvest $(n=3-33)$.

\begin{tabular}{lrrrr}
\hline Layer & Soil organic carbon $(\%)$ & Soil nitrogen $(\%)$ & $\mathrm{C}: \mathrm{N}$ ratio & Bulk density $\left(\mathrm{g} \mathrm{cm}^{-3}\right)$ \\
\hline Litter & $56.2 \pm 2.3$ & $1.7 \pm 0.4$ & $33.2 \pm 2.3$ & $0.005 \pm 0.003$ \\
$0-10 \mathrm{~cm}$ & $55.2 \pm 2.1$ & $2.2 \pm 0.2$ & $24.9 \pm 2.1$ & $0.12 \pm 0.03$ \\
$10-20 \mathrm{~cm}$ & $58.9 \pm 1.6$ & $2.5 \pm 0.2$ & $23.8 \pm 1.6$ & $0.18 \pm 0.02$ \\
$20-30 \mathrm{~cm}$ & $59.1 \pm 0.8$ & $2.4 \pm 0.2$ & $24.6 \pm 0.8$ & $0.13 \pm 0.03$ \\
$30-40 \mathrm{~cm}$ & $59.2 \pm 0.3$ & $2.2 \pm 0.1$ & $26.4 \pm 0.3$ & $0.13 \pm 0.04$ \\
\hline
\end{tabular}

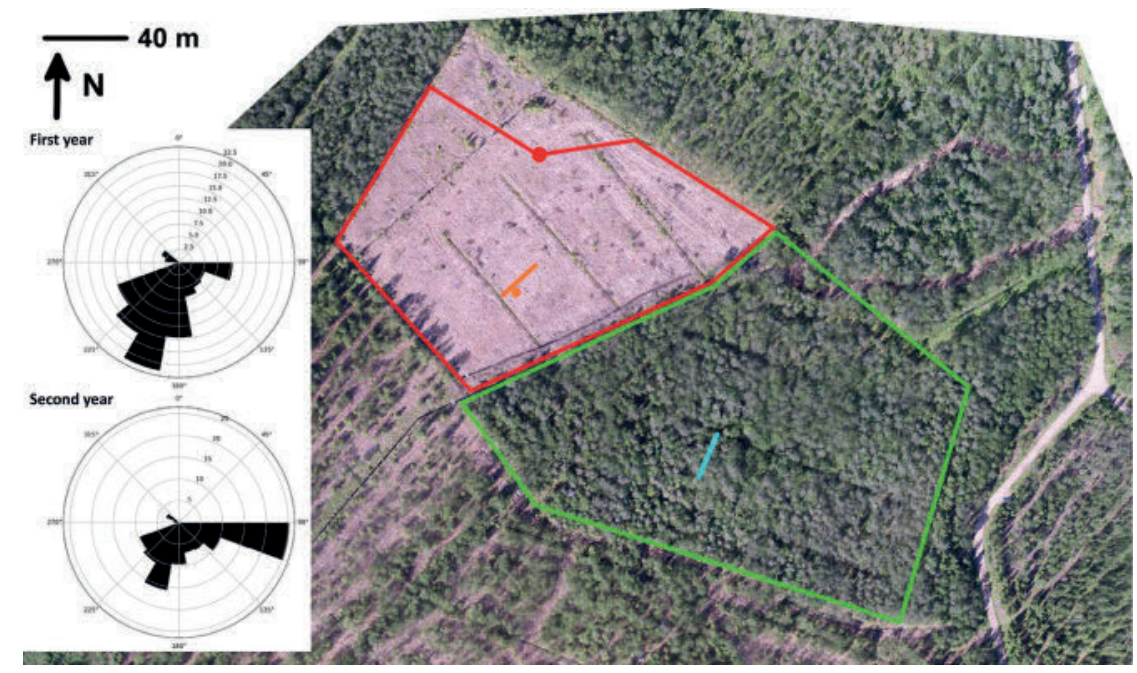

Figure 1. Aerial view of the clear-cut site and the surrounding forest at Lettosuo. The red dot shows the location of the eddy covariance mast, and the red lines surround the target area $\left(80-315^{\circ}\right)$. The meteorological measurements were conducted at the location indicated by the orange dot, while the orange line marks the water table, soil temperature and chamber measurements $(4,8,12$ and $22.5 \mathrm{~m}$ from the ditch). Similar measurements of greenhouse gas fluxes, water table and soil temperature within the control site, surrounded by the green lines, are shown with a light blue line. The wind roses on the left show the cumulative footprint contributions (in percentage) of the accepted flux data.

and $\mathrm{CO}_{2}$ concentration data $<150$ of 18000 . Also, the periods of weak turbulence were discarded by applying a friction velocity $\left(u_{*}\right)$ limit of $0.125 \mathrm{~m} \mathrm{~s}^{-1}$ (Fig. S1 in the Supplement). In addition, the footprint accumulated within the target area shown in Fig. 1 was required to exceed a limit of 0.75 to ensure that the measured flux originated predominantly from the clear-cut site. The footprints were calculated using the model developed by Kormann and Meixner (2001) and input data measured with the sonic anemometer.

In addition to the vertical turbulent fluxes, the $\mathrm{CO}_{2}$ fluxes associated with the storage of $\mathrm{CO}_{2}$ below the measurement height were calculated from the change in the mean $\mathrm{CO}_{2}$ concentration profile between consecutive half-hour periods. It was assumed that the $\mathrm{CO}_{2}$ concentration in the air column from ground level to the measurement height of $2.75 \mathrm{~m}$ was constant.

There were only two periods when a measurement gap in the data was longer than 5 d: 30 September-5 October 2016 and 28 April-4 May 2017. After applying all the data filters described above, $30 \%$ of the 32635 half-hour periods recorded within the measurement period were accepted for further analysis (Table S1, Fig. S2 in the Supplement). The gap-filling procedure and uncertainty analysis of the net ecosystem exchange of $\mathrm{CO}_{2}$ (NEE) are described in Appendices $\mathrm{A}$ and $\mathrm{B}$.

\subsection{Surface energy balance and Bowen ratio}

The surface energy balance can be expressed as

$Q_{\mathrm{H}}+Q_{\mathrm{E}}=Q_{\mathrm{N}}-Q_{\mathrm{G}}-Q_{\mathrm{S}}$,

where $Q_{\mathrm{H}}$ is sensible heat flux, $Q_{\mathrm{E}}$ is latent heat flux, $Q_{\mathrm{N}}$ is net radiation, $Q_{\mathrm{G}}$ is the ground heat flux, and $Q_{\mathrm{S}}$ is the sum of storage fluxes from other energy sinks and sources. In this study, we assumed that $Q_{\mathrm{S}}=0$. 
The Bowen ratio, defined as

$\beta=\frac{Q_{\mathrm{H}}}{Q_{\mathrm{E}}}$,

is used to describe the partitioning of $Q_{\mathrm{N}}-Q_{\mathrm{G}}$ to $Q_{\mathrm{H}}$ and $Q_{\mathrm{E}}$ at the surface. When $\beta<1$, more available energy at the surface is released to the atmosphere as latent heat than as sensible heat (and vice versa when $\beta>1$ ). In this study, we present monthly Bowen ratios that were calculated from the monthly mean daytime (10:00-16:00, UTC +2 ) fluxes of $Q_{\mathrm{H}}$ and $Q_{\mathrm{E}}$.

Gap-filling of the energy fluxes is described in Appendix C.

\subsection{Chamber measurements of GHG fluxes}

For manual chamber measurements, sampling transects were set up within the clear-cut and control sites, where the GHG fluxes were measured between 29 June 2015 and 29 August 2017 , mostly during the snow-free periods. The measurement interval varied between 1 week and 1 month, but there were longer gaps in autumn 2015 and spring 2016. The transect had two flux measurement plots at a distance of $4,8,12$ and $22.5 \mathrm{~m}$ from the ditch, and at each distance there was an automatic WTL logger close to the flux measurement plots (see Sect. 2.7 for details). In addition, all the flux plots included a soil temperature data logger (iButton DS1921G, Maxim Integrated Products) at $5 \mathrm{~cm}$ depth and two of them ( 8 and $22.5 \mathrm{~m}$ from the ditch) also had a similar logger at $30 \mathrm{~cm}$ depth. Before starting the measurements, $2 \mathrm{~cm}$ deep grooves were carved into the soil surface for the chambers, and the grooves were occasionally renewed when necessary to keep the chamber-sealing adequate. It should be noted that, even though logging residues were left at the site, the measurement plots did not have any above-ground residues. The fluxes were measured using a closed-chamber system with an opaque cylindrical chamber (height $30.5 \mathrm{~cm}$, diameter $31.5 \mathrm{~cm}$ ) including a mixing fan. The measurements were made in two different ways: using (1) a portable analyser and (2) a stationary analyser. As a portable analyser, we employed a Gasmet DX4015 (Gasmet Technologies Oy, Helsinki, Finland), based on Fourier transform infrared spectroscopy, to measure $\mathrm{CO}_{2}, \mathrm{CH}_{4}$ and $\mathrm{N}_{2} \mathrm{O}$ mixing ratios every $5 \mathrm{~s}$. At the clear-cut site, only the portable gas analyser was used. In this setup, the sampled air was circulated in a loop between the gas analyser and the chamber, and the closure time was 10-11 min. At the control site, the portable analyser was used in 2015 for all the gases, but from 2016 onwards the analyser was used only for measuring the $\mathrm{N}_{2} \mathrm{O}$ mixing ratios. Starting from 2016 at the control site, we connected the portable gas analyser in series with a Picarro G1130 cavity ring-down spectroscopy gas analyser (Picarro Inc., Santa Clara, CA, USA) to acquire more precise $\mathrm{CO}_{2}$ and $\mathrm{CH}_{4}$ mixing ratios. In this system, the gas analysers were stored in a cabin and connected to the chamber with $50 \mathrm{~m}$ long tub- ing. The instruments were compared against each other and observed to result in very similar flux estimates with the 10 11 min closure time. The error caused by not returning the sampled air back to the chamber was corrected for in the data analysis.

The fluxes were calculated the same way for all the gases (Korkiakoski et al., 2017). In short, both linear and exponential regression models were first fitted to the mixing ratio time series using the least-squares approach. The start and end points of the chamber closure were visually identified from the data for each closure. The first minute of each measurement was discarded to ensure that the sample air was properly mixed inside the chamber. After fitting, the mass flux $(F)$ was calculated as

$$
F=\left(\frac{\mathrm{d} C(t)}{\mathrm{d} t}\right)_{t=0} \frac{\mathrm{MPV}}{\mathrm{RTA}},
$$

where $\left(\frac{\mathrm{d} C(t)}{\mathrm{d} t}\right)_{t=0}$ is the mixing ratio change in time determined from a linear or exponential model at the beginning of the closure; $M$ is the molecular mass of $\mathrm{CO}_{2}, \mathrm{CH}_{4}$, or $\mathrm{N}_{2} \mathrm{O}$ (44.01, 16.04 and $44.01 \mathrm{~g} \mathrm{~mol}^{-1}$, respectively); $P$ is air pressure; $R$ is the universal gas constant $\left(8.314 \mathrm{~J} \mathrm{~mol}^{-1} \mathrm{~K}^{-1}\right) ; T$ is the mean chamber headspace temperature during closure; and $V$ and $A$ are the volume and the base area of the chamber headspace, respectively. The snow depth and the height of mosses and other vegetation in the chamber headspace volume were taken into account, ignoring the pore space in the soil and snow. However, if the soil surface was frozen, the measurements were not made as it was not possible to properly seal the chamber. Finally, analyser-specific flux limits were determined to choose between the linear and exponential models (Korkiakoski et al., 2017). If the flux calculated with the linear model was smaller than the limit, then this estimate was considered more robust for the noisy data and adopted for the later analysis. These limits for the portable system were $5.6 \mu \mathrm{g} \mathrm{CO}_{2} \mathrm{~m}^{-2} \mathrm{~s}^{-1}, 9.7 \mathrm{ng} \mathrm{CH}_{4} \mathrm{~m}^{-2} \mathrm{~s}^{-1}$ and $12.5 \mathrm{ng} \mathrm{N}_{2} \mathrm{O} \mathrm{m}^{-2} \mathrm{~s}^{-1}$. We did not define a corresponding limit for the $\mathrm{CO}_{2}$ flux measured with the Picarro gas analyser at the control site as the fluxes were always sufficiently large for using exponential fitting, but for $\mathrm{CH}_{4}$ the limit was set to $0.7 \mathrm{ng} \mathrm{CH}_{4} \mathrm{~m}^{-2} \mathrm{~s}^{-1}$.

The $\mathrm{CO}_{2}$ flux measured with chambers represents forest floor respiration $\left(R_{\mathrm{ff}}\right)$, which is defined as the sum of heterotrophic and autotrophic respiration. As clear-cutting affects soil processes, it should be noted that the $R_{\mathrm{ff}}$ before and after clear-cutting consists of different components. Before the clear-cutting (the 2015 data), $R_{\mathrm{ff}}$ includes ground vegetation and living roots of trees and ground vegetation, but after clear-cutting (2016-2017) it instead includes the survived and regrown ground vegetation and living and dead roots.

The summertime sum of $R_{\mathrm{ff}}$ was calculated for each summer separately by using Eq. (A3) with hourly soil temperature at $5 \mathrm{~cm}$ depth. The uncertainty of this sum was estimated from the minimum and maximum sums based on the stan- 
dard errors of model parameters $\left(R_{0}\right.$ and $\left.E\right)$. The minimum and maximum sums were slightly asymmetrical around the mean sum, so the largest deviation from the mean sum was adopted as a conservative uncertainty estimate.

\subsection{Water table level measurements and analysis}

The water table levels within both the clear-cut and nonmanaged control site were measured for 1 year before (2015) and 2 years after the clear-cutting (2016-2017). Four automatic monitoring plots consisting of dipwells (perforated plastic tubes $120 \mathrm{~cm}$ long and $3.5 \mathrm{~cm}$ in diameter) were set up at the centre of each site (Fig. 1), located at a distance of 4, 8, 12 and $22.5 \mathrm{~m}$ in a transect perpendicular to the ditch (ditch spacing was $45 \mathrm{~m}$ ). In addition, in order to calibrate the automatic water table measurement data, manually monitored dipwells were installed close to the automatically monitored dipwells within the clear-cut and control sites. WTL was measured manually at weekly or fortnightly intervals during March-November. From the automated dipwells, WTL was recorded with automatic probes (TruTrack WT-HR-logger, Intech Instruments Ltd, Auckland, New Zealand; Odyssey Capacitance Water Level Logger, Dataflow Systems Limited, Christchurch, New Zealand) at hourly intervals. The recorded values were then calibrated with linear regression using the manually measured WTL data from both the control and clear-cut site.

\subsection{Statistical analysis}

The linear mixed-effect model was used for testing for differences in the daily mean $\mathrm{CO}_{2}, \mathrm{CH}_{4}$ and $\mathrm{N}_{2} \mathrm{O}$ fluxes between the clear-cut and control sites and between the years in the chamber measurement data. In both cases, the chamber plots were treated as a random effect. The fixed effects of the model were the site type (clear-cut or control) and the measurement year when comparing the measurements made at different sites and in different years, respectively. The linear mixed-effect model was carried out with the $\mathrm{R}$ programming language (R Core Team, 2018, version 3.5.0) using the "Ime4" package. The normality of model residuals was visually checked using quantile-quantile plots. The differences were tested with Tukey's honestly significant difference post hoc test.

The analysis of the clear-cutting effects on WTL was based on the paired treatment approach (also called calibration period - control area method) (e.g. Kaila et al., 2014; Laurén et al., 2009). We first calculated linear regressions between the WTL within the control and clear-cut sites for the pretreatment period using the WTL logger data from 2015. Then we used this regression model and the post-treatment WTL data from the control site to predict WTL for the clearcut site as if it had not been harvested. The clear-cut effect was calculated as the difference between the calibrated post- clear-cut WTL measurements and the predicted background WTL values in the clear-cut site after the harvest.

\section{Results}

\subsection{Meteorological and hydrological conditions}

The long-term (1981-2010) mean annual, winter (DJF) and summer (JJA) air temperatures at the nearby (Jokioinen, $35 \mathrm{~km}$ northwest of Lettosuo) weather station were 4.6 , -5.3 and $15.2^{\circ} \mathrm{C}$, respectively (Pirinen et al., 2012). The mean annual temperature before the clear-cutting in 2015 at Jokioinen was $6.2^{\circ} \mathrm{C}$. Also, the winter (2015-2016) before the clear-cutting was warmer $\left(-3.4^{\circ} \mathrm{C}\right)$, while summer 2015 was colder $\left(14.4^{\circ} \mathrm{C}\right)$ than the long-term mean. The mean post-clear-cut annual air temperatures at the EC site during the first and second EC measurement year were 5.6 and $4.4^{\circ} \mathrm{C}$, respectively (Fig. 2a); this difference was reflected in soil temperatures (Fig. 2b). Both post-clear-cut winters were warmer $\left(2016-2017:-3.0^{\circ} \mathrm{C} ; 2017-2018:-3.4^{\circ} \mathrm{C}\right.$ ) than the long-term average. However, the mean summer temperature at the EC site in 2016 was similar to $\left(15.3^{\circ} \mathrm{C}\right)$, and in 2017 was cooler (by $1.6^{\circ} \mathrm{C}$ ) than, in 1981-2010. In addition, compared to the precipitation at Jokioinen (long-term average $627 \mathrm{~mm}$ ), the first EC measurement year was drier $(502 \mathrm{~mm})$ and the second year similar $(656 \mathrm{~mm})$ (Fig. 2c), while the pre-clear-cut year of 2015 was wetter $(680 \mathrm{~mm})$ than both post-clear-cut years. The autumn (SON) 2016 and winter 2016-2017 were especially dry, while the springs and summers were quite similar to the long-term average conditions.

Both winters had a shallower snow cover than the longterm average annual maximum $(28 \mathrm{~cm}$; Pirinen et al., 2012). The maximum snow depths at Jokioinen were 12 and $22 \mathrm{~cm}$ in 2016-2017 and 2017-2018, respectively. Due to the especially shallow snow cover in the first winter and the high temperatures in March, all the snow had melted by 23 March 2017 (Fig. 2d). However, in 2018, the snow cover was still intact when the measurement period ended on 7 April.

The preharvest soil temperatures at $30 \mathrm{~cm}$ depth were similar within the clear-cutting and control sites, but clear-cutting increased their temporal variation (Fig. S3). After clearcutting in late spring, the daily mean $30 \mathrm{~cm}$ soil temperature rose faster and was higher throughout the summer within the clear-cut than at the control site. Also, the $30 \mathrm{~cm}$ temperature within the clear-cut started to decline earlier in autumn and was lower during winter within the clear-cut than the control site. The monthly mean diel variation in soil temperature at $5 \mathrm{~cm}$ depth ranged from 0.8 to $1.3^{\circ} \mathrm{C}$ in JulySeptember 2015 before clear-cutting (Fig. S4). After clearcutting, this variation increased to $2.3-2.9$ and $2.1-3.7^{\circ} \mathrm{C}$ in 2016 and 2017, respectively. On average the diel variation was $1.8^{\circ} \mathrm{C}$ larger in July-September after the clear-cutting 

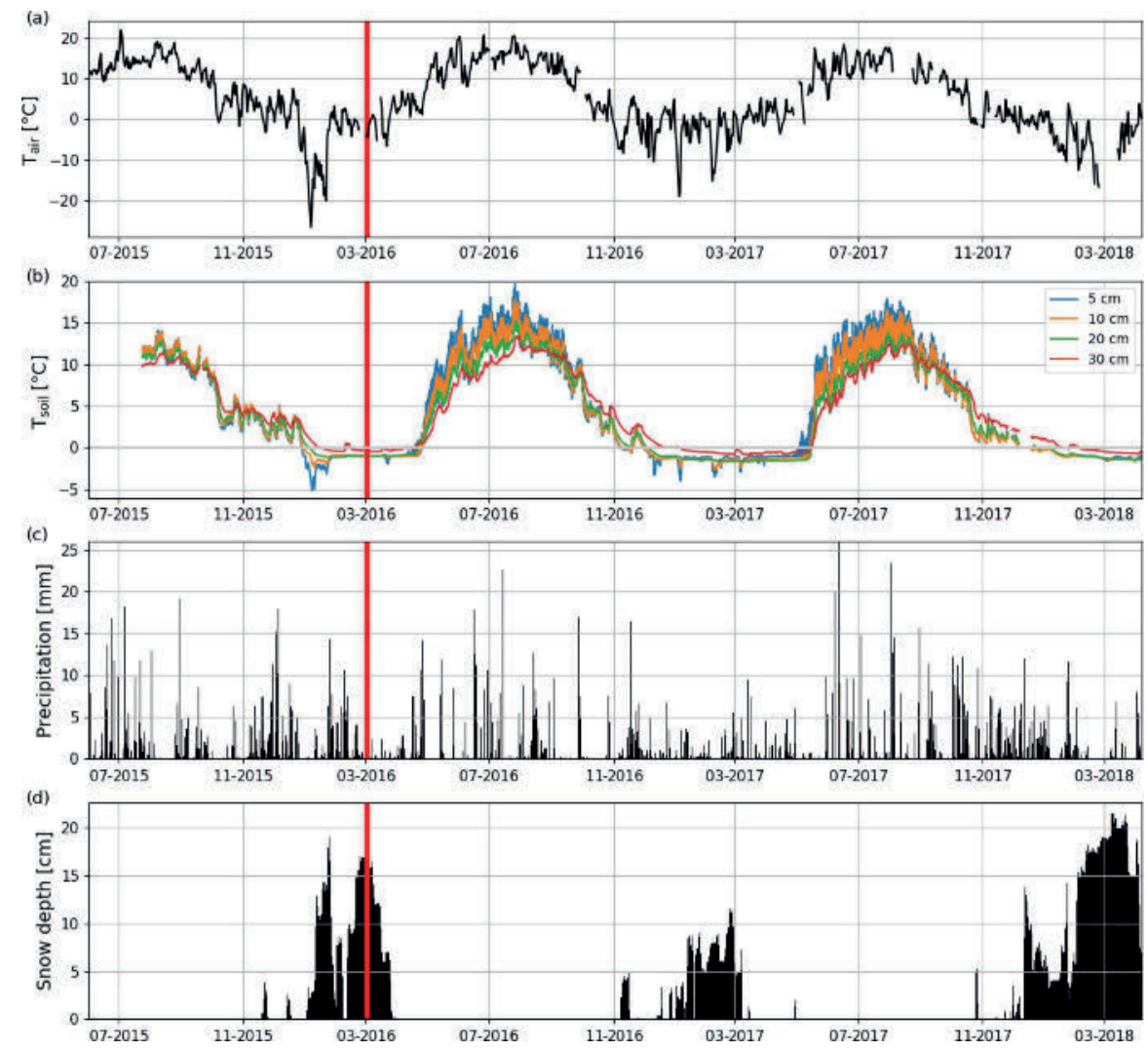

Figure 2. Time series of (a) daily mean air temperature $\left(T_{\text {air }}\right)$ and (b) hourly mean soil temperatures at $5,10,20$, and $30 \mathrm{~cm}$ depths $\left(T_{\text {soil }}\right)$ measured at Lettosuo, and (c) daily precipitation sum and (d) daily mean snow level recorded at the Jokioinen observatory ( $35 \mathrm{~km}$ northwest of Lettosuo). The clear-cutting (red vertical line) was carried out in February-March 2016.

than before it (Figs. 2b and S4). Increases in the diel temperature range were also observed at the $10 \mathrm{~cm}\left(1.2^{\circ} \mathrm{C}\right)$ and $20 \mathrm{~cm}\left(0.33^{\circ} \mathrm{C}\right)$ depths but not at $30 \mathrm{~cm}$.

The mean WTL in July-August 2015 was $-33 \mathrm{~cm}$ within the clear-cut area, while at the control site it was $-50 \mathrm{~cm}$ (Fig. 3). After clear-cutting, the WTL rose and remained continuously at a markedly higher level than the predicted background WTL and the measured WTL at the control site. At the clear-cut site, the WTL rose to -22 and $-27 \mathrm{~cm}$ in JulyAugust 2016 and 2017, respectively. On the other hand, the WTL at the control site sank to $-55 \mathrm{~cm}$ during these months in both post-harvest years. The largest post-treatment rise occurred in July-October when the average WTL was -23 and $-24 \mathrm{~cm}$ in the clear-cut and -46 and $-49 \mathrm{~cm}$ in the background model, corresponding to a 23 and $25 \mathrm{~cm}$ rise in WTL in 2016 and 2017, respectively (Fig. 3). As a consequence of heavy rain episodes in summer and autumn in 2017, the amplitude of WTL variations was larger then than the previous year.

\section{2 $\mathrm{CO}_{2}$ exchange on an ecosystem level}

\subsubsection{Seasonal and diel variations}

When the measurements started at the beginning of April 2016, the daily mean NEE was mainly $<0.08 \mathrm{mgCO}_{2} \mathrm{~m}^{-2} \mathrm{~s}^{-1}$ but started to increase with temperature at the end of April, after the daily mean temperature exceeded $5{ }^{\circ} \mathrm{C}$ (Figs. $2 \mathrm{a}$ and 4 ). There was a substantial temporary drop in NEE in the first half of June after a cold spell when the daily mean temperature decreased from 20 to $10^{\circ} \mathrm{C}$. By the end of June, NEE stabilized at around $0.21 \mathrm{mg} \mathrm{CO}_{2} \mathrm{~m}^{-2} \mathrm{~s}^{-1}$. From the end of August, NEE decreased until reaching a stable level of $0.03 \mathrm{mg} \mathrm{CO}_{2} \mathrm{~m}^{-2} \mathrm{~s}^{-1}$ in January 2017. At the end of March 2017, NEE started to gradually increase, and in mid-May it quickly rose to $0.08 \mathrm{mg} \mathrm{CO}_{2} \mathrm{~m}^{-2} \mathrm{~s}^{-1}$. After this, NEE continued to increase, stabilizing at around $0.13 \mathrm{mg} \mathrm{CO}_{2} \mathrm{~m}^{-2} \mathrm{~s}^{-1}$ in August and then decreasing from the end of September onwards. 


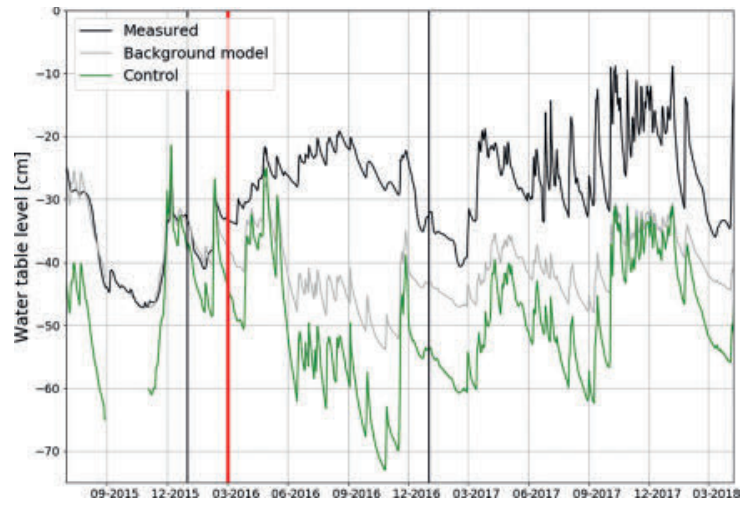

Figure 3. Mean daily water table level at the control site (measured; green) and the clear-cut site with (measured; black line) and without (estimated; grey line) the harvesting effect averaged over all the measurement points $(4,8,12$ and $22.5 \mathrm{~m}$ from the ditch) from June 2015 to October 2017. The clear-cutting (red vertical line) was carried out in February-March 2016.

Even though all the big trees were removed in clearcutting and most of the ground vegetation was destroyed, some small understorey trees were left at the site and weak photosynthesis could be observed simultaneously with the increased respiration in the end of April 2016 (Fig. 4). In May, the estimated magnitude of gross primary production (|GPP|, Appendix A) increased to $0.05 \mathrm{mg} \mathrm{CO}_{2} \mathrm{~m}^{-2} \mathrm{~s}^{-1}$, which was about $25 \%$ of the respiration rate at that time. However, $|\mathrm{GPP}|$ decreased to $0.02 \mathrm{mg} \mathrm{CO}_{2} \mathrm{~m}^{-2} \mathrm{~s}^{-1}$ in June, after which it started to increase again, reaching its maximum at $0.08 \mathrm{~g} \mathrm{CO}_{2} \mathrm{~m}^{-2} \mathrm{~s}^{-1}$ at the end of July and the beginning of August. From that point on, photosynthesis started to weaken, marking the ending of the growing season, and ceased in mid-October, about a month before the first snow. In 2017, |GPP| increased from mid-May until July, when it stabilized at around $0.11 \mathrm{mg} \mathrm{CO}_{2} \mathrm{~m}^{-2} \mathrm{~s}^{-1}$. Similarly to in 2016, $\mid$ GPP $\mid$ decreased from August onwards.

The correlation between the night-time NEE (i.e. $R_{\text {eco }}$ in Eq. A3) and the $5 \mathrm{~cm}$ soil temperature was stronger in summer 2017 than 2016 (Fig. 5a). The model fits (Eq. A3) indicate that the temperature response of ecosystem respiration (parameter $E$ ) was also stronger in 2017. However, the base respiration rate $R_{0}\left(R_{\mathrm{eco}}\right.$ at $\left.10^{\circ} \mathrm{C}\right)$ was larger in the first than the second summer $\left(0.199\right.$ vs. $\left.0.173 \mathrm{mg} \mathrm{CO}_{2} \mathrm{~m}^{-2} \mathrm{~s}^{-1}\right)$. In addition, no correlation was found between the model residuals and WTL in either summer (Fig. S5). Like the temperature response of $R_{\mathrm{eco}}$, the light response of GPP was stronger in summer 2017 than 2016 (Fig. 5b). Also, the corresponding maximum gross photosynthesis rate $\left(\mathrm{GP}_{\max }\right.$, Eq. A2) more than doubled ( -0.226 vs. $\left.-0.100 \mathrm{mg} \mathrm{CO}_{2} \mathrm{~m}^{-2} \mathrm{~s}^{-1}\right)$.
The site was on average a $\mathrm{CO}_{2}$ source throughout the day during the summer as well. It should be noted, however, that there were still multiple half-hour periods, especially in August 2017, when the site acted as a $\mathrm{CO}_{2}$ sink. A noticeable diel variation in NEE was observed mainly from April to October (Fig. 6). Between April and August, the mean diel NEE cycle had a minimum during the morning hours (05:00 10:00, UTC+2) and the highest emissions during the evening and night (21:00-01:00). After August, the lowest emissions took place later, at around noon. On the other hand, the highest emissions were observed earlier, at 20:00 in September and at 18:00 in October. In October, the diel cycle of NEE was still noticeable; it vanished in November and reappeared in March 2017. In spite of the different mean fluxes, the amplitudes of their diel cycle were rather similar in 2016 and 2017, except from July to September when the amplitudes were much larger in 2017. Also, unlike in 2016, systematic diel variation was still obvious in November 2017. Even though such variation indicates significant photosynthesis during the midday hours, the monthly mean diel NEE cycle consistently showed positive fluxes.

\subsection{2 $\mathrm{CO}_{2}$ balances}

The annual $\mathrm{CO}_{2}$ balances of the first and the second year after clear-cutting were $3086 \pm 148 \mathrm{~g} \mathrm{CO}_{2} \mathrm{~m}^{-2}$ ( \pm uncertainty; see Appendix) and $2072 \pm 124 \mathrm{~g} \mathrm{CO}_{2} \mathrm{~m}^{-2}$, respectively. About half of the annual $\mathrm{CO}_{2}$ emissions during both EC measurement years took place during the summer months (JJA), totalling $1558 \pm 99 \mathrm{~g} \mathrm{CO}_{2} \mathrm{~m}^{-2}$ (Table 2, Fig. 7), and $73 \%$ $\left(2256 \pm 146 \mathrm{~g} \mathrm{CO}_{2} \mathrm{~m}^{-2}\right)$ of the annual total was accumulated during the May-September period. In 2017, however, these emissions decreased to $915 \pm 79 \mathrm{~g} \mathrm{CO}_{2} \mathrm{~m}^{-2}$ (June-August) and $1401 \pm 109 \mathrm{~g} \mathrm{CO}_{2} \mathrm{~m}^{-2}$ (May-September), i.e. by $41 \%$ and $38 \%$, respectively. The effect of storage fluxes on the $\mathrm{CO}_{2}$ balance was negligible as the daily mean storage flux typically varied within $\pm 0.009 \mathrm{mg} \mathrm{CO}_{2} \mathrm{~m}^{-2} \mathrm{~s}^{-1}$ during summer and within $\pm 0.004 \mathrm{mg} \mathrm{CO}_{2} \mathrm{~m}^{-2} \mathrm{~s}^{-1}$ during the other seasons.

The most significant period of $\mathrm{CO}_{2}$ uptake was from June to September (Fig. 7). Considering only the summer months (JJA), the integrated GPP was 389 and $761 \mathrm{~g} \mathrm{CO}_{2} \mathrm{~m}^{-2}$ in 2016 and 2017, respectively (Table 2); i.e. the mean $\mathrm{CO}_{2}$ uptake in the second summer after clear-cutting increased by $96 \%$ from the first summer. On the other hand, the total summertime $R_{\text {eco }}$ decreased by $14 \%$, from $1928 \mathrm{~g} \mathrm{CO}_{2} \mathrm{~m}^{-2}$ in 2016 to $1652 \mathrm{~g} \mathrm{CO}_{2} \mathrm{~m}^{-2}$ in 2017 (Table 2).

\subsection{Soil GHG fluxes}

The summertime (JJA) $R_{\mathrm{ff}}$ measured at the soon-to-be clearcut site in 2015 was $1611 \pm 191 \mathrm{~g} \mathrm{CO}_{2} \mathrm{~m}^{-2}$ ( \pm uncertainty; see Sect. 2.5), and the measured $\mathrm{CO}_{2}$ fluxes varied from 0.04 to $0.36 \mathrm{~g} \mathrm{CO}_{2} \mathrm{~m}^{-2} \mathrm{~s}^{-1}$ (Fig. 8a). The $\mathrm{CH}_{4}$ flux averaged over all the measurement plots was $-26 \pm$ 

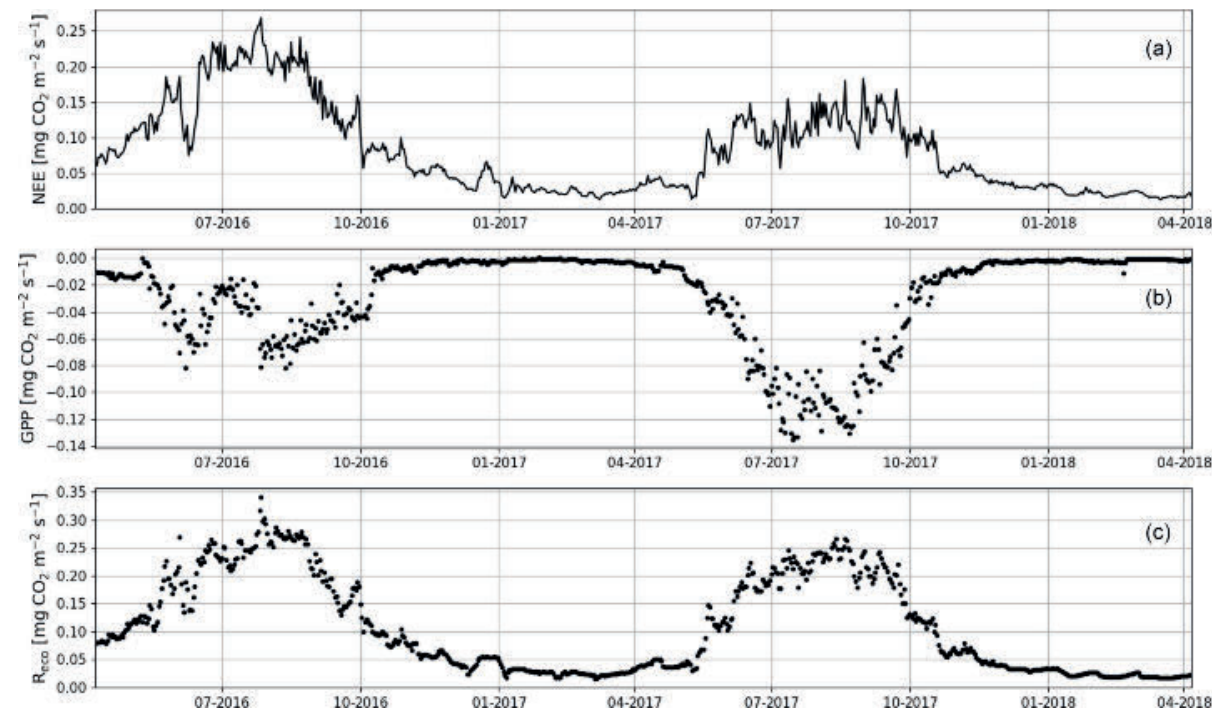

Figure 4. The gap-filled time series of daily mean net ecosystem exchange (NEE, a) and the corresponding modelled gross primary production $(\mathrm{GPP}, \mathbf{b})$ and ecosystem respiration $\left(R_{\mathrm{eco}}, \mathbf{c}\right)$ based on Eqs. (A2) and (A3), respectively.
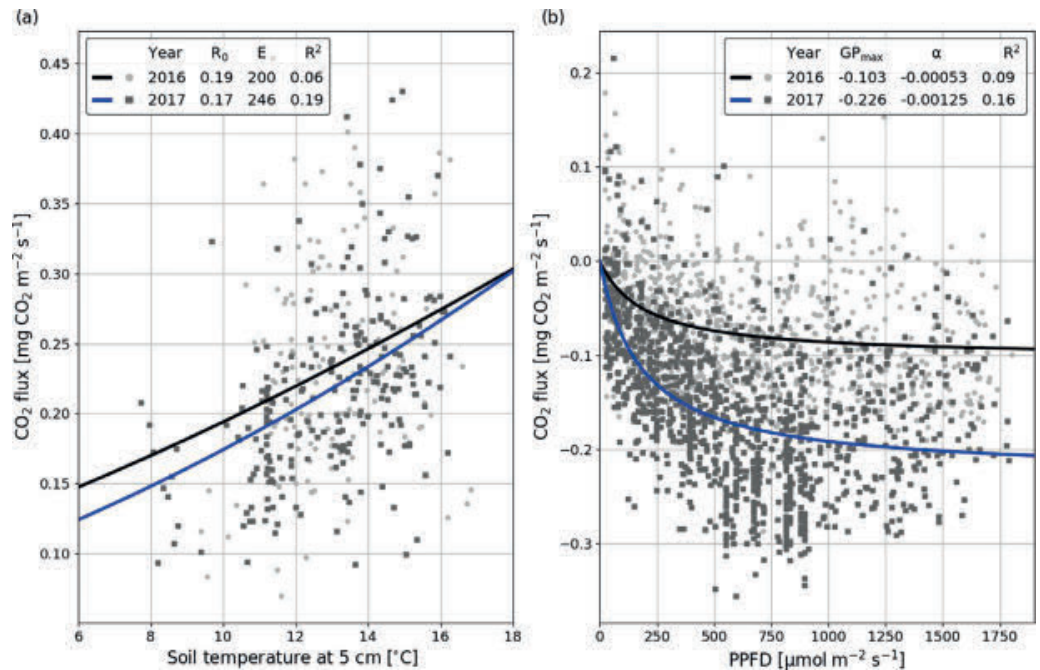

Figure 5. Temperature (a; Eq. A3) and light responses (b; Eq. A2) of $30 \mathrm{~min} \mathrm{CO}_{2}$ fluxes for the summers of (JJA) 2016 (black) and 2017 (blue). The temperature response equation was fitted to the night-time data ( $P P F D<20 \mu \mathrm{mol} \mathrm{m} \mathrm{m}^{-2} \mathrm{~s}^{-1}$ ), and the light response equation was fitted to the daytime (PPFD $>20 \mu \mathrm{mol} \mathrm{m}^{-2} \mathrm{~s}^{-1}$ ) data.

$5 \mathrm{ng} \mathrm{CH}_{4} \mathrm{~m}^{-2} \mathrm{~s}^{-1}$ before the clear-cutting. All the measured $\mathrm{CH}_{4}$ fluxes were negative (Fig. 8b) ranging from -103 to $-2 \mathrm{ng} \mathrm{CH}_{4} \mathrm{~m}^{-2} \mathrm{~s}^{-1}$. $\mathrm{N}_{2} \mathrm{O}$ fluxes varied mostly from -17 to $33 \mathrm{ng} \mathrm{N}_{2} \mathrm{O} \mathrm{m}^{-2} \mathrm{~s}^{-1}$ and averaged at $1 \pm 5 \mathrm{ng} \mathrm{N}_{2} \mathrm{O} \mathrm{m}^{-2} \mathrm{~s}^{-1}$ (Fig. 8c). At the control site, the summertime fluxes of $\mathrm{CO}_{2}$ (from 0.03 to $0.39 \mathrm{~g} \mathrm{CO}_{2} \mathrm{~m}^{-2} \mathrm{~s}^{-1}$ ) and $\mathrm{N}_{2} \mathrm{O}$ (mean: $11 \pm 9 \mathrm{ng} \mathrm{N}_{2} \mathrm{O} \mathrm{m}^{-2} \mathrm{~s}^{-1}$ ) in 2015 were not significantly differ- ent from those at the soon-to-be clear-cut site. However, the $\mathrm{CH}_{4}$ fluxes (mean: $-10 \pm 3 \mathrm{ng} \mathrm{CH}_{4} \mathrm{~m}^{-2} \mathrm{~s}^{-1}$ ) at the control site were significantly $(p<0.02)$ larger than at the soon-tobe clear-cut site.

After the clear-cutting, the total summertime $R_{\mathrm{ff}}$ decreased to $980 \pm 299 \mathrm{~g} \mathrm{CO}_{2} \mathrm{~m}^{-2}$ in summer 2016 and remained at the same level $\left(1047 \pm 113 \mathrm{~g} \mathrm{CO}_{2} \mathrm{~m}^{-2}\right)$ in 2017 . These num- 
Table 2. Annual and summertime (JJA) balances of net ecosystem exchange (NEE), modelled gross primary production (GPP), and modelled total ecosystem respiration $\left(R_{\mathrm{eco}}\right)$, as well as the modelled summertime sums of forest floor respiration $\left(R_{\mathrm{ff}}\right)$.

\begin{tabular}{lrr|rr}
\hline & \multicolumn{2}{c|}{ Annual } & \multicolumn{2}{c}{ Summer (JJA) } \\
\cline { 2 - 5 } & Apr 2016-Mar 2017 & Apr 2017-Mar 2018 & 2016 & 2017 \\
\hline $\mathrm{NEE}\left[\mathrm{g} \mathrm{CO}_{2} \mathrm{~m}^{-2}\right]$ & $3086 \pm 148$ & $2072 \pm 124$ & $1558 \pm 99$ & $915 \pm 79$ \\
$|\mathrm{GPP}|\left[\mathrm{g} \mathrm{CO}_{2} \mathrm{~m}^{-2}\right]$ & 659 & 1106 & 389 & 761 \\
$R_{\mathrm{eco}}\left[\mathrm{g} \mathrm{CO}_{2} \mathrm{~m}^{-2}\right]$ & 3727 & 3135 & 1928 & 1652 \\
$R_{\mathrm{ff}}\left[\mathrm{g} \mathrm{CO}_{2} \mathrm{~m}^{-2}\right]$ & - & - & $980 \pm 299$ & $1047 \pm 113$ \\
\hline
\end{tabular}

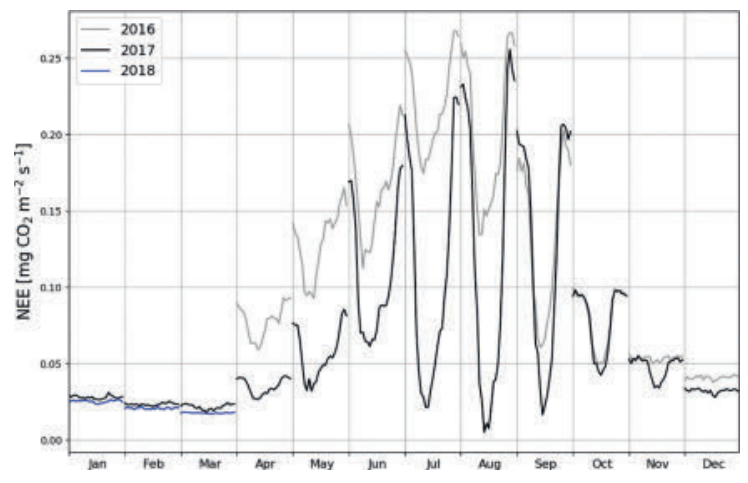

Figure 6. Monthly mean diel cycles of gap-filled net ecosystem exchange (NEE) measurements in the first (2016, grey), second (2017, black) and third (2018, blue) calendar year after the clear-cutting.

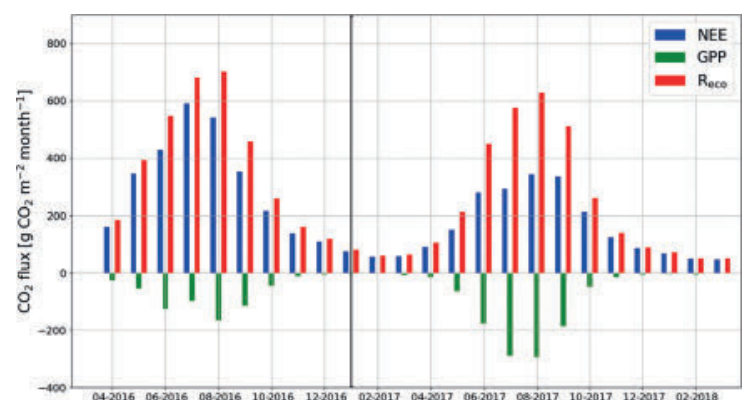

Figure 7. The monthly sums of net ecosystem exchange (NEE), gross primary production (GPP) and ecosystem respiration $\left(R_{\mathrm{eco}}\right)$ based on EC data in April 2016-March 2018.

bers were $51 \%$ and $63 \%$ of the $R_{\text {eco }}$ for the summers of 2016 and 2017, respectively (Fig. 9). Also, the temperature response of $R_{\mathrm{ff}}$ got weaker, and the $R_{0}$ parameter $\left(R_{\mathrm{ff}}\right.$ at $10^{\circ} \mathrm{C}$ ) decreased, while at the control site the responses remained quite similar over the years (Fig. 10). The strength of temperature response and $R_{0}$ partly recovered in 2017 but were still weaker than before the clear-cutting. In contrast to the $R_{\mathrm{ff}}$ at the clear-cut, the summertime $R_{\mathrm{ff}}$ at the control site increased from $1852 \pm 1353 \mathrm{~g} \mathrm{CO}_{2} \mathrm{~m}^{-2}$ in 2015 to
$2280 \pm 346 \mathrm{~g} \mathrm{CO}_{2} \mathrm{~m}^{-2}$ and $2438 \pm 225 \mathrm{~g} \mathrm{CO}_{2} \mathrm{~m}^{-2}$ in 2016 and 2017, respectively. However, the increase was significant only when comparing the summers of 2015 and 2017 $(p<0.05)$. The clear-cut and control sites were significantly different from each other in both summers $(p<0.001)$ after clear-cutting.

$\mathrm{CH}_{4}$ fluxes changed markedly after the clear-cutting, as the previously small mean $\mathrm{CH}_{4}$ sink turned into a small $\mathrm{CH}_{4}$ source in the first $\left(4 \pm 3 \mathrm{ng} \mathrm{CH}_{4} \mathrm{~m}^{-2} \mathrm{~s}^{-1}\right)$ and second $(6 \pm$ $2 \mathrm{ng} \mathrm{CH}_{4} \mathrm{~m}^{-2} \mathrm{~s}^{-1}$ ) year after the clear-cutting (Fig. 8b); the changes were significant for both years $(p<0.001)$. However, the post-clear-cut years were not significantly different from each other $(p=0.85)$. The post-clear-cut fluxes varied mostly from -14 to $28 \mathrm{ng} \mathrm{CH}_{4} \mathrm{~m}^{-2} \mathrm{~s}^{-1}$, with some occasional emission peaks reaching up to $140 \mathrm{ng} \mathrm{CH}_{4} \mathrm{~m}^{-2} \mathrm{~s}^{-1}$. Most of the measured fluxes were positive (emission), even though a single measurement plot could act both as a source and a sink on different measurement days. The control site remained as a $\mathrm{CH}_{4}$ sink in 2016 and 2017 and neither of the mean summer fluxes were significantly different from the preharvest summer mean. However, the mean $\mathrm{CH}_{4}$ fluxes were significantly different $(p<0.001)$ between the sites in both post-harvest summers.

Similarly to $\mathrm{CH}_{4}$, the post-clear-cut $\mathrm{N}_{2} \mathrm{O}$ fluxes were significantly higher than the pre-clear-cut ones $(p<0.001)$, and the post-clear-cut years did not differ significantly from each other. After the clear-cutting, the mean annual fluxes were $228 \pm 26$ and $212 \pm 21 \mathrm{ng} \mathrm{N}_{2} \mathrm{O} \mathrm{m}^{-2} \mathrm{~s}^{-1}$ in 2016 and 2017, respectively (Fig. 8c). All the measurement plots turned to large $\mathrm{N}_{2} \mathrm{O}$ sources, and the largest measured emission was $1339 \mathrm{ng} \mathrm{N}_{2} \mathrm{O} \mathrm{m}^{-2} \mathrm{~s}^{-1}$. All the measured fluxes were positive, except for a plot furthest from the ditch that acted as a temporary $\mathrm{N}_{2} \mathrm{O}$ sink in 2017 , especially in the June-July period. The $\mathrm{N}_{2} \mathrm{O}$ fluxes at the control site remained low in summer 2016 (mean: $16 \pm 11 \mathrm{ng} \mathrm{N}_{2} \mathrm{O} \mathrm{m}^{-2} \mathrm{~s}^{-1}$ ) but increased in summer 2017 (mean: $70 \pm 10 \mathrm{ng} \mathrm{N}_{2} \mathrm{O} \mathrm{m}^{-2} \mathrm{~s}^{-1}$ ). However, the post-harvest emissions at the control site were significantly lower than those at the clear-cut site $(p<0.001)$. Both the spatial and temporal variations were large: the largest emissions occurred in June while from July onwards the emissions decreased (Fig. 8c). 
(a)
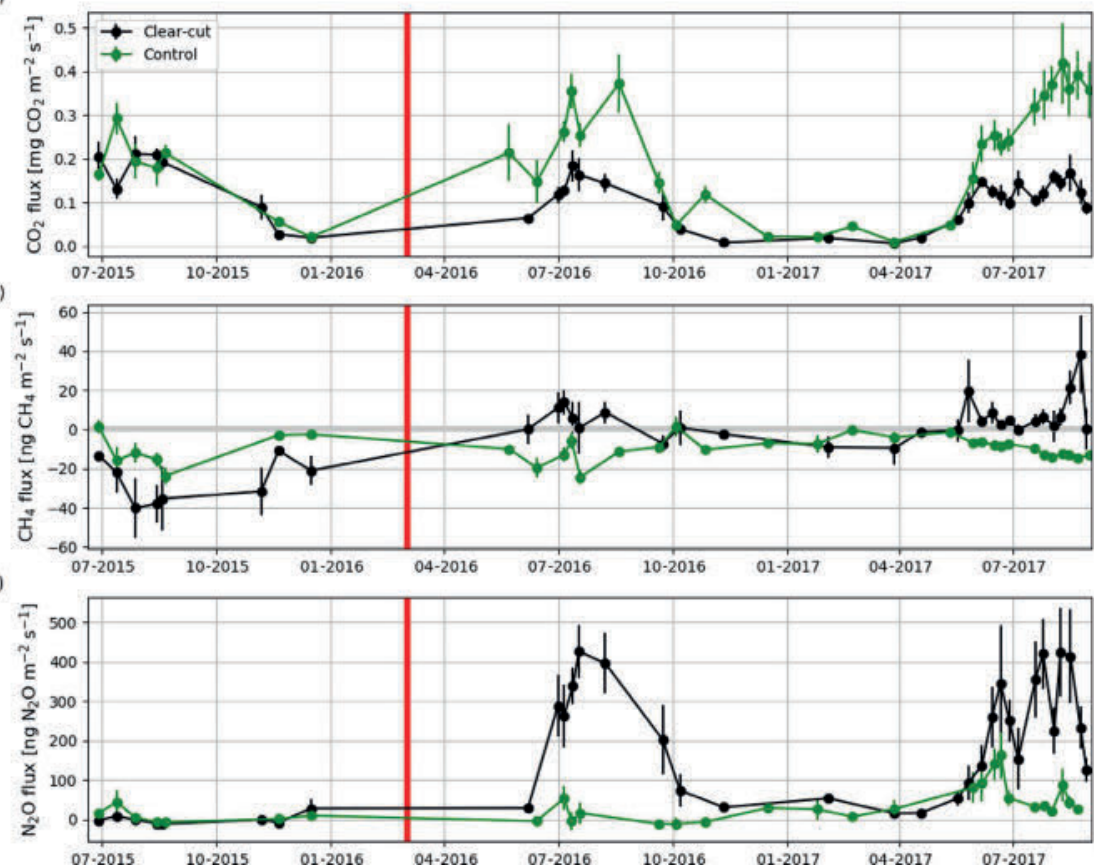

Figure 8. Hourly mean fluxes measured with manual chambers of (a) $\mathrm{CO}_{2}$, (b) $\mathrm{CH}_{4}$ and (c) $\mathrm{N}_{2} \mathrm{O}$ averaged over all measurement points (4, 8,12 and $22.5 \mathrm{~m}$ from the ditch) at the clear-cut (black) and control (green) sites from June 2015 to August 2017. The error bars show the standard error of the mean. The clear-cutting (red vertical line) was carried out in February-March 2016.

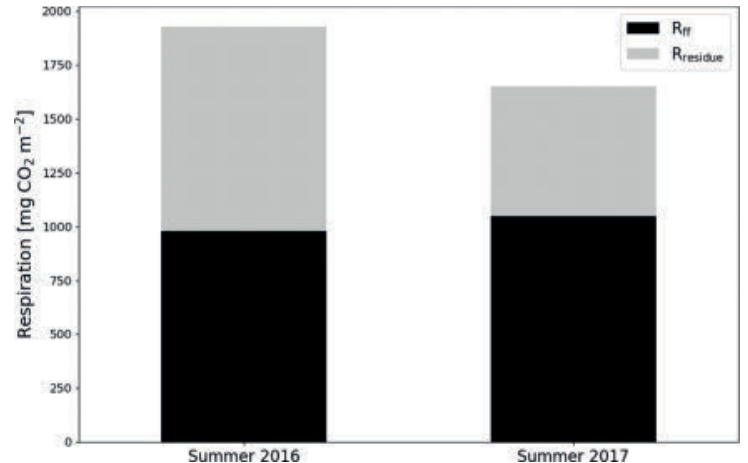

Figure 9. The division of ecosystem respiration $\left(R_{\mathrm{eco}}\right.$, based on EC measurements) to forest floor respiration $R_{\mathrm{ff}}$ (chamber measurements $)$ and respiration of logging residues $\left(R_{\text {residue }}=R_{\mathrm{eco}}-R_{\mathrm{ff}}\right)$ for the summers of 2016 and 2017

\subsection{Energy fluxes}

The daily sums of sensible heat $\left(Q_{\mathrm{H}}\right)$ were about $1 \mathrm{MJ} \mathrm{m}^{-2} \mathrm{~d}^{-1}$ on average at the start of the EC measurement period in April 2016 and increased to a maximum of $4.7 \mathrm{MJ} \mathrm{m}^{-2} \mathrm{~d}^{-1}$ in June (Fig. 11). In July, the daily $Q_{\mathrm{H}}$ sum was already decreasing with the decreasing net radiation $\left(Q_{\mathrm{N}}\right)$ and turned negative in October. On the other hand, the daily sums of latent heat flux $\left(Q_{\mathrm{E}}\right)$ were quite stable from April until August, averaging at $1.0 \pm 0.04 \mathrm{MJ} \mathrm{m}^{-2} \mathrm{~d}^{-1}$ ( \pm standard error of mean). In September, $Q_{\mathrm{E}}$ started to decrease and reached zero at the end of October. The ground heat flux $\left(Q_{\mathrm{G}}\right)$ varied within $0-0.5 \mathrm{MJ} \mathrm{m}^{-2} \mathrm{~d}^{-1}$ from April to August, after which it varied mostly between -0.5 and $0 \mathrm{MJ} \mathrm{m}^{-2} \mathrm{~d}^{-1}$ until the end of April 2017.

In 2017 , the seasonal dynamics of the energy fluxes were similar to 2016, but the magnitude of fluxes changed considerably. The summertime average daily sum of $Q_{\mathrm{H}}$ decreased from 1.8 to $1.2 \mathrm{MJ} \mathrm{m}^{-2} \mathrm{~d}^{-1}$, while that of $Q_{\mathrm{E}}$ increased from 1.3 to $2.3 \mathrm{MJ} \mathrm{m}^{-2} \mathrm{~d}^{-1}$. Also, the monthly sums of these fluxes were markedly different in the second year after the clear-cutting. During the period of the highest fluxes (April-September), the $Q_{\mathrm{H}}$ sum was $33 \%$ smaller in 2017 than 2016, while the $Q_{\mathrm{E}}$ and $Q_{\mathrm{N}}$ sums were higher by $40 \%$ and $13 \%$, respectively. The changes in $Q_{\mathrm{G}}$ were minor.

The monthly mean midday $Q_{\mathrm{H}}$ in May and June 2016 were 206 and $165 \mathrm{~W} \mathrm{~m}^{-2}$, respectively (Fig. 12a). After June, the midday $Q_{\mathrm{H}}$ started to decrease with decreasing $Q_{\mathrm{N}}$, and the night-time $Q_{\mathrm{H}}$ turned from zero to slightly negative. The midday $Q_{\mathrm{E}}$ also increased from April to June, reaching $88 \mathrm{~W} \mathrm{~m}^{-2}$, and remained quite stable until September. The 

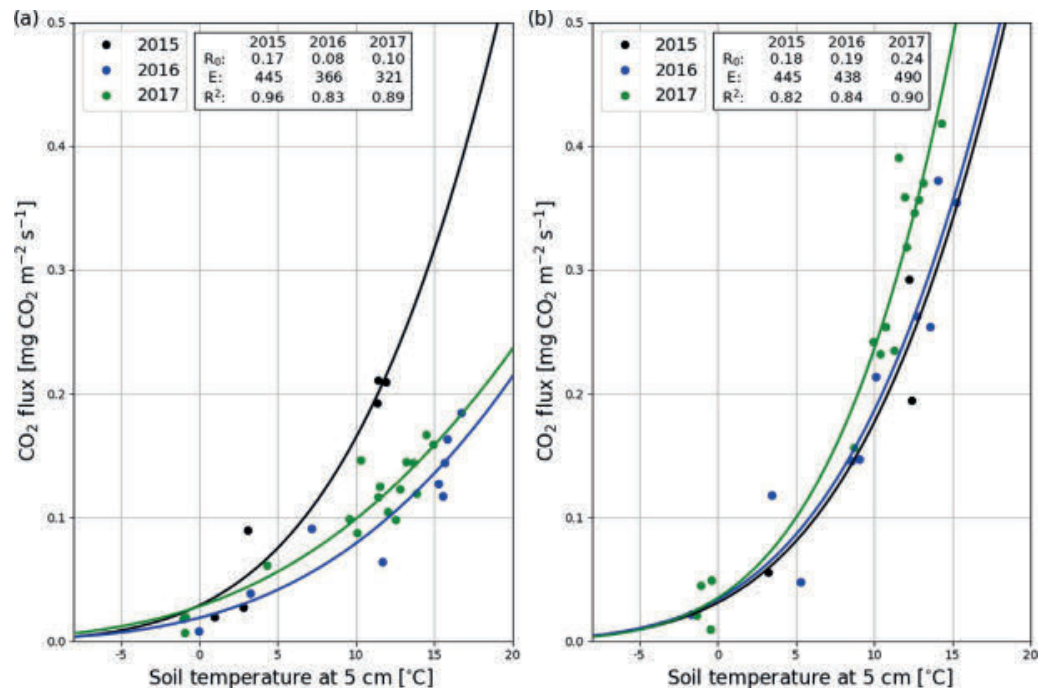

Figure 10. Temperature response (Eq. A3) of the hourly mean $\mathrm{CO}_{2}$ fluxes measured with manual chambers at the clear-cut (a) and control (b) site in 2015 (black), 2016 (blue) and 2017 (green).
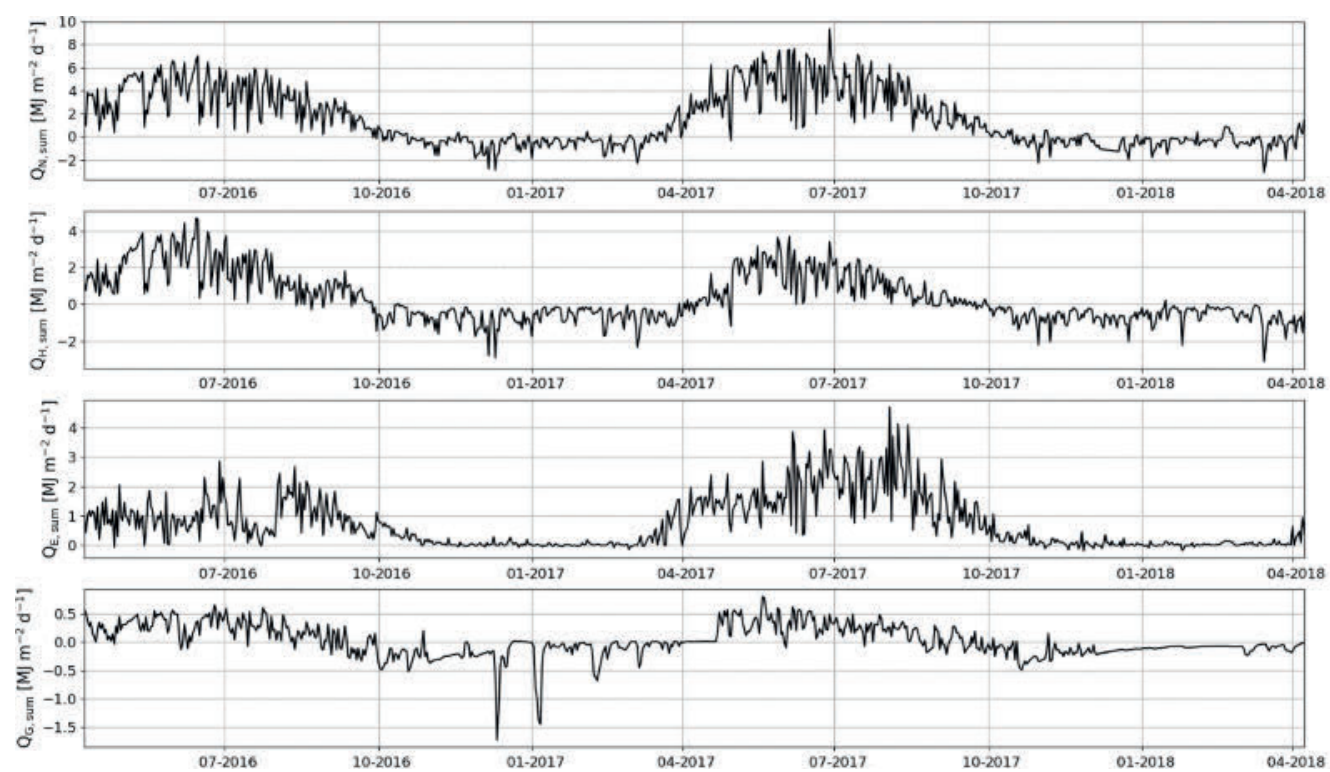

Figure 11. Daily sums of net radiation $\left(Q_{\mathrm{N}}\right)$, sensible heat flux $\left(Q_{\mathrm{H}}\right)$, latent heat flux $\left(Q_{\mathrm{E}}\right)$ and ground heat flux $\left(Q_{\mathrm{G}}\right)$.

resulting monthly mean daytime Bowen ratio $(\beta)$, increased from 1.7 in April to 2.6 in May 2016 and then declined to 0.8 in August. In 2017, the mean midday $Q_{\mathrm{H}}$ was similar to that in 2016, except in July and September when the fluxes were $34 \%$ and $23 \%$ lower, respectively, than in 2016 (Fig. 12b). However, the daily maximum $Q_{\mathrm{E}}$ was either similar to or higher (up to $48 \%$ ) than $Q_{\mathrm{H}}$ in all months except May 2017.
Correspondingly, $\beta$ was lower than 1 (0.6-1.0) during the period of high fluxes in 2017, except in May when it was 1.7. 
(a)
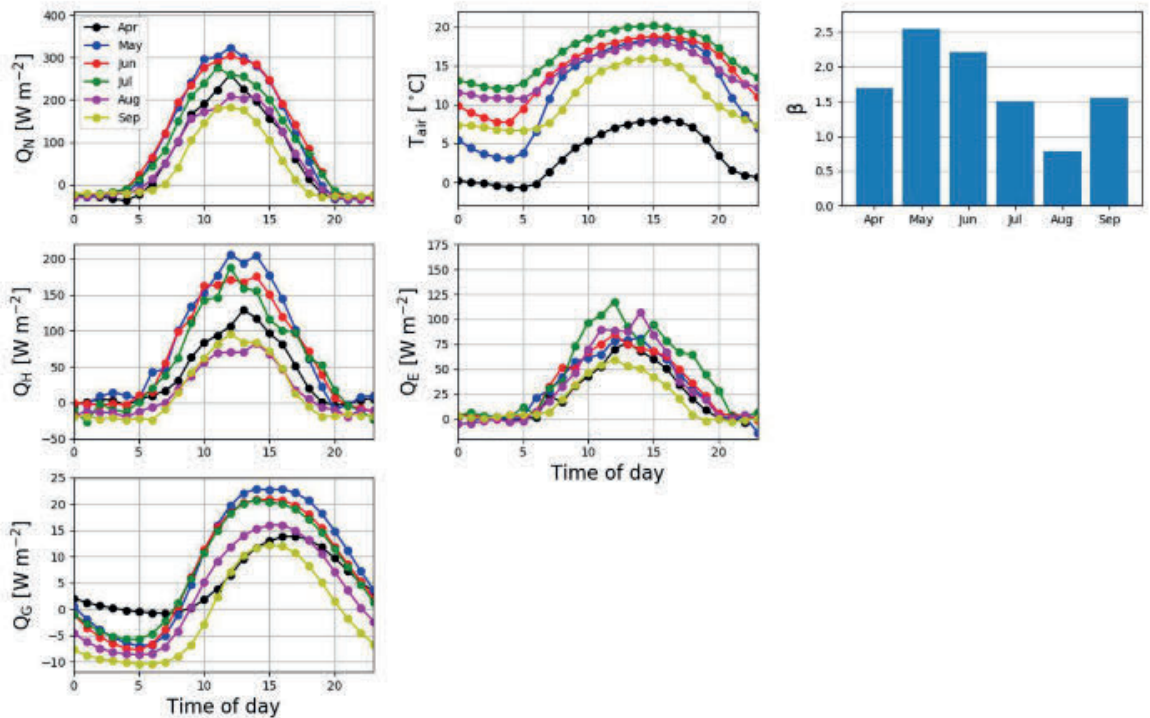

(b)
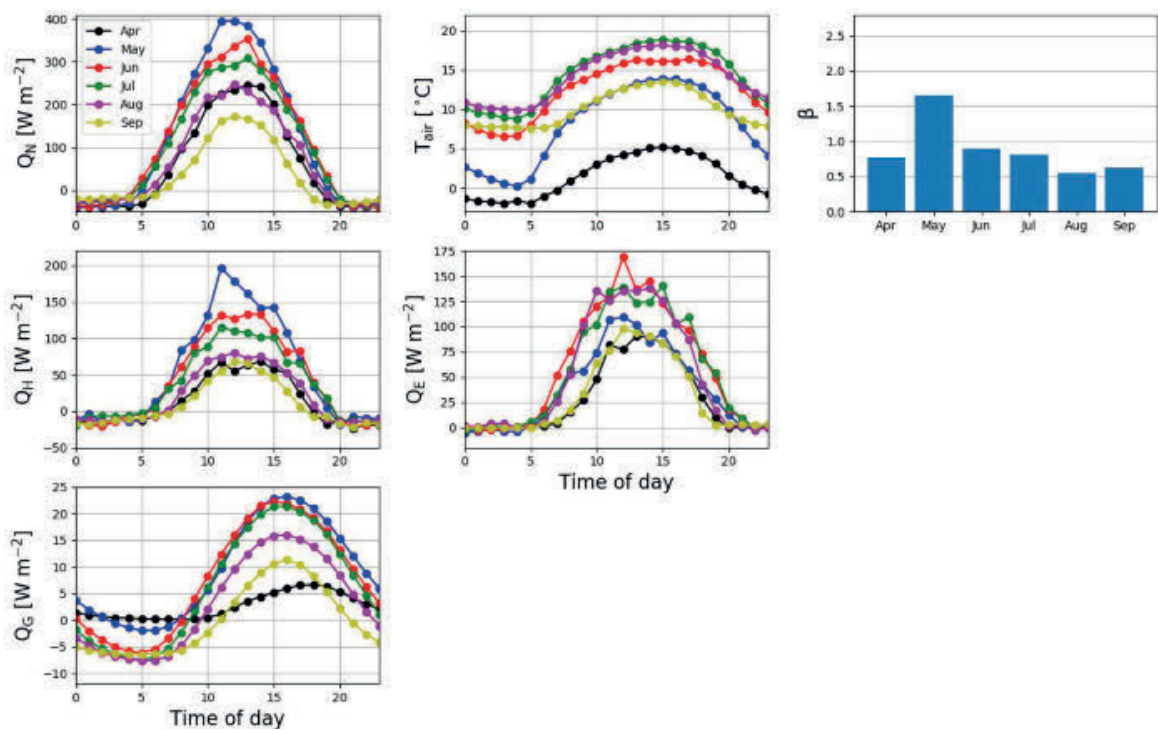

Figure 12. Monthly mean diel cycles of net radiation $\left(Q_{\mathrm{N}}\right)$, air temperature $\left(T_{\text {air }}\right)$, sensible heat flux $\left(Q_{\mathrm{H}}\right)$, latent heat flux $\left(Q_{\mathrm{E}}\right)$, ground heat flux $\left(Q_{\mathrm{G}}\right)$ and the monthly mean daytime (10:00-16:00, UTC+2) Bowen ratios $(\beta)$ from April to September in 2016 (a) and 2017 (b).

\section{Discussion}

\subsection{Dynamics of the $\mathrm{CO}_{2}$ fluxes and flux components}

The study site was a large source of $\mathrm{CO}_{2}$ during the $2 \mathrm{EC}$ measurement years after clear-cutting, but the emissions were $33 \%$ smaller in the second than the first year. $|\mathrm{GPP}|$ remained low and stable during the first summer after clearcutting, reflecting the fact that neither vascular ground vegetation nor moss cover had developed substantially by that time. However, during the second summer, the total $|\mathrm{GPP}|$ increased by $96 \%$ from the first post-clear-cut summer, and the increase in the coverage of ground vegetation was already noticeable (although not directly measured). This rela- 
tively fast recovery of ground vegetation is similar to the leaf area index changes observed by Mäkiranta et al. (2010) after clear-cutting in a nutrient-poor peatland forest. $R_{\text {eco }}$ was larger in the first summer than in the second post-harvest year, which could be due to the first year being warmer or due to changes in the respiration of either residues or forest floor in the second year. The chamber measurements, which were not affected by aboveground logging residues, showed a $39 \%$ and $35 \%$ decrease in $R_{\mathrm{ff}}$ after clear-cutting in the first and second summer after clear-cutting, respectively. Possible reasons for this decrease include reduced peat decomposition due to raised WTL, ceased autotrophic respiration of (the harvested) trees roots and decreased autotrophic respiration of ground vegetation, even though the latter slightly recovered during the summer as the ground vegetation started to regrow. The $\mathrm{CO}_{2}$ flux from the decomposing below-ground logging residues (roots) was not sufficiently large to compensate for this decrease in $R_{\mathrm{ff}}$. In summer $2016, R_{\mathrm{ff}}$ was $51 \%$ of the $R_{\text {eco }}$, suggesting that half of the $R_{\text {eco }}$ during that time originated from the above-ground logging residues, which were not included in the chamber measurements of $R_{\mathrm{ff}}$. In summer 2017 , however, $R_{\text {eco }}$ decreased by $14 \%$, but $R_{\mathrm{ff}}$ remained about the same, indicating that a larger proportion $(63 \%)$ of $R_{\text {eco }}$ originated from the forest floor respiration than in the previous summer. This could be due to the decrease in decomposition rate of the aboveground logging residues due to lower temperatures and because the residues had already partly decomposed during the previous summer. However, the lower temperatures would also decrease $R_{\mathrm{ff}}$, but this did not happen because in 2017 WTL was $5 \mathrm{~cm}$ lower, which enhanced peat decomposition. In addition, the NEE in summer 2017 was approximately equal to $R_{\mathrm{ff}}$, which means that the increase in $|\mathrm{GPP}|$ was sufficient to balance the $\mathrm{CO}_{2}$ emissions from the logging residues but not from soil and plants.

After the removal of the canopy, more solar radiation reached the ground surface, heating it more during the daytime, while the heat transfer from the soil to the atmosphere was enhanced during the night; together these resulted in a higher diel variation in soil temperature. On the other hand, the insulating impact of logging residues may have partly dampened the amplitude of the diel temperature cycle, as observed by Ojanen et al. (2017). The higher soil temperatures during the daytime may have enhanced peat respiration in the layer closest to the surface. However, it has been shown in previous studies that the temperature response of respiration weakens when the soil gets dry, often resulting in lower respiration rates (Mäkiranta et al., 2009, 2010). Such weakening of the temperature response was also observed at Lettosuo, especially in the first summer after the harvest when the almost bare soil surface was exposed to more solar radiation after clear-cutting. Also, summer 2016 was warmer and drier than on average, which probably enhanced this effect. Moreover, the addition of logging residues may have increased $R_{\text {eco }}$ substantially, as demonstrated by Mäkiranta et al. (2012), who observed that the plots with logging residues had a $\mathrm{CO}_{2}$ efflux twice as high as the plots without them. However, a later study by Ojanen et al. (2017) did not show a consistent increase in soil organic matter decomposition rates at similar sites. In previous studies, a decrease has been observed in both $R_{\text {eco }}$ (Kowalski et al., 2004, 2003; Takagi et al., 2009) and $R_{\mathrm{ff}}$ (Mäkiranta et al., 2010; Takagi et al., 2009; Zerva and Mencuccini, 2005) after clear-cutting in peatland and upland forests. However, also increasing $R_{\text {eco }}$ and $R_{\mathrm{ff}}$ have also been reported (Kowalski et al., 2004; Londo et al., 1999). The differences between these results are most likely caused by a different effect of the harvest on soil microbial activity, which is mostly controlled by soil temperature, moisture and nutrient availability (Davidson et al., 1998; Fontaine et al., 2004, 2007; Lloyd and Taylor, 1994). Other possible reasons for this variability include differences in, for example, root respiration, the type and amount of logging residue, and WTL, especially in peatland forests.

In peat soils, the decomposition of organic matter is mainly controlled by soil temperature and WTL (Blodau et al., 2004; Mäkiranta et al., 2009; Silvola et al., 1996), but soil temperature is typically the most influential factor for explaining the temporal dynamics in $R_{\mathrm{ff}}$ (e.g. Mäkiranta et al., 2008; Ojanen et al., 2010). At Lettosuo, the correlation between the half-hourly $R_{\text {eco }}$ and soil temperature was mostly weak. This could be due to logging residues, as their decomposition rate probably does not depend as much on soil temperature as on the temperature and moisture of the logging residues themselves. At times, especially when the temperature range was larger (in May and June), a significant relationship (correlation coefficient peaking at 0.57) was observed, and there was also an obvious temperature response that followed the annual cycle. Also, when WTL is closer $(>-15 \mathrm{~cm})$ to the surface, it is usually a significant predictor of $R_{\mathrm{ff}}$ in peat soils (Chimner and Cooper, 2003; Riutta et al., 2007). At Lettosuo after clear-cutting, WTL varied mostly within $20-30 \mathrm{~cm}$ below the soil surface, and there was no correlation between $R_{\text {eco }}$ and WTL after removing the effect of soil temperature on $R_{\text {eco }}$ (Fig. S5). Because $R_{\text {eco }}$ combines many respiration components in addition to $R_{\mathrm{ff}}$, it is likely that the high $\mathrm{CO}_{2}$ efflux from logging residues, for example, masks the possible WTL effect on $R_{\mathrm{ff}}$.

Our results show that, after clear-cutting, a peatland forest is a large source of $\mathrm{CO}_{2}$ to the atmosphere. Nutrientrich drained peatland forests with a growing tree stand have generally been found to be $\mathrm{CO}_{2}$ neutral or small sinks of $\mathrm{CO}_{2}$ (Meyer et al., 2013; Ojanen et al., 2013; Uri et al., 2017), as the carbon accumulated by trees typically balances the carbon emissions caused by the decomposing peat layer. This suggests that Lettosuo was probably also close to a $\mathrm{CO}_{2}$-neutral state before the clear-cutting. Thus, the impact of clear-cutting from $\mathrm{CO}_{2}$ neutral to a source of $3086 \pm$ $148 \mathrm{~g} \mathrm{CO}_{2} \mathrm{~m}^{-2} \mathrm{yr}^{-1}$ in the first year after clear-cutting must be considered substantial. This also means that the site may need to be considered a net $\mathrm{CO}_{2}$ source in terms of the long- 
term balance even if the forest had been a $\mathrm{CO}_{2}$ sink at a particular growth stage (Hommeltenberg et al., 2014), depending on how long the post-clear-cut emissions continue. In this study, however, we only focus on the immediate impact of clear-cutting.

Mäkiranta et al. (2010) measured $\mathrm{CO}_{2}$ exchange in a clear-cut nutrient-poor peatland forest with soil chambers during a growing season (May-October) and reported slightly smaller $\mathrm{NEE}\left(1990 \mathrm{~g} \mathrm{CO}_{2} \mathrm{~m}^{-2}\right.$ season $\left.{ }^{-1}\right)$ than the NEE we measured at Lettosuo during a similar timeframe (2340 $\mathrm{g} \mathrm{CO}_{2} \mathrm{~m}^{-2}$ season $\left.{ }^{-1}\right)$. Among mineral soil forests, on the other hand, the annual $\mathrm{CO}_{2}$ exchange measured with the EC method right after the clear-cutting varies a lot; the annual balances ranging from ca. 400 to $4700 \mathrm{~g} \mathrm{CO}_{2} \mathrm{~m}^{-2} \mathrm{yr}^{-1}$ (Amiro et al., 2010; Clark et al., 2004; Humphreys et al., 2005; Kowalski et al., 2004, 2003; Takagi et al., 2009; Williams et al., 2013). If considering only mineral soil forests, the forests in warmer climates typically emit more carbon after the harvest, but they also recover faster than the boreal forests (Amiro et al., 2010). Compared to the studies cited above, the clear-cut site at Lettosuo was the second largest source of $\mathrm{CO}_{2}$ immediately after clear-cutting, being second only to the slash pine plantation in Florida (Clark et al., 2004). The high $\mathrm{CO}_{2}$ emission at Lettosuo as compared to other clear-cut sites on mineral soil is apparently due to the decomposition of the oxic peat layer in this nutrientrich forest, which are known to act as $\mathrm{CO}_{2}$ sources up to $1000 \mathrm{~g} \mathrm{CO}_{2} \mathrm{~m}^{-2} \mathrm{yr}^{-1}$ (Ojanen et al., 2013; Uri et al., 2017). Mineral soil forests do not have a peat layer or any other carbon storage that could cause $\mathrm{CO}_{2}$ emissions of such magnitude.

\subsection{Soil $\mathrm{CH}_{4}$ and $\mathrm{N}_{2} \mathrm{O}$ fluxes}

The $\mathrm{CH}_{4}$ flux in peat soils is mostly controlled by WTL (Martikainen et al., 1995; Roulet et al., 1993), which divides the peat column into anoxic and oxic layers in which $\mathrm{CH}_{4}$ production and oxidation occur, respectively. After clearcutting, the WTL rose from $-33 \mathrm{~cm}$ in 2015 to $-22 \mathrm{~cm}$ in 2016 during July-August, and the highest estimated rise in WTL occurred in July-October when clear-cutting was estimated to raise WTL by $23 \mathrm{~cm}$ on average when compared to the background model. This made the topsoil oxic layer much thinner and the conditions less favourable for $\mathrm{CH}_{4}$ oxidation, allowing a smaller amount of the $\mathrm{CH}_{4}$ produced in the anoxic layer to be oxidized before reaching the atmosphere. The WTL rise was enough to turn the clear-cut site from a $\mathrm{CH}_{4}$ sink into a small $\mathrm{CH}_{4}$ source, while the control site remained a consistent $\mathrm{CH}_{4}$ sink. A similar turn of a clear-cut site from a $\mathrm{CH}_{4}$ sink to a source has previously been found for both peat (Zerva and Mencuccini, 2005) and mineral soils (Sundqvist et al., 2014). However, Huttunen et al. (2003) measured mostly net $\mathrm{CH}_{4}$ uptake in two drained peatland forest sites in southern Finland also after clear-cutting, and the difference between the control and clear-cut sites was not statistically significant in either case.

The $\mathrm{N}_{2} \mathrm{O}$ fluxes were highly variable both before and after clear-cutting. However, there was a strong increase from the mean pre-clear-cut average flux of $1 \pm 5 \mathrm{ng} \mathrm{N}_{2} \mathrm{O} \mathrm{m}^{-2} \mathrm{~s}^{-1}$ to the post-clear-cut flux of $228 \pm 26 \mathrm{ng} \mathrm{N}_{2} \mathrm{O} \mathrm{m}^{-2} \mathrm{~s}^{-1}$. On the other hand, the emissions were small at the control site in 2016 but increased in 2017, especially in June, even though the increase was markedly smaller than at the clearcut site. This is probably due to higher precipitation in 2017, which increased soil moisture and enhanced denitrification. Increases in $\mathrm{N}_{2} \mathrm{O}$ emissions after clear-cutting have also been observed in peat and mineral soil forests by Huttunen et al. (2003) and Saari et al. (2009), but the fluxes at these sites were an order of magnitude smaller than at Lettosuo. It should be noted that the $\mathrm{N}_{2} \mathrm{O}$ measurements in this study do not include any above-ground logging residues, which are expected to raise $\mathrm{N}_{2} \mathrm{O}$ emissions further; Mäkiranta et al. (2012) found $\mathrm{N}_{2} \mathrm{O}$ emissions about 3 times as large from the plots with logging residues as those from the plots without them.

Compared to the change in NEE (i.e. $\mathrm{CO}_{2}$ fluxes) at the site, the change in $\mathrm{CH}_{4}$ emissions is negligible when considering its climatic impact in terms of the global warming potential over 100 years $\left(\mathrm{GWP}_{100}=34\right.$; IPCC, 2013). Even though the change in $\mathrm{N}_{2} \mathrm{O}$ fluxes to the present level at our site was large, the climatic effect of $\mathrm{N}_{2} \mathrm{O}$ was only about $10 \%$ of that due to the even larger change in NEE, when considering GWP over a period of up to 100 years $\left(\mathrm{GWP}_{100}=298\right.$; IPCC, 2013).

\subsection{Energy fluxes}

The mean daily $Q_{\mathrm{E}}$ at Lettosuo during the spring and summer right after the clear-cutting varied mostly within $0.5-$ $2.5 \mathrm{MJ} \mathrm{m}^{-2} \mathrm{~d}^{-1}$ and within $1.0-4.0 \mathrm{MJ} \mathrm{m}^{-2} \mathrm{~d}^{-1}$ during the second spring and summer. Compared to the values of 2 $10 \mathrm{MJ} \mathrm{m}^{-2} \mathrm{~d}^{-1}$ measured in an upland forest in western Russia (Mamkin et al., 2016), our numbers are low. In the case of $Q_{\mathrm{H}}$, the fluxes at Lettosuo were systematically lower than those reported by Mamkin et al. (2016), but the difference was not as large as for $Q_{\mathrm{E}}$.

At Lettosuo, $\beta$ was lower in the second summer after the clear-cutting as compared to the first summer: in summer $2016 \beta$ was $>1$ most of the time, whereas in summer 2017 it was $<1$ for the whole summer. Thus, the pattern was somewhat different from the results of Mamkin et al. (2016), who reported that $\beta<1$ already throughout the first summer after the clear-cutting. One reason for the smaller $Q_{\mathrm{E}}$ at Lettosuo could be the drier-than-normal summers in 2016 and 2017 and the drier surface layer of the peat.

In summer 2017 at Lettosuo, $Q_{\mathrm{H}}$ decreased slightly and $Q_{\text {E }}$ almost doubled compared to 2016, suggesting a recovery of transpiration due to the gradual recovery of ground vegetation. This is in agreement with the results obtained by 
Williams et al. (2013) for a clear-cut Norway spruce plantation in the northeastern USA, where a recovery of evapotranspiration and a decrease in $Q_{\mathrm{H}}$ were observed across the years after the clear-cutting. Moreover, the recovered ground vegetation at Lettosuo most likely increased albedo and thus prevented the soil from heating as much as in 2016, resulting in a smaller $Q_{\mathrm{H}}$ over the whole summer. The clear-cut site at Lettosuo is small, but a larger-scale clear-cutting would probably affect local and regional climate due to changes in surface energy balance fluxes. This is because $Q_{\mathrm{H}}$ and $Q_{\mathrm{E}}$ affect the properties and growth rate of the planetary boundary layer, influencing convection and the long-range transport of heat and humidity.

\section{Conclusions}

Based on our measurements, we conclude that after clearcutting a nutrient-rich peatland forest is a large $\mathrm{CO}_{2}$ source. This is due both to the decomposition of peat and logging residues and to the reduction of gross primary production as a result of the removal of photosynthesizing trees and the decline of ground vegetation and understorey. Removing the trees decreased transpiration, which caused the WTL to rise by $23 \mathrm{~cm}$ compared to the background model during July-October, which in turn likely decreased the peat decomposition rate due to the decreased volume of aerobic peat. Plant respiration also decreased as the plants were removed or destroyed. On the other hand, decomposition of logging residues increased $\mathrm{CO}_{2}$ emissions from the site; the emissions from the residues were estimated to be $49 \%$ of the total ecosystem respiration in the first summer after clearcutting. In the second summer, ground vegetation and its primary production recovered noticeably. On the other hand, the $\mathrm{CO}_{2}$ emissions from the logging residues decreased, as part of the residues had decomposed during the previous summer. In total, these changes reduced the net $\mathrm{CO}_{2}$ emissions of the site by $41 \%$ compared to the first summer.
The soil turned from a small $\mathrm{CH}_{4}$ sink into a small source after clear-cutting due to the WTL rise. However, the radiative forcing related to this change was insignificant compared to that due to the change in NEE. Clear-cutting turned the soil into a substantial source of $\mathrm{N}_{2} \mathrm{O}$. This change produced a 100-year GWP of about $10 \%$ of that due to the increased NEE at the site.

The mean daytime latent heat flux almost doubled from the first to the second year after clear-cutting, suggesting that the transpiration of ground vegetation had recovered. The recovered ground vegetation most likely also increased albedo and thus prevented the soil from heating as much as in 2016 , which resulted in a smaller sensible heat flux.

Overall, the results of this study show that clear-cutting peatland forests exerts a strong climatic warming effect through accelerated emissions of greenhouse gases. However, this study only demonstrates a short-term impact of 2 years, and more extensive measurements are required to gain knowledge of the long-term effects of clear-cutting in peatland forests.

Data availability. The measured flux and meteorological data are available at Zenodo (https://doi.org/10.5281/zenodo.3384791, Korkiakoski et al., 2019). 


\section{Appendix A: Gap-filling $\mathrm{CO}_{2}$ data}

To calculate seasonal and annual $\mathrm{CO}_{2}$ balances, full time series are needed and thus any gaps in the $\mathrm{CO}_{2}$ flux data need to be filled. For this reason and to analyse the components of the carbon balance, we partitioned the measured $\mathrm{CO}_{2}$ flux, i.e. net ecosystem exchange (NEE), into gross primary production (GPP) and total ecosystem respiration $\left(R_{\mathrm{eco}}\right)$ :

$$
\mathrm{NEE}=\mathrm{GPP}+R_{\mathrm{eco}}
$$

For gap-filling, we expressed GPP as a function of irradiance (e.g. Aurela et al., 2015):

$\mathrm{GPP}=\frac{\alpha \times \mathrm{PPFD} \times \mathrm{GP}_{\max }}{\alpha \times \mathrm{PPFD}+\mathrm{GP}_{\max }}$,

where PPFD is the photosynthetic photon flux density, $\alpha$ is the initial slope of the NEE response to PPFD and $\mathrm{GP}_{\max }$ is the asymptotic gross photosynthesis rate in optimal light conditions. $R_{\text {eco }}$ was assumed to follow the Arrhenius-type model described by Lloyd and Taylor (1994):

$R_{\text {eco }}=R_{0} \times \exp \left[E\left(\frac{1}{T_{0}}-\frac{1}{T_{\text {soil }}-T_{1}}\right)\right]$,

where $R_{0}$ is the ecosystem respiration at $10^{\circ} \mathrm{C}, E$ is the temperature sensitivity of the respiration, $T_{\text {soil }}$ is the measured soil temperature at $5 \mathrm{~cm}$ depth, $T_{0}=56.02 \mathrm{~K}$ and $T_{1}=$ $227.13 \mathrm{~K}$.

The parameters $E$ and $R_{0}$ were defined from the nighttime data (PPFD $<20 \mu \mathrm{mol} \mathrm{m}{ }^{-2} \mathrm{~s}^{-1}$ ) in two parts. First, the parameter $E$, which was allowed to vary within $200-500 \mathrm{~K}$, was determined with a $15 \mathrm{~d}$ moving window for each day, with the minimum number of observations set to 12 . If there were not enough observations within a time window, then the window size was increased by $1 \mathrm{~d}$ both in the beginning and at the end until enough data were found. The resulting window size varied between 15 and $27 \mathrm{~d}$, but only 22 gapfilled days had a longer window than $15 \mathrm{~d}$. Next, all the $E$ values that hit the allowed boundary values (200 and $500 \mathrm{~K}$ ) were discarded and filled with $14 \mathrm{~d}$ moving medians. Finally, a $15 \mathrm{~d}$ moving window, similar to the one in the first part, was used to determine $R_{0}$ by using the fixed $E$ values. Also, using the same moving window, $\mathrm{GP}_{\max }$ and $\alpha$ were determined from the daytime data. However, from 1 November 2016 until 8 March 2017, with no significant $\mathrm{CO}_{2}$ uptake, a $5 \mathrm{~d}$ moving average was used to fill the gaps in the measured NEE.

All the calculations and analyses were made with the Python programming language (Python Software Foundation, version 2.7, https://www.python.org, last access: 5 September 2019). For the fits, the least-squares method was used through the "polyfit" function of the NumPy (http: //www.numpy.org/, last access: 5 September 2019) library for the linear regression and the "curve_fit" function of the SciPy (http://www.scipy.org/, last access: 5 September 2019) library for the nonlinear fits.

\section{Appendix B: Uncertainty analysis of NEE}

The $\mathrm{CO}_{2}$ balance obtained from EC measurements has multiple potential error sources due to instrumental, statistical and methodological uncertainties. We included the most significant, although not all, random error sources. The random error including the statistical measurement error $\left(E_{\text {meas }}\right)$ inherent in EC measurements and the error caused by gap filling of missing data $\left(E_{\text {gap }}\right)$ was estimated as follows (Räsänen et al., 2017):

$E_{\text {meas } / \text { gap }}=\sqrt{\sum_{i} \frac{\left(\mathrm{NEE}_{i, \mathrm{obs}}-\mathrm{NEE}_{i, \mathrm{mod}}\right)^{2}}{n_{\mathrm{obs} / \mathrm{mod}}}} \sqrt{n_{\text {meas } / \text { gap }}}$,

where $\mathrm{NEE}_{\mathrm{obs}}$ is the $30 \mathrm{~min}$ flux that passed all the filtering procedures, $\mathrm{NEE}_{\text {mod }}$ is the corresponding fitted $\mathrm{NEE}$ (Eqs. A1-A3), and $n_{\text {meas/gap }}$ is the number of the measured or gap-filled data. This method provides a conservative estimate for $E_{\text {meas }}$ (Aurela et al., 2002) and for $E_{\text {gap }}$ includes the effect of random variability on the model fits.

The annual systematic error caused by the friction velocity filtering $\left(E_{\text {ustar }}\right)$ was estimated by recalculating the annual balance with modified data sets that were screened with two different $u_{*}$ limits $\left(0.075\right.$ and $\left.0.175 \mathrm{~m} \mathrm{~s}^{-1}\right)$. $E_{\text {ustar }}$ was calculated as the average difference between the annual balance calculated with the optimal $u_{*}$ threshold $\left(0.125 \mathrm{~m} \mathrm{~s}^{-1}\right)$ and with the annual balances calculated with the modified $u_{*}$ limits. Similarly, two additional different footprint limits $(0.65$ and 0.85$)$ were adopted to estimate the annual error caused by the footprint filtering $\left(E_{\mathrm{fp}}\right)$.

The total uncertainty of the annual balance $\left(E_{\mathrm{tot}}\right)$ was calculated with the standard error propagation principle:

$E_{\mathrm{tot}}=\sqrt{E_{\mathrm{meas}}^{2}+E_{\mathrm{gap}}^{2}+E_{\mathrm{ustar}}^{2}+E_{\mathrm{fp}}^{2}}$.

\section{Appendix C: Gap-filling energy fluxes}

Energy fluxes were gap-filled in several steps following the procedure described by Kowalski et al. (2003). First, the gaps in daytime $Q_{\mathrm{H}}\left(Q_{\mathrm{N}}>0\right)$ were filled with monthly linear regressions with net radiation. Next, the night-time $\left(Q_{\mathrm{N}}<0\right)$ gaps in $Q_{\mathrm{H}}$ were replaced by the corresponding $Q_{\mathrm{N}}$. Finally, the daytime gaps in $Q_{\mathrm{E}}$ were filled in such a way that the monthly mean energy balance closure was achieved, while during the night the missing $Q_{\mathrm{E}}$ data were set to 0 . 
Supplement. The supplement related to this article is available online at: https://doi.org/10.5194/bg-16-3703-2019-supplement.

Author contributions. TP, PO, KM, TL and AL designed the study. Field measurements and maintenance were carried out by MK, JR, TL and AL. JPT made spectral corrections and footprint analysis for the EC data. SS and PO corrected the WTL data and did the WTL background modelling. The rest of the data analysis was carried out by MK. MK wrote the paper with contributions from all co-authors.

Competing interests. The authors declare that they have no conflict of interest.

Acknowledgements. We are grateful for the financial support from the Maj and Tor Nessling foundation and from the Ministry of Transport and Communications through the Integrated Carbon Observing System (ICOS) research.

Financial support. This research has been supported by the Maj ja Tor Nesslingin Säätiö (grant no. 201700450) and by the Ministry of Transport and Communications through the Integrated Carbon Observing System (ICOS) research.

Review statement. This paper was edited by Frank Hagedorn and reviewed by three anonymous referees.

\section{References}

Amiro, B. D., Barr, A. G., Barr, J. G., Black, T. A., Bracho, R., Brown, M., Chen, J., Clark, K. L., Davis, K. J., Desai, A. R., Dore, S., Engel, V., Fuentes, J. D., Goldstein, A. H., Goulden, M. L., Kolb, T. E., Lavigne, M. B., Law, B. E., Margolis, H. A., Martin, T., McCaughey, J. H., Misson, L., Montes-Helu, M., Noormets, A., Randerson, J. T., Starr, G., and Xiao, J.: Ecosystem carbon dioxide fluxes after disturbance in forests of North America, J. Geophys. Res.-Biogeo., 115, G00K02, https://doi.org/10.1029/2010JG001390, 2010.

Aubinet, M., Vesala, T., and Papale, D. (Eds.): Eddy Covariance: a practical guide to measurement and data analysis, Springer Science \& Business Media, 2012.

Aurela, M., Laurila, T., and Tuovinen, J.-P.: Annual $\mathrm{CO}_{2}$ balance of a subarctic fen in northern Europe: Importance of the wintertime efflux, J. Geophys. Res.-Atmos., 107, 1-12, https://doi.org/10.1029/2002JD002055, 2002.

Aurela, M., Lohila, A., Tuovinen, J.-P., Hatakka, J., Penttilä, T., and Laurila, T.: Carbon dioxide and energy flux measurements in four northern-boreal ecosystems at Pallas, Boreal Environ. Res., 20, 455-473, 2015.

Betts, A. K., Desjardins, R. L., and Worth, D.: Impact of agriculture, forest and cloud feedback on the surface energy budget in BOREAS, Agr. Forest Meteorol., 142, 156-169, https://doi.org/10.1016/j.agrformet.2006.08.020, 2007.
Bhuiyan, R., Minkkinen, K., Helmisaari, H.-S., Ojanen, P., Penttilä, T., and Laiho, R.: Estimating fine-root production by tree species and understorey functional groups in two contrasting peatland forests, Plant Soil, 412, 299-316, https://doi.org/10.1007/s11104-016-3070-3, 2017.

Blodau, C., Basiliko, N., and Moore, T.: Carbon turnover in peatland mesocosms exposed to different water table levels, Biogeochemistry, 67, 331-351, https://doi.org/10.1023/B:BIOG.0000015788.30164.e2, 2004.

Chimner, R. A. and Cooper, D. J.: Influence of water table levels on $\mathrm{CO}_{2}$ emissions in a Colorado subalpine fen: An in situ microcosm study, Soil Biol. Biochem., 35, 345-351, https://doi.org/10.1016/S0038-0717(02)00284-5, 2003.

Clark, K. L., Gholz, H. L., and Castro, M. S.: Carbon dynamics along a chronosequence of slash pine plantations in north Florida, Ecol. Appl., 14, 1154-1171, 2004.

Clarke, D. and Rieley, J.: Strategy for Responsible Peatland Management, edited by: Clarke, D. and Rieley, J., International Peat Society, Saarijärvi, Finland, 2010.

Davidson, E., Belk, E., and Boone, R. D.: Soil water content and temperature as independent or confounded factors controlling soil respiration in a temperate mixed hardwood forest, Glob. Change Biol., 4, 217-227, https://doi.org/10.1046/j.13652486.1998.00128.x, 1998.

Drzymulska, D.: Peat decomposition - Shaping factors, significance in environmental studies and methods of determination; A literature review, Geologos, 22, 61-69, https://doi.org/10.1515/logos2016-0005, 2016.

Edwards, N. T. and Ross-Todd, B. M.: Soil Carbon Dynamics in a Mixed Deciduous Forest Following Clear-Cutting with and without Residue Removal, Soil Sci. Soc. Am. J., 47, 1014-1021, https://doi.org/10.2136/sssaj1983.03615995004700050035x, 1983.

Fischlin, A., Midgley, G. F., Price, J., Leemans, R., Gopal, B., Turley, C., Rounsevell, M., Dube, P., Tarazona, J., and Velichko, A.: Ecosystems, their properties, goods, and services, in: Climate Change 2007: Impacts, Adaptation and Vulnerability. Contribution of working group II to the Fourth Assessment Report of the Intergovernmental Panel on Climate Change, edited by: Parry, M. L., Canziani, O. F., Palutikof, J. P., van der Linden, P. J., and Hanson, C. E., Cambridge University Press, Cambridge, available at: http://www.treesearch.fs.fed.us/pubs/33102 (last access: 5 September 2019), 2007.

Foken, T. and Wichura, B.: Tools for quality assessment of surfacebased flux measurements, Agr. Forest Meteorol., 78, 83-105, https://doi.org/10.1016/0168-1923(95)02248-1, 1996.

Fontaine, S., Bardoux, G., Abbadie, L., and Mariotti, A.: Carbon input to soil may decrease soil carbon content, Ecol. Lett., 7, 314 320, https://doi.org/10.1111/j.1461-0248.2004.00579.x, 2004.

Fontaine, S., Barot, S., Barré, P., Bdioui, N., Mary, B., and Rumpel, C.: Stability of organic carbon in deep soil layers controlled by fresh carbon supply, Nature, 450, 277-280, https://doi.org/10.1038/nature06275, 2007.

Fredeen, A. L., Waughtal, J. D., and Pypker, T. G.: When do replanted sub-boreal clearcuts become net sinks for $\mathrm{CO}_{2}$ ?, Forest Ecol. Manage., 239, 210-216, https://doi.org/10.1016/j.foreco.2006.12.011, 2007.

Hommeltenberg, J., Schmid, H. P., Drösler, M., and Werle, P.: Can a bog drained for forestry be a stronger carbon sink 
than a natural bog forest?, Biogeosciences, 11, 3477-3493, https://doi.org/10.5194/bg-11-3477-2014, 2014.

Howard, E. A., Gower, S. T., Foley, J. A., and Kucharik, C. J.: Effects of logging on carbon dynamics of a jack pine forest in Saskatchewan, Canada, Glob. Change Biol., 10, 1267-1284, https://doi.org/10.1111/j.1529-8817.2003.00804.x, 2004.

Humphreys, E. R., Black, T. A., Morgenstern, K., Li, Z., and Nesic, Z.: Net ecosystem production of a Douglas-fir stand for 3 years following clearcut harvesting, Glob. Change Biol., 11, 450-464, https://doi.org/10.1111/j.1365-2486.2005.00914.x, 2005.

Huttunen, J. T., Nykänen, H., Martikainen, P. J., and Nieminen, M.: Fluxes of nitrous oxide and methane from drained peatlands following forest clear-felling in southern Finland, Plant Soil, 255, 457-462, https://doi.org/10.1023/A:1026035427891, 2003.

IPCC: Climate Change 2013: The Physical Science Basis. Contribution of Working Group I to the Fifth Assessment Report of the Intergovernmental Panel on Climate Change, edited by: Stocker, T. F., Qin, D., Plattner, G.-K., Tignor, M., Allen, S. K., Boschung, J., Nauels, A., and Xia, Y., Cambridge University Press, Cambridge, UK and New York, NY, USA, 2013.

Kaila, A., Sarkkola, S., Laurén, A., Ukonmaanaho, L., Koivusalo, H., Xiao, L., O'Driscoll, C., Asam, Z. U. Z., Tervahauta, A., and Nieminen, M.: Phosphorus export from drained Scots pine mires after clear-felling and bioenergy harvesting, Forest Ecol. Manage., 325, 99-107, https://doi.org/10.1016/j.foreco.2014.03.025, 2014.

Kaimal, J. C. and Finnigan, J. J.: Atmospheric boundary layer flows: their structure and measurement, Oxford University Press, Oxford, 1994.

Kolari, P., Pumpanen, J., Rannik, Ü., Ilvesniemi, H., Hari, P., and Berninger, F.: Carbon balance of different aged Scots pine forests in Southern Finland, Glob. Change Biol., 10, 1106-1119, https://doi.org/10.1111/j.1529-8817.2003.00797.x, 2004.

Korkiakoski, M., Tuovinen, J.-P., Aurela, M., Koskinen, M., Minkkinen, K., Ojanen, P., Penttilä, T., Rainne, J., Laurila, T., and Lohila, A.: Methane exchange at the peatland forest floor automatic chamber system exposes the dynamics of small fluxes, Biogeosciences, 14, 1947-1967, https://doi.org/10.5194/bg-141947-2017, 2017.

Korkiakoski, M., Tuovinen, J.-P., Penttilä, T., Sarkkola, S., Ojanen, P., Minkkinen, K., Rainne, J., Laurila, T., and Lohila, A.: Greenhouse gas and energy fluxes in a boreal peatland forest after clearcutting, Zenodo, https://doi.org/10.5281/zenodo.3384791, 2019.

Kormann, R. and Meixner, F. X.: An analytical footprint model for non-neutral stratification, Bound.-Lay. Meteorol., 99, 207-224, https://doi.org/10.1023/A:1018991015119, 2001.

Kowalski, A. S., Loustau, D., Berbigier, P., Manca, G., Tedeschi, V., Borghetti, M., Valentini, R., Kolari, P., Berninger, F., Rannik, Ü., Hari, P., Rayment, M., Mencuccini, M., Moncrieff, J., and Grace, J.: Paired comparisons of carbon exchange between undisturbed and regenerating stands in four managed forest in Europe, Glob. Change Biol., 10, 1707-1723, https://doi.org/10.1111/j.13652486.2004.00846.x, 2004.

Kowalski, S., Sartore, M., Burlett, R., Berbigier, P., and Loustau, D.: The annual carbon budget of a French pine forest (Pinus pinaster) following harvest, Glob. Change Biol., 9, 1051-1065, https://doi.org/10.1046/j.1365-2486.2003.00627.x, 2003.
Laurén, A., Heinonen, J., Koivusalo, H., Sarkkola, S., Tattari, S., Mattsson, T., Ahtiainen, M., Joensuu, S., Kokkonen, T., and Finér, L.: Implications of uncertainty in a pre-treatment dataset when estimating treatment effects in paired catchment studies: Phosphorus loads from forest clear-cuts, Water. Air. Soil Poll., 196, 251-261, https://doi.org/10.1007/s11270-008-9773-1, 2009.

Lloyd, J. and Taylor, J. A.: On the Temperature Dependence of Soil Respiration, Funct. Ecol., 8, 315-323, 1994.

Londo, A. J., Messina, M. G., and Schoenholtz, S. H.: Forest Harvesting Effects on Soil Temperature, Moisture, and Respiration in a Bottomland Hardwood Forest, Soil Sci. Soc. Am. J., 63, 637-644, https://doi.org/10.2136/sssaj1999.03615995006300030029x, 1999.

Machimura, T., Kobayashi, Y., Iwahana, G., Hirano, T., Lopez, L., Fukuda, M., and Fedorov, A. N.: Change of carbon dioxide budget during three years after deforestation in eastern siberian larch forest, J. Agr. Meteorol., 60, 653-656, 2005.

Mäkiranta, P., Minkkinen, K., Hytönen, J., and Laine, J.: Factors causing temporal and spatial variation in heterotrophic and rhizospheric components of soil respiration in afforested organic soil croplands in Finland, Soil Biol. Biochem., 40, 1592-1600, https://doi.org/10.1016/j.soilbio.2008.01.009, 2008.

Mäkiranta, P., Laiho, R., Fritze, H., Hytönen, J., Laine, J., and Minkkinen, K.: Indirect regulation of heterotrophic peat soil respiration by water level via microbial community structure and temperature sensitivity, Soil Biol. Biochem., 41, 695-703, https://doi.org/10.1016/j.soilbio.2009.01.004, 2009.

Mäkiranta, P., Riutta, T., Penttilä, T., and Minkkinen, K.: Dynamics of net ecosystem $\mathrm{CO}_{2}$ exchange and heterotrophic soil respiration following clearfelling in a drained peatland forest, Agr. Forest Meteorol., 150, 1585-1596, https://doi.org/10.1016/j.agrformet.2010.08.010, 2010.

Mäkiranta, P., Laiho, R., Penttilä, T., and Minkkinen, K.: The impact of logging residue on soil GHG fluxes in a drained peatland forest, Soil Biol. Biochem., 48, 1-9, https://doi.org/10.1016/j.soilbio.2012.01.005, 2012.

Maljanen, M., Sigurdsson, B. D., Guðmundsson, J., Óskarsson, H., Huttunen, J. T., and Martikainen, P. J.: Greenhouse gas balances of managed peatlands in the Nordic countries present knowledge and gaps, Biogeosciences, 7, 2711-2738, https://doi.org/10.5194/bg-7-2711-2010, 2010.

Mamkin, V., Kurbatova, J., Avilov, V., Mukhartova, Y., Krupenko, A., Ivanov, D., Levashova, N., and Olchev, A.: Changes in net ecosystem exchange of $\mathrm{CO}_{2}$, latent and sensible heat fluxes in a recently clear-cut spruce forest in western Russia: results from an experimental and modeling analysis, Environ. Res. Lett., 11, 125012, https://doi.org/10.1088/1748-9326/aa5189, 2016.

Martikainen, P. J., Nykänen, H., Alm, J., and Silvola, J.: Change in Fluxes of Carbon-Dioxide, Methane and Nitrous-Oxide Due To Forest Drainage of Mire Sites of Different Trophy, Plant Soil, 168, 571-577, https://doi.org/10.1007/bf00029370, 1995.

McMillen, R. T.: An eddy correlation technique with extended applicability to non-simple terrain, Bound.-Lay. Meteorol., 43, 231-245, https://doi.org/10.1007/BF00128405, 1988.

Meyer, A., Tarvainen, L., Nousratpour, A., Björk, R. G., Ernfors, M., Grelle, A., Kasimir Klemedtsson, Å., Lindroth, A., Räntfors, M., Rütting, T., Wallin, G., Weslien, P., and 
Klemedtsson, L.: A fertile peatland forest does not constitute a major greenhouse gas sink, Biogeosciences, 10, 7739-7758, https://doi.org/10.5194/bg-10-7739-2013, 2013.

Minkkinen, K., Laine, J., and Hökkä, H.: Tree stand development and carbon sequestration in drained peatland stands in Finland - a simulation study, Silva Fenn., 35, 55-69, https://doi.org/10.14214/sf.603, 2001.

Moore, C. J.: Frequency response corrections for eddy correlation systems, Bound.-Lay. Meteor., 37, 17-35, https://doi.org/10.1007/BF00122754, 1986.

Ojanen, P., Minkkinen, K., Alm, J., and Penttilä, T.: Soilatmosphere $\mathrm{CO}_{2}, \mathrm{CH}_{4}$ and $\mathrm{N}_{2} \mathrm{O}$ fluxes in boreal forestrydrained peatlands, Forest Ecol. Manage., 260, 411-421, https://doi.org/10.1016/j.foreco.2010.04.036, 2010.

Ojanen, P., Minkkinen, K., and Penttilä, T.: The current greenhouse gas impact of forestry-drained boreal peatlands, Forest Ecol. Manage., 289, 201-208, https://doi.org/10.1016/j.foreco.2012.10.008, 2013.

Ojanen, P., Mäkiranta, P., Penttilä, T., and Minkkinen, K.: Do logging residue piles trigger extra decomposition of soil organic matter?, Forest Ecol. Manage., 405, 367-380, https://doi.org/10.1016/j.foreco.2017.09.055, 2017.

Ojanen, P., Minkkinen, K., Alm, J., and Penttilä, T.: Corrigendum to "Soil-atmosphere $\mathrm{CO}_{2}, \mathrm{CH}_{4}$ and $\mathrm{N}_{2} \mathrm{O}$ fluxes in boreal forestrydrained peatlands" [Forest Ecol. Manage., 260, 411-421, https://doi.org/10.1016/j.foreco.2010.04.036], Forest Ecol. Manage., 412, 95-96, https://doi.org/10.1016/j.foreco.2018.01.020, 2018.

Päivänen, J. and Hånell, B.: Peatland ecology and forestry?: a sound approach, University of Helsinki Department of Forest Sciences Publications 3, Helsinki, Finland, 2012.

Pearson, M., Saarinen, M., Minkkinen, K., Silvan, N., and Laine, J.: Short-term impacts of soil preparation on greenhouse gas fluxes: A case study in nutrient-poor, clearcut peatland forest, Forest Ecol. Manage., 283, 10-26, https://doi.org/10.1016/j.foreco.2012.07.011, 2012.

Pirinen, P., Simola, H., Aalto, J., Kaukoranta, J.-P., Karlsson, P., and Ruuhela, R.: Climatological statistics of Finland 1981-2010, Reports 2, Finnish Meteorological Institute, Helsinki, Finland, 2012.

Pypker, T. G. and Fredeen, A. L.: Ecosystem $\mathrm{CO}_{2}$ flux over two growing seasons for a sub-Boreal clearcut 5 and 6 years after harvest, Agr. Forest Meteorol., 114, 15-30, https://doi.org/10.1016/S0168-1923(02)00139-9, 2002.

Rannik, Ü., Vesala, T., and Keskinen, R.: On the damping of temperature fluctuations in a circular tube relevant to the eddy covariance measurement technique, J. Geophys. Res.-Atmos., 102, 12789-12794, 1997.

Rannik, Ü., Altimir, N., Raittila, J., Suni, T., Gaman, A., Hussein, T., Hölttä, T., Lassila, H., Latokartano, M., Lauri, A., Natsheh, A., Petäjä, T., Sorjamaa, R., Ylä-Mella, H., Keronen, P., Berninger, F., Vesala, T., Hari, P., and Kulmala, M.: Fluxes of carbon dioxide and water vapour over Scots pine forest and clearing, Agr. Forest Meteorol., 111, 187-202, https://doi.org/10.1016/S0168-1923(02)00022-9, 2002.

Räsänen, M., Aurela, M., Vakkari, V., Beukes, J. P., Tuovinen, J.-P., Van Zyl, P. G., Josipovic, M., Venter, A. D., Jaars, K., Siebert, S. J., Laurila, T., Rinne, J., and Laakso, L.: Carbon balance of a grazed savanna grassland ecosystem in South Africa,
Biogeosciences, 14, 1039-1054, https://doi.org/10.5194/bg-141039-2017, 2017.

R Core Team: R: A language and Environment for Statistical Computing, available at: https://www.r-project.org (last access: 5 September 2019), 2018.

Riutta, T., Laine, J., and Tuittila, E.-S.: Sensitivity of $\mathrm{CO}_{2}$ exchange of fen ecosystem components to water level variation, Ecosystems, 10, 718-733, https://doi.org/10.1007/s10021-007-9046-7, 2007

Roulet, N., Ash, R., Quinton, W., and Moore, T.: Methane flux from drained northern peatlands: Effect of a persistent water table lowering on flux, Global Biogeochem. Cy., 7, 749-769, 1993.

Saari, P., Saarnio, S., Kukkonen, J. V. K., Akkanen, J., Heinonen, J., Saari, V., and Alm, J.: DOC and $\mathrm{N}_{2} \mathrm{O}$ dynamics in upland and peatland forest soils after clear-cutting and soil preparation, Biogeochemistry, 94, 217-231, https://doi.org/10.1007/s10533009-9320-1, 2009.

Sarkkola, S., Hökkä, H., Koivusalo, H., Nieminen, M., Ahti, E., Päivänen, J., and Laine, J.: Role of tree stand evapotranspiration in maintaining satisfactory drainage conditions in drained peatlands, Can. J. For. Res., 40, 1485-1496, https://doi.org/10.1139/X10-084, 2010.

Schulze, E.-D., Lloyd, J., Kelliher, F. M., Wirth, C., Rebmann, C., Luhker, B., Mund, M., Knohl, A., Milyukova, I. M., Schulze, W., Ziegler, W., Varlagin, A. B., Sogachev, A. F., Valentini, R., Dore, S., Grigoriev, S., Kolle, O., Panfyorov, M. I., Tchebakova, N., and Vygodskaya, N. N.: Productivity of forests in the eurosiberian boreal region and their potential to act as a carbon sink - a synthesis, Glob. Change Biol., 5, 703-722, https://doi.org/10.1046/j.1365-2486.1999.00266.x, 1999.

Silvola, J., Alm, J., Ahlholm, U., Nykänen, H., and Martikainen, P. J.: $\mathrm{CO}_{2}$ Fluxes from Peat in Boreal Mires under Varying Temperature and Moisture Conditions, J. Ecol., 84, 219-228, 1996.

Sundqvist, E., Vestin, P., Crill, P., Persson, T., and Lindroth, A.: Short-term effects of thinning, clear-cutting and stump harvesting on methane exchange in a boreal forest, Biogeosciences, 11 , 6095-6105, https://doi.org/10.5194/bg-11-6095-2014, 2014.

Takagi, K., Fukuzawa, K., Liang, N., Kayama, M., Nomura, M., Hojyo, H., Sugata, S., Shibata, H., Fukazawa, T., Takahashi, Y., Nakaji, T., Oguma, H., Mano, M., Akibayashi, Y., Murayama, T., Koike, T., Sasa, K., and Fujinuma, Y.: Change in $\mathrm{CO}_{2}$ balance under a series of forestry activities in a cool-temperate mixed forest with dense undergrowth, Glob. Change Biol., 15, 1275 1288, https://doi.org/10.1111/j.1365-2486.2008.01795.x, 2009.

Turunen, J., Tomppo, E., Tolonen, K., and Reinikainen, A.: Estimating carbon accumulation rates of undrained mires in Finlandapplication to boreal and subarctic regions, Holocene, 12, 69-80, https://doi.org/10.1191/0959683602hl522rp, 2002.

Uri, V., Kukumägi, M., Aosaar, J., Varik, M., Becker, H., Morozov, G., and Karoles, K.: Ecosystems carbon budgets of differently aged downy birch stands growing on well-drained peatlands, Forest Ecol. Manage., 399, 82-93, https://doi.org/10.1016/j.foreco.2017.05.023, 2017.

Webb, E. K., Pearman, G. I., and Leuning, R.: Correction of flux measurements for density effects due to heat and water vapour transfer, Q. J. Roy. Meteor. Soc., 106, 85-100, https://doi.org/10.1002/qj.49710644707, 1980.

Williams, C., Vanderhoof, M., Khomik, M., and Ghimire, B.: Post-clearcut dynamics of carbon, water and energy ex- 
changes in a midlatitude temperate, deciduous broadleaf forest environment, Glob. Change Biol., 20, 992-1007, https://doi.org/10.1111/gcb.12388, 2013.

$\mathrm{Yu}, \mathrm{Z}$.: Holocene carbon flux histories of the world's peatlands: Global carbon-cycle implications, Holocene, 21, 761-774, https://doi.org/10.1177/0959683610386982, 2011.
Zerva, A. and Mencuccini, M.: Short-term effects of clearfelling on soil $\mathrm{CO}_{2}, \mathrm{CH}_{4}$, and $\mathrm{N}_{2} \mathrm{O}$ fluxes in a Sitka spruce plantation, Soil Biol. Biochem., 37, 2025-2036, https://doi.org/10.1016/j.soilbio.2005.03.004, 2005. 

III 



\title{
Impact of partial harvest on $\mathrm{CH}_{4}$ and $\mathrm{N}_{2} \mathrm{O}$ balances of a drained boreal peatland forest
}

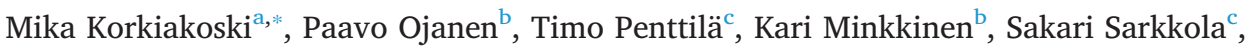 \\ Juuso Rainne ${ }^{\mathrm{a}}$, Tuomas Laurila ${ }^{\mathrm{a}}$, Annalea Lohila, ${ }^{\mathrm{a}} \mathrm{d}$ \\ ${ }^{\text {a }}$ Finnish Meteorological Institute, P.O. Box 503, FI-00101 Helsinki, Finland \\ ${ }^{\mathrm{b}}$ Department of Forest Sciences, University of Helsinki, P.O. Box 27, 00014 Helsinki, Finland \\ ${ }^{\mathrm{c}}$ Natural Resources Institute Finland, Viikinkaari 4, 00790 Helsinki, Finland \\ ${ }^{\mathrm{d}}$ Institute for Atmospheric and Earth System Research (INAR), University of Helsinki, Gustaf Hällströmin katu 2, P.O. Box 64, o0014 Helsinki, Finland
}

\section{A R T I C L E I N F O}

\section{Keywords:}

Methane

Nitrous oxide

Flux

Peatland forestry

Selective harvest

Disturbance

\begin{abstract}
A B S T R A C T
Rotation forestry including clearcutting is a common method of practising forestry in Fennoscandia. Clearcutting in peatland forests markedly increases environmental loading: leaching of nutrients and methane $\left(\mathrm{CH}_{4}\right)$ and nitrous oxide $\left(\mathrm{N}_{2} \mathrm{O}\right)$ fluxes from soil. Continuous cover forestry has been suggested as an alternative because it does not include clearcutting but partial harvesting. However, impacts of partial harvesting on greenhouse gas fluxes are not well understood and in peatlands have not been studied at all. We conducted a partial harvest by removing $70 \%$ of the total stem volume in a mature nutrient-rich peatland forest in Southern Finland. The aim was to investigate how partial harvesting a peatland forest affects $\mathrm{CH}_{4}$ and $\mathrm{N}_{2} \mathrm{O}$ balances, and how much different surface types contribute to the balances. We used automatic and manual chamber methods to measure fluxes from both harvest and uncut control site. Fluxes were measured from the forest floor, logging trails, and ditches. Fluxes from these surface types were upscaled to obtain net ecosystem-level fluxes during two postharvest summers (June-August 2016 and 2017). After the harvest, forest floor $\mathrm{CH}_{4}$ fluxes did not change significantly at the harvested site compared to the control site. However, fluxes at logging trails increased significantly. $\mathrm{N}_{2} \mathrm{O}$ fluxes increased at the harvest site in the post-harvest years, but so did those at the control site as well. Upscaling $\mathrm{CH}_{4}$ fluxes to ecosystem-level indicated that despite their small area (2.4\%), emissions from ditches could be large on ecosystem-scale, but their uncertainty was high, while the logging trail $\mathrm{CH}_{4}$ fluxes ( $20 \%$ of the total area) were small. In contrast, $\mathrm{N}_{2} \mathrm{O}$ fluxes from ditches were low, but the logging trail fluxes comprised $35-38 \%$ of the total surface balance. The overall conclusion is that partial harvesting did not cause considerable changes in $\mathrm{CH}_{4}$ and $\mathrm{N}_{2} \mathrm{O}$ fluxes from a forestry-drained peatland.
\end{abstract}

\section{Introduction}

The most important greenhouse gases (GHG) behind climate change, after carbon dioxide $\left(\mathrm{CO}_{2}\right)$, are methane $\left(\mathrm{CH}_{4}\right)$ and nitrous oxide $\left(\mathrm{N}_{2} \mathrm{O}\right)$. Their atmospheric concentrations are much smaller than that of $\mathrm{CO}_{2}$, but due to their stronger radiative forcing on per-mass, $\mathrm{CH}_{4}$ and $\mathrm{N}_{2} \mathrm{O}$ constitute about $20 \%$ and $7 \%$ of the global radiative forcing (Myhre et al., 2013), therefore significantly contributing to global climate change. Peatlands store about a third of the global soil carbon (C) pool (Gorham, 1991; Turunen et al., 2002), making them an essential part of global $\mathrm{C}$ and nitrogen $(\mathrm{N})$ cycles and contributing significantly to ecosystem-atmosphere exchange of $\mathrm{CH}_{4}$ and $\mathrm{N}_{2} \mathrm{O}$. They cover ca. $3 \%$ of the Earth's land surface (Clarke and Rieley, 2010), and most of them are located in the boreal region (Fischlin et al., 2007).

About 15 million hectares of the boreal peatlands and more than half of the original 10 million ha mire area in Finland has been drained for forestry (Päivänen and Hånell, 2012). Forestry on peatlands, where drainage of the site is one of the most profound measures, affects the conditions for $\mathrm{CH}_{4}$ and $\mathrm{N}_{2} \mathrm{O}$ production significantly. Drainage of peatlands lowers the WTL, which leads to increased oxygen availability in the peat soil above the WTL (Prévost et al., 1997), and thus decreases the $\mathrm{CH}_{4}$ fluxes from the soil. This is because the $\mathrm{CH}_{4}$ production ceases in the oxic peat, but also because there is more $\mathrm{CH}_{4}$ oxidation in the thicker oxic peat layer. In minerotrophic sedge-dominated mires, an even more important factor is the disappearance of sedges following drainage: the input of easily decomposable substrate (labile $\mathrm{C}$ ) to the

\footnotetext{
* Corresponding author.

E-mail address: mika.korkiakoski@fmi.fi (M. Korkiakoski).
} 
anoxic peat layers through sedge roots (Joabsson et al., 1999) ends, and so does the transport of $\mathrm{CH}_{4}$ from the anoxic layers to the atmosphere through sedge aerenchyma. However, the drainage ditches still emit $\mathrm{CH}_{4}$ and may negate much of the emission-reducing impact of the drainage (Minkkinen et al., 1997; Minkkinen and Laine, 2006). Drainage typically increases $\mathrm{N}_{2} \mathrm{O}$ fluxes only from fertile/nutrient-rich sites (Martikainen et al., 1993). In peatlands, high $\mathrm{N}_{2} \mathrm{O}$ fluxes occur mainly from sites with a soil C:N-ratio lower than 25 (Ernfors et al., 2008; Klemedtsson et al., 2005). About 40\% of drained peatlands in Finland represent herb-rich and Vaccinium myrtillys types (Korhonen et al., 2017), with C:N-ratios typically below 25 (Minkkinen et al. 2020, unpublished results).

Rotation forestry, which is the most common forest management method in Finland and other Nordic countries, includes clearcutting with stem wood harvest at the end of the rotation. Most of the logging residues produced in the harvesting operation are typically placed on the logging trails to create support for the heavy harvesting machinery, and after the harvest, the residues are either collected or left on the site. After clearcutting, the site is typically mounded or harrowed, and the new tree seedlings are planted or seeds sown. In addition to a radical change in hydrological conditions, the soil preparation method after clearcutting influences the $\mathrm{CH}_{4}$ and $\mathrm{N}_{2} \mathrm{O}$ fluxes (Pearson et al., 2012). Clearcutting has been shown to switch forest sites from net $\mathrm{CH}_{4}$ sinks to sources in both peat (Korkiakoski et al., 2019) and mineral soils (Sundqvist et al., 2014) due to the rise of WTL, although in some studies $\mathrm{CH}_{4}$ fluxes did not change significantly despite increased WTL (Huttunen et al., 2003; Saari et al., 2009). According to Ojanen et al. (2010, 2013), $\mathrm{CH}_{4}$ emissions only increase when the WTL is higher than $-30 \mathrm{~cm}$. Also, $\mathrm{N}_{2} \mathrm{O}$ emissions usually increase after clearcutting (Huttunen et al., 2003; Korkiakoski et al., 2019; Neill et al., 2006; Robertson et al., 1987; Saari et al., 2009), although contrary results with no effect have also been reported (Nieminen, 1998). The reasons behind the increase in $\mathrm{N}_{2} \mathrm{O}$ fluxes are unclear, but logging residues have been suggested to enhance $\mathrm{N}_{2} \mathrm{O}$ fluxes (Mäkiranta et al., 2012). Clearcutting has also been shown to influence forest micrometeorology by changing surface albedo, net radiation, surface roughness and consequently the energy fluxes (McCaughey \& Brintnell 1984; Amiro 2001; Rannik et al. 2002; Kowalski et al. 2003), which indirectly affect $\mathrm{CH}_{4}$ and $\mathrm{N}_{2} \mathrm{O}$ exchange between soil and the atmosphere.

Shifting from rotation forestry towards methods applied in continuous cover forestry (CCF) has been suggested to mitigate the harmful environmental impacts resulting from clearcutting in peatlands (Nieminen et al., 2018). In CCF, only part of the tree stand is removed in cuttings. The cuttings usually include harvesting from above and below (bigger and smaller trees), so that the remaining stand can grow larger and the open places are naturally regenerated. Thus the stand is typically uneven-aged and uneven-structured, it is never clear-cut, and the forestry is not based on stand rotations. The effects of partial harvesting have been studied on various upland forests (Li et al., 2010; Mazza et al., 2019; Sundqvist et al., 2014) but measurements from peatland forests are lacking.

This study investigates how partial harvesting in a mature, drained boreal pine-dominated peatland forest affects the exchange of $\mathrm{CH}_{4}$ and $\mathrm{N}_{2} \mathrm{O}$ between the forest floor and the atmosphere, and what is the contribution of ditches and the logging residues and trails on site-level $\mathrm{CH}_{4}$ and $\mathrm{N}_{2} \mathrm{O}$ balances. WTL raise after partial harvesting is expected to remain smaller than after clearcutting, and therefore, $\mathrm{CH}_{4}$ emissions should increase less than after clearcutting. Also, $\mathrm{N}_{2} \mathrm{O}$ emissions are expected to increase from pre-harvest conditions as mineral $\mathrm{N}$ is liberated from decomposing logging residues while fewer trees are taking it up. In this study, the purpose of the partial harvesting was to regenerate the stand naturally by releasing the spruce understorey, leaving most of the birches for contributing to the transpiration potential of the retained stand and as shelter wood for the desired new spruce seedlings expected to show up after harvesting. Should the transpiration potential of the retained stand prove sufficient regarding drainage and, thereby, proper recovery and future growth of the released understorey, ditch network maintenance may not be needed in this connection. Further, with sufficient regeneration of new seedlings, the development towards an uneven-structured, mixed birch-spruce stand could be enabled.

\section{Materials and methods}

\subsection{Site description}

The measurements were carried out in a nutrient-rich peatland forest called Lettosuo located in southern Finland $\left(60^{\circ} 38^{\prime}\right.$ N, $\left.23^{\circ} 57^{\prime} \mathrm{E}\right)$. The site was sparsely drained in the 1930s, but proper drainage was carried out in 1969. After the drainage, the site was fertilised with phosphorus and potassium. The distance between the ditches is on average $45 \mathrm{~m}$, and they were dug ca. $1 \mathrm{~m}$ deep but have since been partially filled with vegetation. Before partial harvesting in 2016, the two-storeyed tree stand was composed of Scots pine (Pinus sylvestris) with some pubescent birch (Betula pubescens) in the dominant tree storey with stem numbers of 470 and 190 per ha, dominant heights of 21 and $18.5 \mathrm{~m}$, and standing stem volumes of 184 and $41 \mathrm{~m}^{3} \mathrm{ha}^{-1}$, respectively. The understorey included mostly Norway spruce (Picea abies) (ca. 1000 stems ha $^{-1} ; 34 \mathrm{~m}^{3} \mathrm{ha}^{-1}$ ) and some small-sized pubescent birch (ca. 450 stems ha ${ }^{-1} ; 7 \mathrm{~m}^{3} \mathrm{ha}^{-1}$ ). The tree stand was quite dense, and its irregular shading resulted in patchy and variable ground vegetation. Detailed description of the ground vegetation and soil can be found from (Bhuiyan et al., 2017) and (Korkiakoski et al., 2017, 2019), respectively. At present, the site represents the minerotrophic Vaccinium myrtillus site type (Mtkg II) of drained peatlands (for the site type classification in more detail, see Vasander and Laine, 2008).

The partial harvesting (hereafter harvesting) at Lettosuo was performed in 2016 between February $29^{\text {th }}$ and March $16^{\text {th }}$ in an area of 13 ha (Fig. 1a) where all the pine trees (ca. $70 \%$ of the total stem volume) were harvested. The logging residues were left at the site, mostly on the logging trails to improve bearing capacity for the harvesting machinery. The trees close to the automatic and manual chambers were harvested without heavy machinery to avoid breaking the measurement setup and instruments. No soil preparation or seedling planting was performed at the harvest site. Also, the ditches were left intact.

A control site of 3.1 ha, with a similar tree stand and vegetation composition (Fig. 1a), located north-east of the harvest site, was left intact. On average, total stem volume on the control site was ca $20 \%$ smaller than on the harvest site (245 and $295 \mathrm{~m}^{3} \mathrm{ha}^{-1}$, respectively); this ratio applied similarly to the dominant pine and the understorey spruce. For birch, the basal areas $\left(7.1 ; 6.8 \mathrm{~m}^{2} \mathrm{ha}^{-1}\right)$ and stem volumes (53; $52 \mathrm{~m}^{3} \mathrm{ha}^{-1}$ ) were very similar on both sites. When selecting the locations for the intensive study plots (automatic chambers, manual chamber transects), we preferred locations where spruce understoreys were as similar as possible. After harvesting, basal areas of retained spruce around these intensive study plots were 6.8 and $7.4 \mathrm{~m}^{2} \mathrm{ha}^{-1}$, and stem volumes 31 and $43 \mathrm{~m}^{3} \mathrm{ha}^{-1}$, in the control and harvest site, respectively.

\subsection{Automatic chamber measurements}

The automatic chamber system at the harvest site was the same as used in $\mathrm{CO}_{2}$ flux measurements by Koskinen et al. (2014) and $\mathrm{CH}_{4}$ flux measurements by Korkiakoski et al. (2017). In addition to the system used by Korkiakoski et al. (2017), we added a $\mathrm{N}_{2} \mathrm{O}$ gas analyser in the line (see below). A similar automatic chamber system was installed to both the harvest site (Fig. 1c) and the control site (Fig. 1b); however, two different $\mathrm{N}_{2} \mathrm{O}$ gas analysers were deployed at the control site for a shorter period (Fig. S1).

Both chamber systems consisted of six transparent chambers with dimensions $57 \mathrm{~cm} \times 57 \mathrm{~cm} \mathrm{x} 40 \mathrm{~cm}$ (length $\mathrm{x}$ width $\mathrm{x}$ height). The chambers equipped with a fan, photosynthetically active radiation 


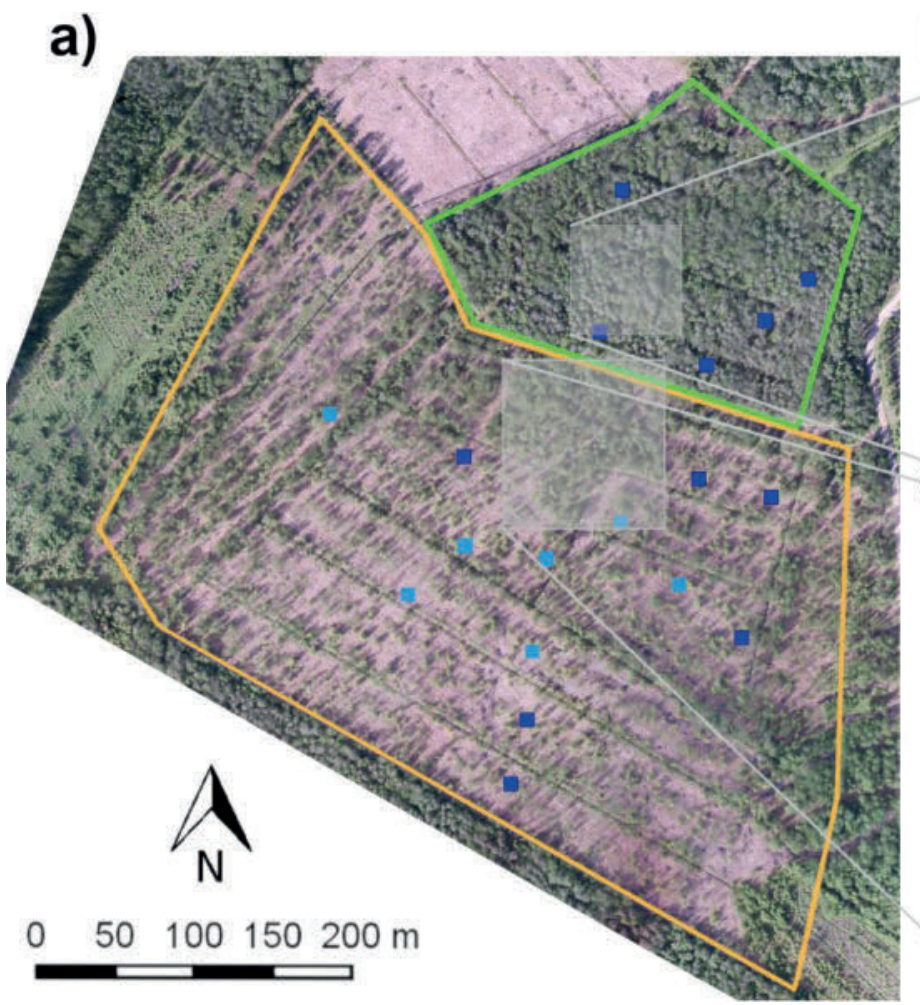

b)

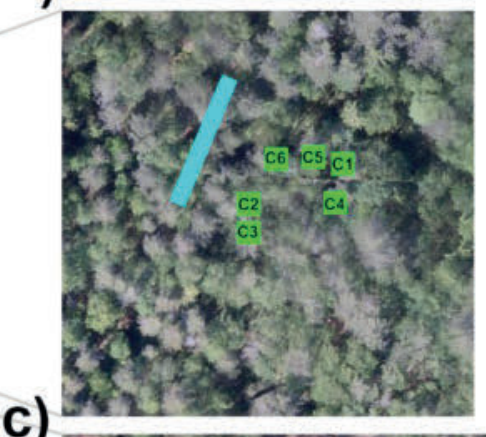

c)

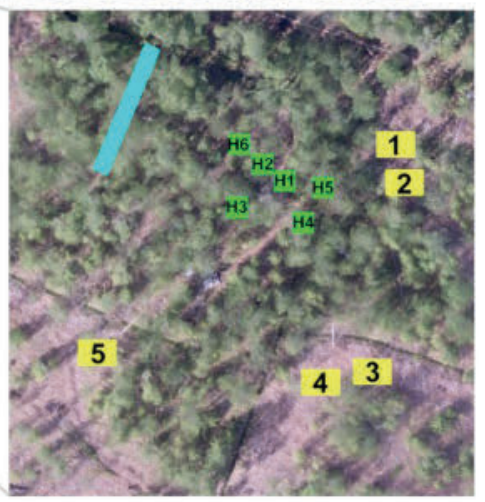

Fig. 1. Aerial view of the site taken in August 2016 (a) and the zoomed view of the chamber measurements at the control (surrounded by the green lines, b) and harvest (surrounded by the orange lines, c) site. The dark blue squares (a) show the automatic WTL measurements started in June 2016 and the light blue squares (a) show the WTL measurements added November 2016. Transect and ditch measurements were located in the cyan rectangles (b, c) and the yellow rectangles (c) show the locations of the logging trail measurements. The automatic chambers were located in the green squares (b, c). (For interpretation of the references to color in this figure legend, the reader is referred to the web version of this article.)

(PAR; PQS1 PAR Quantum Sensor, Kipp \& Zonen, Delft, The Netherlands) and a radiation-shielded temperature sensor were used with permanently installed steel collars (height $5 \mathrm{~cm}$, inserted at a depth of $2 \mathrm{~cm}$ ) to cover different ground vegetation compositions (Table S1) around ca. $15 \mathrm{~m}$ radius from the measurement cabin containing the measurement instruments. During winter 2016-2017, an extension collar (height $16 \mathrm{~cm}$ ) was placed between the chamber frame and the soil to raise the frame above the snow level. In addition, there was a soil temperature profile at 5 and $30 \mathrm{~cm}$ depths (Pt100, PT4T, Nokeval Oy, Nokia, Finland) about $15 \mathrm{~m}$ distance to the chambers at both harvest and control sites. Air temperature was measured with HMP45D (Vaisala oyj, Vantaa, Finland) from top of a mast at $25.7 \mathrm{~m}$ height, and from $2 \mathrm{~m}$ height at harvest and control site. A more detailed description of the chamber system can be found in Koskinen et al. (2014) and Korkiakoski et al. (2017).

A Picarro G1130 cavity ring-down spectroscopy gas analyser (Picarro Inc., Santa Clara, CA, USA) was used to measure the $\mathrm{CH}_{4}$ and water vapour concentrations with about $4 \mathrm{~s}$ interval, and a continuouswave quantum cascade laser absorption spectrometer (LGR-CW-QCL, Model N2O/CO-23d, Los Gatos Research Inc., Mountain View, CA, USA) was used to measure $\mathrm{N}_{2} \mathrm{O}$ concentration with $2 \mathrm{~s}$ interval. However, at the control site, Gasmet DX4015 based on Fourier transform infrared spectroscopy (Gasmet Technologies Oy, Helsinki, Finland) was also used in 2017 to measure the $\mathrm{N}_{2} \mathrm{O}$ concentration (Fig. S1). The chambers closed once an hour for six minutes. Linear and exponential regressions were applied for flux calculation as described in more detail in Appendix A. Data was filtered with normalised root mean square (NRMSE) and iterative standard deviation methods

\section{(Appendix B)}

Snow depth inside the automatic and manual (Section 2.3) chambers was measured 1-2 times per month during winter. The precipitation and air pressure data was acquired from the closest official weather station operated by Finnish Meteorological Institute at Jokioinen $(\sim 35$ $\mathrm{km}$ northwest of Lettosuo).

\subsection{Manual chamber measurements}

\subsubsection{Transect and ditch measurements}

Manual chamber sampling transects (Fig. 1bc) were set up on harvest and control sites similarly as described in Korkiakoski et al. (2019). Measurements were made between 29 June 2015 and 29 August 2017, mostly during the snow-free periods. The measurement interval mainly varied between one week and one month; however, there were a few longer gaps in autumn 2015 and spring 2016.

To have a spatially representative sampling in relation to the ditches at the harvest and control sites, two parallel flux measurement points were established (located within $2 \mathrm{~m}$ from each other) in the ditch and at a distance of 4, 8, 12 and $22.5 \mathrm{~m}$ from the ditch (hereafter 'transect'). $2 \mathrm{~cm}$ deep grooves were carved into the soil surface for the chambers, and were renewed when necessary to keep the chamber sealing adequate. However, if the soil surface was frozen, the measurements were not made as it was not possible to seal the chamber properly. No aboveground logging residues were introduced into the manual chamber points. For ditch measurements, extra collars (height $30 \mathrm{~cm}$ ) were installed into the ditch one hour before the measurement.

The fluxes were measured using a closed-chamber system with an 
opaque cylindrical chamber (height $30.5 \mathrm{~cm}$, diameter $31.5 \mathrm{~cm}$ ) including a mixing fan. The analysis of gas concentrations was made either using (1) a portable analyser or (2) inside-cabin laser analysers which were detached from the automatic chambers during the manual measurements. As a portable analyser, we employed the same Gasmet DX4015 (Gasmet Technologies Oy, Helsinki, Finland), which was also used in the automatic chamber system at the control site. The air circulated in a loop between the gas analyser and the chamber with a closure time of 10-11 min. The portable gas analyser was used at the transects in harvest and control sites in 2015 (Fig. S1). However, after the harvest in March 2016, more precise inside-cabin analysers coupled with the automatic chamber system were exploited in manual measurements at both transects. This method allowed capturing lower fluxes, especially $\mathrm{CH}_{4}$, more precisely with a shorter closure time (5 min). At the control transect, $\mathrm{N}_{2} \mathrm{O}$ fluxes were measured with the Gasmet DX4015 connected to the automatic chamber system, with a 10 min chamber closure time.

\subsubsection{Logging trail and residue measurements}

Five parallel plots with four different types of measurement points were set up on the harvest site (Fig 1c.) at the beginning of May 2016 by installing chamber collars $(55 \times 55 \times 20 \mathrm{~cm}$, length $\mathrm{x}$ width $\mathrm{x}$ height) $15 \mathrm{~cm}$ deep into the soil. The measurements continued until November 2017 (Fig. S1). Two of the points were located on the logging trail where the residues were piled for additional support for the harvesting machinery. The first point was established on the ground compressed by the wheels of the heavy machinery while the second one was set up on the uncompressed ground. The other two points with a small amount and no logging residues were located outside the logging trail. One of these two points simulated a case where trees were harvested, but a small amount of residues were left on the ground while the other one simulated an area which was left untouched during the harvest. Each point had a temperature sensor (iButton DS1921G, Maxim Integrated Products) inserted at $5 \mathrm{~cm}$ depth. Also, the points on the logging trail had a similar sensor on the soil surface under the residues. The dry mass of the logging residues in each collar was determined in May 2016 as follows: The residues inside the collars were temporarily removed from the collars and divided into five groups: Pinus Sylvestris twigs with needles and branches without needles, Picea abies twigs with needles and branches without needles, and Betula pubescens branches and twigs. The fresh weight of each of these groups was recorded, and then the residues were returned inside the collars. Also, similar sample groups nearby the collars were taken and weighed and dried at $105{ }^{\circ} \mathrm{C}$. After drying the needles were separated from the twigs, and the dry weight of the sample groups was measured. The relations of these dry and fresh masses were used to determine the dry mass of the needles and woody material (branches and twigs) inside each collar (Table S2). The vegetation composition at the points was recorded on 6 September 2016 (Table S3).

The flux measurements were made by exploiting the instruments used in the automatic chamber system similarly to the transect measurements from 2016 onwards (Sect. 2.3.1) using an angular chamber $(60 \times 60 \times 30 \mathrm{~cm}$, length $\mathrm{x}$ width $\mathrm{x}$ height).

\subsection{WTL measurements and calculations}

WTL was monitored hourly with automatic probes (TruTrack WTHR, Intech Instruments Ltd, Auckland, New Zealand; Odyssey Capacitance Water Level Logger, Dataflow Systems Limited, Christchurch, New Zealand) in dipwells (perforated plastic tubes 120 $\mathrm{cm}$ long, $3.5 \mathrm{~cm}$ diameter) in multiple locations at both partially harvest and control site. Four dipwells were set up at both automatic chamber systems (Sect. 2.2) next to the chambers in December 2015. When the chambers were close to each other, only one dipwell was installed between them. At the transects, dipwells were installed in May 2015 at each four distance $(4,8,12,22.5 \mathrm{~m})$ from the ditch next to the chamber points (Sect. 2.3.1). Also, each plot on the logging trails (Sect. 2.3.2) had one WTL probe since May 2016 until October 2017. In addition to WTL measurements next to the chambers, WTL was also monitored around the control and harvest sites. Five dipwells with automatic WTL probes were installed at the control site (Fig. 1a) in June 2016. Also, at the harvest site, six dipwells were installed in June 2016, and 7 additional dipwells were installed in November 2017 (Fig. 1a). All these WTL measurements were later used in flux upscaling (Sect. 2.5). The WTL measured at the logging trail plots was used to estimate the WTL at each point in the plots by taking into account the ground elevation. These estimated WTLs were used in the mixed-model analysis when investigating the environmental variables affecting the logging trail fluxes (Sect. 2.6).

\subsection{Upscaling of the $\mathrm{CH}_{4}$ and $\mathrm{N}_{2} \mathrm{O}$ chamber measurements}

To upscale the chamber measurements to the whole harvest and control sites, we used a combination of drone and satellite images to identify the sizes of the different surface types at the site. First, the length of the ditches was measured from the drone images assuming a ditch width of $1 \mathrm{~m}$. Due to lack of any data about the wetness of the ditches, we assumed half of the ditches dry like the ditch measured at the control site, and half wet like the measured ditch at the harvest site. For the harvest site, the ditch area was estimated at 0.315 hectares, which was about $2.4 \%$ of the total harvest area (13 ha). For comparison, the share of the ditch area was assumed to be the same for the control site as well. The remaining surface type was forest floor, which at the harvest site was further divided to logging trails and non-logging trails while the whole forest floor at the control site was classified as forest floor without logging trails. The width of the logging trails was 4 $\mathrm{m}$. There were usually two logging trails across one strip (width $\sim 40$ $\mathrm{m}$ ); therefore, the area of the logging trails was assumed $20 \%$ of the total forest floor area.

The upscaling was performed for summers (JJA) 2016 and 2017 for harvest and control site separately. The upscaling was limited to summertime only when the measurement interval of all forest floor types was the highest. The method was based on the relationship of daily WTL and $\mathrm{CH}_{4}$ flux (Fig. S2) and any other possible factors affecting the flux were ignored. However, there was no clear correlation between $\mathrm{N}_{2} \mathrm{O}$ flux and environmental variables (data not shown). Therefore, the $\mathrm{N}_{2} \mathrm{O}$ flux upscaling was based only on the emission levels of the different surface types and their share of the total area. The ditch fluxes of both gases were gap filled with linear interpolation separately for the ditches located at the harvest and control sites, and later combined by taking a daily mean between the sites. This averaging assumes that $50 \%$ of the ditches were wet and 50\% were dry and that the harvesting did not affect the ditch fluxes. For the forest floor, daily mean fluxes of automatic, transect and logging trail chamber measurements were binned into WTL bins with a size of $5 \mathrm{~cm}$ ranging from -10 to $-75 \mathrm{~cm}$. The binning was made separately for logging trails and non-logging trail forest floor. Logging trails included the chamber measurements made on the logging trails while the forest floor measurements included the automatic chamber and transect chamber measurements, but also the logging trail chamber measurements made outside the logging trails (Sect. 2.3.2.). Next, the mean flux for each WTL bin was calculated. Then, control and harvest sites were divided into equally sized plots according to the number of automated WTL measurements located around the site in different compass directions. The areal share of ditches, forest floor with logging trails and forest floor without logging trails were assumed to be the same across the plots (for harvest: $2.4 \%$, $20 \%$ and $77.6 \%$ ). The control site had five automated WTL loggers; therefore, it was divided into five plots, and the harvest site, due to a different amount of WTL dipwells in summers (Sect. 2.4), was divided into 6 and 13 plots in 2016 and 2017, respectively. At each plot, the daily mean $\mathrm{CH}_{4}$ flux was acquired from the WTL bin corresponding to the daily mean WTL. Finally, the mean fluxes across the plots were 
Table 1

Annual and summertime (JJA) mean air temperatures and precipitation, and the annual maximum snow depth during the measurement years (2015 - 2017) and the previous climatological normal period (1981 - 2010; Pirinen et al., 2012).

\begin{tabular}{|c|c|c|c|c|c|}
\hline & \multicolumn{2}{|c|}{ Air temperature $\left[{ }^{\circ} \mathrm{C}\right]$} & \multicolumn{2}{|c|}{ Precipitation [mm] } & \multirow{2}{*}{$\begin{array}{l}\text { Maximum snow } \\
\text { depth }[\mathrm{cm}] \\
\text { Annual }\end{array}$} \\
\hline & Annual & Summer & Annual & Summer & \\
\hline $1981-2010$ & 4,6 & 15,2 & 627 & 218 & 28 \\
\hline 2015 & 6,3 & 14,4 & 680 & 208 & 33 \\
\hline 2016 & 5,3 & 15,5 & 536 & 199 & 19 \\
\hline 2017 & 5,2 & 14,1 & 657 & 240 & 12 \\
\hline
\end{tabular}

calculated for each surface type and added together to acquire the $\mathrm{CH}_{4}$ balance of the whole forest.

The uncertainty of the upscaling was estimated by taking into account the most significant uncertainty sources. The ditch area uncertainty was estimated at $51 \%$, which included both the uncertainty of the ditch area $(10 \%)$ and the uncertainty of the wetness of the ditches (50\%). We did not know how wet the ditches were, which can have a large impact on the $\mathrm{CH}_{4}$ fluxes. The uncertainties of the forest floor fluxes were estimated from the summertime balance uncertainties (Appendix C) measured by the automatic chambers. The mean uncertainty between the chambers was calculated for the harvest and control site separately for each year. For the ditch and logging trail fluxes, the uncertainty was estimated by dividing the standard error of the mean with the mean summertime flux. The estimated uncertainties and their sizes are shown in Table S4. The errors of the areas and the fluxes were combined with the standard error propagation principle to acquire the total uncertainty of the upscaling.

The flux calculations and data analysis excluding statistical tests mentioned above were made with the Python programming language (Python Software Foundation, version 2.7, https://www.python.org) using NumPy (http://www.numpy.org/), SciPy (http://www.scipy. org/), Pandas (http://pandas.pydata.org/), and matplotlib (http:// www.matplotlib.org) libraries. The flux calculation methods for the automatic chambers were the same as used in Korkiakoski et al. (2017). For the fits, the least-squares method was used through the "polyfit" function of NumPy library for the linear regression and the "curve_fit" function of SciPy library for the nonlinear fits.

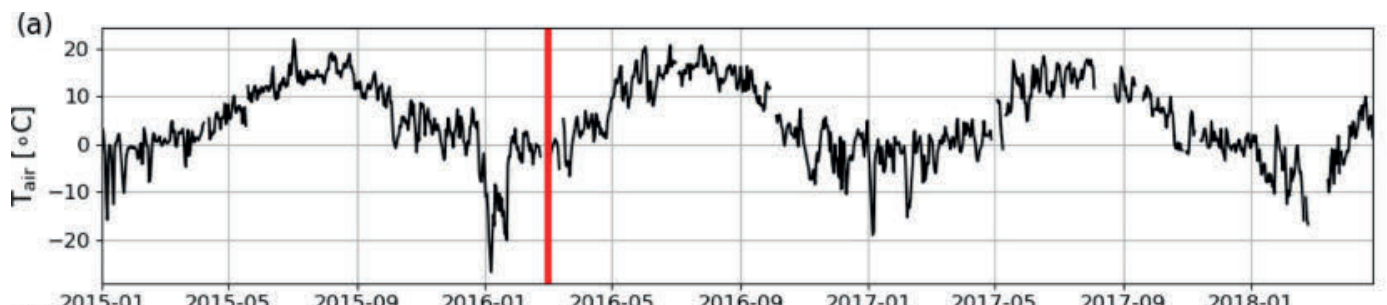

(b)

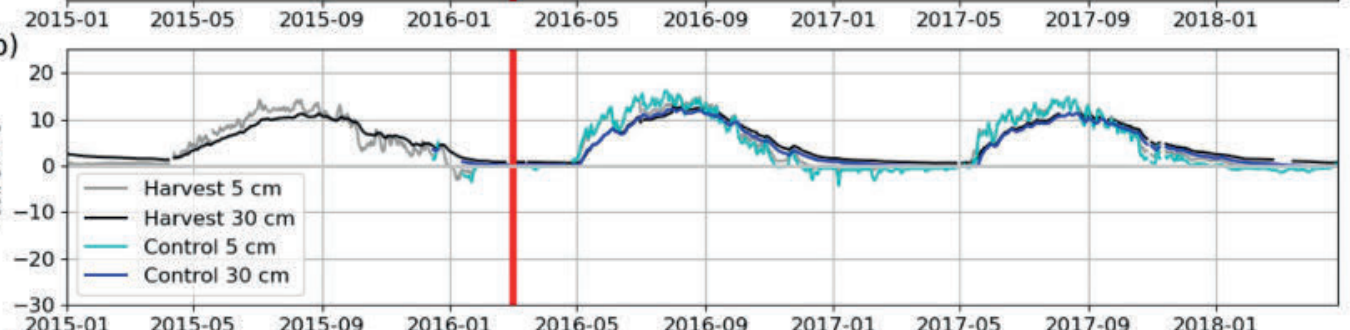

(c)

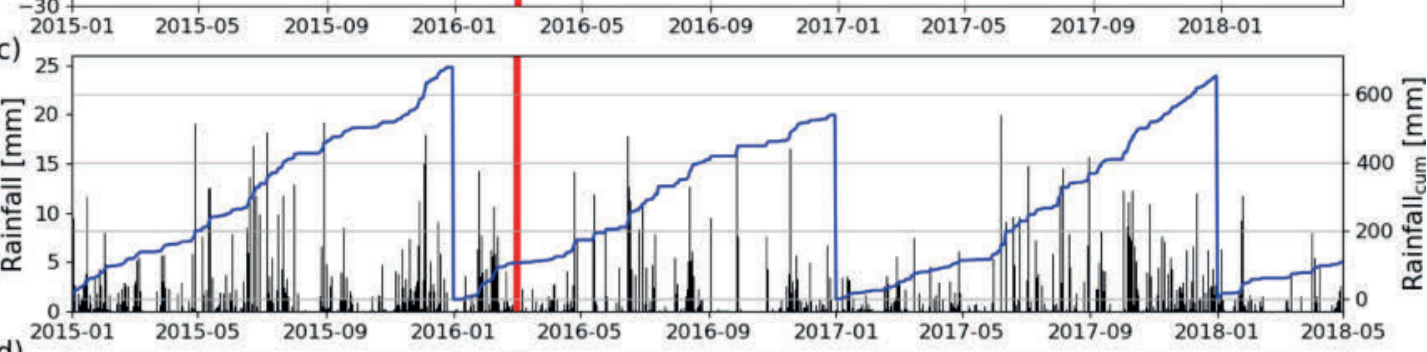

(d)

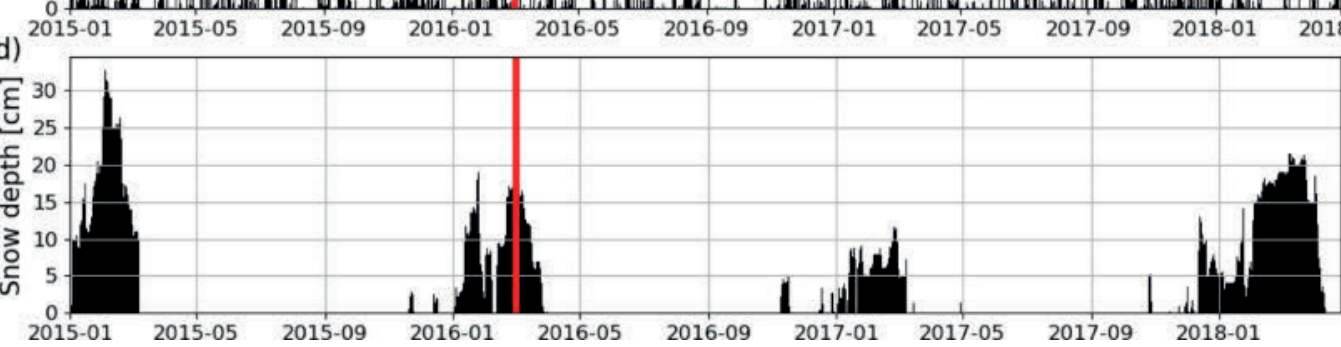

Fig. 2. Time series of (a) daily mean air temperature $\left(T_{\text {air }}\right)$ and (b) hourly mean soil temperatures at 5 and $30 \mathrm{~cm}$ depths $\left(T_{\text {soil }}\right)$ measured at the harvest and control sites, and (c) daily precipitation sum (black) and annual cumulative rainfall sum (blue), and (d) daily mean snow level recorded at the Jokioinen observatory (35 km northwest of Lettosuo) in January 2015 - April 2018. The harvesting (red vertical line) was carried out in February-March 2016. (For interpretation of the references to color in this figure legend, the reader is referred to the web version of this article.) 


\subsection{Statistical analysis}

Linear mixed-effect model was used for testing the statistical significance of differences in daily mean $\mathrm{CH}_{4}$ and $\mathrm{N}_{2} \mathrm{O}$ fluxes between the harvest and control sites, and between the years for both automatic and transect chamber measurements. In both cases, the chamber points were treated as a random effect. The linear mixed-effect model was carried out with the R programming language (R Core Team, 2018, version 3.5.0) using 'Ime4' package (Bates et al., 2015). The normality of the model residuals was visually checked using quantile-quantile plot (Q-Q plot) method. Tukey's HSD post hoc test was used for comparison of harvest and control sites, and different measurement years for $\mathrm{CH}_{4}$ and $\mathrm{N}_{2} \mathrm{O}$ fluxes.

The linear mixed-effect model was also used for explaining the $\mathrm{CH}_{4}$ and $\mathrm{N}_{2} \mathrm{O}$ fluxes. The logging trail (LT, i.e. was the point located on the logging trail or not), dry mass of the needles $\left(D M_{n}\right)$, total dry mass of the logging residues ( $D M_{\text {tot }}$, including needles, and branches and twigs of pines, spruces and birches), water table level (WTL) and soil temperature at $5 \mathrm{~cm}(S T)$ were included as fixed effects in the initial model. Chamber points were treated as a random effect (u). The best model was selected by using stepwise selection. We started with a full model and reduced the number of variables one by one using the Akaike information criterion (AIC) as the criteria, which was conducted using the drop1 function in R. The initial model including all factors was:

$F_{G H G}=\beta_{0}+\beta_{1} L T+\beta_{2} D M_{n}+\beta_{3} D M_{\text {tot }}+\beta_{4} W T L+\beta_{5} S T+\beta_{6}(u+e)$

where $F_{\mathrm{GHG}}$ is either $\mathrm{CH}_{4}$ or $\mathrm{N}_{2} \mathrm{O}$ flux, $e$ is the model error, $\beta_{0}$ is the intercept of the model, and parameters from $\beta_{1}$ to $\beta_{6}$ are the regression coefficients of the explaining variables. We used $95 \%$ confidence interval $(p<0.05)$ to determine whether the results were statistically significant.

\section{Results}

\subsection{Meteorological and hydrological conditions}

The mean annual air temperature at the nearby (Jokioinen, $35 \mathrm{~km}$ northwest of Lettosuo) weather station before the harvest in 2015 was $6.2{ }^{\circ} \mathrm{C}$, which was about $1{ }^{\circ} \mathrm{C}$ higher than the post-harvest mean temperatures in 2016, 2017 (Table 1; Fig. 2a). The annual temperatures of these three years were higher than the long-term (1981-2010) average at Jokioinen weather station (Table 1), which was also reflected in soil temperatures (Fig. 2b). All three winters (DJF) during the measurement period were warmer than the long-term average (Table 1). The mean summer (JJA) temperatures were variable; summers 2015 and 2017 were $0.8{ }^{\circ} \mathrm{C}$ and $1.1{ }^{\circ} \mathrm{C}$ cooler, respectively than the long-term average (Table 1), while the mean summer temperature in 2016 was similar to the long-term average. In addition, compared to the precipitation at Jokioinen (Table 1), 2015 and 2017 were slightly wetter while 2016 was drier (Fig. 2c; Table 1). In particular, autumns (SON) 2016 and winter 2016-2017 were much drier, while the springs and summers, were quite similar to the long-term average.

The snow cover was shallower than the long-term average annual maximum every winter during the measurement period (Table 1; Fig. 2d). Only the winter before starting the measurements (i.e. the beginning of 2015) had thicker snow cover than the long-term average annual maximum.

The seasonal inspection of pre-harvest soil temperatures at 5 and 30 $\mathrm{cm}$ depth shows that the temperatures were $0.4^{\circ} \mathrm{C}$ higher at the control than at the harvest site in summer 2015 (Fig. 2b). However, the soil temperatures were on average $0.3{ }^{\circ} \mathrm{C}$ higher at the partially harvest site in both post-harvest summers in 2016 and 2017 as compared to the control site. The summertime soil surface temperatures measured under the logging residues had smaller diel amplitude than the $2 \mathrm{~m}$ air temperature measured at the harvest site, but larger than the soil temperatures (Fig. S3). Also, the diel amplitude of the $5 \mathrm{~cm}$ soil temperature was smaller when there were residues on top of the soil. The monthly mean summertime diel amplitude of the $2 \mathrm{~m}$ air temperature varied within $7.3-11.2{ }^{\circ} \mathrm{C}$, while the surface temperature under the residues varied within $4.0-6.5^{\circ} \mathrm{C}$. The mean differences between the air and surface temperature amplitudes were 3.9 and $4.3{ }^{\circ} \mathrm{C}$ in summer 2016 and 2017, respectively. Similarly, the soil temperatures varied within $1.0-2.0{ }^{\circ} \mathrm{C}$ with residues on the surface and within $2.4-3.9{ }^{\circ} \mathrm{C}$ without residues. The mean differences between the soil temperatures with and without residues were 1.7 and $1.5{ }^{\circ} \mathrm{C}$ for summer 2016 and 2017, respectively.

Comparing the summertime PAR measured from six points at each site during daytime $(06: 00-18: 00$, UTC +3$)$ revealed that the light conditions between the sites were quite similar (harvest mean: $41 \mu \mathrm{mol}$ $\mathrm{m}^{-2} \mathrm{~s}^{-1}$, control mean: $32 \mu \mathrm{mol} \mathrm{m} \mathrm{m}^{-2} \mathrm{~s}^{-1}$ ). However, after the harvest, the amount of PAR reaching the surface increased markedly (Fig. S4), averaging at 104 and $109 \mu \mathrm{mol} \mathrm{m} \mathrm{m}^{-2} \mathrm{~s}^{-1}$ in 2016 and 2017, respectively. At the control site, the PAR remained similar to the pre-harvest mean (2016: $31 \mu \mathrm{mol} \mathrm{m}{ }^{-2} \mathrm{~s}^{-1}, 38 \mu \mathrm{mol} \mathrm{m}^{-2} \mathrm{~s}^{-1}$ ).

The mean WTL in the harvest $(-48 \mathrm{~cm})$ and control $(-49 \mathrm{~cm})$ transects were similar during the pre-treatment summer (JJA) in 2015 (Fig. 3). The mean WTL at the harvest site was $10 \mathrm{~cm}$ and $14 \mathrm{~cm}$ higher than at the control site in summer 2016 and 2017, respectively. There was, however, a lot of spatial variation around the site during summers. Outside the transects, the WTL typically varied within -15 and $-45 \mathrm{~cm}$, and -25 and $-75 \mathrm{~cm}$ (Fig. S5) in the harvest and control sites, respectively.

WTL was higher in the middle of the strip (22.5 $\mathrm{m}$ from the ditch) at the harvest site, inferred from transect WTL measurements (Fig. S6). On average, the summertime WTL was $23 \mathrm{~cm}$ higher in the middle of the strip when compared to the point located $4 \mathrm{~m}$ from the ditch. However, at the control site, there was not such a clear trend, and generally, the WTL was higher at the $12 \mathrm{~m}$ point while the WTL was similar at the rest of the points.

\subsection{Automatic chamber fluxes}

\subsection{1. $\mathrm{CH}_{4}$ exchange}

$\mathrm{CH}_{4}$ fluxes showed an apparent seasonal variation at both harvest and control sites (Fig. 4a). Generally, the fluxes were close to zero in the February-April period, but noticeable sink started to develop in May after the soil surface had thawed. The soil sink continued increasing until September when the sink started to decrease with decreasing soil temperatures. In February and March, the $\mathrm{CH}_{4}$ flux was close to zero. $\mathrm{CH}_{4}$ emissions were rare and observed only after some heavy rainfall events.

Here we report the $\mathrm{CH}_{4}$ balances in 6-month periods because this allowed us to compare the balances after the harvest directly to those before the harvest. Before the harvest in 2015, the mean half-year (July-December) $\mathrm{CH}_{4}$ balances were $-156 \pm 10 \mathrm{mg} \mathrm{CH} \mathrm{m}^{-2}$ ( \pm uncertainty, see Sect 2.6) and $-167 \pm 8 \mathrm{mg} \mathrm{CH}_{4} \mathrm{~m}^{-2} 6$ months $^{-1}$ for harvest and control site (Table S5), respectively; and did not differ significantly from each other. The variation between the measurement points was high at both the harvest and the control sites (from $-60 \pm 5$ to $-248 \pm 57 \mathrm{mg} \mathrm{CH} \mathrm{m}^{-2}$ and from $-75 \pm 10$ to $-215 \pm 36 \mathrm{mg} \mathrm{CH}$ $\mathrm{m}^{-2}$ ), respectively. After the harvest, in 2016, the half-year net $\mathrm{CH}_{4}$ uptake decreased on average by $44 \%$ at the harvest site and by $31 \%$ at the control site (Table S5). The net uptake decreased in all 12 measurement points, but the relative and absolute changes varied. Even though the decrease in net $\mathrm{CH}_{4}$ uptake from 2015 was significant $(p<$ 0.001 ) in both sites, the harvest and control sites still did not differ significantly from each other in 2016. In 2017, the net $\mathrm{CH}_{4}$ uptake at the harvest site was similar to the 2016 values in three measurement points while in the three other points the net uptake decreased further (Table S5). In contrast to the harvest site, the net $\mathrm{CH}_{4}$ uptake at the control site in 2017 was in between the uptake rates measured in 2015 


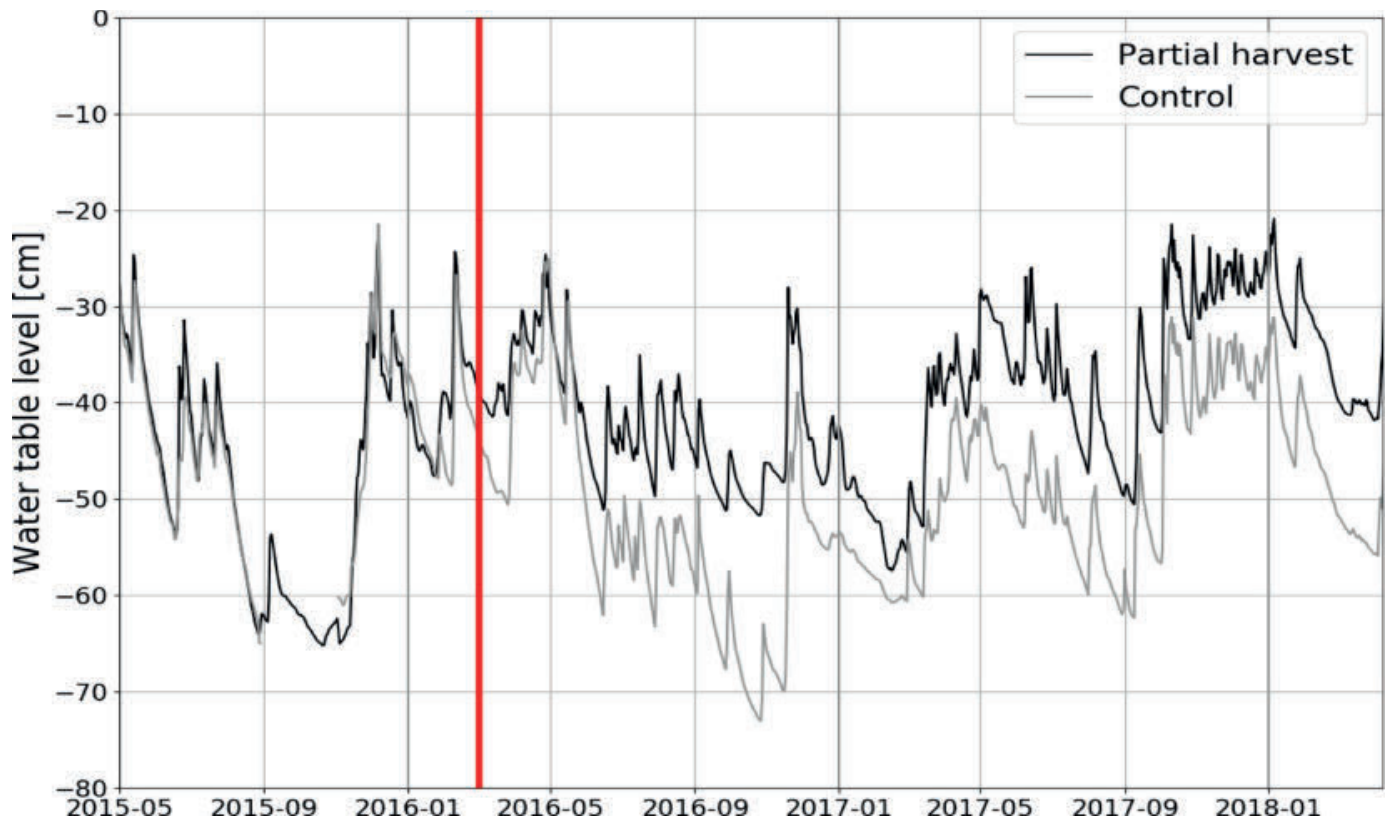

Fig. 3. Daily mean water table level in the control (grey) and harvest site (black line) averaged over all the forest transect measurement points (4, 8 , 12 and $22.5 \mathrm{~m}$ from the ditch) from May 2015 to April 2018. The harvesting (red vertical line) was carried out in February-March 2016. (For interpretation of the references to color in this figure legend, the reader is referred to the web version of this article.)

and 2016 (Table S5). However, the difference in net $\mathrm{CH}_{4}$ uptake was still not statistically significant between the sites on half-annual nor seasonal timescales; in other words, the harvest did not have a significant impact on the soil $\mathrm{CH}_{4}$ uptake, when inferred from the automatic chamber measurements.

\subsection{2. $\mathrm{N}_{2} \mathrm{O}$ exchange}

At the harvest site, the magnitude of the $\mathrm{N}_{2} \mathrm{O}$ fluxes varied markedly between the measurement points. However, the temporal dynamics remained quite similar before and after harvesting. The emissions were typically highest in summer (JJA, Fig. 4b) when on average 34\% (April 2016 - March 2017) and 47\% (April 2017 - March 2018) of the annual emissions were recorded. In autumn (SON), the emissions were relatively low, but typically in December or January, the emissions increased again after the soil froze $\left(\mathrm{T}_{5 \mathrm{~cm}}<0{ }^{\circ} \mathrm{C}\right)$. These elevated emissions after soil freezing could last up to three months and have a large contribution to the annual balance. The contribution to annual balance varied between $15-48 \%$ when inspecting the annual period of April

(a)

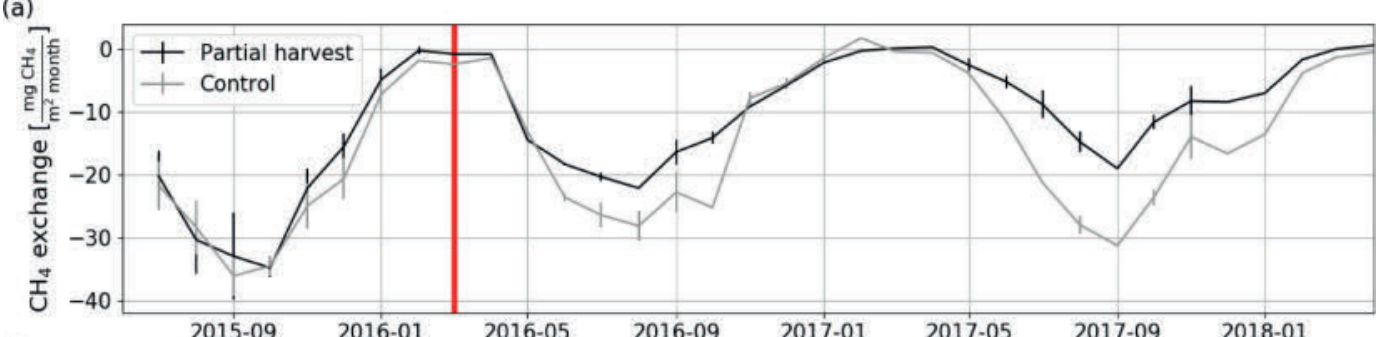

(b)

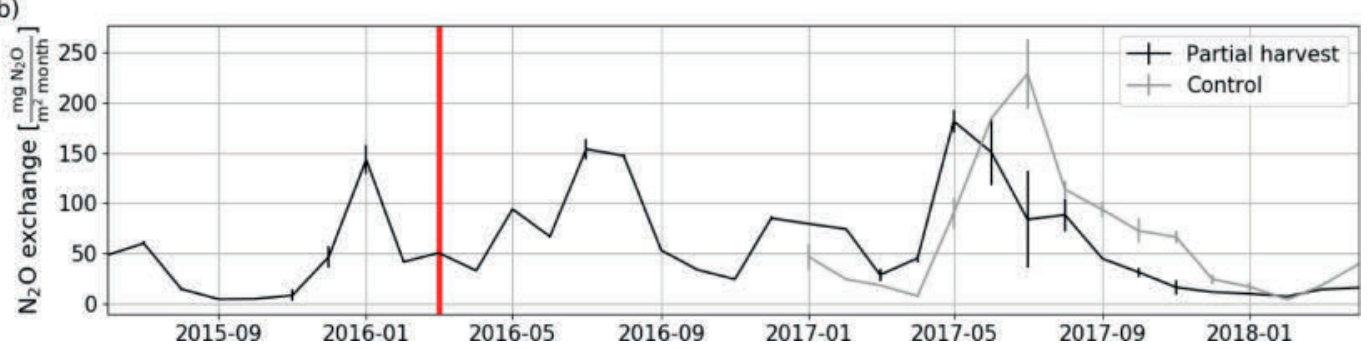

Fig. 4. Monthly mean sum time series of $\mathrm{CH}_{4}$ (a) and $\mathrm{N}_{2} \mathrm{O}$ (b) exchange of six automatic chambers at the harvest (black) and control (grey) sites in June 2015 - April 2018. The error bars show the estimated uncertainty of the monthly balance (Appendix C). The harvesting (red vertical line) was carried out in February-March 2016. (For interpretation of the references to color in this figure legend, the reader is referred to the web version of this article.) 
2016 - March 2017. The contribution of these elevated winter emissions was higher in points with relatively low annual emissions. Unlike in previous years, no elevated emissions in winter were observed in late 2017 or early 2018. Between elevated emissions in winter and summer, there was a period of low emissions typically in March and April similarly to autumn.

Before the harvest, the half-year (July-December) $\mathrm{N}_{2} \mathrm{O}$ balance at the harvest site averaged at $138 \pm 12 \mathrm{mg} \mathrm{N}_{2} \mathrm{O} \mathrm{m}^{-2}$ ( \pm uncertainty, see Appendix $\mathrm{C}$ ), with considerable variation between the measurement points $\left(52 \pm 17-222 \pm 23 \mathrm{mg} \mathrm{N}_{2} \mathrm{O} \mathrm{m}^{-2}\right.$ ). After harvesting in 2016, all six points recorded increased emissions, but the relative and absolute increases varied (Table S5). The mean post-harvest $\mathrm{N}_{2} \mathrm{O}$ emission across all the points in 2016 was $498 \pm 10 \mathrm{mg} \mathrm{N}_{2} \mathrm{O} \mathrm{m}^{-2}$, and the change from 2015 was statistically significant $(p<0.001)$. The mean $\mathrm{N}_{2} \mathrm{O}$ balance at the harvest site in 2017 was in between the balances of 2015 and 2016 at $277 \pm 52 \mathrm{mg} \mathrm{N}_{2} \mathrm{O} \mathrm{m}^{-2}$ and was significantly different from previous years $(p<0.001)$.

At the control site, we only had automatic chamber measurements in 2017. The half-year cumulative emissions from the measurement points C1-C6 averaged at $600 \pm 39 \mathrm{mg} \mathrm{N}_{2} \mathrm{O} \mathrm{m} \mathrm{m}^{-2}$ varying from $145 \pm 20$ to $1449 \pm 178 \mathrm{mg} \mathrm{N}_{2} \mathrm{O} \mathrm{m}^{-2}$ (Table S5). Comparing this same period to the measurements at the harvest site (mean: $277 \pm 52 \mathrm{mg}$ $\mathrm{N}_{2} \mathrm{O} \mathrm{m}^{-2}$ ) showed that the emissions from the control site were not significantly different during the latter half of 2017. Also, comparing annual periods of $1 / 2017-12 / 2017$ and $4 / 2017-3 / 2018$ did not reveal significant differences between the sites.

\subsection{Manual chamber fluxes at the transects}

Both the harvest and control site acted as $\mathrm{CH}_{4}$ sinks both before and after the harvest (Fig. 5 and S7a). $\mathrm{CH}_{4}$ emissions were observed at 12 out of 16 possible points across the sites at least once, but only at five of them emissions were observed more than once. Again, there was a lot of spatial and temporal variation in fluxes, which varied between -484 and $24 \mu \mathrm{g} \mathrm{CH}_{4} \mathrm{~m}^{-2} \mathrm{~h}^{-1}$, and -158 and $51 \mu \mathrm{g} \mathrm{CH}_{4} \mathrm{~m}^{-2} \mathrm{~h}^{-1}$ during summer

(a)
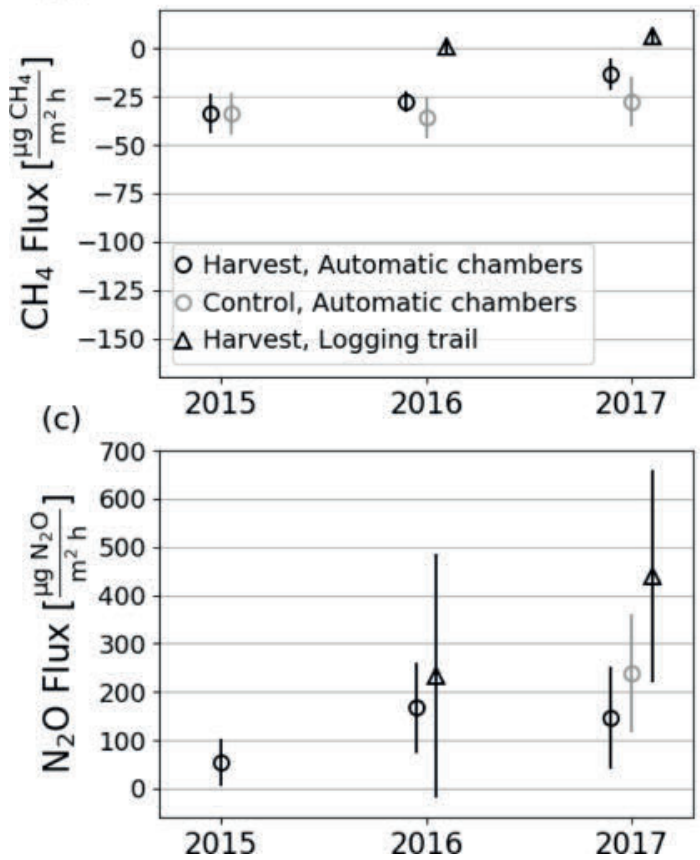

(JJA) at the harvest and control site, respectively. At the harvest site, measurement points $4 \mathrm{~m}$ from the ditch had significantly higher sink ( $p$ $<0.05)$ in all calendar years than the points farther from the ditch. In contrast, at the control site, the fluxes generally did not differ significantly between the measurement points. Even though the mean preharvest summertime $\mathrm{CH}_{4}$ uptake rate at the control site was only $49 \%$ of that of the harvest site (harvest: $-95 \pm 34 \mu \mathrm{g} \mathrm{CH}_{4} \mathrm{~m}^{-2} \mathrm{~h}^{-1}$, control: $-47 \pm 11 \mu \mathrm{g} \mathrm{CH} \mathrm{CH}_{4} \mathrm{~m}^{-2} \mathrm{~h}^{-1}$; \pm standard error of the mean; Fig. 5), the sites were not significantly different. The net uptake decreased after the harvest by $41 \%$ (mean flux: $-56 \pm 6 \mu \mathrm{g} \mathrm{CH}_{4} \mathrm{~m}^{-2} \mathrm{~h}^{-1}$ ) in 2016 and remained so also in 2017 , both post-harvest summers were significantly different from the pre-harvest summer (2016: $p<0.01$, 2017: $p<$ 0.001). At the control site, the post-harvest $\mathrm{CH}_{4}$ sink was similar to the pre-harvest sink. Comparing the harvest and control sites against each other showed that they did not differ significantly in either of the postharvest summers.

The pre- and post-harvest $\mathrm{N}_{2} \mathrm{O}$ fluxes were spatially and temporally highly variable at both harvest and control site (Fig. S7b). Before the harvest, the mean summertime fluxes were $178 \pm 109 \mu \mathrm{g} \mathrm{N}_{2} \mathrm{O} \mathrm{m}^{-2} \mathrm{~h}^{-1}$ ( \pm standard error of the mean) and $38 \pm 33 \mu \mathrm{g} \mathrm{N} \mathrm{N}_{2} \mathrm{O} \mathrm{m}^{-2} \mathrm{~h}^{-1}$ at the harvest and control site, respectively. However, the two sites were not significantly different with respect to mean summer (JJA) $\mathrm{N}_{2} \mathrm{O}$ fluxes before the harvest. At the harvest site, the fluxes did not change significantly after the harvest. At the control site, summertime fluxes in 2017 (mean: $251 \pm 37 \mu \mathrm{g} \mathrm{N} \mathrm{O} \mathrm{m}^{-2} \mathrm{~h}^{-1}$ ) were significantly higher when compared to two previous summers (2015: $p<0.01$, 2016: $p<0.001$ ). However, the post-harvest summertime fluxes in 2016 and 2017 did not differ significantly between the harvest and control sites. In conclusion, the transect measurements did not show any significant harvest-related changes in $\mathrm{N}_{2} \mathrm{O}$ fluxes.

\subsection{Logging trail and logging residue fluxes}

Three of the four measurement point types acted most of the time as $\mathrm{CH}_{4}$ sink; fluxes were varying mostly between -40 and $0 \mu \mathrm{CH}_{4} \mathrm{~m}^{-2}$

(b)

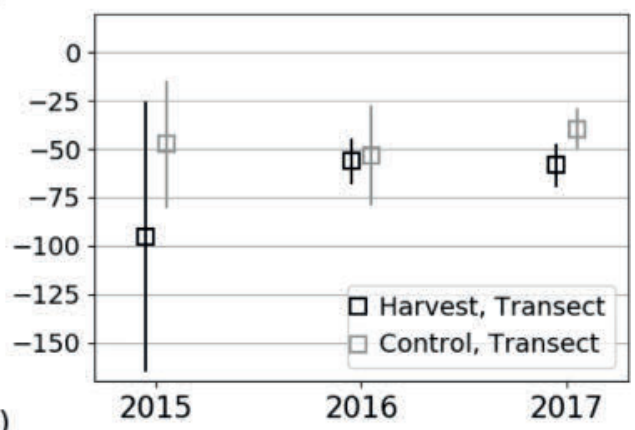

(d)

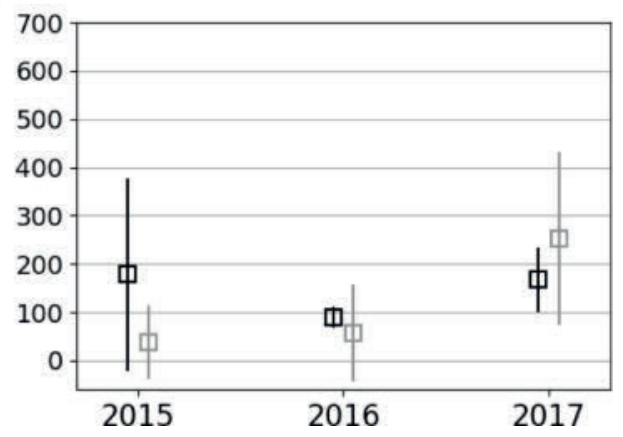

Fig. 5. Summertime (JJA) mean of the hourly $\mathrm{CH}_{4}$ (a, b) and $\mathrm{N}_{2} \mathrm{O}$ (c, d) fluxes ( \pm standard deviation) measured at the harvest (black) and control site (grey) by automatic chambers (circle), manual chambers at the transect (square) and the logging trail (triangle). 

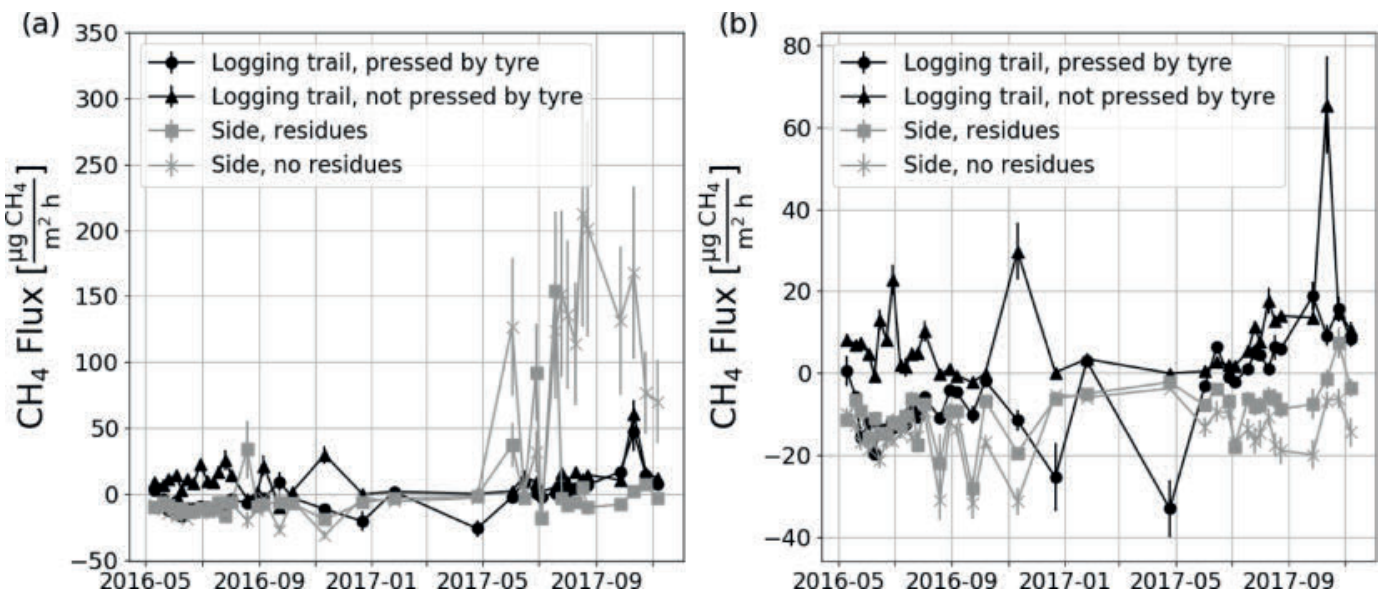

Fig. 6. Daily mean (a: $n=5$, b: $n=4$ ) $\mathrm{CH}_{4}$ flux ( \pm standard error of the mean) time series measured with manual chambers on the tyre pressed (black circle) and not tyre pressed (black triangle) part of the logging trail, and on the side of the logging trail with small amount (grey square) and without (grey cross) logging residues in May 2016 - November 2017. The time series represent data with (a) and without (b) plot \#5.

$\mathrm{h}^{-1}$, while the points located in the uncompressed part of the logging trail commonly acted as $\mathrm{CH}_{4}$ sources (Fig. 6). In 2016, small $\mathrm{CH}_{4}$ emissions ( $<30 \mu \mathrm{g} \mathrm{CH}_{4} \mathrm{~m}^{-2} \mathrm{~h}^{-1}$ ) were sporadically observed also from the compressed points on the logging trail, whereas in 2017 the emissions from the compressed points were frequent from all plots except \#2 (Fig. S8). The fluxes from the logging trail were also significantly higher when compared to the transect measurements at the harvest site $(p<0.001$; Sect. 3.3). The points on the side of the logging trail were mostly $\mathrm{CH}_{4}$ sinks in 2016 in all but plot \#5 where several relatively high $\mathrm{CH}_{4}$ emissions were recorded ( $>600 \mu \mathrm{g} \mathrm{CH}_{4} \mathrm{~m}^{-2} \mathrm{~h}^{-1}$; Fig. S8). In 2017, small emissions were also observed on plots \#3 and \#4 from the points on the side of the logging trail. Also, the emissions on plot \#5 increased from the previous year (Fig. 6a; Fig. S8). When inspecting the whole dataset, no significant differences between the point types were found. Also, none of the inspected variables influenced the $\mathrm{CH}_{4}$ fluxes significantly. Because plot \#5 was noticeably wetter than the other plots, the analysis concerning the dependence of $\mathrm{CH}_{4}$ fluxes on environmental variables was also carried out without plot \#5 (Fig. 6b). Removing plot \#5 enhanced the statistical significance observed in $\mathrm{CH}_{4}$ flux between the points in and outside the logging trail $(p<0.01$; Table S6). Also, now using the whole dataset the points on the uncompressed part of the logging trail differed significantly from both points outside the trail. Without plot \#5, explanatory factors for $\mathrm{CH}_{4}$ flux were found, and the best model indicated that the $\mathrm{CH}_{4}$ flux was most influenced by WTL $(p<0.001)$ and the location of the measurement point in or outside of the logging trail $(p<0.04$ ). The model explained $36 \%$ of the variation in $\mathrm{CH}_{4}$ fluxes, and the contribution of the fixed effects was $24 \%$.

All the plot types acted as $\mathrm{N}_{2} \mathrm{O}$ source (Fig. 7) during the whole measurement period. During the first two months of the measurements (May-June 2016) the emissions within plots were somewhat similar, but $\mathrm{N}_{2} \mathrm{O}$ emissions started to increase in July commonly from the points located on the logging trail (Fig. S9). Again, the emissions were highly variable varying within two orders of magnitude, and none of the plot types differed significantly from each other when inspecting the whole dataset. However, the fluxes from the points on the logging trail were significantly $(p<0.03)$ higher than those outside of the trail. Generally, the daily mean $\mathrm{N}_{2} \mathrm{O}$ flux over all the points outside the trail was $<200 \mu \mathrm{N} \mathrm{N}_{2} \mathrm{O} \mathrm{m}^{-2} \mathrm{~h}^{-1}$ while the mean emissions from the trail were more variable (generally between: $100-900 \mu \mathrm{g} \mathrm{N}_{2} \mathrm{O} \mathrm{m}{ }^{-2} \mathrm{~h}^{-1}$; Figs. 7 and S9). Also, the logging trail points had significantly higher emissions than the emissions measured from the forest floor with automatic chambers at harvest $(p<0.01$; Sect. 3.2.2; Fig. 5). The best model

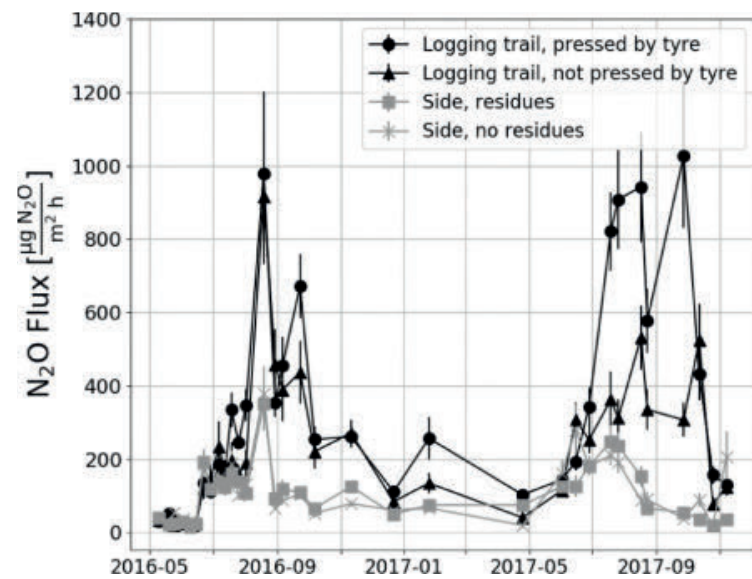

Fig. 7. Daily mean $(n=5) \mathrm{N}_{2} \mathrm{O}$ time series measured with manual chambers on the tyre pressed (black circle) and not tyre pressed (black triangle) part of the logging trail, and on the side of the logging trail with small amount (grey square) and without (grey cross) logging residues in May 2016 - November 2017. The error bars show the standard error of the mean.

explaining the $\mathrm{N}_{2} \mathrm{O}$ fluxes showed that the $\mathrm{N}_{2} \mathrm{O}$ flux was most influenced by WTL $(p<0.001)$ and $5 \mathrm{~cm}$ soil temperature $(p<0.01)$ followed by the location of the point on the logging trail $(p<0.02)$ and the total dry mass of the residues ( $p<0.03$ ). The model explained $48 \%$ of the variation in $\mathrm{N}_{2} \mathrm{O}$ fluxes, but it was mostly due to random effects as the $r^{2}$ of the fixed effects was only $14 \%$ (Table S6).

\subsection{Ditch fluxes}

The mean $\mathrm{CH}_{4}$ emissions from the ditches were significantly $(p<$ 0.001 ) higher during the whole measurement period at the harvest site than at the control site. However, as the ditches were so different (water-filled at the harvest and moss-filled at the control site) and the number of measurement points in the ditches was small, it was not sensible to estimate the effect of harvest on ditch fluxes. The means of all the measured $\mathrm{CH}_{4}$ fluxes from the ditches were $2754 \pm 642 \mu \mathrm{g} \mathrm{\textrm {CH } _ { 4 }}$ $\mathrm{m}^{-2} \mathrm{~h}^{-1}$ ( \pm standard error of the mean) and $127 \pm 45 \mu \mathrm{g} \mathrm{CH} \mathrm{CH}^{-2}$ $\mathrm{h}^{-1}$, and the fluxes varied within 0-10894 $\mu \mathrm{g} \mathrm{CH}_{4} \mathrm{~m}^{-2} \mathrm{~h}^{-1}$ and 
-238-1905 $\mu \mathrm{CH}_{4} \mathrm{~m}^{-2} \mathrm{~h}^{-1}$ (Fig. S10a) at the water- and moss-filled ditch, respectively. The fluxes at the water-filled ditch were more temporally variable than at the moss-filled ditch. Also, the fluxes were mostly zero in both ditches during November-March. In the moss-filled ditch, occasional net $\mathrm{CH}_{4}$ uptake was measured, but fluxes were always zero or above at the water-filled ditch. No statistically significant differences were found when comparing the $\mathrm{CH}_{4}$ fluxes between the years or summers in the water-filled ditch. However, the year and summer 2015 were significantly $(p<0.05)$ different from both respective periods in 2016 and 2017 at the moss-filled ditch.

The $\mathrm{N}_{2} \mathrm{O}$ fluxes from the ditches were low; the mean fluxes over the whole measurement period were $13 \pm 5 \mu \mathrm{g} \mathrm{N}_{2} \mathrm{O} \mathrm{m}^{-2} \mathrm{~h}^{-1}$ ( \pm standard error of the mean) and $40 \pm 19 \mu \mathrm{g} \mathrm{N}_{2} \mathrm{O} \mathrm{m}^{-2} \mathrm{~h}^{-1}$ (Fig. S10b) at the waterand moss-filled ditch, respectively. The fluxes were more variable in the moss-filled ditch ranging from $-140 \mu g \mathrm{~N}_{2} \mathrm{O} \mathrm{m}^{-2} \mathrm{~h}^{-1}$ to $690 \mu \mathrm{g} \mathrm{N} \mathrm{N}_{2} \mathrm{O} \mathrm{m}^{-2}$ $\mathrm{h}^{-1}$ than in the water-filled ditch where the fluxes varied within -39 and $150 \mu \mathrm{g} \mathrm{N}_{2} \mathrm{O} \mathrm{m}^{-2} \mathrm{~h}^{-1}$ (Fig. S10b). The $\mathrm{N}_{2} \mathrm{O}$ fluxes in the moss-filled ditch were not significantly different between years. However, in the waterfilled ditch, the year 2017 was significantly different from the respective periods. In the water-filled ditch, the fluxes were $<54 \mu \mathrm{g} \mathrm{N} \mathrm{N}_{2} \mathrm{O}$ $\mathrm{m}^{-2} \mathrm{~h}^{-1}$ in 2015 and 2016, but in 2017 several emission peaks up to 150 $\mu \mathrm{g} \mathrm{N}_{2} \mathrm{O} \mathrm{m}^{-2} \mathrm{~h}^{-1}$ were observed. In addition, summer 2015 was the only period when water- and moss-filled ditches differed significantly $(p<$ 0.01 ) in $\mathrm{N}_{2} \mathrm{O}$ fluxes.

\subsection{Upscaling $\mathrm{CH}_{4}$ and $\mathrm{N}_{2} \mathrm{O}$ fluxes to ecosystem level}

Upscaling the $\mathrm{CH}_{4}$ fluxes on ecosystem-scale using all the chamber measurements in previous chapters (Sects. 3.2, 3.3, 3.4), except data from logging trail plot \#5, revealed that both the harvest and control sites were around $\mathrm{CH}_{4}$ neutral during summertime (Table 2). In 2016, the harvest site was a small $\mathrm{CH}_{4}$ source $\left(10 \pm 21 \mathrm{mg} \mathrm{CH}_{4} \mathrm{~m}^{-2}\right)$ as the emissions from the ditches $\left(43 \pm 21 \mathrm{mg} \mathrm{CH}_{4} \mathrm{~m}^{-2}\right.$ ) were larger than the net $\mathrm{CH}_{4}$ uptake in the forest floor $\left(-31 \pm 2 \mathrm{mg} \mathrm{CH}_{4} \mathrm{~m}^{-2}\right)$. During the following summer, the emissions from the ditches increased, and the forest floor uptake decreased; therefore, the $\mathrm{CH}_{4}$ balance of the harvest site increased to $47 \pm 33 \mathrm{mg} \mathrm{CH} \mathrm{m}^{-2}$. The fluxes from the logging trails had no significant impact on ecosystem-level balance during the summers of 2016 or 2017. The estimated forest floor uptake was more substantial at the control site than at the harvest site, which resulted in smaller net $\mathrm{CH}_{4}$ emissions at the control site during both summers. In 2016, the control site acted as a net $\mathrm{CH}_{4}$ sink $\left(-18 \pm 22 \mathrm{mg} \mathrm{CH}_{4} \mathrm{~m}^{-2}\right)$ while in 2017, the site was a small source $\left(19 \pm 33 \mathrm{mg} \mathrm{CH}_{4} \mathrm{~m}^{-2}\right)$.

Both the harvest and control sites acted as $\mathrm{N}_{2} \mathrm{O}$ sources during the summers (Table 2). At the harvest site, forest floor contributed the most to the ecosystem $\mathrm{N}_{2} \mathrm{O}$ balance (2016: $65 \%, 2017: 62 \%$ ), while the rest of the ecosystem-level $\mathrm{N}_{2} \mathrm{O}$ emissions originated from the logging trails.
The fluxes from the ditches were insignificant. At the control site, only the emissions from the undisturbed forest floor were significant on ecosystem-scale. The $\mathrm{N}_{2} \mathrm{O}$ emissions at the harvest site $(368 \pm 29 \mathrm{mg}$ $\mathrm{N}_{2} \mathrm{O} \mathrm{m}^{-2}$ ) were larger than the emissions at the control site $(120 \pm 39$ $\mathrm{mg} \mathrm{N} \mathrm{O} \mathrm{m}^{-2}$ ) in 2016. However, in 2017 the emissions increased in both sites, but the increase at the control site was so large that the total emissions became similar between both sites (harvest: $533 \pm 114 \mathrm{mg}$ $\mathrm{N}_{2} \mathrm{O} \mathrm{m}^{-2}$, control $495 \pm 46 \mathrm{mg} \mathrm{N}_{2} \mathrm{O} \mathrm{m}^{-2}$ ). When considering the climatic effect of these gases in terms of their global warming potential up to 100 years with climate-carbon feedbacks $\left(\mathrm{CH}_{4}: \mathrm{GWP}_{100}=34 ; \mathrm{N}_{2} \mathrm{O}\right.$ : $\mathrm{GWP}_{100}=298$; IPCC, 2013), the total emissions of $\mathrm{CH}_{4}$ were on average only $0.8 \%$ of the $\mathrm{N}_{2} \mathrm{O}$ emissions (Table 2).

\section{Discussion}

\subsection{Partial harvest has lower $\mathrm{N}_{2} \mathrm{O}$ and $\mathrm{CH}_{4}$ emissions than clearcutting}

In this study, we found that the partial harvesting did not have a significant impact on $\mathrm{CH}_{4}$ and $\mathrm{N}_{2} \mathrm{O}$ fluxes in a drained nutrient-rich peatland forest when comparing the pre- and post-harvest situations at the harvest site. Decrease in $\mathrm{CH}_{4}$ uptake have previously been observed in partially harvested boreal upland forests (Sundqvist et al., 2014), but increase in $\mathrm{CH}_{4}$ uptake was recorded in a Mediterranean upland forest (Mazza et al., 2019). Papers studying the effects of thinning on $\mathrm{N}_{2} \mathrm{O}$ fluxes are scarcer, but increases in emissions have been observed (Li et al., 2010). However, it is difficult to compare different thinning studies as the method of thinning varies, which affects the measured greenhouse gas fluxes (Mazza et al., 2019). According to the previous study at the site made in the same time period as this study (Korkiakoski et al., 2019), clearcutting increased $\mathrm{N}_{2} \mathrm{O}$ emissions markedly and turned the clear-cut forest floor from $\mathrm{CH}_{4}$ sink into a small $\mathrm{CH}_{4}$ source, and raised WTL by $23 \mathrm{~cm}$. Despite a slight increase of $10-14 \mathrm{~cm}$ in water level, the forest floor at the partial harvest site remained as a small $\mathrm{CH}_{4}$ sink (Fig. 5), which was due to WTL staying mostly under $-30 \mathrm{~cm}$ (Fig. 3) that has been considered a limit above which $\mathrm{CH}_{4}$ emissions may occur in peatland forests (Ojanen et al., 2010, 2013). Also, the mean annual $\mathrm{CH}_{4}$ balance measured by the automatic chambers (from $-87 \pm 4$ to $-169 \pm 4 \mathrm{mg} \mathrm{CH}_{4} \mathrm{~m}^{-2}$ year $^{-1}$ ) was smaller than measured at the same forest in 2011-2013 $\left(-219 \mathrm{mg} \mathrm{CH}_{4} \mathrm{~m}^{-2}\right.$ year $^{-1}$; Korkiakoski et al., 2017), but still within typical uptake rates of 10-970 $\mathrm{mg} \mathrm{CH}_{4} \mathrm{~m}^{-2}$ year $^{-1}$ reported in drained peatland forests in Finland (Lohila et al., 2011; Minkkinen et al., 2007; Ojanen et al., 2010). It should be noted, however, that the $\mathrm{CH}_{4}$ emissions (mean balance: $0.8 \mathrm{~g} \mathrm{CO}_{2}$-eq $\mathrm{m}^{-2}$ summer $^{-1}$ ) at Lettosuo after partial harvesting and even after clearcutting (Korkiakoski et al., 2019) were negligible compared to $\mathrm{N}_{2} \mathrm{O}$ emissions (mean balance: $113 \mathrm{~g} \mathrm{CO}_{2}$-eq $\mathrm{m}^{-2}$ summer $^{-1}$ ) when considering their climatic impact in terms of the

Table 2

Upscaled $\mathrm{CH}_{4}$ and $\mathrm{N}_{2} \mathrm{O}$ balances ( \pm uncertainty, see Sect. 2.5) from different surface types weighted by their respective share of surface area for summers 2016 and 2017. The balances are also reported in $\mathrm{CO}_{2}$-equivalents in terms of the global warming potential up to 100 years.

\begin{tabular}{|c|c|c|c|c|c|c|}
\hline \multicolumn{5}{|c|}{$\mathrm{CH}_{4}$ flux $\left[\mathrm{mg} \mathrm{CH} \mathrm{Cm}^{-2}\right.$ summer $\left.{ }^{-1}\right]$} & \multirow{2}{*}{\multicolumn{2}{|c|}{ Total $\left[\mathrm{g} \mathrm{CO}_{2}\right.$-eq $\mathrm{m}$-2 summer-1] }} \\
\hline Area \& Year & Total & Ditch & Forest & Logging trail & & \\
\hline Harvest 2016 & $10 \pm 28$ & $43 \pm 28$ & $-31 \pm 2$ & $-1.8 \pm 0.9$ & $0.3 \pm 1.0$ & \multirow[b]{6}{*}{ Total $\left[\mathrm{g} \mathrm{CO}_{2}\right.$-eq $\mathrm{m}$-2 summer-1] } \\
\hline Harvest 2017 & $47 \pm 43$ & $64 \pm 43$ & $-19 \pm 4$ & $2.1 \pm 0.5$ & $1.6 \pm 1.5$ & \\
\hline Control 2016 & $-18 \pm 28$ & $43 \pm 28$ & $-61 \pm 5$ & NA & $0.6 \pm 1.0$ & \\
\hline Control 2017 & $19 \pm 43$ & $64 \pm 43$ & $-45 \pm 3$ & NA & $0.6 \pm 1.5$ & \\
\hline \multicolumn{5}{|c|}{$\mathrm{N}_{2} \mathrm{O}$ flux $\left[\mathrm{mg} \mathrm{N}_{2} \mathrm{O} \mathrm{m}{ }^{-2}\right.$ summer $\left.^{-1}\right]$} & & \\
\hline Area \& Year & Total & Ditch & Forest & Logging trail & & \\
\hline Harvest 2016 & $368 \pm 29$ & $-0.2 \pm 0.3$ & $240 \pm 17$ & $129 \pm 24$ & $110 \pm 9$ & \\
\hline Harvest 2017 & $533 \pm 114$ & $0.6 \pm 0.4$ & $331 \pm 111$ & $201 \pm 26$ & $159 \pm 34$ & \\
\hline Control 2016 & $120 \pm 39$ & $-0.2 \pm 0.2$ & $120 \pm 39$ & NA & $36 \pm 12$ & \\
\hline Control 2017 & $495 \pm 46$ & $0.6 \pm 0.3$ & $494 \pm 46$ & NA & $148 \pm 14$ & \\
\hline
\end{tabular}


global warming potential up to 100 years.

Based on both manual and automatic chamber data, the effect of partial harvest on $\mathrm{N}_{2} \mathrm{O}$ fluxes was not significant. Nevertheless, this means that the partial harvest did not cause a similar increase in $\mathrm{N}_{2} \mathrm{O}$ emissions as the clearcutting of the same forest (Korkiakoski et al., 2019) where the change was apparent. Smaller changes in $\mathrm{N}_{2} \mathrm{O}$ fluxes were expected as clearcutting removes more trees, raises the WTL, produces more logging residues and severely disturbs ground vegetation, which releases a large amount of reactive nitrogen $\left(\mathrm{NO}_{3}^{-}, \mathrm{NH}_{4}^{+}\right)$. Thus, an increased amount of mineral $\mathrm{N}$ is converted to $\mathrm{N}_{2} \mathrm{O}$ as the uptake by vegetation is diminished. Partial harvesting produces less logging residues as not all the trees are harvested, and ground vegetation is less disturbed, except on the logging trails where most of the vegetation is covered by logging residues. Indeed, $\mathrm{N}_{2} \mathrm{O}$ emissions from the logging trails were significantly larger than the emissions outside the logging trails (Fig. 7). Comparing these two harvesting methods at the same site shows that the mean $\mathrm{N}_{2} \mathrm{O}$ flux measured by the automatic $\left(368 \pm 10 \mu \mathrm{g} \mathrm{N} \mathrm{O}_{2} \mathrm{O} \mathrm{m}^{-2} \mathrm{~h}^{-1}\right.$ ) and manual chambers (178 $\pm 109 \mu \mathrm{g} \mathrm{N} \mathrm{N}_{2} \mathrm{O}$ $\mathrm{m}^{-2} \mathrm{~h}^{-1}$ ) after harvesting in summer 2016 is noticeably smaller than at the clear-cut site where the fluxes increased markedly from about zero up to $1000 \mu \mathrm{g} \mathrm{N} \mathrm{N}_{2} \mathrm{O} \mathrm{m}^{-2} \mathrm{~h}^{-1}$ on average (Korkiakoski et al., 2019). Comparing the automatic chamber measurements made in this study shows that the mean annual $\mathrm{N}_{2} \mathrm{O}$ balances at Lettosuo $(0.69 \pm 0.06-$ $0.92 \pm 0.04 \mathrm{~g} \mathrm{~N}_{2} \mathrm{O} \mathrm{m}^{-2}$ year $^{-1}$ ) are at the higher end of the range $\left(-0.03-0.92 \mathrm{~g} \mathrm{~N}_{2} \mathrm{O} \mathrm{m}^{-2}\right.$ year $\left.^{-1}\right)$ previously reported at drained peatland forests in Finland (Lohila et al., 2011; Ojanen et al., 2010).

\subsection{The effect of partial harvesting on $\mathrm{CH}_{4}$ fluxes}

Partial harvesting did not significantly affect the forest floor $\mathrm{CH}_{4}$ fluxes (Sect. 3.2.1; 3.3). There were significant differences between the years, but these were unlikely due to the harvest as similar changes were observed at the control site as well. Harvesting raised the WTL on average by $10-14 \mathrm{~cm}$ due to decreased transpiration. Higher WTL makes the oxic layer on the top soil thinner and conditions for $\mathrm{CH}_{4}$ oxidation less favourable, which allows less $\mathrm{CH}_{4}$ produced in the anoxic layer to be oxidised before reaching the atmosphere (e.g. Lai, 2009). The decreases in net half-year $\mathrm{CH}_{4}$ uptakes in both harvest (2016: 49\%) and control (2016: 26\%) sites (Sect. 3.2.1) are likely attributed to higher WTLs during autumn 2016 than in 2015, which was further increased at the harvest site due to reduced transpiration after the removal of transpiring trees. Removal of the trees also increased photosynthetically active radiation under the canopy, which could have dried the exposed soil surface due to increased soil temperatures during the daytime (Londo et al., 1999). This could have counteracted parts of the decreased $\mathrm{CH}_{4}$ oxidation due to WTL rise after the harvest. Soil temperature is also known to affect $\mathrm{CH}_{4}$ production and oxidation (e.g. Malyan et al., 2016), but the difference in temperature between the sites was rather small $\left(2015:<0.4{ }^{\circ} \mathrm{C} ; 2016\right.$ and $\left.2017:<0.3{ }^{\circ} \mathrm{C}\right)$. A previous study concerning the changes in forest floor GHG fluxes after clearcutting at Lettosuo concluded that the site turned from $\mathrm{CH}_{4}$ sink into a small $\mathrm{CH}_{4}$ source due to a $23 \mathrm{~cm}$ rise of mean summertime WTL to the level of $-24 \mathrm{~cm}$ (Korkiakoski et al., 2019). Partial harvesting raised WTL less $(10-14 \mathrm{~cm})$ than the clearcutting, keeping WTL generally below $-30 \mathrm{~cm}$, which did not significantly affect the soil $\mathrm{CH}_{4}$ sink. Similar results have been found from a boreal forest in central Sweden where clearcutting turned the site to a $\mathrm{CH}_{4}$ source, but after the thinning, the site continued acting as a $\mathrm{CH}_{4}$ sink (Sundqvist et al., 2014).

The net $\mathrm{CH}_{4}$ emissions were higher from the plots located on the logging trail than at the plots outside of the logging trail (Fig. 6b). The emissions could have increased due to the compression of soil by heavy machinery used in the tree harvesting. The compression of soil lowered the soil surface, probably decreasing the thickness of the oxic layer and the amount of oxygen in the soil, which then either reduced $\mathrm{CH}_{4}$ oxidation or increased production by creating anoxic spots in the soil. Contrary to other plots, the $\mathrm{CH}_{4}$ emissions at plot \#5 were higher from the plots outside of the logging trail. This was probably caused by higher soil moisture leading to the growth of Eriophorum vaginatum which acts as a conduit for $\mathrm{CH}_{4}$ release (Greenup et al., 2000) and is a relatively high $\mathrm{CH}_{4}$ source compared to other vegetation communities (Minkkinen and Laine, 2006). Logging residues change the soil environmental conditions by decreasing soil temperature and conserving soil moisture (Ojanen et al., 2017; Roberts et al., 2005), which both are known to affect $\mathrm{CH}_{4}$ fluxes. We also observed a dampened diel cycle on the soil surface under the residues when compared to the air temperature. However, we did not measure soil moisture close to these measurement points, and we did not find a significant relationship between the soil temperature nor any other environmental variables and $\mathrm{CH}_{4}$ fluxes. However, after ignoring the wet plot $\# 5, \mathrm{CH}_{4}$ flux was found to be significantly influenced by the location on the logging trail and by the WTL, which affects the thickness of the aerated layer in the soil. Our findings agree with Mäkiranta et al. (2012) that logging residues do not impact significantly to $\mathrm{CH}_{4}$ fluxes. At our site, the changes in soil physical properties on the logging trail were behind the higher $\mathrm{CH}_{4}$ emissions at the logging trail than in the forest.

Even though the $\mathrm{CH}_{4}$ fluxes were small, there was some spatial variation observed on different surface types (Sect. 3.6). Therefore, we combined all our measurements to upscale the measured fluxes to ecosystem level by using WTL as a proxy. As a result, the cumulative $\mathrm{CH}_{4}$ balances at the partial harvest forest floor during summers 2016 and 2017 were $-31 \pm 2 \mathrm{mg} \mathrm{CH} \mathrm{m}^{-2}$ and $-19 \pm 4 \mathrm{mg} \mathrm{CH}_{4} \mathrm{~m}^{-2}$, respectively, which were $49 \%$ and $34 \%$ lower than the sinks estimated from the automatic chamber measurements. This was due to higher, but also variable WTL inside the harvested site. The contribution of logging trails to the ecosystem balance was negligible due to a combination of small fluxes and relatively small surface area (20\% of total area). However, even though the ditches constitute only $2.4 \%$ of the total harvested area, they could play a considerable role in the total ecosystem $\mathrm{CH}_{4}$ balance due to their relatively high $\mathrm{CH}_{4}$ emissions. The $\mathrm{CH}_{4}$ emissions from the ditches on the ecosystem level were higher than the forest floor sink at the harvest site during both summers and also at the control site in summer 2017 (Table 2). However, the ecosystem-level ditch fluxes had high uncertainty due to high variability in fluxes, and the fact that only two ditches were measured.

In conclusion, the partial harvest site was likely a $\mathrm{CH}_{4}$ neutral or a small source due to high emissions from the ditches and decreased sink in the forest floor. However, it should be noted that even though the uncertainties were relatively large, even in the worst-case scenario, the site would still be only a small source of $\mathrm{CH}_{4}$. Also, the climatic impact of $\mathrm{CH}_{4}$ emissions in terms of global warming potential over 100 years (mean: $0.8 \pm 0.6 \mathrm{~g} \mathrm{CO}_{2}$-eq $\mathrm{m}^{-2}$ summer $^{-1}$ ) is negligible when compared against $\mathrm{N}_{2} \mathrm{O}$ emissions (mean: $113 \pm 10 \mathrm{~g} \mathrm{CO}_{2}$-eq m $\mathrm{m}^{-2}$ summer $^{-1}$ ) at Lettosuo.

\subsection{The effect of partial harvesting on $\mathrm{N}_{2} \mathrm{O}$ fluxes}

Forest floor $\mathrm{N}_{2} \mathrm{O}$ fluxes were temporally and spatially variable at both harvest and control sites, and no significant difference between them was found due to the harvest (Sect. 3.2.2; 3.3). Based on the data from the automatic chambers at the harvest site, the fluxes were significantly different between all the years. However, no such differences were found in the manual chamber measurements. The contradiction between the automatic chamber and manual chamber measurements was at least partly due to the high spatial variation between the plots and due to lower measurement interval in the transect. Despite the slight, unexplained discrepancy between the methods, it is good to note that at the clear-cut site of the same forest (Korkiakoski et al., 2019), a large increase in $\mathrm{N}_{2} \mathrm{O}$ fluxes was observed during the same time period using the same manual measurement system as in this study. Comparing the results of this study to Korkiakoski et al. (2019) suggests that the effect of the partial harvest on $\mathrm{N}_{2} \mathrm{O}$ fluxes was negligible as it was not observable by manual nor automatic measurements. 
An interesting result from the automatic chambers was the bimodal behaviour of $\mathrm{N}_{2} \mathrm{O}$ fluxes during the year, showing high emissions in summer and in winter (Fig. 4b). This phenomenon has been observed in multiple studies in upland and agricultural sites, and the emissions during these cycles can be a substantial part of annual $\mathrm{N}_{2} \mathrm{O}$ balance (Luo et al., 2012; Papen and Butterbach-Bahl, 1999; Peng et al., 2019; Röver et al., 1998). Large emissions after soil thawing can be explained by $\mathrm{N}_{2} \mathrm{O}$ accumulation under the ice (Peng et al., 2019; Teepe et al., 2001). Also, increased emissions have been observed when the soil is frozen, which could occur due to increased amount of substrates during soil freezing (Herrmann and Witter, 2002; Matzner and Borken, 2008; Song et al., 2017). These substrates could be used by microbes living in small unfrozen water films in soil pores (Congreves et al., 2018; Papen and Butterbach-Bahl, 1999).The manual chamber measurements showed significant differences in $\mathrm{N}_{2} \mathrm{O}$ fluxes between the summers at the control site, but not at the harvest site. This might be attributed to the counteracting effect of harvesting and the environmental conditions: summer 2016 was drier than 2015 which inhibited $\mathrm{N}_{2} \mathrm{O}$ emissions at the control, however at the harvest site, the water-level drawdown due to dry conditions was not marked enough to inhibit emissions. The drier summer might thus explain the smaller $\mathrm{N}_{2} \mathrm{O}$ emissions in 2016 at the control because low soil moisture has been attributed to relatively low $\mathrm{N}_{2} \mathrm{O}$ emissions (Ciarlo et al., 2007; Dalal et al., 2003; Gelfand et al., 2015).

$\mathrm{N}_{2} \mathrm{O}$ emissions were higher on the logging trail than on the side of the logging trail (Fig. 7) and on the forest floor measured by the automatic chambers at harvest site (Fig. 5). The $\mathrm{N}_{2} \mathrm{O}$ fluxes were significantly correlated with the location on the logging trail, WTL, soil temperature and the mass of the logging residues. The mass of needles did not significantly correlate with $\mathrm{N}_{2} \mathrm{O}$ fluxes. However, the model explained only a small part of the variation in fluxes. Thus, other factors such as soil moisture, which is known to drive $\mathrm{N}_{2} \mathrm{O}$ fluxes (e.g. Brown et al., 2012), might have had some effect. Soil moisture could have increased due to soil compression, which enhanced denitrification and $\mathrm{N}_{2} \mathrm{O}$ emissions. Also, logging residues stabilised soil temperature and possibly moisture by preventing direct sunlight and evaporation which favour mineralisation and nitrification processes in the organic layer of soil (Roberts et al., 2005; Rosén and Lundmark-Thelin, 1987). Upscaling fluxes to the ecosystem-level revealed that the $\mathrm{N}_{2} \mathrm{O}$ emissions from the logging trails were $35-38 \%$ of total site balance (Table 2) making the logging trails an essential part of the ecosystem $\mathrm{N}_{2} \mathrm{O}$ balance. However, there was an exception with logging trail plot \#5 where WTL was around $-20 \mathrm{~cm}$ or higher. The $\mathrm{N}_{2} \mathrm{O}$ emissions at that plot were low because the conditions were too wet for nitrification and $\mathrm{N}_{2} \mathrm{O}$ production to occur.

\section{Conclusions}

Partial harvesting a nutrient-rich peatland forest did not affect $\mathrm{CH}_{4}$ or $\mathrm{N}_{2} \mathrm{O}$ balances considerably, and the site remained as $\mathrm{CH}_{4}$ neutral and a small source of $\mathrm{N}_{2} \mathrm{O}$ even after the harvest. The logging trails acted as a small $\mathrm{CH}_{4}$ source due to soil compression which likely increased soil moisture and decreased $\mathrm{CH}_{4}$ oxidation, but on ecosystem-level, logging trail $\mathrm{CH}_{4}$ fluxes were insignificant. Given the small number of measurements and the large uncertainties related to the ditch $\mathrm{CH}_{4}$ fluxes, the exact quantification of ditch fluxes was not made. However, $\mathrm{CH}_{4}$ fluxes in peatland forest seem to have a negligible climatic impact, even after the harvest.

The emissions of $\mathrm{N}_{2} \mathrm{O}$ from the logging trails were significantly higher than from the forest surface where no changes were observed after harvesting. The higher emissions from the logging trails could have been caused by soil compression, which increases soil moisture and enhances denitrification. Also, decomposing logging residues release reactive nitrogen and prevent direct sunlight and evaporation, which favour nitrification processes in the organic layer of soil. On ecosystem-level, the emissions from the logging trails were an essential part of the $\mathrm{N}_{2} \mathrm{O}$ balance of the site constituting $35-38 \%$ of the total emissions while the forest floor emitted the rest. The fluxes from the ditches were insignificant. Despite capturing the high temporal and spatial variability in $\mathrm{N}_{2} \mathrm{O}$ fluxes by different chamber measurement methods, and recording increased emissions from the logging trails, no considerable harvesting effect in $\mathrm{N}_{2} \mathrm{O}$ fluxes was observed when compared to the control site.

Overall, the results in this study show that partial harvesting of peatland forests causes less $\mathrm{CH}_{4}$ and $\mathrm{N}_{2} \mathrm{O}$ emissions compared to clearcutting. However, the results here show only the impact of partial harvesting for the first two post-harvest years and more measurements are required to make conclusions of long-term effects of partial harvesting in peatland forests.

\section{Declaration of Competing Interest}

The authors declare that they have no known competing financial interests or personal relationships that could have appeared to influence the work reported in this paper.

\section{Acknowledgements}

This study was funded by the Maj and Tor Nessling Foundation (grant no. 201700450), the Academy of Finland project "Role of upland forest soils in regional methane balance: from catchment to global scales" (project no. 308511), and the Ministry of Transport and Communications through the Integrated Carbon Observing System (ICOS) research.

\section{Supplementary materials}

Supplementary material associated with this article can be found, in the online version, at doi:10.1016/j.agrformet.2020.108168.

\section{Appendix A. Flux calculation}

The fluxes were calculated the same way as described in Korkiakoski et al. (2017) for both gases. Dilution and spectral corrected $\mathrm{CH}_{4}$ and $\mathrm{N}_{2} \mathrm{O}$ concentrations reported by Picarro G1130 and LGR N2O/CO-23d were used to calculate the fluxes. Even though the lag caused by tubing was taken into account, $30 \mathrm{~s}$ from the beginning of each closure data was removed (Korkiakoski et al., 2017) because the flow rate varied slightly in time, and it takes time for the air inside the chamber to mix properly. In short, both linear and exponential regression models were first fitted to the mixing ratio time series using the least-squares approach.

After fitting, the mass flux $(F)$ was calculated as

$F=\left(\frac{d C(t)}{d t}\right)_{t=0} \frac{M P V}{R T A}$, 
where $\left(\frac{d C(t)}{d t}\right)_{t=0}$ is the concentration change over time from a linear or exponential model at the beginning of the closure, $M$ is the molecular mass of $\mathrm{CH}_{4}$ or $\mathrm{N}_{2} \mathrm{O}$ (16.04 and $44.01 \mathrm{~g} \mathrm{~mol}^{-1}$, respectively), $P$ is air pressure, $R$ is the universal gas constant $\left(8.314 \mathrm{~J} \mathrm{~mol}^{-1} \mathrm{~K}^{-1}\right), T$ is the mean chamber headspace temperature during the closure, and $V$ is the air volume of the chamber and the possible collar, and $A$ is the base area of the chamber or collar. The collar height, snow depth and the height of mosses and other vegetation in the chamber headspace volume were taken into account, ignoring the pore space in the soil and snow. Finally, analyser-specific flux limits were determined to choose between the linear and exponential models (Korkiakoski et al., 2017). If the flux calculated with the linear model was smaller than the limit, then this estimate was considered more robust and used in the later analysis. These limits for the automatic chamber system at the harvest site were $2.5 \mu \mathrm{g} \mathrm{CH}_{4} \mathrm{~m}^{-2} \mathrm{~h}^{-1}$ and $3 \mu \mathrm{g} \mathrm{N} \mathrm{O} \mathrm{m}^{-2} \mathrm{~h}^{-1}$. At the control chamber system, the $\mathrm{CH}_{4}$ limit was the same, but $\mathrm{N}_{2} \mathrm{O}$ limit was $5 \mu \mathrm{g} \mathrm{N}_{2} \mathrm{O} \mathrm{m}^{-2} \mathrm{~h}^{-1}$ for the LGR analyser.

At the control site, the LGR and Gasmet instruments were simultaneously connected to the chamber system in July - December 2017 to compare the instruments. The comparison revealed that the $6 \mathrm{~min}$ closure time used in the automatic chambers was not long enough for Gasmet to determine the flux by using exponential regression. Therefore, only linear regression was used to calculate the fluxes when using only the Gasmet analyser in the first half of 2017 (Fig. S1). The $\mathrm{N}_{2} \mathrm{O}$ fluxes calculated from the Gasmet data were generally underestimated by $10-20 \%$, depending on the flux magnitude when compared to the fluxes estimated from the LGR data. This underestimation was corrected for the automatic measurements at the control for Jan-Jul period in 2017.

For the manual chamber measurements, the fluxes were calculated with nearly the same procedure for the data collected from transects and logging trails. The start and endpoints of the chamber closure were visually identified in the flux calculation. The fluxes were calculated similarly to the automatic chamber measurements so that the specific flux limits for the Gasmet analyser were determined to select between the linear and exponential models as explained in (Korkiakoski et al., 2017). The flux limits for the portable Gasmet system were $35 \mu \mathrm{g} \mathrm{CH} \mathrm{m}^{-2} \mathrm{~h}^{-1}$ and $45 \mu \mathrm{g} \mathrm{N} \mathrm{N}_{2} \mathrm{O}$ $\mathrm{m}^{-2} \mathrm{~h}^{-1}$ which is about ten times as high as for the LGR and Picarro instruments used in the automatic chamber system due to lower precision of the portable gas analyser.

When using the inside-of-cabin analysers to measure the manual chamber fluxes at the logging trail plots and transects in 2016 and 2017 , a 5 min closure time was used at the harvest site. However, at the control transect, a 10 min closure time was used because the $\mathrm{N}_{2} \mathrm{O}$ flux was calculated from the data measured with the Gasmet analyser which required a longer closure time to capture the small fluxes more precisely. For the data collected from the control site, the $\mathrm{CH}_{4}$ flux was calculated by using the first 5 min data acquired from the Picarro analyser. However, $\mathrm{N}_{2} \mathrm{O}$ was analysed the same way as the measurements made with the Gasmet analyser described above. When using the automatic chamber system in logging trail plots and transect measurements, the sampled air was not returned to the chamber, causing underpressure inside the chamber and underestimation in the flux estimation. Because the chambers had a vent-tube, we corrected the leakage with an assumption that the underpressure consisted of ambient air.

In this study, a micrometeorological sign convention is used: a positive flux indicates a flux from the ecosystem to the atmosphere (emission) and a negative flux indicates a flux from the atmosphere into the ecosystem (uptake).

\section{Appendix B. Quality control of the flux data}

Same filtering methods were used for $\mathrm{CH}_{4}$ and $\mathrm{N}_{2} \mathrm{O}$ fluxes measured with the automatic chamber system as in (Korkiakoski et al., 2017). In short, the hardware problems of the chambers were detected by calculating the normalised root mean square error (NRMSE) of the exponential fit to the $\mathrm{CO}_{2}$ data measured by Picarro analyser and if NRMSE was $>0.05$ the $\mathrm{CH}_{4}$ and $\mathrm{N}_{2} \mathrm{O}$ data were discarded. Also, random spiking was removed by using an iterative standard deviation ( \pm 8 standard deviation) filtering with a 14-day window and one-day time step. At the harvest site, 7.5\% of the measured $\mathrm{CH}_{4}$ fluxes were filtered, and the average number of accepted $\mathrm{CH}_{4}$ fluxes measured by each chamber was 17427 and 18026 at harvest and control site, respectively. For $\mathrm{N}_{2} \mathrm{O}$ fluxes, the filtered percentage was similar to the $\mathrm{CH}_{4}$ fluxes, but the number of accepted fluxes was slightly larger at the harvest site $(n=18525)$ and markedly lower $(n=6464)$ at the control site. These differences were attributed to different instrument availabilities. The measurements conducted at the logging trail and transect points were checked visually, and only some of the ditch measurements required filtering due to ebullition. The cases of ebullition were visually identified and discarded from further analysis.

\section{Appendix C. Gap-filling and uncertainties of gas balances}

The gaps in the automatic chamber data need to be filled to calculate the seasonal and annual balances of $\mathrm{CH}_{4}$ and $\mathrm{N}_{2} \mathrm{O}$. All the gap-filling procedures described next were conducted separately for each automatic chamber and gas. First, the gaps shorter than one day were filled with linear interpolation and the daily sums were calculated from this gap-filled data. Next, the gaps longer than one day were filled with linear interpolation of the daily sums. From these gap-filled daily sums, the monthly, seasonal, and annual sums were calculated. However, chamber H5 at the harvest site had a three-month gap in 7-10/2015, and this method of gap filling would have probably induced too big of an error in the monthly balances. So, we gap filled the chamber $\mathrm{H} 5$ fluxes with linear regression of last three months in 2015 between the chambers $\mathrm{H} 5$ and $\mathrm{H} 4$ ( $\mathrm{r}=0.86$ ), and $\mathrm{H} 5$ and $\mathrm{H} 2$ $(\mathrm{r}=0.89)$ for $\mathrm{CH}_{4}$ and $\mathrm{N}_{2} \mathrm{O}$, respectively.

The uncertainties of the gas balances were calculated based on the method in (Korkiakoski et al., 2017) which included: (1) the random error of the linear/exponential fit in flux calculation and (2) the error caused by gap filling. The random and gap-filling errors were combined with the standard accumulation principle of independent errors to get the total error estimate.

\section{References}

Amiro, B.D., 2001. Paired-tower measurements of carbon and energy fluxes following disturbance in the boreal forest. Global Change Biol. 7 (3), 253-268. https://doi.org/ 10.1046/j.1365-2486.2001.00398.x.

Bates, D., Maechler, M., Bolker, B., Walker, S., 2015. Fitting linear mixed-effects models using lme4. J. Stat. Softw. 67 (1), 1-48. https://doi.org/10.18637/jss.v067.i01.

Bhuiyan, R., Minkkinen, K., Helmisaari, H.-S., Ojanen, P., Penttilä, T., Laiho, R., 2017. Estimating fine-root production by tree species and understorey functional groups in two contrasting peatland forests. Plant Soil 412 (1-2), 299-316. https://doi.org/10. 1007/s11104-016-3070-3.
Brown, J.R., Blankinship, J.C., Niboyet, A., van Groenigen, K.J., Dijkstra, P., Le Roux, X., Leadley, P.W., Hungate, B.A., 2012. Effects of multiple global change treatments on soil $\mathrm{N}_{2} \mathrm{O}$ fluxes. Biogeochemistry 109 (1-3), 85-100. https://doi.org/10.1007/ s10533-011-9655-2.

Ciarlo, E., Conti, M., Bartoloni, N., Rubio, G., 2007. The effect of moisture on nitrous oxide emissions from soil and the $\mathrm{N}_{2} \mathrm{O} /\left(\mathrm{N}_{2} \mathrm{O}+\mathrm{N}_{2}\right)$ ratio under laboratory conditions. Biol. Fertil. Soils 43 (6), 675-681. https://doi.org/10.1007/s00374-006-0147-9.

Clarke, D., Rieley, J., 2010. Strategy for responsible peatland management. In: Clarke, D., Rieley, J. (Eds.), International Peat Society. Saarijärvi, Finland.

Congreves, K.A., Wagner-Riddle, C., Si, B.C., Clough, T.J., 2018. Nitrous oxide emissions and biogeochemical responses to soil freezing-thawing and drying-wetting. Soil Biol. Biochem. 117, 5-15. https://doi.org/10.1016/j.soilbio.2017.10.040. 
Dalal, R.C., Wang, W., Robertson, G.P., Parton, W.J., 2003. Nitrous oxide emission from Australian agricultural lands and mitigation options: a review. Aust. J. Soil Res. 41 (2), 165-195. https://doi.org/10.1071/SR02064.

Ernfors, M., Von Arnold, K., Stendahl, J., Olsson, M., Klemedtsson, L., 2008. Nitrous oxide emissions from drained organic forest soils - An up-scaling based on C:N ratios. Biogeochemistry 89 (1), 29-41. https://doi.org/10.1007/s10533-008-9190-y.

Fischlin, A., Midgley, G.F., Price, J., Leemans, R., Gopal, B., Turley, C., Rounsevell, M., Dube, P., Tarazona, J., Velichko, A., 2007. Ecosystems, their properties, goods, and services, in: Climate Change 2007: Impacts, Adaptation and Vulnerability. In: Parry, M.L., Canziani, O.F., Palutikof, J.P., van der Linden, P.J., Hanson, C.E. (Eds.), Contribution of working group II to the Fourth Assessment Report of the Intergovernmental Panel on Climate Change. Cambridge University Press, Cambridge edited by [online] Available from: http://www.treesearch.fs.fed.us/pubs/33102.

Gelfand, I., Cui, M., Tang, J., Robertson, G.P., 2015. Short-term drought response of $\mathrm{N}_{2} \mathrm{O}$ and $\mathrm{CO}_{2}$ emissions from mesic agricultural soils in the US Midwest. Agric. Ecosyst. Environ. 212, 127-133. https://doi.org/10.1016/j.agee.2015.07.005.

Gorham, E., 1991. Role in the carbon cycle and probable responses to climatic warming. Ecol. Appl. 1 (2), 182-195. https://doi.org/10.2307/1941811.

Greenup, A.L., Bradford, M.A., Mcnamara, N.P., Ineson, P., Lee, J.A., 2000. The role of Eriophorum vaginatum in $\mathrm{CH}_{4}$ flux from an ombrotrophic peatland. Plant Soil 227 , 265-272. https://doi.org/10.1023/A:1026573727311.

Herrmann, A., Witter, E., 2002. Sources of C and N contributing to the flush in mineralization upon freeze-thaw cycles in soils. Soil Biol. Biochem. 34 (10), 1495-1505. https://doi.org/10.1016/S0038-0717(02)00121-9.

Huttunen, J.T., Nykänen, H., Martikainen, P.J., Nieminen, M., 2003. Fluxes of nitrous oxide and methane from drained peatlands following forest clear-felling in southern Finland. Plant Soil 255 (2), 457-462. https://doi.org/10.1023/A:1026035427891.

IPCC, 2013. Climate Change 2013: the physical science basis. In: Stocker, T.F., Qin, D., Plattner, G.-K., Tignor, M., Allen, S.K., Boschung, J., Nauels, A., Xia, Y. (Eds.); Contribution of Working Group I to the Fifth Assessment Report of the Intergovernmental Panel on Climate Change. Cambridge University Press, Cambridge, United Kingdom and New York, NY, USA.

Joabsson, A., Christensen, T.R., Wallén, B., 1999. Vascular plant controls on methane emissions from northern peatforming wetlands. Trends Ecol. Evol. 14 (10), 385-388. https://doi.org/10.1016/S0169-5347(99)01649-3.

Klemedtsson, L., Von Arnold, K., Weslien, P., Gundersen, P., 2005. Soil CN ratio as a scalar parameter to predict nitrous oxide emissions. Glob. Chang. Biol. 11 (7), 1142-1147. https://doi.org/10.1111/j.1365-2486.2005.00973.x.

Korhonen, K., Ihalainen, A., Ahola, A., Heikkinen, J., Henttonen, H.M., Hotanen, J.-P., Nevalainen, S., Pitkänen, J., Strandström, M., Viiri, H., 2017. Suomen metsät 2009-2013 ja niiden kehitys 1921-2013 [Finnish forests 2009-2013 and their evolution 1921-2013]. Natural Resources Institute Finland, Helsinki, Finland.

Korkiakoski, M., Tuovinen, J.-P., Aurela, M., Koskinen, M., Minkkinen, K., Ojanen, P., Penttilä, T., Rainne, J., Laurila, T., Lohila, A., 2017. Methane exchange at the peatland forest floor - Automatic chamber system exposes the dynamics of small fluxes. Biogeosciences 14 (7), 1947-1967. https://doi.org/10.5194/bg-14-1947-2017.

Korkiakoski, M., Tuovinen, J.-P., Penttilä, T., Sarkkola, S., Ojanen, P., Minkkinen, K., Rainne, J., Laurila, T., Lohila, A., 2019. Greenhouse gas and energy fluxes in a boreal peatland forest after clearcutting. Biogeosciences 16, 3703-3723. https://doi.org/10. 5194/bg-16-3703-2019.

Koskinen, M., Minkkinen, K., Ojanen, P., Kämäräinen, M., Laurila, T., Lohila, A., 2014. Measurements of $\mathrm{CO}_{2}$ exchange with an automated chamber system throughout the year: challenges in measuring night-time respiration on porous peat soil. Biogeosciences 11 (2), 347-363. https://doi.org/10.5194/bg-11-347-2014.

Kowalski, S., Sartore, M., Burlett, R., Berbigier, P., Loustau, D., 2003. The annual carbon budget of a French pine forest (Pinus pinaster) following harvest. Global Change Biology 9 (7), 1051-1065. https://doi.org/10.1046/j.1365-2486.2003.00627.x. https://doi.org/.

Lai, D.Y.F., 2009. Methane dynamics in northern peatlands: a review. Pedosphere 19 (4), 409-421. https://doi.org/10.1016/S1002-0160(09)00003-4.

Li, H., Fu, S., Zhao, H., Xia, H., 2010. Effects of understory removal and N-fixing species seeding on soil $\mathrm{N}_{2} \mathrm{O}$ fluxes in four forest plantations in southern China. Soil Sci. Plant Nutr. 56 (4), 541-551. https://doi.org/10.1111/j.1747-0765.2010.00498.x.

Lohila, A., Minkkinen, K., Aurela, M., Tuovinen, J.-P., Penttilä, T., Ojanen, P., Laurila, T., 2011. Greenhouse gas flux measurements in a forestry-drained peatland indicate a large carbon sink. Biogeosciences 8 (11), 3203-3218. https://doi.org/10.5194/bg-83203-2011.

Londo, A.J., Messina, M.G., Schoenholtz, S.H., 1999. Forest harvesting effects on soil temperature, moisture, and respiration in a bottomland hardwood forest. Soil Sci. Soc. Am. J. 63 (3), 637-644. https://doi.org/10.2136/sssaj1999. 03615995006300030029x.

Luo, G.J., Brüggemann, N., Wolf, B., Gasche, R., Grote, R., Butterbach-Bahl, K., 2012. Decadal variability of soil $\mathrm{CO}_{2}, \mathrm{NO}, \mathrm{N}_{2} \mathrm{O}$, and $\mathrm{CH}_{4}$ fluxes at the Höglwald Forest, Germany. Biogeosciences 9 (5), 1741-1763. https://doi.org/10.5194/bg-9-17412012.

Mäkiranta, P., Laiho, R., Penttilä, T., Minkkinen, K., 2012. The impact of logging residue on soil GHG fluxes in a drained peatland forest. Soil Biol. Biochem. 48, 1-9. https:// doi.org/10.1016/j.soilbio.2012.01.005.

Malyan, S.K., Bhatia, A., Kumar, A., Gupta, D.K., Singh, R., Kumar, S.S., Tomer, R., Kumar, O., Jain, N., 2016. Methane production, oxidation and mitigation: A mechanistic understanding and comprehensive evaluation of influencing factors. Sci. Total Environ. 572, 874-896. https://doi.org/10.1016/j.scitotenv.2016.07.182.

Martikainen, P.J., Nykänen, H., Crill, P.M., Silvola, J., 1993. Effect of a lowered water table on nitrous oxide fluxes from northern peatlands. Nature 366, 51-53.

Matzner, E., Borken, W., 2008. Do freeze-thaw events enhance C and N losses from soils of different ecosystems? A Review. Eur. J. Soil Sci. 59 (2), 274-284. https://doi.org/10. 1111/j.1365-2389.2007.00992.x.

Mazza, G., Agnelli, A.E., Cantiani, P., Chiavetta, U., Doukalianou, F., Kitikidou, K., Milios, E., Orfanoudakis, M., Radoglou, K., Lagomarsino, A., 2019. Short-term effects of thinning on soil $\mathrm{CO}_{2}, \mathrm{~N}_{2} \mathrm{O}$ and $\mathrm{CH}_{4}$ fluxes in Mediterranean forest ecosystems. Sci. Total Environ. 651, 713-724. https://doi.org/10.1016/j.scitotenv.2018.09.241.

McCaughey, J.H., Brintnell, J.H., 1984. Evaluation of a Bowen ratio measurement system over forest and clear-cut sites at Petawawa, Ontario. J. Atmos. Ocean. Tech. 1, 276-282. doi:10.1175/1520-0426(1984)001<0276:EOABRM> 2.0.CO;2.

Minkkinen, K., Laine, J., 2006. Vegetation heterogeneity and ditches create spatial variability in methane fluxes from peatlands drained for forestry. Plant Soil 285 (1-2), 289-304. https://doi.org/10.1007/s11104-006-9016-4.

Minkkinen, K., Laine, J., Nykänen, H., Martikainen, P.J., 1997. Importance of drainage ditches in emissions of methane from mires drained for forestry. Can. J. For. Res. 27 (6), 949-952. https://doi.org/10.1139/x97-016.

Minkkinen, K., Penttilä, T., Laine, J., 2007. Tree stand volume as a scalar for methane fluxes in forestry-drained peatlands in Finland. Boreal Environ. Res. 12 (2), 127-132.

Myhre, G., Shindell, D., Bréon, F.-M., Collins, W., Fuglestvedt, J., Huang, J., Koch, D., Lamarque, J.-F., Lee, D., Mendoza, B., Nakajima, T., Robock, A., Stephens, G., Takemura, T., Zhang, H., 2013. Climate Change 2013: The Physical Science Basis Contribution Working Group I to Fifth Assessment Report of the Intergovernmental Panel on Climate Change. pp. 659-740. https://doi.org/10.1017/ CBO9781107415324.018.

Neill, C., Piccolo, M.C., Cerri, C.C., Steudler, P.A., Melillo, J., 2006. Soil solution nitrogen losses during clearing of lowland Amazon forest for pasture. Plant Soil 281 (1-2), 233-245. https://doi.org/10.1007/s11104-005-4435-1.

Nieminen, M., 1998. Changes in nitrogen cycling following the clearcutting of drained peatland forests in southern Finland. Boreal Environ. Res. 3 (1), 9-21. https://doi. org/10.1016/S0021-9290(98)00152-3.

Nieminen, M., Hökkä, H., Laiho, R., Juutinen, A., Ahtikoski, A., Pearson, M., Kojola, S., Sarkkola, S., Launiainen, S., Valkonen, S., Penttilä, T., Lohila, A., Saarinen, M., Haahti, K., Mäkipää, R., Miettinen, J., Ollikainen, M., 2018. Could continuous cover forestry be an economically and environmentally feasible management option on drained boreal peatlands? For. Ecol. Manag. 424 (April), 78-84. https://doi.org/10. 1016/j.foreco.2018.04.046.

Ojanen, P., Minkkinen, K., Alm, J., Penttilä, T., 2010. Soil-atmosphere $\mathrm{CO}_{2}, \mathrm{CH}_{4}$ and $\mathrm{N}_{2} \mathrm{O}$ fluxes in boreal forestry-drained peatlands. For. Ecol. Manag. 260 (3), 411-421. https://doi.org/10.1016/j.foreco.2010.04.036.

Ojanen, P., Minkkinen, K., Penttilä, T., 2013. The current greenhouse gas impact of forestry-drained boreal peatlands. For. Ecol. Manag. 289, 201-208. https://doi.org/10. 1016/j.foreco.2012.10.008.

Ojanen, P., Mäkiranta, P., Penttilä, T., Minkkinen, K., 2017. Do logging residue piles trigger extra decomposition of soil organic matter? For. Ecol. Manag. 405 (June), 367-380. https://doi.org/10.1016/j.foreco.2017.09.055.

Papen, H., Butterbach-Bahl, K., 1999. A 3-year continuous record of nitrogen trace gas fluxes from untreated and limed soil of a N-saturated spruce and beech forest ecosystem in Germany. 2. NO and $\mathrm{NO}_{2}$ fluxes. J. Geophys. Res. 104 (15), 487-503. https://doi.org/10.1029/1999JD900293.

Päivänen, J., Hånell, B., 2012. Peatland Ecology and Forestry: A Sound Approach. Unicersity of Helsinki Department of Forest Sciences Publications 3, Helsinki, Finland.

Peng, B., Sun, J., Liu, J., Dai, W., Sun, L., Pei, G., Gao, D., Wang, C., Jiang, P., Bai, E., 2019. $\mathrm{N}_{2} \mathrm{O}$ emission from a temperate forest soil during the freeze-thaw period: a mesocosm study. Sci. Total Environ. 648 (72), 350-357. https://doi.org/10.1016/j . scitotenv.2018.08.155

Pirinen, P., Simola, H., Aalto, J., Kaukoranta, J.-P., Karlsson, P., Ruuhela, R., 2012. Climatological Statistics of Finland 1981-2010, Reports, 2. Finnish Meteorological Institute, Helsinki, Finland.

Prévost, M., Belleau, P., Plamondon, A.P., 1997. Substrate conditions in a treed peatland: responses to drainage. Ecoscience 4 (4), 543-554. https://doi.org/10.1080/ 11956860.1997.11682434

R Core Team: R: a language and Environment for Statistical Computing., [online] Available from: https://www.r-project.org, 2018.

Rannik, Ü., Altimir, N., Raittila, J., Suni, T., Gaman, A., Hussein, T., Hölttä, T., Lassila, H., Latokartano, M., Lauri, A., Natsheh, A., Petäjä, T., Sorjamaa, R., Ylä-Mella, H., Keronen, P., Berninger, F., Vesala, T., Hari, P., Kulmala, M., 2002. Fluxes of carbon dioxide and water vapour over Scots pine forest and clearing. Agric. Forest Meteorol. 111 (3), 187-202. https://doi.org/10.1016/S0168-1923(02)00022-9. https://doi. org/.

Roberts, S. D., Harrington, C. A. and Terry, T. A.: Harvest residue and competing vegetation affect soil moisture, soil temperature, $\mathrm{N}$ availability, and Douglas-fir seedling growth, 205, 333-350, doi:10.1016/j.foreco.2004.10.036, 2005.

Robertson, G.P., Vitousek, P.M., Matson, P.A., Tiedje, J.M., 1987. Denitrification in a clearcut Loblolly pine (Pinus taeda L.) plantation in the southeastern US. Plant Soil 97 (1), 119-129. https://doi.org/10.1007/BF02149830.

Rosén, K., Lundmark-Thelin, A., 1987. Increased nitrogen leaching under piles of slash-A consequence of modern forest harvesting techniques. Scand. J. For. Res. 2 (1-4), 21-29. https://doi.org/10.1080/02827588709382443.

Röver, M., Heinemeyer, O., Kaiser, E.A., 1998. Microbial induced nitrous oxide emissions from an arable soil during winter. Soil Biol. Biochem. 30 (14), 1859-1865. https:// doi.org/10.1016/S0038-0717(98)00080-7.

Saari, P., Saarnio, S., Kukkonen, J.V.K., Akkanen, J., Heinonen, J., Saari, V., Alm, J. 2009. DOC and $\mathrm{N}_{2} \mathrm{O}$ dynamics in upland and peatland forest soils after clear-cutting and soil preparation. Biogeochemistry 94 (3), 217-231. https://doi.org/10.1007/ s10533-009-9320-1.

Song, Y., Zou, Y., Wang, G., Yu, X., 2017. Altered soil carbon and nitrogen cycles due to the freeze-thaw effect: a meta-analysis. Soil Biol. Biochem. 109, 35-49. https://doi. 
org/10.1016/j.soilbio.2017.01.020.

Sundqvist, E., Vestin, P., Crill, P.M., Persson, T., Lindroth, A., 2014. Short-term effects of thinning, clear-cutting and stump harvesting on methane exchange in a boreal forest. Biogeosciences 11 (21), 6095-6105. https://doi.org/10.5194/bg-11-6095-2014.

Teepe, R., Brumme, R., Beese, F., 2001. Nitrous oxide emissions from soil during freezing and thawing periods. Soil Biol. Biochem. 33 (9), 1269-1275. https://doi.org/10. 1016/S0038-0717(01)00084-0.
Turunen, J., Tomppo, E., Tolonen, K., Reinikainen, A., 2002. Estimating carbon accumulation rates of undrained mires in Finland-application to boreal and subarctic regions. The Holocene 12 (1), 69-80. https://doi.org/10.1191/0959683602hl522rp.

Vasander, H., Laine, J., 2008. Site Type Classification on Drained Peatlands. In: Korhonen, R., Korpela, L., Sarkkola, S. (Eds.), Finland - Fenland: Research and Sustainable Utilisation of Mires and Peat. Finnish Peatland Society Maahenki, Helsinki, pp. 146-151. 

IV 



\section{Vegetation controls of water and energy balance of a drained peatland forest: Responses to alternative harvesting practices}

Kersti Leppä ${ }^{\mathrm{a}, *}$, Mika Korkiakoski ${ }^{\mathrm{b}}$, Mika Nieminen ${ }^{\mathrm{a}}$, Raija Laiho ${ }^{\mathrm{a}}$, Juha-Pekka Hotanen ${ }^{\mathrm{a}}$, Antti-Jussi Kieloaho ${ }^{\mathrm{a}}$, Leila Korpela ${ }^{\mathrm{a}}$, Tuomas Laurila ${ }^{\mathrm{b}}$, Annalea Lohila ${ }^{\mathrm{b}, \mathrm{d}}$, Kari Minkkinen ${ }^{\mathrm{c}}$, Raisa Mäkipääa ${ }^{a}$ Paavo Ojanen ${ }^{c}$, Meeri Pearson ${ }^{c}$, Timo Penttilä $^{\mathrm{a}}$, Juha-Pekka Tuovinen ${ }^{\mathrm{b}}$, Samuli Launiainen ${ }^{\mathrm{a}}$

${ }^{\text {a }}$ Natural Resources Institute Finland, Helsinki, Finland

${ }^{\mathrm{b}}$ Finnish Meteorological Institute, Helsinki, Finland

${ }^{\mathrm{c}}$ Department of Forest Sciences, University of Helsinki, Helsinki, Finland

${ }^{\mathrm{d}}$ Institute for Atmospheric and Earth System Research/Physics (INAR), University of Helsinki, Finland

\section{A R T I C L E I N F O}

\section{Keywords:}

Eddy-covariance

Evapotranspiration

Partial harvesting

Peatland forestry

Soil-plant-atmosphere transfer model

Water table level

\begin{abstract}
A B S T R A C T
We quantified the response of peatland water table level (WTL) and energy fluxes to harvesting of a drained peatland forest. Two alternative harvests (clear-cut and partial harvest) were carried out in a mixed-species ditch-drained peatland forest in southern Finland, where water and energy balance components were monitored for six pre-treatment and three post-treatment growing seasons. To explore the responses caused by harvestings, we applied a mechanistic multi-layer soil-plant-atmosphere transfer model. At the clear-cut site, the mean growing season WTL rose by $0.18 \pm 0.02 \mathrm{~m}$ (error estimate based on measurement uncertainty), while net radiation, and sensible and latent heat fluxes decreased after harvest. On the contrary, we observed only minor changes in energy fluxes and mean WTL $(0.05 \pm 0.03 \mathrm{~m}$ increase $)$ at the partial harvest site, although as much as $70 \%$ of the stand basal area was removed and leaf-area index was reduced to half. The small changes were mainly explained by increased water use of spruce undergrowth and field layer vegetation, as well as increased forest floor evaporation. The rapid establishment of field layer vegetation had a significant role in energy balance recovery at the clear-cut site. At partial harvest, chlorophyll fluorescence measurements and model-data comparison suggested the shade-adapted spruce undergrowth was suffering from light stress during the first post-harvest growing season. We conclude that in addition to stand basal area, species composition and stand structure need to be considered when controlling WTL in peatland forests with partial harvesting. Our results have important implications on the operational use of continuous cover forestry on drained peatlands. A continuously maintained tree cover with significant evapotranspiration capacity could enable optimizing WTL from both tree growth and environmental perspectives.
\end{abstract}

\section{Introduction}

Water table level (WTL) is central for biogeochemical processes and resulting provisioning and regulatory ecosystem services of peatlands. WTL determines the depth of the oxic layer, which, together with the nutrient regime, controls vegetation composition and dynamics in pristine peatlands (Malhotra et al., 2016; Weltzin et al., 2003), as well as the productivity of forested (Hånell, 1988; Hökkä et al., 2008b; Préfontaine and Jutras, 2017) and agricultural peatlands (Berglund and Berglund, 2011; Musarika et al., 2017). WTL further affects peat decomposition and soil greenhouse gas emissions (Martikainen et al.,
1993; Moore and Knowles, 1989; Ojanen et al., 2013, 2010; Ojanen and Minkkinen, 2019), and nutrient and carbon leaching to water courses (Kaila et al., 2014; Koskinen et al., 2011; Nieminen et al., 2015). Peatland water balance and WTL are driven by climatic forcing and sitespecific factors including vegetation characteristics, soil properties and topography, as well as artificial drainage and changes in land-use and management (Holden, 2006; Holden et al., 2006; Waddington et al., 2015). It has been suggested that optimizing WTL to simultaneously support multiple ecosystem services can improve the sustainability of peatland use across boreal, temperate and tropical regions (Nieminen et al., 2018; Regina et al., 2015; Renger et al., 2002).

\footnotetext{
* Corresponding author. Latokartanonkaari 9, FI-00790 Helsinki, Finland.

E-mail address: kersti.leppa@luke.fi (K. Leppä).
} 
Globally, about 15 million ha of peatlands have been drained for forestry since the early 1900s. Most of that area is in northern Europe. The peatland forests currently provide an important source of woodbased biomass; in Finland for instance, drained peatlands contribute by ca. $20 \%$ to the total annual stem volume increment (Päivänen and Hånell, 2012). In the Nordic countries, the prevailing management of peatland forests has been even-aged forestry with 60-100 year stand rotation, during which two or three thinnings are recommended (Kojola et al., 2004). As drainage ditches deteriorate over time, ditch cleaning is recommended every 20-40 years (Sikström and Hökkä, 2016). After clear-cutting, establishing the new tree generation is ensured by site preparation and regeneration by sowing, planting or through natural seeding. Many peatlands are potentially excellent forest soils when not excessively wet, due to the relatively high soil nitrogen content (Westman and Laiho, 2003). However, maintaining a ditch network means extra costs, and there are more environmental detriments involved in forestry on peat soils than on mineral soils.

Forest management on peatlands has impaired water quality and affected downstream aquatic habitats, mainly through erosion induced by ditch cleaning (Joensuu et al., 1999; Nieminen et al., 2010) and enhanced leaching of phosphorus, nitrogen, and dissolved organic carbon during high WTL periods after clear-cut (Kaila et al., 2015, 2014; Nieminen et al., 2015). In terms of peatland greenhouse gas balance, anoxic conditions after clear-cut increase soil methane emissions, while in mature, densely stocked stands greater peat aeration accelerates decomposition enhancing carbon dioxide $\left(\mathrm{CO}_{2}\right)$ and nitrous oxide emissions (Korkiakoski et al., 2019a; Ojanen et al., 2013, 2010). The latter being especially true for fertile drained peatland forests (Ojanen et al., 2010).

Recently, continuous cover forestry (CCF) has been proposed preferential to even-aged management from both environmental and economic perspectives (Juutinen et al., 2018; Nieminen et al., 2018; Tahvonen, 2016). CCF replaces clear-cuts by partial harvests, avoids site preparation and relies on natural regeneration (Pommerening and Murphy, 2004). In peatland forests that are often structurally heterogeneous even when managed according to the principles of even-aged management (Sarkkola et al., 2005, 2003), moving to CCF could be particularly feasible. By relying on natural regeneration, CCF would reduce the costs associated with regeneration by planting or sowing and soil preparation (Juutinen et al., 2018; Nieminen et al., 2018). Moreover, maintaining a continuous tree cover with significant evapotranspiration (ET) capacity could reduce the need for regular ditch cleanings and result in more stable WTL than in even-aged forests, which could be favorable from water quality and climatic perspectives (Nieminen et al., 2018). In the hydrological context, moving to CCF means a transition from ensuring satisfactory drainage by regular ditch cleanings towards relying on the ET capacity of the tree stand. This requires in-depth understanding on the water and energy balance of drained peatland forests which are linked through ET. Especially on how ET components, i.e. canopy interception evaporation, plant transpiration and forest floor evaporation, are affected by species water use traits, leaf-area index (LAI) and stand structure (Banerjee and Linn, 2018; Bowden and Bauerle, 2008; Launiainen et al., 2016), and how these are reflected in WTL.

Studies on boreal drained peatland forests show that mean growing season WTL correlates with stand volume (Ahti and Hökkä, 2006; Hökkä et al., 2008b, 2008a; Sarkkola et al., 2010), but that the shape and strength of this relationship is affected by climatic conditions, site type and drainage configuration (Hökkä et al., 2008a; Sarkkola et al., 2010). The relationship between WTL and stand volume is most pronounced in late summer, and has been attributed to high ET (Ahti, 1987, p. 198; Heikurainen, 1967; Sarkkola et al., 2013, 2010). Further, experimental studies show consistent increase in WTL by 0.2-0.4 m following clear-cut (Dubé et al., 1995; Heikurainen, 1967; Jutras and Plamondon, 2005; Sarkkola et al., 2013), indicating that ditch drainage is seldom sufficient to compensate for the lowered ET. However, the processes contributing to the recovery of WTL after clearcut, and the impacts of partial harvests on peatland water and energy balance are not well described.

Partial harvest reduces stand volume and LAI, and alters the vertical foliage distribution and species composition, triggering changes in the coupled energy, water and carbon cycles. In a more open canopy, radiation, wind and vapor pressure deficit (VPD) increase in the lower canopy layers (Banerjee and Linn, 2018; Bladon et al., 2006; Launiainen et al., 2016; Vesala et al., 2005). As leaf photosynthetic $\mathrm{CO}_{2}$ demand and stomatal conductance respond to these environmental variables (Katul et al., 2010; Launiainen et al., 2011), transpiration both at individual leaves and tree-level are likely to increase after partial harvest (Bladon et al., 2006; Bréda et al., 1995; Lagergren and Lindroth, 2004). At stand-scale, this is expected to partially compensate for the reduced LAI, as suggested by the studies from mineral soil sites showing that transpiration decreases proportionally less than LAI or basal area (Bréda et al., 1995; Gebhardt et al., 2014; Lagergren et al., 2008). This may be explained by changes in species composition (Bladon et al., 2006), adaptation to altered microclimatic conditions (Gebauer et al., 2011), or reduced resource competition (Bréda et al., 1995; Lagergren and Lindroth, 2004).

Trees affect site water balance also through interception evaporation, i.e. precipitation captured by the canopy and evaporated back to the atmosphere, and it has been suggested that stand interception scales with stand density (Mazza et al., 2011). After partial harvest, the understory receives more throughfall and light, and becomes dynamically more coupled with the atmosphere, enhancing transpiration of the undergrowth trees and the field layer vegetation, and evaporation from the forest floor (Boczoń et al., 2016; Simonin et al., 2007). Following disturbance and altered microclimate, the field layer vegetation often undergoes rapid changes in terms of species composition and coverage (Bergstedt and Milberg, 2001; Hamberg et al., 2019; Hannerz and Hånell, 1993; Mäkiranta et al., 2010). However, the role of field layer vegetation development after harvesting in peatland energy balance and WTL are poorly understood.

The overall objective of this study is to increase understanding on the role of vegetation on WTL, energy fluxes and water balance in boreal drained peatland forests. Such information is important for the proposed transition towards CCF and optimizing WTL for multiple ecosystem services on drained peatlands (Nieminen et al., 2018). Specifically, we address the following research questions:

1) How do growing season WTL and energy fluxes respond to clear-cut and partial harvest in a fertile boreal drained peatland forest?

2) What is the role of vegetation recovery in water and energy balances during post-treatment years?

3) How do stand structure, species composition and inter-annual meteorological variability affect WTL and ET components?

To find answers to these questions, a field experiment with two alternative harvesting treatments was conducted in a fertile, mixedspecies peatland forest in southern Finland. ET and energy fluxes were measured using eddy-covariance (EC) technique for six pre-treatment and three post-treatment growing seasons, accompanied by systematic WTL monitoring, meteorological measurements and vegetation surveys. As field experiments alone do not necessarily reveal the causes of observed changes, a multi-layer soil-plant-atmosphere transfer model (Launiainen et al., 2015) was applied. The model was first run for the pre-treatment period, and then to used explain the underlying mechanisms of altered energy fluxes and WTL following harvesting. Finally, the model was used to disentangle the roles of vegetation and meteorological conditions on ET and WTL, to explore the hypothesis that species composition and structure of remaining vegetation are key factors in controlling WTL in peatland forests after partial harvest. 


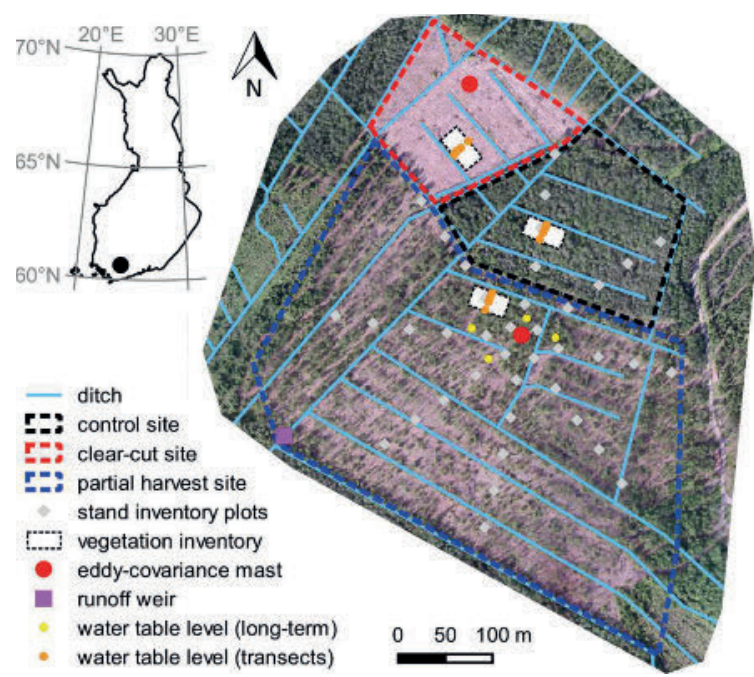

Fig. 1. Location of the Lettosuo site $\left(60^{\circ} 38^{\prime} \mathrm{N}, 23^{\circ} 57^{\prime} \mathrm{E}\right)$ in southern Finland and an aerial photograph of the site after harvesting. The graphics depict the ditches and the monitoring setup.

\section{Material and methods}

\subsection{Study site}

The Lettosuo site is a fertile peatland forest located in southern Finland $\left(60^{\circ} 38^{\prime} \mathrm{N}, 23^{\circ} 57^{\prime} \mathrm{E}\right.$; Fig. 1). The site was originally a mesotrophic birch-pine fen, drained with widely spaced, manually dug ditches probably during the 1930s, and later in 1969 more effectively with ditches spaced ca. $45 \mathrm{~m}$ apart and ca. $1 \mathrm{~m}$ deep. The area is flat, with an average slope of $0.2^{\circ}$. The peat layer thickness varies within $1.5-2.5 \mathrm{~m}$, and the average carbon-nitrogen (C:N) ratio is 27 , which is typical for sites with mesotrophic fen history. Before the harvest treatments, the two-storied tree stand consisted of a mixture of Scots pine (Pinus sylvestris, stem volume $180 \mathrm{~m}^{3} \mathrm{ha}^{-1}$ ) and pubescent birch (Betula pubescens, $48 \mathrm{~m}^{3} \mathrm{ha}^{-1}$ ) in the dominant layer, with a dense undergrowth of Norway spruce (Picea abies, $34 \mathrm{~m}^{3} \mathrm{ha}^{-1}$ ). Field layer vegetation was patchy, featuring mostly herbs (Dryopteris carthusiana, Trientalis europaea) and dwarf shrubs (Vaccinium myrtillus). The forest floor was covered by litter and a patchy moss layer dominated by feather mosses (Pleurozium schreberi and Dicranum polysetum).

The long-term (1981-2010) annual mean temperature and precipitation at the nearby weather station were $4.6{ }^{\circ} \mathrm{C}$ and $627 \mathrm{~mm}$, respectively (Pirinen et al., 2012). Snow typically covers the ground from December to April. Monitoring of the site started in the autumn of 2009 when an EC mast was installed in the center of the site to measure energy and $\mathrm{CO}_{2}$ fluxes above the forest canopy (Fig. 1). In March 2016, two harvesting treatments were carried out, creating three parallel sites (Fig. 1): an area of 2.3 ha was clear-cut, 13 ha were partially harvested by removing the dominant pine trees, and the remaining 3.1 ha were left intact as a control. At the clear-cut site, a second EC mast was established in April 2016, the soil was prepared by mounding (see e.g. Nieminen, 2003) in August 2016, and spruce seedlings were planted in 2017.

\subsection{Soil-plant-atmosphere transfer model}

The soil-plant-atmosphere transfer model pyAPES (Launiainen et al., 2015) was used to analyze the observed changes in water and energy fluxes following the harvesting treatments, and to disentangle the relative roles of vegetation vs. meteorological controls on peatland water balance. pyAPES simulates water, energy and $\mathrm{CO}_{2}$ fluxes in a forest ecosystem in a one-dimensional column. The forest ecosystem is described by a multi-species tree stand, field layer vegetation, a forest floor covered by mosses or litter, and an underlying soil profile. As forcing variables, the model uses time-averaged (here halfhourly) meteorological variables at a reference level above the canopy. Forcing variables are precipitation, downwelling longwave radiation, direct and diffuse photosynthetically active and near-infrared radiation (PAR and NIR), wind speed, atmospheric pressure, air temperature, and mixing ratios of $\mathrm{H}_{2} \mathrm{O}$ and $\mathrm{CO}_{2}$.

Canopy structure is described by a vertical leaf area density (LAD, $\mathrm{m}^{2} \mathrm{~m}^{-3}$ ) distribution that forms a layered porous medium, which is used to solve the transfer and absorption of shortwave and longwave radiation (Zhao and Qualls, 2006, 2005), and the turbulent transport of scalars (air temperature, $\mathrm{H}_{2} \mathrm{O}, \mathrm{CO}_{2}$ ) and momentum within the canopy. The turbulent transport in the canopy air space and resulting vertical gradients of wind speed, air temperature, $\mathrm{H}_{2} \mathrm{O}, \mathrm{CO}_{2}$ are modelled using standard first order closure schemes (Launiainen et al., 2015). Partitioning of precipitation between interception and throughfall, as well as the energy balance of wet leaves are solved in the canopy layers following Watanabe and Mizutani (1996).

The canopy LAD distribution is the superposition of the LAD distributions of individual plant types (here the tree species pine, birch and spruce and the field layer vegetation). Each plant type is characterized by its unique structural (LAD, leaf size etc.) and physiological properties, including photosynthetic parameters, water use traits and phenology. Leaf gas and energy exchange is solved separately for sunlit and shaded leaves of each plant type and canopy layer. Well-established solutions of coupled photosynthesis-stomatal conductance and leaf energy balance are applied (Farquhar et al., 1980; Medlyn et al., 2011) iteratively with the solution of canopy air-space scalar gradients and longwave radiation. During times with no snowpack, the forest floor is described as a mosaic of moss and litter. Both the moss and litter compartments are solved for water and energy balance and $\mathrm{CO}_{2}$ exchange (Kieloaho and Launianen, 2018; Launiainen et al., 2015). Snow accumulation and melt is described here with a simple temperaturebased approach and parameterized as in Launiainen et al. (2019).

Vertical water flow in the soil is solved using Richards' equation and the van Genuchten scheme for water retention and unsaturated hydraulic conductivity following van Dam and Feddes (2000). Soil heat flow is computed based on heat conduction in the soil column. Heat flow in the soil is affected by freezing and thawing processes, calculated based on a freezing curve (e.g., Koivusalo et al., 2001). The lateral ditch drainage out of the soil column follows Hooghoudt's (1940) equation. We described macropore bypass flow by transporting $70 \%$ of the infiltrated water directly to the topmost water-saturated soil layer. This reproduced well the observed patterns in WTL also after strong infiltration events through otherwise poorly conductive dry peat layers during periods of deep WTL.

The model was first applied to the pre-treatment period (September 2009 to March 2016) to explore whether it could adequately reproduce the observed energy and water balances. Thereafter (March 2016 to December 2018), the model was applied to the three parallel sites. The model was forced, parameterized, and evaluated using measurement data described in Section 2.3. Parameters affected by the treatments include tree species' LAD distributions and LAI, field layer LAI, and forest floor coverage by moss and litter. Other model parameters, largely based on earlier literature, can be found in Tables S1 and S2. In the model runs, we divided the canopy into 100 canopy layers extending to the height of $25 \mathrm{~m}$, and a $2 \mathrm{~m}$ deep soil profile with layer thickness ranging from $0.01 \mathrm{~m}$ at the soil surface to $0.1 \mathrm{~m}$ in deeper parts.

\subsection{Measurements and data processing}

\subsubsection{Vegetation and peat characteristics}

Tree stands were measured in November 2014 before harvest and in 


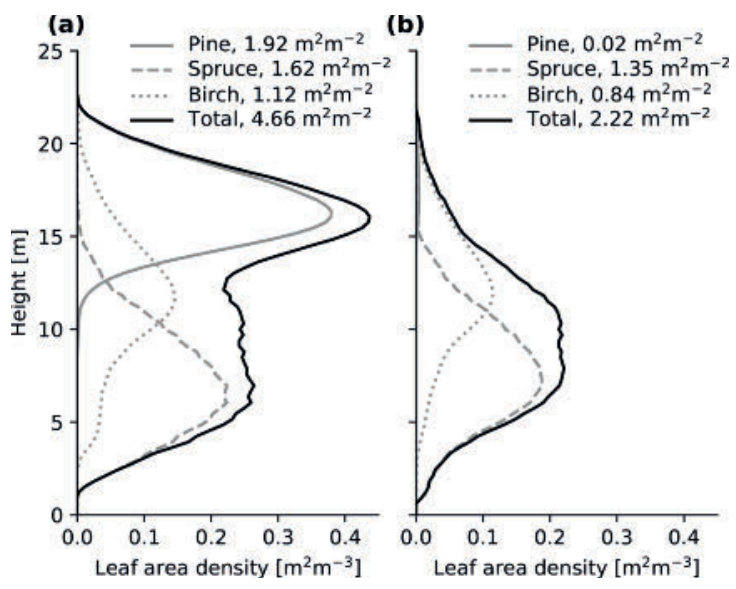

Fig. 2. Leaf area density distributions and leaf area indices of tree species: (a) before harvest in 2014, and (b) after partial harvest in 2016.

May 2016 after harvest on altogether 39 circular stand inventory plots. They were located systematically on eight radial transects extending $160-200 \mathrm{~m}$ from the central EC mast and covering an area of $4000 \mathrm{~m}^{2}$ in total (Fig. 1). Tree species were identified and stem diameter at the height of $1.3 \mathrm{~m}(\mathrm{DBH})$ was recorded for all trees with DBH $>25 \mathrm{~mm}$. Additionally, an earlier inventory of the same plots was carried out in 2009 to measure tree heights and crown lengths of sample trees. These data consisted of 57 pine, 40 spruce, and 37 birch trees distributed evenly on the inventory plots and covering the entire DBH ranges of each species. The partial harvest reduced the canopy density considerably; the number of stems decreased from $2100 \mathrm{ha}^{-1}$ to about $1100 \mathrm{ha}^{-1}$ and basal area from $32 \mathrm{~m}^{2} \mathrm{ha}^{-1}$ to $10 \mathrm{~m}^{2} \mathrm{ha}^{-1}$. Pine, spruce and birch accounted for $60 \%, 20 \%$ and $20 \%$ of basal area before harvest, and $2 \%, 51 \%$ and $47 \%$ after harvest, respectively. The stand inventory data were used to derive vertical LAD distributions for each tree species and tree stand LAI during pre- and post-treatment conditions (Fig. 2; details in Appendix A).

To evaluate the physiological status of the foliage of remaining spruce undergrowth after partial harvest, chlorophyll fluorescence, more precisely the ratio of variable fluorescence to maximal fluorescence (Fv/Fm), was measured. Fv/Fm describes the maximum efficiency of Photosystem II (PS II) (Murchie and Lawson, 2013). Measurements were taken from current-year and one-year-old needles of 70 spruce trees ranging from 1 to $16 \mathrm{~m}$ in height: 50 in different parts of the partial harvest area and 20 in the control area. Altogether 19 measurement times during the growing seasons of 2016 and 2017 were chosen to follow the post-harvest dynamics of Fv/Fm in the two parallel sites. Each time, one lateral shoot from the upper third of the live canopy per tree was detached, placed in a plastic bag, and stored cool before the measurement (max. $3 \mathrm{~h}$ ). In the laboratory, the target needles (the two age classes separately for each shoot) were first dark adapted for 30 min using PPEA/LC dark adaptation leafclips (Hansatech Instruments, King's Lynn, Norfolk, UK). Then, measurements were done with a Pocket PEA continuous excitation chlorophyll fluorimeter (Hansatech Instruments; measure duration $1 \mathrm{~s}$, illumination $3500 \mathrm{mi}-$ cromoles).

The understory vegetation was monitored by assessing the projection coverage of field layer species (dwarf shrubs, herbs, graminoids, and tree and shrub seedlings and saplings up to $0.5 \mathrm{~m}$ height) and that of moss species and litter on the forest floor. The species names used for vascular plants and mosses follow the nomenclatures of HämetAhti et al. (1998) and Ulvinen et al. (2002), respectively. Inventories were carried out in the tree stand inventory plots in 2009, 2017, and 2018 (only in partial harvest site in 2018), as well as in a systematic
Table 1

Leaf area indices (LAI) and moss coverage at different treatments ${ }^{\mathrm{a}}$.

\begin{tabular}{llll}
\hline & $\begin{array}{l}\text { Pre-treatment } / \\
\text { Control }\end{array}$ & $\begin{array}{l}\text { Partial } \\
\text { harvest }\end{array}$ & Clear-cut \\
\hline Tree stand LAI $\left(\mathrm{m}^{2} \mathrm{~m}^{-2}\right)$ & 4.66 & 2.22 & 0.0 \\
Field layer LAI $\left(\mathrm{m}^{2} \mathrm{~m}^{-2}\right)$ & 1.0 & $0.4^{\mathrm{b}}-1.2$ & $0.3^{\mathrm{b}}-1.3$ \\
Moss projection coverage & 40 & 40 & 10
\end{tabular}

(\%)

a The field layer LAI ranges for the harvested sites describe the development after harvest during 2016-2018.

b Estimated for 2016 assuming a similar change as observed between 2017 and 2018.

Table 2

Peat profile hydraulic characteristics.

\begin{tabular}{lllllll}
\hline Depth (m) & $\begin{array}{c}\theta_{\mathrm{s}}\left(\mathrm{m}^{3}\right. \\
\left.\mathrm{m}^{-3}\right)\end{array}$ & $\begin{array}{c}\theta_{\mathrm{r}}\left(\mathrm{m}^{3}\right. \\
\left.\mathrm{m}^{-3}\right)\end{array}$ & $\alpha_{\mathrm{vg}}\left(\mathrm{m}^{-1}\right)$ & $\beta_{\mathrm{vg}}(-)$ & $\mathrm{K}_{\text {Vsat }}\left(\mathrm{m} \mathrm{h}^{-1}\right)$ & $\mathrm{K}_{\mathrm{Hsat}}\left(\mathrm{m} \mathrm{h}^{-1}\right)$ \\
\hline $0-0.1$ & 0.94 & 0.002 & 20.2 & 1.35 & 0.18 & $30 \times \mathrm{K}_{\text {Vsat }}$ \\
$0.1-0.2$ & 0.88 & 0.010 & 4.4 & 1.35 & 0.12 & $20 \times \mathrm{K}_{\text {Vsat }}$ \\
$0.2-0.3$ & 0.88 & 0.010 & 4.4 & 1.35 & 0.07 & $10 \times \mathrm{K}_{\text {Vsat }}$ \\
$0.3-2.0$ & 0.88 & 0.010 & 4.4 & 1.35 & $0.05-0.0004$ & $\mathrm{~K}_{\text {Vsat }}$ \\
\hline
\end{tabular}

$\theta_{\mathrm{s}}=$ soil porosity; $\theta_{\mathrm{r}}=$ residual water content; $\alpha_{\mathrm{vg}}, \beta_{\mathrm{vg}}=$ van Genuchten water retention curve parameters;

$\mathrm{K}_{\mathrm{Vsa}}, \mathrm{K}_{\mathrm{Hsat}}=$ saturated vertical and horizontal hydraulic conductivity.

grid of 32 vegetation plots in each parallel site. The latter plots were located around the WTL transects (Fig. 1) and were mapped for vegetation in 2015, 2017, and 2018 (only the harvested sites in 2018). The moss projection coverage on the forest floor and the field layer vegetation LAI were derived from these data for each treatment (Table 1; details in Appendix A).

To characterize the hydraulic properties of peat (Table 2), peat samples were collected from three locations. They were analyzed for peat type and degree of humification (von Post, 1922) for each $0.1 \mathrm{~m}$ layer extending from soil surface to the depth of $0.5 \mathrm{~m}$. The top layer consisted of organic matter accumulated after drainage ("raw humus") and the lower layers were Carex peat with the degree of decomposition varying from 4 to 6 (von Post scale). Water retention characteristics and hydraulic conductivities of the peat layers were defined based on Päivänen (1973): The soil layers below $0.1 \mathrm{~m}$ from the soil surface were described with water retention parameters fitted to all the Carex peat data presented by Päivänen (1973), while the water retention parameters of the topmost $0.1 \mathrm{~m}$ layer were set based on the Carex sample with the poorest water retention capacity. Saturated hydraulic conductivity for each $0.1 \mathrm{~m}$ layer was defined in relation to depth with the functions presented for Carex peat. The horizontal hydraulic conductivities of the top $0.3 \mathrm{~m}$ of the peat profile were further adjusted by manual calibration against WTL and runoff measurements during the pre-treatment period.

\subsubsection{Meteorological conditions}

Meteorological data were recorded as $30 \mathrm{~min}$ averages. The utilized data included air temperature (HMP45D, Vaisala Corporation), relative humidity (HMP45D, Vaisala Corporation), atmospheric pressure (PMT16A, Vaisala Corporation), incoming global radiation $\left(\mathrm{R}_{\mathrm{g}}\right.$; Pyranometer CMP3, Kipp \& Zonen, Delft, The Netherlands), incoming PAR (PQS1 PAR Quantum sensor, Kipp \& Zonen), wind speed and friction velocity (METEK USA-1, METEK GMbH) measured at the central EC mast at $25.5 \mathrm{~m}$. In addition, precipitation (Casella Ltd Par NO 10000E-04) was measured at $6 \mathrm{~m}$. Meteorological data from three nearby weather stations (Jokioinen $\left(60^{\circ} 48^{\prime} \mathrm{N}, 23^{\circ} 30^{\prime} \mathrm{E}\right)$, Somero $\left(60^{\circ} 39^{\prime} \mathrm{N}, 23^{\circ} 48^{\prime} \mathrm{E}\right)$, and Salo Kiikala $\left(60^{\circ} 27^{\prime} \mathrm{N}, 23^{\circ} 39^{\prime} \mathrm{E}\right)$ ), operated by the Finnish Meteorological Institute, were used to complete the wintertime precipitation data and to fill the gaps in the on-site 
Table 3

Coverage of EC measurements and energy balance closure during May-September.

\begin{tabular}{|c|c|c|c|c|c|c|c|c|c|c|c|c|}
\hline & \multicolumn{6}{|c|}{ Pre-treatment } & \multicolumn{3}{|c|}{ Partial harvest } & \multicolumn{3}{|c|}{ Clear-cut } \\
\hline & 2010 & 2011 & 2012 & 2013 & 2014 & 2015 & 2016 & 2017 & 2018 & 2016 & 2017 & 2018 \\
\hline Coverage of $\mathrm{H}[\%]$ & 55.4 & 60.2 & 73.7 & 66.7 & 54.0 & 68.9 & 22.7 & 17.4 & 16.1 & 28.1 & 35.4 & 22.3 \\
\hline Coverage of LE [\%] & 48.3 & 52.1 & 63.4 & 53.2 & 42.3 & 58.1 & 22.1 & 16.0 & 15.0 & 28.0 & 35.2 & 22.3 \\
\hline Energy balance closure $[-]^{\mathrm{a}}$ & 0.99 & 0.93 & 1.03 & 0.93 & 0.97 & 0.99 & 1.00 & 1.03 & 1.14 & 0.82 & 0.82 & 0.79 \\
\hline
\end{tabular}

a slope of the linear least-squares regression of half-hourly $(H+L E)$ against $\left(R_{n}-G\right) H=$ sensible heat flux; $L E=$ latent heat flux; $R_{n}=$ net radiation; $G=$ ground heat flux.

meteorological time series.

Downwelling longwave radiation $\left(\mathrm{LW}_{\mathrm{d}}\right)$ was recorded since 2013 at the Tervalamminsuo mire (CGR4 Pyrgeometer, Kipp \& Zonen), ca. $1 \mathrm{~km}$ northeast of the study site. Before 2013 and for gaps in data, $\mathrm{LW}_{\mathrm{d}}$ was estimated from air temperature and atmospheric emissivity with cloudcover fraction derived from $\mathrm{R}_{\mathrm{g}}$ following Song et al. (2009). The method proposed by Song et al. (2009) was also applied for decomposing measured $\mathrm{R}_{\mathrm{g}}$ into its direct and diffuse components. A constant $\mathrm{CO}_{2}$ mixing ratio of $400 \mathrm{ppm}$ was used as model input.

\subsubsection{Energy balance components and gross primary production}

The two EC setups were used to measure vertical ecosystem-atmosphere fluxes of $\mathrm{CO}_{2}$, sensible heat $(\mathrm{H})$ and latent heat (LE) (Fig. 1). The $25.5 \mathrm{~m}$ high central EC mast provided data for the pretreatment period (2010-2015) and for the partial harvest thereafter (Mar 2016-Dec 2018). The lower $2.75 \mathrm{~m}$ EC mast provided data for the clear-cut site (Apr 2016-Dec 2018) (Korkiakoski et al., 2019a). The study design did not enable detecting turbulent fluxes $\left(\mathrm{CO}_{2}, \mathrm{H}\right.$ and $\left.\mathrm{LE}\right)$ with EC from the control area after harvesting. The measurement setup also included net radiation $\left(\mathrm{R}_{\mathrm{n}}\right)$ at both EC stations (Nr-lite net radiometer, Kipp \& Zonen), as well as reflected shortwave radiation at the central EC mast (Pyranometer CMP3, Kipp \& Zonen). Ground heat flux (G) was measured at each parallel site from one location at a depth of $0.07 \mathrm{~m}$ (HFP01, Hukseflux Thermal Sensors B.V., Delft, the Netherlands). The relation between energy fluxes can be expressed as the surface energy balance:

$\underbrace{(1-\alpha) R_{g}+\varepsilon_{s}\left(L W_{d}-\sigma T_{s}^{4}\right)}_{R_{n}}=H+L E+G+\frac{d F}{d t}$

where $\alpha$ is broadband albedo, $\varepsilon_{\mathrm{s}}$ is emissivity, $\sigma$ is the Stefan-Boltzman constant, $\mathrm{T}_{\mathrm{s}}$ is effective surface temperature, and $\mathrm{dF} / \mathrm{dt}$ is the change in energy storage within the aboveground vegetation, air volume, and topsoil above the depth of $\mathrm{G}$ measurements.

The EC system setup and data processing for the clear-cut site was described in detail by Korkiakoski et al. (2019a). This system included a three-axis sonic anemometer (uSonic-3 Scientific, METEK, Elmshorn, Germany) for wind speed and air temperature and a closed-path infrared gas analyzer (LI-7000, LI-COR Biosciences, Lincoln, NE, USA) for $\mathrm{CO}_{2}$ and $\mathrm{H}_{2} \mathrm{O}$ mixing ratios. The system at the central EC mast had the same gas analyzer model, but a different sonic anemometer (METEK USA-1, METEK).

Half-hourly turbulent fluxes of $\mathrm{H}$ and LE were calculated from the EC data and filtered using standard methods (Aubinet et al., 2012). The $10 \mathrm{~Hz}$ raw data were block-averaged, and a double rotation of the coordinate system was applied (McMillen, 1988). The time lags between anemometer and gas analyzer were determined by a cross correlation analysis. $\mathrm{CO}_{2}$ fluxes were calculated from the dry mixing ratios to eliminate water vapor fluctuations (Webb et al., 1980). The transfer function method of Moore (1986) with an empirically determined time response of each measurement system was used to compensate for the attenuation of high-frequency fluctuations (Korkiakoski et al., 2019a). The flux data from both sites were screened according to the following criteria: relative stationarity (Foken and Wichura, 1996) $<100 \%$, internal analyzer pressure $>60 \mathrm{kPa}$ (central mast) or $>75 \mathrm{kPa}$ (clear- cut), $\mathrm{CO}_{2}$ mixing ratio $>350 \mathrm{ppm}$, wind direction within 90-300 (central mast after partial harvest) or $80-315^{\circ}$ (clear-cut), and number of spikes in the vertical wind speed and $\mathrm{CO}_{2}$ concentration data $<150$ of 18,000 . Periods of weak turbulence were discarded by applying a friction velocity limits of $0.125 \mathrm{~m} \mathrm{~s}^{-1}$ at the clear-cut and $0.225 \mathrm{~m} \mathrm{~s}^{-1}$ at the central mast. The flux footprints were calculated using the model by Kormann and Meixner (2001) and input data measured with the sonic anemometer. The footprint accumulated within the target area was required to exceed $75 \%$ to ensure the measured flux originated predominantly from the target site. At the central EC mast in January 2012, heating of the anemometer was switched on, which is known to affect especially fluxes of $H$ (Goodrich et al., 2016). Here, the effect seemed to be a rather constant overestimation of ca. $33 \mathrm{~W} \mathrm{~m}^{-2}$ and thus, after January 2012, H was corrected accordingly.

Data coverage of the EC measurements was considerably lower for the post- than the pre-treatment years (Table 3, see Figs. S1-S6 in the Supplement for full visualization of data), because of occasional instrument failures and unavoidable wind direction filtering. The coverage was higher during daytime (zenith angle $<90^{\circ}$ ) than nighttime: $65-74 \%$ vs. $27-40 \%$ during pre-treatment, $23-25 \%$ vs. $6 \%$ at partial harvest, and $35 \%$ vs. $15 \%$ at clear-cut, respectively. $78 \%, 42 \%$ and $66 \%$ of the missing values occurred during gaps shorter than one day long in the pre-treatment, partial harvest and clear-cut data, respectively. Each treatment had a few gaps longer than 14 days, the longest (38 days) occurring in 2018 at the partial harvest.

In the analyses of EC data, we primarily use measured half-hourly $\mathrm{LE}$ and $\mathrm{H}$ fluxes but also daily fluxes (for days with $>50 \%$ of measurements available) and estimates of cumulative ET. For the latter two purposes, LE and $\mathrm{H}$ fluxes were gap-filled using the REddyProc online tool (Wutzler et al., 2018). It applies marginal distribution sampling for gap-filling, which consists of a combination of look-up tables (based on global radiation, air temperature and vapor pressure deficit) and mean diurnal variation of fluxes. For seasonal ET, we additionally present the uncertainty of the estimates that is based on the variability of the halfhourly fluxes associated with the bins used for gap-filling (Wutzler et al., 2018). Uncertainties were aggregated to seasonal values accounting for correlations between records.

The energy balance closure in May-September (Table 3) was evaluated as the slope of the linear least-squares regression of half-hourly $\mathrm{H}$ $+\mathrm{LE}$ against $\mathrm{R}_{\mathrm{n}}-\mathrm{G}$ without considering storage terms (Leuning et al., 2012). At the central EC mast, energy balance closure was close to 1.0 except for the year 2018 (1.14), while at the clear-cut site, it was about 0.8 .

In addition to energy fluxes $\left(R_{n}, H, L E\right.$, and $\left.G\right)$, we also used gross primary production (GPP) to assess the model performance during the pre-treatment period and the role of vegetation recovery after partial harvest and clear-cut. Half-hourly GPP values were estimated from the measured $\mathrm{CO}_{2}$ fluxes by partitioning them using the environmental response functions and procedures described by Minkkinen et al. (2018) and Korkiakoski et al. (2019a). In short, the measured $\mathrm{CO}_{2}$ flux, i.e. net ecosystem exchange, was assumed to be the sum of ecosystem respiration and GPP, which were modelled as a function of air temperature and photosynthetically active radiation, respectively. In the modeldata comparison of half-hourly turbulent fluxes, we excluded time periods with $>5 \mathrm{~mm}$ of rainfall within the last $24 \mathrm{~h}$ to avoid the 
uncertainties introduced by wet-canopy conditions to EC measurements (Kang et al., 2018; van Dijk et al., 2015).

\subsubsection{WTL and water balance components}

The distance of the water table from the soil surface, WTL, was monitored since May 2010 with four automatic loggers (TruTrack WTHR, Intech Instruments Ltd, Auckland, New Zealand) located around the central EC mast (Fig. 1). Additionally, four loggers (Odyssey Capacitance Water Level Logger, Dataflow Systems Limited, Christchurch, New Zealand) were installed on each site in December 2014 or July 2015 (clear-cut site). The four loggers were installed on transects running from the mid-strip to ditch (Fig. 1). All loggers recorded WTL at an hourly interval. The paired catchment approach (e.g., Kaila et al., 2014) was used to produce post-treatment WTL data that were comparable to the pre-treatment data (details in Appendix B).

Discharge was measured at an hourly interval since March 2012 using a V notch weir $\left(90^{\circ}\right)$ and a capacitance water level logger (TruTrack WT-HR). The weir was located at the southwest end of the area (Fig. 1). The water level data was calibrated against manual measurements taken at regular intervals, and discharge was calculated using the stage-discharge relationship. The weir design limited discharge measurements to $601 \mathrm{~s}^{-1}$, corresponding to a runoff of $1.3 \mathrm{~mm}$ $\mathrm{h}^{-1}$. For the rare cases of higher discharge, this maximum value was applied. The discharge was converted to runoff using the estimated weir catchment area of 17.1 ha.

To calculate the May-September water balance during the pretreatment period, measured WTLs were converted into changes in soil water storage (dS/dt) using the hydraulic characteristics defined in Table 2 and assuming that soil water in unsaturated peat profile is in hydraulic equilibrium. The resulting change in soil water storage was compared to precipitation (P), runoff $(\mathrm{Q})$ and EC-based ET as defined by the water balance equation:

$\frac{d S}{d t}=P-(E T+Q)$

\section{Results and discussion}

\subsection{Meteorological conditions}

The meteorological conditions during the growing seasons of 2010-2018 varied considerably (Table 4). The third post-treatment year 2018 was in many ways extreme; it had the highest mean air temperature, VPD and $\mathrm{R}_{\mathrm{g}}$, resulting in largest equilibrium evaporation (ET eq; calculated following McNaughton and Jarvis (1983)). Precipitation during May-September was also the lowest in 2018. The year 2010 had the highest pre-treatment $\mathrm{ET}_{\text {eq }}$, and the year 2012 the lowest. The summer of 2014 was the rainiest ( $411 \mathrm{~mm}$ ), while 2017 was the coldest and most humid growing season.

Table 4

Meteorological characteristics in May-September during 2010-2018 ${ }^{\text {a }}$

\begin{tabular}{llllllllll}
\hline $\begin{array}{l}\text { Period } \\
\text { Year }\end{array}$ & \multicolumn{3}{c}{ Pre-treatment } & & & \multicolumn{5}{c}{ Post-treatment } \\
& 2010 & 2011 & 2012 & 2013 & 2014 & 2015 & 2016 & 2017 & 2018 \\
\hline $\mathrm{T}_{\text {air }}\left[{ }^{\circ} \mathrm{C}\right]$ & 14.5 & 14.4 & 12.7 & 14.3 & 13.6 & 12.7 & 14.1 & $\underline{12.1}$ & $\mathbf{1 5 . 5}$ \\
$\mathrm{VPD}[\mathrm{kPa}]$ & 0.53 & 0.45 & 0.38 & 0.45 & 0.43 & 0.38 & 0.43 & $\underline{0.37}$ & $\mathbf{0 . 6 5}$ \\
$\mathrm{R}_{\mathrm{g}}[\mathrm{W} \mathrm{m}$ & -2 \\
$\left.\mathrm{P}_{[\mathrm{mm}}\right]$ & 182 & 179 & $\underline{176}$ & 182 & 179 & 179 & 178 & 181 & $\mathbf{1 9 9}$ \\
$\mathrm{ET}_{\text {eq }}[\mathrm{mm}]^{\mathrm{b}}$ & 306 & 376 & 324 & 245 & $\mathbf{4 1 1}$ & 285 & 315 & 290 & $\underline{212}$ \\
& 348 & 337 & $\underline{314}$ & 341 & 332 & 320 & 329 & 318 & $\mathbf{3 8 9}$ \\
\hline
\end{tabular}

a The minimum value is underlined and maximum value bolded for each variable.

b Calculated following McNaughton and Jarvis (1983) using net radiation $\mathrm{R}_{\mathrm{n}}=0.67 \mathrm{R}_{\mathrm{g}}-21$ (see Fig. 7a)

$\mathrm{T}_{\mathrm{air}}=$ air temperature; VPD = vapor pressure deficit; $\mathrm{R}_{\mathrm{g}}=$ global radiation; $\mathrm{P}=$ precipitation; $\mathrm{ET}_{\mathrm{eq}}=$ equilibrium evaporation.

\subsection{Pre-treatment period and model validation}

According to measurements, mid-growing season $\mathrm{R}_{\mathrm{n}}$ was about $60 \%$ of $R_{g}$ during the pre-treatment period (Fig. 3a). Partitioning of $R_{n}$ into its components showed distinct seasonal patterns (Fig. 3a-d). The daily mean $\mathrm{H}$ peaked before mid-June, while LE reached its peak in July. G increased sharply after snowmelt in April-May and had a decreasing trend thereafter. The relation between $\mathrm{H}$ and LE is typically expressed as the Bowen ratio $(\beta=\mathrm{H} / \mathrm{LE})$, whose seasonal dynamics are shown in Fig. 3e. H dominated over LE until mid-June $(\beta>1)$, while the opposite was true thereafter. The Priestley-Taylor parameter $\left(\alpha_{\mathrm{pt}}=\mathrm{ET} /\right.$ $\mathrm{ET}_{\text {eq }}$; Fig. 3f) indicates that $\mathrm{ET}$ was close to $\mathrm{ET}_{\mathrm{eq}}$ from mid-June to late August. The observed $\beta$ and $\alpha_{\mathrm{pt}}$ are in the range previously reported for boreal coniferous forests (Amiro, 2001; Launiainen et al., 2016). The seasonal patterns are in line with observations for boreal forests and managed peatland ecosystems (Alekseychik et al., 2018; Arneth et al., 2006; Launiainen, 2010), where stomatal control of LE and energy partitioning are affected by dormancy recovery in early growing season (Kolari et al., 2007; Launiainen, 2010).

The model reproduced the seasonal energy flux dynamics and the mean diel cycles reasonably well (Figs. 3 and 4). However, $R_{n}$ was systematically overestimated during daytime (Fig. 4a) resulting in a ca. $20 \mathrm{~W} \mathrm{~m}^{-2}$ overestimation of daily averages (Fig. 3a). As the net shortwave radiation was well reproduced (Fig. 4b), the slight mismatch in $R_{n}$ is most likely due to the longwave radiation balance, which may be attributed by the absence of downwelling longwave radiation measurements at the site (see Section 2.3.2). The lowest coefficient of determination $\left(R^{2}=0.60\right)$ was between the modelled and measured LE (Fig. 4d). This was likely caused by the presence of interception evaporation events, which cause high peaks in the modelled LE that are difficult to capture on a half-hourly time scale because of uncertainties in precipitation input and in EC measurements during wet-canopy conditions (Kang et al., 2018; van Dijk et al., 2015). The comparison already excluded time periods with $>5 \mathrm{~mm}$ of rainfall within the last $24 \mathrm{~h}$ but limiting the data even further to time periods with no rainfall within the last $24 \mathrm{~h}$, improved the fit to $\mathrm{R}^{2}=0.68$. The additional slight mismatch in the diel cycles of H, LE and GPP (Fig. 4c, $d$ and f) may be related to the inertia in the response of stomatal control to the surrounding microclimate, which is not accounted for in the coupled leafscale photosynthesis-stomatal control model applied in pyAPES.

ET was the dominant component of the May-September water balance, exceeding even precipitation during all growing seasons except 2011 and 2014 (Fig. 5a). Over the growing season, the measured and modelled ET were $85-108 \%$ and $96-104 \%$ of $\mathrm{ET}_{\text {eq }}$ (Table 4), respectively. This is typical for boreal forests on both peat and mineral soils at similar latitudes, where ET is commonly reported to exceed growing season precipitation (Grelle et al., 1997; Launiainen, 2010; Sarkkola et al., 2013). Since 2012, when runoff data were available from the site, water balance was closed reasonably well $(-11 \% \ldots+7 \%)$ by the measurements (Fig. 5a). The presented water balance components are expected to close the water balance as we only consider the snow-free growing season. The most significant storage delaying water flow through the system during this time is the soil water storage, which was here computed from WTL based on assumptions presented in Section 2.3.4. Both the EC measurements and model showed highest ET in 2010 (Fig. 5a-b); this was the warmest and driest summer during the pre-treatment period (Table 4). On the other hand, the most humid and coldest summers (2012 and 2015) produced the lowest modelled ET, while the lowest measured ET occurred during the rainiest summer (2014). This difference can be caused by underestimated EC-based ET during wet-canopy conditions when evaporation of intercepted rainfall is significant (Kang et al., 2018; van Dijk et al., 2015).

According to the modeling, total transpiration was on average $64 \%$ of growing season ET (Fig. 5b), and tree stand transpiration covered $59 \%$ of ET. This agrees with earlier findings from boreal forests that show tree stand transpiration is $39-48 \%$ of ET in more northern 

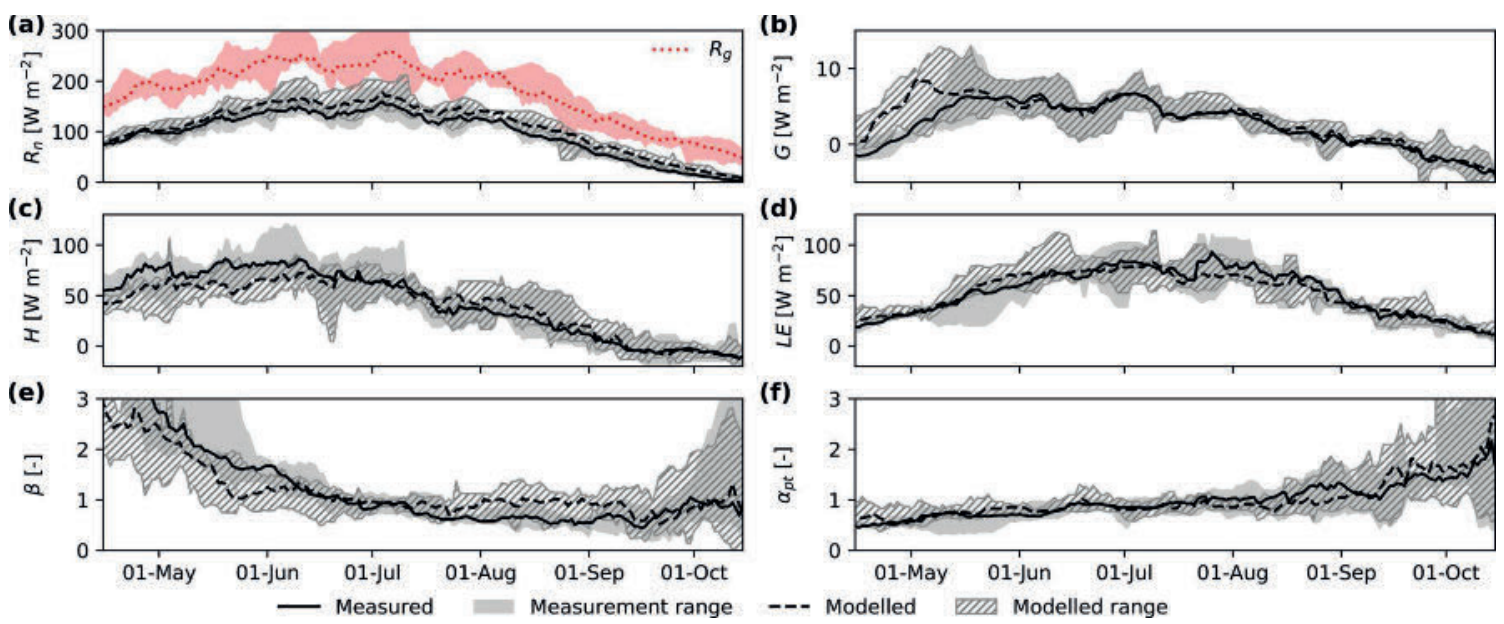

Fig. 3. Seasonal dynamics of variables characterizing the surface energy balance during the pre-treatment period 2010-2015: (a) net raditation, $R_{n}$, and global raditaion, $R_{g}$; (b) ground heat flux, $G$; (c) sensible heat flux, H; (d) latent heat flux, LE; (e) Bowen ratio, $\beta$; (f) Priestley-Taylor parameter, $\alpha_{\mathrm{pt}}$. Shaded areas show the range of yearly 14-day rolling means and the lines show the median values. The days with more than $50 \%$ of gap-filling and with $>5.0$ mm of rainfall are excluded. Bowen ratio only includes periods when zenith angle was $<90^{\circ}$.
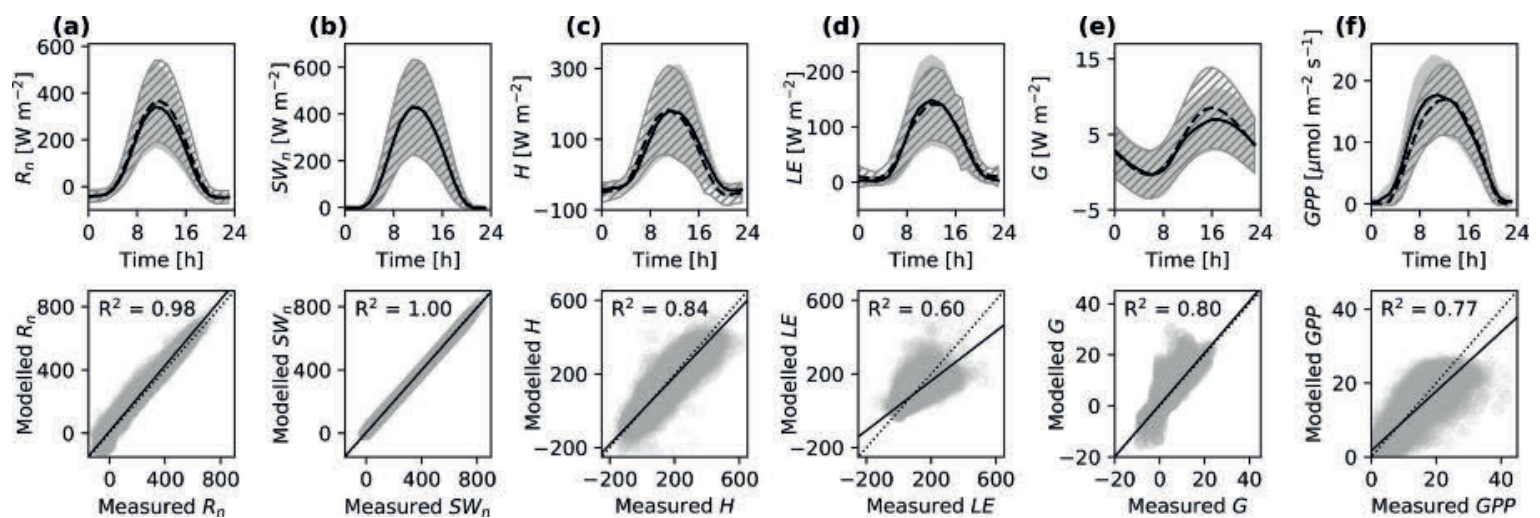

Fig. 4. Mean diel cycles of measured (solid line \pm standard deviation as gray shade) and modelled (dashed line \pm standard deviation as hatched lines) fluxes, and scatter plots of modelled vs. measured fluxes: (a) net radiation, $\mathrm{R}_{\mathrm{n}}$; (b) net shortwave radiation, $\mathrm{SW}_{\mathrm{n}}$; (c) sensible heat flux, $\mathrm{H}$; (d) latent heat flux, LE; (e) ground heat flux, G; and (f) gross primary production, GPP. Plots include data from May-September, excluding periods with $>5.0$ mm of rainfall within the past $24 \mathrm{~h}$. Linear least-squares regressions are fitted to the half-hourly data (black line), 1:1 line shown as dotted, and $\mathrm{R}^{2}$ denotes the coefficient of determination.

locations (Kozii et al., 2019; Sarkkola et al., 2013) and 65\% in a more southern location (Grelle et al., 1997) compared to the location of Lettosuo. The model suggested that transpiration by the dominant pines was $47 \%$ and by birches $27 \%$ of total transpiration. The undergrowth spruces with just $15 \%$ smaller LAI than pine contributed only by $17 \%$ and field layer vegetation by $9 \%$. This suggests that suppressed spruces and field layer vegetation have a minor role in a mature forest, but may have potential to increase their transpiration when the canopy opens up, as reported for undergrowth spruces by Lagergren and Lindroth (2004) following thinning.

The measured WTL ranged from $-0.1 \mathrm{~m}$ during spring down to $-0.7--0.5 \mathrm{~m}$ in late summer (Fig. 5c). Average WTL in August was $-0.54 \mathrm{~m}$. This is in line with late summer WTL measured in managed peatland forest in southern Finland with tree stand volumes exceeding $200 \mathrm{~m}^{3} \mathrm{ha}^{-1}$ (Sarkkola et al., 2010) as in Lettosuo. The model reproduced the measured WTL with reasonable accuracy (Fig. 5c); the mean absolute error during May-September ranged from 0.03 to $0.09 \mathrm{~m}$ depending on the year. Overall, the comparisons between model predictions and measurement-based observations, and the outcomes being well in line with earlier studies in boreal forests, suggest that the model can be used to support the evaluation of harvest-induced effects.

\subsection{Responses to harvesting}

\subsubsection{Observed WTL and ET}

After harvesting, the largest WTL differences between the sites occurred during June-September while the differences were the smallest during the snowmelt period in April (Fig. 6). At the clear-cut site, WTL was up to $0.45 \mathrm{~m}$ higher compared to the control site. At the partial harvest site, the WTL rise was never more than $0.15 \mathrm{~m}$, even though the partial harvest reduced the basal area by $70 \%$ and LAI by $50 \%$. The smallest WTL differences between treatments were observed during the coldest and most humid growing season 2017. The exceptionally warm and dry 2018 yielded the largest differences, as well as the lowest WTL observed during the whole study period 2010-2018 (Figs. 5c and 6a). Compared to the control site, the average WTL rise for May-September during the post-treatment period (2016-2018) was $0.05 \pm 0.03 \mathrm{~m}$ and $0.18 \pm 0.02 \mathrm{~m}$ at the partial harvest and clear-cut sites, respectively 

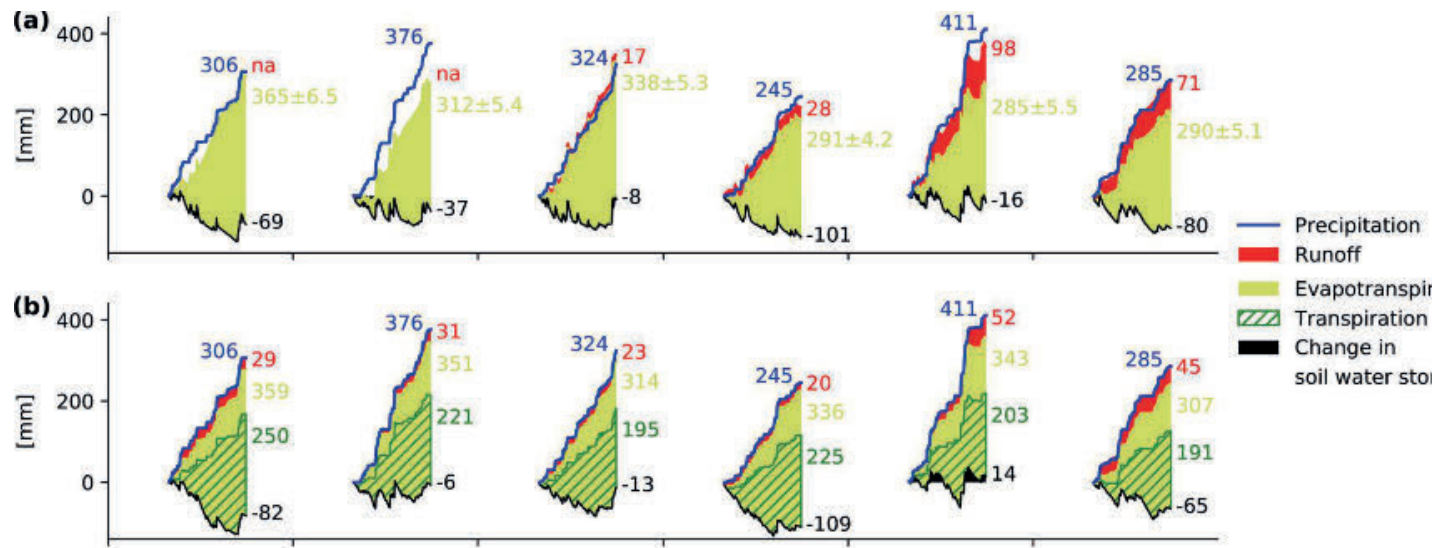

Evapotranspiration
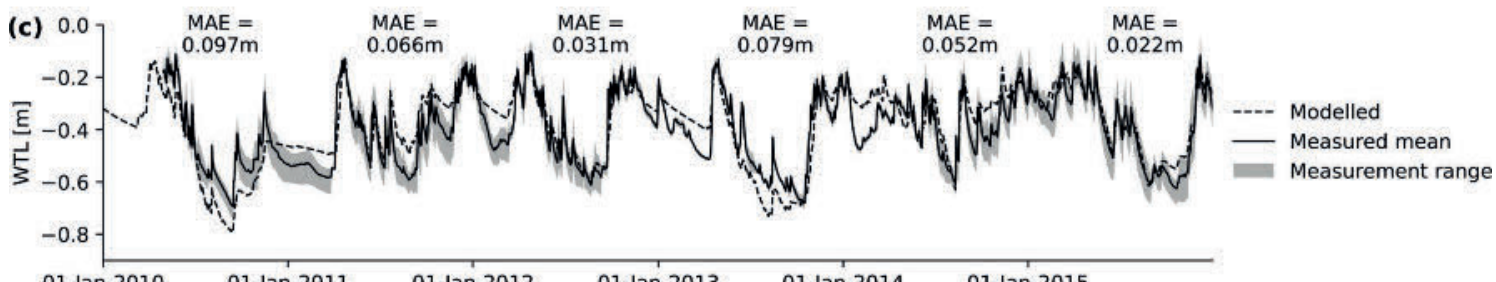

$$
\text { 01-Jan-2010 01-Jan-2011 01-Jan-2012 01-Jan-2013 01-Jan-2014 01-Jan-2015 }
$$

Fig. 5. Cumulative water balance during May-September for the pre-treatment period according to (a) measurements, and (b) model results; and (c) comparison of measured and modelled daily water table level (WTL). Error estimates of seasonal evapotranspiration (a) are derived from eddy-covariance data processing (see Section 2.3.3.). MAE denotes the mean absolute error of the modelled WTL in May-September. na = not available.

(error estimate is the standard deviation derived from the WTL measurements).

Seasonal cumulative ET derived from the EC measurements suggested that ET was about 30\% lower at the clear-cut than at the partial harvest in 2016 and 2018 (Table 5). In 2017, however, ET was about the same for both sites (Table 5), which is inconsistent with the WTL observations (Fig. 6). The uncertainty induced by gap-filling to seasonal
ET due to the low coverage of EC measurements (Table 3) is likely causing this inconsistency. The larger ET uncertainty estimates during the post-treatment (Table 5) compared to pre-treatment (Fig. 5) indicate this to some extent, although the uncertainty caused by filling longer gaps is not included in the error estimates. Compared to the modelled ET of the non-harvested control stand, ET changes after both harvests were largest during the first post-treatment year 2016

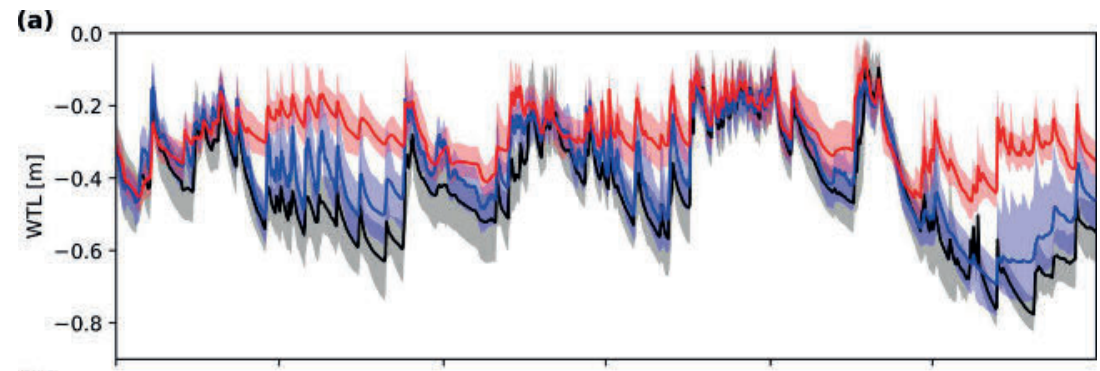

(b)

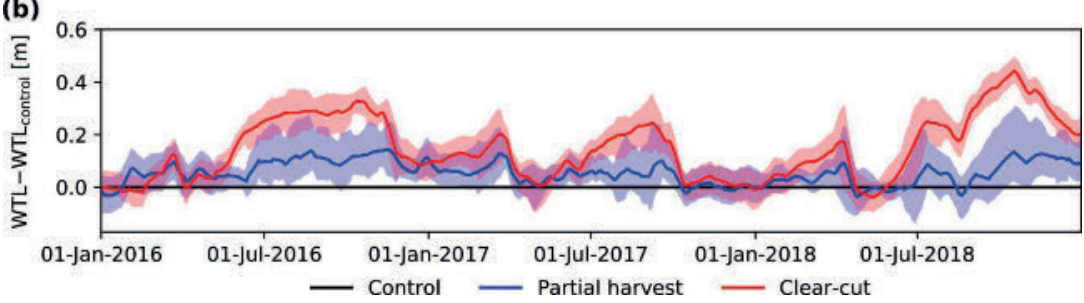

Fig. 6. (a) Post-treatment water table level (WTL) at each site, and (b) its difference compared to the control site as 14-day rolling mean. Lines and shaded areas indicate the mean and variability range of WTL measurements. 
Table 5

Cumulative May-September evapotranspiration (ET) for the three post-treatment years. Error estimates are derived from eddy-covariance data processing (see Section 2.3.3.).

\begin{tabular}{llll}
\hline & $\begin{array}{l}\text { ET }[\mathrm{mm}]^{\mathrm{a}} \\
\text { Year }\end{array}$ & 2016 & 2018 \\
\hline Partial harvest $^{\mathrm{a}}$ & $264 \pm 9.5$ & $263 \pm 6.4$ & $388 \pm 14.3$ \\
Clear-cut $^{\mathrm{a}}$ & $176 \pm 8.0$ & $261 \pm 7.4$ & $268 \pm 8.1$ \\
Control $^{\mathrm{b}}$ & 320 & 294 & 380 \\
\hline
\end{tabular}

${ }^{\text {a }}$ Based on eddy-covariance measurements.

b Modelled.

(Table 5). In 2018, ET at the partial harvest was similar to the control site but at the clear-cut it was still clearly lower.

The significant rise of WTL after clear-cut, that is commonly observed in peatlands (Dubé et al., 1995; Heikurainen, 1967; Jutras and Plamondon, 2005; Sarkkola et al., 2013), is addressed in operational peatland forestry by recommending ditch cleaning soon after clear-cut to maintain efficient drainage. The notably smaller WTL rise after partial harvest suggests ditch cleaning may not be necessary, which is a strong environmental and economical benefit compared to clear-cutting (Nieminen et al., 2018). The necessity of ditch cleaning in connection with partial harvest was questioned already by Päivänen and Sarkkola (2000) after their experiment where up to $30 \%$ of the stand volume was removed. Heikurainen and Päivänen (1970) reported that removing $60 \%$ of the volume of a Scots pine stand resulted in a WTL rise that was half of the response observed at a parallel clear-cut site. Here the observed WTL rise at the partial harvest was about $30 \%$ of that at the parallel clear-cut site (Fig. 6b), thus less drastic than the WTL rise after partial harvest observed by Heikurainen and Päivänen (1970).

\subsubsection{Impacts on energy balance}

Compared to the pre-treatment conditions, $R_{n}$ decreased after both harvests (Figs. 7a and 8a). At the partial harvest site, the change was smaller than at the clear-cut but still statistically significant (evaluated as $95 \%$ confidence interval of regression curve coefficients in Fig. 7a). Two factors may jointly decrease $R_{n}$ : (1) increased albedo and decreased absorption of solar radiation and (2) increased emittance of longwave radiation as a result of increased surface temperature (see Eq. (1)). Ecosystem-scale albedo, computed from the reflected vs. incoming $\mathrm{R}_{\mathrm{g}}$ measured at the central EC mast, indicated that mean growing season albedo increased from 0.09 to 0.12 after partial harvest. The increase in albedo with decreasing LAI is in line with what has been observed across boreal coniferous stands (Kuusinen et al., 2014; Lukeš et al., 2013). Thus, about half of the decrease in $R_{n}$ after partial harvest may be attributed to albedo changes. The albedo was not measured at the clear-cut site, but the decrease in $R_{n}$ there should be affected both by increased albedo and increased surface temperature (Mamkin et al., 2019; McCaughey, 1981).

Both $\mathrm{H}$ and LE were significantly reduced after the clear-cut (Figs. 7b-c and $8 \mathrm{~b}-\mathrm{c}$ ), as could be expected based on the results of earlier studies (Amiro, 2001; Mamkin et al., 2019; Rannik et al., 2002). Moreover, their relationship with $\mathrm{R}_{\mathrm{g}}$ became more linear compared to the pre-treatment conditions (Fig. $7 \mathrm{~b}-\mathrm{c}$ ), presumably due to decreased transpiration and stomatal control of LE. After partial harvesting, LE also decreased and $\mathrm{H}$ slightly increased but the changes were marginal compared to the clear-cut (Fig. 8b-c). Especially in 2016, the Bowen ratio increased as a response to decreasing ET at the partial harvest site (Fig. 8b-c). However, the scaling of $\mathrm{H}$ and $\mathrm{LE}$ against $\mathrm{R}_{\mathrm{g}}$ remained unaltered (Fig. $7 \mathrm{~b}-\mathrm{c}$ ). $\mathrm{G}$ had a stronger diurnal amplitude and higher daily net heat flux into the soil at the clear-cut than at the tree-covered sites (Fig. 8d), in line with Amiro et al. (2001) and Mamkin et al. (2019). Even at the clear-cut, G still remained an order of magnitude smaller than $H$ and LE. Marginal changes in $H$ and $R_{n}$ after thinning of a Scots pine stand in southern Finland were also reported by Vesala et al. (2005). The results are also in accordance with Launiainen et al. (2016), who suggested that the sensitivity of boreal forest energy exchange to LAI variations (here created by harvests) is strongest in sparse stands with LAI $<2 \mathrm{~m}^{2} \mathrm{~m}^{-2}$.

\subsubsection{Role of post-treatment vegetation recovery on energy and water balance}

Both at the clear-cut and partial harvest sites the changes in LE, GPP and seasonal ET were most pronounced during the first post-treatment year 2016, and partial recovery of these fluxes occurred thereafter (Fig. 8 and Table 5). To explore to which degree the development of field layer vegetation can explain such trends, the model was run for the treated sites with the treatment-specific characteristics (Fig. 2b and Table 1), where the field layer LAI varies according to the range inferred from the post-treatment vegetation inventories. Additionally, the corresponding model outputs for WTL changes in comparison to measurements were evaluated.

At the clear-cut, the observed LE was within the lower end of the model-predicted range (corresponding to small field layer LAI) in 2016, and within its higher end in 2017 and 2018 (corresponding to increased field layer LAI) (Fig. 8c). Thus, we postulate that the rapid establishment of pioneering ground vegetation species and the consequent increase in LAI (Table 1), which enhances plant water use and rainfall interception, is the likely reason for the increasing LE. Model runs with increased field layer LAI also captured the increase in $R_{n}$ observed at the clear-cut after 2016 (Fig. 8a), which according to the model was a result of decreased surface temperature in response to increased LE, and decreased surface albedo. The role of field layer vegetation establishment is also supported by Fig. 9, where the lower envelope curve representing simulations with high field layer LAI matches the observed WTL changes better in 2017 and 2018. The sensitivity of WTL to field layer LAI at the clear-cut was similar in 2016 and 2017 but much wider during the dry summer 2018 (Fig. 9). The limited effect of field layer LAI on WTL during wet years 2016 and 2017 is because changes in ET are compensated by runoff (Fig. 10b vs. 10d). For example, in 2017 the decrease in field layer LAI results in an ET decrease that is of same magnitude as the increase in runoff, while in 2018 only about half of the ET decrease is compensated by increased runoff. On the other hand, comparison between Fig. 10a and c reveals that at the partial harvest site changes in ET are more directly reflected to WTL because runoff plays a smaller role than at the clear-cut site (Fig. 10b and d).

Contrary to the clear-cut site, the model runs for the partial harvest site with the range of field layer LAI (Table 1) were not able to capture the observed changes during the first post-treatment year 2016. The modelled LE and GPP were overestimated and $\mathrm{H}$ underestimated in 2016 (Fig. 8b-c and e), and correspondingly the change in WTL was underestimated (Fig. 9). This indicates that ET and GPP were restricted due to some other phenomenon in 2016. In the model runs, leaf-level photosynthetic and water-use traits of tree and field layer vegetation species were kept constant in time (Table S2), thus omitting possible feedbacks of altered microclimatic conditions and resource competition on leaf physiology. The chlorophyll fluorescence measured from spruce needles, however, showed lower quantum efficiency of PS II (Fv/Fm) at the partial harvest relative to the control site in 2016 (Fig. 11), especially in one-year old needles. Such decrease in $\mathrm{Fv} / \mathrm{Fm}$ is indicative of a stress response of the photosynthetic apparatus in the shade-adapted spruce undergrowth (e.g., Gnojek, 1992). The needles seemed to adapt rapidly to the altered microclimate, as the difference in Fv/Fm decreased already during the first growing season and leveled out in the 

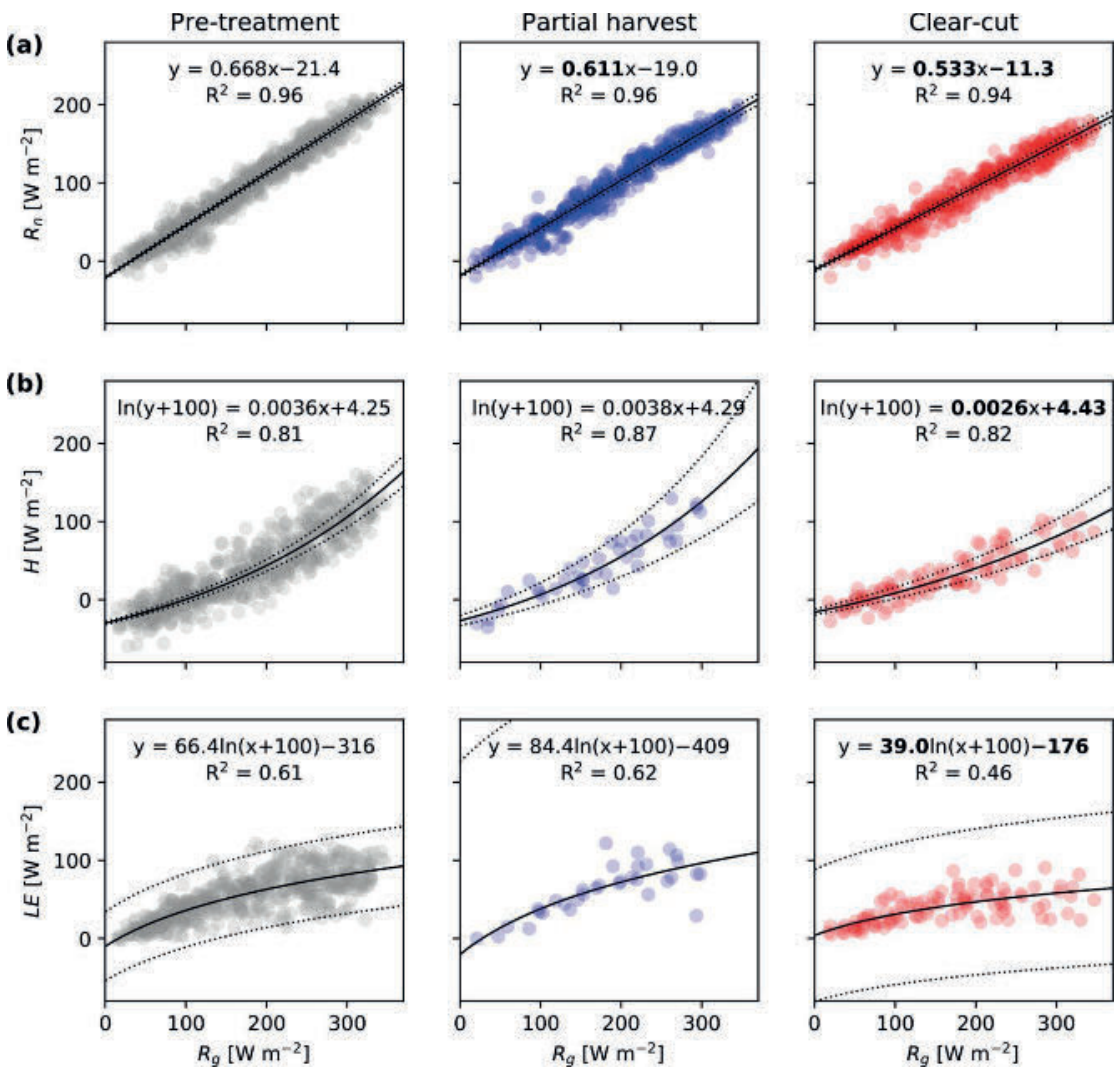

Fig. 7. Dependency of daily measured (a) net radiation, $R_{n}$, (b) sensible heat flux, $H$, and (c) latent heat flux, LE, on global radiation, $R_{g}$, during the pre- and posttreatment periods. $\mathrm{R}^{2}$ denotes the coefficient of determination for the regression curve (least-squares); the regression coefficients differing significantly from pretreatment values are shown in bold font. Dotted lines show the 95\% confidence intervals. To avoid uncertainty induced by gap-filling, only days in May-September with less than $50 \%$ of gap-filled observations are included.

second post-treatment year (Fig. 11), which is surprisingly fast (cf. Gnojek, 1992). It is likely that field layer vegetation undergoes a similar stress period, and if leaf marginal water use efficiency (i.e. change of photosynthesis per unit change of transpiration) is not significantly altered after partial harvest, the reduced photosynthetic $\mathrm{CO}_{2}$ demand of previously shade-adapted vegetation layers will results in lower stomatal conductance and transpiration rate (Medlyn et al., 2011). A stronger reduction in stand transpiration during the first year after forest thinning has also been reported in earlier studies (Bréda et al., 1995; Lagergren et al., 2008).

\subsection{Generalizing the role of tree stand in controlling ET and WTL}

The nine-year measurements at Lettosuo showed strong seasonal and inter-annual variability in WTL (Figs. 5c and 6a). It is therefore important to disentangle the effect of meteorological variability from harvest responses, something that is seldom possible in empirical studies with a limited number of monitored pre- and post-treatment years. The inter-annual variability in mean growing season WTL, cumulative ET and its components caused by meteorological forcing (2010-2018) and LAI changes were predicted based on model runs. In the simulations, tree stand LAI was set to vary from the non-harvested stand to the clear-cut (Fig. 12) while the species composition was kept constant, i.e. pines, spruces, and birches covered $41 \%, 35 \%$ and $24 \%$ of tree stand LAI and their relative LAD profiles were as in Fig. 2a.

This analysis revealed that inter-annual variability of WTL caused by meteorological conditions is much larger than the effect of forest harvesting (Fig. 12a). The role of tree stand LAI on WTL is most pronounced during dry growing seasons, and primarily due to non-linear increase of stand transpiration with LAI (Fig. 12c). During summers with high precipitation and elevated WTL (such as 2014 and 2011), the biological drainage through stand ET has clearly less impact on WTL, resulting into small variations across the simulated LAI range (Fig. 12a). For the same reason, inter-annual variability in WTL decreases with decreasing tree stand LAI (Fig. 12a) and the WTL difference to the control stand varies depending on the year (Fig. 12b). The tree stand volume was shown to have stronger impact on peatland WTL during dry than wet summers also by Sarkkola et al. (2010), meaning that ditch drainage has a more dominant role in the water balance during wet summers.

Depending on the year, the cumulative May-September ET decreased from 294 - to $380 \mathrm{~mm}$ to $192-229 \mathrm{~mm}$ when moving from the non-harvested stand to the clear-cut. This results from the changes in ET components in response to decreasing tree stand LAI (Fig. 12c) (Kozii et al., 2019; Launiainen et al., 2016). First, cumulative rainfall interception responds almost linearly to changes in tree stand LAI 

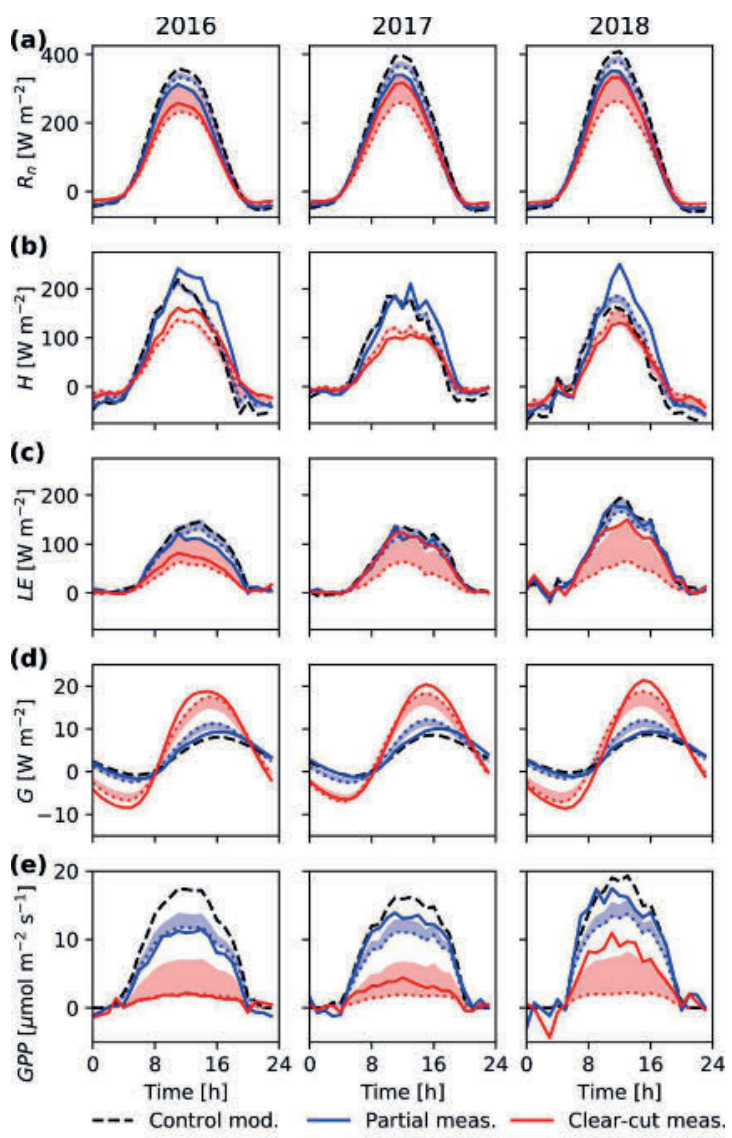

Fig. 8. Measured mean diel cycles at the partial harvest and clear-cut sites during post-treatment growing seasons: (a) net radiation, $\mathrm{R}_{\mathrm{n}}$; (b) sensible heat flux, H; (c) latent heat flux, LE; (d) ground heat flux, G; and (e) gross primary production, GPP. The plotted cycles are based only on such periods during May-September when measurements were available from both sites, excluding periods with $>5.0 \mathrm{~mm}$ of rainfall within the past $24 \mathrm{~h}$. The corresponding model predictions for the non-harvested stand (control) are presented as reference, and the shaded areas show the modelled range for the harvested sites when field layer leaf area index is varied as in Table 1 . Dotted lines represent model results with low field layer leaf area index.

(Mazza et al., 2011). Second, tree stand transpiration decreases nonlinearly and proportionally less than LAI as leaf and tree-level transpiration is enhanced in response to changes in microclimate, increased light availability in particular (Bladon et al., 2006; Bréda et al., 1995;
Lagergren and Lindroth, 2004; Launiainen et al., 2016). For Lettosuo, the model suggests spruce transpiration is roughly doubled after opening the overlying canopy in partial harvest. Third, field layer ET and forest floor evaporation increase non-linearly with reduced tree stand LAI as the lower layers become exposed to more light and wind, and higher VPD. This increase in field layer and forest floor ET has a compensating effect on total ET, that in some cases has led to even an increase in total ET after partial harvest (Boczoń et al., 2016).

The WTL change after partial harvest at Lettosuo falls out of the shaded area shown in Fig. 12b because the species composition and vertical LAD profiles were also drastically changed (Fig. 2). Before harvest, Scots pine with conservative water use strategy and thus low transpiration capacity was the dominant species, while after harvest the stand consisted of birch and spruce. This led to a smaller WTL rise at Lettosuo compared to modelled partial harvest in which the LAI of all species was reduced equally (Fig. 12b). The change in species compositions may also explain why our results show smaller WTL rise compared to earlier results on thinning impacts on pure pine stands (Heikurainen and Päivänen, 1970; Päivänen and Sarkkola, 2000).

To further investigate this, model simulations were next made to replicate alternative harvesting strategies: we started from the nonharvested stand as in Fig. 12 but varied the amount and shares of harvested species until reaching clear-cut conditions (Fig. 13). In other words, we altered the species composition as well as the stand structure. The resulting variation in WTL (Fig. 13a) depended mostly on species composition, reflecting the varying transpiration capacity of the tree species, but was also due to the stand structure, which affected the microclimate within the canopy and conditions for forest floor evaporation (Fig. 13c). The removal of dominant pines was associated with the lower end of the WTL range, while removing birches resulted in the greatest WTL rise with decreasing LAI.

In practical forestry, stand volume and basal area are typical metrics to plan harvests, and therefore it is illustrative to consider also the WTL to basal area relationship (Fig. 13b). It differs from the LAI response as allometric relationships, such as diameter to leaf-mass ratio and specific leaf area, vary among species. Partial harvests may in practice be done in several different ways (Nieminen et al., 2018) that may lead to widely varying remaining basal area and LAI. Fig. 13b shows this can lead to a wide range of WTL depending on structure and species composition of the remaining stand. In practical terms, this means that the initial stand heterogeneity and species water use traits can be utilized in harvest planning in order to preserve sufficient ET capacity and biological drainage to control WTL. Favoring mixed stands when possible and, especially, maintaining an admixture of deciduous species with high leaf to basal area ratio and liberal water use strategy (e.g., Lin et al., 2015) could be a cost-effective way to avoid ditch cleaning and also to support biodiversity in peatland forestry. As naturally regenerated undergrowth birches with high transpiration rate per unit leaf area are a typical feature of peatland forests (Sarkkola et al., 2005), retaining such undergrowth in partial harvests should be considered to keep WTL sufficiently low for undisturbed growth of trees with high quality and economical value.

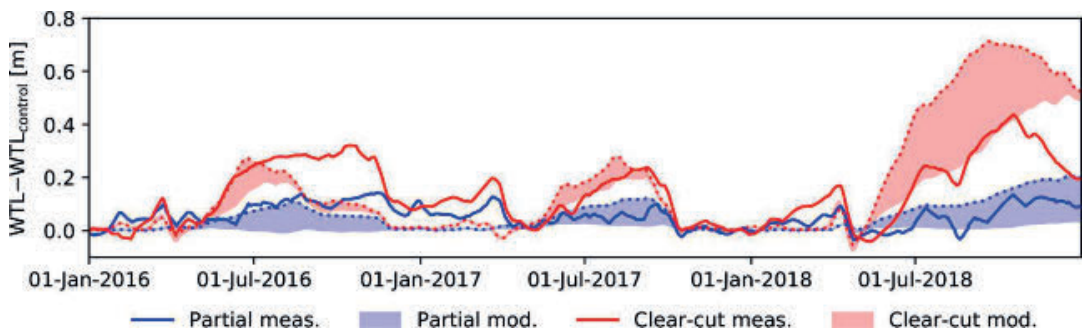

Fig. 9. Mean measured and range of modelled water table level (WTL) difference compared to the control site as 14-day rolling mean during post-treatment years. The shaded areas show the model results when field layer leaf area index is varied as in Table 1 with the dotted line corresponding to the low field layer leaf area index. 
(a) Partial harvest, low field layer LAI

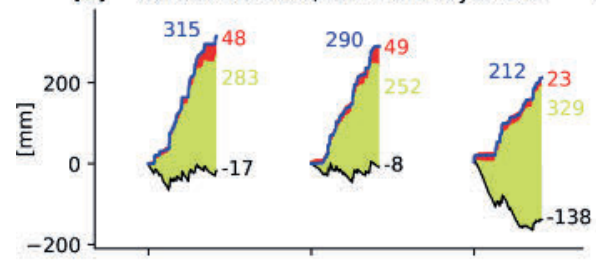

(c) Partial harvest, high field layer LAI

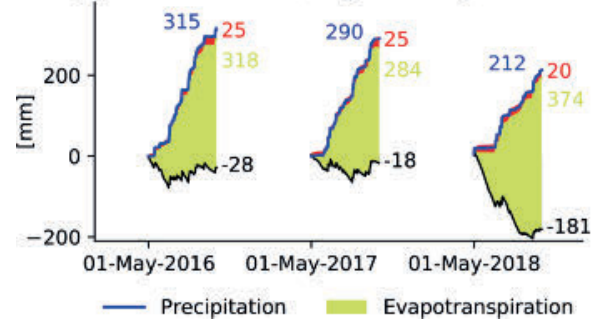

(b)

Clear-cut, low field layer LAl

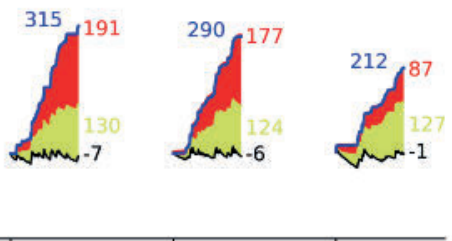

(d) Clear-cut, high field layer LAI

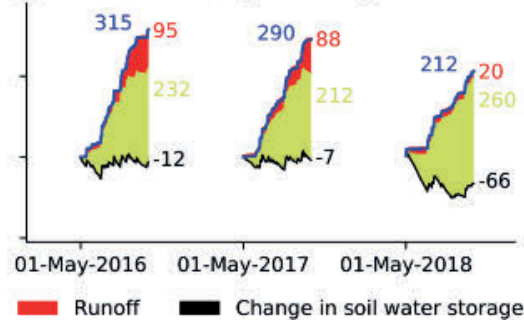

Fig. 10. Cumulative water balance during May-September for the post-treatment period modelled with (a-b) low and (c-d) high field layer leaf area index (LAI) for (a, c) the partial harvest and (b, d) the clear-cut sites. See Table 1 for values of field layer leaf area indices.

\section{Conclusions}

This study aimed to quantify changes in growing season water balance, WTL and energy fluxes after clear-cutting and partial harvest in a drained boreal peatland forest. To this end, WTL and surface-atmosphere energy and $\mathrm{CO}_{2}$ exchange were measured at a fertile mixed peatland forest in southern Finland for six pre-treatment and three post-treatment years. The data analysis was accompanied with soil-plant-atmosphere transfer modeling to explore the causal mechanisms behind the observed changes and to disentangle the vegetation controls on water and energy balance from inter-annual meteorological variability. Regarding the three research questions framed in the introduction, our conclusions are as follows:
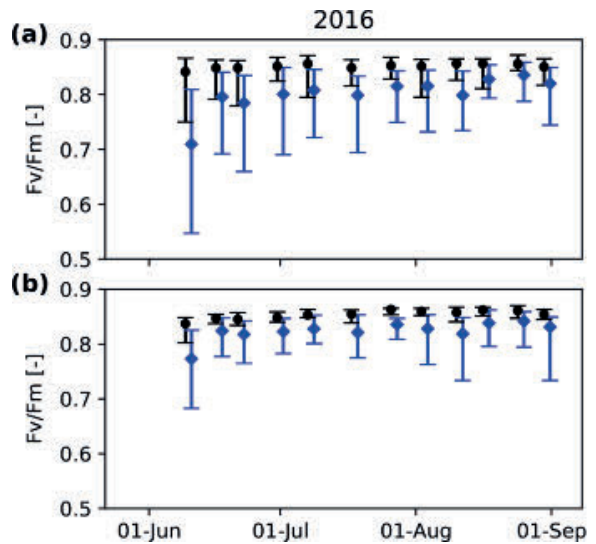

1) After partial harvest, where $70 \%$ of basal area and $50 \%$ of LAI was removed, mean growing season WTL rose by only $0.05 \mathrm{~m}$ compared to the intact stand, while the response was much greater at the clearcut site $(+0.18 \mathrm{~m}) . \mathrm{R}_{\mathrm{n}}, \mathrm{H}$ and LE were significantly reduced and $\mathrm{G}$ increased at the clear-cut site, while changes were surprisingly small at the partial harvest site considering the strong reductions in LAI and basal area. The observed changes in energy fluxes were the strongest during the first post-treatment year and partial recovery occurred already during the second year.

2) According to model predictions, the importance of field layer vegetation on ecosystem water and energy fluxes increased after harvests. At the clear-cut, rapid development of field layer vegetation increased ET, and was likely to alter surface albedo and $\mathrm{R}_{\mathrm{n}}$ after the first post-treatment year. The model-data comparison and
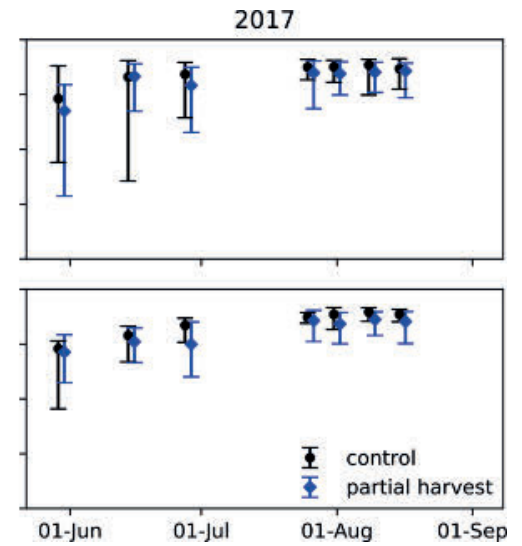

Fig. 11. The chlorophyll fluorescence (Fv/Fm) measured from (a) one-year-old and (b) current-year spruce needles at control and partial harvest sites in 2016 and 2017. Median values and 5...95 percentile ranges are shown as markers and error bars, respectively. 

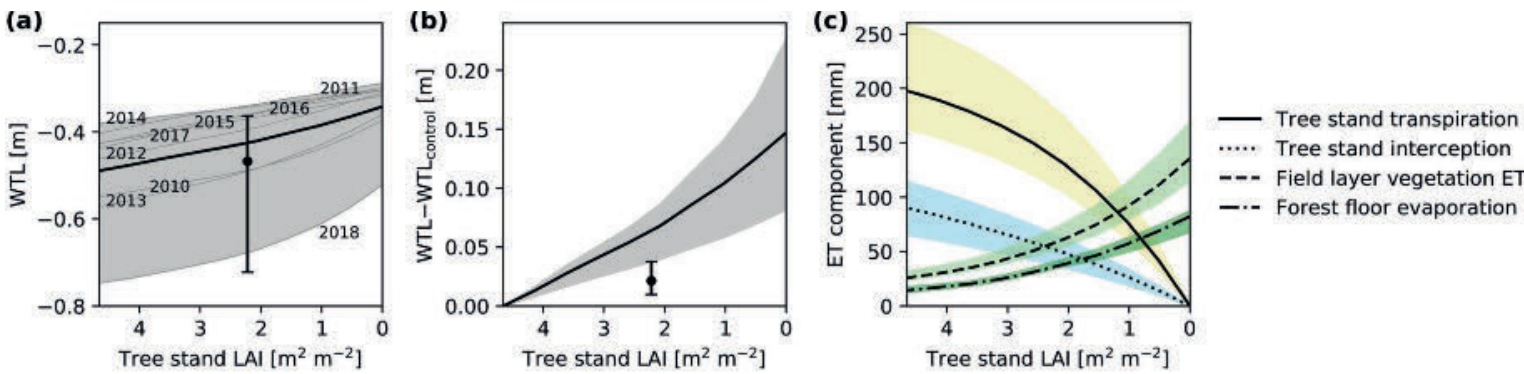

Fig. 12. Modelled (a) mean water table level (WTL), (b) mean WTL difference compared to the non-harvested stand, and (c) cumulative evapotranspiration (ET) components during May-September as a function of tree stand leaf area index (LAI) that is varied from the non-harvested stand ( $4.66 \mathrm{~m}^{2} \mathrm{~m}^{-2}$. Fig. $2 \mathrm{a}$ ) to the clear-cut $\left(0 \mathrm{~m}^{2} \mathrm{~m}^{-2}\right)$ while keeping the species composition constant. Markers in panels a and b show model results for the partial harvest stand (LAI $=2.22 \mathrm{~m}^{2} \mathrm{~m}{ }^{-2}$ Fig. $\left.2 \mathrm{~b}\right)$. The shaded areas and error bars show the effect of meteorological variability during 2010-2018 (years indicated in panel a), and the lines and dots show the corresponding mean values. LAI of field layer vegetation and surface coverage of moss were fixed to $1.0 \mathrm{~m}^{2} \mathrm{~m}^{-2}$ and $40 \%$, respectively.

(a)

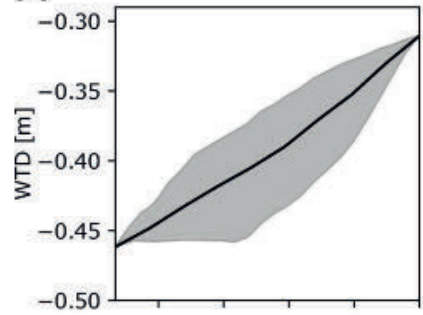

(c)

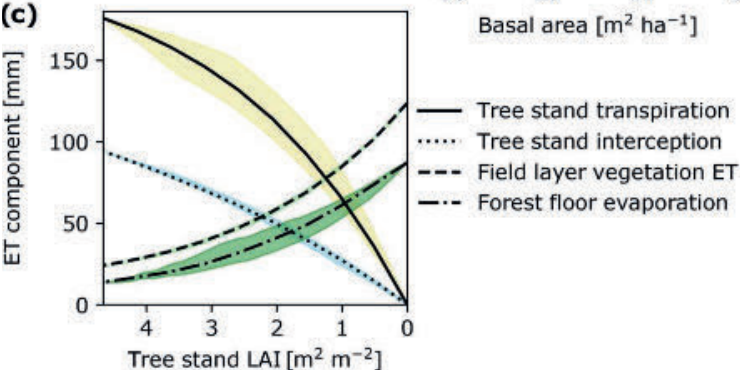

Fig. 13. Modelled (a,b) mean water table level (WTL), and (c) cumulative evapotranspiration (ET) components during May-September 2012 as a function of $(\mathrm{a}, \mathrm{c})$ tree stand leaf area index (LAI) and (b) stand basal area, ranging from the non-harvested stand (Fig. 2a) to the clear-cut. The shaded areas show the variability caused by the species composition of the remaining stand, and the lines show the case with the species composition of the initial stand. LAI of field layer vegetation and surface coverage of moss were fixed to $1.0 \mathrm{~m}^{2} \mathrm{~m}^{-2}$ and $40 \%$, respectively.

chlorophyll fluorescence measurements suggested that transpiration of the shade-adapted spruce undergrowth was reduced during the first post-treatment growing season due to light-induced stress. However, this was ameliorated already during the second posttreatment year. Better understanding of microclimatic variations, plant stress responses and recovery rates would be an important future research topic for considering the applicability of continuous cover forestry on peatlands.

3) The results indicated that the inter-annual variability in meteorological conditions has a stronger impact on mean growing season WTL than decrease in LAI, reflecting the different roles of ditch drainage vs. ET during wet and dry summers. The WTL response to reduced LAI is non-linear, differs between wet and dry summers, and is sensitive to changes in species composition (water use traits). The non-linearity of WTL and energy exchange in response to changes in LAI or basal area emphasizes that the effect of harvesting depends strongly on initial stand structure. Removing overstory pines but leaving spruces and birches with high transpiration capacity at the partial harvest site explained the small WTL rise observed. This implies that accounting for species composition and vegetation structure in management planning can provide additional control on WTL in peatland forests. Especially, preserving naturally regenerated deciduous undergrowth could limit the WTL rise after partial harvest.

\section{Data availability}

Ecosystem flux and meteorological data measured at the central EC mast are available through the ICOS Carbon Portal (10.18160/0jhqbzmu, ICOS Ecosystem Thematic Centre, 2019). Data for the clear-cut site for two post-treatment years are available through Zenodo (10. 5281/zenodo.3384791, Korkiakoski et al., 2019b). WTL and chlorophyll fluorescence data are made available here. The model source code and further data can be obtained from the corresponding author.

\section{Declaration of Competing Interest}

The authors declare that they have no known competing financial interests or personal relationships that could have appeared to influence the work reported in this paper.

\section{Acknowledgments}

This work was supported by the Academy of Finland projects CCFPeat (no. 310203), CLIMOSS (no. 296116 and 307192), and SOMPA, which was funded by the Strategic Research Council at the Academy of Finland (no. 312912); Kone Foundation; the EU LIFE program through LIFE18 CCM/LV/001158 OrgBalt; the Maj and Tor Nessling foundation; and the Ministry of Transport and Communications through the Integrated Carbon Observing System (ICOS) research. The authors wish to acknowledge CSC - IT Center for Science, Finland, for computational resources. The Finnish Meteorological Institute is acknowledged for their openly available meteorological data (Jokioinen, Somero, Salo Kiikala). 


\section{Supplementary materials}

Supplementary material associated with this article can be found, in the online version, at doi:10.1016/j.agrformet.2020.108198.

\section{Appendix A. Deriving stand and understory characteristics for model}

Leaf area density (LAD) distributions for the main tree species (pine, spruce and birch) were derived using crown shape models, and one-sided leaf area indices (LAI) estimated by an allometric method. First, species specific equations for tree height as a function of DBH (Näslund, 1936) and for trunk base height as a linear function of tree height were determined. This was done using the subset of trees that were measured for trunk base and tree height in addition to DBH. LAI for each tree was then derived based on DBH, trunk base height and tree height using foliage biomass functions (Lehtonen et al., 2020; Tupek et al., 2015) and specific leaf area values (Härkönen et al., 2015). Normalized LAD distributions were derived based on species, tree height and trunk base height (Tahvanainen and Forss, 2008). LAD for each species was obtained as a sum of all individual tree LAD distributions of that species. The LAI and LAD for each species in 2014 and after partial harvest in 2016 are shown in Fig. 2.

Inventory results of field layer vegetation coverage by species and the coverage of moss and litter on the forest floor are shown in Fig. A1. LAI of field layer vegetation was derived by first converting coverage to biomass for each plant type functional group and then total biomass to LAI. Coverage to biomass regressions (Fig. A2a-c) were established from the inventory results of 2009 when field layer vegetation biomass was determined by species in addition to their coverage. In 2018, selected plots in the partial harvest area were measured for vegetation biomass and LAI (Licor LAI-2000) at the same time, which provided a relationship between LAI and biomass (Fig. A2d). Estimated field layer LAI corresponding to each inventory is presented in Fig. Ala. These values were used for model parameterization (see Table 1), however, excluding site VP ${ }_{\text {par }}$ because of disturbance caused by proximity of EC mast.
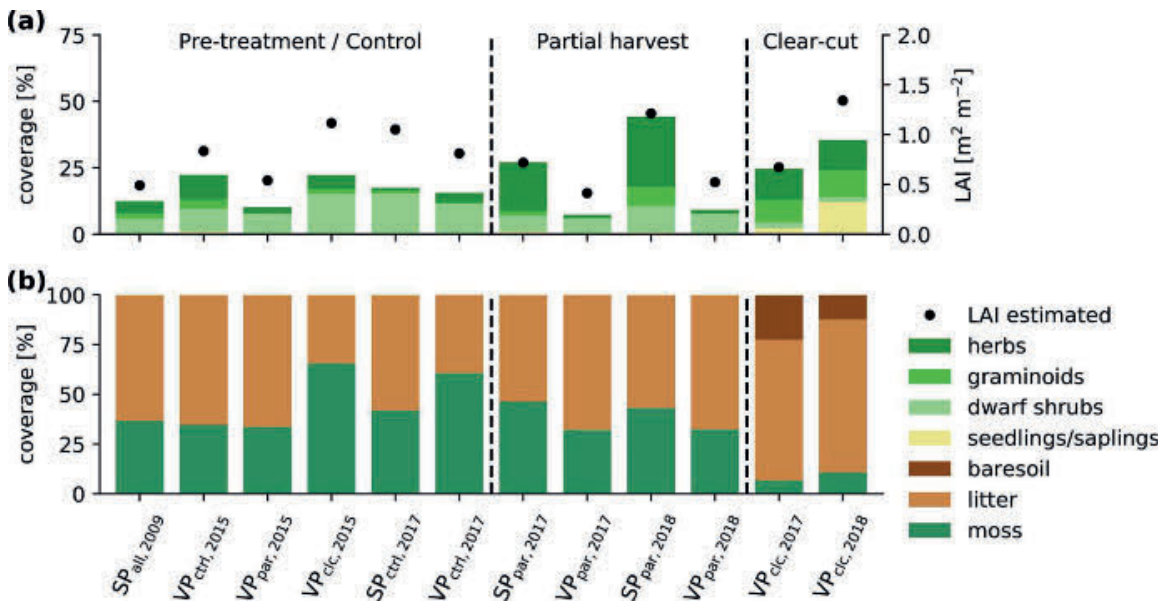

Fig. A1. Results from understory inventories carried out in Lettosuo 2009-2018: (a) projection coverage of field layer vegetation and estimated leaf area index (LAI), and (b) projection coverages of forest floor. SP = stand inventory plots, VP = vegetation inventory plots (see Fig. 1). Subscripts ctrl, clc and par refer to control, clearcut and partial harvest areas in Fig. 1 and all refers to the whole area.
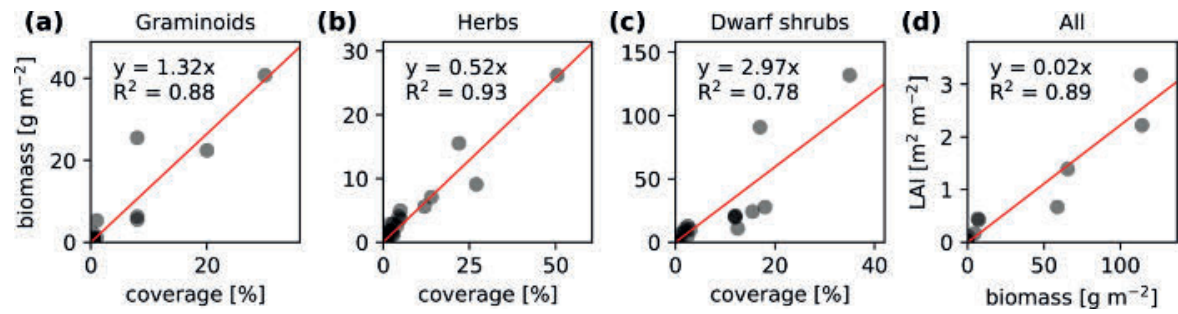

Fig. A2. Relationship between (a-c) field layer vegetation biomass and projection coverage by functional group, and (d) total field layer vegetation leaf area index (LAI) and biomass. $\mathrm{R}^{2}$ denotes the coefficient of determination for the linear least-squares regression with the intercept forced to zero.

\section{Appendix B. Processing WTL data}

WTL was monitored since May 2010 with four automatic loggers and with an additional set of four loggers in each parallel site since 2014-2015 (Fig. 1). The long-term loggers were within the site that was subsequently partially harvested and thus represented partial harvest conditions since March 2016. As WTL measurements were conducted in variable locations (e.g., distance to ditch, local soil hydraulic characteristics, connectivity between pipe and surrounding soil), the data were pre-processed both to discard unreliable measurements and to provide comparable WTL time series for the parallel sites. First, one of the four long-term loggers was discarded due to low correlation with the other loggers and inconsistent dynamics. Linear regressions with a forced slope of unity were then fitted between the remaining three reference time series and the 12 WTL time 
series from the transects using the period before the harvesting operations (calibration period). Transect loggers whose average coefficients of determination during the calibration period were $<0.7$ when regressed against the reference time series were discarded ( 5 out of 12 ). The levels of the remaining 7 WTL time series were corrected to correspond to each of the reference time series based on the fitted regressions. As a result, we obtained a range of WTL for each parallel site, which were comparable to the long-term WTL measurements at the site.

\section{References}

Ahti, E., 1987. Water Balance of Drained Peatlands On the Basis of Water Table Simulation During the Snowless Period. Communicationes Instituti Forestalis Fenniae, pp. 141.

Ahti, E., Hökkä, H., 2006. Effects of the growth and volume of Scots pine stands on the level of the water table on peat in central Finland. In: Hydrology and Management of Forested Wetlands, Proceedings of the International Conference, April 8-12, 2006. American Society of Agricultural and Biological Engineers, New Bern, North Carolina, pp. 37.

Alekseychik, P., Mammarella, I., Lindroth, A., Lohila, A., Aurela, M., Laurila, T., Kasurinen, V., Lund, M., Rinne, J., Nilsson, M.B., Peichl, M., Minkkinen, K., Shurpali, N.J., Tuittila, E.S., Martikainen, P.J., Tuovinen, J.P., Vesala, T., 2018. Surface energy exchange in pristine and managed boreal peatlands. Mires Peat 21, 14. https://doi. org/10.19189/MaP.2018.OMB.333.

Amiro, B.D., 2001. Paired-tower measurements of carbon and energy fluxes following disturbance in the boreal forest. Glob. Change Biol. 7, 253-268. https://doi.org/10. 1046/j.1365-2486.2001.00398.x.

Arneth, A., Lloyd, J., Shibistova, O., Sogachev, A., Kolle, O., 2006. Spring in the borea environment: observations on pre-and post-melt energy and CO2 fluxes in two central Siberian ecosystems. Boreal Environ. Res. 11, 311-328.

Aubinet, M., Vesala, T., Papale, D., 2012. Eddy covariance: a Practical Guide to Measurement and Data Analysis. Springer Science \& Business Media.

Banerjee, T., Linn, R., 2018. Effect of vertical canopy architecture on transpiration, thermoregulation and carbon assimilation. Forests 9, 198. https://doi.org/10.3390/ f9040198.

Berglund, Ö., Berglund, K., 2011. Influence of water table level and soil properties on emissions of greenhouse gases from cultivated peat soil. Soil Biol. Biochem. 43 , 923-931. https://doi.org/10.1016/j.soilbio.2011.01.002.

Bergstedt, J., Milberg, P., 2001. The impact of logging intensity on field-layer vegetation in Swedish boreal forests. For. Ecol. Manag. 154, 105-115. https://doi.org/10.1016/ S0378-1127(00)00642-3.

Bladon, K.D., Silins, U., Landhäusser, S.M., Lieffers, V.J., 2006. Differential transpiration by three boreal tree species in response to increased evaporative demand after variable retention harvesting. Agric. For. Meteorol. 138, 104-119. https://doi.org/ 10.1016/j.agrformet.2006.03.015.

Boczoń, A., Dudzińska, M., Kowalska, A., 2016. Effect of thinning on evaporation of Scots pine forest. Appl. Ecol. Environ. Res. 14, 367-379.

Bowden, J.D., Bauerle, W.L., 2008. Measuring and modeling the variation in speciesspecific transpiration in temperate deciduous hardwoods. Tree Physiol 28 , 1675-1683. https://doi.org/10.1093/treephys/28.11.1675.

Bréda, N., Granier, A., Aussenac, G., 1995. Effects of thinning on soil and tree water relations, transpiration and growth in an oak forest (Quercus petraea (Matt.) Liebl.). Tree Physiol 15, 295-306. https://doi.org/10.1093/treephys/15.5.295.

Dubé, S., Plamondon, A.P., Rothwell, R.L., 1995. Watering up after clear-cutting on forested wetlands of the St. Lawrence lowland. Water Resour. Res. 31, 1741-1750. https://doi.org/10.1029/95WR00427.

Farquhar, G.D., Caemmerer, S.V., Berry, J.A., 1980. A biochemical model for photosynthetic CO2 assimulation in leaves of C3 species. Planta 149, 78-90. https://doi. org/10.1007/BF00386231.

Foken, Th., Wichura, B., 1996. Tools for quality assessment of surface-based flux measurements. Agric. For. Meteorol. 78, 83-105. https://doi.org/10.1016/01681923(95)02248-1.

Gebauer, R., Volařík, D., Urban, J., Børja, I., Nagy, N.E., Eldhuset, T.D., Krokene, P., 2011. Effect of thinning on anatomical adaptations of Norway spruce needles. Tree Physiol 31, 1103-1113. https://doi.org/10.1093/treephys/tpr081.

Gebhardt, T., Häberle, K.-.H., Matyssek, R., Schulz, C., Ammer, C., 2014. The more, the better? Water relations of Norway spruce stands after progressive thinning. Agric. For. Meteorol. 197, 235-243. https://doi.org/10.1016/j.agrformet.2014.05.013.

Gnojek, A.R., 1992. Changes in chlorophyll fluorescence and chlorophyll content in suppressed Norway spruce [Picea abies (L.) Karst.] in response to release cutting. Trees 6, 41-47. https://doi.org/10.1007/BF00224498.

Goodrich, J.P., Oechel, W.C., Gioli, B., Moreaux, V., Murphy, P.C., Burba, G., Zona, D., 2016. Impact of different eddy covariance sensors, site set-up, and maintenance on the annual balance of $\mathrm{CO} 2$ and $\mathrm{CH} 4$ in the harsh Arctic environment. Agric. For. Meteorol. 228-229, 239-251. https://doi.org/10.1016/j.agrformet.2016.07.008.

Grelle, A., Lundberg, A., Lindroth, A., Morén, A.-.S., Cienciala, E., 1997. Evaporation components of a boreal forest: variations during the growing season. J. Hydrol. 197, 70-87. https://doi.org/10.1016/S0022-1694(96)03267-2.

Hamberg, L., Hotanen, J.-.P., Nousiainen, H., Nieminen, T.M., Ukonmaanaho, L., 2019. Recovery of understorey vegetation after stem-only and whole-tree harvesting in drained peatland forests. For. Ecol. Manag. 442, 124-134. https://doi.org/10.1016/j. foreco. 2019.04.002.

Hämet-Ahti, L., Suominen, J., Ulvinen, T., Uotila, P., 1998. Field Flora of Finland. 4th ed. Finnish Museum of Natural History, Botanical Museum, Helsinki.

Hånell, B., 1988. Postdrainage forest productivity of peatlands in Sweden. Can. J. For. Res. 18, 1443-1456. https://doi.org/10.1139/x88-223.
Hannerz, M., Hånell, B., 1993. Changes in the vascular plant vegetation after different cutting regimes on a productive Peatland site in Central Sweden. Scand. J. For. Res. 8, 193-203. https://doi.org/10.1080/02827589309382769.

Härkönen, S., Lehtonen, A., Manninen, T., Tuominen, S., Peltoniemi, M., 2015. Estimating forest leaf area index using satellite images: comparison of k-NN based Landsat-NFI LAI with MODIS-RSR based LAI product for Finland. Boreal Environ. Res. 20.

Heikurainen, L., 1967. Influence of cuttings on the water economy of drained peatlands. Acta For. Fenn. 82, 1-45. https://doi.org/10.14214/aff.7175.

Heikurainen, L., Päivänen, J., 1970. The effect of thinning, clear cutting and fertilization on the hydrology of peatland drained for forestry. Acta For. Fenn. 104. https://doi. org/10.14214/aff.7538.

Hökkä, H., Koivusalo, H., Ahti, E., Nieminen, M., Laine, J., Saarinen, M., Lauren, A., Alm, J., Nikinmaa, E., Klöve, B., 2008a. Effects of tree stand transpiration and interception on site water balance in drained peatlands: experimental design and measurements. In: International Peat Congress, pp. 169-171.

Hökkä, H., Repola, J., Laine, J., 2008b. Quantifying the interrelationship between tree stand growth rate and water table level in drained peatland sites within Central Finland. Can. J. For. Res. 38, 1775-1783. https://doi.org/10.1139/X08-028.

Holden, J., 2006. Peatland hydrology. Dev. Earth Surf. Process 9, 319-346.

Holden, J., Evans, M.G., Burt, T.P., Horton, M., 2006. Impact of land drainage on peatland hydrology. J Env. Qual 35, 1764-1778. https://doi.org/10.2134/jeq2005.0477.

Hooghoudt, S.B., 1940. General consideration of the problem of field drainage by parallel drains, ditches, watercourses, and channels. Publ. No. 7. In: Contribution to the Knowledge of Some Physical Parameters of the Soil. Bodemkundig Instituut, Groningen, The Netherlands.

ICOS Ecosystem Thematic Centre, 2019. Drought-2018 ecosystem eddy covariance flux product from Lettosuo (Version 1.0) [Data set]. 10.18160/0jhq-bzmu.

Joensuu, S., Ahti, E., Vuollekoski, M., 1999. The effects of peatland forest ditch maintenance on suspended solids in runoff. Boreal Env. Res 4, 343-356.

Jutras, S., Plamondon, A.P., 2005. Water table rise after harvesting in a treed fen previously drained for forestry. Suo 56, 95-100.

Juutinen, A., Ahtikoski, A., Mäkipää, R., Shanin, V., 2018. Effect of harvest interval and intensity on the profitability of uneven-aged management of Norway spruce stands. For. Int. J. For. Res. 91, 589-602. https://doi.org/10.1093/forestry/cpy018.

Kaila, A., Laurén, A., Sarkkola, S., Koivusalo, H., Ukonmaanaho, L., O'Driscoll, C., Xiao, L., Asam, Z., Nieminen, M., 2015. Effect of clear-felling and harvest residue removal on nitrogen and phosphorus export from drained Norway spruce mires in southern Finland. Boreal Environ. Res. 20.

Kaila, A., Sarkkola, S., Laurén, A., Ukonmaanaho, L., Koivusalo, H., Xiao, L., O'Driscoll, C., Tervahauta, A., Nieminen, M., 2014. Phosphorus export from drained Scots pine mires after clear-felling and bioenergy harvesting. For. Ecol. Manag. 325, 99-107. https://doi.org/10.1016/j.foreco.2014.03.025.

Kang, M., Kim, J., Malla Thakuri, B., Chun, J., Cho, C., 2018. New gap-filling and par titioning technique for $\mathrm{H}_{2} \mathrm{O}$ eddy fluxes measured over forests. Biogeosciences 15 , 631-647. https://doi.org/10.5194/bg-15-631-2018.

Katul, G., Manzoni, S., Palmroth, S., Oren, R., 2010. A stomatal optimization theory to describe the effects of atmospheric $\mathrm{CO} 2$ on leaf photosynthesis and transpiration. Ann. Bot. 105, 431-442. https://doi.org/10.1093/aob/mcp292.

Kieloaho, A.-J., Launianen, S., 2018. Effects of functional traits of bryophyte layer on water cycling and energy balance in boreal and arctic ecosystems. In: EGU General Assembly Conference Abstracts, pp. 11786.

Koivusalo, H., Heikinheimo, M., Karvonen, T., 2001. Test of a simple two-layer parameterisation to simulate the energy balance and temperature of a snow pack. Theor. Appl. Climatol. 70, 65-79. https://doi.org/10.1007/s007040170006.

Kojola, S., Penttila, T., Laiho, R., 2004. Impacts of different thinning regimes on the yield of uneven-structured Scots pine stands on drained peatlands. Silva Fenn 38, 393-403. https://doi.org/10.14214/sf.407.

Kolari, P., Lappalainen, H.K., Hänninen, H., Hari, P., 2007. Relationship between temperature and the seasonal course of photosynthesis in Scots pine at northern timberline and in southern boreal zone. Tellus Ser. B-Chem. Phys. Meteorol. 59, 542-552. https://doi.org/10.1111/j.1600-0889.2007.00262.x.

Korkiakoski, M., Tuovinen, J.-.P., Penttilä, T., Sarkkola, S., Ojanen, P., Minkkinen, K., Rainne, J., Laurila, T., Lohila, A., 2019a. Greenhouse gas and energy fluxes in a boreal peatland forest after clear-cutting. Biogeosciences 16, 3703-3723. https://doi. org/10.5194/bg-16-3703-2019.

Korkiakoski, M., Tuovinen, J.-.P., Penttilä, T., Sarkkola, S., Ojanen, P., Minkkinen, K., Rainne, J., Laurila, T., Lohila, A., 2019b. Greenhouse gas and energy fluxes in a boreal peatland forest after clearcutting [Data set]. 10.5281/zenodo.3384791.

Kormann, R., Meixner, F.X., 2001. An Analytical Footprint Model For Non-Neutra Stratification. Bound.-Layer Meteorol. 99, 207-224. https://doi.org/10.1023/ A:1018991015119.

Koskinen, M., Sallantaus, T., Vasander, H., 2011. Post-restoration development of organic carbon and nutrient leaching from two ecohydrologically different peatland sites. Ecol. Eng., Biogeochemical aspects of ecosystem restoration and rehabilitation 37, 1008-1016. https://doi.org/10.1016/j.ecoleng.2010.06.036.

Kozii, N., Haahti, K., Tor-ngern, P., Chi, J., Hasselquist, E.M., Laudon, H., Launiainen, S., Oren, R., Peichl, M., Wallerman, J., Hasselquist, N.J., 2019. Partitioning the forest water balance within a boreal catchment using sapflux, eddy covariance and process- 
based model. Hydrol. Earth Syst. Sci. Discuss. 1-50. https://doi.org/10.5194/hess2019-541.

Kuusinen, N., Tomppo, E., Shuai, Y., Berninger, F., 2014. Effects of forest age on albedo in boreal forests estimated from MODIS and Landsat albedo retrievals. Remote Sens. Environ. 145, 145-153. https://doi.org/10.1016/j.rse.2014.02.005.

Lagergren, F., Lankreijer, H., Kučera, J., Cienciala, E., Mölder, M., Lindroth, A., 2008. Thinning effects on pine-spruce forest transpiration in central Sweden. For. Ecol. Manag., Large-scale experimentation and oak regeneration 255, 2312-2323. https: / doi.org/10.1016/j.foreco.2007.12.047.

Lagergren, F., Lindroth, A., 2004. Variation in sapflow and stem growth in relation to tree size, competition and thinning in a mixed forest of pine and spruce in Sweden. For. Ecol. Manag. 188, 51-63. https://doi.org/10.1016/j.foreco.2003.07.018.

Launiainen, S., 2010. Seasonal and inter-annual variability of energy exchange above a boreal Scots pine forest. Biogeosciences 7, 3921-3940. https://doi.org/10.5194/bg 7-3921-2010.

Launiainen, S., Guan, M., Salmivaara, A., Kieloaho, A.-.J., 2019. Modeling boreal forest evapotranspiration and water balance at stand and catchment scales: a spatial approach. Hydrol. Earth Syst. Sci. 23. https://doi.org/10.5194/hess-23-3457-2019.

Launiainen, S., Katul, G.G., Kolari, P., Lindroth, A., Lohila, A., Aurela, M., Varlagin, A., Grelle, A., Vesala, T., 2016. Do the energy fluxes and surface conductance of boreal coniferous forests in Europe scale with leaf area? Glob. Change Biol 22, 4096-4113. https://doi.org/10.1111/gcb.13497.

Launiainen, S., Katul, G.G., Kolari, P., Vesala, T., Hari, P., 2011. Empirical and optimal stomatal controls on leaf and ecosystem level $\mathrm{CO} 2$ and $\mathrm{H} 2 \mathrm{O}$ exchange rates. Agric. For. Meteorol. 151, 1672-1689. https://doi.org/10.1016/j.agrformet.2011.07.001.

Launiainen, S., Katul, G.G., Lauren, A., Kolari, P., 2015. Coupling boreal forest CO2, H2O and energy flows by a vertically structured forest canopy - Soil model with separate bryophyte layer. Ecol. Model. 312, 385-405. https://doi.org/10.1016/j.ecolmodel. 2015.06.007.

Lehtonen, A., Heikkinen, J., Petersson, H., Ťupek, B., Liski, E., Mäkelä, A., 2020. Scots pine and Norway spruce foliage biomass in Finland and Sweden - Testing traditional models vs. the pipe model theory. Can. J. For. Res. 50, 146-154. https://doi.org/10. 1139/cjfr-2019-0211.

Leuning, R., van Gorsel, E., Massman, W.J., Isaac, P.R., 2012. Reflections on the surface energy imbalance problem. Agric. For. Meteorol. 156, 65-74. https://doi.org/10. 1016/j.agrformet.2011.12.002

Lin, Y.-.S., Medlyn, B.E., Duursma, R.A., Prentice, I.C., Wang, H., Baig, S., Eamus, D., de Dios, V.R., Mitchell, P., Ellsworth, D.S., de Beeck, M.O., Wallin, G., Uddling, J., Tarvainen, L., Linderson, M.-.L., Cernusak, L.A., Nippert, J.B., Ocheltree, T.W., Tissue, D.T., Martin-StPaul, N.K., Rogers, A., Warren, J.M., De Angelis, P., Hikosaka, K., Han, Q., Onoda, Y., Gimeno, T.E., Barton, C.V.M., Bennie, J., Bonal, D., Bosc, A., Löw, M., Macinins-Ng, C., Rey, A., Rowland, L., Setterfield, S.A., Tausz-Posch, S., Zaragoza-Castells, J., Broadmeadow, M.S.J., Drake, J.E., Freeman, M., Ghannoum, O., Hutley, L.B., Kelly, J.W., Kikuzawa, K., Kolari, P., Koyama, K., Limousin, J.-.M., Meir, P., Lola da Costa, A.C., Mikkelsen, T.N., Salinas, N., Sun, W., Wingate, L., 2015. Optimal stomatal behaviour around the world. Nat. Clim. Change 5, 459-464. https://doi.org/10.1038/nclimate2550.

Lukeš, P., Stenberg, P., Rautiainen, M., 2013. Relationship between forest density and albedo in the boreal zone. Ecol. Model. 261-262, 74-79. https://doi.org/10.1016/j. ecolmodel.2013.04.009.

Mäkiranta, P., Riutta, T., Penttilä, T., Minkkinen, K., 2010. Dynamics of net ecosystem $\mathrm{CO} 2$ exchange and heterotrophic soil respiration following clearfelling in a drained peatland forest. Agric. For. Meteorol. 150, 1585-1596. https://doi.org/10.1016/j. agrformet.2010.08.010.

Malhotra, A., Roulet, N.T., Wilson, P., Giroux-Bougard, X., Harris, L.I., 2016. Ecohydrological feedbacks in peatlands: an empirical test of the relationship among vegetation, microtopography and water table. Ecohydrology 9, 1346-1357. https:// doi.org/10.1002/eco.1731.

Mamkin, V., Kurbatova, J., Avilov, V., Ivanov, D., Kuricheva, O., Varlagin, A., Yaseneva, I., Olchev, A., 2019. Energy and CO2 exchange in an undisturbed spruce forest and clear-cut in the Southern Taiga. Agric. For. Meteorol. 265, 252-268. https://doi.org/ 10.1016/j.agrformet.2018.11.018.

Martikainen, P.J., Nykänen, H., Crill, P., Silvola, J., 1993. Effect of a lowered water table on nitrous oxide fluxes from northern peatlands. Nature 366, 51.

Mazza, G., Amorini, E., Cutini, A., Manetti, M.C., 2011. The influence of thinning on rainfall interception by Pinus pinea L. in Mediterranean coastal stands (Castel Fusano-Rome). Ann. For. Sci. 68, 1323-1332. https://doi.org/10.1007/s13595011-0142-7.

McCaughey, J.H., 1981. Impact of Clearcutting of Coniferous Forest on the Surface Radiation Balance. J. Appl. Ecol. 18, 815-826. https://doi.org/10.2307/2402372.

McMillen, R.T., 1988. An eddy correlation technique with extended applicability to nonsimple terrain. Bound.-Layer Meteorol. 43, 231-245. https://doi.org/10.1007/ BF00128405.

McNaughton, K.G., Jarvis, P.G., 1983. Predicting effects of vegetation changes on transpiration and evaporation. Water Deficits Plant Growth 7, 1-47.

Medlyn, B.E., Duursma, R.A., Eamus, D., Ellsworth, D.S., Prentice, I.C., Barton, C.V.M., Crous, K.Y., Angelis, P.D., Freeman, M., Wingate, L., 2011. Reconciling the optimal and empirical approaches to modelling stomatal conductance. Glob. Change Biol. 17, 2134-2144. https://doi.org/10.1111/j.1365-2486.2010.02375.x.

Minkkinen, K., Ojanen, P., Penttilä, T., Aurela, M., Laurila, T., Tuovinen, J.-.P., Lohila, A., 2018. Persistent carbon sink at a boreal drained bog forest. Biogeosciences 15, 3603-3624. https://doi.org/10.5194/bg-15-3603-2018.

Moore, C.J., 1986. Frequency response corrections for eddy correlation systems. Bound.Layer Meteorol. 37, 17-35. https://doi.org/10.1007/BF00122754.

Moore, T.R., Knowles, R., 1989. The Influence of Water Table Levels on Methane and Carbon Dioxide Emissions from Peatland Soils. Can. J. Soil Sci. 69, 33-38. https:// doi.org/10.4141/cjss89-004.

Murchie, E.H., Lawson, T., 2013. Chlorophyll fluorescence analysis: a guide to good practice and understanding some new applications. J. Exp. Bot. 64, 3983-3998. https://doi.org/10.1093/jxb/ert208.

Musarika, S., Atherton, C.E., Gomersall, T., Wells, M.J., Kaduk, J., Cumming, A.M.J., Page, S.E., Oechel, W.C., Zona, D., 2017. Effect of water table management and elevated $\mathrm{CO} 2$ on radish productivity and on $\mathrm{CH} 4$ and $\mathrm{CO} 2$ fluxes from peatlands converted to agriculture. Sci. Total Environ. 584-585, 665-672. https://doi.org/10. 1016/j.scitotenv.2017.01.094.

Näslund, M., 1936. Skogsförsöksanstaltens Gallringsförsök I Tallskog (Report). Stockholm.

Nieminen, M., 2003. Effects of clear-cutting and site preparation on water quality from a drained Scots pine mire in southern Finland. Boreal Environ. Res. 8, 53-59.

Nieminen, M., Ahti, E., Koivusalo, H., Mattsson, T., Sarkkola, S., Laurén, A., 2010. Export of suspended solids and dissolved elements from peatland areas after ditch network maintenance in South-Central Finland. Silva Fenn 44, 39-49. https://doi.org/10. 14214/sf.161.

Nieminen, M., Hökkä, H., Laiho, R., Juutinen, A., Ahtikoski, A., Pearson, M., Kojola, S., Sarkkola, S., Launiainen, S., Valkonen, S., Penttilä, T., Lohila, A., Saarinen, M., Haahti, K., Mäkipää, R., Miettinen, J., Ollikainen, M., 2018. Could continuous cover forestry be an economically and environmentally feasible management option on drained boreal peatlands? For. Ecol. Manag. 424, 78-84. https://doi.org/10.1016/j. foreco.2018.04.046.

Nieminen, M., Koskinen, M., Sarkkola, S., Laurén, A., Kaila, A., Kiikkilä, O., Nieminen, T.M., Ukonmaanaho, L., 2015. Dissolved organic carbon export from harvested peatland forests with differing site characteristics. Water. Air. Soil Pollut. 226, 181. https://doi.org/10.1007/s11270-015-2444-0.

Ojanen, P., Minkkinen, K., 2019. The dependence of net soil CO2 emissions on water table depth in boreal peatlands drained for forestry. Mires Peat 24. https://doi.org/10. 19189/MaP.2019.OMB.StA.1751.

Ojanen, P., Minkkinen, K., Alm, J., Penttilä, T., 2010. Soil-atmosphere CO2, CH4 and N2O fluxes in boreal forestry-drained peatlands. For. Ecol. Manag. 260, 411-421. https://doi.org/10.1016/j.foreco.2010.04.036.

Ojanen, P., Minkkinen, K., Penttilä, T., 2013. The current greenhouse gas impact of forestry-drained boreal peatlands. For. Ecol. Manag. 289, 201-208. https://doi.org/10. 1016/j.foreco.2012.10.008.

Päivänen, J., 1973. Hydraulic conductivity and water retention in peat soils. Acta Fenn 129, 1-70. https://doi.org/10.14214/aff.7563.

Päivänen, J., Hånell, B., 2012. Peatland Ecology and Forestry - a Sound Approach. University of Helsinki Department of Forest Sciences Publication 3, Helsinki, Finland.

Päivänen, J., Sarkkola, S., 2000. The effect of thinning and ditch network maintenance on the water table level in a Scots pine stand on peat soil. Suo 51, 131-138.

Pirinen, P., Simola, H., Aalto, J., Kaukoranta, J.-.P., Karlsson, P., Ruuhela, R., 2012. Tilastoja Suomen ilmastosta 1981-2010 (Climatological statistics of Finland 19812010).

Pommerening, A., Murphy, S.T., 2004. A review of the history, definitions and methods of continuous cover forestry with special attention to afforestation and restocking. For. Int. J. For. Res. 77, 27-44. https://doi.org/10.1093/forestry/77.1.27.

Préfontaine, G., Jutras, S., 2017. Variation in stand density, black spruce individual growth and plant community following 20years of drainage in post-harvest boreal peatlands. For. Ecol. Manag. 400, 321-331. https://doi.org/10.1016/j.foreco.2017 06.029 .

Rannik, Ü., Altimir, N., Raittila, J., Suni, T., Gaman, A., Hussein, T., Hölttä, T., Lassila, H., Latokartano, M., Lauri, A., Natsheh, A., Petäjä, T., Sorjamaa, R., Ylä-Mella, H., Keronen, P., Berninger, F., Vesala, T., Hari, P., Kulmala, M., 2002. Fluxes of carbon dioxide and water vapour over Scots pine forest and clearing. Agric. For. Meteorol. 111, 187-202. https://doi.org/10.1016/S0168-1923(02)00022-9.

Regina, K., Sheehy, J., Myllys, M., 2015. Mitigating greenhouse gas fluxes from cultivated organic soils with raised water table. Mitig. Adapt. Strateg. Glob. Change 20, 1529-1544. https://doi.org/10.1007/s11027-014-9559-2.

Renger, M., Wessolek, G., Schwärzel, K., Sauerbrey, R., Siewert, C., 2002. Aspects of peat conservation and water management. J. Plant Nutr. Soil Sci. 165, 487-493 10.1002/ 1522-2624(200208)165:4<487::AID - JPLN487> 3.0.CO;2-C.

Sarkkola, S., Alenius, V., Hökkä, H., Laiho, R., Päivänen, J., Penttilä, T., 2003. Changes in structural inequality in Norway spruce stands on peatland sites after water-level drawdown. Can. J. For. Res. 33, 222-231. https://doi.org/10.1139/x02-179.

Sarkkola, S., Hökkä, H., Koivusalo, H., Nieminen, M., Ahti, E., Päivänen, J., Laine, J., 2010. Role of tree stand evapotranspiration in maintaining satisfactory drainage conditions in drained peatlands. Can J For. Res 40, 1485-1496. https://doi.org/10. 1139/X10-084.

Sarkkola, S., Hökkä, H., Laiho, R., Päivänen, J., Penttilä, T., 2005. Stand structural dynamics on drained peatlands dominated by Scots pine. For. Ecol. Manag. 206, 135-152. https://doi.org/10.1016/j.foreco.2004.10.064.

Sarkkola, S., Nieminen, M., Koivusalo, H., Laurén, A., Ahti, E., Launiainen, S., Nikinmaa, E., Marttila, H., Laine, J., Hökkä, H., 2013. Domination of growing-season evapotranspiration over runoff makes ditch network maintenance in mature peatland forests questionable. Mires Peat 11, 1-11.

Sikström, U., Hökkä, H., 2016. Interactions between soil water conditions and forest stands in boreal forests with implications for ditch network maintenance. Silva Fenn. 50. https://doi.org/10.14214/sf.1416.

Simonin, K., Kolb, T.E., Montes-Helu, M., Koch, G.W., 2007. The influence of thinning on components of stand water balance in a ponderosa pine forest stand during and after extreme drought. Agric. For. Meteorol. 143, 266-276. https://doi.org/10.1016/j. agrformet.2007.01.003.

Song, C., Katul, G., Oren, R., Band, L.E., Tague, C.L., Stoy, P.C., McCarthy, H.R., 2009. Energy, water, and carbon fluxes in a loblolly pine stand: results from uniform and 
gappy canopy models with comparisons to eddy flux data. J. Geophys. Res. Biogeosciences 114, G04021. https://doi.org/10.1029/2009JG000951.

Tahvanainen, T., Forss, E., 2008. Individual tree models for the crown biomass distribution of Scots pine, Norway spruce and birch in Finland. For. Ecol. Manag. 255, 455-467. https://doi.org/10.1016/j.foreco.2007.09.035.

Tahvonen, O., 2016. Economics of rotation and thinning revisited: the optimality of clearcuts versus continuous cover forestry. For. Policy Econ. 62, 88-94. https://doi, org/10.1016/j.forpol.2015.08.013.

Tupek, B., Mäkipää, R., Heikkinen, J., Peltoniemi, M., Ukonmaanaho, L., Hokkanen, T., Nöjd, P., Nevalainen, S., Lindgren, M., Lehtonen, A., 2015. Foliar turnover rates in Finland-comparing estimates from needle-cohort and litterfall-biomass methods. Boreal Environ. Res. 22.

Ulvinen, T., Syrjänen, K., Anttila, S., 2002. Bryophytes of Finland-Distribution, ecology and red list status (in Finnish). Suom. Ymp. Hels. 353.

Van Dam, J.C., Feddes, R.A., 2000. Numerical simulation of infiltration, evaporation and shallow groundwater levels with the Richards equation. J. Hydrol. 233, 72-85. https://doi.org/10.1016/S0022-1694(00)00227-4.

van Dijk, A.I.J.M., Gash, J.H., van Gorsel, E., Blanken, P.D., Cescatti, A., Emmel, C., Gielen, B., Harman, I.N., Kiely, G., Merbold, L., Montagnani, L., Moors, E., Sottocornola, M., Varlagin, A., Williams, C.A., Wohlfahrt, G., 2015. Rainfall interception and the coupled surface water and energy balance. Agric. For. Meteorol. 214-215, 402-415. https://doi.org/10.1016/j.agrformet.2015.09.006.

Vesala, T., Suni, T., Rannik, Ü., Keronen, P., Markkanen, T., Sevanto, S., Grönholm, T., Smolander, S., Kulmala, M., Ilvesniemi, H., Ojansuu, R., Uotila, A., Levula, J., Mäkelä, A., Pumpanen, J., Kolari, P., Kulmala, L., Altimir, N., Berninger, F., Nikinmaa, E., Hari, P., 2005. Effect of thinning on surface fluxes in a boreal forest. Glob. Biogeochem. Cycles 19. https://doi.org/10.1029/2004GB002316. von Post, L., 1922. Sveriges Geologiska Undersöknings torvinventering och n\a agra ay dess hittills vunna resultat. Sven. Mosskulturforeningens Tidskr. 1-37.

Waddington, J.M., Morris, P.J., Kettridge, N., Granath, G., Thompson, D.K., Moore, P.A., 2015. Hydrological feedbacks in northern peatlands. Ecohydrology 8, 113-127. https://doi.org/10.1002/eco.1493.

Watanabe, T., Mizutani, K., 1996. Model study on micrometeorological aspects of rainfall interception over an evergreen broad-leaved forest. Agric. For. Meteorol. 80, 195-214. https://doi.org/10.1016/0168-1923(95)02301-1.

Webb, E.K., Pearman, G.I., Leuning, R., 1980. Correction of flux measurements for density effects due to heat and water vapour transfer. Q. J. R. Meteorol. Soc. 106, 85-100. https://doi.org/10.1002/qj.49710644707.

Weltzin, J.F., Bridgham, S.D., Pastor, J., Chen, J., Harth, C., 2003. Potential effects of warming and drying on peatland plant community composition. Glob. Change Biol. 9, 141-151. https://doi.org/10.1046/j.1365-2486.2003.00571.x.

Westman, C.J., Laiho, R., 2003. Nutrient dynamics of drained peatland forests. Biogeochemistry 63, 269-298. https://doi.org/10.1023/A:1023348806857.

Wutzler, T., Lucas-Moffat, A., Migliavacca, M., Knauer, J., Sickel, K., Šigut, L., Menzer, O., Reichstein, M., 2018. Basic and extensible post-processing of eddy covariance flux data with REddyProc. Biogeosciences 15, 5015-5030. https://doi.org/10.5194/bg15-5015-2018.

Zhao, W., Qualls, R.J., 2006. Modeling of long-wave and net radiation energy distribution within a homogeneous plant canopy via multiple scattering processes. Water Resour. Res. 42. https://doi.org/10.1029/2005WR004581.

Zhao, W.G., Qualls, R.J., 2005. A multiple-layer canopy scattering model to simulate shortwave radiation distribution within a homogeneous plant canopy. Water Resour. Res. 41, A08409. https://doi.org/10.1029/2005WR004016. 
